\title{
Reconstrucción de
}

subjetividades e identidades en contextos de guerra y posguerra

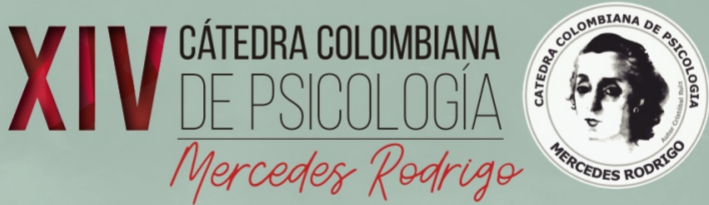

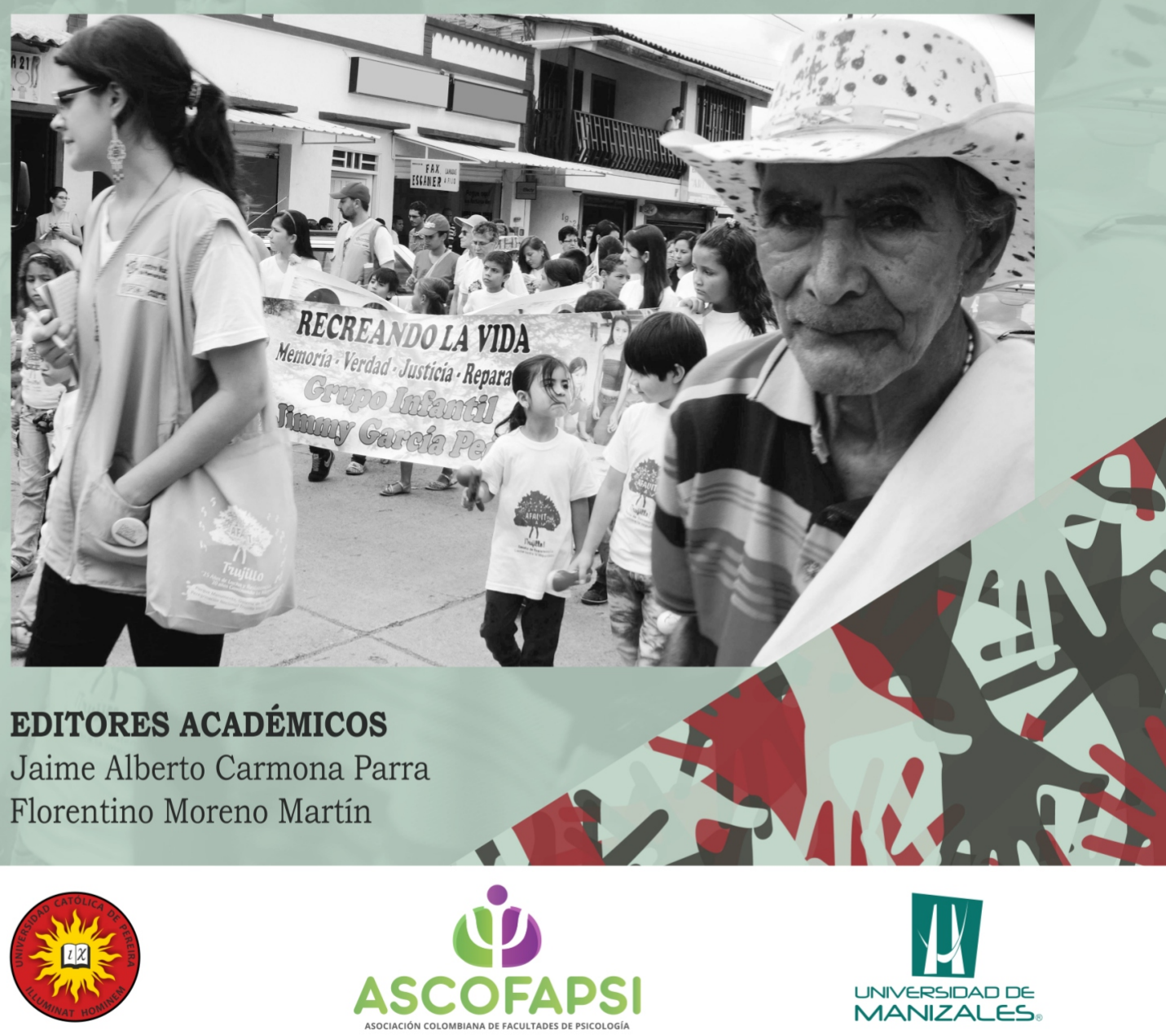




\title{
Reconstrucción de subjetividades e identidades en contextos de guerra y posguerra
}

\author{
CÁTEDRA COLOMBIANA DE PSICOLOGÍA \\ MERCEDES RODRIGO - 2019
}




\title{
Reconstrucción de subjetividades e identidades en contextos de guerra y posguerra
}

\section{CÁTEDRA COLOMBIANA DE PSICOLOGÍA MERCEDES RODRIGO - 2019}

\author{
EDITORES ACADÉMICOS \\ Jaime Alberto Carmona Parra \\ Florentino Moreno Martín
}

COMPILADORES Jaime Alberto Carmona Parra Mariela Narváez Marín Ana Sofia Gaviria Cano Gina Marcela Arias Rodríguez 
$$
\text { H }
$$ \\ UNIVERSIDAD DE \\ MANIZALES
}

\author{
Guillermo Orlando Sierra Sierra \\ Rector \\ Jorge Iván Jurado Salgado \\ Vicerrector \\ Denis Rincón Grajales \\ Secretaria General \\ Gonzalo Tamayo Giraldo \\ Decano Facultad de Ciencias Sociales y Humanas
}

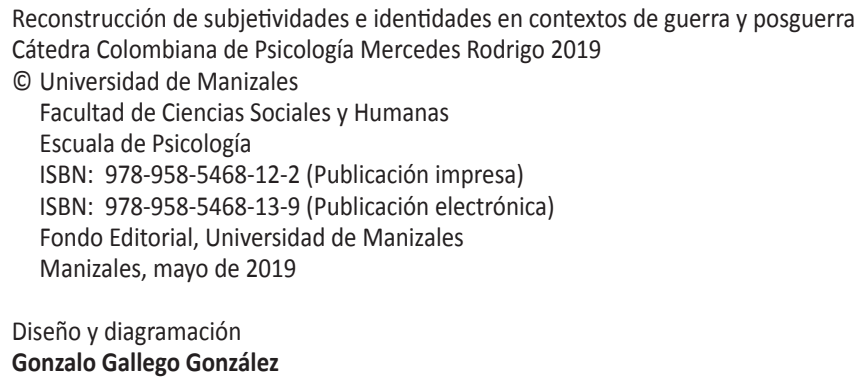

Todos los derechos reservados. Ninguna parte de esta publicación puede ser reproducida, almacenada en sistema recuperable o transmitida en ninguna forma por medios electrónico, mecánico, fotocopia, grabación u otros, sin la previa autorización por escrito del Centro Editorial Universidad de Manizales y de los autores. Los conceptos expresados en este documento son responsabilidad exclusiva de los autores y no necesariamente comprometen a la Universidad de Manizales.

Reconstrucción de subjetividades e identidades en contextos de guerra y posguerra. Cátedra Colombiana de Psicología Mercedes Rodrigo - 2019 / Jaime Alberto Carmona Parra y Florentino Moreno Martín, eds. - Manizales: Fondo Editorial Universidad de Manizales, Facultad de Ciencias Sociales y Humanas, Escuela de Psicología, 2019.

498 p.: il.

ISBN: 978-958-5468-12-2

1. Construcción social. 2. Subjetividades. 3. Identidad. 4. Procesos sociales. 5. Psicología - Investigaciones. I. Carmona Parra, Jaime Alberto, ed. II. Moreno Martín, Florentino, ed. III. Título. 


\section{Contenido}

Página

Los Autores. 7

Reconocimiento a las universidades

y grupos de investigación participantes .......................................................... 15

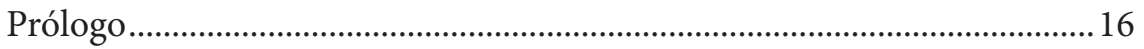

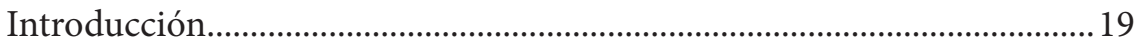

1. ASCOFAPSI: breve semblanza de un compromiso con la calidad de la formación de los psicólogos en Colombia ............22

2. Cátedra Mercedes Rodrigo: un espacio para compartir conocimiento ...31

I. REFERENTE TEÓRICO

3. Reconstrucción de subjetividades, identidades y del tejido social.......39

4. Construcción y reconstrucción social de subjetividades e identidades en contextos de guerra y posguerra en Colombia

\section{ESTUDIOS DOCUMENTALES}

5. Narrativas y testimonios de víctimas del conflicto armado en el Oriente Antioqueño: escenarios de transformaciones políticas en medio del horror y la resistencia

6. Memoria, duelo y olvido. Elementos para la reconciliación en tiempos de construcción de paz

7. Reintegración social de excombatientes en Colombia .........................126

8. Ser o no ser: subjetivación política de las víctimas del conflicto armado en Colombia

\section{ESTUDIOS EMPÍRICOS SOBRE INFANCIA}

9. Construcción social de subjetividades políticas de niños y niñas desde sus primeros años: narrativas colectivas de agenciamiento para la paz, en contextos de conflicto armado.

10. Agenciamientos sobre construcción de paz de niños en contextos de guerra en Colombia 


\section{ESTUDIOS EMPÍRICOS SOBRE LA MUJER}

11. ¿Mujeres víctimas? Víctimas empoderadas, dolidas y emputadas.....207

12. Devenir lideresa en el conflicto armado en Colombia: un tránsito de víctima a reclamante de justicia

13. La experiencia del teatro: resignificación de historias y configuación de subjetividades políticas de mujeres

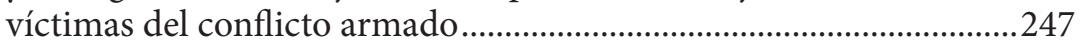

14. Subjetividad de mujeres víctimas del conflicto armado ........................260

15. Narrativas para la emergencia de subjetividades y reconstrucción de tejido social: las mujeres afrocolombianas sobrevivientes de la guerra 277

16. Los retos del empoderamiento. Las interseccionalidades entre el enfoque de género y diferencial....295

\section{ESTUDIOS EMPÍRICOS SOBRE OTRAS POBLACIONES}

17. Narrativas de sobrevivencia y restauración con personas afectadas por el conflicto armado en Caldas

18. Capacidades relacionales para la construcción de paz en líderes comunitarios

19. Huellas silenciosas de una guerra que no se nombra. Análisis de representaciones en las bitácoras del Salón del Nunca Más, de Granada (Antioquia)

20. Representaciones sociales del enemigo como barreras psicosociales para la construcción de la paz y la reconciliación en Colombia ........365

21. Emociones sociales que constituyen barreras psicosociales para el perdón y la reconciliación en Medellín 388

22. "Ser víctima", "Violencia sociopolítica" y "Paz":

lo que piensan los habitantes de una zona implicada en el asunto ...408

23. La construcción del enemigo en pilotos militares colombianos ........424

24. Construcción de paz y conflictos socioambientales en Sumapaz ......447

25. Narrativa identitaria de un fotógrafo de guerra colombiano.

Estudio de caso desde una perspectiva transdisciplinar

VI. METAANÁLISIS

Metaanálisis 


\section{Los Autores}

\section{PRÓLOGOS}

\section{Diego Alveiro Restrepo Ochoa}

Psicólogo de la Universidad de San Buenaventura, Medellín. Doctor en Salud Pública de la Universidad de Antioquia. Decano de la Facultad de Psicología, Universidad CES - Medellín. Integrante del grupo de investigación: Psicología Salud y Sociedad de la Universidad CES - Medellín. Orcid: 0000-0002-4469-6260. Correo electrónico: drestrepo@ces.edu.co

\section{María Astrid Triana Cifuentes}

Psicóloga de la Universidad Incca de Colombia. Especialista en Desarro1lo Intelectual y Educación. Corporación Iberoamericana. Directora Ejecutiva de Ascofapsi. Correo electrónico: direcciónejecutiva@ascofapsi.org.co

\section{Gonzalo Tamayo Giraldo}

Psicólogo de la Universidad de Manizales. Doctor en Psicología con énfasis cognitivo - existencial de la Universidad de Flores de Buenos Aires. Decano de la Facultad de Ciencias Sociales y Humanas de la Universidad de Manizales. Integrante del grupo de investigación "Psicología Clínica y Procesos de Salud" de la Universidad de Manizales. Correo electrónico: gotamayo@umanizales.edu.co

\section{EDITORES ACADÉMICOS}

\section{Jaime Alberto Carmona Parra}

Psicólogo de la Universidad Autónoma (Monterrey). Doctor en Psicología Social Summa cum laude de Universidad Complutense de Madrid. Coordinador de Investigaciones y Posgrados de la Facultad de Ciencias Sociales y Humanas de la Universidad de Manizales. Integrante del grupo de investigación "Psicología del Desarrollo" de la Universidad de Manizales. Orcid 0000-0001-5263-2374. Correo electrónico: jcarmona@ umanizales.edu.co

\section{Florentino Moreno Martín}

Psicólogo de la Universidad Complutense de Madrid. Doctor en Psicología de la Universidad Complutense de Madrid. Profesor titular de la 
Universidad Complutense de Madrid. Integrante del grupo de investigación "Psicosociología de la violencia social y del género" de la Universidad Complutense de Madrid. Orcid 0000-0002-0333-5995. Correo electrónico: fmoreno@psi.ucm.es

\section{COMPILADORES Y AUTORES}

\section{Mariela Narváez Marín}

Psicóloga de Universidad de Manizales. Especialista en Farmacodependencia - Universidad Católica Luis Amigó. Docente de la Universidad de Manizales. Integrante del grupo de investigación "Psicología Clínica y Procesos de Salud" de la Universidad de Manizales. Orcid 0000-0003-10198535. Correo electrónico: maye888@gmail.com

\section{Ana Sofía Gaviria Cano}

Psicóloga de la Universidad Católica de Pereira. Magíster en Pedagogía y Desarrollo Humano de la Universidad Católica de Pereira. Docente de la Universidad Católica de Pereira. Integrante del grupo de investigación "Comunicación, Educación y Cultura" de la Universidad Católica de Pereira. Orcid: 0000-0002-8805-7284. Correo electrónico: ana.gaviria@ucp.edu.co

\section{Gina Marcela Arias Rodríguez}

Psicóloga de la Universidad Católica Popular del Risaralda. Doctora en Ciencias Sociales y Políticas, Universidad Iberoamericana de México. Docente de planta de la Universidad Católica de Pereira. Integrante del grupo de investigación "Comunicación y Conflicto" de la Universidad Católica de Pereira. Orcid: 0000-0002-1759-818X. Correo electrónico: gina.arias@ucp.edu.co

\section{Jaime Arbey Atehortúa Sánchez}

Comunicador Social - Periodista de la Universidad de Antioquia. Magíster en Lingüística de la Universidad de Antioquia. Docente de la Universidad Católica de Oriente. Integrante del grupo de investigación "Gibpsicos" de la Universidad Católica de Oriente. Orcid 0000-0003-2176-9559. Correo electrónico: jatehortua@uco.edu.co

\section{Carlos Germán Celis Estupiñán}

Psicólogo de la Universidad Autónoma de Bucaramanga. Magíster en Semiótica de la Universidad Industrial de Santander. Docente investigador de la Universidad Autónoma de Bucaramanga Director del grupo de in- 
vestigación "Violencia, Lenguaje y Estudios Culturales" de la Universidad Autónoma de Bucaramanga. Orcid 0000-0002-5319-0114. Correo electrónico: ccelis2@unab.edu.co

\section{Martha del Rosario Peña-Sarmiento}

Psicóloga de la Fundación Universitaria Konrad Lorenz. Doctora en Psicología de la Universidad de Los Andes. Líder del Laboratorio de Procesos Psicosociales (LAPSO) del Centro de Estudios e Investigaciones en Psicología (CEIPS) de la Universidad Católica de Colombia. Integrante del grupo de investigación "EUROPSIS" de la Universidad Católica de Colombia. Orcid 0000-0002-0351-3333. Correo electrónico: mrpena@ucatolica.edu.co

\section{Olga Lucía Valencia Casallas}

Psicóloga de la Universidad Católica de Colombia. Doctora en Psicología Clínica, Legal y Forense de la Universidad Complutense de Madrid. Docente investigadora de la Universidad Externado de Colombia. Integrante del grupo de investigación "SICO" (Sistemas de información y control organizacional). Orcid 0000-0001-6103-7147. Correo electrónico: olgaluciavalenciacasallas@gmail.com

\section{Kethy Luz Perez Correa}

Psicóloga de la Universidad Autónoma de Bucaramanga. Doctor en Psicología con Orientación en Neurociencias Cognitivas Aplicadas de la Universidad Maimónides de Buenos Aires. Profesora de tiempo completo de la Universidad Cooperativa de Colombia. Integrante del grupo de investigación: "ESI" Estudios Sociales Interdisciplinares de la Universidad Cooperativa de Colombia. Orcid 0000-0001-8256-7278. Correo electrónico: kethy.perez@ucc.edu.co

\section{Wilson Miguel Salas Picón}

Psicólogo de la Universidad Cooperativa de Colombia. Magíster en Psicología Jurídica de la Universidad Santo Tomás. Profesor investigador de la Universidad Cooperativa de Colombia. Integrante y coordinador del grupo de investigadores en Ciencias Sociales y Jurídicas -GICSOJ- de la Universidad Cooperativa de Colombia. Orcid 0000-0003-1458-6770. Correo electrónico: wilson.salas@campusucc.edu.co

\section{María Camila Ospina Alvarado}

Psicóloga de la Universidad de Los Andes. Magíster en Psicología Clínica con Énfasis Sistémico de la Universidad de Los Andes, Candidata a Doctora en Ciencias Sociales, Niñez y Juventud Universidad de Manizales-CINDE. 
Coordinadora Nacional Investigaciones CINDE. Integrante del grupo de investigación "Perspectivas Políticas, Éticas y Morales de la Niñez y la Juventud" del CINDE y la Universidad de Manizales. Orcid 0000-00027271-151X. Correo electrónico: mospina@cinde.org.co

\section{Sara Victoria Alvarado Salgado}

Psicóloga de la Pontificia Universidad Javeriana. Doctora en Ciencias Sociales, Niñez y Juventud de la Universidad de Manizales-CINDE. Directora del Centro de Estudios Avanzados en Niñez y Juventud (CINDEUniversidad de Manizales). Integrante y líder del grupo de investigación "Perspectivas Políticas, Éticas y Morales de la Niñez y la Juventud". Orcid orcid.org/0000-0002-0115-8075.Coreo electrónico: s.v.alvarado.s@, gmail.com

\section{María Alejandra Fajardo Mayo}

Terapeuta Ocupacional de la Universidad Nacional de Colombia, Magíster en Desarrollo Educativo y Social de la Universidad Pedagógica Nacional - CINDE. Asistente de Investigaciones del Centro de Estudios Avanzados en Niñez y Juventud. Universidad de Manizales - CINDE. Integrante del grupo de investigación "Perspectivas Políticas, Éticas y Morales de la Niñez y la Juventud". Orcid 0000-0003-0323-1085. Correo electrónico: mafajardom@gmail.com

\section{Isabel Cristina Posada Zapata}

Psicóloga de la Universidad de Antioquia. Candidata a Doctora en Ciencias Sociales Niñez y Juventud, Universidad de Manizales-Cinde. Profesora asociada de la Universidad de Antioquia. Integrante del grupo de investigación "Salud Mental" de la Universidad de Antioquia. Orcid 00000003-4953-6490. Correo electrónico: isabel.posada@udea.edu.co

\section{Magda Victoria Díaz Alzate}

Psicóloga de la Universidad Católica Luis Amigó. Magíster en Educación y Desarrollo Humano de la Universidad de Manizales - CINDE. Docente Investigadora de la Universidad Católica Luis Amigó. Integrante del grupo de investigación "Estudios de Fenómenos Psicosociales"de la Universidad Católica Luis Amigó. Orcid 0000-0002-7712-8462. Correo electrónico: magda.diazal@amigo.edu.co

\section{Mariana Yepes Bustamante}

Psicóloga de la Universidad Católica Luis Amigó. Coordinadora Departamento de Gestión Humana de la Universidad Católica Luis Ami- 
gó. Orcid 0000-0002-1010-671X. Correo electrónico: coor.ghumana@, amigo.edu.co

\section{Luz Adriana Aristizábal Becerra}

Psicóloga de la Universidad Surcolombiana. Doctora en Persona y Sociedad en el Mundo Contemporáneo de la Universidad Autónoma de Barcelona. Docente Titular Tiempo Completo de la Universidad Autónoma de Bucaramanga. Integrante del grupo de investigación "Violencia, Lenguaje y Estudios Culturales". Orcid 0000-0002-3620-6276. Correo electrónico aristizabalb@gmail.com

\section{Miguel Ángel Cárdenas Medina}

Psicólogo de la Universidad Autónoma de Bucaramanga. Magíster en Terapia Familiar Sistémica de la Universidad Autónoma de Barcelona. Docente investigador de la Corporación Universitaria Iberoamericana. Integrante del grupo de investigación "Psicología, Ciencia y Tecnología" de la Corporación Universitaria Iberoamericana. Orcid 0000-0002-6280-6187. Correo electónico: mcardenas.ps@gmail.com

\section{Aida Milena Cabrera Lozano}

Psicólogo de la Universidad Cooperativa de Colombia. Magíster en Desarrollo Educativo y Social. CINDE - Universidad Pedagógica Nacional. Docente - Líder de Investigación de la Universidad Santo Tomás. Integrante del grupo de investigación "Psicología, Familia y Redes" de la Universidad Santo Tomás. Orcid 0000-0002-4377-2516.Correo electrónico: aidacabrera@, usantotomas.edu.co

\section{Diana Britto Ruiz}

Psicóloga de la Universidad del Valle, Doctorado en Estudios Latinoamericanos - Universidad de Ámsterdam. Docente de la Universidad de San Buenaventura de Cali. Integrante del grupo de investigación GEUS. Orcid 0000-0003-3934-2721. Correo electrónico: dabrittor@usbcali.edu.co

\section{Paula Vanessa Sánchez Agudelo}

Psicóloga de la Universidad de Manizales. Magíster en Desarrollo Infantil de la Universidad de Manizales. Docente investigadora de la Universidad Católica Luis Amigó. Integrante del grupo de investigación "Estudios de Fenómenos Psicosociales" de la Universidad Católica Luis Amigó. Orcid 0000-0002-6624-7087. Correo electrónico: paula.sanchezag@amigo.edu.co 


\section{Nathalia Aguirre Alvarez}

Psicóloga de la Universidad de Manizales. Magíster en Psicología Clínica de la Pontificia Universidad Javeriana. Docente-Investigadora de la Universidad Católica Luis Amigó. Integrante del grupo de investigación "Estudios de Fenómenos Psicosociales". Orcid 0000-0002-8560-9856. Correo electrónico: nathalia.aguirreal@amigo.edu.co

\section{Nicolasa María Durán Palacio}

Psicóloga de la Universidad de San Buenaventura, Medellín. Doctora en Filosofía de la Universidad Pontificia Bolivariana, Medellín. DocenteInvestigadora de la Universidad Católica Luis Amigó de Medellín. Integrante y líder del grupo de investigación "Estudios de Fenómenos Psicosociales" de la Universidad Católica Luis Amigó. Medellín. Orcid 0000-0001-54926931. Correo electrónico: nicolasa.duranpa@amigo.edu.co

\section{Heidi Smith Pulido Varón}

Psicóloga de la Universidad de Antioquia. Magíster en Desarrollo de la Universidad Pontificia Bolivariana, Medellín. Docente-Investigadora de la Universidad Católica Luis Amigó. Medellín. Integrante del grupo de investigación "Estudios de Fenómenos Psicosociales" de la Universidad Católica Luis Amigó. Medellín. Orcid 0000-0001-8198-0896. Correo electrónico: heidi.pulidova@amigo.edu.co

\section{Marda Zuluaga Aristizábal}

Psicóloga de la Universidad de Antioquia. Magíster en Historia y Memoria, Universidad Nacional de La Plata, Argentina. Profesora asistente, Departamento de Psicología de la Universidad EAFIT. Integrante del grupo de investigación "El método analítico y sus aplicaciones en las ciencias sociales y humanas". Orcid 0000-0002-3038-6683. Correo electrónico: mzulua12@eafit.edu.co

\section{Juan David Villa Gómez}

Psicólogo de la Pontificia Universidad Javeriana, Bogotá. Doctor en Migraciones Internacionales y Cooperación al Desarrollo. Docente asociado e investigador de la Universidad Pontificia Bolivariana. Integrante del "Grupo de Investigación en Psicología (GIP): Sujeto, Sociedad y Trabajo". Orcid 0000-0002-9715-5281. Correo electrónico: juan.villag@upb.edu.co

\section{Carlos Esteban Estrada Atehortúa}

Psicólogo de la Universidad de San Buenaventura, Medellín. Magíster en Psicología (USB Medellín). Docente investigador de la Universidad de 
San Buenaventura Medellín. Integrante del "Grupo de Estudios Clínicos y Sociales en Psicología" de la Facultad de Psicología de la Universidad de San Buenaventura - Medellín. Orcid 0000-0003-2356-7176. Correo electrónico: carlos.estrada@usbmed.edu.co

\section{Juan Fernando Oliveros Ossa}

Psicólogo de la Universidad de San Buenaventura, Medellín. Magíster en Gobierno y Políticas Públicas - Universidad EAFIT, Medellín. Docente de la Fundación Universitaria Claretiana. Integrante del grupo de investigación " Grupo de Estudios Clínicos y Sociales En Psicología" de la Facultad de Psicología de la Universidad de San Buenaventura, Medellín. Orcid: 0000-0001-9573-3589. Correo electrónico: juanferoliveros@gmail.com

\section{Leidy Paola Rentería Hernández}

Psicóloga de la Universidad de San Buenaventura, Medellín. Coordinadora del Colectivo de Mujeres Wiwas. Integrante del "Grupo de Estudios Clínicos y Sociales En Psicología" de la Facultad de Psicología de la Universidad de San Buenaventura, Medellín. Orcid 0000-0002-7873-654X. Correo electrónico: Leidyp.renteria@gmail.com

\section{Julio César Moreno Correa}

Psicólogo de la Universidad de Antioquia. Magíster en Educación de la Universidad de Antioquia. Profesor Investigador de la Universidad Cooperativa de Colombia. Integrante del grupo de investigación "Grupo de investigadores en Ciencias Sociales y Jurídicas -GICSOJ" de la Universidad Cooperativa de Colombia. Orcid 0000-0002-9222-5586. Correo electrónico: julio.moreno@campusucc.edu.co

\section{Katerine Andrade Gordillo}

Psicóloga de la Universidad del Bosque, Bogotá. Magíster en Psicología de la Universidad de San Buenaventura Cali. Labora en el rol de Especialista en Psicología en la Fuerza Aérea Colombiana. Integrante del grupo de investigación "Estéticas Urbanas y Socialidades - GEUS" de la Universidad de San Buenaventura de Cali. Orcid 0000-0002-1173-0864. Correo electrónico: katerineagh@hotmail.com

\section{Manuel Alejandro Moreno Camacho}

Psicólogo de la Universidad de San Buenaventura Cali. Magíster en Sociología, Universidad del Valle. Profesor, Escuela de Trabajo Social 
y Desarrollo Humano de la Universidad del Valle. Integrante del grupo de investigación "Estudios de Familia y Sociedad" de la Universidad del Valle. Orcid 0000-0002-4314-2215. Correo electrónico: moreno.manuel@, correounivalle.edu.co

\section{John Alexander Quintero Torres}

Psicólogo de la Universidad de San Buenaventura, Cali. Magíster en Psicoanálisis de la Universidad John F. Kennedy, Argentino. Profesor de la Facultad de Psicología de la Universidad de San Buenaventura, Cali. Integrante del grupo de investigación "Estéticas Urbanas y Socialidades - GEUS" de la Universidad de San Buenaventura Cali. Orcid 0000-00016944-0117. Correo electrónico: jaqtorre@usbcali.edu.co

\section{Diana Carolina Urbina Vanegas}

Psicóloga, Magíster en Antropología Social. Docente Universidad Piloto de Colombia. Integrante del grupo de investigación "Desarrollos Humanos, Educativos y Organizacionales" de la Universidad Piloto de Colombia. Orcid 0000-0002-8693-2081. Correo electrónico: durbina17@upc.edu.co

\section{Mary Natalia Ortegon Cifuentes}

Psicóloga de la Universidad Santo Tomás. Magíster en Psicología Clínica y de la Familia,Universidad Santo Tomás. Docente del Politécnico Grancolombiano. Integrante del grupo de investigación "Psicología, Educación y Cultura”. Orcid 0000-0001-9439-036. Correo electrónico: marynataliao@ gmail.com

\section{Daniel Enrique Monje Abril}

Realizador de cine y televisión de la Universidad Nacional de Colombia. Doctorado en Imagen, Arte, Cultura y Sociedad de la Universidad Autónoma del Estado de Morelos, México. Docente Investigador de la Universidad Manuela Beltrán. Integrante del grupo de investigación "REC- Reflexiones en torno a la producción cultural" de la Universidad Manuela Beltrán. Orcid 0000-0001-6104-1576. Correo electrónico daniel.monje@docentes. umb.edu.co 


\section{RECONOCIMIENTO A LAS UNIVERSIDADES \\ Y GRUPOS DE INVESTIGACIÓN PARTICIPANTES}

\begin{tabular}{|c|c|}
\hline UNIVERSIDAD & GRUPO DE INVESTIGACIÓN \\
\hline Universidad de Manizales & $\begin{array}{l}\text { - Psicología del Desarrollo } \\
\text { - Psicología Clínica y Procesos de Salud } \\
\text { - Perspectivas Políticas, Éticas y Morales de la Niñez y la } \\
\text { Juventud (CINDE -U. Manizales) }\end{array}$ \\
\hline Universidad Complutense de Madrid & Psicosociología de la Violencia Social y del Género \\
\hline \multirow{2}{*}{ Universidad Católica de Pereira } & Comunicación y Conflicto \\
\hline & Comunicación, Educación y Cultura \\
\hline Universidad de Antioquia & Salud Mental \\
\hline Universidad Católica Luis Amigó & Estudios de Fenómenos Psicosociales \\
\hline Corporación Universitaria Iberoamericana & Psicología, Ciencia y Tecnología \\
\hline Universidad Católica de Oriente & Grupo de Investigación Gibpsicos \\
\hline Universidad de San Buenaventura, Medellín & Grupo de Estudios Clínicos y Sociales \\
\hline $\begin{array}{l}\text { Universidad Pontifica Bolivariana, } \\
\text { Medellín }\end{array}$ & $\begin{array}{l}\text { Grupo de Investigación en Psicología (GIP): Sujeto, } \\
\text { Sociedad y Trabajo }\end{array}$ \\
\hline Universidad de San Buenaventura, Cali & GEUS. Grupo Estéticas Urbanas y Socialidades \\
\hline Universidad Piloto de Colombia & Desarrollos Humanos, Educativos y Organizacionales \\
\hline Universidad Cooperativa de Colombia & $\begin{array}{l}\text { - Grupo de Investigadores en Ciencias Sociales y } \\
\text { Jurídicas -GICSOJ- } \\
\text { - Estudios Sociales Interdisciplinares - ESI }\end{array}$ \\
\hline Universidad Autónoma de Bucaramanga. & Violencia, Lenguaje y Estudios Culturales \\
\hline Fundación Universitaria Konrad Lorenz & Ciencias del Comportamiento \\
\hline Corporación Universitaria Iberoamericana & Psicología, Ciencia y Tecnología \\
\hline $\begin{array}{l}\text { Institución Universitaria Politécnico } \\
\text { Grancolombiano }\end{array}$ & Psicología, Educación y Cultura \\
\hline Universidad Manuela Beltrán & Reflexiones en Torno a la Producción Cultural \\
\hline Universidad EAFIT & $\begin{array}{l}\text { El método analítico y sus iplicaciones en las Ciencias } \\
\text { Sociales y Humanas }\end{array}$ \\
\hline Universidad del Valle & Estudios de Familia y Sociedad \\
\hline Universidad Santo Tomás & Psicología, Familia y Redes \\
\hline
\end{tabular}




\section{PRÓLOGO}

\section{Gonzalo Tamayo Giraldo ${ }^{1}$}

Es un doble placer académico darle apertura a la cátedra Mercedes Rodrigo 2019 "Reconstrucción de subjetividades e identidades en contextos de guerra y posguerra". En primer lugar por la noble relación de apoyo que la Universidad de Manizales y su Programa de Psicología le ha dado a lo largo de la historia a la Cátedra y en segundo lugar por la gratitud que le debemos a ASCOFAPSI como faro que orienta la formación de psicólogos en Colombia.

Nos sentimos felices de hacer realidad este sueño escritural, seguros de nuestra responsabilidad histórica por ser miembros fundadores de ASCOFAPSI y por compartir los múltiples saberes que desde cada una de las facultades y programas de psicología hemos construido.

La Universidad de Manizales ha asumido en la Asociación distintos roles, desde su presidencia y su vicepresidencia hasta ser miembro cooperador en la construcción de proyectos de impacto para la psicología en el país; en cada uno de ellos hemos creído profundamente en la pertinencia y necesidad de una ASCOFAPSI cercana a las dinámicas académicas de la psicología y rigurosa como faro orientador de la ciencia psicológica.

Estas iniciativas se recogen claramente en los 21 estudios que en este texto se presentan, seguimos creando una psicología que responda con pertinencia a los embates de la vida actual. El Eje Cafetero, Colombia y Latinoamérica deben verse impactadas por lo que aquí se refleja: una ciencia psicológica que apoya la búsqueda del bienestar de las personas, los grupos y las comunidades.

El deseo de una América Latina con más oportunidades, respetuosa de las diferencias, con el criterio que el diálogo escritural es el mecanismo apropiado para socializar saber; el deseo que la psicología puede aportarle, en comunicación interdisciplinar, una mejor manera de vivir a nuestro continente; la apuesta es la de una América Latina en donde se activen formas de solución de conflictos basadas en la conversación intercultural e interdisciplinar. Este deseo se basa, en estos tiempos de reflexión-acción, en la comprensión de la realidad como una construcción colectiva y en que todos somos responsables de lo que hoy padecemos. Por eso, debemos

1 Decano Facultad de Ciencias Sociales y Humanas, Universidad de Manizales. gotamayo@ umanizales.edu.co 
ponernos manos a la obra para transformar lo que sea necesario y convertir a la psicología en un bálsamo en tiempos difíciles.

Son tiempos en los que se necesitan espacios de reflexión, de conversación, en lo que la psicología puede contribuir a darle sentido a este mundo enloquecido por el mercado, por el consumo y por la guerra. Este llamado es un mandato ético y un desafío de conocimiento. Es preciso pensar nuevas formas de conocer y de hacer psicología, hoy la cátedra Mercedes Rodrigo nos presenta esta opción como camino.

Lo anterior solo será posible mediante investigaciones rigurosas, que puedan ir más allá de los datos, que repliquen con rigor sistemático sus hallazgos; y sobre todo, deben ser investigaciones que indaguen con sentido ético lo que realmente acontece en la vida humana, que indaguen por sus insatisfacciones, que conozcan sus intereses y que le aporten a la construcción de países incluyentes, respetuosos del otro, amables y con oportunidades. Sin perder el rigor científico, la psicología tendrá que seguir el camino de una apuesta por la humanidad.

En este sentido, hay que preguntarse por la manera como se piensa, se enseña y se aprende la psicología. La forma como se piensan sus lecciones, sus laboratorios, sus talleres y sus proyectos sociales. El campo de sus problemas, la dinámica de sus refutaciones, el control de sus errores, el horizonte de sus enigmas, sus anomalías y sus programas de investigación. Es preciso preguntarse cómo se piensa la disciplina psicológica en sus vigilancias epistémicas, en sus rupturas, en sus contextos. Cómo se concreta en sus comunidades científicas, en sus grupos de investigación, en sus colectivos docentes y en sus currículos.

Queremos saber la forma como la psicología se percibe en sus opciones y sus decisiones, en sus elecciones, en sus actuaciones y sus realizaciones. Cómo se observa en sus reflexiones, en su imagen, en su estructura disciplinar. Cómo se piensa la psicología en sus pretensiones, en sus predicciones, en sus potencias y en sus fragilidades.

Cómo se encuentra en sus acumulaciones y en sus progresiones. Cómo se hace visible ante los ojos prevenidos de quien la consulta.

Y unas preguntas más:

- ¿La psicología que hacemos contribuye con sus propuestas o sus críticas a los desarrollos curriculares para la formación de los psicólogos en el contexto latinoamericano? 
- ¿Tenemos canales de comunicación expeditos para socializar los hallazgos científicos o nos conformamos con que solo las élites académicas conozcan nuestras búsquedas?

- ¿Hemos puesto nuestras prácticas científicas y profesionales al servicio de la transformación de nuestra región y del mundo?

- ¿Nos hemos pensado en futuro y hemos concebido la ciencia psicológica como preponderante para el país que queremos construir?

Hoy los invito a seguir reflexionando en algunos de estos interrogantes, y a poner la mirada de la psicología en la vida diaria de las personas que habitamos el planeta. Estos 21 estudios lo hacen transitando por los laberintos de una paz imperfecta y una guerra que no queremos más. Hoy la Cátedra Colombiana de Psicología Mercedes Rodrigo 2019 nos permite reconocer los avatares de una guerra fratricida y los alcances de humanidad de una paz que construye, potencia y dignifica nuestro ser humanos. 


\section{Introducción}

\section{Jaime Alberto Carmona Parra ${ }^{1}$}

Este texto reúne 21 estudios sobre los procesos de reconstrucción de la subjetividad, la identidad y el tejido social en contextos afectados por la guerra en Colombia. Estos estudios fueron realizados por investigadores vinculados a los grupos de investigación de las Facultades de Psicología, adscritas a la Asociación Colombiana de Facultades de Psicología-ASCOFAPSI. En este sentido podemos decir que es un aporte en el que se materializa el compromiso de las Facultades de Psicología articuladas en ASCOFAPSI con la investigación y la discusión de los caminos de la posguerra que intenta empezar a transitar el País.

La historia de esta publicación se origina en la ciudad de Valledupar, en el mes de marzo del año 2017. En la Asamblea Anual de Ascofapsi, realizada allí, se aprueba la propuesta presentada por la Universidad de Manizales y la Universidad Católica de Pereira para la realización de la Cátedra Mercedes Rodrigo en el año 2019, en torno a la reconstrucción de la subjetividad, la identidad y el tejido social en contextos de guerra y posguerra en Colombia. A partir de este momento se conforma un comité de compilación integrado por académicos de las dos universidades en el que se decide que sean los investigadores de las facultades adscritas a ASCOFAPSI con sus productos, los protagonistas de esta versión número XIV de la Cátedra. Para ello se definen unos criterios de pertinencia y calidad de los productos de investigación que se presentarán y se diseña un cronograma de trabajo.

Con esta perspectiva se presentó una primera convocatoria a todos los investigadores vinculados a las facultades adscritas a ASCOFAPSI, en la que se informaba el tema de la cátedra, los criterios de selección de los trabajos y el calendario del proceso, y se invitaba a enviar un primer resumen, con el propósito de garantizar el ajuste de los trabjaos al enfoque y tema de la cátedra. En esta fase se recibieron 41 resúmenes. El Comité Compilador Interinstitucional hizo un primer análisis y aprobó 31 de ellos. A estos se les envió la invitación para que presentaran el borrador final del capítulo con la estructura de artículo producto de investigación. De ellos 25 enviaron este producto. Nuevamente los integrantes del Comité Interinstitucional realizaron la revisión de los productos, aprobaron 21 trabajos y rechazaron

1 Universidad de Manizales. Coordinador de la Cátedra Colombiana de Psicología Mercedes Rodrigo 2019. Correo: jcarmona@umanizales.edu.co 
cuatro. A varios de los trabajos aprobados se les hicieron recomendaciones de contenido y forma para garantizar la calidad de la publicación.

Finalmente, una vez estructurado el libro con todos sus componentes revisados y ajustados, se invitó al Dr. Flortentino Moreno Martín de la Universidad Complutense de Madrid, un experto en la temática, como coeditor internacional de la obra, para revisar y validar los productos de investigación y para que escribiera un capítulo teórico introductorio. De esta revisión surgió la decisión de organizar el libro por secciones y se realizaron algunos ajustes. Una vez reorganizado y ajustado el texto, se presentó al Comité Editorial de la Universidad de Manizales para ser enviado a pares evaluadores de Colciencias.

La estructura del libro es la siguiente: la primera sección está conformada por dos capítulos teóricos de los editores académicos (tres y cuatro) que aportan lineamientos conceptuales actualizados para la investigación y teorización del problema en torno al cual gira la Cátedra Mercedes Rodrigo 2019, en el tercero se introducen las ideas centrales del trabajo académico realizado en entornos de guerra y en el cuarto se sitúa la orientación teórica del libro.

Las tres secciones siguientes contienen los 21 estudios de los investigadores de ASCOFAPSI: la segunda sección está conformada por los capítulos cinco al ocho, son estudios teóricos que contribuyen al desarrollo investigativo en el campo de la obra en cuanto aportan al debate para la problematización y perfilamiento de algunos conceptos fundamentales en este campo como: "víctima", "sobreviviente", "discurso", "relato", "narrativa", "testimonio", "síntoma", "duelo" etc. Las secciones tercera, cuarta y quinta contienen las investigaciones empíricas, que se organizan por poblaciones para efectos de facilitar a los lectores el estudio de la obra. La tercera sección comprende los capítulos nueve y diez, son estudios empíricos de infancia. La cuarta sección comprende los capítulos 11 al 16, son estudios empíricos sobre mujeres. La quinta sección comprende los capítulos 17 al 25 y se ocupa de otras poblaciones diferentes a niños y mujeres. Finalmente, la sexta y última sección es el metaanálisis en el que se hace un balance de los principales aportes de los capítulos al estudio del problema propuesto.

Esperamos que los lectores de este libro encuentren en él elementos de análisis que contribuyan a la reflexión y la discusión sobre la manera como millones de niñas, niños, jóvenes y adultos, en las montañas y en los poblados de Colombia, reconstruyen sus subjetividades, sus identidades 
y el tejido social, en este período especial de la historia del país en el que estamos apostando a transitar por la senda de una posguerra con uno de los ejércitos insurgentes más antiguos del mundo, mientras tratamos de mantener viva la negociación con otro ejército todavía alzado en armas, de otra guerra que aún no termina. 


\section{ASCOFAPSI: breve semblanza de un compromiso con la calidad de la formación de los psicólogos en Colombia}

\section{Diego Alveiro Restrepo OchoA ${ }^{2}$}

El crecimiento en el número de programas de formación de psicólogos en Colombia durante la década de los 80 , la expansión de la Psicología profesional y la emergencia de nuevos retos ligados a la situación sociopolítica del país, constituyeron un momento histórico muy importante de la Psicología Colombiana, en el cual se hizo evidente la necesidad de organizar dicho crecimiento y de establecer los lineamientos para el desarrollo científico y profesional de la Psicología. Es así como en el año 1986 un grupo de académicos decide crear la Asociación Colombiana de Facultades de Psicología (ASCOFAPSI), integrada en sus inicios por 12 programas de Psicología, que tenían como propósito generar un espacio para la reflexión y la acción en torno a los problemas más relevantes en la formación de psicólogos que permitiera dar respuesta a los retos y necesidades del país y a las vicisitudes propias de la disciplina en nuestro contexto.

ASCOFAPSI se ha convertido en un actor fundamental de la Psicología en Colombia y ha logrado convocar más de 70 programas en todo el país para trabajar de la mano con los docentes, investigadores, estudiantes y directivos en el cumplimiento de su misión: "velar por el mejoramiento de la formación universitaria del psicólogo en Colombia, con la colaboración permanente de sus miembros, para contribuir al desarrollo científico, profesional, ético y social de la Psicología"

En respuesta a los compromisos con el desarrollo de la Psicología, ASCOFAPSI ha asumido un importante liderazgo político y académico en los diferentes escenarios en los que se debaten y se toman decisiones sobre temas relacionados con la formación en Psicología y en general con el desarrollo de la disciplina en el país. Así mismo, ha venido gestando un

2 Universidad CES. Presidente de Ascofapsi. Correo: drestrepo@ces.edu.co 
conjunto de redes y alianzas estratégicas a nivel nacional e internacional que le permiten tener una permanente interlocución con el gremio, con la comunidad académica internacional y con el sector público.

A continuación se describen los principales proyectos y actividades de la Asociación, organizados en torno a cinco líneas: investigación y gestión de conocimiento, formación y capacitación, creación y fortalecimiento de redes y alianzas, participación política y fortalecimiento institucional en temas de calidad.

\subsection{Investigación y gestión de conocimiento}

Esta primera línea tiene como propósito la generación, divulgación y transferencia de conocimiento en temas relacionados con la formación en Psicología y con el desarrollo de la Psicología en Colombia.

Los proyectos que se desarrollan en esta línea son:

\section{Congreso Colombiano de Psicología}

Es el principal evento académico de la Psicología en Colombia que se realiza en alianza con el Colegio Colombiano de Psicólogos -COLPSICcada dos años, de manera itinerante por las diferentes regiones del país. ASCOFAPSI es el responsable de la organización y programación académica del mismo, logrando con ello la participación de los docentes e investigadores de los programas miembros en calidad de conferencistas centrales, pares evaluadores, participantes de simposios y talleres. Así mismo, los miembros de ASCOFAPSI participan de una agenda paralela para el abordaje de temas específicos relacionados con la formación (prácticas, internacionalización, currículo, normatividad, etc.).

\section{Observatorio de la calidad en educación superior en Psicología en Colombia}

El observatorio tiene como propósito la recopilación, organización y divulgación de información confiable y actualizada sobre la Psicología en Colombia:

La Misión del Observatorio de la Calidad en la Educación Superior en Psicología en Colombia es ofrecer un sistema confiable de información sobre diferentes aspectos de la educación en Psicología en el país, que pueda ser utilizado por instituciones y agremiaciones públicas y privadas para el conocimiento del estado de la formación y producción académica de la Psicología colombiana. 
El Observatorio busca recopilar información básica sobre los programas académicos de pregrado y postgrado en Psicología, sobre la producción académica investigativa de los diferentes grupos de investigación en todas las áreas de la Psicología, sobre el estado de las competencias de los egresados de los diferentes programas a nivel nacional, sobre el impacto del ejercicio profesional de la Psicología en Colombia y sobre el impacto de la psicología colombiana en América Latina y el mundo. El Observatorio busca además generar indicadores de calidad que permitan el seguimiento del estado de la formación y la producción de la psicología colombiana a través del tiempo, en los aspectos antes mencionados. Finalmente, el Observatorio pretende generar estrategias investigativas y aplicadas para el mejoramiento de la calidad de la psicología colombiana, basadas en las fortalezas y debilidades detectadas por el análisis de toda la información disponible. (http://observatorio.ASCOFAPSI.org.co/)

\section{Convocatoria de investigaciones}

ASCOFAPSI realiza anualmente convocatorias para financiar proyectos de investigación propuestos por los programas miembros, en temas relacionados con la formación, la historia de la Psicología en Colombia y con los problemas propios de cada uno de los nodos de investigación de ASCOFAPSI

\section{Apoyo a publicaciones}

La Asociación cofinancia la publicación de libros derivados de la actividad investigativa, las reflexiones curriculares o las experiencias de formación de los programas miembros.

\subsection{Formación y capacitación}

En esta línea se agrupan todos los proyectos y actividades orientadas al desarrollo de capacidades y la cualificación de los docentes y estudiantes en temas de formación, ética profesional y problemas fundamentales de la Psicología

\section{Cátedra Colombiana Mercedes Rodrigo}

La Cátedra Colombiana de Psicología Mercedes Rodrigo viene realizándose desde 2005, liderada y aprobada por la Asamblea de ASCOFAPSI, en conmemoración por la creación del Instituto de Psicología Aplicada en la Universidad Nacional de Colombia el 20 de noviembre de 1947, que fue impulsado por la psicóloga española Mercedes Rodrigo. 
La Cátedra brinda la posibilidad a los diferentes programas miembros de ASCOFAPSI, de proponer ejes temáticos de amplio desarrollo en sus unidades académicas y apoyados por las acciones de los nodos de investigación. Con esto, se busca fortalecer el trabajo en red entre las universidades que participan en su organización, promover la flexibilidad curricular entre los programas de Psicología, y generar espacios de formación extracurricular por medio de una Cátedra que presente los desarrollos y avances de la Psicología colombiana, con temas de actualidad e interés para docentes, egresados y profesionales en general.

Esta actividad se realiza anualmente en el primer semestre y los estudiantes pueden tomarla por trasmisión vía web, de forma tal que para las instituciones se convierte en una posible materia electiva homologable dentro del plan de estudios, contribuyendo así a la movilidad académica.

Formación en ética para el desarrollo de la Psicología

El portal web "Ética Psicológica" es un proyecto desarrollado conjuntamente por ASCOFAPSI y COLPSIC, con la colaboración de la Universidad del Rosario.

Teniendo en cuenta que la institucionalización de los Tribunales de Ética Profesional en Colombia es muy reciente, una gran parte de los psicólogos y psicólogas que ejercen en el país pueden no estar muy familiarizados con los desarrollos normativos del ejercicio ético de la profesión. En este sentido, el portal "Etica Psciológica" pretende promover el acceso a conocimientos actualizados sobre ética profesional para facilitar la toma de decisiones y la correcta práctica de la Psicología en Colombia.

Para tal fin recopila artículos originales, reseñas de las principales leyes y doctrinas, análisis de casos y material pedagógico sobre el tema. (www. eticapsicologica.org)

Programa de formación continua

El programa de formación continua ofrece múltiples acciones de trabajo conjunto orientadas a la cualificación de docentes, administrativos y estudiantes de los programas miembros de ASCOFAPSI:

- Cursos virtuales: se ofrece formación certificada y gratuita para docentes y directivos de los programas miembros a fin de contribuir con el desarrollo de competencias necesarias para la gestión académica, ya sea a nivel administrativo o para el trabajo de aula, a través de cursos 
desarrollados por expertos en los diversos temas y la implementación de los mismos en el campus virtual de ASCOFAPSI.

- Encuentros ASCOFAPSI: se realizan encuentros de formación y capacitación en diferentes ciudades del país, dirigidas a directivos y docentes a partir de temáticas que previamente se escogen como prioritarias para la Psicología en el país.

- Videoconferencias: semestralmente se programan entre 5 y 6 videoconferencias dirigidas a docentes y estudiantes sobre temas fundamentales de la formación, las cuales se trasmiten vía web para los programas interesados. Estas conferencias quedan disponibles en la página WEB de ASCOFAPSI y en el canal de Youtube, como material pedagógico para los programas.

Becas docentes

A partir del año 2018, se implementó el programa de becas docentes que busca contribuir a la formación posgradual de los docentes de programas miembros. Las becas se otorgarán a través de convocatoria abierta para adelantar estudios de maestría en programas miembros de ASCOFAPSI.

\subsection{Creación y fortalecimiento de redes y alianzas}

A través de esta línea, la asociación buscar generar e impulsar redes de trabajo entre los programas miembros e igualmente generar alianzas nacionales o internacionales que contribuyan al cumplimiento de su misión Nodos y encuentros de investigadores

ASCOFAPSI ha creado una red de nodos de investigación que busca la organización y gestión de la actividad investigativa en Psicología y el trabajo colaborativo entre los grupos de investigación de las instituciones que hacen parte de la asociación. Actualmente existen 13 nodos de investigación que trabajan en proyectos coordinados.

Cada dos años ASCOFAPSI organiza el Encuentro de Investigadores en el que se reúnen los diferentes nodos para socializar sus avances y para definir las agendas de trabajo conjunto en lo que respecta a proyectos, publicaciones, eventos, etcétera. 


\section{Redes ASCOFAPSI}

El trabajo en red ha demostrado su importancia para lograr desarrollos y compartir conocimientos y experiencias exitosas, que contribuyan a mejorar el trabajo de los miembros participantes de la misma. Por ello la Asociación ha contribuido a la formación de proyectos de trabajo en red. A continuación, se reseñan las redes conformadas con el auspicio de ASCOFAPSI.

- Red de prácticas profesionales REPPSI: convoca a los coordinadores responsables de las prácticas en los programas de Psicología y ofrece apoyo para estructurar, evaluar y hacer seguimiento tanto a los escenarios de práctica como a los supervisores y estudiantes que las realizan. De igual manera trabaja en la definición de los estándares y reglamentaciones que orientan las prácticas a fin de que las instituciones den respuesta a las mismas.

- Red de instituciones de servicios universitarios de atención psicológica ISUAP: agrupa a las Instituciones de Servicios Universitarios de Atención Psicológica y su trabajo se orienta al estudio, evaluación e implementación de acciones de mejoramiento en los espacios de atención psicológica externa o interna que ofrecen los programas de Psicología. Se busca compartir la normatividad, tener claridades sobre exigencias legales, reconocer el papel del profesional en estos espacios, así como el rol de los diferentes participantes de los consultorios.

- Red de editores: agrupa los editores de revistas de los diversos programas. Su objetivo es compartir experiencias de trabajo y buenas prácticas, así como estrategias de posicionamiento y reconocimiento de las revistas de Psicología que se editan en el país.

- Red de laboratorios: agrupa a los coordinadores de laboratorios con el objetivo de compartir experiencias sobre el desarrollo de los laboratorios y su uso en los procesos de formación e investigación.

- Red de doctorados: convoca los programas de doctorado en Psicología y busca compartir experiencias, visibilizar los productos de investigación y analizar el impacto de la formación doctoral de los estudiantes en el panorama de la Psicología del país.

Internacionalización

ASCOFAPSI participa constantemente en eventos internacionales que le permiten fortalecer sus redes investigativas y realizar aportes a la organización de la Psicología a nivel regional. Se han establecido vínculos para 
avanzar en temas de interés con la APA, la SIP y en la actualidad se encuentra en proceso de desarrollo el proyecto de Observatorio Latinoamericano de la Psicología, en convenio con el Colegio Colombiano de Psicólogos.

\subsection{Participación política}

ASCOFAPSI participa activamente en la discusión, implementación y evaluación de políticas públicas en temas relacionados directa o indirectamente con la formación en Psicología. Algunas de las entidades e instancias de participación política son:

- Instituto Colombiano para la Evaluación de la Educación Superior ICFES.

- Las mesas de reglamentación de la Ley de Salud Mental -Ley 1616-

- Los foros de socialización en diferentes instituciones de educación superior.

- Comité nacional interinstitucional para la prevención y erradicación de la explotación sexual comercial de niñas, niños y adolescentes ESCNNA-.

- Comité de Políticas Públicas conformado por el Colegio Colombiano de Psicólogos y ASCOFAPSI.

- Comisión intersectorial del talento humano en salud.

- Comité técnico del proyecto ESCNNA

- Comisión de Salud Mental

- Ministerio de Educación

- Ministerio de Salud

Esta activa participación política no solo impacta positivamente la toma de decisiones en temas de gran relevancia para el desarrollo de la Psicología, sino que también permite a los programas miembros estar actualizados en las más recientes disposiciones normativas.

\subsection{Fortalecimiento institucional en temas de calidad}

En esta línea se desarrollan diversas actividades orientadas a acompañar a los programas miembros y a las instituciones públicas en temas de evaluación, obtención de registros calificados, acreditación de alta calidad, docencia-servicio, entre otros 
Exámenes de calidad de la educación superior Saber Pro en Psicología

ASCOFAPSI fue seleccionada por el ICFES para coordinar el proceso de diseño de las pruebas de Evaluación de Calidad de la Educación Superior del Programa de Psicología y ha participado en este proceso desde el año 2003.

Programa Par Amigo

ASCOFAPSI considera el registro calificado y la acreditación de los programas de Psicología como factores fundamentales para el fortalecimiento de la calidad en la formación de profesionales. En este sentido, ofrece a los programas de Psicología, la posibilidad de tener acompañamiento en los procesos de autoevaluación con miras a la autorregulación, acreditación y registro calificado.

Premio a la innovación docente

A partir de 2018 se otorgará un premio nacional a la innovación docente, que busca visibilizar el trabajo docente y las prácticas innovadoras en aula como un incentivo a las búsquedas pedagógicas y didácticas de los profesores.

Estas y otras actividades dan cuenta del dinamismo de ASCOFAPSI y de su valioso aporte a la Psicología del país. En estos más de 30 años de historia, la asociación ha logrado consolidar una comunidad académica vibrante, reflexiva y crítica, ha permitido a los programas mantener un diálogo permanente y constructivo y ha tendido puentes desde la academia con el gremio, el sector público y el sector productivo para aportar a la construcción de una psicología que logre dar respuesta a las necesidades del contexto

Este texto que hoy celebramos entra a formar parte de la historia material de la asociación y condensa magistralmente la producción intelectual de investigadores pertenecientes a instituciones ASCOFAPSI, en torno a un tema de gran relevancia para el momento histórico que vive Colombia: Reconstrucción de subjetividades, identidades y del tejido social en contextos afectados por la guerra.

ASCOFAPSI agradece el liderazgo de la Universidad de Manizales en la organización de la Cátedra Mercedes Rodrigo 2019 y en la preparación de este libro. Igualmente expresamos nuestra gratitud y admiración a los Editores Académicos de esta obra Jaime Alberto Carmona Parra y Florentino Moreno Martín; a los Compiladores Jaime Alberto Carmona Parra, Ana Sofía 
Cátedra Colombiana de Psicología

Mercedes Rodrigo 2019

Gaviria Cano, Mariela Narváez Marín, y Gina Marcela Arias Rodríguez y a cada uno de los autores que generosamente han aportado sus trabajos para dar vida a este proyecto. 


\section{Cátedra Mercedes Rodrigo: un espacio para compartir conocimiento}

\section{Astrid Triana Cifuentes ${ }^{3}$}

La Cátedra Mercedes Rodrigo ha sido un proyecto de ASCOFAPSI que ha tenido una alta repercusión académica y se ha posicionado como una espacio de visibilización de las investigaciones y trabajos de las universidades miembros y una posibilidad de generar movilidad y flexibilidad a los planes de estudio de los programas miembros.

El uso de los recursos de las TIC permite que todos los programas puedan beneficiarse de ella en la medida en que se puede acceder desde cualquier ciudad y compartir el conocimiento desarrollado por colegas y otros profesionales, en temas de interés de la Psicología.

A lo largo de los años y desde su nacimiento ha ofrecido a estudiantes y docentes opciones de diálogo académico, intercambio de experiencias, puntos de de reflexión compromiso y establecimiento de vínculos, que nacidos en el marco puntual de este espacio, se han traducido en publicaciones, alianzas y trabajo colaborativo que redunda en la calidad de la formación del psicólogo colombiano.

\subsection{Algo de historia}

En el año 2004, el profesor Juan Guerrero de la Universidad Nacional propone, en la asamblea de miembros de la Asociación Colombiana de Psicología ASCOFAPSI, la creación de una cátedra interinstitucional denominada PSIQUE cuyo objetivo sea socializar las investigaciones realizadas en los diferentes programas adscritos a la Asociación. En la propuesta se plantea que se realice durante un semestre académico, tenga periodicidad quincenal y se oferte en modalidades presencial y virtual. Esta iniciativa es aprobada por la Asamblea.

Para materializar la iniciativa se reunieron en el mes de diciembre del mismo año representantes de las facultades de Psicología de las universidades: Católica de Colombia, El Bosque, Santo Tomás, U. del Valle, Konrad Lorenz, Nacional, Sabana, Javeriana Cali e Iberoamericana y la dirección

3 ASCOFAPSI, Directora Ejecutiva. Correo: direccionejecutiva@ascofapsi.org.co 
ejecutiva de ASCOFAPSI, con el fin de precisar el tema, hacer ajustes a la propuesta inicial y llevar avances de esta la iniciativa a la siguiente Asamblea.

Efectivamente en el año 2005, el Acta de la Asamblea Ordinaria de Miembros realizada en Medellín consigna: "La Cátedra Colombiana de Psicología "Mercedes Rodrigo" es un escenario para el diálogo permanente de los programas de Psicología afiliados a ASCOFAPSI, para identificar las fortalezas de las universidades, avanzar en la construcción de énfasis disciplinares. No necesariamente la implementación de la Cátedra en una institución afecta la estructura del plan de estudios, pero sí se pretende que tenga valor a currículo. Ahora bien, las formas de evaluación son un asunto operativo a resolver" (ASCOFAPSI, 2005). Como puede verse, la denominación inicial de la Cátedra se cambia y se asume el nombre que desde ese momento ha acompañado esta iniciativa: Cátedra Colombiana de Psicología Mercedes Rodrigo. El nombre seleccionado hace un reconocimiento a la psicóloga española Mercedes Rodrigo Belillo quien fundó la Sección de Psicotecnia de la Universidad Nacional, que posteriormente daría paso al primer programa académico de formación en Psicología, en la Universidad Nacional en 1947.

La primera versión de la Cátedra Mercedes Rodrigo se desarrolló en la Universidad Nacional de Colombia sede Bogotá, durante el segundo semestre del año 2005. Se desarrollaron 14 sesiones con la participaron 10 programas de Psicología, ofertadas presencial y virtualmente. La segunda versión de la Cátedra estuvo a cargo de la Universidad Santo Tomás, y se realizó en el segundo semestre del año 2006 (agosto 19 a noviembre 18), con 13 sesiones de trabajo y la participación de ponentes de doce (12) universidades.

Estas dos primeras versiones de la Cátedra se caracterizaron por incluir temas de diversos ámbitos teóricos y campos aplicados, de forma tal que cada sesión agotaba el tema presentado y en la siguiente abordaba uno nuevo. Se daba cabida a conferencias de orden teórico (reflexiones, revisiones) como a resultados de investigaciones terminadas o en curso.

Sin embargo, la tercera versión de la Cátedra cambia esta dinámica y propone desarrollar un tema específico en torno al cual se desarrollaran todas las sesiones. La versión 2007, que desarrolla la Universidad de Los Andes propone entonces abordar un eje conductor que gire en torno a los problemas del contexto social del país. La programación se presenta en dos módulos: El primero orientado al desarrollo de temas relacionados con violencia política y trauma psicosocial, el segundo a la convivencia y prevención de la agresión. En esta versión además del cambio de formato se incluye la 
invitación a conferencistas provenientes de otras organizaciones (diferentes a programas de Psicología) y a invitados de universidades extranjeras. Además de lo anterior se propone que sea manejado como un seminario de profundización con un valor de tres créditos académicos y se plantean requerimientos de asistencia, lectura y evaluación para ser certificada.

A partir de la cuarta versión de la Cátedra, liderada por el Programa de Psicología de la Universidad Javeriana Cali, se implementaron otras medidas en la organización: se pidió un profesor tutor que hiciera seguimiento a los estudiantes participantes de las diversas instituciones, se trabajó a través de la red Renata, se creó un aula virtual en la cual se dejaba el material para ser consultado posteriormente y al final del semestre se aplicó un instrumento de evaluación que se entregó a la Asociación en el cual se presentaban los estadísticos descriptivos de los resultados.

Progresivamente la Cátedra ha venido transformándose, de acuerdo con las propuestas de las universidades organizadoras. Algunas incluyen una gran cantidad de invitados internacionales, como es el caso de la versión VIII, en la cual nueve de las sesiones estuvieron a cargo de invitados internacionales. En otras se cuenta con la participación de invitados de profesiones diferentes de la Psicología, como sucedió en la versión VII La memoria y sus trastornos, en la que fueron invitados médicos, antropólogos, arquitectos a disertar sobre el tema central en relación con sus profesiones particulares.

Un hito importante lo constituye la versión XI en la cual la Universidad de Ibagué lidera la producción de un libro de memorias que compila las intervenciones realizadas. Así, el producto derivado de la Cátedra se convierte en material de consulta para estudiantes y profesionales. (Para consulta y descarga ingresar a la web de la Asociación, sección de publicaciones).

\subsection{Cátedra Mercedes Rodrigo a través de los años}

A continuación, se incluyen las diferentes versiones que hasta la fecha se han realizado (tabla 1). Es posible observar la variedad temática de cada una y con ello tener una idea de los intereses académicos del momento, pero también de los énfasis y motivaciones de los programas que en cada momento fueron responsables de liderar este proyecto. Es importante anotar que hubo un año en el cual no se realizó la Cátedra por cuanto la programación del segundo semestre de la misma coincidía con el desarrollo del Congreso Colombiano de Psicología. Por ello, en el año 2013 se decidió que las siguientes versiones de la Cátedra se realizaran el primer semestre 
del año, a fin de no tener en paralelo dos actividades que requieren para Ascofapsi una logística importante.

Tabla 1. Cátedra Mercedes Rodrigo a través de los años

\begin{tabular}{|c|c|c|c|}
\hline Año & Versión & Instituciones & Tema \\
\hline 2005 & I & Universidad Nacional & Cátedra Colombiana de Psicología Mercedes Rodrigo \\
\hline 2006 & II & Universidad Santo Tomás & Cátedra Colombiana de Psicología Mercedes Rodrigo \\
\hline 2007 & III & Universidad de Los Andes & Cátedra Colombiana de Psicología Mercedes Rodrigo \\
\hline 2008 & IV & Universidad Javeriana Cali & Impacto social de la disciplina psicológica \\
\hline 2009 & V & $\begin{array}{l}\text { Universidad de Manizales } \\
\text { U. Católica Popular de Risaralda }\end{array}$ & $\begin{array}{l}\text { La Psicología contemporánea frente a los desafíos de } \\
\text { nuestro tiempo }\end{array}$ \\
\hline 2010 & VI & $\begin{array}{l}\text { U. de San Buenaventura } \\
\text { U. de la Sabana }\end{array}$ & $\begin{array}{l}\text { La Psicología Colombiana en el contexto } \\
\text { latinoamericano. Perspectivas básicas y aplicadas. }\end{array}$ \\
\hline 2011 & VII & $\begin{array}{l}\text { Universidad San Buenaventura } \\
\text { Universidad de Antioquia } \\
\text { U. Pontificia Bolivariana } \\
\text { Fundación Universitaria Luis Amigó } \\
\text { Universidad CES }\end{array}$ & La memoria y sus trastornos \\
\hline 2012 & VIII & $\begin{array}{l}\text { Universidad Nacional } \\
\text { Universidad del Rosario } \\
\text { Universidad de Los Andes } \\
\text { Universidad Santo Tomás } \\
\text { U. Externado de Colombia }\end{array}$ & De las neuronas a la sociedad \\
\hline 2014 & $\mathrm{IX}$ & $\begin{array}{l}\text { U. de San Buenaventura, Cali } \\
\text { Universidad Icesi } \\
\text { Universidad Libre, Cali }\end{array}$ & Conflicto armado y región: una lectura necesaria \\
\hline 2015 & $\mathrm{X}$ & $\begin{array}{l}\text { Universidad Pedagógica y } \\
\text { Tecnológica de Colombia }\end{array}$ & $\begin{array}{l}\text { Violencias interpersonales y autoinflingidas: } \\
\text { experiencias exitosas de intervención y prevención. }\end{array}$ \\
\hline 2016 & $\mathrm{XI}$ & $\begin{array}{l}\text { Universidad de Ibagué } \\
\text { Universidad Surcolombiana } \\
\text { U. de San Buenaventura, Ibagué }\end{array}$ & $\begin{array}{l}\text { Psicología y neurociencias: acercamientos y } \\
\text { aplicaciones }\end{array}$ \\
\hline 2017 & XII & $\begin{array}{l}\text { Universidad Simón Bolívar } \\
\text { Barranquilla } \\
\text { Corporación Universitaria del } \\
\text { Caribe } \\
\text { Universidad Pontificia Bolivariana } \\
\text { Montería } \\
\text { Universidad de la Costa } \\
\text { Universidad del Norte } \\
\text { Universidad del Magdalena } \\
\text { Universidad del Sinú } \\
\text { Universidad Metropolitana } \\
\text { Universidad Tecnológica de } \\
\text { Bolívar }\end{array}$ & $\begin{array}{l}\text { Intervención psicosocial: aproximaciones teóricas, } \\
\text { contextos y realidades emergentes }\end{array}$ \\
\hline 2018 & XIII & $\begin{array}{l}\text { Universidad de Los Andes } \\
\text { U. Externado de Colombia }\end{array}$ & Convivencia y Ética \\
\hline
\end{tabular}




\subsection{Versión XIV - 2019}

La versión que nos ocupa, "Reconstrucción de subjetividades, identidades y del tejido social en contextos afectados por la guerra en Colombia: socialización de productos de investigaciones" ha desarrollado una metodología de trabajo que vuelve a la idea original de convocar a los investigadores del país para visibilizar sus productos y lo hace evidente desde su denominación. Por ende, este año seremos testigos de las tendencias, metodologías y formas de abordaje del tema central.

Las Universidades de Manizales y Católica de Pereira, con el liderazgo del Dr. Jaime Alberto Carmona Parra, se dieron a la tarea de estructurar esta versión de una forma diferente, que garantizara una convocatoria amplia e incluyente y desde el mes de abril del 2018 hacen pública la forma de participar del evento. Esta temprana invitación genera una respuesta de motivación y un interés renovado por la Cátedra, que da como resultado la recepción de un elevado número de propuestas que, sometidas a una rigurosa evaluación de pares, conformarán de una parte, las conferencias de cada una de las sesiones, y de otra, esta publicación que formará parte de los libros de necesaria consulta para estudiantes y profesionales.

La versión XIV de la Cátedra Mercedes Rodrigo se convierte en elemento central del posacuerdo: cómo reconstruir lo que la guerra nos arrebató, cómo volver a reconocernos y rescatar lo que nos identifica, cómo rehacer las redes y avanzar en encuentros con los otros, cómo volver a la convivencia, para que más allá de soñar un futuro de paz, seamos artífices de caminos que, paso a paso y hombro a hombro, nos conduzcan a hacer realidad el sueño. Esa es, para la Psicología, una tarea de responsabilidad social y desde este escenario la estamos asumiendo. 



\section{REFERENTE TEÓRICO}





\section{Reconstrucción de subjetividades, identidades y del tejido social}

\section{Florentino Moreno Martín ${ }^{4}$}

Que la cátedra que inspira este trabajo lleve el nombre de Mercedes Rodrigo, tiene una extraordinaria carga simbólica para el contenido de este libro. Quien fuera la pionera de la psicología colombiana, fundando, entre otras cosas, la Facultad de Psicología de la Universidad Nacional (Rodrigo, 1949), quien realizó estudios de validación de pruebas psicométricas como las de Stanford-Binet, quien colaboró con Piaget, participó en congresos presididos por Freud y dirigió instituciones de elevadísimo prestigio científico, en un tiempo en el que era casi impensable que una mujer estudiara en la universidad (Carpintero, 1994), representa en su biografía un espejo retrospectivo de los efectos de la violencia política.

Mercedes Rodrigo tuvo que exiliarse en 1939, en los últimos momentos de la Guerra Civil Española. No había participado en política formalmente ni estaba afiliada a ninguno de los partidos del bando republicano, pero el haber dirigido distintas instituciones públicas de carácter sanitario en el Madrid del "No Pasarán" hubiera sido un pasaporte directo a las purgas franquistas, como les sucedió a sus colaboradores por el simple hecho de haber pasado, en los años 30, sus pruebas psicométricas (Herrero, 2000).

Cargó sus enseres y recaló en Colombia donde es bien conocida su labor durante casi dos décadas. Un nuevo arranque de furia bélica en 1949, el baño de sangre conocido como El Bogotazo, sitúan a Mercedes Rodrigo a las puertas de un nuevo exilio, en esta ocasión por las acusaciones de ser comunista lanzadas contra ella por medios conservadores que, nuevamente, tomaron las pruebas diseñadas por Rodrigo para el acceso a la Universidad Nacional como motivo para atribuirle tendencias subversivas (Martínez Gorroño, 1999).

Mercedes Rodrigo fue, en dos ocasiones, lo que hoy llamaríamos una refugiada. Expulsada de su lugar de trabajo y de su hogar por la imposición de las armas. Pero esta pionera de la Psicología tiene también otra entrañable relación con el contenido de este trabajo. En plena Guerra del Rif, la contienda colonial librada por España en Marruecos, hizo un estudio con 819 escolares de ocho a 15 años de colegios públicos y privados, para averiguar

4 Universidad Complutense de Madrid. Correo: fmoreno@psi.ucm.es 
cuáles eran sus opiniones acerca de la guerra. En las últimas páginas del estudio, Rodrigo hace una afirmación conmovedora y premonitoria: "De esta encuesta pueden sacar provecho los partidarios y los adversarios de las guerras. Como toda nuestra simpatía está con estos últimos, deseamos que sean ellos los que saquen más ventajas. " (Rodrigo y Roselló, 1922, p. 425; tomado de Herrero, 2000).

Ese debería ser el propósito de todos los estudios realizados por quienes nos dedicamos a la Psicología: que nuestras investigaciones contribuyeran de forma efectiva a la desaparición de las guerras. No a paliar sus efectos, sino a evitar su inicio. Que aquellos dirigentes que buscan resolver los conflictos de forma pacífica sacaran ventaja de nuestros estudios y pesquisas.

\subsection{Psicología al servicio de la guerra y la paz}

Lamentablemente esa no es la tendencia mayoritaria ni la referencia normativa de nuestra profesión. En nuestra disciplina conviven desde hace décadas dos tendencias: quienes propugnan, como Mercedes Rodrigo, estudios para empujar la paz y quienes ponen sus conocimientos al servicio de la maquinaria bélica. Podemos tomar como ejemplo a la organización psicológica más poderosa del mundo, la APA, donde el 11 de agosto de 1990, unos días después de la invasión iraquí de Kuwait que abrió la puerta a la guerra del Golfo, se crea la división 48 de Psicología de la Paz con el propósito de investigar y aplicar estrategias pacíficas de resolución de conflictos (Ardila, 2001; Christie, 2006). En esta misma asociación ya existía, desde 1945, la división de Psicología Militar. Cuarenta y cinco años de adelanto. El desequilibrio entre estas dos tendencias de la profesión es descomunal. La Psicología Militar emplea a decenas de miles de psicólogos y psicólogas en las fuerzas armadas de todo el mundo con una formación reglada y unas funciones específicas con alto reconocimiento profesional. La Psicología de la paz, donde tiene entidad institucional, que es en muy pocos lugares, suele ser una pequeña organización de académicos que dedican parte de su tiempo a la investigación o a la formación.

La Psicología ha tenido desde sus orígenes como disciplina científica una relación muy estrecha con la guerra, al menos en tres dimensiones (Moreno, De la Corte y Sabucedo, 2004).

La primera y más obvia es la de la utilización del conocimiento psicológico como arma de guerra. Algunas de las investigaciones sobre temas psicológicos mejor financiadas han sido realizadas con intereses o fines bélicos y dirigidas por psicólogos que fueron contratados por institucio- 
nes militares o que servían como oficiales de algún ejército (Christie \& Montiel, 2013; Poundstone, 1992). Como sucede con la tecnología que inicialmente se ensaya en la industria militar y después se aplica a la vida civil (láser, microondas, GPS, etc.), buena parte de lo que hoy conocemos sobre comunicación persuasiva deriva de experimentos orientados a "bajar la moral del enemigo", desarrollados antes y durante la Segunda Guerra Mundial. De igual modo las actuales técnicas de tortura psicológica (Pérez, 2016), de destrucción de la identidad cultural, o de entrenamiento para la resistencia psíquica (Díaz e Ibáñez 1997) han sido desarrolladas por expertos en nuestra disciplina. Es difícil encontrar alguna aportación teórica de la Psicología que no se haya aplicado a la preparación de la guerra o a su optimización. Todos los ejércitos del mundo cuentan con algún departamento de Psicología Militar. Las funciones que desarrollan el grueso de estos profesionales son variadas y aparentemente están poco vinculadas a la optimización de la destructividad humana. Generalmente dedican la mayor parte de su trabajo a actividades como la selección, clasificación y formación del personal, la atención clínica de los soldados, etc. En los últimos años, con la ampliación de funciones de los ejércitos, como la Unidad Militar de Emergencias de Española (Gómez y Vega, 2008), estas funciones se han alejado aún más de la lógica bélica al ocuparse de la intervención en catástrofes o de la ayuda humanitaria. Por razones obvias, es mucho menos conocida la actividad orientada directamente a la utilización de la Psicología como arma de guerra, especialmente en la lógica contrainsurgente. Esta labor suele estar sometida al secreto militar y se desarrolla habitualmente en círculos opacos de la administración. Su funcionamiento se suele conocer a través de antiguos militares o civiles que tuvieron acceso a ellas (Central de Inteligencia Americana, 1985; Watson, 1978). Los atentados del 11-S en Estados Unidos avivaron la reflexión sobre los límites de la acción profesional de la Psicología y sus relaciones con el códio ético. El debate sigue abierto entre quienes observan conflictos de valores entre determinadas actividades de la Psicología Militar y principios deontológicos recogidos en los códigos que regulan la conducta ética de psicólogos y psicólogas (Arrigo, Eidelson \& Bennett, 2012).

\subsection{Las guerras en la mente de los hombres}

La segunda relación de la Psicología con el mundo bélico tiene hoy aparentemente un recorrido mucho menor pero durante años fue un terreno de debate muy intenso. Se trata de las reflexiones para establecer nexos entre la psicología humana y las causas de la guerra. ¿Existe una disposición 
psicológica innata que nos empuje a hacer la guerra? La importancia de este debate puede ser calibrada por algunos hechos protagonizados por personajes históricos e instituciones universales. El 16 de noviembre de 1945, dos meses después de acabada la II Guerra Mundial, se aprueba la Constitución de la Organización de las Naciones Unidas para la Educación, la Ciencia y la Cultura, cuya primera frase reza "puesto que las guerras nacen en la mente de los hombres, es en la mente de los hombres donde deben erigirse los baluartes de la paz. (UNESCO, 1945).

Unos años antes, en el periodo de altísma tensión que precedió a la llegada del régimen nazi a Alemania, con Mussolini gobernando en Roma, Albert Einstein escribió una carta al más famoso de los psicólogos de su tiempo, Sigmund Freud, pidiéndole una explicación psicológica del origen de la guerra, Freud le contestó: "es inútil tratar de librarse completamente de las pulsiones agresivas humanas, basta con intentar desviarlas para que no tengan que canalizarse hacia la guerra. Si la disposición a la guerra es un producto del instinto de destrucción, lo más fácil será apelar a su antagonista, al Eros. Todo lo que establezca vínculos afectivos entre los hombres debe actuar contra la guerra (Freud, 1932, p. 208).

Si volvemos todavía más atrás nuestra mirada en el tiempo encontramos otra explicación poderosa del padre del funcionalismo, el primer psicólogo pacifista de la historia (Deutsch, 1995). William James pronunció en 1906 una conferencia en la universidad de Stanford que tituló "El equivalente moral de la guerra". En esta inspiradora charla James parte de la base de que la guerra provee al hombre de orgullo, le permite mostrar su valentía, la capacidad de sacrificio, su patriotismo, su fortaleza y tiene una función disciplinaria. Valores que en aquella época se consideraban centrales y muy superiores al terror que ocasionaba la muerte y las penurias. Ante semejante fortaleza psicológica, la única opción que le queda al antimilitarismo es proponer algún equivalente moral que satisfaga esos valores y desde luego las propuestas que irónicamente se calificaban a principio de siglo como la promoción de "un mundo de oficinistas y profesores, de co-educación $y$ cuidado de los animales", eran en aquella época demasiado débiles e insulsas como para contraponer al espíritu militarista (James, 1910/1995).

\subsection{Del estrés postraumático al trauma psicosocial}

Este libro se ocupa una tercera relación entre psicología y guerra: cómo abordar los efectos psicológicos de los conflictos armados. Y lo hace conforme a lo que Ortega llamaba el espíritu de su tiempo, la lógica que 
imprime la generación dominante en todos los órdenes del saber y del hacer (Ortega, 2005). Y este nuevo tiempo en el que nos encontramos difiere de forma sustancial de otras épocas en las que las posibilidades de actuación de la psicología se entendían de otro modo. Por no remontarnos a tiempos remotos, las concepciones de las que hoy somos herederos directos podemos situarlas a finales de los años 70 del siglo XX (Moreno, De la Corte y Sabucedo, 2004). Es en aquellos momentos cuando la comunidad académica y profesional se volcó en la concreción de los síntomas producidos por la guerra tanto en los soldados como en la población civil. Y lo hizo introduciendo en 1980 el concepto de estrés postraumático en la clasificación DSM III. Es bien conocido que esta objetivación de los síntomas y la propuesta de intervención para paliarlos estuvo fuertemente influida por lo que se conocía en aquellos momentos como el síndrome que la guerra de Vietnam que se concretaba en las emociones y conductas experimentadas por los jóvenes que regresaban de las junglas asiáticas a unos Estados Unidos y eran recibidos de un modo muy distinto a como fueron acogidos otros veteranos de guerras anteriores (Blom, 2000).

La irrupción del Post-Traumatic Stress Disorder (PTSD) revolucionó la visión que hasta entonces se tenía sobre la psicopatología de guerra y las diversas aproximaciones relacionadas con el trauma (Moreno, 2004). La extraordinadria rapidez con que se extendió este criterio diagnóstico, tanto en el mundo académico como en el clínico, se vio reforzada por la popularidad internacional de las películas producidas por los grandes estudios de Hollywood (The Deer Hunter, Born on the Fourth of July, Platoon, Full Metal Jacket y tantas otras) que reproducían con milimétrica exactitud los síntomas de los manuales de diagnóstico en sobrevivientes de la guerra. La descripción del PTSD no se limitaba a las personas que hubieran vivido directamente los hechos traumáticos como los soldados. También incluía a cualquiera que hubiera tenido, directa o indirectamente relación con los hechos traumatógenos. Eso hizo que su aplicabilidad aumentara: "el individuo es testigo de un acontecimiento donde se producen muertes, heridos, o existe una amenaza para la vida de otras personas; o bien conoce a través de un familiar o cualquier otra persona cercana acontecimientos que implican muertes inesperadas o violentas, daño serio o peligro de muerte o heridas graves" (American Psychiatric Association 1980, p. 435).

Los acontecimientos generadoradores de este trastorno se producían a diario en centenares de lugares en Colombia y en distintos puntos de América Latina, en los convulsos años 80 del pasado siglo. Tal vez por haber sido pensado el PTSD para circunstancias excepcionales de países seguros 
y estables, su aplicación como herramienta psicológica no fue la referencia que siguieron quienes, desde la psicología, se acercaron a dar apoyo a las víctimas de las guerras centroamercianas de los 80 (ACISAM, 1988; Metraux, 1989; Pacheco, 1988) o de las dictaduras del Cono Sur (ILAS, 1994; Lira y Weinstein, 1984). La figura de Ignacio Martín Baró ejerció un contrapeso que resultó determinante a la hora de consolidar la idea de que era imposible entender el trauma en su dimensión individual al estilo del PTSD, proponiendo la categoría, hoy ya de uso común, de trauma psicosocial (Martín Baró, 1986, 1988, 1990). Su asesinato en 1989, lejos de acallar un modo comprometido de entender la acción del intelectual, multiplicó su visión por todo el mundo y sus textos han servido de referencia para cientos de profesionales de la Psicología que se acercan al fenómeno de la violencia política, intentando evitar "una asepsia cientifica ubicada por encima de las preocupaciones y conflictos concretos de la vida social" (Martín Baró, 1983, p. 44).

\subsection{Intervención psicosocial con víctimas y reconstrucción}

La necesidad de superar la visión psicopatologizante de las víctimas de guerra, llevó a un cambio de enfoque en el trabajo de muchos profesionales de la Psicología que intervinieron en conflictos bélicos en los años 90, especialmente en las guerras que asolaron la antigua Yugoslavia. Tanto la Agencia de Naciones Unidas para los Refugiados (ACNUR) como algunas organizaciones no gubernamentales de carácter internacional como Médicos del Mundo, Médicos sin Fronteras o la Cruz Roja, crearon divisiones de trabajo psicosocial para promover acciones que fueran más allá del tratamiento individual de las víctimas, especialmente en los campos de refugiados. Los programas de intervención con víctimas tuvieron una amplia difusión en todo tipo de conflictos, tanto en las guerras abiertas (Moreno, 1999, 2000) como en la atención de víctimas de atentados terroristas (De la Corte, Sabucedo y Moreno, 2004).

Con el cambio de siglo, sin descuidar los ámbitos descritos, una buena parte de los profesionales de la Psicología se han interesado, con distintos grados de protagonismo, por el estudio de la dimensión psicosociológica de los procesos postbélicos. No estamos ya ante un profesional cualificado que es contratado por una organización no gubernamental o por una instancia pública para dar asistencia a comunidades afectadas por la violencia, sino ante personas que se involucran en procesos de reconciliación, de recuperación de la memoria, de acompañamiento de víctimas en Comisiones de la Verdad, de 
resignificación a través de construcción de rituales o conmemoraciones, de actos de reparación o justicia restaurativa (Martín Beristain y Páez, 2000; Páez, Martín, González, Basabe y De Rivera, 2011, Portillo, Gaborit y Cruz, 2005).

Este libro se ocupa, fundamentalmente, de esta compleja realidad de la reconstrucción, donde la Psicología puede, al menos así lo creemos, hacer aportaciones que ayuden a ir más allá del alivio de los síntomas individuales de personas golpeadas por décadas de abusos, y contribuya a crear procesos que desequen las fuentes de donde se nutren quienes, en palabras de Mercedes Rodrigo "sacan provecho de la guerra".

\section{Referencias}

ACISAM (Asociación de Capacitación e Investigación para la Salud Mental) (1988). Efectos de la guerra civil: relaciones sociales deshumanizantes. Avance, Octubre-Diciembre, 4-16.

American Psychiatric Association -APA. (1980). Diagnostic and Statistical Manual of Mental Disorders (DSM-III), (3rd Ed.). Washington: American Psychiatric Association. (Traducción al español en Barcelona: Masson, 1984).

Ardila, R. (2001). ¿Qué es la Psicologia de la Paz? Revista Latinoamericana de Psicología, 33(1), 39-43.

Arrigo, J. M., Eidelson, R. J., \& Bennett, R. (2012). Psychology Under Fire: Adversarial Operational Psychology and Psychological Ethics. Peace and Conflict: Journal of Peace Psychology, 18(4), 384-400.

Bloom, S. L. (2000). Our hearts and our hopes are turned to peace: Origins of the International Society for Traumatic Stress Studies. In A. Shalev, R. Yehuda \& S. Mcfarlane (Eds.). International Handbook of Human Response to Trauma (pp. 27-50). New York: Plenum.

Carpintero, H. (1994). Historia de la Psicología en España. Madrid: Euderna.

Central de Inteligencia Americana (1985). Manuales de guerra sabotaje y guerra psicológica de la CIA para derrocar al gobierno sandinista. Madrid: Editorial Fundamentos.

Christie, D. J. (2006). What is Peace Psychology the Psychology of? Journal of Social Issues, 62(1), 1-17.

Christie, D. J. \& Montiel, C. J. (2013). Contributions of Psychology to War and Peace. American Psychologist, 68(7), 502-513.

De la Corte, L., Sabucedo, J. M. y Moreno Martín, F. (2004). Dimensiones psicosociales del terrorismo. En L. De la Corte; A. Blanco y J.M. Sabucedo (Eds.). Psicología y derechos humanos (pp. 189-220). Barcelona: Icaria.

Deutsch, M. (1995). William James: The first peace psychologist. Peace and Conflict: Journal of Peace Psychology, 1, 27-36.

Díaz del Peral, D. \& Ibáñez, V. (1997). Socioplastia, guerra y psiquiatría. Revista de la Asociación Española de Neuropsiquiatría, 17(64), 763-771. 
Freud, S. (1932). Why war? Standard Edition, 22, 197-215. London: Hogarth Press.

Gómez, M. y Vega, E. (2008). Protección Civil y Fuerzas Armadas: la Unidad Militar de Emergencias. Madrid: Fundación Alternativas.

Herrero, F. (2000). Mercedes Rodrigo: una pionera de la Psicología Aplicada en España y en Colombia (Tesis doctoral). Madrid: Universidad Complutense de Madrid.

ILAS (Instituto Latinoamericano de Salud Mental y Derechos Humanos). (1994). Trauma psicosocial y adolescentes latinoamericanos: formas de acción grupal. Santiago de Chile: Ediciones ChileAmerica CESOC.

James, W. (1910/1995). The moral equivalent of war. Peace and Conflict: Journal of Peace Psychology, 1, 17-26.

Lira, E., y Weinstein, E. (Eds). (1984). Psicoterapia y represión política. México: Siglo XXI.

Martín Baró, I. (1983). Acción e Ideología. Psicología Social desde Centroamérica. San Salvador: UCA Editores.

Martín Baró, I. (1986). Hacia una Psicología de la liberación. Boletín de Psicología UCA, $22,219-231$.

Martín Baró, I. (1988). La violencia política y la guerra como causas del trauma psicosocial en El Salvador. Revista de Psicología de El Salvador. 7(28), 123-141.

Martín Baró, I. (Ed.). (1990). Psicología social de la guerra. San Salvador: UCA Editores

Martín Beristain, C. y Páez Rovira, D. (2000). Violencia, apoyo a las víctimas y reconstrucción social. Madrid: Fundamentos.

Martínez Gorroño, M. E. (1999). Españolas en Colombia. La huella cultural de mujeres exiliadas tras la guerra civil. Madrid: Fundación "Españoles en el Mundo".

Metraux, J.C. (1989). Los niños. Victimas de la guerra. Managua: Centro de Publicaciones del INIES.

Moreno Martín, F. (1999). Reflexiones previas a los programas de intervención. En P. Pérez (Ed.), Actuaciones psicosociales en guerra y violencia política (pp. 181186). Madrid: Exlibris.

Moreno Martín, F. (2000). Criterios para la intervención psicológica con menores víctimas de la guerra. En J.M. Fernández Martos y F. Miralles Sangro (Eds.), Sin lugar para ser humano: intervención psicológica en crisis humanitarias (pp. 115-132). Madrid: Universidad Pontificia de Comillas.

Moreno Martín, F. (2004). Reflexiones sobre el trauma psicológico y la violencia política. De las guerras centroamericanas al 11 de Marzo de 2004. Clínica y Salud, 15(3), 253-271.

Moreno Martín, F., De la Corte, L. y Sabucedo, J. M. (2004). Psicosociología de la guerra: causas y efectos, En L. De la Corte, A. Blanco y J.M. Sabucedo (Eds.). Psicología y derechos humanos (pp. 145-187). Barcelona: Icaria.

Ortega y Gasset, José (2005). En torno a Galileo. Madrid: Biblioteca Nueva. Original de 1933. 
Páez Rovira, D., Martín Beristain, C., González-Castro, J., Basabe Barañano, N. y De Rivera, J. (2011). Superando la violencia colectiva y construyendo cultura de paz. Madrid: Fundamentos.

Pacheco, G. (1988). Aspectos psicosociales en problemática de los refugiados nicaragüenses de origen campesino. San José: Confederación Universitaria Centroamericana (CSUCA).

Pérez, P. (2016). Psychological Torture. Definition, Evaluation and Measurement. London: Routledge.

Portillo, P. N. A., Gaborit, M., \& Cruz, J. M. (2005). Psicología Social en la posguerra: Teoría y aplicaciones desde El Salvador. San Salvador: UCA Editores.

Poundstone, W. (1992). Prisioner's Dilemma. New York: Anchor Books

Rodrigo, M. (1949). Instituto de Psicología Aplicada: Fundación y plan de estudios. Bogotá: Universidad Nacional.

Rodrigo, M., y Roselló, P. (1922). Lo que piensan de la guerra los niños españoles. Revista de Pedagogía, 11(año 0), 422-425

UNESCO. (1945). UNESCO Constitution. London: UNESCO.

Watson, P. (1978). War on the Mind. The Military Uses and Abuses of Psychology. New York: Basic Books Inc. Publishers. 


\section{Construcción y reconstrucción social de subjetividades e identidades en contextos de guerra y posguerra en Colombia}

\section{Jaime Alberto Carmona Parra ${ }^{5}$}

El objetivo de este primer capítulo es aportar algunos elementos teóricos para pensar los procesos de construcción y reconstrucción de subjetividades e identidades, como un telón de fondo conceptual para comprender los sorprendentes procesos que agencian millones de seres humanos afectados por el conflicto armado en Colombia.

\subsection{La construcción social de la subjetividad}

En las líneas que siguen abordaremos el proceso de constitución de la subjetividad en su relación con las construcciones colectivas de identidades, como un proceso dialógico entre las múltiples determinaciones -históricoculturales, socioeconómicas, familiares y vinculares- que intervienen en ambos procesos, y el elemento de irreductibilidad fundamental que es propio de la condición humana. En este recorrido nos guiarán las ideas de autores como George Mead, Martin Heidegger y Keneth Gergen.

Para iniciar este recorrido, quizás sea de ayuda partir de algunas consideraciones que son ampliamente aceptadas en el campo de las Ciencias Sociales. Cuando un ser humano llega al mundo, lo está esperando una familia y sus estructuras de parentesco con sus prohibiciones y atribuciones; un mundo sexuado con sus estructuras conscientes e inconscientes que organizan el deseo humano y los destinos sociales en función de la adscripción del ser humano a una determinada condición sexual. También el neonato nace en un contexto histórico-cultural que constituye a la vez un patrimonio que hereda, con sus dioses y demonios, con sus mitos y tabúes, sus tradiciones e ideales, sus imágenes de la gloria y la ignominia, de felicidad y desdicha; también hacen parte de ese legado algunas deudas simbólicas de las que debe hacerse cargo cada ser humano que ingresa en un contexto cultural,

5 Universidad de Manizales. Correo: jcarmona@umanizales.edu.co 
relacionadas, por ejemplo, con las infamias y crímenes cometidas por sus ancestros; y finalmente, sin pretender ser exhaustivos en esta enumeración, podemos decir que todo ser humano nace dentro de unas estructuras socio-económicas que, de antemano le asignan un lugar en el mundo como perteneciente a una clase proletaria o burguesa, campesina o terrateniente, como perteneciente a los poderosos o a los humillados y ofendidos.

\subsection{El papel de las estructuras}

Estas estructuras traen aparejadas sus propias violencias que serán los punzones y los martillos que labrarán la forma del nuevo ser que llega al mundo. El lenguaje será el vehículo mediante el cual se van a introducir y a reproducir en recién llegado. Más aún, el lenguaje será el hábitat mismo, la madera y el barro de las que estará hecha la humanidad de ese nuevo "ser". Estas estructuras, -pese a las connotaciones de la metáfora que está en la base del concepto, las cuales sugieren algo fijo- no hay que pensarlas como construcciones inamovibles, sino, al contrario, como lo sugiere Enrique Pichón Riviere, hay que entenderlas como "Gestalt, gestaltung" (2001, p. 190) estructuras estructurándose, es decir con una estabilidad relativa pero en proceso continuo de transformación. Las diferentes relaciones entre los actores sociales dentro de cada estructura no son solamente de cooperación y complementariedad, son también relaciones de contradicciones y luchas que se pueden dirimir en el campo de lo político, pero que no pocas veces se tramitan mediante diversas formas de violencia simbólica y física, incluyendo la guerra.

Las estructuras de parentesco, de sexuación, económicas, sociales, etc., que organizan todos los campos de la experiencia humana en cada contexto cultural, no son creaciones de la naturaleza, son productos históricos resultantes de conflictos y pulsos de fuerza entre individuos y grupos que agencian intereses y detentan diferentes formas de poder, en torno a un campo específico, en largos períodos de tiempo. Una implicación de esto es que las estructuras mismas a la vez que proporcionan "una definición de la situación" (Thomas, 1923, p. 211) en un determinado campo (la sexualidad, la familia, la sociedad, la economía, etc) definen unas reglas del juego explícitas y con ello garantizan las condiciones de una cierta estabilidad son también, en sí mismas, una fuente de violencia, ya que por su condición de producciones humanas e históricas, no son neutras, ni necesariamente orientadas en función de los intereses colectivos. Con frecuencia son la sedimentación de infamias e injusticias que se han sostenido, legitimado y naturalizado en largos períodos históricos en un determinado contexto cultural. 
Las violencias de género a menudo tienen como punto de partida las estructuras de la sexuación propias de cada contexto cultural; la familia es un escenario de múltiples luchas simbólicas y a veces físicas, entre los géneros y las generaciones; las luchas sociales no se desarrollan solo entre las clases, sino también entre los campos (el clero y el poder político, el poder económico y el político, etc.), y entre diferentes tendencias y agenciamientos en el interior de las instituciones que se organizan en torno a cada campo (las iglesias, los organismos del Estado, las empresas...)

Las estructuras pueden ser naturalizadas o incluso "reificadas" (Berger, 2001, p. 150) y por tanto ajenas a cualquier posibilidad de crítica y transformación, por sujetos o grupos sociales en función de cálculos de conveniencia, esquemas referenciales rígidos o enajenaciones, pero en su condición de construcciones humanas están sujetas a cambios, e incluso a la desaparición, en la medida en que desaparecen las circunstancias históricas que les dieron origen o se debilitan los grupos humanos que las usufructúan y velan por su sostenimiento.

En el proceso de enculturación de un ser humano se interiorizan las estructuras fundamentales que organizan el universo simbólico que habita y esta interiorización incluye su dimensión conflictiva y sus contradicciones. Esta dimensión dinámica y conflictiva de las estructuras que se interiorizan y constituyen la subjetividad de todo ser humano es fundamental para entender la dimensión política de dicha subjetividad. Efectivamente se trata de estructuras -de parentesco, sexuación, socioeconómicas etc.- en las que lo político es una dimensión fundamental, ya que en todas está en juego el ejercicio de poderes, desde la fuerza legítima e ilegítima, pasando por las diversas formas de uso y abuso de los lugares que otorgan alguna forma de superioridad, hasta las formas del poder alternativos como la resistencia, la denuncia y la seducción. En el proceso de constitución de la subjetividad, no se interioriza tal o cual actor social (el padre o la madre, el actor masculino o el femenino, el amo o el siervo) se interioriza la estructura en toda su complejidad, con sus dinámicas de interacción, sus vínculos y sus roles.

\subsection{La historicidad de los primeros vínculos}

El psicoanálisis ha mostrado el carácter estructurante del deseo y de la subjetividad inconsciente que dejan los vínculos con primeros objetos parciales: el pecho, la voz, la mirada, las heces (Lacan, Seminario IV, 1994). Desde estas relaciones primordiales con estas formas del objeto "a" ya están presentes la ambivalencia, el conflicto, la violencia y las estrategias de pose- 
sión, control, dominio, incluso de destrucción. Quizás no sobre agregar que, pese a que se trate de objetos parciales, en la relación del neonato con estos objetos primordiales está presente un sujeto histórico (la madre) y por lo tanto sexuado, perteneciente a una cultura, a una clase social, que ocupa un lugar en una estructura familiar determinada. Estos factores incidirán en la marca particular que dejarán estos primeros vínculos, en las gratificaciones y las privaciones, las armonías y las tensiones, las carencias y los excesos.

Luego vendrá el proceso de constitución del yo, en el que esas marcas fantasmáticas dejadas por los vínculos con estos primeros objetos parciales van a ser los lugares en los que se asentarán las identificaciones con los otros significativos. La identificación es el mecanismo fundamental en la constitución del yo (luego vamos a ver la importancia de diferenciar, y en algunos casos oponer, la identificación como mecanismo por excelencia de la constitución de la subjetividad, de la construcción de identidades como proceso eminentemente social).

Es conocida la metáfora de Freud que compara la estructura del yo con una cebolla (1979, p. 19) que está compuesta por sucesivas capas, que serían las identificaciones. Si hiciéramos un ejercicio de deconstrucción del yo, levantando una por una las identificaciones que lo constituyen, no encontraríamos al final algo parecido a una esencia o a un "yo verdadero" "real" o "íntimo". Lo mismo que cuando pelamos una cebolla, levantando una por una todas sus capas, al final no queda nada. Esta es quizás una de las evidencias más rotundas de la construcción social de la subjetividad.

Esta visión del yo en el proceso de constitución de la subjetividad tiene varias implicaciones, la primera de ellas y la más importante es la constatación de lo que Lacan va a llamar posteriormente la "división subjetiva" (1975, p. 286), el yo en su misma estructuración es una realidad dividida, múltiple, incluso conflictiva. Las sucesivas identificaciones que conforman el yo no son necesariamente compatibles y armónicas entre sí. En algunos casos esto puede ser la ocasión de conflictos internos, pero también tiene aspectos generativos: a mayor diversidad y divergencia entre las identificaciones, mejores condiciones simbólicas para el pensamiento y la creatividad. Esto concuerda con lo propuesto por Gergen en el campo de la experiencia social: "Cuando los mundos de significado se interceptan, pueden ocurrir resultados creativos. Nuevas formas de relacionarse, nuevas realidades y nuevas posibilidades pueden emerger" (2011).

Esta división subjetiva producto de las múltiples identificaciones que conforman el yo y la condición de "ser en el lenguaje" propia de la expe- 
riencia humana, crean las condiciones de posibilidad para la reflexividad, que consiste en la capacidad que tenemos los humanos de tomarnos a nosotros mismos como objetos: de amor, de odio, de crítica, de sugestión, de recompensas, incluso de engaños. Gracias a la reflexividad, podemos amarnos hasta el delirio narcisista, odiarnos hasta el suicidio melancólico, sugestionarnos deliberada o inadvertidamente para predisponernos contra alguien o algo, también podemos premiarnos, incluso mentirnos.

\subsection{La reflexividad}

Gracias a la reflexividad, las luchas, las relaciones de poder, las injusticias, las segregaciones y las violencias del mundo exterior se reproducen en el sujeto. En ciertos estados de enfermedad mental se pueden constatar las auténticas batallas internas que se libran en el interior de un ser humano y en ciertos cuadros clínicos se pueden constatar los efectos destructivos que pueden tener ciertas identificaciones con agresores que luego pueden agenciar diferentes formas de violencia que pueden llevar incluso al suicidio del individuo (1979, pp. 212-3).

La reflexividad es también la condición del pensamiento, que es concebido por autores como George Herbert Mead, como un diálogo interno (Mead, 1973). La potencia y la originalidad de este diálogo, como ya lo indicamos, está en relación directa con la calidad, la pluralidad y diversidad de las identificaciones que constituyen el yo.

También la capacidad de autocrítica, la moralidad y la capacidad de autotransformación son posibles gracias a la reflexividad. Es justamente porque el ser humano puede tomarse a sí mismo como objeto que tiene la posibilidad de evaluar-se, juzgar-se, comparar sus acciones con sus principios y sus ideales y plantear-se acciones correctivas, incluso obligar-se, por ejemplo, a reparar un daño hecho a otro, aun venciendo poderosas resistencias internas.

Esta condición de sujeto moral, es a la vez la que permite al ser humano devenir sujeto político, justamente porque la reflexividad introduce unos márgenes de auto-determinación que podemos llamar con todo derecho márgenes de libertad, en el sentido más humano y más político de la palabra. Esta autodeterminación, entendida como la capacidad de gobernar-se es el principio para orientar la propia acción, inicialmente de manera individual y luego de manera colectiva en función de propósitos, ideas o ideales que van más allá de la satisfacción de los apetitos primarios que compartimos con otras especies de la naturaleza. 
Los animales se encuentran presos de su información genética y de las respuestas instintivamente programadas ante ciertos estímulos externos. El conocimiento de estos principios es explotado por los seres humanos para diversos fines, como la caza, la productividad y la domesticación. Si el comportamiento del ser humano se pudiera explicar solamente como la respuesta a estímulos internos (necesidades y apetitos) o externos (peligros, amenazas, etc.) sin la mediación del pensamiento y la reflexividad, no existiría diferencia alguna entre la Etología y la Psicología. Lo que agrega a la subjetividad humana un nivel de complejidad mayor es el papel que juegan el lenguaje y la reflexividad.

Gracias a la reflexividad un ser humano se puede liberar, por decirlo así, de la tiranía de sus necesidades y pulsiones y también de los condicionamientos de ciertos estímulos que vienen del mundo exterior. Debido a la capacidad de desdoblarse interiormente y tomarse a sí mismo como objeto, un ser humano puede enseñorearse de sus necesidades, pulsiones y apetitos hasta límites notables. Las historias de algunos grandes líderes políticos evidencian esto de manera elocuente.

\subsection{Subjetividad politica}

Gracias a los márgenes de libertad y autodeterminación que posee el humano debido al lenguaje, y que diferencia su comportamiento de la programación instintiva propias de los animales, el ser humano es por excelencia, un sujeto político, ya que en su relación con el otro sus comportamientos no están determinados mecánicamente por respuestas programadas por los genes sino por un proceso que le permite decidir sobre su acción y orientarla en función de unos fines o de otros. Esta condición de sujeto político es independiente de cualquier juicio sobre carácter acertado o errado de sus actos, o sobre los resultados finales de los mismos, ya que el desenlace de cualquier acción humana no depende solamente de la voluntad de los sujetos individuales y colectivos; depende también de las fuerzas que se oponen a ellas y de otras contingencias.

Lo que hemos dicho hasta este momento podríamos resumirlo en dos frases, una de Mead: "La persona, en cuanto puede ser un objeto para sí, es esencialmente una estructura social y surge en la experiencia" (Mead, 1973, p. 172) y otra de Torregrosa \& Fernández, quienes afirman que la socialización es el proceso de "interiorización de la estructura social" (Torregrosa, 1984), a lo que nosotros agregaríamos: "con sus debates, contradicciones, confrontaciones y violencias". Por ello habríamos de decir que, 
la subjetividad humana es política en el proceso mismo de su constitución, no solamente por la necesidad que tenemos los seres humanos de tener una posición crítica, activa y transformadora frente a nuestros vínculos y las estructuras simbólicas que los rigen, sino porque en el interior de cada sujeto están presentes y actuantes esos vínculos y esas estructuras con sus historicidades, sus contradicciones y las luchas que les dieron lugar.

La reflexión sobre el lenguaje ha acompañado nuestro recorrido hasta ahora, pero vamos a ver amerita un tratamiento más específico. Partamos nuevamente de algunas constataciones básicas. Cuando un ser humano llega al mundo no lo espera "el lenguaje" en el sentido amplio que tiene esta palabra sino "una lengua" es decir una expresión particular del lenguaje con la que tiene contacto por la vía del habla (Saussure, 1987) de su contexto inmediato que suele ser en primera instancia la familia y luego otras instituciones. El habla de un grupo humano específico al que llega cada neonato es un universo significante que está poblado con sus mitologías, religiones, sus artes, sus ciencias, sus filosofías; también por sus tradiciones, canciones y narraciones populares; su sentido común cifrado en adagios, refranes, chistes, etc. Las estructuras que hemos mencionado atraviesan estas construcciones y son vehiculizadas por ellas.

\subsection{Sujetos de un habla politizada}

Diríamos entonces que la forma más inmediata que toma "la casa" que espera al "ser" no es propiamente el lenguaje como estructura abstracta de posibilidades, sino un habla particular, es decir un universo de significaciones concretas, en el que ya está definido qué es un hombre y una mujer, un padre y un hijo, un ciudadano y un delincuente, el pecado y la virtud, la felicidad y la dicha, la gloria y la ignominia. Esto coincide con lo que propone Gergen en el primero de los nueve principios del Construccionismo Social: "Vivimos en mundos de significados. Nosotros entendemos y valoramos el mundo y los diferentes caminos que emergen de nuestra historia personal y la cultura compartida" (2011).

Hegel dice que empezamos a ser humanos a partir del momento en que decimos "yo" (Hegel, 1987), es decir en el momento en que damos cuenta de la reflexividad al usar el lenguaje para nombrar-nos a nosotros mismos. Gracias al lenguaje el ser humano adquiere una "conciencia de sí" que es la condición de la moralidad y la política.

Cuando un nuevo ser llega al mundo se realizan con él algunos rituales simbólicos sencillos pero decisivos. Con el bautismo se le asigna nombre y 
unos apellidos que le definen un lugar en las estructuras de sexuación (no es lo mismo ser llamado fulano que fulana), de parentesco (con la asignación de los apellidos) que le asignan un lugar en una familia. Ciertamente, no es lo mismo llegar al mundo como el varón primogénito de una familia judía, que en el cuarto lugar de las mujeres de una pareja que busca un hijo varón. Con la pertenencia a una familia, el recién llegado también se inserta dentro de un linaje y un estrato socioeconómico. Con el registro en la instancia gubernamental que determina cada país, queda además inscrito como oriundo de una determinada localidad y una nación.

Ingresar a un universo de significaciones implica para cada ser humano quedar ubicado en un lugar determinado en cada una de las estructuras que organizarán su experiencia, lo cual definirá unas posibilidades y a la vez unos límites, también las violencias de las que será objeto y las que podrán o no agenciar de manera legitimada o, incluso, legal. Ser representado por los significantes, primogénito, varón, y además por un apellido de una familia de clase alta europea, ciertamente es distinto a ser representado por los significantes, mujer, campesina con un apellido de una familia sumida en la miseria en el tercer mundo. Es por ello que podemos hablar de la construcción socio-simbólica de la subjetividad: nos construimos a nosotros mismos y somos construidos socialmente por medio de dispositivos simbólicos que organizan nuestra experiencia y nos asignan un lugar en el mundo.

Podemos decir que por medio del lenguaje cada ser humano va ingresando en el mundo humano en el que "ser" es ser representado por un significante para los otros (Lacan, 1975). Cada significante asigna recién llegado un papel en un juego de roles que está organizado por una estructura y que funciona como un juego de lenguaje. El rol de hijo confiere un lugar en la familia, el de varón en el mundo de la sexuación, el de campesino en unas estructuras socioeconómicas, entre otros.

Con el desarrollo del proceso vital, cada ser humano entra en el juego de adjudicación y asunción de roles, que en todos los casos implican posicionamientos en lugares de lenguaje, es decir ser representado por un significante particular ante otros significantes. Hay algunos roles que no se eligen como el de hijo, nieto, hijo de familia obrera, y en cierta medida también la nacionalidad. Finalmente hay roles por los que se puede optar y luego abandonar como aquellos relacionados con actividades y oficios: maestro, ebanista, vendedor, policía, guerrillero, paramilitar.

Ahora bien, lo que nos interesa subrayar de esta vicisitud de "ser sujetos de lenguaje" (Lacan, 1975), de hacerse a un "ser" jugando juegos de roles 
(Mead, 1973) que son "juegos de lenguaje" (Wittgenstein, 1921) es que, de un lado el lenguaje sujeta, en la medida en que cada campo define posibilidades y límites, violencias que se padecen y ejercen, pero, a la vez, todos los seres humanos sin excepción habitamos el lenguaje en calidad de intérpretes.

Esto no es un asunto de voluntad o una competencia que se puede desarrollar en mayor menor medida, sino algo inherente a la condición humana. Este hecho de habitar el lenguaje como intérpretes va a ser fundamental para comprender la reflexividad, la libertad, la ética y la política, también, por supuesto, para el proceso de construcción colectiva de identidades y para los posicionamientos y las luchas identitarias.

\subsection{El yo social y los juegos de roles}

El concepto de rol es de una gran utilidad teórica porque nos permite articular lo individual con lo social, la subjetividad con las identidades, lo particular con lo común. En un contexto social determinado todos los sujetos que son representados por el significante de un determinado rol tienen algo en común: los niños, los jóvenes, las madres, los maestros, los policías, los sacerdotes, las prostitutas; pero también podemos decir que no hay una madre igual a otra, ni una maestra, presidente, sacerdote, igual a otro etc., tampoco un niño ni un joven. Cada actor social le imprime, inexorablemente, su sello particular a su manera de desempeñar su rol y con ello al significante que lo representa. Por ello, Munné (1989) afirma que "el concepto de rol es un lugar de encuentro de la Psicología y la Sociología. Donde ambas se articulan, lo que significa (para Rometweit, 1955) que es la mayor unidad de investigación psicológica y la menor sociológica" (p. 262).

Para Berger y Luckmann (2001), los roles son tipificaciones de formas de acción objetivadas lingüísticamente, que son encarnadas por actores sociales en contextos específicos:

La tipificación de formas de acción requiere que estas posean un sentido objetivo, lo que a su vez, requiere una objetivación lingüística. Vale decir, que habrá un vocabulario referente a esas formas de acción (por ejemplo el rol de "zurrar sobrinos", que corresponderá a una estructura lingüística mucho más vasta relativa al parentesco y sus derechos y obligaciones) (2001, p. 96)

Diríamos que el rol que designa a un actor social (el tío que zurra a los sobrinos) es un articulador entre los procesos lingüísticos de significación y la acción social. Gergen enfatiza la condición de los seres humanos como 
habitantes intérpretes en el universo de significaciones que dimana de su mundo social: "Los mundos de significados se relacionan con la acción. Actuamos principalmente en términos de lo que interpretamos como real, lo racional, satisfactorio y bueno. Sin un significado no valdría la pena hacerlo" (2011).

Esta condición de habitar un universo simbólico, como intérprete de roles objetivados lingüísticamente, hace que cada ser humano sea por definición un agente activo, transformador de los significados que configuran ese rol, sus vínculos con los demás roles y, con ellos, de su propio mundo, gracias a la marca particular que hace a cada uno de los roles que desempeña. Esta marca puede ser modesta o monumental, torpe o genial, de acuerdo con la índole de cada actor social. La condición de agente activo del ser humano no depende de la evaluación o valoración que se haga de la marca propia que le imprime al desempeño de sus roles, como lo constata Herbert Blumer:

El hecho de que un acto humano sea dirigido o elaborado por un "sí mismo" no significa en absoluto que el agente haga una excelente labor de construcción; en realidad, dicha labor puede dejar mucho que desear. Puede no advertir las cosas de las que debería ser consciente, puede malinterpretarlas, aventurar un juicio banal, cometer errores al planear determinadas líneas de conducta, y ser débil a la hora de enfrentarse con actitudes obstinadas (Blumer, 1982, p. 47).

Gracias a esta labor imperceptible de transformación de los roles que realizan millones de actores sociales a lo largo del tiempo, no es lo mismo ser niño, joven, madre, o maestro, en el siglo XIX que en el XXI; tampoco es lo mismo serlo en Oslo que en Cundinamarca. Con la transformación de los roles se transforman los vínculos (madre-hijo, niño-adulto, maestro-alumno, obrero-patrón); y con la transformación de los vínculos se transforman las instituciones (la crianza, la enseñanza, el trabajo) y, en largos períodos históricos, las estructuras en las que se apoyan.

\subsection{Interacción dialógica del sujeto con las estructuras}

En virtud de esta interacción dialógica entre las estructuras sociales y las subjetividades, la importancia y el lugar social de las instituciones cambia, algunas desaparecen, devienen ilegales o sufren mutaciones. La esclavitud y el apartheid son instituciones extintas, al menos en sus versiones legales; el trabajo infantil y el uso de niños con fines militares, que hace medio siglo eran exaltados en algunos contextos, hace unas pocas décadas han sido declarados ilegales y hoy son objeto de rechazo y sanción judicial. La 
significación de algunas instituciones como la escuela, el matrimonio han sufrido contemporáneamente un cambio de valor y una redefinición importante en los roles de los actores sociales que las conforman.

Cuando hablamos de una interacción dialógica entre el sujeto y las estructuras sociales, lo hacemos en el sentido más estricto que le asigna Edgar Morín a este concepto, a saber, como una relación "a la vez concurrente, complementaria y antagónica entre dos instancias necesarias" (1983, p. 183). Las estructuras sociales y los seres humanos actúan de manera concurrente en la construcción y el mantenimiento de la cultura; son complementarios en la medida en que se diferencian unas de otros como instancias particulares dentro de un mismo proceso histórico, y a la vez son antagónicos en la medida en que ningún ser humano reproduce de manera idéntica la herencia simbólica que recibe; siempre la transforma inexorablemente y en esa medida se opone a ella, al menos a la condición de reproductor fiel de la misma. Ese es un potencial del sujeto humano, con importantes implicaciones políticas.

Insistimos nuevamente en lo que ya hemos mencionado en otros apartados: no se trata de un atributo de unos pocos, sino de algo inherente a la subjetividad que le confiere la condición de ser una subjetividad política. También aquí vale la pena subrayar que el reconocimiento del carácter político a la subjetividad, no depende de la evaluación o la valoración que hagamos de sus manifestaciones. Antes bien, este reconocimiento es más bien un punto de partida para poder interrogar, criticar, problematizar y, en lo posible, fomentar las condiciones para potenciar, la dimensión política de la subjetividad.

Ahora bien, por diferentes razones, son las niñas, los niños y los jóvenes los sujetos con una mayor disposición a jugar con los significados que habitan, recrearlos, transformarlos, incluso reinventarlos. En la teoría del desarrollo de la subjetividad de George Mead, vamos a encontrar algunos elementos para entender la razón de esto y, a la vez, para examinar las potencialidades para la formación y el desarrollo de las potencias políticas en estos actores sociales.

El autor inicia su teoría de la constitución y el desarrollo de la subjetividad con una diferencia fundamental entre el jugueteo animal y el juego humano. Según Mead un tigre o un gato pueden juguetear con sus cachorros, pero no juegan en el mismo sentido que juegan los niños, porque en el jugueteo cada uno de los animales siempre son lo que son, tigre y gato, mientras que el juego en el humano es ante todo jugar a desempeñar un rol, es decir, jugar a ser otro, abandonar una posición subjetiva y adoptar otra: "los perros no 
adoptan un papel definido en el sentido en que un niño adopta deliberadamente el papel de otro" (1973, pp. 180-1).

Para el autor, el juego no solamente es un elemento esencial que diferencia la animalidad de la humanidad, sino también la esencia misma del proceso de constitución de la subjetividad, una poderosa herramienta en los diferentes procesos formativos, en el que nosotros incluiríamos la formación política. Podríamos agregar también que la capacidad de jugar sería también un indicador de salud mental y, en el límite, la medida misma de la humanidad de un humano. En este sentido coincidimos con Frederich Muné quien define el ser humano como un "homo ludens en el sentido de actor que representa un personaje a través de acciones dotadas de significación social" (1989, p. 260)

\subsection{El juego y la construcción de la subjetividad}

Mead construye una propuesta original del proceso de constitución de la subjetividad basada en esta noción del juego como actividad esencial de la experiencia humana que consiste en la interpretación y transformación de significaciones a partir de juegos de roles, con implicaciones prácticas, vinculares, ontológicas y políticas, es decir, que tienen consecuencias en las acciones sociales, las definiciones de los vínculos, la subjetividad de los actores y las correlaciones de poder entre ellos.

El autor aprovecha las dos palabras que existen en inglés para designar el juego, como conceptos para nombrar dos fases del desarrollo infantil claramente diferenciadas: la "fase del play" y la "fase del game".

Veamos como describe la fase del "play":

El juego en ese sentido, especialmente la etapa que precede a los deportes organizados, es un juego a algo. El niño juega a ser una madre, un maestro, un policía; es decir, adopta diferentes papeles, como decimos nosotros.... Esta tendencia por parte de los niños es la que nos ocupa en el jardín de infantes, donde los papeles que los niños asumen son convertidos en base para la educación (1973, pp. 180-1).

Acaso no sea gratuito que algunos de los roles y los vínculos con los que el niño juega privilegiadamente en esta fase, son aquellos en los que para él son más evidentes factores de poder en los que se puede representar a merced del poder de otro de una manera real o imaginaria: madre-hijo, maestro-alumno, policía-delincuente. 
Nuevamente constatamos el carácter eminentemente social de la constitución de la subjetividad y el papel que juega la alteridad en este proceso. El juego infantil, que según Mead es: "la forma más sencilla de ser otro para la propia persona" (1973, pp. 180-1). La consolidación de esta primera fase evidencia la aptitud de sujeto para habitar y desempeñarse en juegos de lenguaje y alternar roles dentro de un mismo juego. Esta fase es, lógica y cronológicamente, condición de la siguiente, en la que emerge una dimensión fundamental de lo político, la fase del game:

Es un período en el que (al niño) le agrada "pertenecer", e ingresa en organizaciones que nacen y desaparecen. Se convierte en algo que puede funcionar como un todo organizado, y de tal manera tiende a determinarse en su relación con el grupo al que pertenece. Ese proceso constituye una notable etapa en el desarrollo de la moral del niño. Le convierte en un miembro, consciente de sí, de la comunidad a la que pertenece (1973, p. 189).

Esta fase coincide con ese momento evolutivo en el que el niño empieza a vivenciar con júbilo el abandono progresivo del solar de la infancia y el ingreso tímido en la calle del mundo. Son los primeros aleteos que lo llevan del ámbito privado del oikos al ámbito público de la polis. Este gusto de pertenecer es la base misma del deseo por la acción colectiva, el ingresar y salir de organizaciones y la conciencia de los efectos en la conciencia de sí y el significado de sí mismo para los otros, a partir de su rol de integrante de la organización. En esta fase también se puede evidenciar el júbilo con el que las chicas y los chicos vivencian la existencia de otras estructuras organizativas y otras regulaciones diferentes a la de su familia y su comunidad inmediata, lo cual les evidencia el carácter contingente, y por ello mismo susceptible de ser transformado y subvertido, de todos los juegos de roles y las estructuras simbólicas que los sostienen: "El niño entra en el deporte y éste expresa una situación social en la que puede intervenir por completo; su moral puede tener mayor atracción para él que la de la familia a la cual pertenece o la de la comunidad en la que vive" (1973, p. 189).

Pero hay todavía un elemento más radicalmente político en esta segunda fase de los juegos organizados, -que prefiguran lo que serán posteriormente los campos de juegos de lenguaje que constituyen la vida social de la vida adulta-, en lo que podríamos situar la emergencia de un deseo orientado de una manera clara hacia la política en el sentido más fuerte y auténtico de la palabra. 
Los niños dedican un gran interés a las reglas. Las improvisan en el acto, a fin de ayudarse a salvar dificultades. Parte del placer del juego reside en establecer esas reglas. Ahora bien, las reglas son la serie de reacciones que provoca una actitud esencial. Uno puede exigir una determinada reacción a otros, si adopta cierta actitud (1973, p. 43).

Efectivamente, en la pasión por las reglas de los juegos, por transformarlas y crearlas reside esta disposición hacia lo político. Es notorio que la posición de los niños en esta fase hacia las reglas no sea la de su aceptación pasiva o de su naturalización sino, por el contrario, de la interrogación y la transformación de las mismas y la asunción de que están hechas para ser modificadas mediante el debate y los consensos, siempre que contribuyan mejor al desarrollo del juego. También es notorio el ejercicio subjetivo que, según el autor, implica este juego a transformar las reglas del juego, nada menos que adoptar la actitud del otro, que no es otra cosa que ponerse en el lugar de él.

Si aceptamos esta propuesta de la constitución y el desarrollo de la subjetividad, estaríamos concernidos a preguntarnos, cómo ocurre que muchos seres humanos pierdan esta disposición a interrogar y transformar las reglas de las estructuras simbólicas que regulan sus vínculos y adopten la posición contraria de naturalizarlas, acatarlas de manera acrítica y en algunos casos, incluso, convertirse en defensores de ellas.

Decíamos que las organizaciones en las que discurre el mundo de los adultos tienen la estructura de un game, es decir un juego colectivo que establece unos roles diferenciados con sus respectivas atribuciones y límites, que está regulado por unas reglas (llámense estatutos, reglamentos, leyes), que pueden ser modificadas en ciertos momentos y bajo ciertos procedimientos. De esta constatación se puede derivar una pregunta de trabajo sobre la importancia de aprovechar esta fase del desarrollo de la subjetividad del niño para el fortalecimiento de las potencias políticas de los futuros adultos que definirán y redefinirán las reglas del juego que regirán la sociedad en su conjunto.

Para completar la visión de la constitución de la subjetividad que propone el autor, y su importancia en la concepción de un sujeto político, es necesario que introduzcamos todavía dos conceptos que serán fundamentales para comprender la capacidad de agencia, como expresión fundamental de la irreductibilidad fundamental de la condición humana y principio fundamental de la acción política. Se trata de la visión de la subjetividad, que el autor denomina el "self" (sí mismo), como un proceso de interacción dialógica 
permanente entre dos instancias fundamentales que el autor denomina el "mí" y el "yo".

\subsection{El "self": un proceso sociopolitico de interacciones entre el "yo" y el "mi"}

Para decirlo de una manera general, en el "mí" se congregarían las sucesivas identificaciones de las que hablamos anteriormente: "El "mí', decimos, responde a las actitudes organizadas de los otros que nosotros asumimos definidamente, y que, en consonancia determinan nuestra conducta (...) si usamos una expresión freudiana, el "mí" es en cierto sentido un sensor" (1973, pp. 232-3). En otras palabras el "mí" es el representante de las estructuras sociales, interiorizadas en la subjetividad. En palabras del autor es el representante del "Otro generalizado" en la subjetividad.

El "yo" es una instancia que interactúa dialógicamente con el "mí":

los valores que acompañan al "yo" se encuentran en la actitud inmediata del artista, el inventor, el hombre de ciencia en su descubrimiento: en general en la acción del yo que no puede ser calculada y que representa una reconstrucción de la sociedad (...). Estos valores no son peculiares al artista, al inventor y al descubridor científico, sino que corresponden a la experiencia de todas las personas en que existe un yo que responde a un mí. (Mead, 1973, p. 237).

Mientras que el mí representa el patrimonio sociocultural interiorizado en la subjetividad, el yo es el que explica la aparición de los emergentes, las producciones inéditas de la subjetividad que no son predecibles. Por ello el autor los vincula con la actitud del artista, el inventor y el científico que son creadores por excelencia, aunque luego aclara que no es privativo de ellos, es decir que la dialogicidad entre el yo y el mí en toda subjetividad hace posible la creación, la construcción de articulaciones significantes y acciones sociales que no son meras reproducciones de las estructuras interiorizadas en el "mí", sino que constituyen emergentes que recrean y contribuyen a la transformación de las mismas.

Este es el núcleo fundamental de lo que hemos denominado la irreductibilidad del ser humano, la cual se puede entender como la imposibilidad de agotar la explicación de la experiencia humana y sus acciones individuales y colectivas a partir de las múltiples determinaciones que influyen en la organización de subjetividad y que se expresan en ella. Esta irreductibilidad, entendida en el sentido más fuerte, nos obliga a renunciar a la ilusión 
determinista de los enfoques empírico-analíticos en las Ciencias Sociales, de llegar a poder explicar y predecir plenamente el comportamiento humano, e introduce un principio fundamental de admitir una región de impredictibilidad y la consecuente imposibilidad de explicar la totalidad de las producciones de la subjetividad, especialmente aquellas relacionadas con la emergencia de inéditos en el campo de la acción, el pensamiento y demás construcciones simbólicas, individuales o colectivas. Este principio está en congruencia con uno de los nueve principios del construccionismo social, formulado por Gergen: "Nuevos mundos de significado son posibles. No estamos poseídos o determinados por el pasado. Podemos abandonar o disolver las formas disfuncionales de vida y juntos crear alternativas" (2011).

La constatación y afirmación radical de este principio fundamental de irreductibilidad humana y de la consecuente introducción del principio que admite una región de impredictibilidad, no implica en ningún momento pasar de un determinismo radical laplaciano, que no dejaría lugar a ninguna posibilidad de autodeterminación, transformación o creación individual o colectiva (porque para éste todas las acciones serían producto de la compleja maquinaria de los determinismos), a un indeterminismo escolástico, igualmente radical, que afirma la total libertad y autodeterminación del ser humano.

La visión dialógica de la relación entre lo subjetivo y lo social implica precisamente que no se puede pensar lo uno sin lo otro; que las creaciones, los inéditos, las revoluciones y las innovaciones humanas los campos de lo social, lo científico, o artístico o en la experiencia modesta y cotidiana de los seres humanos, no surgen en el vacío y no se pueden comprender sino en su relación férrea y profunda con los contextos socio-simbólicos en los que emergen y las estructuras que los organizan.

Una visión dialógica de la relación entre las subjetividades y las estructuras sociales y de la misma dinámica interna de la subjetividad como esta, es indispensable como presupuesto antropológico y ontológico para poder edificar sobre bases sólidas un concepto como el de "capacidad de agencia". Es completamente ilegítimo, incongruente y contradictorio desarrollar una teorización determinista (unicausal o multicausal) de lo social y lo subjetivo, explicándolos exclusivamente como producto de las variables y las estructuras y al final de la misma elaborar propuestas relacionadas con el "empoderamiento", "las potencias", el "agenciamiento", los márgenes de "autodeterminación”, "resistencia", “creatividad", "libertad” etc. Para que estos términos sean legítimos, la concepción del ser humano y la explica- 
ción de la relación de lo subjetivo y lo social, debe incluirlos de una manera explícita, en todo momento. De lo contrario, aparecen como un conejo sacado del sombrero de un mago, como ocurre con mayor frecuencia de la deseable en los apartados de las conclusiones y las recomendaciones de muchas investigaciones en el campo de las Ciencias Sociales.

\subsection{El agenciamiento}

En las páginas anteriores consideramos haber desarrollado los trazos fundamentales de una visión de la subjetividad que sea congruente con la noción de "capacidad de agencia". Esta la vamos a entender, siguiendo a Álvaro y Garrido, como:

La capacidad que tienen las personas de transformar el medio en el que viven; el Interaccionismo Simbólico reconoce la capacidad de agencia en los individuos. El ser humano, a diferencia de los animales, tiene la capacidad de ser un objeto para sí mismo (Alvaro, 2004, p. 87).

Es decir, que los seres humanos de manera individual y colectiva no son solamente sujetos de las estructuras -y por lo tanto reproductores y sustento de las mismas-, sino también, a la vez, opositores, transformadores e inventores de otras alternativas, es decir, sujetos políticos.

Esta noción de la "capacidad de agencia" fue desarrollada en la segunda mitad del siglo XX en el campo de la Economía por Amartya Sen, y profundizada y desplegada con mayores alcances en el campo de la Filosofía Política, por su discípula Martha Nussbaum, pero sus fundamentos filosóficos, epistemológicos y sus desarrollos teóricos más sólidos, en el campo de las Ciencias Sociales, se sitúan en la tradición que inicia con el interaccionismo simbólico y se renueva y adquiere una nueva potencia con el construccionismo social, especialmente con los desarrollos de Keneth Gergen.

Para situar con precisión el lugar de la capacidad de agencia en cualquier investigación, en el campo de las Ciencias Sociales y Humanas, hay que hacer un doble movimiento:

El primer movimiento es ponerla en relación con las estructuras, los juegos de lenguaje que se fundan en ellas, los vínculos y los roles que establecen estos juegos de lenguaje. Para poner un ejemplo extremo que ya citamos más arriba, es claro que no puede desplegar la misma capacidad de agencia una mujer campesina, menor de edad, de clase baja, del tercer mundo que un hombre adulto, de clase alta, del primer mundo. La capacidad de agencia no se puede pensar como un elemento derivado exclusivamente de los 
atributos personales de un ser humano como su inteligencia, su carisma, su capacidad de persuasión, seducción, etc.; es algo que está profundamente ligado al rol o los roles que desempeña en los juegos de lenguaje en los que participa y las atribuciones que le confieren a esos roles las estructuras simbólicas subyacentes que les sirven de base.

Esta reflexión nos permite introducir otra categoría que es inseparable de la idea de la subjetividad política y de unos márgenes de libertad, autodeterminación, con sus implicaciones éticas: nos referimos a la noción de "la responsabilidad". La responsabilidad individual y social de un sujeto por sus acciones está en relación con la amplitud de su capacidad de agencia. No es ciertamente la misma en un niño que en un adulto, en un delincuente común que en un oficial de policía, en un ciudadano sencillo que en un gobernante.

En este sentido, en los análisis sociales y políticos, en el momento interrogarse por las responsabilidades es fundamental situar primero la amplitud de la capacidad de agencia de los actores sociales implicados en cada acción, en función de los roles. La condición de sujeto político del ser humano implica que ninguno puede eludir la responsabilidad que le corresponde por las violencias asociadas a los roles sociales que agencia, incluidos los heredados. Justamente porque las acciones humanas no son la resultante de automatismos instintivos o programaciones genéticas, un marido machista latinoamericano que golpea a su mujer es responsable de la violencia que ejerce y no puede atribuirla al determinismo cultural, así como el empresario que explota y viola los derechos de sus trabajadores no puede excusar su responsabilidad política en nombre de su destino de clase social.

Si se lleva más allá de límites razonables, este primer movimiento de poner la capacidad de agencia en relación con las estructuras y sus manifestaciones, puede terminar convertido en una expresión más de los determinismos. Por eso es necesario el segundo movimiento en dirección inversa, que consiste en poner la capacidad de agencia en una relación férrea y profunda con el principio de la irreductibilidad e impredictibilidad de la condición humana y la imposibilidad de explicar totalmente un fenómeno individual o social en función de las determinaciones y las estructuras. Es en este segundo movimiento, que no admite eludir el primero, que la noción de capacidad de agencia muestra todo su brillo y su potencia, porque orienta la mirada hacia esas acciones y producciones de los seres humanos situados, es decir, en el desempeño de un rol específico, en las que se despliega la capacidad crítica, la resistencia a la reproducción pasiva, la vocación creadora, revolucionaria e inventiva, en el respectivo campo de la experiencia. Son estos gestos los 
que ayudan a comprender las transformaciones modestas o a gran escala en los diferentes ámbitos, desde la experiencia cotidiana de una pareja, una familia o un pequeño grupo de jóvenes, hasta las grandes transformaciones en el campo del arte, la ciencia y la política.

Esas condiciones individuales que mencionamos en párrafos anteriores, como la inteligencia, la sabiduría, la creatividad, el carisma, la capacidad de persuasión etc., y que cuestionamos su valor como explicación exclusiva de la capacidad de agencia, adquieren otra significación una vez son puestas en relación con sujetos situados, es decir en el ejercicio de roles específicos, especialmente en coyunturas cruciales. Eso hace la diferencia entre un presidente en una situación decisiva para su país, un líder estudiantil ante la oportunidad de incidir de manera fundamental en un cambio en la legislación, un padre de familia ante el drama de uno de sus hijos, un joven desplazado o un niño en riesgo de reclutamiento por parte de grupos armados ilegales.

La noción de capacidad de agencia nos obliga a los científicos sociales a renunciar a la omnipotencia de pretender agotar las explicaciones de los actores sociales con nuestros esquemas conceptuales, por complejos y poderosos que ellos sean, y nos invitan a abrirnos a la emergencia de los inéditos que generan los actores sociales. Esto tiene también una implicación fundamental para los procesos de intervención o de estudios que se realizan desde la perspectiva de la investigación-acción, a saber, que el rol del investigador puede estar más al servicio de favorecer la aparición y el despliegue de esos emergentes que de dirigir, desde sus teorías e instrumentos, el trabajo colectivo.

La noción de capacidad de agencia es importante en la fundamentación de otras nociones como la resiliencia, el empoderamiento, la responsabilización y el protagonismo de los actores sociales, a nivel individual y colectivo; también es importante en la definición de acciones para salir de situaciones críticas, para operar importantes cambios en sus contextos, etc., pero su máximo valor se revela en la iluminación de esos momentos excepcionales y definitivos de los seres humanos, a nivel individual o colectivo, en los que la emergencia de un inédito cambia de manera radical su historia. Ejemplos emblemáticos recientes de la capacidad de agencia en los que, además se puede constatar la acción de la causalidad recursiva (1983, p. 184) entre lo individual y lo social, son la revolución pacífica de la India gracias a la cual lograron liberarse del colonialismo inglés, la superación del apartheid en Suráfrica y en Norteamérica. La teoría del agenciamiento reconoce el papel que juegan los líderes en los procesos sociales, pero no reduce la 
explicación de estos a la influencia o iluminación de aquellos. La visión dialógica y recursiva de procesos como estos permite concebir a los líderes mismos como emergentes de los procesos históricos y sociales de los que hacen parte, sin que ello impida reconocer los aportes inéditos, las marcas particulares y la genialidad de la propia marca en el desempeño del rol que hizo la diferencia con otros seres humanos que, en ese mismo lugar, quizás no hubiesen logrado lo mismo.

Una adecuada comprensión de esta perspectiva del agenciamiento, se convierte en una herramienta teórica y epistemológica que permite iluminar un costado de ciertos fenómenos que sin esta categoría pueden quedar a oscuras. Para no quedarnos solamente en los grandes acontecimientos y en las grandes figuras de la historia, podemos mencionar un caso modesto de una investigación reciente sobre niñez y conflicto armado. Es el caso del municipio de Dabeiba en el Noroccidente de Antioquia. Este municipio se caracterizó en la primera década de este siglo por tener una de las tasas más altas de vinculación de niñas y niños a los grupos armados en el Departamento. Este fenómeno era agudo en todas las veredas del municipio, con excepción de una de ellas. En un proceso investigativo (Carmona, 2012) después de un trabajo paciente de observación y entrevistas en profundidad apareció un elemento diferenciador entre esta vereda y las demás, que estaba en relación con la escuela y particularmente con una maestra apasionada por la música que, gracias a sus esfuerzos y su carisma, logró seducir a sus estudiantes para que en el tiempo libre conformaran una banda de música. El entusiasmo de los chicos por este proyecto fue tan contundente que se convirtió en un factor de protección frente a los intentos de los grupos armados de seducirlos para que se vincularan a sus filas. El relato más amplio de este caso podría dar para muchos análisis. Bástenos aquí destacar que la maestra de una manera logró, mediante una estrategia lúdica, actuar sobre uno de los factores de riesgo de la vinculación de los chicos a los grupos armados en ese contexto específico y transformó una realidad que no pudieron transformar los maestros de las otras veredas.

Si se implementa de manera adecuada esta perspectiva de análisis, se verá que la vida cotidiana está llena de ejemplos admirables de la capacidad de agenciamiento de actores de todas las condiciones socioeconómicas, sexuales, incluso de edad.

Antes de seguir adelante, es necesario responder a una pregunta legítima: ¿en qué momento del desarrollo del niño aparece la capacidad de agencia y cómo se evidencia? Sorpresivamente, la capacidad de agencia se evidencia 
de una manera muy clara desde momentos inusitadamente tempranos de la vida. Las abuelas, las madres y las maestras de los jardines infantiles suelen atestiguar los cambios comportamentales intencionados de los niños pequeños ante unos actores sociales u otros y la capacidad de manipulación que desarrollan con relación a aquellos en los que les interesa ejercer una influencia en función de sus intereses. Para apreciar adecuadamente la capacidad de agencia es preciso, siempre, hacer un análisis en contexto.

\subsection{El agenciamiento en la niñez}

El admitir la existencia de la capacidad de agencia en los niños desde edades tempranas tiene consecuencias en la visión de los procesos de socialización. Desde una perspectiva determinista estos se han concebido como dinámicas unidireccionales en los que unos agentes socializadores adultos producen unos efectos, con aciertos y errores, en los niños, que en éste desempeñan un papel fundamentalmente pasivo. Esta nueva perspectiva que abre la noción de agenciamiento supondría una visión de la socialización como un proceso de interacción en el que ambas partes están en una posición activa y son afectadas en la dinámica:

Lo que realmente reviste importancia es la idea de la «socialización recíproca», que se puede constatar en la mayoría de las relaciones interpersonales y que contrasta con la más clásica de la «socialización unidireccional», en la cual el aprendizaje y la transformación del comportamiento o los valores solo se hace desde los poseedores de recursos y poder hacia los desposeídos. Evidentemente detrás de estas dos conceptualizaciones del poder socializador están dos actitudes éticas o políticas y no simplemente dos posicionamientos científicos (2003, p. 59).

Vamos a ver un ejemplo sencillo de otro proceso de investigación en el que se evidencia con claridad la capacidad de agencia de un niño de doce años en un contexto de violencia generalizada. Se trata de un chico de una familia desplazada que vive en el municipio de La Estrella, Antioquia, en un barrio marginal azotado por las bandas criminales, la violencia entre los vecinos e incluso en el contexto de su propia familia. En una entrevista en profundidad, su madre aporta el siguiente relato:

Mi hijo todo el tiempo evita violencia [...] hay veces lo cascan, lo insultan y él no me cuenta, porque él sabe que yo de una salgo volada a pelear con todo el mundo [...] él lo que hace es que me coge, me abraza y comienza a besarme. Me coge de la mano y me dice: Pare- 
ces un torito, camine mi torito; entonces me hace reir y se me pasa. [...] él evita que yo pelee, si no fuera por él yo ya le habría cascado a más de uno (mamá de un niño 12 años) ${ }^{6}$

Si nos atuviéramos a las determinaciones históricas, sociales y familiares de este niño, que vive en un contexto de naturalización de la violencia, deberíamos decir que lo esperado sería que reproduzca esta violencia o se valga de la capacidad de ejercerla a través de un adulto significativo, como una respuesta ante las provocaciones. Sin embargo, el relato de la madre da cuenta de que él hace una lectura de contexto, logra anticipar las consecuencias de su acción, hace un reposicionamiento subjetivo y, en vez de poner la queja, que sería lo normal en un chico de su edad que ha sido agredido, realiza una acción mal calculada, con la intención de evitar situaciones de violencia en su familia y su barrio.

\subsection{Las identidades, más allá de las identificaciones}

Desarrollaremos ahora el último apartado de la promesa que aparece consignada en el título y en el primer párrafo de este capítulo, relacionada con el concepto de identidades, el cual abordaremos aprovechando los desarrollos que hemos realizado hasta el momento.

Quizás pueda ser útil como introducción una definición que Amartya Sen da de sí mismo:

Me defino como un asiático, ciudadano indio, bengalí, de Bangladesh, ciudadano británico, hombre feminista... Tengo, pues, numerosas identidades, siempre en conflicto, pero a veces, según el contexto, una resulta más pertinente. Ante la crisis reciente estoy a favor del estado-providencia y veo argumentos fuertes a favor de la intervención socialista. Pero cuando veo el hambre en Ucrania, o en Corea del Norte, mi identidad es la de querer la libertad contra la opresión. No es una cuestión de identidad, sino de razonamiento. Cuando existe un conflicto, la cuestión que se debe plantear es: ¿qué tengo más razones para hacer?

6 Narrativa generada en el proceso del trabajo de campo del proyecto: "Procesos de construcción social de la niñez en contextos de conflicto armado en el Eje cafetero, Antioquia y área metropolitana de Bogotá: la paz, la reconciliación y la democracia desde la perspectiva de narrativas generativas de niños y niñas", que hace parte del proyecto de investigación: "Sentidos y prácticas políticas de niños, niñas y jóvenes en contextos de vulnerabilidad en el Eje Cafetero, Antioquia y Bogotá: un camino posible de consolidación de la democracia, la paz y la reconciliación mediante procesos de formación ciudadana". 
El autor pone en primer plano que la identidad hay que entenderla como una pluralidad, incluso como un campo de contradicciones y luchas en el que el sujeto, gracias a su capacidad de agencia, en cada situación toma partido por una opción, lo cual puede tener consecuencias éticas y políticas, ante las cuales el sujeto se afirma como responsable.

Vamos a abordar el tema de las identidades y su relación con la subjetividad. Vamos a ver que el concepto de identidad tiene un alcance profundamente político y que para poderlo situar de manera adecuada es indispensable contar con la noción de agenciamiento y todas sus implicaciones.

Lo primero que debemos decir es que un recién llegado al mundo no elige el contexto en el que se va a constituir su subjetividad, la capacidad de agencia que está presente desde el nacimiento mismo (y que se manifiesta en la interacción amorosa y conflictiva, desde el toma y daca de leche y caca) no tiene en esta época los alcances que permitan al niño elegir sus primeros referentes identificatorios.

Los procesos de adopción de identidades, por el contrario, son decisiones en las que se afirma la capacidad de agencia de un sujeto y en las elige un rol mediante el cual se hace representar por un significante para los demás significantes y además hace su propia marca en el ejercicio de ese rol, mediante la cual afirma su singularidad dentro de la comunidad. Se trata de un gesto que tiene profundas implicaciones políticas.

Insistamos en que la noción de agenciamiento no escamotea la condición situada de los sujetos. Con lo cual podemos decir que la opción por las identidades no se realiza en abstracto ni en una especie de campo simbólico neutral (lo cual sería un contrasentido en los términos) sino en el contexto de una subjetividad inscrita en un universo simbólico con sus determinaciones estructurales y cargado de significaciones. Con lo cual la adopción, creación y recreación de identidades la hace un sujeto en situación, con otros, y constituye en primera instancia una respuesta política a su propia historia, a su subjetividad, a sus identificaciones y a los significantes que le han sido adjudicados y que designan los roles que le confieren unos lugares a partir de los cuales se relaciona con los otros y con el mundo.

Para tomar un ejemplo sencillo, nacer en una ciudad del Norte de los Estados Unidos, como hijo de una familia de inmigrantes económicos de América Latina, define un contexto de emergencia de una subjetividad, con unos referentes de identificación contradictorios y unas violencias simbólicas que no se eligen. Un sujeto situado en estas coordenadas significantes, que le asignan un lugar ante los otros, entra en procesos de interacción, en cada 
uno de los cuales emerge o construye (depende del punto de vista desde el cual lo abordemos) diferentes identidades, que dependerán de su posicionamiento ante el otro y ante sí mismo, más exactamente ante su "mí', que encarna su patrimonio y a la vez su carga simbólica.

Este mismo sujeto podrá exhibir diferentes identidades según los vínculos. Ante sus padres y hermanos mayores podrá exhibir una posición altiva y despectiva expresada en la negativa a hablarles en su lengua y una posición servil y sumisa ante sus pares de origen local, manfiesta en su deseo de agradarles y parecerse a ellos en su apariencia y en sus hábitos de consumo. Pero también puede ocurrir que bajo esas mismas coordenadas simbólicas opte por afianzar su identidad en la valoración de sus orígenes y el fortalecimiento de los vínculos con los suyos y en la relación con los pares de origen local mostrar una apertura a la vez respetuosa y crítica. Una tercera vía, entre muchas otras posibles, podría ser que se posicione desde una reivindicación contestataria y beligerante ante su familia y ante sus pares. En este caso se cumpliría el séptimo principio del construccionismo social, según el cual "cuando los mundos de significado están en conflicto pueden llevar a la alineación y agresión, socavando así las relaciones y su potencial creativo" (2011). En cualquiera de los casos la capacidad de agencia será lo que marque la diferencia entre un posicionamiento y otro.

La identidad, o mejor las identidades, son por excelencia un hecho social. Goffman habla del "yo social" (Goffman, 2001), Mancuso \& Sarbin hablan de "yoes de segundo orden" (Mancuso, 1983). Por su parte, Gergen enfatiza que "Las identidades nunca son individuales; cada una está sostenida en una gama de relaciones precariamente situadas" (1996, p. 258).

Gergen va a ser más radical aún: "desde el punto privilegiado del construccionista no existe ninguna demanda inherente en cuanto a la identidad de coherencia y estabilidad. El enfoque construccionista no considera la identidad para uno, como un logro de la mente, sino más bien, de la relación" (1996, p. 254)

Esta visión de la identidad contradice la ilusión de unidad y síntesis que la mayoría de las personas construyen en torno a sí mismas y desde la cual afirman "yo me conozco". Sin embargo, una auto-observación de la experiencia cotidiana nos muestra las profundas diferencias que exhibe cada ser humano en diferentes vínculos. En un contexto vincular puede ser timorato y errático, mientras que en otro puede ser locuaz y asertivo (en el primero se encuentra ante su jefe con el que tiene una relación tensa, y en el segundo está en su rol de guía de jóvenes scouts). Pero, más significativos son aquellos 
casos en los que un ser humano exhibe dos identidades diferentes ante dos personas con las que sostiene un vínculo de la misma índole; es el caso de muchas adolescentes que ante dos chicos que las cortejan exhiben identidades opuestas; en una de ellas son altivas y autocráticas y en otra dóciles y sumisas. En ciertas situaciones extremas, que no necesariamente se relacionan con la patología, muchos seres humanos se confrontan a sí mismos con asombro con la emergencia de identidades inéditas en situaciones críticas, las cuales provocan frases típicas como "me desconozco", "ese no era yo".

Desde que una niña o un niño empiezan a salir de su ámbito familiar y a incursionar en otros campos de la socialización, como la escuela y la comunidad, los procesos de adopción y abandono, transformación, construcción y destrucción de identidades se vuelve un tema apasionante.

La adhesión a diversos tipos de agrupaciones relacionadas con el deporte, la música, la política, la sexualidad, la religión, y para la exploración de ciertas experiencias como la embriaguez, la iniciación sexual y el goce de ciertas experiencias de transgresión se convierte en un elemento fundamental. (Ospina-Alvarado, Carmona, \& Alvarado, 2014)

El grupo proporciona la experiencia de la identidad colectiva, el sentimiento de pertenencia a un Otro con mayúscula, lo cual no solamente le revela a la niña y el niño la experiencia de poder en el marco de las acciones conjuntas, sino que también le ofrece una red vincular que alivia el sentimiento de soledad a aquellos que en otros contextos son minorías excluidas.

Las nuevas identidades que les ofrecen a los chicos las diferentes agrupaciones sociales, cumplen una función crucial, al servicio de la necesidad ontológica de alteridad. Los vínculos con los integrantes del grupo y con éste como conjunto le proporcionan a las niñas y los niños un alivio a la tiranía de las significaciones que gobiernan el contexto de su socialización primaria.

\subsection{Agenciamiento y construcción de paz}

En contextos en los que los grupos armados tienen un dominio militar, el agenciamiento en la construcción de la paz de los niños y niñas toma la forma de la desconfianza, la sospecha, la crítica, la resistencia; incluso, las actitudes sutiles o abiertas de desafío. En niños y niñas que han sido reclutados por las filas de los grupos armados, se expresa en su capacidad de tomar distancia de sus comandantes y los valores guerreros del grupo, también en los gestos de solidaridad y compasión ajenos a los valores bélicos, en la capacidad de construir y llevar a cabo planes de fuga, incluso 
en la evitación de la vinculación de otros niños y niñas. En los contextos de programas de retorno a la vida civil, el agenciamiento y las potencias para la paz se evidencian en la capacidad de reconstrucción de su propia identidad, la construcción de vínculos afectivos con otros niños y niñas que estuvieron vinculados a grupos enemigos, en la apertura y la actitud festiva con la que asumen su nuevo rol como ciudadanos libres. En esta exposición privilegiaremos los testimonios de niñas por tratarse de una población más invisibilizada en la revisión de la literatura publicada sobre el tema. (Moreno, Carmona, \& Tobón, 2012)

Veamos algunos fragmentos de relatos tomados de procesos de investigación en los que se evidencia la capacidad crítica frente a los diferentes actores armados: Yo con los paramilitares no me la llevo porque me tocó ver cómo robaban y maltrataban los campesinos de la vereda donde yo vivía y entonces yo le tengo mucha rabia a los paras. Los guerrilleros obligaban a la gente a que asistieran a la reunión, entonces mi primo dijo que no, que él no se quería meter en problemas con nadie, que no iba a ir, que si llegaba el Ejército y lo encontraba ahí que él no quería tener problemas con nadie, y lo amarraron, le decian que lo iban a matar. De ahí creció algo en mí, como una cosa contra la guerrilla. (Carmona, 2014, p. 30)

La capacidad crítica de las niñas ha sido resaltada por otros autores frente a acciones desarrolladas por el ejército: "El Ejército bajaba por ahí y se robaba, por ejemplo, las gallinas de la gente" (Carmona, 2014, p. 124)

Algunas niñas, que estuvieron vinculadas a grupos armados ilegales, una vez estuvieron allí, construyeron un significado de esa experiencia que no estaba ligada a lo militar, sino con valores relacionados con el amor, la protección de la vida, la solidaridad con el otro, incluso el desarrollo de actividades culturales:

Más que todo lo que yo más hice allá fue enfermería, que era ayudarles mucho a los civiles, a los que estaban enfermos, que yo iba, les aplicaba medicinas, les recetaba medicinas, a los civiles normales y a los milicianos. Me sentía muy bien siendo enfermera allá, porque me sentía útil (...) y uno saber que uno le coloca la mano a alguien y que ese alguien se alivia, para mi es como ese orgullo. (Carmona, 2014, p. 64)

Otras investigaciones han mostrado del mismo modo la posibilidad de construir significados alternativos al pasado vivido: "Me gustaban la vida del grupo y la recreación. Yo dramatizaba, yo cantaba, bailaba, pasaba rico. 
Esas otras cosas yo las hacía también de muy buena manera, porque eso es un deber del guerrillero" (Carmona, 2014, p. 157).

La resistencia con los valores bélicos algunas veces se manifiestaba bajo la forma del desinterés por los discursos legitimadores y de exaltación de la guerra, como lo han señalado investigaciones previas: "En las charlas de política... me aburría, me aburría mucho, así como escuchando hablar y hablar y hablar, muy maluco ¿sí me entiende? yo para esas charlas no servía. Prefería irme a prestar guardia" (Carmona, 2014, p. 78)

Esas reuniones me aburrían, porque la política es muy cansona. Y yo me sentaba allá con una muchacha y yo era: “¡qué pereza esto!”, un día me escucharon a mí hablando ahí y ahí mismo me sacaron al frente que para que dijera y yo: "no, es que yo no sé, sanciónenme, pero es que yo no sé eso, no sé, a mí no me gusta" y me sancionaron cargando leña, 30 días de leña”. (Carmona, 2014, p. 78)

Es llamativo encontrar expresiones de autocrítica, en un medio que favorece la exaltación del militarismo.

Un 24 de diciembre, me tocó la guardia a media noche... yo me ponía a imaginarme todas esas cosas y ahí fue donde yo empecé como a pensar, y yo: "Dios mío, yo qué estoy haciendo aquí matando gente que a lo mejor están aquí o están allá así como estoy yo, sin hacer nada, o sea, inocentes, que se pelean así como por nada, entonces nos matamos, y yo ¿de cuándo acá tengo tantos enemigos? (Carmona, 2014, p. 150)

Yo decía: "qué pereza”, yo pensaba: “¡ay no!, qué pereza, qué cosa tan horrible esto, es que uno, así como le quita la vida a otra persona, otro se la va a quitar a uno"; entonces yo me estremecía, me corría como un escalofrío por los pies. (Carmona, 2014, p. 150)

Son mucho más significativos los relatos en los que las niñas arriesgaban sus propias vidas, contrariando las órdenes de sus comandantes, para evitar que otras niñas corrrieran la misma suerte que ellas: "una muchacha sí me dijo que ella tenía ganas de irse porque estaba muy aburrida en la casa..., ahí mismo le dije yo: "no se vaya a ir" y a mi hermanita también le dije: "no se vaya", nosotras la aconsejamos mucho" (Carmona, 2014, p.161).

Esta búsqueda de la protección de las compañeras ha sido igualmente descrita en estudios previos: 
Una vez una peladita me rogó dizque que me la llevara. Entonces yo le dije: "si usted quiere ir allá a aguantar frío y hambre, mija, váyase, pero lo que es yo, conmigo no cuente". Y también le advertí que no fuera a decir que yo le había dicho, porque, pues, obviamente yo iba era perdiendo" (Carmona, 2014, p. 147)

Como lo han referido estudios previos quizá había otra forma de resistencia más íntima y sutil, pero más decisiva, que consistía en empezar a resignificar el grupo y a desvalorizar algunos de los elementos, como los uniformes, las armas y sus mismos integrantes:

A lo último ya no es mucho lo que a uno le gustan los uniformes, porque uno ya se acostumbra a que lo vean, ya no se siente uno como tan orgulloso... Al principio es que uno se siente como orgulloso con el fusil, ya a lo último ya uno hasta se aburre con esa cosa, cargando eso para donde va. (Carmona, 2009, p. 147)

En la construcción de la decisión de desvincularse de los grupos armados, arriesgando sus propias vidas, se evidencia una subjetividad capaz de evaluar críticamente su situación y orientar su acción de manera congruente con dicha evaluación: "yo me voy para mi casa, si no tengo oportunidad al menos veo a mi mamá y si tengo la posibilidad de salirme me salgo también facilito, me voy por ahí mismo"; "Yo estaba aburrida y ya había pedido retirada para mi casa del todo y no me la dieron, y yo decía 'yo en estos días me voy de acá', y preciso: cuando fui a la casa me entregué" (Carmona, 2014, p. 160).

En el proceso de retorno a la vida civil, como ha sido mencionado en estudios previos, las potencias y la capacidad de agencia se manifiestan en el entusiasmo con el que se empoderan del proceso de la reconstrucción de su identidad:

Fue muy rico volver a llamarme como me llamo, súper rico, emocionante, ... Yo empecé a sentirme de nuevo con mi nombre como al llevar algunos días en el CAE, que ya estaba como estudiando, que estaba trabajando, que ya me sentí como individual, como que esa era yo ... y que ya hacía tiempo no era. (Carmona, 2014, p. 150)

La desaparición de algunos sentimientos que se instalaron en las niñas mientras hicieron parte del grupo armado: "Otra vez con el mismo nombre era la misma de antes, otra vez me sentía la misma mujer que era en la civil, normal, se me salió la rabia, el odio y eso, ya me sentía lo mismo que antes". 
La afirmación de la nueva identidad de estas niñas, ajena a los referentes de la guerra y articulada con el estudio el trabajo, su condición de mujeres libres evidencia su capacidad de contribuir a la construcción de paz, reconciliación, a pesar de haber vivido en un contexto de naturalización de la guerra y haber padecido de manera directa los efectos del conflicto armado: "Estoy estudiando, estaba estudiando pues, estamos en vacaciones. Y sí, estoy muy contenta, he conocido muchas personas, he conversado mucho, he tenido mucha amistad por acá, y sí, me siento feliz” (Carmona, 2014, p. 159).

Uno de los aspectos más significativos en los que se puede constatar la capacidad para construir reconciliación y paz, son las interacciones con otros menores de edad desvinculados de grupos armados contrarios, en la institución en que realizaban el proceso de retorno a la vida civil: "La relación era difícil porque había 'paramilitares'; yo tuve un problema con una muchacha 'paraca', fue difícil, pero a lo último fuimos las amigas perfectas, nos hicimos amigas" (Carmona, 2014, p. 141).

Con uno de los muchachos yo discutía, pues él defendía a los paramilitares y yo defendía a la guerrilla. Él decía que los guerrilleros que son unos ladrones, y yo le decía: "papito, yo estuve en la guerrilla y nunca me tocó presenciar un robo de la guerrilla... Es que los paramilitares sí son unos ladrones legítimos. Y, después, normal, pues seguíamos bien, no le parábamos como muchas bolas, decíamos: "es que nosotros ya no somos nada de eso, qué va” (Carmona, 2014, p. 149).

Quizá la muestra más radical de la autenticidad de su nueva identidad y su manera de estar en el mundo se pueda constatar en la capacidad de construir relaciones de pareja y proyectos de familia con excombatientes de grupos contrarios.

Cuando yo llegué y supe que había "paracos”, umm... ¡huy, no! Vea, a mí me dio de todo, (...) a mí me provocaba era volverme, voltear la cola y decir que no... pero ya después con los días pues que iba ahí yo no hablaba con nadie de ellos, y éste (se refiere a su pareja, un joven desvinculado de los grupos paramilitares), como era tan mala clase ¡ay, Señor! Éste lo miraba a uno y lo quería matar con la mirada ¡oiga! (Carmona, 2014, p. 141)

Esta capacidad de construir relaciones y proyectos de familia ha sido referida en estudios previos:

Yo me cuadré con un "paraco”. ¡Era más bonito...! Yo le decía a él: "oiga ¿a usted no le parece como raro ese cuadre con una guerrillera 
siendo que usted estuvo peleando con nosotros y nosotros con ustedes?", y él dizque: "no, normal, es que aquí, ya de civil, estamos en paz", "yo paz con usted no hago", le decía yo así, pues, cuando era novia de él. Allá era normal que las exguerrilleras se cuadraran con los "paracos". Normal, ¿y, ya no eran civiles, pues? (Carmona, 2014, p. 194)

Dentro de los resultados debemos destacar un hecho sorprendente: algunos niños y niñas que estuvieron vinculados a grupos armados y se implicaron más profundamente en acciones de guerra, son los que se empoderan de una manera más decida de su proceso de retorno a la vida civil y colaboran de una manera más entusiasta con los otros, lo cual es una muestra más de la capacidad de agencia, de autotransformación y de construcción de reconciliación y la paz de los niños y las niñas afectados por el conflicto armado.

\section{Referencias}

Alvaro, J. \&. (2004). Psicología Social. Perspectivas Teóricas y Metodológicas. Madrid: McGraw Hill.

ASCOFAPSI. (2005). Acta asamblea ordinaria de miembros. Medellín.

Berger, P. \&. (2001). La construcción social de la realidad. Buenos Aires: Amorrortu.

Blumer, H. (1982). Interaccionismo simbólico, perspectiva y método. Barcelona: Hora.

Carmona, J. (2012). La Carrera de las niñas en los grupos guerrilleros y paramilitares en Colombia. Medellín: Fondo Editorial Funlam.

Carmona, J. (2014). Las niñas de la guerra en Colombia. Madrid: Centro Editorial Universidad Católica de Manizales.

Fernández, C. (2003). Psicologías Sociales en el umbral del siglo XXI. Madrid: Fundamentos.

Freud, S. (1979). Obras Completas, v. X. Buenos Aires: Amorrortu.

Gergen, K. (1996). Realidades y relaciones: aproximaciones a la construcción social. Barcelona: Paidós.

Gergen, K. (2011). Social Construction: Orienting Principles. PhD program in Social Sciences. TAOS Institute- Tilburg University.

Goffman, E. (2001). Estigma. La identidad deteriorada. Buenos Aires: Amorrortu.

Hegel, F. (1987). Fenomenología del espíritu. México: Fondo de Cultura Económica.

Lacan. (1975). Escritos I. México: Siglo XXI.

Mancuso, J. \&. (1983). The Self narrative in the enactment of roles. En T. \&. Sarbin, Studies in Social Identity. New York: Praeger. 
Mead, G. (1973). Espiritu, Persona y Sociedad. Barcelona: Paidós.

Moreno, F., Carmona, J., \& Tobon, J. (2012). Why do girls join Guerrilla and Paramilitary Groups in Colombia? Revista Latinoamericana de Psicología, 3(42), 453-467.

Morin, E. (1983). El Método III. Madrid: Cátedra.

Munné, F. (1989). El interaccionismo simbólico y tendencias afines. Barcelona: Hora

Ospina-Alvarado, M., Carmona, J., \& Alvarado, S. (2014). Niños en contexto de conflicto armado: narrativas generativas de paz. Infancia Imágenes, 1(13).

Riviere, P. (2001). El Proceso Grupal. Buenos Aires: Nueva Visión.

Saussure, F. (1987). Curso de Lingüística General. Madrid: Losada.

Thomas, W. (1923). The Childhood in América. New York: Academic Press.

Torregrosa, J. \&. (1984). La interiorización de la estructura social. En J. y. En Torregrosa, Estudios Básicos de Psicología Social. Barcelona: Hora.

Wittgenstein, L. (1921). Tractatus. [en línea] Disponible en: http://www.philosophia.cl/ biblioteca/Wittgenstein/Tractatus\%20logico-philosophicus.pdf: Universidad ARCIS. 


\section{ESTUDIOS DOCUMENTALES}





\title{
5. Narrativas y testimonios de víctimas del conflicto armado en el Oriente Antioqueño: escenarios de transformaciones politicas en medio del horror y la resistencia
}

\author{
JaIME Arbey Atehortúa SÁNChEZ
}

\section{Resumen}

Entre 1996 y 2003 el Oriente Antioqueño vivió lo que en el panorama nacional se conoce como la época de agudización, recrudecimiento o escalada del conflicto armado. Luego de ello, comenzaron a aparecer compilados periodísticos e institucionales que buscaban registrar y sistematizar los testimonios y las narrativas de las víctimas de los municipios más afectados en la región. En ese orden de ideas, el artículo pretende configurar posibles alternativas de abordaje investigativo, que busquen aprovechar este cúmulo de narrativas y testimonios que se erigen como visiones alternativas a la memoria oficial. Para ello, el texto alude a la manera como las víctimas del Oriente Antioqueño han trasegado en medio de un conflicto que las ha trasformado de manera paulatina de un estado de dolor a una búsqueda de la dignidad en medio de la adversidad, en la que las relaciones y los escenarios sociales y políticos de una comunidad se trasforman y se reconfiguran -en este caso, a partir de las narrativas y los testimonios - para crear nuevas realidades. Esto en respuesta a los estudios sincrónicos que se concentran en el fenómeno del conflicto solo desde las secuelas inmediatas, todas con características negativas. El objetivo final es enrutar todos estos puntos de partida teóricos hacia las posibilidades que representa el enfocar las narrativas y los testimonios de las víctimas, desde los análisis de estos constructos textuales, a partir del diálogo transdisciplinar de las Ciencias Sociales.

Palabras clave: narrativas, víctimas, memoria colectiva, conflicto armado, Oriente Antioqueño

7 Universidad Católica de Oriente (Rionegro, Antioquia, Colombia). Correo: jatehortua@uco. edu.co 


\section{Abstract}

Between 1996 and 2003 the Antioquian East experienced what in the national panorama is known as the period of aggravation, escalation or escalation of the armed conflict. After that, journalistic and institutional compilations began to appear that sought to register and systematize the testimonies and narratives of the victims of the most affected municipalities in the region. In this order of ideas, the article intends to configure possible alternatives of investigative approach, that seek to take advantage of this accumulation of narratives and testimonies that are erected as alternative visions to the official memory. For this, the text alludes to the way in which the victims of Eastern Antioquia have ravaged in the midst of a conflict that has gradually transformed them from a state of pain to a search for dignity in the midst of adversity, in which relationships and the social and political scenarios of a community are transformed and reconfigured - in this case, from narratives and testimonies - to create new realities. This in response to synchronic studies that focus on the phenomenon of conflict only from the immediate aftermath, all with negative characteristics. The final objective is to route all these theoretical points of departure towards the possibilities represented by focusing the narratives and the testimonies of the victims from the analysis of these textual constructs from the transdisciplinary dialogue of the Social Sciences.

Keywords: Narratives, victims, collective memory, armed conflict, East Antioquia.

\subsection{Introducción}

El Oriente Antioqueño fue una de las regiones de Colombia que vivió con mayor intensidad la escalada del conflicto armado interno en las postrimerías del siglo XX. Sus habitantes, en especial los de las municipalidades más apartadas, fueron afectados por el recrudecimiento de la guerra interna que ha azotado al país desde la década de los años 50, y que tuvo su punto de mayor tensión cuando los tres actores armados - guerrillas, paramilitares y fuerzas estatales - coincidieron en espacios, tiempos e intereses. Estas comunidades han sido el foco de atención en el ámbito nacional y en el panorama mundial, no solo por la manera como han afrontado otros fenómenos inherentes al conflicto armado, sino también por la forma como las víctimas y sus asociaciones configuran recursos y mecanismos para registrar sus miradas de lo ocurrido y preservar la memoria. 
Las visiones y versiones que las víctimas del Oriente Antioqueño y del país han tenido y construido de los horrores padecidos en esa época de agudización del conflicto armado han llamado la atención del Estado, de la institucionalidad, de profesionales del periodismo y de otros comunicadores populares, oriundos de las comunidades afectadas, que se han puesto en la tarea de sistematizar y registrar las narraciones y los testimonios de los sobrevivientes de esta crisis humanitaria, con el fin de preservar en esas páginas las versiones no oficiales de lo ocurrido, en un esfuerzo por complementar, completar o contraponer los correlatos detallados y extendidos de estos familiares de desaparecidos y asesinados con los registros que los medios de comunicación y otras voces estandarizadas consignaban en sus espacios regulares de divulgación.

En el plano estrictamente local, las publicaciones que han sido realizadas del conflicto armado y las víctimas en el Oriente Antioqueño centran su atención en las vivencias de poblaciones muy concretas, como San Carlos (Olaya, 2012), Granada (Tamayo, 2013), Sonsón (Gallego, 2013), San Luis (Rivera, 2014), Guatapé (Idárraga, 2015), San Rafael (Jaramillo y Gómez, 2016) y San Francisco (Gallego, 2016), factor que posibilita la configuración de categorías que permitan hacer un análisis comparativo de las realidades sufridas por las víctimas del conflicto en diversas partes de la región, y que se erigen como insumos significativos para profundizar los procesos de construcción de memoria colectiva, que hoy por hoy identifican a estas comunidades como modelos nacionales e internacionales de resiliencia y de resistencia civil. Estos trabajos contrastan con las publicaciones de la institucionalidad (Centro Nacional de Memoria Histórica, 2011; Colectivo de Derechos Humanos Semillas de Libertad, Codehsel, 2007; Programa de las Naciones Unidas para el Desarrollo PNUD, 2010), pues en las primeras el testimonio de las víctimas cumplen un rol principal, mientras que en las segundas tienden a acompañar el recuento de los hechos y la lectura de lo ocurrido en términos de cifras y estadísticas. Así mismo, existen otras publicaciones que reúnen testimonios de víctimas en el ámbito nacional, tanto de investigadores, como de la institucionalidad que configura la memoria oficial $^{8}$. Algunos de ellos incluyen capítulos dedicados al Oriente Antioqueño, y otros sirven de base para contextualizar y relacionar el fenómeno con lo ocurrido en otros escenarios.

8 Al respecto, el Centro Nacional de Memoria Histórica cuenta en su página web http://www. centrodememoriahistorica.gov.co/ con otros trabajos de memoria en relación con las víctimas del conflicto armado en toda Colombia. 
Es evidente el esfuerzo de estas comunidades por no dejar que otros cuenten la historia, sino que sean ellos mismos los que reconstruyan los pedazos desperdigados de lo que ocurrió. Muchas de esas versiones, afortunadamente, han sido capturadas para la posteridad por "emprendedores de la memoria" (Jelin, 2002, p. 86), esto es, por periodistas, por comunicadores populares que emergieron de estas municipalidades y de las mismas entrañas del conflicto, por las instituciones que acompañaron el proceso de madurez de las asociaciones de víctimas. Pinceladas de esos testimonios han sido reproducidas por los medios masivos. También han servido de apoyo y de punto de partida para investigaciones de corte académico que se han ocupado del fenómeno, de los cuales se destacan las miradas que se han hecho desde la Psicología, la Antropología y la Sociología, que figuran en las publicaciones de la institucionalidad y del Estado. Sin embargo, no hay referentes ni indicios de estudios que, desde el análisis discursivo, textual o de contenido, propongan un enfoque de interpretación de estas narrativas desde la transdisciplinariedad de las Ciencias Sociales. Tampoco se tiene conocimiento de apuestas por profundizar en los sentidos que estos testimonios encierran en relación con las perspectivas que las propias víctimas tienen de su condición. Estos y otros horizontes investigativos se convierten en los retos y las perspectivas de investigación que a continuación se esbozarán.

Para ello, la primera parte de este andamiaje teórico introducirá las categorías discurso, relato y narrativas para indicar las diferencias entre estos conceptos generalmente tratados como sinónimos, pero que para los objetivos que persigue la presente propuesta de investigación no lo son. Posteriormente, en un segundo momento, interesa analizar el concepto de víctima, partiendo de los diversos matices que tiene esta categorías desde la victimología (disciplina que surgió luego de la II Guerra Mundial para analizar las diversas características que esta situación tiene, y que se le han escapado a la criminología), hasta llegar a los aportes de la Sociología de Veena Das (en la que la figura de la víctima adquiere dos dimensiones complementarias y continuas: como agentes de dolor y como ciudadanos) y de los preceptos que consignan los Derechos Humanos y la normatividad colombiana. En la categoría de víctima, per se ambigua, se espera determinar los diversos estadios que se evidencian en las narrativas de las víctimas, diferentes a los propuestos por la victimología, y que se sitúan en las caracteristicas sui generis del conflicto colombiano.

En el tercer apartado hablaremos de las narrativas como los constructos verbales que, a partir del relato o la selección de secuencias y escenas que hace un testigo o testimoniante, sirven para configurar el universo ideológico 
o discurso que tiene un individuo acerca de los acontecimientos sufridos o experimentados. Más adelante, en un cuarto momento la reflexión girará en torno de la importancia de los testimonios de las víctimas como posibilidades de acceder a los análisis de las situaciones traumáticas. En este punto se espera que el presente artículo retome el debate de la veracidad de estos constructos que, al igual que las narrativas, corresponden a las subjetividades y los intereses de un particular. Para ello, se espera recurrir a las ideas de la filósofa alemana Hannah Arendt, como la de solitud y la de imaginación, con las que se podría impregnar en estos dispositivos de memoria unos hálitos de confianza. Finalmente, en el quinto acápite se recurre a la noción de memoria colectiva para indicar la manera como en la investigación estas narrativas y testimonios particulares se erigen como muestras representativas de los intereses y posiciones de colectividades, de grupos, de comunidades que, si bien tienen sus luchas de memoria interna, también logran reconocerse en esas relaciones consigo mismas y con los otros.

El objetivo final es enrutar todos estos puntos de partida teóricos hacia las posibilidades que representa el enfocar las narrativas y los testimonios de las víctimas, desde los análisis discursivos y lingüísticos de estos constructos textuales, a partir del diálogo transdisciplinar de las Ciencias Sociales.

\subsection{Método}

Este artículo, fruto de la investigación doctoral titulada "Análisis de las representaciones de las narrativas de víctimas en el discurso del Centro Nacional de Memoria Histórica: caso Oriente Antioqueño", es un estudio cualitativo descriptivo, cuyo método de recolección y análisis de la información fue la selección y compilación de información a través de la lectura y crítica de documentos y materiales bibliográficos; en concreto, textos científicos y académicos que giraban en torno de las categorías que le interesan al marco teórico de la investigación doctoral: en primer lugar, la diferenciación epistémica entre conceptos afines como "testimonios", "relatos", "narrativas" y "discursos" (en el que los principales referentes son Paul Ricoeur, Gérard Genette, Michael Foucault y Mijaíl Bajtin). En segundo lugar, las variaciones que en el conflicto armado adquiere el concepto de víctima, desde la victimología hasta las visiones filosóficas, sociológicas y politólogas de Hannah Arendt, Veena Das y Seyla Benhabib, específicamente por ser aquellas que basan su reflexión en la mutación de un estado

9 Doctorado en Ciencias Humanas y Sociales, Universidad Nacional de Colombia sede Medellín. Asesora de la tesis: Dra. Mary Luz Alzate 
de vulnerabilidad a un nuevo rol como ciudadano que, paradójicamente, no deja atrás la condiciones de precariedad ya experimentadas. Finalmente, estas categorías se triangularon con las concepciones de memoria colectiva, partiendo de las nociones clásicas (Pierre Norá, Tzvetan Todorov) hasta llegar a las más contemporáneas, sobre todo pertinentes para el contexto latinoamericano (Claudia Feld, Elsa Blair, Elizabeth Jelin y Ludmila Da Silva Catela). Con este método cualitativo documental, basado en artículos publicados en bases de datos y en algunos libros, se buscó la consolidación de unas categorías conceptuales y teóricas que le interesan a los estudios acerca de víctimas que se hagan en el contexto colombiano, en concreto, en el Oriente Antioqueño.

\subsection{Resultados}

\subsubsection{Discursos, relatos y narrativas de víctimas}

¿Qué dificultades encierra el detenerse en fenómenos del pasado, y que son mostrados no como son, sino mediatizados por las subjetividades de quienes los padecieron? Cuando una persona, ya sea en su rol de testigo o actor, construye un texto - entendido como unidad comunicativa-, en relación con las experiencias de las que fue testigo o de las que fue el protagonista, nos encontramos ante dos instancias: el hecho, y el relato. El hecho, que aquí se propone denominar acontecimiento ${ }^{10}$ (Das, 1999) en contraste con el ambiguo término de historia, se refiere a las situaciones padecidas, evidenciadas o experimentadas, que se instauran en un pasado, y que solo tienen ocasión una vez en una realidad. Y aunque esa misma situación se vuelva a presentar, lo cierto del caso es que hará su incursión en otra realidad, en otro cronotopo (Bajtin, 1989), es decir, en otro espacio y en otro tiempo. Un secuestro, una muerte, una tortura, un desplazamiento, entre otros, son acontecimientos que se ubican en un pasado y, por ello, son imposibles de trasmitir de manera fiel y completa porque lo pasado queda en el pasado. En este orden de ideas, los periodistas, los literatos,

10 Para Das (1999), un acontecimiento (critical event) demanda la inserción de unas nuevas formas de acción histórica que esa situación no incluía en su inventario. He ahí la demanda para las Ciencias Sociales, y he ahí el porqué es imperativo detenerse en estos sucesos aún vigentes. Un acontecimiento, desde la perspectiva de la antropóloga hindú citada, se constituye en la medida en que estas experiencias encierran experiencias traumáticas o de sufrimiento para las comunidades. La agudización del conflicto armado en el Oriente Antioqueño es, entonces, un acontecimiento, no solo por las secuelas en la experiencia humana producto de la influencia de fuerzas beligerantes, sino también, por el impacto ideológico e identitario en los que directa o implícitamente se vieron afectadas, en últimas, las víctimas 
los historiadores, los académicos, en general, no plasman en sus páginas acontecimientos, sino versiones particulares y subjetivas de lo que en una realidad sucedió de manera objetiva.

Las narrativas de las víctimas incluidas en las compilaciones periodísticas que surgieron luego del declive el conflicto armado son, en suma, versiones, mas no acontecimientos. Son traducciones o correlatos condicionados por varias circunstancias: el vínculo que el narrador tiene con el hecho (testigo, protagonista, actor secundario...); el nivel de recuerdo; la capacidad de retener emociones, sensaciones e imágenes; el olvido; la censura; la autocensura; la locuacidad y demás recursos lingüísticos; los intereses y las posiciones, el efecto perlocutivo o efecto que busca en el receptor. Todo esto se podría resumir en una sentencia: quien construye un texto lo hace de acuerdo con unas imbricadas relaciones entre lo que dice y el hecho al que se refiere. En otras palabras, la relación sujeto-objeto crea un nuevo objeto, llamado texto, y esta relación está mediada por las intencionalidades comunicativas de quien construye el relato. Cuando estos propósitos tienen tintes ideológicos o políticos, en el sentido de propender por el poder (Foucault, 1999) y de plasmar las posiciones e intereses en relación con el acontecimiento, nos encontraremos ante un discurso. Un discurso es, en consecuencia, el resultado de una posición activa - política - de un sujeto en relación con un acontecimiento, pues aparte de hacer alusión a informaciones y a sucesos instaurados en una praxis, en un pasado real, también incluye las lecturas y los sentidos de este suceso en la experiencia particular.

El discurso, entonces, es una entidad abstracta que se establece en la mente, que inclusive ya está instaurado antes que pueda ser transmitido. Las ideas, los pensamientos, los argumentos y los juicios son la materia prima del discurso; las palabras, los textos, las construcciones simbólicas, los gestos, el arte... son formas que utiliza el discurso para su concreción. Así, con Ricoeur (1999) se llamará relato a las formas discursivas que se derivan de una perspectiva personal de un participante real o potencial, cuya relación con el hecho le da un privilegio al momento de enunciar (cf. Genette, 1972). Luego los relatos de las víctimas se erigen como un nuevo objeto que es producido a partir de la relación entre el acontecimiento (como hecho o situación traumática) y el discurso (como ideología). El periodista también hace relatos a partir de la relación que establece entre el hecho noticioso y sus ideologías - individuales y del medio de comunicación- (cf. Hoyos, 2003). El historiador construye relatos a partir de la relación que establece entre el hecho del pasado y sus intereses (ya académicos, ya institucionales, 
ya divulgativos ${ }^{11}$. En todos estos, como en los otros casos en los que hay construcción de relatos, opera un grado de manipulación de información - en el sentido de selección, evocación, retención, recuerdo, omisión, olvido, sublimación, minimización-. Esta manipulación se debe entender como trasformación, mas no como el interés de tergiversar la realidad para modificar o condicionar la recepción en los receptores de acuerdo con los intereses particulares del emisor, enfoque del cual se ocupa Chomsky (2008). Todo relato es, en definitiva, un resultado de la manipulación que un sujeto, mediatizado por sus posiciones, hace de un acontecimiento.

Ahora bien, hay diversas formas de construir relatos. La lengua ofrece incontables recursos para reconstruir los acontecimientos. La estructura de un relato puede ser variada. Los hablantes o quienes dan un testimonio no cuentan con un guión preconcebido para ir organizando las situaciones discursivas, aunque sea otra persona quien lo condicione con preguntas. $\mathrm{Y}$ aunque los diversos discursos (académicos, periodísticos, científicos, literarios, cotidianos...) tengan estructuras más o menos preestablecidas, esto no significa que haya homogeneidad en los textos desde el aspecto formal. Estas maneras de confeccionar los relatos, de establecer relaciones entre las situaciones internas es lo que se conoce como narrativas, tema que ampliaremos más adelante.

Por lo pronto, preguntémonos: si las víctimas no construyen acontecimientos sino relatos (producto de la relación entre el suceso y sus discursos, y que se concreta en narrativas) ¿cuánto de verdad hay en esas versiones? ¿qué del discurso entra en detrimento del acontecimiento? ¿cómo confiar en los testimonios de un ser cargado de intereses y posiciones, elementos que condicionan su versión de la realidad? Esto es, precisamente, los retos y las oportunidades de las Ciencias Sociales. Ahí radica su fuerza, su potencial. Es en ese entramado de versiones, de traducciones, de semiosis infinita (Eco, 1988) y de semiosis ilimitada (Peirce, 1931-1958) donde las interpretaciones progresivas replantean y resignifican los cánones de la ciencia.

11 Veyne (1984) argumenta que la historia es un relato de acontecimientos, por ello, la pluma del historiador no plasma lo que experimentaron los protagonistas, sino más bien una síntesis espontánea que hace alguien de un suceso. El historiador — como el periodista, como el académico, como el literato- reúne en sus textos significantes, más que hechos. La ciencia es, entonces, prisionera del lenguaje. En ese sentido, aunque ambas son anecdóticas, la diferencia entre la historia y la literatura es que la primera se ocupa de la verdad, mientras que la segunda, de la verosimilitud. 
Desde luego que esta problemática aún queda insatisfecha, y ese es el reto que deberían afrontar futuras investigaciones. Ahora nos detendremos en la categoría de víctima del conflicto armado.

\subsubsection{El concepto de víctimas: entre el horror y la resistencia}

A partir de la II Guerra Mundial, se comenzó a hablar - sobre todo en el ámbito jurídico - de una nueva disciplina, la victimología, como una corriente que trataba de llenar los vacíos de la criminología, debido a que en esta la figura de la víctima era emergente ante el énfasis que se hacía desde la parte jurídica y normativa a la categoría de criminal. Podemos decir, grosso modo, que esta ciencia (Díaz, 2006) se ocupa del análisis de la víctima desde tres perspectivas, todas en relación con el sufrimiento: como objeto de investigación en los procesos estatales, como secuela directa del crimen, y como sujeto de dolor que remite a demás estadios con cargas negativas (marginación social, secuelas psicológicas). Para el presente artículo importan estas dos últimas acepciones.

El concepto de víctima, empero, no deja de ser complejo, cargado de polivalencias semánticas y polisemias culturales (Arias, 2012). Por un lado, porque dentro de las diferentes clasificaciones que le competen a la victimología aparecen tipologías tan diversas y disímiles como las relacionadas con las catástrofes naturales, en contraste con las situaciones de violencia, las relaciones que la víctima establece con el hecho delictivo (inocencia, culpabilidad por ignorancia, infractor voluntario, como resultado de una legítima defensa, con ánimo de lucro, víctima que se convierte en victimario), y los diversos estadios psicosociales que experimenta una víctima (depresión, marginalidad, ambición, soledad, tormento, agresión, exclusión, menosprecio). Por el otro, porque representa un alto grado de dificultad analizar los fenómenos de víctimas debido a que cada circunstancia depende en exclusiva de situaciones particulares del acontecimiento, para lo cual no es suficiente con enfocar la problemática desde lo biopsicosocial ni lo jurídico ni lo criminal. Además, porque los fenómenos relacionados con las víctimas no solo están definidos por el contexto, sino que a la vez generan nuevos contextos (Das, 2008).

De hecho, algunos de los vacíos de la victimología tienen que ver con las categorías que nos preocupan aquí, esto es, con la constitución de un sujeto político, con las lecturas que las propias víctimas hacen de su condición y que se desprenden de sus narrativas, y con las maneras como las víctimas resignifican, quizás de manera diferencial, los fenómenos traumáticos en relación con las acciones de subversión, de la contrainsurgencia y de las fuerzas estatales. En suma, la victimología asocia a la figura de víctimas 
términos como daño, afección, violación de derechos, sufrimiento, dolor e injusticia como consecuencia de las acciones de un otro causante del ilícito, pero deja de lado aspectos relacionados con la dignidad, la emancipación, la resiliencia, la resistencia, la protesta y el empoderamiento como ciudadano, como sujeto político, como actor de cambio social y como sujeto de derechos, categorías abordadas por los teóricos que se han ocupado de la dignidad humana en los momentos de crisis (Das, 2008). Sin lugar a dudas, esta dicotomía inherente a la víctima aparece en las situaciones evidenciadas durante la agudización del conflicto armado en el Oriente Antioqueño. En ellas también hay una tendencia, al igual que otros contextos (Ospina, Carmona, Alvarado y Arroyo, 2018) a ser reconocidos como "constructores de paz y como instauradores de prácticas democráticas y de reconciliación que como víctimas determinadas por el pasado de las violencias asociadas al conflicto armado, razón por la que creemos necesario escuchar sus voces y darles un lugar fundamental en la agenda política de nuestro país" (p. 274)

Así mismo, hay tres características propias del fenómeno de victimización, que responden al porqué la figura de la víctima viene llamando la atención de las Ciencias Sociales: su relación con el concepto de memoria, las lecturas a la luz de los derechos humanos, y el giro hacia lo que antes parecía insignificante: la visibilización del sufrimiento (Arias, 2012). Estos aspectos, sumados a la misma etimología de la palabra - desde la teología, víctima como ser vivo sacrificado a un Dios, y como un ser consagrado o escogido (Arias, 2012) - deberían tener su corresponsabilidad en las dinámicas de las víctimas del conflicto en el Oriente Antioqueño, quienes constantemente aluden al recuerdo, a conceptos como la igualdad, a sus penurias, a la religiosidad y al destino como atenuantes ante la barbarie.

Desde la institucionalidad y el aspecto judicial, el concepto de víctima también debe ser tenido en cuenta al momento de reflexionar en torno de esta figura. Para la Asamblea Nacional General de las Naciones Unidas (2005), las víctimas pueden ser individuales y colectivas, los daños pueden ser morales o físicos, y las causas pueden ser la acción violatoria o la omisión manifiesta a las normas internacionales del derecho humanitario. Esta condición se relaciona, de igual manera, con conceptos como la restitución (de libertad, de empleo, de bienes); la indemnización y la rehabilitación de los daños físicos y psicológicos, la satisfacción y verificación de los hechos de forma pública, y las garantías de no repetición. En el caso de Colombia, y para efectos legales, además de las anteriores consideraciones, se inscribe en la categoría de víctimas a las parejas y a los familiares de primer grado de consanguinidad de desaparecidos o de personas que murieron por causas 
del conflicto armado (República de Colombia, 2011). Para algunos teóricos (Díaz, 2006; Arias, 2012), muchas de estas leyes terminan por lograr un efecto contraproducente, pues los sujetos suelen ser victimizados por la propia ley. Esta idea tiene relación con la del pasado continuo de Das (1998), de tal manera que la víctima termina siendo esclava de su propia condición, y todas las acciones del presente y del pasado procuran intereses como la compasión, la derrota e, inclusive, el lucro (Rodríguez, 2009), tendencias o fantasmas (Ortega, 2008) que suelen ser hereditarios. ¿Será este también uno de los resultados no esperados de los enfoques de las Ciencias Sociales en torno de la figura de la víctima? ¿Es este el efecto perlocutivo que inconsciente o conscientemente buscan las compilaciones periodísticas e institucionales de las narrativas de las víctimas? Preguntas que deben ser objeto de futuras investigaciones.

Finalmente, hay otras tres acepciones de víctimas que interesan acá. En primer lugar, la que incluye en esta categoría a los familiares, allegados y conocidos de la víctima (Díaz, 2006) y que se pueden denominar como sobrevivientes, afectados o damnificados (Rodríguez, 2009). Acá se podría hablar de una comunidad víctima pues, como en el caso de muchas poblaciones del Oriente Antioqueño, es difícil encontrar un poblador que no haya sido afectado en su núcleo cercano por las situaciones derivas del conflicto. Así, la víctima no queda referida al sacrificio, sino que se inscribe en un espectro determinado por el daño del que puede ser objeto -material e inmaterial, simbólico, moral, entre otros- (Observatorio de Paz y Conflicto, 2015). En segundo lugar, la que se preocupa por las lecturas que las víctimas hacen de las acciones (y sus efectos) no solo de la insurgencia y la contrainsurgencia, sino también de las fuerzas oficiales. Y en tercer lugar, la que se detiene en la dicotomía víctima-victimario (y viceversa), pues muchas de las personas desaparecidas o que perecieron durante la agudización del conflicto armado también hacían parte de las fuerzas beligerantes, ya subversivas, ya paramilitares, o ya estatales. Esta realidad acerca a las víctimas más al concepto de dolor compartido que al de inocencia, estrategia discursiva empleada constantemente, por ejemplo, en los guías del Salón del Nunca Más en el municipio de Granada y en muchas de las narrativas que son consignadas en los compilados periodísticos que han surgido luego del declive el conflicto armado.

\subsubsection{Las narrativas de las víctimas: formas de tramitar el dolor}

Una narrativa, como ya se había sugerido, es la manera como un sujeto estructura, relaciona, encadena y presenta su correlato de un acontecimiento. 
La narración conforma una perspectiva empírica que media la comprensión de un hecho (Barrio, 2015). Para ello, el autor de la narrativa recurre a efectos retóricos, literarios y lingüísticos que se adecuan a sus intencionalidades: solo de esta manera el texto se convierte en discurso, es decir, en un producto comunicativo cargado de intenciones y posiciones, en muchos casos, políticas. En ese orden de ideas, no es concebible la idea de memoria sin la de narración, pues esta no solo reconstruye la memoria, sino que se convierte en la mejor manera de expresarla y de representarla en una escena pública (Blair, 2008). De hecho, la narración es una alternativa para que las víctimas sobrevivientes se reinventen, hagan una elaboración privada del duelo a partir de este discurso público, y se defiendan ante situaciones nuevas y, sin embargo, análogas (Todorov, 2000).

A la narrativa le importa, por ende, la manera como quien cuenta la historia se posiciona en relación con el relato: si es homodiegético y relata desde una primera o segunda persona, ya sea como protagonista, personaje o testigo; o si es heterodiegético y prefiere describir los sucesos desde una instancia externa al texto, ya sea empleando la tercera persona omnisciente o periférica. También le compete la estructura del texto, la manera como el relator organiza las secuencias y las acciones en relación con la situación real o acontecimiento - rara vez la narración sigue la reproducción lineal y exacta de la sucesión de eventos del acontecimiento-. A la narrativa le interesa la omisión y sublimación de detalles, el énfasis y la atenuación, y demás estrategias que dotan de sentido y significado al relato. Y, desde luego, le atañen los recursos lingüísticos (los modalizadores, los conectores, la adjetivización, la ponderación, el uso de tropos de sentido y de figuras del pensamiento, los refranes, entre otros) que sirven como elementos indicadores de una intencionalidad discursiva. La selección del punto de vista, la manera como se hilvana la historia, y las variaciones y combinaciones de los diversos recursos estilísticos representan posibilidades de sentido para futuros trabajos.

Gracias a las narrativas, el testimonio logra trascender en el tiempo, pues el tránsito de la oralidad a la escritura posibilita que la historia y las futuras generaciones se alimenten de esa memoria colectiva (Ricoeur, 2005). Para ello, según Ricoeur (2004) las narrativas se configuran mediante tres momentos. En primera instancia, la mímesis I, que es la preconfiguración o el pre-texto - experiencia práctica que antecede la producción escrita, y que incluye las estructuras simbólicas y temporales que son detonadas por la acción y que cobran sentido en un contexto particular-. En segundo lugar, la mímesis II, que se preocupa por la mediación entre la manera como se representará ese universo simbólico anterior y el sentido que se quiere im- 
primir. Esta unión fondo-forma se concreta en una trama, esto es, la organización y concatenación de los sucesos en escenas y en acciones articuladas. Acá opera un elemento creativo donde el narrador ordena las secuencias de acuerdo con sus intereses, y no según con la lógica del acontecimiento real. Y por último, la mímesis III, que es la puesta en público de la narración, y es donde ocurre un encuentro anacrónico entre el lector, el texto y el autor. Es en este último momento donde se recobran las intencionalidades que se instauran en el primer estadio, y donde opera la cooperación de un lector que tenga curiosidad, posición activa, capacidad de problematizar, empatía y compasión (Jelin, 2002); en últimas, capacidad de escucha a partir de marcos de interpretación que propendan por trabajar hacia un posible sentido. Precisamente es en la mímesis III donde se sitúa la presente propuesta de enfoque investigativo.

Al igual que Ricoeur, Feld (2002) menciona tres dimensiones que se deben tener en cuenta al momento de analizar las memorias: la narrativa, la espectacular, y la veritativa. La primera se concentra en los mecanismos empleados para seleccionar y presentar las voces más adecuadas para la construcción de sentidos. La segunda se interesa en la puesta en escena, es decir, por los dispositivos narrativos o espacios de memoria que hagan verosímil el relato sobre el pasado. La tercera se preocupa por propender por una posible verdad, que se constituye a partir de las luchas por imponerse entre las demás, que suele ocurrir entre las diversas memorias. Este diálogo es lo que autores como Norá (2008) y Rueda (2013) rotulan como memoria histórica razonada, es decir, como un punto de articulación entre memoria e historia.

Si nos concentramos en los últimos momentos de Ricoeur y Feld, es factible concluir que el análisis de las narrativas no solo se debe preocupar por el fondo y la forma, sino también por los efectos y las intencionalidades. Es decir, que el contenido proposicional solo es la puerta de entrada para hurgar en los propósitos (acto ilocutivo) y en los fines de la comunicación (acto perlocutivo). Pero, insistimos, para poder determinar el porqué y el para qué se dice, es fundamental partir del cómo y del qué, es decir, de las narrativas y de los testimonios.

\subsubsection{Las victimas y sus testimonios:}

una visión alternativa de la historia

En los estudios relacionados con los textos de las víctimas aparecen, además de las categorías de narrativas, discursos y relatos, otra variante 
relacionada con las anteriores, pero que para efectos metodológicos vamos a definir y diferenciar. Se trata de la categoría de testimonio. Entendemos el testimonio como los contenidos proposicionales o enunciados que las víctimas dan, sobre todo, cuando se les pregunta acerca de algo.

Si bien el testimonio se deriva de la palabra testigo, esto no indica que únicamente las personas que hayan presenciado o vivenciado los actos puedan construir testimonios. Para evitar esta ambigüedad, se asociará el concepto con el de voz y, mejor aún, con el de versión, declaración o cita. Una persona que no haya sido testigo de un hecho, pero que puede dar su versión gracias a la proximidad topográfica o cultural que tiene con el hecho, o debido a que ha sido afectada, también podrá alzar su voz en calidad de testimoniante o como testigo-sobreviviente (Blair, 2008). Los testimonios, en consecuencia, son los fragmentos que emplean periodistas, académicos e instituciones para matizar sus textos, y que son extractados de sus fuentes de información. Por ello, las acotaciones que hacen los periodistas o científicos del suceso del que se habla también se convierten en testimonios, en su rol de testigo delegativo (Blair, 2008). Por todo lo anterior, la noción de testimonio es vital para los estudios relacionados con acontecimientos traumáticos pues, para algunos (Felman y Laub, 1992) luego de la II Guerra Mundial, vivimos en la era del testimonio.

En las compilaciones periodísticas e institucionales que comenzaron a surgir a mediados de 2004, fecha que se considera como el declive del conflicto armado en el Oriente Antioqueño (Acnur, 2004; IPC, 2006; Observatorio de Paz y Reconciliación del Oriente Antioqueño, 2007; Pnud, 2010; González, 2010; García y Aramburo, 2011; Centro Nacional de Memoria Histórica, 2013) se puede encontrar tanto la presencia de testimonios como la de narrativas. El primer recurso es habitual en los trabajos de la institucionalidad y en los de periodistas profesionales, de tal manera que el testimonio se supedita al discurso del comunicador o de la entidad, a manera de fragmento. El segundo recurso aparece cuando el periodista (sobre todo, el empírico) sirve de medio para que sea la misma fuente quien cuente su versión. Acá la labor del escritor es la de editar, organizar, pulir y, desde luego, omitir (seguramente no habrá espacio para incluirlo todo) lo que dice una fuente de primera mano. De esta manera, la narración se convierte en un testimonio sostenido, en una experiencia (Rey, 2008), de tal suerte que el lector experimenta la sensación de escuchar, más leer. Y esta escucha hace que el lector se convierta en otro testigo en la medida en que operan en él la indignación y la empatía (Reyes, 2003). 
El testimonio ha ganado prestigio por la emergencia de corrientes alternativas, como la historia oral, que busca recuperar el bagaje popular y las versiones de los protagonistas de eventos históricos - misión emparentada con la de los Estudios Subalternos (Thompson, 1989) y los Estudios Culturales (Hall, 1981) - que son invisibilizados en la historiografía convencional que se ha escrito "a fuerza de voces acalladas y memorias borradas" (Herrera y Pertuz, 2015, p. 151). Precisamente la potencia del testimonio radica no solo en la relación directa del sujeto con el hecho, sino también en su carácter de denuncia en la medida en que se erige como una voz que se antepone no solo ante los excesos y el silencio del poder, sino también ante su discurso hegemónico (Blair, 2008) representado por la historia oficial, los medios de comunicación y la institucionalidad, donde se da prominencia a los vencedores, a las élites dominantes.

Un acontecimiento (Das, 1999) suele ser la oportunidad para que surjan los testimonios de los vencidos. No obstante, las voces de los ausentes, de los desaparecidos y los muertos, tienen que ser representadas por las versiones de sus allegados, de sus familiares, de los sobrevivientes, de su comunidad. Es casi imposible contar con la versión de las personas que padecieron de forma directa un fenómeno de violencia, y cuyas voces han sido acalladas. Jelin (2002) hace notar que no solo esta representación, sino también el carácter subjetivo, pueden poner en tela de juicio el carácter de confiabilidad del testimonio, por lo que resulta difícil establecer el límite entre la fantasía y la ficción. En el apartado anterior se relacionaba el concepto de relato con la manipulación - en el buen sentido del término- que hace un sujeto de una realidad experimentada o percibida. Eso mismo sucede con el testimonio (a propósito, en relación con el relato, un testimonio de refiere a una intervención verbal, lingüística, oral, en contraste con la amplitud del término relato, que puede ser textual, pero también simbólica, cultural o audiovisual. Un testimonio, en últimas, es una clase de relato).

Si los testimonios tienen una fuerte carga de subjetividad, ¿cómo se puede confiar en ellos? Al respecto, es necesario decir que el carácter significativo del testimonio no está en la veracidad - la relación de correspondencia fiel entre las versiones y los hechos-, sino en la verosimilitud - lo aceptable, lo posible, lo factible - . La verosimilitud depende de la convergencia siempre flexible de voces en torno de un mismo suceso (Rey, 2008), de la confianza que se desprende de las conversaciones cotidianas en la palabra del otro, de la posibilidad que se tiene de confrontar cada voz con otras versiones similares - ya sea del mismo sujeto en diferentes tiempos, de otros sujetos que hayan vivenciado la misma realidad, o de la misma historia oficial—, 
y de la relación que guarda quien da el testimonio con el hecho del pasado, factor que le imprime autoridad por el grado de implicación que tiene con el suceso (Ricoeur, 2005). Esta distancia que otorga el tiempo de solitud (Arendt, 1978) es la que posibilita que esta versión tenga fiabilidad, porque justamente quien testimonia llena los vacíos y los silencios de lo que posiblemente ocurrió, gracias a sus archivos de memoria y a sus experiencias visuales. Hannah Arendt (1978) distingue la solitud (solitude) de la soledad (loneliness), pues la primera se produce cuando se hace compañía a uno mismo, mientras que la segunda es un encuentro solo, pero privado de la compañía humana y de la propia compañía. En la solitude el individuo se encuentra con sí mismo y con su álter ego, en términos de reflexión, de distancia. Esta relación está mediatizada por el lenguaje (por ello, no es extraño que una persona, cuando se encuentra sola, hable consigo misma). La filósofa alemana incluye el concepto de imaginación (Arendt, 1978) para explicar la forma como es posible representar lo que ya no está o lo que está ausente, lejos en el tiempo y de los sentidos. Con este principio, Arendt insiste en que la fuerza de una narración no radica en su verdad o falsedad, sino en su grado de significación, esto es, la capacidad que tiene de remitir - hacer visible - a un contenido ausente, y la posibilidad que se puedan emitir juicios o reflexiones acerca de tal contenido ${ }^{12}$. La significación parte del supuesto de que el lenguaje es el medio por el que se manifiesta el pensamiento (Arendt, 2002).

Quien da un testimonio, en últimas, no solo informa o referencia, sino que además reflexiona ${ }^{13}$ e interpreta de acuerdo con sus lecturas particulares del evento, lo que constituye una creación, una trasformación, nueva $\operatorname{verdad~}^{14}$ (Jelin, 2002), porque a medida que se elabora el testimonio se va construyendo un sentido, que muchas veces la misma fuente ignoraba tener (Quiceno, 2008). El lenguaje y su cualidad performativa ${ }^{15}$ posibilita lo que se ha denominado como semiosis ilimitada o infinita, y es justamente lo

12 Mientras que la imaginación trabaja con representaciones de cosas que no están ausentes, la reflexión posibilita el juzgar cosas concretas, que están a la mano (Barrio, 2015). Este tránsito convoca, inefablemente, a la interpretación.

13 Cf. Arendt (1978, pág. 31): "what becomes manifest when we speak about psychic experiences is never the experience itself but whatever we think about it when we reflect upon it".

14 Al respecto, Blair (2002) habla de dos verdades: la factual y la moral. "La primera alude a los hechos, a la verdad de lo que ocurrió; la segunda, a la verdad sobre el porqué y a causa de qué" (p. 13)

15 Por extensión, el lenguaje tiene la capacidad de producir efectos y generar acciones en quien recibe el contenido comunicativo. Estos fines pueden estar en consonancia con las intencionalidades de quien emite el mensaje, pero a veces también se escapan de estos propósitos. 
que demanda que estas versiones no solo sean registradas, sistematizadas o corroboradas. Sobre todo, deben ser escuchadas, es decir, interpretadas, más aun si se tiene en cuenta que su objetivo es recuperar los agujeros negros que quedan de un acontecimiento ante la imposibilidad de que los verdaderos testigos puedan hablar (Jelin, 2002; Cohen, 2006).

A pesar de que los testimonios pueden enriquecer la perspectiva que se tiene de una realidad, también existe la paradoja de que el testigo o el testimoniante tenga sus propios silencios, sus implícitos, sus censuras, que en todo caso no se podrían calificar como olvidos (Da Silva, 2000), sino como estrategias para sobrevivir, para conservar y marcar la intimidad del sufrimiento, para defenderse ante la reminiscencia devastadora y el dolor crónico (Quiceno, 2008), como vacíos insondables entre los significados y sus posibles significantes (es decir, la imposibilidad que el lenguaje tiene para representar de manera fiel algunas sensaciones traumáticas), o como necesidades, pues no es posible recordarlo todo (Todorov, 2000) ${ }^{16}$. No obstante, estos silencios suelen ser mitigados, ya por la temporalidad que ayuda a sepultar las penas, ya porque quien escucha no hace parte de un órgano de control que cumpla las veces de fiscalizador (como un tribunal de justicia, una comisión de la verdad o un representante de cualquiera de los bandos involucrados en el conflicto), ya por la relación afectiva y empática que genera confianza entre la fuente y el entrevistador (más aun si este tiene una cercanía con las comunidades afectadas, como es el caso de los comunicadores empíricos y profesionales que han realizado diversos compilados de narrativas y testimonios de víctimas), ya por la selección de los lugares y tiempos en los que ocurren los encuentros entre entrevistador y entrevistado (Da Silva, 2010). Los silencios que aún persisten pueden ser interpretados desde teorías relacionadas con análisis textual, enfoque que aún no ha sido empleado para el caso del Oriente Antioqueño.

Si bien es cierto que los testimonios proceden de una memoria con tintes subjetivos, también es cierto que se diferencian de la autobiografía porque contribuyen a la conformación de una memoria colectiva (Jelin, 2002), a un conocimiento culturalmente compartido por sociedades ligadas a un pasado en común (Vélez, 2003) que convergen en un sujeto plural en medio de un escenario de luchas políticas (Blair, 2008). Es decir, las compilaciones de textos que incluyen narrativas y testimonios de sobrevivientes del conflicto armado en el Oriente Antioqueño se instauran en una realidad que le

16 Por ello, para autores como Todorov (2000) y Martín Barbero (2001) no existe una verdadera oposición entre memoria y olvido, pues solo olvida quien tiene la capacidad de recordar. 
compete a una comunidad, y que se enriquece por las polifonías de quienes alzan su voz. Esta noción de memoria colectiva implica un compromiso político, pues el lenguaje es empleado para autoexhibirse, para mostrarse y fijar una posición en relación con los otros (Arendt, 1978). A continuación se ampliarán las nociones precedentes.

\subsubsection{La memoria colectiva y el diálogo intercultural}

En el caso del conflicto armado en el Oriente Antioqueño, la memoria colectiva de las víctimas se inscribe en lo que Hannah Arendt (1951) y Seyla Benhabib (2008) denominaron como el "derecho a tener derechos", es decir, el derecho de reconocer al otro y de ser reconocido en el marco de una comunidad humana. En este sentido, lo que perseguían las asociaciones de víctimas - como nuevas subjetividades colectivas y nuevas comunidades que comparten experiencias - era defenderse ante el olvido estatal, a la par que buscaban un reconocimiento como agentes políticos, con membresía dentro de una colectividad, en medio del trauma padecido (Arroyave, 2015). Para ello, las víctimas emplean los dispositivos de memoria, dentro de los cuales se inscriben sus narrativas, con el fin de revisar y reinterpretar lo sucedido. Benhabib (2005a) llama iteraciones democráticas a estas prácticas que cobran sentido político en la medida en que propenden por la reapropiación de los derechos universales, al tiempo que cuestionan la manera como el poder mina esos ideales universales. La memoria colectiva, en definitiva, surge en aquellos acontecimientos donde el sujeto se siente extranjero en su propio territorio al ser excluido de una nacionalidad o territorialidad — como sucede con los desplazados - y su objetivo es recordarle al poder el derecho que tienen las minorías a tener derechos y a participar en las deliberaciones públicas mediante un diálogo argumentado. Si bien la citada filósofa estadounidense aplica sus teorías en fenómenos de migración y extranjería, se nos antoja válido recurrir a sus aportes porque precisamente la agudización del conflicto armado en el Oriente Antioqueño ocasionó una desnacionalización (Benhabib, 2005a) de las comunidades afectadas, quienes no veían en el Estado un garante para sus derechos.

Las iteraciones democráticas, en el marco de una memoria colectiva, acuden al discurso como herramienta dialógica para pretender llegar a acuerdos, a partir del reconocimiento propio y del otro, mediante principios básicos de la democracia: reciprocidad, respeto mutuo, igualdad en medio de la diversidad, en un marco de historicidad tanto social como personal, que posibilite comprender el entramado difícil entre la subjetividad, la identidad y los sentimientos (López, 2015). Lo anterior, según Benhabib (2006) indica 
que el diálogo político -y, por ende, los relatos y las narrativas- se mueve en continuas tensiones, controversias, conflictos y negociaciones entre nosotros y ellos, entre nosotros y los otros (el plural debido a que, como se ha insistido, no existe una memoria individual). Ese otro, dice Benhabib (1990) se identifica a partir de sus narrativas como otro generalizado desde una visión moral, quizás abstracta, en la que la reciprocidad y el respeto a todo participante es un imperativo social categórico; pero también como otro concreto en la medida en que su identidad se manifiesta, y ya lo abstracto de la categoría anterior se configura en una historia de vida, en una imagen estática de alguien con unas características afectivas y emocionales específicas. Acá, cuando el individuo puede ser situado, la comprensión es recíproca, complementaria y se constituye en un imperativo universal, porque el yo (nosotros) también logra concretarse ante los ojos del otro a partir de sus respectivos puntos de vista. Pero, esto que Benhabib (2008) denomina universalismo interactivo, solo es posible en la medida en que el diálogo, a partir de las narrativas, se realice en un escenario público condicionado a las situaciones contextuales específicas (no como un reflejo simplemente mecánico), de tal suerte que las subjetividades políticas de las víctimas se adecúen a las construcciones colectivas y a las reconfiguraciones de los sentidos (Ospina, Carmona y Alvarado, 2014). El reto para las Ciencias Sociales consiste en tener en cuenta el punto de vista del participante, a partir de los relatos narrativos compartidos, en contraste con la visión holística de la cultura, propia de las disciplinas, porque los observadores enfocan estas narrativas desde un ámbito externo, con el fin de controlar (Sánchez, 2009).

En suma, los diálogos entre culturas posibilitan no solo la reivindicación y el reconocimiento de las minorías, sino que también generan dentro de cada grupo intrincados procesos dinámicos que llegan inclusive a modificar las aspiraciones compartidas y, por ende, a que los individuos que no se sientan representados en estas nuevas realidades se desagreguen y busquen nuevos grupos en los que se vean representados. Lo anterior anima a Benhabib (2005b) a concluir, a partir de sus estudios acerca del feminismo, que la posmodernidad trae consigo la muerte del sujeto y de todo principio identitario.

\subsection{Conclusiones}

La época del escalonamiento del conflicto armado en el Oriente Antioqueño representa, en clave metonímica, la crisis humanitaria que vivió el país, donde la población civil estuvo en medio del fuego cruzado de las fuerzas subversivas, contrainsurgentes y del Estado. Coincide el tiempo de 
esta agudización con otros fenómenos bélicos, que precisamente presentan su punto más álgido en los albores de un nuevo siglo. De ahí la importancia de detenerse en las narrativas en torno de un fenómeno que, si bien responde a las características internas y particulares de una región, también sirve de muestra inductiva de la condición humana y, en concreto, de uno de los fenómenos históricos más trascendentales en la historia de la Colombia contemporánea. Al respecto, entonces, vale la pena preguntarse: ¿Cuáles son las características de esa época del recrudecimiento del conflicto armado que se desprenden de los testimonios de las propias víctimas? ¿Es susceptible encontrar variaciones entre las lecturas que las víctimas hacen de su propia condición con la manera como el discurso dominante - del Estado, de los actores armados, de la institucionalidad, de los medios de comunicación, de la propia academia - las ha visibilizado? ¿Es posible, desde un análisis de contenido y textual, detectar los sentidos profundos encerrados en esos testimonios de víctimas, que han sido compilados en textos periodísticos que comenzaron a abundar en la época del declive del conflicto? Estos pueden ser puntos de partida para futuros abordajes investigativos desde un compromiso ético-político de las Ciencias Sociales, sobre todo en esos escenarios donde los ciudadanos no se percatan de la deformación interesada de la verdad por parte del poder totalizador de una ideología dominante (Durán, 2015).

Hay un común denominador que caracteriza las publicaciones periodísticas que emergieron luego del declive del conflicto armado: el uso de la primera persona protagonista, detalle que indica que la manipulación que hace el periodista o escritor está más relacionada con la estructura que con el contenido. Generalmente, los formatos del periodismo narrativo-como el perfil, la crónica y el reportaje — que aparecen en los medios de comunicación masiva son narrados en tercera persona (para tener un radio de acción más amplio del hecho narrado $\mathrm{y}$, de esta manera, poder incluir diferentes versiones que incluyen contrastaciones de fuentes), o en primera persona testigo (donde el periodista describe y cuenta un suceso haciendo hincapié en los protagonistas y el hecho como tal, al tiempo que incluye sus propias observaciones e inclusive interpretaciones). En las compilaciones ya aludidas, en cambio, el escritor sirve de medio entre quienes cuentan la historia - los protagonistas, las víctimas - y sus lectores, de tal manera que quien escribe opera con cierto grado de invisibilidad. Esta mínima contaminación del testimonio (si se permiten los términos) hace que llegue a los ojos del decodificador el relato crudo, casi producto de la transcripción literal de las versiones. Desde luego, el uso de la primera persona protagonista tiene desventajas: la mirada constreñida y, por ende, la imposibilidad de incluir 
de manera paralela otros puntos de vista acerca del mismo fenómeno; la supeditación del hecho a la fuente, con el peligro de quedar esclavo de las posibles tergiversaciones o manipulación que haga de los hechos quien habla; las circunstancias físicas del encuentro periodista-fuente y las situaciones emocionales y anímicas experimentadas en el momento del intercambio por quien da la información, aspectos que condicionan el testimonio, eso sin contar otras, como la relación de caracteres y de empatías entre el entrevistador y su fuente, o el vínculo de quien habla con el conflicto armado como tal (de actor a paciente). No obstante, las reconstrucciones subjetivas sirven, en beneficio de inventario, como plataformas de acercamiento al pathos que configura el ethos de la víctima, es decir, a las sensaciones, sufrimientos y emociones que se desprenden de la condición de víctimas y que precisamente estructuran esta identidad.

La situación anterior tiene un colofón: la distancia que todo testimonio guarda en relación con el fenómeno al que se refiere, además de la posición de quien narra. Todo constructo textual, toda expresión que se hace a partir de una realidad es una reconstrucción, un correlato, una traducción que incluye la óptica de quien narra: su subjetividad, su posición en relación con el fenómeno, sus intereses, sus posiciones, su individualidad. No estamos, en últimas, ante una realidad, sino ante la versión de alguien que padeció o vivió esa historia. Los hechos hacen parte del pasado; las versiones actualizan esas situaciones ya vividas, pero no solo para mostrarlas como fueron, sino para reflejar la lectura que los protagonistas hacen de lo acontecido. Allí habrá, entonces, silencios, omisiones, sublimaciones, énfasis, perspectivas, recuerdos y construcciones in situ (a veces los testimonios configuran otras realidades que no se creían que existían, si se quiere, sentimientos, pensamientos y evocaciones que sorprenden a la misma fuente que da su testimonio). Estos universos consignados en dichas compilaciones posibilitan que se pueda reconstruir el escenario de lo acontecido a partir de los puntos de vista de quienes vivieron en carne propia lo acaecido, en contraste con las versiones que aún prevalecen y que corresponden a lo que la ideología dominante quiso que se instaurara como única versión. Lo anterior explica que la semiosis ilimitada (la interpretación de interpretaciones) se mueve en la disyuntiva de riesgo y posibilidad. Pero esa acción sostenida de conjeturar es la que ha posibilitado que la ciencia se reinvente y se renueve.

Los acontecimientos que generan traumas sociales (Villa, 2013), como el caso de la agudización del conflicto armado en el Oriente Antioqueño, son los escenarios propicios para que el discurso de los marginados se configure y aparezca en lo público. Este discurso, que se concreta en narrativas 
y testimonios, sirve a la vez para que las Ciencias Sociales viren su mirada hacia estas nuevas realidades que le demandan compromisos y retos: el compromiso es para enfocar su atención en los grupos marginados, diferentes a los hegemónicos que históricamente han representado al poder; el reto es para generar diálogos interdisciplinares y transdisciplinares que tomen como objeto de estudio estas realidades textuales para ser escuchadas, es decir, interpretadas.

Un acontecimiento, entendido como el punto máximo de una situación crítica, demanda que las Ciencias Sociales agoten todos sus recursos para poder entender las situaciones que van a seguir siendo latentes en el presente y el pasado de estas comunidades, del país. A pesar de todas las inversiones estatales y privadas, que se concretan en ayudas logísticas, psicosociales y económicas, estos acontecimientos se convierten en un punto de quiebre que perennemente influirán en los individuos y en la sociedad, a manera de un pasado continuo, así operen trasformaciones políticas en las identidades de los pobladores.

Una tarea aplazada de las Ciencias Sociales en relación con las narrativas y los testimonios de las víctimas es la escucha, no en clave de sistematización o registro, sino en clave hermenéutica. La etnografía ha sido efectiva, y la apuesta de psicólogos, sociólogos, antropólogos, juristas y periodistas no ha sido en vano. Pero el vacío que falta por llenar es detenerse en los sentidos de esas versiones, y en sus significados. Falta escudriñar en esas voces que siguen navegando en los mares de los cientos y miles de páginas que han sido publicadas, pero poco examinadas.

El potencial de las páginas de estos compilados periodísticos no está solo en su carácter informativo ni referencial, sino sobre todo en su impronta representativa que posibilita la creación de nuevas realidades. No es posible tener acceso a las voces de los directos testigos, las personas cuya presencia fue esfumada, cuya palabra fue acallada. Pero los testigos sobrevivientes, los familiares, los allegados, los que comparten una memoria colectiva, sirven de insumos para poder acercarse, más que a lo que ocurrió, a las lecturas y correlatos que tienen los que vivieron en carne propia esas situaciones de barbarie.

Como dispositivos de memoria colectiva, los testimonios y las narrativas de las víctimas del conflicto armado en el Oriente Antioqueño sirven para acceder a las posturas políticas e ideológicas de los colectivos de víctimas y de las comunidades oprimidas, pero también sirven para que se puedan conciliar - en el marco de las iteraciones democráticas y de la lucha entre 
memorias - las diferentes posiciones que hay, hegemónicas y alternativas, en relación con uno de los hitos más significativos de la historia reciente de la región y del país. Es toda una tarea que apenas comienza.

\section{Referencias}

ACNUR, Oficina del Alto Comisionado de las Naciones Unidas para los Refugiados. (2004). Panorama actual del Oriente Antioqueño. Bogotá: autor. Disponible en: http://www.acnur. org/t3/ uploads/media/COI_632.pdf.

Arendt, H. (1951). Los orígenes del totalitarismo. London: Secker and Warburg.

Arendt, H. (1978). The life of the mind. New York: Harcourt Brace and Company.

Arendt, H. (2002) La vida del espíritu. Barcelona: Paidós.

Arias Vanegas, B. E. (2012). Análisis comparativo de los procesos de socialización y su relación con las competencias sociales de los niños y las niñas en la ciudad de Medellín. (Tesis de doctorado). Universidad de Manizales-CINDE.

Arroyave Álvarez, O. (2015). Memoria, reconocimiento y conflicto armado. En S. N. Cogollo Ospina (coord.). Imaginar la paz en Colombia: cavilaciones desde la academia, Medellín: Funlam.

Asamblea Nacional General de las Naciones Unidas -ONU. (2005). Resolución 60/147: principios y directrices básicos sobre el derecho de las víctimas de violaciones manifiestas de las normas internacionales de derechos humanos y de violaciones graves del derecho internacional humanitario a interponer recursos y obtener reparaciones. Disponible en: www.ohchr.org/SP/ProfessionalInterest/Pages/RemedyAndReparation. aspx.

Bajtin, M. (1989). Teoría y estética de la novela. Madrid: Taurus.

Barrio, C. (2015). La función del pensamiento y el discurso en Hannah Arendt. De los juicios reflexivos a los juicios políticos. Ideas y Valores, 64(159), 109-130.

Benhabib, S. (1990). El otro generalizado y el otro concreto: la controversia Kohlberg-Gilligan y la teoría feminista. En S. Benhabib y D. Cornell (eds.) Teoría feminista y teoría crítica. Valencia: Ediciones Alfons et Magnánim.

Benhabib, S. (2005a). Los derechos de los otros. Extranjeros, residentes y ciudadanos. Gabriel Zadunaisky (trad.). Barcelona: Gedisa.

Benhabib, S. (2005b). Feminismo y Posmodernidad: una difícil alianza. En C. Amoros y A. de Miguel (eds.) Teoría feminista: de la ilustración a la globalización, (pp. 319- 342.) Madrid: Minerva Ediciones.

Benhabib, S. (2006). Las reivindicaciones de la cultura. Igualdad y diversidad en la era global. Buenos Aires: Katz.

Benhabib, S. (2008). Otro universalismo: sobre la unidad y la diversidad de los derechos humanos. D. Álvarez (trad.). Revista de Filosofía Moral y Politica, 39, 175-203. 
Blair Trujillo, E. (2002). Memoria y narrativa: la puesta del dolor en la escena pública. Estudios Políticos, 21, pp. 9-28.

Blair Trujillo, E. (2008). Los testimonios o las narrativas de la(s) memoria(s). Estudios Politicos, 32, 83-113.

Centro Nacional de Memoria Histórica. (2011). San Carlos: memorias del éxodo en la guerra. Bogotá: Taurus.

Centro Nacional de Memoria Histórica. (2013). ¡Basta ya! Colombia: Memorias de guerra y dignidad. Santa Fe de Bogotá. Informe general Grupo de Memoria Histórica.

Centro Nacional de Memoria Histórica. (2013b). Memorias desde el retorno. Sistematización de las prácticas de memoria impulsadas en los programas de retorno al municipio de San Carlos, Antoquia, entre 2009 y 2013. Santafé de Bogotá: autor.

Centro Nacional de Memoria Histórica. (2016). Granada: memorias de guerra, resistencia y reconstrucción. Bogotá: autor.

Chomsky, N. (2008). Cómo nos venden la moto. Información, poder y concentración en medios. Barcelona: Ícara

Chomsky, N. y Herman, E. (1990). Los guardianes de la libertad. Carme Castells (trad). Barcelona: Grijalbo Mondadori.

Cohen, E. (2006). Los narradores de Auschwitz. México: Fineo y Lilmond.

Colectivo de Derechos Humanos Semillas de Libertad -Codehsel. (2007). Ejecuciones extrajudiciales: el caso del Oriente Antioqueño. Santa Fe de Bogotá: Observatorio de derechos humanos y derecho humanitario. Documentos regionales 2.

Congreso de la República de Colombia. (10 de junio de 2011). Ley 1448 de 2011, por la cual se dictan medidas de atención, asistencia y reparación integral a las víctimas del conflicto armado interno y se dictan otras disposiciones. Diario Oficial 48.096.

Da Silva Catela, L. (2010). Pasados en conflictos: de memorias dominantes, subterráneas y denegadas. Ponencia presentada en la celebración de los 10 años del grupo de Investigación Cultura, Violencia y Territorio del Instituto de Estudios Regionales -INER- Medellín.

Da Silva Catela, L. (2000). De eso no se habla. Cuestiones metodológicas sobre los límites y el silencio de entrevistas a familiares de desaparecidos políticos. Historia Antropología y Fuentes Orales, HAFO, 24, p. 69-75.

Das, V. (1999). Critical Events. An anthropological perspective on contemporary India. Oxford: University Press.

Das, V. (2008). Wittgenstein y la antropología. En F. A. Ortega (ed.) Veena Das: Sujetos de dolor, agentes de dignidad (pp. 295-342). Bogotá: universidad Nacional de Colombia.

Das, V. (2008) Sujetos de dolor, agentes de dignidad. Bogotá: Universidad Nacional de Colombia, Facultad de Ciencias Humanas. 
Díaz Colorado, F. (2006). Una mirada desde las víctimas: el surgimiento de la victimología. Ensayo Umbral Cientifico, 9, 141-159.

Durán Palacio, N. M. (2015). Compromiso ético-político de los profesionales de las Ciencias Sociales. Revista Colombiana de Ciencias Sociales, 6(1), 11-13.

Eco, U. (1988). De los espejos y otros ensayos. Barcelona: Lumen.

Feld, C. (2002). Del estrado a la pantalla: las imágenes del juicio a los excomandantes en Argentina. Madrid: Siglo XXI.

Feld, C. (2013). La memoria, esa vieja cuchara. Revista Prácticas de Oficio: Investigación y reflexión en Ciencias Sociales, 11-12, 1-4.

Felman, S. y Laub, D. (1992). Testimony. Crises of Witnessing in Literature, Psychoanlaysis, and History. New York: Routledge.

Foucault, M. (1999). Estética, ética y hermenéutica. Barcelona: Paidós.

Gallego Castro, J. C. (2013). Con el miedo esculpido en la piel. Crónicas de la violencia en el corregimiento La Danta (San Luis, Ant.). Proyecto ganador de la primera convocatoria de estímulos al Talento Creativo. Medellín: Hombre Nuevo Editores.

Gallego Castro, J. C. (2016). Aquitania: siempre se vuelve al primer amor. Medellín: Sílaba Editores.

García, C. I. y Aramburo, C. I. (eds.). (2011). Geografias de la guerra, el poder y la resistencia. Oriente y Urabá antioqueños 1990-2008. Medellín: Instituto de Estudios Regionales, Universidad de Antioquia.

Genette, G. (1972). Discurso del relato: ensayo de método. Figures III. Paris: Editions du Seuil.

Gómez, J. A. (2010). El camino sembrado, Serie Crónicas: estudio de caso del proceso de apropiación y poblamiento de los corregimientos de Aquitania, El Prodigio, San Miguel, Jerusalen y la Danta. Medellín: Acción Social, Antioquia para todos.

González Gil, A. (2010). Viajeros de ausencias: desplazamiento forzado y acción colectiva en Colombia. (Tesis de doctorado). Estudios de América Latina Contemporánea. Madrid: Universidad Complutense.

Harsin, J., \& Hayward, M. (2013). Stuart Hall's “Deconstructing the Popular": Reconsiderations 30 Years Later. Communication, Culture \& Critique, 6(2), 201-207.

Herrera Cortés, M. C. y Pertuz Bedoya, C. (2015). Narrativas femeninas del conflicto armado y la violencia política en Colombia: contar para rehacerse. Revista de Estudios Sociales, 53, 150-162.

Hoyos, J. J. (2003). Escribiendo historias del arte y el oficio de narrar en el periodismo. Medellín: Editorial Universidad de Antioquia.

Idárraga Alzate, Á. (2015). Voces que se llevaron. Paso del conflicto armado por Guatapé. Medellín: Editorial Soluciones. 
Instituto Popular de Capacitación - IPC. (2006). Píldoras para la memoria. Violaciones de derechos humanos y crímenes de lesa humanidad en el Valle de Aburrá y en el Oriente Antioqueño (2000-2004). Medellín: autor.

Jaramillo, A. M. y Gómez, J. A. (2016). Memorias de una masacre olvidada: los mineros de El Topacio, San Rafael (Antioquia), 1988. Bogotá: Centro Nacional de Memoria Histórica.

Jelin, E. (2002). Los trabajos de la memoria. Madrid: Siglo XXI.

López Arboleda, G. M. (2015). Del guerreo al ciudadano. Experiencias y sentimientos sociales en la historia de los desmovilizados del conflicto armado colombiano. Saarbrücken, Alemania: Editorial Academia Española.

Norá, P. (2008). Les Lieux de Mémoire. Montevideo: Trilce

Observatorio de Paz y Conflicto - OPC. (2015). Debates en torno a la noción de víctima. Bogotá: Universidad Nacional de Colombia.

Observatorio de Paz y Reconciliación del Oriente Antioqueño. (2007). Estudio de diagnóstico y contextualización de los 23 municipios del Oriente Antioqueño sobre la situación del conflicto político armado, los derechos humanos, el derecho internacional humanitario, las organizaciones sociales y la gobernabilidad democrática. Rionegro: Corporación Vida, Justicia y Paz.

Olaya R., C. H. (2012). Nunca más contra nadie. Ciclos de violencia en la historia de San Carlos, un pueblo devastado por la guerra. Medellín: Cuervo Editores.

Ortega, F. (2008). Rehabilitar la cotidianidad. En V. Das. Sujetos de dolor, agentes de dignidad (pp. 15-70). Bogotá: Universidad Nacional de Colombia.

Ospina Alvarado, M. C., Carmona Parra, J. A. y Alvarado Salgado, S. V. (2014). Niños en contexto de conflicto armado: narrativas generativas de paz. Revista Infancias Imágenes, $13(1), 52-60$.

Ospina Alvarado, M. C., Carmona Parra, J. A., Alvarado Salgado, S. V. y Arroyo Ortega, A. (ed). (2018). Construcción social de niñas y niños en contextos de conflicto armado: narrativas generativas para la construcción de paz. Bogotá: Universidad Pedagógica Nacional, Fundación Centro Internacional de Educación y Desarrollo Humano CINDE

Peirce, C. (1931-1958). Collected Papers (C.P), v. 1-8. Electronic Edition de J. Deely, Intelex Charlottesvill.

Programa de las Naciones Unidas para el Desarrollo - PNUD. (2010) Oriente Antioqueño: Análisis de la conflictividad. Bogotá: Área de Paz, Desarrollo y Reconciliación.

Quiceno, N. (2008). Puesta en escena, silencios y momentos del testimonio. El trabajo de campo en contextos de violencia. Estudios Políticos, 33, 183-210.

Rey, G. (2008). Representación, relato y experiencia. La comunicación más allá de la seguridad. En G. Rey y O. Rincón (eds.). Más allá de víctimas y culpables. Relatos de experiencias en seguridad ciudadana y comunicación, América Latina, (pp. 11-25). Bogotá: Centro de Competencia en Comunicación para América Latina Friedrich Ebert Stiftung. 
Reyes Mate, M. (2003). Por los campos del exterminio. Barcelona: Anthropos

Ricoeur, P. (1999). La lectura del tiempo pasado: memoria y olvido. Madrid: Ediciones de la Universidad Autónoma de Madrid.

Ricoeur, P. (2004). Tiempo y narración I. México: Siglo XXI.

Ricoeur, P. (2005). La memoria, la historia, el olvido. Madrid: Fondo de Cultura Económica.

Rivera Marín, D. (2014). Volver para qué - Crónica sobre el desarraigo. Medellín: Fondo Editorial Eafit.

Rodríguez González, A. (2009). El concepto de víctima. En A. Iñaki Markez, A. Fernández Liria y P. Pérez-Sales (coord.) Violencia y salud mental. Salud mental y violencias institucional, estructural, social y colectiva (pp. 37-42). Madrid: Asociación Española de Neuropsiquiatría.

Rueda Arenas, J. F. (2013). Memoria histórica razonada. Una propuesta incluyente para las víctimas del conflicto armado interno colombiano. Historelo. Revista de Historia Regional y Local, 5(10), 15-52.

Sánchez Muñoz, C. (2009). Seyla Benhabib: hacia un universalismo interactivo y globalizado. En R. Maíz (comp.). Teorías politicas contemporáneas (pp. 272-309). Valencia: Tirant lo Blanch.

Tamayo Gomez, H. de J. (2013). Desde el salón del nunca más. Crónicas de desplazamiento, desaparición y muerte. Medellín: Inversiones Tamayo Palacio.

Thompson, E. (1989). La formación de la clase obrera en Inglaterra. Barcelona: Editorial Crítica.

Todorov, T. (2000). Los abusos de la memoria. Barcelona: Paidós.

Vélez Rendón, J. C. (2003). Violencia, memoria y literatura testimonial en Colombia. Entre las memorias literales y las memorias ejemplares. En Estudios Políticos, 22, 31-54.

Veyne, P. (1984) ¿Cómo se escribe la historia? Madrid: Alianza.

Villa Gómez, J. D. (2013). El rol de la memoria colectiva en la recuperación emocional de la violencia política en Colombia. International Journal of Psychological Research, 6(Issue 2), 37-49.

Zuluaga Ceballos, G. (2007). 24 Negro. Medellín: Hombre Nuevo Editores. 


\title{
6. Memoria, duelo y olvido. Elementos para la reconciliación en tiempos de construcción de paz
}

\author{
Carlos Germán Celis Estupiñán ${ }^{17}$
}

\section{Resumen}

El presente estudio se ocupa de los procesos de memoria, duelo y olvido como elementos fundamentales para la construcción de paz. En esta vía, a partir de una orientación analítica metodológica inspirada en planteamientos de la Arqueología del saber de Michel Foucault, que trata los fenómenos como formaciones de discurso, se propone una interrogación en torno a lo que se entiende por psicosocial; y desde el psiquismo anudado a lo social por la vía del síntoma se plantea pensar el duelo como una tensión entre la memoria y el olvido. En este orden se sirve de la doble cara del síntoma no para unir, sino para señalar una tensión productiva entre el psiquismo, como lo propio de la subjetividad y la colectividad, de manera que sea posible explorar la producción del recuerdo, el olvido como tentación y exceso, y el duelo como un proceso que se efectúa con el lenguaje y el tiempo.

\section{Abstract}

The present study is centered in the processes of memory, mourning and forgetfulness as fundamental elements for peace construction. In this way, following an analytical methodology, inspired by Michel Foucault's approach developed in The Archeology of knowledge, consisting of the treatment of phenomena as discursive formations, an interrogation of what is apprehended as psychosocial is proposed. As well as the possibility to consider mourning as a tension between memory and forgetfulness, taking into account the knotting of the psychic and social dimensions by means of the symptom. According to this, the double facet of the symptom points to a productive tension between psychism, as a dimension related to the subjectivity, and the collectivity, allowing an exploration of the memory

17 Universidad Autónoma de Bucaramanga. Correo: ccelis2@unab.edu.co 
production, the forgetfulness as temptation and excess, and mourning as a process that requires language and time.

\subsection{Introducción}

Cuestiones preliminares en torno a un debate necesario. Una pregunta por lo psicosocial

En Colombia acontece un momento coyuntural importante en el que confluyen múltiples discursos y prácticas en torno a un fenómeno que resulta tan ajeno como anhelado, a saber, la paz. En este sentido es pertinente, desde los saberes propios de la disciplina psicológica, indagar en torno a la idea de paz que resultaría posible para un país que ha hecho de la guerra un cierto modo de vida. El siguiente escrito presenta una reflexión de carácter epistémico que se espera constituya un aporte a los esfuerzos propios de la intervención psicosocial, con el propósito de trascender el asistencialismo y aportar en la producción de saber con respecto a las particularidades del malestar que han tejido la historia y las aspiraciones de este contexto. Por lo anterior es importante indagar acerca de qué se entiende, en este caso, por intervención psicosocial y analizar la manera en que esta acción se articula a procesos como la memoria, el duelo y el olvido, que tienen funciones estructurales y sintomáticas tanto a nivel de la subjetividad como de las colectividades. Es propio de la universidad procurar un espacio crítico de debate que es a la vez un ejercicio científico y político, y esto porque su función social es enmarcar su hacer en el rigor de la ciencia y la ética, en la estructura conceptual que formaliza su práctica y evalúa los efectos tanto a nivel de la formación como en la comunidad.

Antes de indagar acerca del carácter psíquico y social de procesos como la memoria, el duelo y el olvido, y su incidencia en la construcción de paz resulta necesario interrogar qué se entiende por intervención psicosocial. En este punto es importante tomar la intervención psicosocial en su dimensión significante, es decir, como una expresión que carece de una definición oficial; no obstante, su uso generalizado ha dado lugar a una comprensión superficial de la complejidad que enmarca y al olvido de los fundamentos que le dan sentido como unidad de discurso. Respecto a la dificultad de definir la intervención psicosocial, Peláez, Cañón y Noreña (2007) afirman que se trata de una acción de asesoramiento profesional que desde la psicología aplicada se dirige a un colectivo para brindar ayuda y tratamiento con el fin de "(...) aconsejar habilidades y comportamientos anacrónicos 
para optimizar los adecuados" (p.192). Otra manera de entender es aportada por Alviz (2009) quien señala que se trata de una "(...) actividad dirigida a la solución de problemáticas sociales, que privilegia la participación de los intervenidos con los interventores en la construcción de cambio social y emancipación" (p.4). Por su parte, tanto Villa (2012) como López y Rodríguez (2012) lo entienden como un enfoque que tiene en cuenta las particularidades de la población víctima o que sufre para reconocer los múltiples contextos políticos, sociales y culturales en los que se encuentran y junto con ellos llevar a cabo un acompañamiento integral. El Programa de Atención Psicosocial y Salud Integral a Víctimas del conflicto armado -PAPSIVI- del Ministerio de Salud (2017) lo asume como un enfoque cuya finalidad es la comprensión y el reconocimiento de los múltiples factores que comportan las expresiones del daño, con el objetivo de aportar procesos de atención física, mental y psicosocial dirigidos a las necesidades propias de las víctimas del conflicto armado.

Las anteriores aproximaciones corresponden a la reflexión de investigadores colombianos en torno al tema, quienes están de acuerdo en señalar lo relevante de comprender el contexto y las particularidades de las víctimas, así como la importancia de su participación en los procesos de cambio social. No obstante, más que conceptualizar el núcleo epistémico de lo psicosocial se ocupan de describir lo que debería ser. La cuestión problemática de lo anterior radica en que no se hace énfasis en un elemento diferencial que desde la Psicología sea tenido en cuenta como psicosocial, y en ese sentido el aporte puede ser el mismo desde cualquier perspectiva de las ciencias sociales o de la salud, lo cual suele disolverse en intervenciones de carácter asistencialista como es frecuente a imitación del modelo médico y sus brigadas de salud. Para el discurso médico, que reduce la noción de salud a una cuestión orgánica y no a una práctica social, el asistencialismo resulta útil pues provee atención básica de carácter externo a la comunidad, que no se encarga de generar soluciones estructurales. Al ocuparse de dificultades emergentes aportan paliativos "(...) para disminuir las consecuencias de las problemáticas mas no para resolverlas" (Cruz, 2012). Estas modalidades de atención dan lugar a dependencias y a la persistencia del malestar.

Es importante desmarcar la intervención psicosocial del intervencionismo asistencialista en el sentido de que lo psicosocial, si bien está llamado a procurar alternativas eficaces respecto a las problemáticas sociales, resulta necesario inscribirlas en la lógica de los procesos más que en la inmediatez. Las prácticas asistencialistas están caracterizadas por el cubrimiento y el impacto; les interesa producir evidencias como fotografías, videos y listas 
de asistencia, en lugar de comprometerse con un acompañamiento continuo que permita evaluar los procesos. Esto también tiene efectos en las comunidades quienes, a causa del intervencionismo, descreen del trabajo de los profesionales y solo esperan beneficios como donativos que satisfagan sus necesidades inmediatas, cuestión que los aleja de la posibilidad de empoderarse de sus problemáticas. En este sentido, lo psicosocial se presenta a modo de una unidad de discurso que funciona como una herramienta al servicio de intereses utilitaristas.

El proceder metodológico se orienta por la propuesta de Foucault (2007) quien alerta sobre el efecto de tomar ciertos enunciados como unidades incuestionables o sobreentendidas que sirven para "reagrupar una sucesión de acontecimientos dispersos, referirlos a un mismo y único principio organizador (...)" (p. 34). Así, se tiene en cuenta que se trata de términos que se establecen por comunidades de sentido que se deslizan sin examen por una conciencia colectiva legitimados a partir del uso. Por eso, señala que es importante desalojarlos de la costumbre e interrogar su decir y su función para un cierto campo de discurso. Tal es el caso de formaciones discursivas como castro-chavismo que une dos campos semánticos diversos en torno a un discurso sobre la ideología comunista. Este enunciado pone a funcionar un sentido vinculado a la izquierda y, por tanto, en contra de los valores propios del capitalismo y el liberalismo económico. Con esta formación que no se adjudica a un sujeto en particular, pero es divulgada por sujetos a quienes se les atribuye autoridad, se formula una realidad efectiva que permite difundir el miedo a los efectos que los sistemas de gobierno de izquierda produjeron en Cuba y Venezuela. Estos excesos son propios del discurso pero, al ser considerados en tanto acontecimientos, es decir, suscritos a la evanescencia del tiempo y el lenguaje son, por una parte, inagotables y, por otra, analizables. Pese a que pueda parecer exagerado tomar el castrochavismo como pretexto para interrogar lo psicosocial, estas unidades de discurso coinciden en que son de uso generalizado pero irreflexivo sobre lo que les da consistencia como unidad de discurso, lo cual da lugar a un modo de hacer que carece de una fundamentación epistémica que sirva como orientador y sobre la cual más bien reposan un conjunto de supuestos e ideales, que hacen de la intervención una práctica quizá con impacto pero sin efecto.

Aunque para algunos las nociones fundamentales parezcan lugares comunes e incluso superadas es necesario volver a los cimientos de la disciplina, a los rudimentos que hicieron posible la constitución de un conocimiento. Por eso, es importante dispersar ese núcleo rígido del uso del término psicosocial y retornar sin nostalgias a su composición, desde una actitud expectante por 
un recurso que permita pensar el presente, renovar y actualizar el sentido. Psiqué es un vocablo griego utilizado para designar el alma humana, es decir, el aliento vital que se desprende del cuerpo cada vez que un hombre habla y se desaloja cuando muere (Rohde, 2006). Por su parte, en el término "psicología", Logos refiere a conocimiento, pero también es traducido por lógica; no obstante, en griego $\lambda o ́ \gamma o \varsigma$ también refiere a "enunciado, juicio" (Heidegger, 1997, p.17), cualidades que facultan el pensar en tanto representación. Por ello es el fundamento del lenguaje, el habla, el discurso; es el efecto de una reflexión lógica del intelecto humano cuyo propósito es la búsqueda de sentido. Es necesario señalar que tanto el psiquismo como el lenguaje no están en el cerebro, no existe una estructura biológica particular que los aloje, sino que son el efecto de un conjunto de interacciones complejas; sin embargo, fue preferible para ajustarse a los requerimientos de objetividad de la ciencia excluirlos de manera intencional y en su lugar se construyeron abstracciones como la mente y la conducta, susceptibles de ser definidas operacionalmente y reducidas a la cuantificación.

En este orden, negar el psiquismo es negar el lenguaje y, aunque no es posible reducirlos a escalas objetivas, no por ello se pueden tratar como objeto de pseudociencias o de ciencias ocultas, porque aunque no sean objetivos han de ser sometidos a debate. Tanto el psiquismo como el lenguaje no son una esencia, es decir, algo inmutable y permanente que ha estado por siempre en lo más recóndito del ser, aunque sean lo fundamental de la singularidad, sino que son un efecto de sentido que viene de las palabras del otro. El psiquismo de cada uno es un efecto relacional, por eso no es preciso hablar de individuo, término que quiere decir in-diviso, sin división, pues lo que introduce el otro a través del lenguaje es una fractura originaria, demostrable en la no coincidencia estructural entre lo que cada uno imagina de sí y lo que otros ven y piensan entre lo que se dice y lo que se hace. Así, el psiquismo no es sin el otro y por tanto ya es social. Lo social viene del latín socialis y refiere al socius, al compañero, a lo perteneciente a la comunidad, al lazo con el otro, al semejante por el que se siente atracción y a la vez rechazo. Decir psicosocial comporta en cierto modo un exceso pues parece la unión de términos de campos opuestos, incluso hay autores que hablan de una "(...) interconexión entre el individuo y lo colectivo" (Arroyave, 2015, p. 36) sobre la que no hay claridad en qué punto se unen, lo cual genera un uso poco acertado acerca de lo psicosocial, que acentúa un corte entre el psiquismo y lo social como si fueran elementos aparte, unidos para formar un sentido que es más bien una indeterminación. Ahora bien, lo social es el campo del otro y sin el otro no hay psiquismo; esto implica una sujeción. 
En este sentido, hablar de sujeto comporta el psiquismo y lo social, aspecto que da oportunidad de valorar el acierto de Lacan al introducir la noción de sujeto para el psicoanálisis, precisamente porque demuestra la dependencia que cada uno tiene del otro, del lenguaje y de la ley, pues el sujeto es el que se dirige al otro a través del pedido "(...) que implica la demanda en que se presenta" (Lacan, 2003, p.220). Incluso en términos jurídicos se habla de sujeto de derecho porque para ser parte de la vida civilizada hay que depender o alienarse a la ley que es Otro para todos y para cada uno.

Con base en lo anterior, puede decirse que lo psicosocial en tanto relacional implica reconocer el efecto que en cada uno ha producido la entrada en el campo del Otro, que lo expone al no todo, a la insatisfacción y al fallo del lenguaje que, como arma de doble filo permite, por un lado, traducir lo que se siente, porque los sentimientos no vienen en palabras y, por otro, el pathos que implica para el ser hablante quedar arrojado a la división y al mal entendido. El vínculo entre el sujeto y el Otro no es un paradigma de armonía, la no coincidencia suscita agresividad que puede ser disipada a partir del pacto, de la inscripción en el acuerdo, en lo simbólico. El efecto que en cada uno ha dejado como marca la entrada al orden simbólico ha producido una alteración en el organismo, que subvierte el instinto que como impulso vital regula las conductas de los animales. En el sujeto se produce una tendencia a la satisfacción en el exceso que le resulta difícil detener y su efecto es nocivo para la vida, es un impulso propio del humano expuesto a los ideales de la cultura que se le impone como una tendencia a encontrar satisfacción en lo que le hace daño. Freud (2008) llamó a ese empuje pulsión y la entiende como un concepto límite entre lo psíquico y lo somático, es una "exigencia de trabajo que es impuesta a lo anímico a consecuencia de su trabazón con lo corporal” (p. 117).

Esa trabazón describe de manera estructural la no coincidencia entre el organismo y el psiquismo, y funciona como paradigma de las relaciones con el otro. Dicha oposición hace del conflicto no una cuestión accidental sino estructural que tiene sus correlatos tanto en la vida psíquica como en la colectiva, en donde coexisten el amor y el odio cuya oposición implica la ambivalencia de sentimientos que se acentúa, por ejemplo, respecto al ser amado. Lo anterior enseña que entre el sujeto y el Otro hay una hiancia insalvable que los separa pero que el sujeto resuelve a través del síntoma, que es la manera en que responde o se ajusta a lo imposible de los ideales. En este sentido, la función del síntoma es resolver la antinomia entre lo individual y lo social porque el síntoma del sujeto no es sin el Otro y el síntoma social da cuenta de lo que sufre el sujeto. Un ejemplo de ello 
se puede notar en el efecto que tiene sobre las subjetividades el creciente imperativo de belleza, que prolifera en la publicidad y las redes sociales y que se vuelve la condición para ser querido, aceptado o deseado. Algunos sujetos se ajustan a ese imperativo haciendo lazo con el otro a través de condescender a la pulsión que los lleva a someter su cuerpo a las mortíferas exigencias de un ideal irrealizable a través de un síntoma como la anorexia. El descubrimiento freudiano del sentido de los síntomas muestra su doble cara pues, por un lado permite de alguna manera estar sujetado al otro y, por otro, supone pagar un precio en sufrimiento que mortifica la existencia.

En este momento resulta pertinente introducir un principio orientador del trabajo que mantiene una tensión constante entre el sujeto y el Otro, entre el psiquismo y lo social, entre lo subjetivo y lo colectivo. En 1921 Freud publica un ensayo titulado "Psicología de las masas y análisis del yo", allí propone disolver la oposición entre la psicología individual y la social; señala que, si bien lo individual busca aclarar los modos de satisfacción y de sufrimiento desde lo singular, rara vez se puede prescindir de los vínculos con los otros porque en cada uno el otro cuenta como objeto amoroso, como modelo, como enemigo y por eso propone que "la psicología individual es al mismo tiempo y desde un principio psicología social, en un sentido amplio pero plenamente justificado.'(Freud, 2001, p. 2563) Teniendo en cuenta lo anterior, se hace pertinente indagar sobre procesos como la memoria, el duelo y el olvido en tanto se inscriben en la tensión entre lo subjetivo y lo colectivo, y por tanto en una perspectiva de lo psicosocial que implica eso que se resiste a hacer lazo con el otro y que se expresa por la vía de los síntomas para hacer de ellos "(...) una tensión productiva y necesaria en lo que atañe al progreso del saber" (Gallo, 2017, p. 10).

\subsection{Método}

Este artículo, fruto de la investigación doctoral titulada "Análisis de las representaciones de las narrativas de víctimas en el discurso del Centro Nacional de Memoria Histórica: caso Oriente Antioqueño" 18 , es un estudio cualitativo descriptivo, cuyo método de recolección y análisis de la información fue la selección y compilación de información a través de la lectura y crítica de documentos y materiales bibliográficos, en concreto, textos científicos y académicos que giraban en torno de las categorías que le interesan al marco teórico de la investigación doctoral: en primer lugar, la diferenciación

18 Doctorado en Ciencias Humanas y Sociales, Universidad Nacional de Colombia sede Medellín. Asesora de la tesis: Dra. Mary Luz Alzate 
epistémica entre conceptos afines como "testimonios", "relatos", "narrativas" y "discursos" (en el que los principales referentes son Paul Ricoeur, Gérard Genette, Michael Foucault y Mijaíl Bajtin); en segundo lugar, las variaciones que en el conflicto armado adquiere el concepto de víctima, desde la victimología, hasta las visiones filosóficas, sociológicas y politólogas de Hannah Arendt, Veena Das y Seyla Benhabib, específicamente por ser aquellas que basan su reflexión en la mutación de un estado de vulnerabilidad a un nuevo rol como ciudadano que, paradójicamente, no deja atrás la condiciones de precariedad ya experimentadas. Finalmente, estas categorías se triangularon con las concepciones de memoria colectiva, partiendo de las nociones clásicas (Pierre Norá, Tzvetan Todorov) hasta llegar a las más contemporáneas, sobre todo pertinentes para el contexto latinoamericano (Claudia Feld, Elsa Blair, Elizabeth Jelin y Ludmila Da Silva Catela). Con este método cualitativo documental, basado en artículos publicados en bases de datos y en algunos libros, se buscó la consolidación de una categorías conceptuales y teóricas que le interesan a los estudios acerca de víctimas que se hagan en el contexto colombiano, en concreto, en el Oriente Antioqueño.

\subsection{Resultados y discusión}

\subsubsection{El trabajo de la memoria}

A partir de lo anterior se entiende lo psicosocial como una tensión necesaria entre lo subjetivo y lo colectivo; la hipótesis que se pone a prueba es la de la función del síntoma como recurso para movilizar el malestar y hacer lazo con el otro. En esa perspectiva resulta importante pensar la memoria como una noción fronteriza que implica un trabajo de recuerdo fundamental para sostener la tensión entre el sujeto y el Otro de la colectividad a la que pertenece. A la memoria se le ha entendido como un dominio propio de lo individual, incluso perspectivas psicológicas la han explicado como un fenómeno biológico cerebral análogo a los modelos computacionales, que la reducen a un conjunto limitado de operaciones binarias que se ocupan de la recuperación de la información ejecutada por el cerebro de manera idónea según cada situación concreta (Ruiz, 2008). Lo individual de la memoria no está en las posibles particularidades del funcionamiento cerebral sino en que los recuerdos, que no son propiamente información pues no son reductibles a datos concretos, comportan un trabajo de rememoración que implica deformaciones ligadas a la imaginación, a expectativas, fantasías y diversos aspectos que los hacen intransferibles y, por tanto, le dan al sujeto una idea del carácter de lo vivido pero no la experiencia concreta. 
A nivel de la subjetividad, las vivencias infantiles dejan huellas que configuran el psiquismo que no es propiamente un depósito estático, sino que las impresiones se van dispersando con el paso del tiempo de manera que los recuerdos van cambiando su valor dependiendo del significado. $\mathrm{Si}$ se afirma que el trabajo de la memoria es el recuerdo es porque no se trata de una operación extractiva, sino productiva que implica el olvido. En esta vía, el recuerdo comporta algo de olvido, a nivel de la subjetividad, lo que se guarda en la memoria así como lo que se olvida no responde necesariamente a procesos intencionales, pues no pocas veces acontecen al margen de la conciencia del sujeto. En la producción del recuerdo se pone en tensión la memoria y el olvido pues en lo que se recuerda necesariamente se excluye algún contenido. De este modo se entiende que el recuerdo no es un dato estático, sino que en su producción se ligan unos a otros y no de manera lineal. La linealidad puede venir como efecto de la configuración narrativa del recuerdo, se trata más bien de entender que un recuerdo encubre a otro cuyo contenido resulta para el sujeto menos aceptable que aquel al que tiene acceso.

En este caso la función del olvido es representada por la represión que no es propiamente una presión sino, en términos freudianos, un "esfuerzo de desalojo" (Freud, 2008, p. 301), es decir, la dificultad de tolerar un contenido que retorna y que en otro momento fue objeto de la censura, pero no por ello ha quedado clausurado, sino que se expresa de otra manera. Esa otra manera alude a una operación sustitutiva, que es la función del síntoma, pues allí donde no se ha podido decir algo, eso retorna de otro modo como enfermedad o malestar. El síntoma también tiene la doble cara del recuerdo pues, por un lado es indicio de lo que acontece y, por otro, es señal de que de eso no se quiere saber. El análisis de los procesos subjetivos aporta valiosos elementos para ampliar las posibilidades de comprensión sobre los procesos de memoria a nivel de la colectividad, pero no como la aplicación de un campo a otro, sino en términos de transferencia analógica, cuya función es mantener las diferencias y permitir sostener la tensión productiva entre lo psíquico subjetivo y lo social. Lo que se pone en juego en un campo y otro en relación con la memoria es la cuestión de la verdad. Una ilustración al respecto la aporta Lacan (1957) cuando refiere que la historia de la tiranía lo demuestra pues las verdades que censura se expresan de otra manera "(...) en otro registro, en lenguaje cifrado, clandestino" (párr. 16).

Otro aspecto relevante en el esfuerzo de memoria, fundamental para la producción del recuerdo, tiene que ver con que, a nivel de la intimidad propia del trabajo clínico con el sujeto, el recurso de la transferencia permite 
propiciar condiciones para reducir la censura y favorecer la emergencia de esa verdad reprimida, que cuando no se le otorga un lugar persiste, pero traspuesta a otro lenguaje, el del síntoma. Así, el síntoma es portador de una verdad inconsciente que el sujeto des-conoce porque, aunque la porta, no sabe leerla, le resulta indescifrable e insistente y por eso la padece. La función del analista es, a partir de una escucha desprevenida y atenta, al margen de ideales e imperativos, propiciar un espacio de palabra para configurar, sobre las marcas de lo sucedido, lo que emerja en tanto recuerdo.

En cuanto a las colectividades, la memoria es entendida como el conjunto de las huellas dejadas por los acontecimientos propios de la violencia fundacional pues "no existe ninguna comunidad histórica que no tenga su origen en una relación que podemos comparar sin titubeos con la guerra" (Ricoeur, 1999, p. 32). En este sentido, las huellas que configuran la memoria son las marcas que han afectado el curso de la historia de los grupos implicados, que "ponen en escena esos recuerdos comunes con motivo de las fiestas, los ritos y las celebraciones públicas" (Ricoeur, 1999, p. 19). Para la memoria colectiva, la cuestión de la verdad depende de los valores de los vencedores, quienes posan sobre el acontecer histórico el velo de su ideología y con ello su censura. En la vida social se trata de, por medio de la institucionalidad, favorecer el trabajo de recuerdo con recursos como los centros de memoria, la investigación académica y las iniciativas artísticas, entre otros, siempre y cuando no se pongan al servicio de ideologías y su censura, para de este modo dar cabida a la gran diversidad de versiones que van desanudando la coacción y permiten otras maneras de comprender lo enigmático de lo que hace trauma en un colectivo y que se aloja en la sintomática sombra de la represión.

En el caso de Colombia, en términos de método, si se asume la colectividad como un sujeto con su síntoma, es posible pensar un acontecimiento que bien puede hacer parte del síntoma social, por su carácter enigmático de revelación y ocultamiento, se trata del asesinato del líder político Jorge Eliecer Gaitán el 9 de abril de 1948. Al respecto, y después de setenta años, el discurso oficial no se ha pronunciado sobre las causas y los responsables, cuestión que ha dejado una hiancia en el acontecer histórico nacional. No obstante, la memoria no oficial se ha manifestado dándole un lugar a la ficción como posibilidad productiva del recuerdo, facultada para decir lo que la historia no tiene permitido. De este modo, la literatura aporta elementos para configurar una identidad narrada en relación al ocultamiento con que la represión vela la producción de recuerdo; así, debilita el silencio de la historia y al introducirla en la lógica de lo probable "la convierte incluso en 
un recurso terapéutico" (Ricoeur, 1999, p. 46). En este nivel, la colectividad asume la diversidad de versiones sobre un hecho silenciado y aprende a contar su historia de otra forma, se deja contar por otros, por otras generaciones que, si bien heredan lo traumático de esos enigmas, también tienen la posibilidad de narrar de otra manera.

\subsubsection{El olvido, entre la tentación y el exceso}

El olvido es la condición por la cual es posible ocuparse de la memoria. Sin embargo, se lo ha entendido como un adversario pues emerge en tanto amenaza cuando se pretende recuperar el pasado. En este sentido es importante reconocer una función al olvido que tiende a regular los abusos de la memoria, como la tendencia obsesiva a persistir en lo que fue; así mismo es necesario indagar sobre el exceso que implica un obstáculo para la producción y el trabajo de recordar. Lo anterior puede reposar en la oposición memoria olvido; no obstante, en términos de método, resulta poco productivo mantener esa polaridad; es pertinente apuntalar una tensión como la que se propone respecto a lo psicosocial, que se sostiene a partir del síntoma. En este caso se trata de que la tensión memoria-olvido, fundamental para el trabajo del recuerdo, esté anudada por la doble cara de lo sintomático, en donde algo se sabe acerca de lo que no se quiere saber. Ahí hay un efecto de represión sobre el que es importante "(...) inteligir que una cierta resistencia contrarresta la devolución de cada uno de los recuerdos perdidos, y es preciso compensar su magnitud mediante un trabajo" (Freud, 2008, p. 287).

En la expresión los recuerdos perdidos es importante notar un resto que queda de lo que ya no está. Perder significa dar por completo, mientras que recuerdo refiere a volver a pasar por el corazón, es decir, retornar sobre lo que ya no está. Esta oposición entre dar por completo y un resto que queda sobre el que es necesario volver, permite pensar en la dimensión del olvido que no es forzosamente la del cambio destructor e irresistible al paso del tiempo. Lo anterior invita a admitir una forma del olvido que preserva y hace posible la memoria; este es el carácter positivo conveniente al trabajo de recuerdo y al trabajo de duelo. Sin embargo, tanto a nivel de las subjetividades como de la colectividad, es necesario contar con la tentación del olvido que es la puesta a prueba del esfuerzo implicado en recordar y en cierto modo conduce a " $(\ldots)$ reproducir algo que desprendiera displacer o pudiera llevar, en ulterior consecuencia, a un desprendimiento de displacer" (Freud, 2008, p. 287). La desazón que comporta recordar no es de la misma magnitud que el hecho que la produjo; sin embargo, tanto el sujeto como las colectividades se defienden de ella a través del "olvido evasivo" (Ricoeur, 
1999, p. 58) que es tan pasivo como activo y alimenta la voluntad de no saber. Es una forma ambigua de olvido que en el sujeto se impone con la voluntad de no permitirse tratar o pensar aquello que le insiste como malestar, y en lo social se manifiesta con la amnistía y la impunidad.

La consecuencia de la voluntad de no querer saber se expresa a través de la repetición inconsciente, pero no como recuerdo, sino como acto; una y otra vez se realiza lo mismo pero sin darse cuenta; por eso se experimenta como si fuera nuevo. En este sentido se entiende que la repetición opera como una compulsión que "sustituye ahora al impulso de recordar" (Freud, 2007, p. 153), de modo que se da lugar a la obstinación que implica la errancia excesiva de lo mismo. Aquí el síntoma tiene esa doble cara del olvido, la de la tentación de ignorar y evadir lo que se sabe, y el exceso que se convierte en acto al suscribirse como repetición. Ahora bien, el sostenimiento del síntoma depende de la insistencia de lo que quiere ser olvidado, eso que se quiere soslayar se actúa; sin embargo, resulta la vía privilegiada para tramitar lo que se pretende echado al olvido, pero no por eso inexistente, pues por su carácter de huella actualiza algún resto de lo que fue y con ello lo que ha sido, que de cierta forma sigue siendo. Algo del síntoma ocupa en el presente el lugar de lo que ha sido del pasado, y por su estatuto simbólico tiene tanto de revelación como de ocultamiento. Así el trabajo de recuerdo sucede con recursos que velan y revelan como las palabras, lo cual demuestra que "El lenguaje es esta función que hace ser lo que no existe” (Miller, 2011, párr. 6).

El olvido, entre la tentación y el exceso, permite pensar que Colombia tiene una larga historia de procesos de paz que no han logrado disipar la guerra. Si bien son pactos y esfuerzos loables, el acontecer nacional demuestra que no han sido suficientes para el propósito de lograr una paz estable y duradera. En este sentido, vale preguntar respecto de esa serie de procesos cuál es el exceso de olvido propio de lo que se repite. Qué ha quedado como resto intratable e insistente del que se sabe por la violencia sintomática que se actualiza. La repetición se expresa en el conflicto que reclama un nuevo pacto y un proceso que, de manera inconsciente, deja restos de aquello que no se sabe o sobre lo que pesa una voluntad de olvido que se actúa en nuevas violencias. Es importante traducir lo sintomático de la tensión que se da entre la memoria y el olvido, y sin soslayar la tentación de no querer saber y el exceso que se repite en acto violento, procurar espacios para que los actores del conflicto puedan llevar a la palabra la marca de violencia que en cada uno insiste como malestar. Se requiere de un espacio de concertación para dar un lugar a la producción del recuerdo, a la construcción conciliada de la verdad más como patrimonio del deseo de hacer parte del vínculo social 
que como afán justiciero incitador de venganza y rencor. Se trata de un espacio para la acción psicosocial de la producción de memoria, advertido de las trampas y los velos de las ideologías, que permita a los implicados ejercerse como sujetos de derecho y ser escuchados, pero también escuchar la marca que en otros han dejado sus actos y sus palabras. Un proceso de paz es una oportunidad para hacerse a un nuevo destino y para hacer el duelo de lo que por su ausencia se sufre como memoria, se insiste como olvido y se lleva como síntoma.

\subsubsection{Entre el tiempo y el lenguaje: una poética del duelo}

La vida social contemporánea transcurre bajo el imperativo ideal de felicidad en el consumo; en consecuencia, la tristeza, el sufrimiento y el duelo resultan afecciones indeseables. A esto se suma la prisa por obtener la mayor satisfacción en el menor tiempo posible, lo cual provoca una aceleración del vivir que por mezclar la efectividad, la eficacia y la inmediatez, han privilegiado los resultados por sobre los procesos. El afán al que se ha sometido el hombre trae una deshumanización de los afectos, que ha hecho del sufrimiento y del duelo una anormalidad. Paradójicamente, el ideal de felicidad no ha producido seres más felices, sino que ha enmascarado los afectos y se ha propuesto tratar los estados del alma con medicación o con olvido evasivo. Se ignora intencionalmente, a conveniencia del negocio de las farmacéuticas, que el duelo no es un proceso cerebral, no es sin el cerebro, allí solo hay un intercambio de sustancias químicas que se alteran y obedecen a procesos de adaptación. El duelo es irresoluble a ese nivel pues implica la dimensión subjetiva del significado, que un medicamento es incapaz de restituir; se trata de una forma singular de responder ante "(...) la pérdida de una persona amada o de una abstracción que haga sus veces como la patria, la libertad, un ideal (...)" (Freud, 2008, p. 241).

Ahora bien, como se ha propuesto a lo largo de este estudio, es necesario anudar por una mediación, el duelo como proceso subjetivo a la colectividad. Así, si se acepta que el duelo configura a nivel de la subjetividad lo que un proceso de paz para las colectividades, es preciso reconocer la importancia de inscribirlo en el tiempo y el lenguaje. Lo anterior permitiría trascender la coincidencia analógica y tender un lazo entre la subjetividad en duelo y el proceso de paz, a través del síntoma, que es una manera singular de respuesta ante el conflicto propio del vínculo que se da entre el sujeto y el Otro de la cultura. En este caso, la doble cara del síntoma se expresa en que se trata de una solución problemática, pues en tanto padecimiento ocupa el 
lugar de lo que ya no está, al tiempo que constituye un modo de responder ante la prueba de realidad sobre la ausencia del objeto. Un ejemplo de lo anterior, en relación al síntoma social como solución problemática, es la guerra; resulta innegable que, por un lado, hay quienes se benefician de sostenerla, bien por el tráfico de armas o intereses ideológicos, y por otro están los que la padecen porque les cuesta la vida o la dignidad. De este modo se entiende que la solución propuesta por el síntoma es como la de pagar deudas adquiriendo deudas; esto es solo un paliativo sobre el conflicto que insiste porque no se ha tratado lo fundamental.

Lo que se destaca del duelo es que a partir del trabajo de producción de recuerdo es necesario que el sujeto asuma la realidad de la pérdida del objeto, a la que reacciona con resistencia y negación, pues de eso no se quiere saber. Sin embargo, se trata de un proceso que se ejecuta pieza por pieza "(...) con un gran gasto de tiempo y energía" (Freud, 2008 p. 241), dado que el objeto perdido continua tanto en lo psíquico como en la memoria dispersa de la colectividad. De manera que es importante elaborar y tomar uno a uno los recuerdos y las expectativas que se ligan al objeto perdido. A nivel de la colectividad, si bien se requiere un espacio para la producción de la memoria y el recuerdo, es cardinal que ese lugar sirva como una arena para el encuentro entre los diferentes adversarios y sus víctimas. En el caso colombiano, es necesario escuchar en similares condiciones de legitimidad a militares, paramilitares, guerrilleros y víctimas a fin de que pueda producirse la verdad, que no es la correspondencia con los hechos, lo que sería caer en la imposibilidad de extraer del pasado, si no el efecto de trenzar los diversos hilos del discurso y sus vicisitudes, sobre eso que no se ha podido desatar, a fin de configurar el saber que por años ha sido sintomáticamente objeto de la represión.

En esta vía hay dos recursos fundamentales que organizan la trama del duelo y del proceso de paz, se trata del tiempo y el lenguaje. El tiempo al que se hace referencia no es el cronológico pues no es posible saber cuánto tomará la producción de estos recuerdos, porque además son tantos los ausentes, las voces perdidas para siempre, que es labor de quienes están convocados hacer funcionar sus marcas como memoria. Lacan (1945) entiende por tiempo lógico el que corresponde a la subjetividad y aunque es indefinido no implica que no culmine. Se trata de reconocer que hay un inicio donde algo se rompe, al dejar de ser como era concebido, por eso se revela como inédito, incomprensible y por tanto angustiante; a ese momento lo llama instante de ver. Luego es necesario hacerse a un saber sobre lo que sucedió; este tiempo de comprender requiere examen, es decir, 
volver una y otra vez, las veces que sea necesario, sin caer en el abuso de la repetición, para poder contar de las maneras posibles el hecho traumático, con el propósito de entender por qué se insiste en el sostenimiento del malestar. En el caso del duelo se trata de saber qué del objeto fue lo que se perdió, qué se actualiza para el sujeto sobre lo real de su vacío. Producto de esta elaboración se va entrando en el momento de concluir del que se sale con una palabra nueva, un efecto de poiésis, como era el modo en que los griegos llamaban a la creación, una poética del duelo que sea un nuevo modo de nombrar y de relacionarse con lo que ya no está, de otorgar una dignidad a lo perdido pero no olvidado y así autorizarse a estar “(...) libre y desinhibido" (Freud, 2008, p. 241) para amar y construir lazo con objetos sin que el pasado sea una amenaza.

Es importante legitimar un espacio para el duelo, y aunque ha sido soslayado por los procesos de paz, resulta valioso como un lugar de acción psicosocial. Un espacio que, pese a los imperativos del afán y a la orden de estar a felices sostenidos por las falacias de la inmediatez a las que el discurso de la ciencia no pocas veces se pone a su servicio, sirva como forma de reivindicar para el sujeto y la civilización los recursos de producción simbólica sobre las pérdidas. Esto permitirá que los mecanismos de reparación no continúen su proceder analógico que termina sustituyendo una cosa por otra, seres queridos por cosas o por dinero, lo cual dificulta mover a la víctima de su posición y la instala en una condición existencial de la que termina devengando su subsistencia. El proceso de duelo implica un inicio y también el compromiso de una salida; esto se traduce en que a la víctima se la reconoce en su sufrimiento, pero también en un lugar de transición, de elaboración y trabajo de duelo, del que queda un saldo de saber sobre lo que ha perdido, un compromiso con la memoria y con la imposibilidad de lo perdido, reparable por la vía del pacto con la cultura, capaz de construirse como un sujeto responsable del proyecto con el que quiere inventar su vida.

\subsection{Conclusiones}

La importancia de problematizar lo que se entiende por lo psicosocial aporta a la consolidación epistémica de una práctica que se justifica por su acción social y por ser el efecto de una reflexión y formalización científica, como se espera de lo que produce la universidad. En esta vía no se trata de dos nociones que aparentan la unidad de un campo que se sintetiza en un vocablo compuesto, de lo que resulta un sobre-entendido que termina 
dispersando lo propio de lo psicosocial, para caer en el asistencialismo y dificultar lo diferencial del aporte de una disciplina que tiende a soslayar el psiquismo. En este sentido de lo que se trata es de pensar la pertinencia de la intervención psicosocial a través de la relevancia del síntoma, es decir, de las expresiones del malestar. Esto para explorar desde el campo de la subjetividad posibilidades de comprensión de los procesos colectivos, en particular, los concernientes a la memoria, el duelo y el olvido. Como se señaló a lo largo del estudio, no se trata de trasladar de lo subjetivo a las colectividades, sino de analizar que en el decir sobre el sufrimiento se demuestra que el síntoma es social porque es efecto de la relación o del desencuentro con el Otro.

Estos procesos tienen la doble cara del síntoma pues conciernen tanto al sujeto como al colectivo y reactivan su pertinencia en un momento coyuntural como el que vive Colombia, en el que hay claros signos de voluntad para construir la paz. De ahí la importancia de discutir acerca del duelo y ampliar la pertinencia de los modelos desde los cuales se justifican las intervenciones. En este sentido, pensar la memoria como trabajo del recuerdo desplaza de la perspectiva que la reduce a un mero depósito de información, para notar la dificultad de recordar y sus efectos como fenómenos que se ponen en juego en los procesos de duelo. Así mismo, explorar el olvido en su doble cara de posibilidad y obstáculo advierte que ante el sufrimiento hay una tentación de olvidar que es vivenciada tanto por el sujeto como por las colectividades, lo cual puede hacer que se caiga en el exceso de la repetición de aquello que resulta lamentable.

Con estas perspectivas de la memoria y el olvido que a nivel del sujeto y la colectividad se movilizan a partir del síntoma, en tanto expresión del malestar y del resto que queda como insistencia del objeto perdido, se estudia el duelo como proceso inscrito en el lenguaje y en el tiempo. Cuestión que problematiza el imperativo de inmediatez propio del capitalismo actual con el que se ha justificado una creciente patologización del sufrimiento humano, nótese la proliferación de trastornos del DSM IV al $\mathrm{V}$, que ha servido para medicar los afectos, debilitar las formas de hacer vínculos con los otros y aumentar la impotencia para asumir el duelo como aspecto fundamental de la existencia humana. Que a nivel del colectivo es el sustento de los pactos que permiten pensar en la invención de una paz inédita para Colombia que ha hecho de la guerra su síntoma fundamental, al que se ha adaptado y del que teme salir, porque aunque se anhela la paz se carece de la experiencia y del saber de lo que para nosotros significaría vivir en paz. 


\section{Referencias}

Alvis, A. (2009). Aproximación teórica a la intervención psicosocial. Poiésis 17(1) 2-6.

Arroyave, O. (2015). Memoria, reconocimiento y conflicto armado. En S. Cogollo (coord.) Imaginar la paz en Colombia. Cavilaciones desde la academia (pp. 33-49). Medellín: Fundación Universitaria Luis Amigó.

Cruz, J. (2012). Asistencialismo social y modernidad: un proyecto de colonialidad. Poiésis, 24(1), 2-7.

Foucault, M. (2007). La arqueología del saber. México: Siglo XXI

Freud, S. (2008). Sobre el mecanismo psíquico de la desmemoria. En J. Etcheverry (trad.) Obras completas: Sigmund Freud Tomo III (pp. 277-289). Buenos Aires: Amorrortu.

Freud, S. (2008). Pulsiones y destinos de pulsión. En J. Etcheverry (trad.) Obras completas: Sigmund Freud Tomo XIV (pp. 105-134). Buenos Aires: Amorrortu.

Freud, S. (2008). Duelo y melancolía. En J. Etcheverry (trad.) Obras completas: Sigmund Freud Tomo XIV (pp. 235-256). Buenos Aires: Amorrortu.

Freud, S. (2008). Sobre los recuerdos encubridores. En J. Etcheverry (trad.) Obras completas: Sigmund Freud Tomo III (pp. 291-315). Buenos Aires: Amorrortu.

Freud, S. (2007). Recordar, repetir, elaborar. En J. Etcheverry (trad.) Obras completas: Sigmund Freud Tomo XII (pp. 145-157). Buenos Aires: Amorrortu.

Freud, S. (2001). Psicología de las masas y análisis del yo. En L. Ballesteros (trad.) Obras completas: Sigmund Freud Tomo VII (pp. 63-136). Madrid: Biblioteca Nueva.

Gallo, H. (2017). Psicoanálisis e intervención psicosocial. Medellín: Universidad de Antioquia.

Heidegger, M. (1997). ¿Qué quiere decir pensar? Rev. Col. de Psicología, 5(6), 11-17.

Lacan, J. (2003). Del sujeto por fin cuestionado. En J. Lacan. Escritos 1 (pp. 219-226). Buenos Aires: Siglo XXI.

Lacan, J. (1957). Entrevista de Lacan con Madeleine Chapsal. L'express, 310(1), 20-22. Disponible en línea: http://www.eol.org.ar/template.asp?Sec=prensa\&SubSec=europa\& File=europa/2014/14-04-20_Entrevista-de-Lacan-con-Madeleine-Chapsal.html

Lacan, J. (1945). El tiempo lógico y el aserto de certidumbre anticipada. Un nuevo sofisma. En J. Lacan (2008) Escritos 1 (pp. 193-208). Buenos Aires: Siglo XXI.

López, G. Rodríguez, A. (2012). El lugar de los sentimientos, el lugar de los vínculos. Reconfiguración de identidades en el marco del conflicto armado colombiano. Revista colombiana de Ciencias Sociales, 5(1), 83-102.

Miller, J. (2011). Leer un síntoma. Disponible en: http://ampblog2006.blogspot.com/2011/07/ leer-un-sintoma-por-jacques-alain.html 
Ministerio de Salud. (2017). Programa de Atención Psicosocial y Salud Integral a Victimas del Conflicto Armado. Documento Marco. Bogotá: Oficina de promoción social. Disponible en: www.minsalud.gov.co/sites/rid/Lists/BibliotecaDigital/RIDE/DE/PS/ Documento-Marco-papsivi-2017.pdf

Peláez, M. Cañón, O. Noreña, N. (2007). La intervención psicosocial en un contexto investigativo: lecturas psico-sociales sobre jóvenes Agrópolis -sector rural- desde diversos actores que los intervienen. Aletheia, 25(1), 191-202.

Ricoeur, P. (1999). Lectura del tiempo pasado: memoria y olvido. Madrid: Arrecife producciones.

Rohde, E. (2006). Psique. La idea del alma y la inmortalidad entre los griegos. Buenos Aires: Fondo de Cultura Económica.

Ruíz, J. (2008). ¿De qué hablamos cuando hablamos de "memoria histórica”? Reflexiones desde la Psicología cognitiva. Entelequia, 7(1), 53-76.

Villa, J. (2012). La acción y el enfoque psicosocial de la intervención en contextos sociales: ¿podemos pasar de la moda a la precisión teórica, epistemológica y metodológica? Ágora USAB, 12(2), 349-365. 


\title{
7. Reintegración social de excombatientes en Colombia
}

\author{
Martha del Rosario PeÑa-Sarmiento ${ }^{19}$ \\ Olga Lucía Valencia-Casallas ${ }^{20}$
}

\section{Resumen}

Este artículo se centra en el proceso de reintegración social de los desmovilizados en Colombia, presentando en primer lugar, una revisión del proceso de reintegración social dentro del diseño e implantación de la Política de construcción de paz, Desarme, Desmovilización, Reinserción y Reintegración (DDRR). Posteriormente, se presenta una revisión del concepto de dimensión psicosocial con el objetivo de recalcar la naturaleza psicológica, social e interactiva pero también emergente del proceso de reintegración, examinando este aspecto desde la integración entre los resultados de investigaciones sobre las redes sociales personales de los desmovilizados y las características de las comunidades receptoras. Finalmente, se propone el modelo ecológico social como una perspectiva que complementa los esfuerzos que el Estado colombiano ha realizado en materia de reintegración social.

Palabras clave: comunidad receptora, reintegración social, ecología social, excombatientes, conflicto armado colombiano.

\subsection{Introducción}

"La paz presente en un escenario de posconflicto va mucho más allá de la simple reconciliación entre actores armados y el Gobierno, ya que requiere la reconciliación de toda la sociedad, en aras de cerrar episodios de violencia y de dolor" (Carbó, Deas y Powell, 2002).

En Colombia el conflicto armado se había extendido por más de cuarenta años (Joya Ibarra, 2015) y dada su crudeza (Espinoza, 2011; IbáñezLondoño, 2011; Uribe, 2012) la prensa, así como los medios académicos internacionales habían usado varios calificativos para el país como "El Viet-

19 Fundación Universitaria Konrad Lorenz. Correo: mrpena@ucatolica.edu.co

20 Fundación Universitaria Konrad Lorenz: olgaluciavalenciacasallas@gmail.com 
nam Latinoamericano", "La nueva Bosnia", "El nuevo Kosovo" para tratar de describir la difícil y compleja situación del país (Leongómez, 2004). El balance general del impacto de la guerra en Colombia no es positivo, por lo que la dejación de las armas o el silencio de las mismas será, de acuerdo con Fisas (2011), siempre celebrado como una oportunidad para el reencuentro, la reconciliación, la reconstrucción y la cura de las heridas provocadas por el uso de las armas.

Colombia ha registrado experiencias de pactos de paz y acuerdos de desmovilización con varias guerrillas y grupos paramilitares; de forma que desde el Estado y los sucesivos gobiernos se han desarrollado políticas y mecanismos de reintegración de excombatientes a la vida civil (Villarraga, 2013). Sin embargo, la reintegración social de los desmovilizados ha mostrado ser la etapa más desafiante en tanto existen múltiples factores que la ponen en riesgo. Este capítulo se centra, justamente, en el proceso de reintegración social de los desmovilizados en Colombia, presentando, en primer lugar, una revisión del proceso de reintegración social dentro del diseño e implantación de la Política de construcción de Paz, Desarme, Desmovilización, Reinserción y Reintegración. Posteriormente, se presenta una revisión del concepto de dimensión psicosocial con el objetivo de recalcar la naturaleza psicológica, social e interactiva, pero también emergente, del proceso de reintegración, examinando este aspecto desde la integración entre los resultados de investigaciones sobre las redes sociales personales de los desmovilizados y las características de las comunidades receptoras.

\subsection{Método}

El objetivo central de la investigación documental fue identificar estudios empíricos realizados en Colombia relacionados con las redes sociales personales de los excombatientes en proceso de reintegración social y con comunidades receptoras; previa definición y síntesis del marco político del proceso de reintegración social de los excombatientes en Colombia. La revisión se realizó para comprender los enfoques de los estudios, así como para conocer sus resultados tanto con excombatientes como con las comunidades receptoras. Se seleccionaron siete (7) estudios sobre redes sociales personales de excombatientes y tres (3) sobre las comunidades receptoras, publicados entre 2009 y 2015 . Nutrirse del pensamiento original e identificar las aproximaciones investigativas con esos dos actores del proceso de reintegración se consideró esencial en la investigación documental, dado que la reintegración social ha sido conceptualizada como un proceso complejo y multiagente. Los resultados de los estudios 
se contrastaron con otras investigaciones para señalar oportunidades de abordaje y conceptualización.

\subsection{Resultados}

\subsubsection{Politica de construcción de paz, desarme, desmovilización, reinserción y reintegración}

Los actores armados, ya sean estos guerrilleros o paramilitares, han sido objeto de atención a través de la política de construcción de Paz, Desarme, Desmovilización, Reinserción y Reintegración (DDRR), conocida de acuerdo con Fisas (2011), como DDR. Esta política ha estado asociada con la reducción de la probabilidad de reactivar la violencia y con la reunificación de la sociedad en donde se implementa (Muggah, 2007); pues desempeña un rol crítico en la transición de la guerra a la paz (Knight \& Özerdem, 2004). Sin embargo, así como se han presentado experiencias exitosas en Colombia (Visbal, 2014), otras como el caso de las Autodefensas Unidas de Colombia (AUC) en la ciudad de Medellín (Sánchez \& Suárez, 2007) han sido totalmente debatibles frente a las expectativas planteadas ante este tipo de mecanismos de pacificación del país.

DDRR, además de ser considerada como una política de construcción de paz, también se conceptualiza como un proceso (Sánchez \& Suárez, 2007), lo que supone que, aunque existe una normativa general, existen particularidades que es necesario atender con cada grupo o persona que se desmovilice dado que existen, como plantean Velasco y Londoño (2009), necesidades escolares, laborales, familiares, sanitarias y sociales diferentes. Adicionalmente, como lo plantean Sánchez \& Suárez (2007), un proceso DDR se desarrolla en periodos más o menos largos, es costoso y mezcla estrategias, procedimientos y planes de acción, con el propósito de disolver de manera definitiva las estructuras de los grupos armados al margen de la ley, con la aceptación voluntaria de las partes. En este orden de ideas, Arango (2013) ha señalado que la transición colombiana hacia una sociedad más democrática y respetuosa de los derechos humanos no es un proceso de corto plazo y que las condiciones de una paz duradera no pueden ser logradas improvisadamente.

Una evaluación de cada proceso - de paz, de DDR o de simple sometimiento-debe reconocer la naturaleza, las características, las circunstancias y el alcance de cada grupo armado (Villarraga, 2013). Al comparar los procesos DDR de los guerrilleros del M-19, en los años 90, con los desarrollados con 
los paramilitares de las AUC en la primera década del siglo 21, se encuentran claras diferencias (Guáqueta, 2007; Nussio, 2012; Palau y Méndez, 2012) que vale la pena resaltar brevemente. De acuerdo con Villarraga (2013) en los procesos de negociación con la guerrilla predominó el componente político, mientras que para el caso de los paramilitares la búsqueda de garantías jurídicas, ante los graves crímenes cometidos, fue el componente principal. Para Guáqueta (2007) este predominio del componente político en el proceso le posibilitó a la guerrilla mayor audiencia, fluidez del sistema político, concesión de amnistías y reconocimiento político de legitimidad, lo que sugiere que el éxito de los procesos DDR depende de la aceptación de las audiencias y la capacidad de los excombatientes para establecer interacción social y política; lo cual ha resultado más favorable para el caso de las guerrillas que para los paramilitares.

Aunque como mencionan Palau y Méndez (2012) con la creación de la Alta Consejería para la Reintegración, adscrita a Presidencia de la República $^{21}$ y su correspondiente cambio de políticas DDR (mecanismos y criterios de atención, así como de presupuesto oficial) mejoraron algunos aspectos; el contexto de la reintegración para los paramilitares continuó siendo complejo. De acuerdo con Nussio (2012) los factores contextuales que han afectado la reintegración de los exparamilitares están relacionados con el contexto de violencia y el tráfico de drogas. Son a menudo víctimas de violencia, tienen un bajo nivel educativo y en su mayoría no tienen un empleo formal, lo cual los hace vulnerables a reincidir. Sánchez y Suárez (2007) plantean que el paramilitarismo que emergió y se desarrolló en la ciudad de Medellín, por ejemplo, estuvo vinculado, además del narcotráfico, con la existencia de bandas y "combos" de jóvenes, favorecida también por la continua migración a la ciudad de habitantes de sectores rurales (desplazados por el conflicto armado), el poblamiento de los barrios periféricos,

21 La Alta Consejería para la Reintegración, adscrita a Presidencia de la República, se creó en septiembre de 2006 para responder particularmente a las exigencias del proceso de desmovilización masiva de las AUC, concibiendo la reintegración como un proceso de largo plazo por lo que sus programas se orientaron con el principio de sostenibilidad. A la Alta Consejería le había precedido el Programa para la Reincorporación de la Vida Civil (PRVC) que funcionó como parte del Ministerio de Interior y de Justicia entre 2003 y 2006, el cual tenía un enfoque de reinserción de corto plazo y atendía una población de desmovilizados relativamente pequeña. A la Alta Consejería le sucedió la Agencia Colombiana para la Reintegración (ACR) creada en noviembre de 2011, como una Unidad Administrativa Especial -adscrita al Departamento Administrativo de la Presidencia de la República (DAPRE)- encargada de fortalecer la implementación de la Política de Reintegración, la que posteriormente fue renombrada como Agencia para la Reincorporación y Normalización (ARN) con el Decreto Ley 897 de 2017 (ARN, 2017). 
además del marginamiento y la pobreza, que han propiciado la vulnerabilidad social y la informalidad.

La política de construcción de paz -DDR- involucra programas, dispositivos jurídicos y medidas administrativas, orientados al logro de la paz y (o al menos) a propiciar el retorno de contingentes de excombatientes irregulares a la vida civil (Villarraga, 2013). La Presidencia de la República de Colombia, con el Decreto 3043 de 2006 (artículo 2, parágrafo 2), se refirió a la reintegración como "la totalidad de los procesos asociados con la reinserción, reincorporación y estabilización social y económica de menores desvinculados y adultos desmovilizados voluntariamente, de manera individual o colectiva. Estos procesos contemplan de manera particular la vinculación y aceptación de estas personas en la comunidad que los recibe, además de la participación activa de la sociedad en general en su proceso de inclusión a la vida civil y legal del país.”. El Decreto Ley 897 de 2017 (Requisitos materiales de validez constitucional, p. 2) se refirió a la reintegración en otros términos: "además, teniendo en cuenta que los conceptos de reincorporación y normalización comprenden de manera integral los procesos asociados con la reinserción, reintegración y estabilización social y económica de personas y grupos armados organizados al margen de la ley que, en virtud de diálogos, negociaciones o firma de acuerdos con el Gobierno nacional, dejen las armas". De esta manera, comparado con el Decreto 3043 de 2006, se modificó el nivel de generalidad de los conceptos de reintegración, reincorporación y normalización, y la reintegración pasó a considerarse como una etapa dentro del proceso de reincorporación y normalización de los excombatientes.

El Decreto 3046 de 2006 destaca como parte central de la reintegración a la vinculación y aceptación de los excombatientes, por parte de las comunidades receptoras y la participación activa de la sociedad, en general, en el proceso de inclusión de los exmilitantes a la vida civil y legal del país. Por tanto, los mecanismos que garantizan que las acciones derivadas de los procesos DDR en conjunto se ejecuten de manera exitosa y cumplan con la promesa de reintegración, no son solamente políticos o económicos (aunque sí es necesario aclarar que son factores importantes dentro del proceso) son también de orden cultural, social y psicosocial.

La reintegración tiene dos dimensiones: la económica y la social. En la económica, a los excombatientes se les entrena en habilidades que les permitan aprovechar oportunidades económicas viables y las opciones necesarias para desarrollar un medio de vida sostenible en la legalidad (Body, 
2006; Colletta, Kostner, \& Wiederhofer, 1996). La reintegración social se refiere a los procesos y mecanismos informales y formales que pretenden proveer apoyo emocional y psicosocial a los excombatientes, y habilitarlos para construir relaciones con sus familias y con las comunidades a donde retornan (Özerdem, 2012). Kaplan y Nussio (2015) han señalado que no existe consenso sobre la definición del concepto de reintegración social entre académicos y profesionales, lo que se constituye en un obstáculo para estudiar el fenómeno y que, adicionalmente, existe poca evidencia empírica de los determinantes de la reintegración social y de la participación comunitaria entre los excombatientes. No obstante, sí parece existir acuerdo frente a que este fenómeno ocurre en el nivel comunitario (Gordon, 2013; Humphreys \& Weinstein, 2007; Porto, Parsons \& Alden, 2007; Kaplan \& Nussio, 2015). Por otro lado, no hay consenso sobre lo que significa en términos concretos la reintegración social, a nivel comunitario, así como los indicadores que demuestren que ésta realmente ha ocurrido (Alden, 2002; Bowd \& Özerdem, 2013; Janzen, 2014; Özerdem, 2012; McMullin, 2013). Adicionalmente, la reintegración social podría tener diferentes significados e impactos así como enfrentar retos en diferentes transiciones de la guerra interna a la paz (Bowd \& Özerdem, 2013). Los procesos DDR no son simples y la reintegración ha probado ser el aspecto más retador. Mientras el desarme y la desmovilización son fases finitas con resultados mesurables, la reintegración es un proceso social y económico sin límites fijos atado al desarrollo de un país como un todo (Coelho \& Vines, 1995; Jennings, 2008).

La Reintegración Social, por otro lado, dada su naturaleza interactiva dentro del nivel comunitario pone el énfasis en las relaciones con los otros actores (Kaplan y Nussio, 2105) y es justamente la interacción -interpersonal o incluso intergrupal- el aspecto central del proceso. Torres (2001), por ejemplo, ya había realizado algunas reflexiones interesantes sobre las implicaciones de una sociedad diversa como la colombiana en el éxito de la reintegración, así como en el acomodamiento de los programas de acompañamiento psicosocial a las particularidades psicológicas, sociales y culturales de los excombatientes. De acuerdo con Sánchez \& Suárez (2007), el éxito o el fracaso de un proceso de reintegración depende de varios factores dentro de los que se cuenta el diseño de políticas de reconstrucción del tejido social, estrategias de trabajo con las víctimas, con los desmovilizados y con las comunidades, así como de una estructura institucional apropiada para la reinserción local.

Los retos de la reintegración pueden considerarse a nivel individual, comunitario y nacional (Gordon, 2013). En el nivel individual es usual en- 
contrar que los excombatientes comúnmente tienen bajos niveles educativos (Nussio, 2012), pocas habilidades profesionales/ ocupacionales y limitados recursos económicos (Berdal, 1996). Eso explica por qué una parte de los programas de reinserción ${ }^{22}$-fase de apertura de la reintegración- están orientados inicialmente a crear condiciones para la seguridad económica, lo que al mismo tiempo permite ir generando sustitutos de los beneficios alcanzados en el conflicto armado. Otros mecanismos, posteriormente, introducidos son el acceso a educación formal, entrenamiento vocacional y microcréditos para iniciar un negocio propio (Solomon, 2008; Sriram, 2013). El resultado final de esta inversión es relativo a las condiciones económicas de cada país, especialmente a los niveles de empleabilidad y de las características del mercado (Solomon, 2008).

En este nivel también resulta crucial la identificación de necesidades y aspiraciones de los excombatientes, la oferta de asistencia médica y asistencia psicológica, incluyendo atención especializada cuando sea necesario. Algunos autores (Fisher, 2013; Wegner, 2011) han señalado que los niños soldados desmovilizados a menudo tienen mayores dificultades para reintegrarse a la vida civil. Lo mismo ocurre con excombatientes que durante sus actividades, como miembros de los grupos armados, se sometieron a entrenamiento militar y participaron del abuso a civiles (Nussio \& Oppenheim, 2014). La reintegración, de acuerdo con Velasco y Londoño (2009) puede ser considerada como un evento estresor, por lo que resulta vital apoyar a los excombatientes para que logren adaptarse eficazmente al proceso de reintegración social, cumpliendo las exigencias y afrontando los retos que el proceso implica para finalmente pasar nuevamente a la condición de ciudadano.

En el nivel comunitario, los programas deben tener en cuenta las características de los excombatientes y las características de las comunidades en donde se dará continuidad a la reintegración social (Bowd \& Özerdem, 2013; Gordon, 2013). Así como se suelen señalar las necesidades y beneficios para los excombatientes, es necesario reconocer y atender las necesidades de las comunidades receptoras, para no poner en riesgo el éxito del proceso por sobre enfatizar los beneficios para los excombatientes (Bøås \& Hatløy, 2008; Jennings, 2008) o por ignorar las condiciones sociales de las comunidades las cuales sumadas a otras variables aumentan la probabilidad de reincidir. Kaplan y Nussio (2016), por ejemplo, han presentado evidencia

22 En la fase de reinserción, los excombatientes suelen recibir ayudas económicas temporales por parte de los gobiernos durante periodos que se definen al interior del proceso (Berdal, 1996; Solomon, 2008), lo cual suele ser un tema controversial (Knight \& Özerdem, 2004; Waldman, 2010). 
de la relación entre la presencia de grupos criminales y la reincidencia de los excombatientes, así como de otros factores individuales como rasgos de personalidad antisocial y otros más psicosociales como los vínculos débiles con la familia y el fracaso en logros educativos.

La reintegración debe vincularse al desarrollo comunitario particular y diseñar, por lo tanto, programas que reconozcan e incluyan esas particularidades dentro del proceso, pero que también estén orientadas hacia un proceso de reconciliación en el marco de la justicia restaurativa (Colletta \& Muggah, 2009; Gordon, 2013). Subedi \& Jenkins (2017) han argumentado que la pérdida de escenarios de reconciliación en el posconflicto inhabilita a los excombatientes para acumular capital social, lo que afectaría negativamente la reintegración social. En el marco de las intervenciones comunitarias dependientes del contexto, Sánchez \& Suárez (2007) han planteado para el caso colombiano que los modelos de reintegración deben desarrollarse, adicionalmente, atendiendo diferencialmente las características de las ciudades y de las áreas rurales.

A nivel nacional, los gobiernos deben orientar sus acciones para garantizar el desarrollo satisfactorio del proceso y tomar las medidas necesarias para protegerlo, al mismo tiempo que impulsan políticas para el desarrollo del país (Gordon, 2013). Klem \& Douma (2008) han señalado que el proceso debe estar anclado en las políticas estatales, en tanto se ha entendido que la reintegración social debe enmarcarse en el desarrollo sostenible del país y, por lo tanto, su consolidación emerge en el largo plazo.

7.3.2 Factores psicosociales relacionados con la reintegración social: redes sociales personales de los desmovilizados y comunidades receptoras

La interrelación es el componente clave del concepto factor psicosocial pues es identificando el efecto de factores sociales sobre los factores individuales o psicológicos que puede afirmarse que una dimensión es psicosocial (Martikainen, Bartley \& Lahelma, 2002). Dentro del interés por estudiar los fenómenos sociales necesariamente se incluye, como medida de base, el análisis de los individuos y su interacción cara a cara así como con diversos actores de tipo institucional, político, económico, entre otros (Ávila-Toscana \& Madariaga, 2010). Lo psicosocial es considerado por Martikainen, Bartley \& Lahelma (2002) como un concepto de meso nivel modificado por estructuras macrosociales el cual, a su vez, se manifiesta en el nivel micro, y por lo tanto, en las relaciones interpersonales. 
Redes sociales personales de los desmovilizados. Las redes están constituidas por actores y sus relaciones en un contexto social específico (Serrat, 2009) y pueden cambiar a lo largo de la vida (Wrzus, Hänel, Wagner \& Neyer, 2013). Las redes sociales personales, también conocidas como redes de apoyo, describen un tipo de red o subtipo de relaciones personales más cercanas dentro de la red global, integradas por familiares, amigos y otros confidentes más cercanos (Van der Poel, 1993). Los estudios realizados en Colombia, sobre las redes sociales personales de los excombatientes en proceso de reintegración, se han orientado a identificar sus características estructurales así como las relaciones de sus propiedades funcionales con la percepción de apoyo social y otras características psicosociales.

Los estudios realizados sobre redes sociales personales con desmovilizados que viven en zonas rurales han reportado una tendencia a conformar estructuras pequeñas, con baja densidad relacional y referencia de integración con familiares y amigos cercanos, además de mostrar estructuralmente niveles medio-bajos en sus indicadores de centralidad (AmarAmar, Abello-Llanos, Madariaga y Ávila-Toscano, 2011; 2013); aspectos que contrastan un poco con los estudios realizados con desmovilizados que viven en zonas urbanas, con quienes se han reportado redes con un desempeño más favorable a nivel de sus elementos estructurales, mostrando en la conformación una mayor integración con amistades que con la propia familia (Álvarez y Guzmán, 2013; Ávila-Toscano \& Madariaga, 2015). Un resultado consistente de los estudios es la reducida presencia de otros miembros desmovilizados en las redes sociales personales (AmarAmar, Abello-Llanos, Madariaga y Ávila-Toscano, 2011; Ávila-Toscano \& Madariaga, 2010); una tendencia importante dado que de acuerdo con Zukerman (2011) las redes persistentes entre excombatientes pueden crear riesgos de removilización.

La presencia de intercambios caracterizados por apoyo social dentro de la red se ha asociado positivamente con la calidad de vida relacionada con la salud (Gallicchio, Hoffman \& Helzlsouer, 2007; Leung, Pachana \& McLaughlin, 2014; Staniute et al., 2015; Schwartzmann, 2003). Amar-Amar, Abello-Llanos, Madariaga y Ávila-Toscano (2011) realizaron un estudio para explorar la relación entre la red social y la calidad de vida percibida en una muestra pequeña (37) de residentes en una zona de distensión militar en el Caribe colombiano. No encontraron relaciones estadísticamente significativas entre los indicadores estructurales de la red y las dimensiones de calidad de vida evaluadas; mientras que de los indicadores funcionales de la red solo la participación social se asoció positivamente con el com- 
ponente vitalidad de calidad de vida percibida. Reportaron, por otro lado, baja calidad de vida percibida lo cual coincide con otros estudios realizados con muestras mayores de excombatientes (124) en la ciudad de Montería (Ávila-Toscano, 2013) y en zonas desmilitarizadas en el departamento de Córdoba (Amar-Amar, Abello-Llanos, Madariaga y Ávila-Toscano, 2013). Ávila-Toscano (2013) reportó, adicionalmente, que el juicio sobre el componente relaciones sociales de calidad de vida percibida se relacionó con el estado civil; siendo más positivo para los excombatientes que mantenían relaciones conyugales estables.

Estos resultados, sin embargo, contrastan con otros estudios realizados en zonas geográficas diferentes del país, los cuales reportan un juicio más positivo sobre la calidad de vida en los excombatientes (Velasco y Londoño, 2009, 2011; Meneses, Cardona \& Devia, 2010). Interesante señalar que en el estudio de Velasco y Londoño (2009), el 83\% de los desmovilizados entrevistados y reubicados en Bogotá, vivían con su pareja en unión libre, el $98 \%$ reportó tener algún tipo de creencia religiosa y el $88 \%$ se desmovilizó en forma individual con el apoyo de la Alta Consejería para la Reintegración Social y Económica de Personas y Grupos Alzados en Armas (ACR). Velasco y Londoño (2009) reportaron como predictores importantes de la permanencia en el programa de reintegración a la vida civil a la calidad de vida total, satisfacción laboral, satisfacción educativa y a la creencia y práctica religiosa. La composición de redes de apoyo social no predijo la permanencia en el programa de reintegración social.

Las redes sociales personales reducidas parecen estar asociadas negativamente con la salud socioemocional aunque para Ávila-Toscano \& Madariaga (2015) es posible que otra característica como la presencia de interacciones sociales conflictivas se constituya también en un factor importante, en tanto pueden ocurrir independientemente del tamaño de la red. Ávila-Toscano \& Madariaga (2015) realizaron un estudio para identificar diferencias en la estructura de las redes personales y la manifestación de problemas de salud mental en excombatientes, en función de la presencia o ausencia de conflictos en las relaciones sostenidas con los integrantes de dichas redes. Encontraron que la presencia de interacciones conflictivas es mayor en las redes donde la densidad relacional es menor, al igual que la centralidad relativa a cada actor y con altos niveles de cercanía, lo que indica que son redes en donde los lazos principales se definen en pocos contactos y no existe apertura social. Adicionalmente, encontraron que las manifestaciones de síntomas de ansiedad-insomnio así como de depresión tienden a ser mayores en las redes con reportes de conflictos que en las redes sin interacción conflictiva, 
aunque en general la frecuencia de estos síntomas no fue alta en la muestra de excombatientes.

El tamaño es la característica más básica de la estructura de la red y es una característica importante porque indica la existencia de recursos sociales (Wrzus, Hänel, Wagner \& Neyer, 2013), los cuales tienen efectos benéficos para la salud, bienestar de las personas y el logro de las tareas propias de la vida (Bastani, 2007). Sin embargo, para Ueno \& Adams (2006) aún no se tiene un sentido claro de cuál es el tamaño típico de la red. Wrzus, Hänel, Wagner \& Neyer (2013) llevaron a cabo un metaanálisis con 277 estudios tanto transversales como longitudinales y encontraron como tendencias que: (1) la red social global incrementa hasta la adultez joven y luego decrece sostenidamente; (2) tanto la red personal como la red de amigos decrece durante la adultez, (3) la red familiar tiende a ser estable en tamaño desde la adolescencia hasta la vejez; y (4) otras redes como las de los compañeros de trabajo o vecinos fueron solamente importantes en rangos específicos de edad. Estos resultados son muy interesantes por cuanto permiten problematizar la relación propuesta entre el tamaño de la red y el éxito en la reintegración social de los excombatientes en sus respectivas comunidades receptoras, incluso por el hecho de extender el análisis a las redes sociales personales de los miembros de las comunidades receptoras. Por otro lado, como se mencionó atrás, Kaplan y Nussio (2016) presentaron evidencia de la relación entre la reincidencia de los excombatientes y los vínculos débiles con la familia, lo que apoya la idea que el tamaño de la red podría no ser la dimensión central.

Comunidades receptoras. Las políticas de reintegración social y las basadas en comunidades han sido implementadas en países tan diversos como Filipinas, República Democrática del Congo y Colombia, las cuales suponen implícitamente que la participación social de los excombatientes en las comunidades receptoras, así como su aceptación por parte de estas, es útil para promover la reconciliación con las víctimas del conflicto armado y para minimizar su reincidencia en actividades ilegales (Kaplan y Nussio, 2015). Importante señalar que los excombatientes usualmente viven en barrios pobres con baja capacidad institucional y altos niveles de criminalidad. Los miembros de las comunidades receptoras no son conscientes de que los excombatientes conviven en medio de ellos y muchos miembros no participan en organizaciones comunitarias, pero que aquellos que sí lo hacen favorecen la inclusión de los excombatientes en estas organizaciones (Kaplan y Nussio, 2015, citando al Centro Nacional de Consultoría, 2011). 
Dentro de los indicadores de la reintegración social comunitaria, es posible encontrar la aceptación percibida de los excombatientes por parte de sus familias y vecinos (Porto, Parsons \& Alden, 2007; Pugel, 2006), percepción de aceptación por los miembros de las comunidades receptoras hacia los excombatientes, y la participación social de los excombatientes en organizaciones comunitarias (Kaplan \& Nussio, 2015). El Modelo de Reintegración Comunitaria (MRC) de la Agencia para la Reincorporación y la Normalización (ARN) (conocida anteriormente como Agencia Colombiana para la Reintegración-ACR-) incluye dichos indicadores y orienta sus acciones, desde una perspectiva sostenible, con metodologías participativas enfocadas en contextos específicos tanto en áreas urbanas como áreas rurales, haciendo especial énfasis en formación en ciudadanía y participación comunitaria en una práctica situada sociohistóricamente. Adicionalmente, propone cuatro indicadores: pertenencia, aceptación, participación comunitaria y confianza institucional, los cuales se usan para medir el logro de los objetivos señalados en las intervenciones contratadas (ACR, 2013).

La participación social o en organizaciones comunitarias es un tipo de contacto intergrupal (De Greiff, 2009) que tiene el potencial de disminuir la recurrencia de conflictos civiles (Walter, 2004). Kaplan y Nussio (2015) realizaron un estudio en Colombia, entre febrero y marzo de 2008, con una muestra de 1485 excombatientes y reportaron que el $41 \%$ de los encuestados participaba en al menos algún grupo comunitario, con menor participación para exparamilitares $(36 \%)$ que para exguerrilleros de las FARC-EP y el ELN (49\%). Los excombatientes reportaron participar con mayor frecuencia en grupos deportivos (38\%), religiosos $(27 \%)$ y sociales (11\%). Los excombatientes que tendieron a participar más, fueron los que más oportunidades e invitaciones recibieron. En otras palabras, las comunidades organizadas con altos niveles de participación son aquellas en donde la participación social de los excombatientes es mayor, como el caso de ciudad de Medellín. Encontraron también que las tasas de participación comunitaria, así como la aceptación comunitaria están significativa y negativamente asociadas con la participación de excombatientes en grupos legales creados por otros excombatientes; grupos que a su vez son menos frecuentes cuando hay presencia de grupos organizados criminales como las Bacrim.

Este tipo de participación en organizaciones comunitarias suele estar, sin embargo, amenazada por diversos factores dentro de los que se puede identificar a los problemas de seguridad generados por la presencia de grupos armados (Nussio, 2011; Observatorio de Procesos de DDR, 2010; Themner, 2011) o por la existencia de retaliaciones debido a que la participación 
requiere revelar la identidad, así como los hábitos de la vida cotidiana. Sin embargo, Kaplan y Nussio (2015) encontraron que los niveles de inseguridad de los contextos receptores no se asociaron con la participación social en organizaciones comunitarias, dejando abierta la posibilidad para continuar indagando por otras variables centrales, propias de la interacción entre las características de las comunidades receptoras y los excombatientes, o para explorar con mayor detalle bajo qué circunstancias concretas la inseguridad del contexto puede considerarse una amenaza a la participación social.

Humphreys \& Weinstein (2005) reportaron en el periodo de posconflicto en Sierra Leona que el $90 \%$ de los excombatientes no enfrentaron problemas para ganar la aceptación de sus familiares y vecinos en sus respectivas comunidades. Tendencias similares fueron reportados en Liberia (Jennings, 2008) y en Mozambique (Alden, 2003). En Colombia, se encuentran tendencias semejantes para el caso de la percepción de los excombatientes pero no para el caso de las comunidades receptoras. Kaplan y Nussio (2015) reportaron que cerca del $93 \%$ de los excombatientes percibieron aceptación por parte de sus vecinos y el $90 \%$ percibió aceptación por parte de sus familias. En contraste, el Centro Nacional de Consultoría (2011, citado por Kaplan y Nussio, 2015) reportó que, como estimado, el 41\% de los miembros de las comunidades encuestadas ven a los excombatientes con miedo y que desconfían más de los excombatientes que de los vecinos que no lo son.

De acuerdo con Kaplan y Nussio (2015) en Colombia, entre 2007 y 2011, distintas iniciativas comunitarias fueron ejecutadas por la Agencia Colombiana para la Reintegración (ACR) en 84 municipios, con el objetivo explícito de incrementar el nivel de confianza entre las comunidades y los desmovilizados. Iniciativas simbólicas, tales como encuentros deportivos y la recuperación de espacios públicos por los excombatientes, se han llevado a cabo para dar a conocer las actividades de reintegración y promover la aceptación social. El Centro Nacional de Consultoría (2011, citado por Kaplan y Nussio, 2015), por otro lado, ha manifestado que lograr la aceptación de las comunidades receptoras es una tarea desalentadora, ya que los miembros de la comunidad a menudo ven a los excombatientes con miedo y desconfianza. El contexto de la reintegración en Colombia es en general complejo, no solamente por la diversidad que caracteriza al país en distintos órdenes, sino porque demanda acciones desde una perspectiva integrada con los actores del conflicto armado en una sociedad que, como plantean Theidon \& Betancourt (2006), no está realmente integrada por sujetos en transición que posean una firme voluntad para apoyar incondicionalmente la paz y todo lo que esto implique. De Vries \& Wiegink (2011) han señalado 
que el retorno a las comunidades de origen puede ser problemático, porque podrían no estar tan abiertas como se ha asumido.

A pesar de la relevancia de la reintegración social, DDR y los programas de reintegración, sin embargo, suelen ser generalmente evaluados en términos de la reintegración económica (Bowd \& Özerdem, 2013) o política (Blattman, 2009; Özerdem, 2012), lo cual es criticable pues atenúan los indicadores de la reintegración social; vitales para lograr una reconciliación efectiva y, por lo tanto, una paz sostenible (Bowd \& Özerdem, 2013). Las comunidades receptoras, que hacen parte de contextos caracterizados por grandes problemas sociales, pueden tener unas características que de no trabajarlas conjuntamente en los modelos de reintegración social y comunitaria, en lugar de favorecer la reintegración la amenazan, de allí la importancia de tener una perspectiva ecológica social sobre las comunidades receptoras y sus miembros.

Betancourt, McBain, Newnham \& Brennan (2014) desarrollaron un estudio con 243 niños excombatientes en el periodo de posconflicto en Sierra Leona y encontraron que los problemas sociales dentro de la comunidad (violencia física, crimen, drogas y abuso de alcohol) y el estigma percibido en la comunidad estuvo asociado con tasas de externalización (conductas hostiles o agresivas) e internacionalización emocional (síntomas de depresión y ansiedad), así como con problemas de conducta, seis años después de finalizada la guerra. Estos resultados sugieren que, así como es necesario favorecer el cambio y el ajuste de los excombatientes en proceso de reintegración, también parece necesario favorecer el cambio en los miembros de las comunidades receptoras (conscientes o no de la existencia de miembros excombatientes conviviendo en sus comunidades), considerándolo siempre que sea posible dentro de una perspectiva temporal amplia. Para el caso colombiano, Cifuentes, Aguirre y Lugo (2011) han sugerido que la investigación en torno a las consecuencias del conflicto armado en niñas, niños y jóvenes excombatientes; requiere mayor desarrollo para mejorar la formulación de política pública y, por lo tanto, la atención a este tipo de población en aras de contribuir positivamente a su retorno a la vida civil.

La ecología social (Ungar, Ghazinour \& Richter, 2013) pone un gran énfasis en los contextos sociales, culturales e institucionales de las relaciones de las personas con el ambiente (Binder, 1972) pero también plantea que el comportamiento social está influenciado por una variedad de características personales, las cuales, en interjuego dinámico con las variables del contexto, explican la ocurrencia de ciertos comportamientos (Stokols, 1996). Adicio- 
nalmente, la ecología social enfatiza la interdependencia de condiciones ambientales dentro de escenarios particulares y la interconexión entre múltiples escenarios y dominios de la vida (Ej. barrio, trabajo, comunidad, familia, etc.) reconociendo la influencia tanto de ambientes cercanos como unos más remotos (como el nivel nacional) en el comportamiento de las personas. La promoción de actividades comunitarias, como ha sido hasta ahora el énfasis de los programas de reintegración social, son necesarias pero no pueden ser las únicas acciones promovidas en tanto pueden existir otras dimensiones de orden individual, interpersonal y grupal que pueden tener un papel relevante en la aceptación que manifiesta la comunidad frente a las personas en proceso de reintegración.

La perspectiva de los modelos de reintegración social ha enfatizado el nivel comunitario y, dentro del modelo ecológico social, lo comunitario es importante pero no es el único nivel a considerar en el diagnóstico y en la intervención. Posada \& Carmona (2018), al realizar una revisión sistemática de literatura, encontraron que en las crisis bélicas las mujeres son sometidas a violencias de género, en contextos patriarcales que las marginan como sujetos de derechos; pero que si estas crisis se conciben como oportunidades para reconfigurar su subjetividad política y prácticas ciudadanas, es posible repensar y transformar las estructuras culturales y sociales que promueven la inequidad y la violencia como forma de relacionamiento. La capacidad reflexiva de los agentes no se analiza en el nivel comunitario, pero sí que está relacionada con él, por lo que es necesario concebir el cambio psicosocial como un aspecto central dentro del proceso de cambio comunitario. Las comunidades receptoras en Bogotá, por ejemplo, suelen estar ubicadas en localidades caracterizadas por importantes problemas sociales dentro de los que cabe destacar a la violencia de género. Las comunidades se van transformando por ocasión de sus propios problemas y necesidades, lo que al mismo tiempo siembra el terreno para construir contextos de reintegración social enmarcados en una perspectiva de no violencia, con mayores cimientos para su sostenibilidad.

En una perspectiva similar, Cogollo y Durán (2015) enfatizan la necesidad de retomar nuestro rol participativo como ciudadanos, así como nuestra responsabilidad en el cambio hacia la paz y la reconstrucción social. El cambio cultural analizado desde la educación, tanto por parte de la familia como de las instituciones educativas, para retomar la formación moral y en valores que se ha visto minada por una serie de fenómenos entre los que cabe mencionar la cultura de la ilegalidad, el narcotráfico, el facilismo, la anomia y el tradicionalismo a ciegas. En resumen, el contexto de la reintegración 
social implica la consideración de otros niveles los cuales, al ser intervenidos simultáneamente, van sumando al logro de una paz sostenible. Por supuesto que existen necesidades particulares para comunidades específicas, pero en general el contexto de la reintegración social en Colombia no solo debe incluir a las comunidades receptora,s sino en general al país.

\subsection{Conclusión}

La reintegración social se refiere a un proceso complejo por cuanto en él participan una multiplicidad de factores de diversos niveles, que interactúan entre sí para crear condiciones psicosociales que la favorecen, y que tiene como resultado un ajuste exitoso y duradero de los excombatientes al contexto característico de la vida legal y civil. Ese proceso implica un conjunto de interacciones dinámicas entre las partes involucradas, por lo que es vital entender las características psicosociales de cada una de las partes. De esto se deriva que los actores de la reintegración no son solamente los desmovilizados o las organizaciones que los apoyan en su retorno a la vida civil y legal del país. Aunque de acuerdo con Rivas, Méndez y Arias (2007) una parte del éxito del proceso reside en la responsabilidad individual de los beneficiarios del programa respecto a su propio proceso de reintegración; es indiscutible que la otra parte depende de la receptividad que pueda haber por parte de la comunidad hacia esta población. Como consecuencia, no puede suponerse que, terminado el programa de reinserción de un desmovilizado, la reintegración social ocurrirá sin ningún obstáculo pues otros factores comienzan a operar dentro del proceso, lo que incluso puede crear condiciones para observar resultados inesperados. La realidad es cambiante y dinámica (Cornejo, 2006) por lo que no podemos suponer que los planes trazados en materia de reintegración ocurrirán sin tropiezos.

\section{Referencias}

Alden, C. (2002). Making old soldiers fade away: Lessons from the reintegration of demobilized soldiers in Mozambique. Security Dialogue, 33(3), 341-356. doi: 10.1177/ 0967010602033003008

Álvarez, E. \& Guzmán, G. (2013). Redes de apoyo social en personas en proceso de reintegración a la vida civil residentes en la ciudad de Barranquilla (Colombia). Realitas, Revista de Ciencias Sociales, Humanas y Artes, 1(2), 11-17.

Amar-Amar, J., Abello-Llanos, R., Madariaga, C. y Ávila-Toscano, J. H. (2013). Characteristics of Personal Networks Associated with Physical and Psychological Quality of life among Demobilized Individuals from the Colombian Armed Conflict. Journal of Community y Applied Social Psychology, 24, 173-190. doi: 10.1002/casp.2155. 
Amar-Amar, J., Abello-Llanos, R., Madariaga, O. C. \& Ávila-Toscano, J. H. (2011). Relación entre redes personales y calidad de vida en individuos desmovilizados del conflicto armado colombiano. Universitas Psychologica, 10(2), 355-369.

Ávila-Toscano, J. H. (2013). Calidad de vida en ex-integrantes de un grupo armado ilegal reubicados en una ciudad del Caribe colombiano. Realitas, Revista de Ciencias Sociales, Humanas y Artes, 1(1), 19-24.

Ávila-Toscano, J. H., \& Madariaga, C. (2015). Interacción social conflictiva y problemas de salud mental en redes personales de ex combatientes ilegales en Colombia. Terapia psicológica, 33(3), 277-283.

Ávila-Toscano, J. H. \& Madariaga, C. (2010). Redes personales y dimensiones de apoyo en individuos desmovilizados del conflicto armado. Revista Psicología desde el Caribe, $25,179-201$.

Arango, R. (2013). La responsabilidad colectiva ante la crisis moral y política colombiana. Araucaria, Revista Iberoamericana de Filosofia, Política y Humanidades, 15(29), $155-167$.

Bastani, S. (2007). Family comes first: Men's and women's personal networks in Tehran. Social Networks, 29(3), 357-374. doi: 10.1016/ j.socnet.2007.01.004

Berdal, M. R. (1996). Disarmament and demobilisation after civil wars: arms, soldiers and the termination of armed conflicts. Oxford: Oxford University Press.

Betancourt, T. S., McBain, R., Newnham, E. A., \& Brennan, R. T. (2014). Context Matters: Community Characteristics and Mental Health among war-affected youth in Sierra Leone. Journal of Child Psychology and Psychiatry, 55(3), 217-226. doi: 10.1111/ jcpp. 12131 .

Binder, A. (1972). A new context for psychology: Social ecology. American Psychologist, 27(9), 903-908. doi: 10.1037/h0033434

Blattman, C. (2009). From violence to voting: War and political participation in Uganda. American Political Science Review, 103(2), 231-247. doi:10.1017/ S0003055409090212

Bøås, M., \& Hatløy, A. (2008). 'Getting in, getting out': militia membership and prospects for re-integration in post-war Liberia. The journal of modern African studies, 46(1), 3355. doi: 10.1017/S0022278X07003060

Body, T. (2006). Reintegration of Ex-combatants through Micro-enterprise: An operational framework: CPR network. The Pearson Peacekeeping Centre.

Bowd, R., \& Özerdem, A. (2013). How to assess Social Reintegration of Ex-combatants. Journal of Intervention and Statebuilding, 7(4), 453-475. doi: 10.1080/ 17502977.2012.727537

Carbó, E., Deas, M. y Powell, C. (2002). La paz y sus principios. Bogotá: Alfaomega Colombiana.

Centro Nacional de Consultoría (2011). Informe final evaluación de impacto, seguimiento y sistematización de la estrategia de reintegración comunitaria. Bogotá: Centro Nacional de Consultoría. 
Cifuentes, M., Aguirre, N., \& Lugo, N. (2011). Niñas, niños y jóvenes excombatientes: revisión de tema. Eleuthera, 5, 93-125.

Coelho, J. P. B., \& Vines, A. (1995). Pilot Study on Demobilization and Re-integration of Ex-combatants in Mozambique. Refugee Studies Programme. Oxford.

Cogollo, S. y Durán, N. (2015). Paz y posconflicto: compromiso de los ciudadanos para un horizonte imaginado. En: Imaginar la paz en Colombia: cavilaciones desde la academia. Medellín (Colombia): Fundación Universitaria Luis Amigó.

Colletta, N. J., Kostner, M., \& Wiederhofer, I. (eds.) (1996). The Transition from War to Peace in Sub-Sahara Africa. Washington, D.C.: World Bank.

Colletta, N. J., \& Muggah, R. (2009). Context matters: interim stabilisation and second generation approaches to security promotion. Conflict, Security \& Development, 9(4), 425-453. doi: https://doi.org/10.1080/14678800903345762

De Greiff, P. (2009), Articulating the Links between Transitional Justice and Development: Justice and Social Integration. In De Greiff, P. \& Duthie, R. (eds.), Transitional Justice and Development: Making Connections (pp. 28-75). New York: SSRC Publications.

De Vries, H., \& Wiegink, N. (2011). Breaking up and Going Home? Contesting two Assumptions in the Demobilization and Reintegration of Former Combatants. International Peacekeeping, 18(1), 38-51.

Espinosa, M. (2011). Dime qué fuente usas y te diré qué análisis presentas: Balance conceptual y metodológico de bases de datos sobre conflicto armado en Colombia. Universitas humanística, 72, 297-320.

Fisas, V. (2011). Introducción al desarme, desmovilización y reintegración (DDR) de excombatientes. Quaderns de Construcció de Pau, 24, 1-20.

Fisher, K.J. (2013). The Difficult Reintegration. In: Transitional Justice for Child Soldiers. Rethinking Peace and Conflict Studies. London: Palgrave Macmillan.

Gallicchio, L., Hoffman, S. \& Helzlsouer, K. (2007). The Relationship between Gender, Social Support, and Health-related Quality of Life in a Community based study in Washington County, Maryland. Quality of Life Research, 16, 777-786.

Gordon, E. (2013). Why has it often Proved more Difficult to Reintegrate than to Demobilize Soldiers Following Civil Wars. E-International Relations. Available: http://www. e-ir. info/2011/07/26/why-has-it-often-proved-more-difficult-to-reintegratethan-to-demobilise-soldiers-following-civil-wars/.

Guáqueta, A. (2007). The way back in: la reintegración de los grupos armados ilegales en Colombia antes y ahora. Conflicto, Seguridad y Desarrollo, 7(3), 417-456.

Humphreys, M., \& Weinstein, J. (2005). Disentangling the Determinants of Successful Demobilization and Reintegration. Unpublished Manuscript. Paper presented at the annual meeting of the American Political Science Association, Washington, DC, 2005. doi:10.2139/ssrn, 984246 . 
Humphreys, M. \&Weinstein, J.M. (2007). Demobilization and Reintegration. Journal of Conflict Resolution, 51(4), 531-567. doi: 10.1177/0022002707302790

Ibáñez Londoño, A. M. (2011). El desplazamiento forzoso en Colombia: un camino sin retorno hacia la pobreza. Cuadernos Geográficos, 48(1), 301-303.

Janzen, R. (2014). Guatemalan Ex-combatant Perspectives on Reintegration: A grounded theory. The Qualitative Report, 19(41), 1-21. http://nsuworks.nova.edu/tqr/vol19/iss21/1

Jennings, K. M. (2008). Unclear ends, Unclear means: Reintegration in Postwar Societiesthe Case of Liberia. Global Governance: A Review of Multilateralism and International Organizations, 14(3), 327-345.

Joya Ibarra, A. C. (2015). Desarme en procesos de paz: análisis preliminar del caso colombiano. Colombia: Editorial Universidad del Rosario.

Kaplan, O., \& Nussio, E. (2015). Community counts: The Social Reintegration of Ex-combatants in Colombia. Conflict Management and Peace Science, 1-22. doi: $10.1177 / 0738894215614506$

Kaplan, O., \& Nussio, E. (2016). Explaining Recidivism of Ex-combatants in Colombia. Journal of Conflict Resolution, doi: 10.1177/0022002716644326.

Klem, B., Douma, P., Frerks, G., Gompelman, G., \& Laar, S. Van. (2008). The Struggle After Combat: The Role of NGOs in DDR Processes: Synthesis Study. The Hague, the Netherlands: Cordaid.

Knight, M., \& Özerdem, A. (2004). Guns, Camps and Cash: Disarmament, Demobilization and Reinsertion of Former Combatants in Transitions from War to Peace. Journal of Peace Research, 41(4), 499-516. doi: 10.1177/0022343304044479 ISSN 0022-3433

Leongómez, E. P. (2004). Una democracia asediada: balance y perspectivas del conflicto armado en Colombia. Bogotá: Norma.

Leung, J., Pachana, N. A., \& McLaughlin, D. (2014). Social Support and Health-related Quality of Life in Women with Breast Cancer: a Longitudinal Study. Psycho-Oncology, 23(9), 1014-1020. doi: 10.1002/pon.3523

McMullin, J. R. (2013). Integration or Separation? The Stigmatisation of Ex-combatants after War. Review of international studies, 39(2), 385-414. doi: 10.1017/ S0260210512000228

Martikainen, P., Bartley, M., \& Lahelma, E. (2002). Psychosocial Determinants of Health in Social Epidemiology. International Journal of Epidemiology, 31, 1091-1093. doi:10.1093/ ije/31.6.1091

Muggah, R. (2007). Great Expectations: (Dis) integrated DDR in Sudan and Haiti. Humanitarian Exchange Magazine, 37. Available at https://odihpn.org/magazine/great-expectations-disintegrated-ddr-in-sudan-and-haiti/.

Nussio, E. (2011). How Ex-combatants talk about Personal Security. Narratives of Former Paramilitaries in Colombia. Conflict, Security \& Development, 11(5), 579-606. doi: $10.1080 / 14678802.2011 .641725$ 
Nussio, E. (2012). La vida después de la desmovilización, percepciones, emociones y estrategias, de exparamilitares en Colombia. Bogotá: Ediciones Uniandes.

Nussio, E., \& Oppenheim, B. (2014). Anti-social Capital in Former Members of non-state Armed Groups: A Case Study of Colombia. Studies in Conflict \& Terrorism, 37(12), 999-1023. doi: 10.1080/1057610X.2014.962438

Özerdem, A. (2012). A Re-conceptualisation of Ex-combatant Reintegration: Social Reintegration'approach. Conflict, Security \& Development, 12(1), 51-73. doi: 10.1080/14678802.2012.667661

Palau, J., y Méndez, M. (2012). Balance de los procesos de desarme, desmovilización y reintegración (DDR) en Colombia: 1990-2011. En A. Rettberg (comp.) Construcción de paz en Colombia, (pp. 349-381). Bogotá: Ediciones Uniandes.

Porto, J. G., Parsons, I., \& Alden, C. (2007). From Soldiers to Citizens the Social, Economic and Political Reintegration of Unita Ex Combatants. Institute for Security Studies (ISS).

Posada, I. \& Carmona, J. (2018). Subjetividad política y ciudadanía de la mujer en contextos de conflictos armados. Revista Mexicana de Ciencias Políticas y Sociales, 63(233), 69-92. doi: $10.22201 /$ fcpys.2448492xe.2018.233.57835

Pugel, J. (2006). What the Fighters Say: A Survey of Ex-combatants in Liberia. New York: UNDP.

Rivas A., Méndez M. y Arias G. (2007) Revisión de la desmovilización en Colombia. Fundación ideas para la paz. Colombia En: www.ideasparalapaz.org.co/

Sánchez, R. \& Suárez, L. (2007). Un modelo de regreso a la legalidad. Desafios, 17, 102-125.

Serrat, O. (2009). Social Network Analysis. Knowledge Solutions, 28, doi: 10.1007/978981-10-0983-9_9

Schwartzmann, L. (2003). Calidad de vida relacionada con la salud: aspectos conceptuales. Ciencia y enfermería, 9(2), 9-21. doi: 10.4067/S0717-95532003000200002

Solomon, C. (2008). Disarmament, Demobilisation and Reintegration in West Africa: An Overview of Sierra Leone and Liberia. Centre for International Cooperation and Security, Contribution to the project: DDR and Human Security: Postconflict security-building in the interests of the poor.

Sriram, C.L. (2013). Victims, Excombatants and the Communities: Irreconcilable Demands or a Dangerous Convergence? In: Bonacker T., Safferling C. (eds.) Victims of International Crimes: An Interdisciplinary Discourse. T.M.C. Asser Press, The Hague, The Netherlands.

Staniute, M., Brozaitiene, J., Burkauskas, J., Kazukauskiene, N., Mickuviene, N., \& Bunevicius, R. (2015). Type D Personality, Mental Distress, Social Support and Health-related Quality of Life in Coronary Artery Disease Patients with Heart Failure: a Longitudinal Observational Study. Health and Quality of Life Outcomes, 13(1), 1-11. doi: 10.1186/ s12955-014-0204-2 
Stokols, D. (1996). Translating Social Ecological Theory into Guidelines for Community Health Promotion. American Journal of Health Promotion, 10(4), 282-298. doi: 10.4278/0890-1171-10.4.282

Subedi, D. B. (2014). Conflict, Combatants and Cash: Economic Reintegration and Livelihoods of Ex-combatants in Nepal. World Development, 59, 238-250. doi: 10.1016/j. worlddev.2014.01.025

Subedi D.B., \& Jenkins, B. (2017). The Nexus Between Reintegration of Ex-combatants and Reconciliation in Nepal: A Social Capital Approach. In: Jenkins B., Subedi D., Jenkins K. (eds.) Reconciliation in Conflict-Affected Communities. Springer, Singapore.

Theidon, K., \& Betancourt, P. A. (2006). Transiciones conflictivas: combatientes desmovilizados en Colombia. Análisis político, 19(58), 92-111.

Themnér, A. (2011). Violence in Post-Conflict Societies: Remarginalization, Remobilizers and Relationships. London: Routledge.

Tovar Guerra, C., Galindo Villarreal, L. F., \& Guzmán Rodríguez, L. (2008). Demovilization and Local Coexistence: the Viewpoint of Receptive Communities. Diversitas: Perspectivas en Psicología, 4(2), 305-317.

Torres, W. F. (2001). ¿Educar para la inserción social o reconstruir lo colectivo en colectivo? Nómadas, 15, 102-113.

Uribe, M. V. (2012). Memoria en tiempos de guerra, el signo de una ausencia. Estudios de Filosofía, 273-279.

Ueno, K., \& Adams, R. G. (2006). Adult Friendship: A Decade Review. In P. Noller \& J. A. Feeney (eds.), Close Relationships: Functions, Forms and Processes (pp. 151-169). New York, NY: Psychology Press.

Ungar, M., Ghazinour, M., \& Richter, J. (2013). Annual Research Review: What is Resilience within the Social Ecology of Human Development? Journal of Child Psychology and Psychiatry, 54(4), 348-366. doi: 10.1111/jcpp.12025

Van der Poel, M. G. M. (1993). Delineating Personal Support Networks. Social Networks, 15(1), 49-70. doi:10.1016/0378-8733(93)90021-C

Velasco, M., \& Londoño, C. (2009). Determinantes psicosociales de la permanencia en el programa de reintegración social en desmovilizados. Revista Iberoamericana de Psicología: Ciencia y Tecnología, 2(2), 17-32.

Villarraga, Á. (2013). Experiencias históricas recientes de reintegración de excombatientes en Colombia. Colombia internacional, 77, 107-140.

Visbal, J. D. (2014). Del conflicto al posconflicto en el contexto colombiano. Revista Universidad de La Salle, 63, 57-73.

Waldman, M. (2010). Golden Surrender? The Risks, Challenges, and Implications of Reintegration in Afghanistan. Discussion Paper 03/10. Afghanistan Analysts Network. 
Walter, B. F. (2004). Does Conflict Beget Conflict? Explaining Recurring Civil War. Journal of Peace Research, 41(3), 371-388. doi: 10.1177/0022343304043775

Wegner, B. (2011). The Difficult Reintegration of Soldiers to Society and Family after Deployment. ESSAI, 9(41), 150-155. Available at: http://dc.cod.edu/essai/vol9/iss1/41

Wrzus, C., Hänel, M., Wagner, J., \& Neyer, F. J. (2013). Social Network Changes and Life Events Across the Life Span: A meta-analysis. Psychological bulletin, 139(1), 1-28. doi: $10.1037 / \mathrm{a} 0028601$

Zukerman, S. (2011). Bankruptcy, Guns or Campaigns: Explaining Armed Organizations' post-war Trajectories (Doctoral dissertation). Massachusetts Institute of Technology. Available: https://dspace.mit.edu/handle/1721.1/64616\#files-area 


\title{
8. Ser o no ser: subjetivación politica de las víctimas del conflicto armado en Colombia
}

\author{
Kethy Luz Pérez CorReA ${ }^{23}$ \\ WilsON SALAS PicóN ${ }^{24}$ \\ Resumen
}

El presente capítulo tiene como objetivo establecer el estado actual de las interpretaciones y conceptualizaciones desarrolladas sobre la categoría víctima de la violencia sociopolítica en Colombia entre los años 2005 al 2016. Por esta razón se realizó una revisión bibliográfica en las principales bases de datos académicas como Science Direct, Scopus, Web of Science y Scielo, utilizando como criterios de búsqueda las palabras clave, las cuales debían ser expresadas en el título o resumen de los textos seleccionados. En este sentido, se contó con una muestra documental conformada por 20 artículos y un libro de habla hispana (latinoamericanos), derivados de investigación, los cuales cumplieron con los criterios de selección establecidos. Los resultados evidencian una evolución y posicionamiento del concepto de víctima al igual que la imposición de una noción de víctima desde una categoría jurídica que influye en los programas de atención. Ahora bien, los procesos de significación y re-significación, las dinámicas de subjetivación política generadas en procesos de intervención a nivel sociojurídico y político, constituyen un pilar fundamental que emerge desde la reconstrucción de la memoria histórica, el cual instituye un escenario de resistencia simbólica y una revaloración como sujetos políticos. A través de este reconocimiento se aporta a la construcción de una sociedad más justa en Colombia. A partir de lo anterior, se concluye que la intervención psicosocial dirigida a las víctimas debe centrarse desde una perspectiva relacional, dialéctica y subjetiva, permitiendo establecer acciones de atención personalizadas y ajustadas a sus necesidades y no como respuesta a una categoría jurídica. Por lo anterior, la reconfiguración de la experiencia (condición vs. situación) y su

23 Universidad Cooperativa de Colombia - Sede Santa Marta. Correo: kl_perez@hotmail.com

24 Universidad Cooperativa de Colombia - Sede Barrancabermeja. Correo: wilson.salas@campusucc.edu.co 
autoreconocimiento, se convierten en pilares fundamentales para lograr el empoderamiento y con ello, la des-victimización.

Palabras clave: subjetivación política, violencia sociopolítica, víctimas, conflicto armado, significación.

\section{Abstract}

The objective of this chapter is to establish the current state of the interpretations and conceptualizations developed on the category victim of sociopolitical violence in Colombia between 2005 and 2016. This is the reason why a bibliographic review is developed in the main academic databases As Science Direct, Scopus, Web Of Science and Scielo using as keywords the search criteria, which should be expressed in the title or summary of the selected texts. In this sense, there was a documentary sample consisting of 20 articles and one (1) Spanish-speaking book (Latin American), derived from research, which met the established selection criteria. The results show an evolution and positioning of the concept of victim as well as the imposition of a notion of victim from a legal category that influences the attention programs. Now, the processes of meaning and re-signification, the dynamics of political subjectification generated in intervention processes at the socio-legal and political level, constitute a fundamental pillar that emerges from the reconstruction of historical memory, which institutes a scenario of symbolic resistance and a revaluation as political subjects. Through this recognition, it contributes to the construction of a fairer society in Colombia. Based on the foregoing, it is concluded that the psychosocial intervention directed to the victims must be focused from a relational, dialectic and subjective perspective, allowing the establishment of personalized attention actions tailored to their needs and not as a response to a legal category. Therefore, the reconfiguration of experience (condition vs. situation) and its self-recognition, become fundamental pillars to achieve empowerment and with it, de-victimization.

Keywords: Political subjectivity, sociopolitical violence, victims, armed conflict, significance.

\subsection{Introducción}

El conflicto armado en Colombia, a lo largo de los últimos años, ha dejado una infinidad de víctimas y huellas en el tejido social del país, fragmentando, dividiendo y lesionando las estructuras sociales y, en la mayoría de los casos, afectando a las poblaciones con mayores niveles de vulnerabilidad como los campesinos, afrocolombianos, niños y mujeres, que viven contextos sociales 
y económicos complejos. La guerra que ha sufrido el país ha generado una infinidad de resquebrajamientos en la sociedad y cargado de resentimiento las relaciones humanas.

El proceso de victimización genera unas consecuencias en la vida de las personas que han sido afectadas por el conflicto armado en Colombia y, en este sentido, deben generarse unas estrategias, roles y responsabilidades para avanzar en la reconstrucción de la vida pacífica, especialmente en las zonas de mayor vulnerabilidad social. "En las víctimas del conflicto armado colombiano los acontecimientos violentos marcan su trayectoria vital, al modificar sus mundos de sentido y al condicionar la subjetividad expresada en prácticas, discursos y formas de relacionarse" (Tabares, 2011, p. 15). Los horrores sufridos por las víctimas siguen estando presentes durante toda su existencia, y es allí, donde se hace necesario un proceso comprensivo de los significados que se le otorgan a esta categoría desde los diferentes componentes de la sociedad, pero especialmente desde una lente del carácter sociopolítico del Estado.

En este sentido, es importante resaltar que el conflicto armado en Colombia el efecto prisma de la guerra, constituye no sólo un problema de salud pública (impactos en el 15\% de la población colombiana) sino también un escenario de revisión y replanteamiento de la acción pública sobre la dimensión conceptual de la víctima, la cual produce dispositivos de poder, in-visbiliza, genera subjetividades desde una política que des-humaniza e influye en la construcción de ciudadanía.

En la medida que no se superen y resignifiquen las concepciones sobre las víctimas, desde el accionar del Estado, y sus roles en la construcción de una sociedad más justa y pacífica, se seguirán generando dinámicas y procesos de revictimización y aumentando las diferencias sociales (Villa y Insuasty, 2016), considerando que las iniciativas ejecutadas por el Estado tienen una perspectiva burocrática y tecnocrática, relegando a un segundo plano el componente psicosocial como eje transversal de la intervención en las víctimas (Villa, 2016a).

Haciendo énfasis en el carácter histórico del conflicto armado en Colombia, se debe mencionar que éste tiene sus orígenes en dos aspectos centrales: el primero es la Guerra de los Mil Días y el segundo, las luchas por el control de la tierra (Johnson, 1995; Jaime 2003). A partir de estos escenarios se generaron una serie de enfrentamientos entre diversos actores y el Estado, pregonando como elemento central la lucha por los derechos humanos (Yaffe, 2011). A lo largo del tiempo, los ideales de los actores 
involucrados se han ido corrompiendo por otros intereses relacionados con actividades como el narcotráfico, el secuestro y la extorción. Los principales afectados en estas luchas sociales, políticas y militares, han sido las víctimas del conflicto, invisibilizadas por el Estado y por los sistemas de reconocimiento y restablecimiento de derechos, creados en Colombia (Valencia y Daza, 2010). Incluso el reconocimiento político y legal como víctima se torna en un proceso complejo y desprovisto de las herramientas pertinentes para garantizar un proceso de desvictimización efectivo (Nieto, 2010).

Villa, Barrera, Arroyave y Montoya (2017) sostienen que en el marco de la Ley 1448 de 2011se han enontrado "deficiencias graves en procesos de reparación e intervención psicosocial desarrollados por el Estado colombiano" (p. 2). Como consecuencia de lo anterior, Bravo (2011) sostiene que el Estado colombiano principalmente

(...) se ha limitado a satisfacer las necesidades meramente básicas de las víctimas del desplazamiento, proporcionando ayuda humanitaria en los primeros días del mismo pero dejando de lado su historia personal, el impacto emocional producido por el hecho, así como la fragmentación del tejido social y de la familia debido a la pérdida de un ser querido (p. 25)

Los efectos psicosociales producidos por la guerra son incalculables a nivel material e inmaterial. No obstante, las limitaciones y procesos de revictimización producidas por el lenguaje institucional y jurídico para tratar de generar una identidad (subjetividades), se convierten en un escenario de análisis e intervención para re-posesionar a la población afectada por la violencia sociopolítica desde su sentí-pensar y re-conocimiento.

Por esta razón, el presenta trabajo se ha planteado como objetivo la revisión del estado actual de las interpretaciones y conceptualizaciones desarrolladas sobre la categoría víctima de la violencia sociopolítica en Colombia en las investigaciones y publicaciones que han generado en el periodo 2005 al 2016, asumiendo que a partir de este ejercicio se pueden generar un proceso comprensivo de la concepción de víctima y los significados que le otorgan a éstas en el contexto colombiano, en perspectiva de la generación de posibilidades para la efectividad de los procesos de desvictimización. Villa, Londoño, Gallego, Arango y Rosso (2016) expresan que "las estrategias de fortalecimiento comunitario, la formación de líderes y lideresas afectivos/ as, el apoyo entre iguales, la acción psicosocial desde la potenciación de las comunidades y sus redes de apoyo" (p. 427), son herramientas pertinentes para lograr procesos de redignificación de las víctimas, así como el perdón 
y la reconciliación para la reconstrucción del tejido social en contextos de violencia y conflicto armado (Villa, 2016b).

\subsection{Método}

En este apartado se presentan los principales encuadres metodológicos del proceso investigativo que fundamenta las pretensiones de establecimiento del estado actual de las interpretaciones y conceptualizaciones desarrolladas sobre la categoría víctima de la violencia sociopolítica en Colombia, recorriendo el enfoque investigativo, el tipo de investigación, las herramientas investigativas, las fuentes de información y las fases del proceso.

Enfoque investigativo: la presente investigación se configura y desarrolla desde un enfoque hermenéutico-comprensivo de la producción académica relacionada con la categoría víctima de la violencia sociopolítica en Colombia, buscando generar una interpretación conceptual que permita acercarse a la subjetivación, en términos de significaciones que se le otorga a esta categoría desde diversas dimensiones de la sociedad.

En este proceso, el enfoque hermenéutico se entiende en los términos de Saavedra (2005) cuando no la limita a ser un simple instrumento o una metodología, sino como una filosofía de la comprensión. "Es decir, es una reflexión filosófica que nos muestra una vía de acceso a la dimensión de los sentidos en el plano de la investigación" (p. 52).

Tipo de investigación: la presente es una investigación cualitativa cuando esta se asume como "abierta al empleo de diferentes métodos que permitan abordar la vida cotidiana; esta conlleva un compromiso social y ético, rigurosidad, creatividad, pensamiento reflexivo y crítico" (Cifuentes, 2012, p. 135). Así como también es una revisión bibliográfica en cuanto este tipo de investigación permite la configuración de conocimiento a través de un rastreo sistemático de fuentes académicas sobre una temática en específico. (Viloria, Daza y Pérez, 2016; Viloria, Pedraza, Cuesta y Pérez, 2016).

En estos términos, en esta investigación se conjugan dos tipologías investigativas, desde los alcances de la complementariedad (Murcia y Jaramillo, 2001), que permite que las estructuras se vayan configurando a medida que se avanza en los trayectos investigativos.

Herramientas investigativas: en este proceso de reflexión se hace uso del análisis del discurso como herramienta metodológica fundamental en los términos de Van Dijk (1996) cuando expone que 
Este análisis supone que es posible poner "al descubierto" la ideología de hablantes y escritores a través de una lectura minuciosa, mediante la comprensión o una análisis sistemático, siempre y cuando los usuarios "expresen" explícita o inadvertidamente sus ideologías por medio del lenguaje u otros modos de comunicación (p. 14)

Este análisis del discurso se desarrolla utilizando unos protocolos de análisis documental y una matriz de análisis de contenido donde se condensan los comentarios de los autores para la categoría definida, permitiendo develar los aportes de cada texto consultado a las necesidades de la investigación.

Fuentes de información: para este proceso se han definido como fuentes de información las bases de datos académicas de alto reconocimiento internacional: como Scopus, Science Direct, Web of Science, y Scielo. Se consultaron artículos científicos y libros resultados de investigación.

Procedimiento: inicialmente se definieron los criterios de búsqueda de la información, donde se aclara que para la revisión de un documento debe estar publicado en el marco del periodo definido de 2005 a 2016 y que adicionalmente, debía incluir en su título o resumen los elementos de la palabra clave.

$\mathrm{Al}$ realizar la búsqueda en las bases de datos se arrojaron los siguientes resultados: en Scopus se encontraron tres documentos, en Science Direct, 19 publicaciones, en la Web of Science tres resultados, y en Scielo 11 artículos publicados. En total fueron 36 artículos y un libro resultado de investigación; sin embargo, luego de revisar en detalle el extenso de algunos artículos, se excluyeron porque no aportaban información relevante relacionada con la temática.

Luego se procedió a la organización y análisis de los documentos de acuerdo con las capacidades de las herramientas definidas para generar como producto el presente texto académico.

\subsection{Resultados}

Para establecer a través de una revisión documental, el estado actual de las interpretaciones, conceptualizaciones desarrolladas sobre la categoría víctima de la violencia sociopolítica en Colombia, entre los años 2005 al 2016, se contó con una muestra documental conformada por 20 artículos y un libro de habla hispana (latinoamericanos), derivados de investigación, los cuales cumplieron con los criterios de selección establecidos. El análisis se hizo a partir de dos categorías: conceptualizaciones desarrolladas sobre la 
categoría víctima de la violencia sociopolítica y subjetividades emergentes a partir de las conceptualizaciones (interpretaciones) generadas desde los marcos jurídicos y sociales.

El procesamiento de las fuentes primarias de información se realizó a través de fichas bibliográficas, protocolos de análisis documental y una matriz de análisis de contenido, la cual permitió generar una radiografía a cada uno de los documentos.

Ahora bien, los resultados de la revisión literaria evidencian que el conflicto armado no sólo ha tenido como consecuencia efectos psicosociales en la población colombiana, sino también ha sido fuente de generación de nuevas ciudadanías e identidades, las cuales se resisten a los rótulos impuestos por el lenguaje institucional, entre la que se destaca la categoría víctima desde la dimensión jurídica, a las lógicas de dominación saber/poder de la institucionalidad y de organismos que tratan de establecer un significante y significado desde su situación.

La realidad expuesta se materializa en los resultados de la investigación realizada por Delgado (2011):

Las personas afectadas por el conflicto armado han estado asociadas a diversos conceptos: con el "ocupante sin lugar" en los procesos de justicia transicional, con la figura de "testigo" — y en este sentido, con una parte más activa en los procesos penales-, como "sobreviviente", e incluso como sujeto de "orgullo y dignidad" (Guerrero, 2007; Booth, 2007; Wieviorka, 2009, citados por Delgado, 2011, pp. 37-38). En relación con esta última acepción, recientemente se habla de las víctimas como "sujetos de justicia", "testigos históricos de excepción", "portadores de memoria" y portadores de una "superioridad moral" en relación con sus victimarios (Villa et al., 2007; Cepeda, 2006, citados por Delgado, 2011, p. 40).

Asimismo, Acevedo-Arango (2017) en el libro "La episteme de la victimidad: Reposicionar al sobreviviente y reparar a la víctima", plantea una nueva clasificación a partir de su reposicionamiento: sufrientes, sobrevivientes y supervivientes.

Las denominaciones que han perseguido a los sobrevivientes (categoría propuesta por el Centro Nacional de Memoria Histórica) evidencian no sólo una evolución y posicionamiento del concepto de víctima, al igual que la imposición de una noción de víctima desde una categoría jurídica que influye en los programas de atención, sino también las resistencias a ser nombrados y delimitados en un escenario que no los representa, tal como 
lo exponen Bárcena y Mélich (2003). Frente a este aspecto, es importante también entender el papel macabro que han jugado los académicos desde la literatura producida en relación con los efectos del conflicto armado y lugar de los afectados, dado que han aportan al escenario semiótico que se ha venido configurando al respecto. En relación con la premisa expuesta, Foucault (2010) indica: “Todo sistema de educación es una forma política de mantener o de modificar la adecuación de los discursos, con los saberes y los poderes que implican" (p. 45). La adecuación de los discursos propuesta por Foucault, a través del orden del discurso, se materializa a través del efecto que tiene el arte de nombrar, de dar un espacio a los significantes y significados.

En coherencia con lo anterior, se evidencia que los discursos y rótulos producidos desde la conjugación de la sintaxis, pragmática y semántica, para comprender la realidad de los sobrevivientes, tienden a producir modos de subjetivación que influyen en formas de re-des-conocimiento. No obstante, las etiquetas se relacionan con conceptualizaciones que evidencian: una necesidad de reconocimiento desde su orilla y no desde los lenguajes institucionales; el reposicionamiento como sujetos políticos, procesos de recuperación, procesos de memoria des-conocidos. De otro lado, Carrizosa (2011) plantea que la concepción dada a los sobrevivientes debe ubicarlos en un escenario mucho más activo. Mientras que Villa (2014), sobre la cotidianidad de las víctimas, enfatiza "en las capacidades, en la fuerza para asumir, en las salidas que se fueron encontrando, en las luchas cotidianas y en los sentidos encontrados aún en medio del horror" (p. 37). Es por eso que la recuperación de la memoria colectiva se convierte en un instrumento para las transformaciones emocionales de las víctimas (Villa, 2013).

Frente a lo abordado, Delgado-Barón (2015, p. 123) hace un discernimiento interesante:

Cabe preguntarse cómo se han apropiado las víctimas de la Ley de víctimas y restitución de tierras, o cómo se han posicionado frente a la misma, y cómo han resignificado la definición de víctima que allí se ofrece y la que contiene la Ley de Justicia y Paz (Ley 795 de 2005). La Ley de víctimas refleja una instrumentalización política por parte del gobierno, y otra por parte de las asociaciones de víctimas, las cuales se posicionan de un modo determinado frente a esa legislación, de donde deriva que la ley es lo que de ella se hace, una cuestión que también se define por el tipo de relaciones que resultan de la producción de las normas jurídicas: "las normas 
jurídicas no poseen vida propia, por tanto no imponen el orden social; la raíz de ellas, la naturaleza de las normas jurídicas y de sus ordenamientos están determinadas por las relaciones sociales [...]. La forma jurídica se corresponde con la construcción y organización específica del orden social" (Rodríguez, 2010, pp. 6, 28). La premisa planteada ha sido el fundamento para la creación de una pluralidad de modelos de intervención que buscan dar respuesta a los modos de subjetivación y etiquetas generadas por la institucionalidad y la academia. Estos modelos adoptan de manera literaria la dimensión psicosocial, pero esta genera una ruptura al operacionalizarse en la realidad (Villa, 2012/2014).

En la misma sintonía a la premisa expuesta, Delgado-Barón (2015, p. 125), manifiesta:

La lucha por el reconocimiento de las víctimas también se expande al terreno del significado de la noción de víctima. Así, el debate se ha construido alrededor de la pregunta acerca de las formas en que las víctimas se nombran a sí mismas, sin olvidar la carga simbólica y política de la categoría. En esta adquisición de nuevos y diferentes sentidos, se produce una apropiación social de la noción, y si bien en la ley la noción de víctima se limita a una categoría jurídica, en los procesos mencionados se evidencia la naturaleza emocional que encierra (Jimeno, 2010): "la importancia de la categoría de víctima radica en la posibilidad de expresar los hechos de violencia desde quienes los han sufrido, articulando en esta narrativa las emociones con la acción política" (Jimeno, 2010, citada por Carrizosa, 2011, p. 54).

Adicionalmente, Delgado-Barón (2015, p. 126), indica:

La lucha por el reconocimiento y resignificación de la noción de víctima se enmarca en la discusión propuesta acerca de dicha noción como una "condición" casi inmutable, que está dada de una vez y para siempre, a fin de situarla en el terreno de una "situación" transitoria: "puede pensarse en ser víctima no como una condición, sino como una situación, un estado transitorio que no se olvida pero que debe ser punto de partida para otras construcciones de los sujetos" (Carrizosa, 2011, p. 54). Al respecto, Blair (2008) afirma que "las víctimas no sólo son víctimas de acciones, actores y hechos en situaciones y momentos específicos, sino que también y pese a su sufrimiento, su vida no se desarrolla sólo en esa dirección"; esto implica pasar de la noción de víctima como una condición a la noción de víctima ligada a una situación. De esta forma es posible concebir a las víctimas como sujetos activos capaces de generar acciones transformativas, que se 
"apropian de una vivencia de violencia y la transforman en un motor para la acción y para la movilización" (Delgado, 2011, p. 46).

Al llegar a este punto, es importante que el lector se pregunte ¿Cuál es la relevancia de abrir un escenario de discusión sobre las etiquetas y la capacidad de autodenominarse o autoreconocerse? La respuesta radica en la relevancia que tiene el acto de nombrar dado que marca la línea desde donde se desprenden las formas de comprender y con ello, modos de ser y estar, es decir, al nombrar se activan procesos sociales, materialización de conductas (acción) e indudablemente nace la perspectiva de subjetivación política.

Por lo anterior, lo jurídico y judicial plantean escenarios que nombran de manera forzada y establecen una estructura para su comprensión. Por ello, el orden social generado por la ley 1448 de 2011, ha tenido tanto aciertos como desaciertos (los cuales no se abordarán dado que excede lo que se pretende con el escrito), no obstante, es importante mencionar que el marco jurídico ha permitido la in-visibilización al igual que la instrumentalización de las acciones establecidas para su atención, las cuales se caracterizan por no haber sido concertadas con la población, es decir, una política pública que no es tan pública.

Uno de los grandes problemas identificados en los documentos, es el carácter temporal establecido en el escenario del conflicto armado a la población afectada por el conflicto armado, es decir, la perspectiva de condición y no de situación. Lo anterior es abordado por Delgado-Barón (2015, pp. 126-127):

Quedarse en el terreno de la víctima como condición, es caer en la revictimización y reducir u obstruir su espectro de acción; por otra parte, reconocer en las víctimas una capacidad de agencia es identificar que su situación no define exclusivamente su esencia y que, por el contrario, las víctimas pueden transformar la situación, "pasar de la condición de víctima a la situación de víctima impide en cierta forma y grado que se generen dinámicas de revictimización que generalmente se encuentran permeadas por el carácter temporal de la permanencia, que a su vez están cargadas de sospechas de culpabilidad" (Blair, 2008, citada por Delgado, 2011, p. 46).

Si bien se reconoce el carácter transitorio asociado a la noción de víctima, en un primer momento esta situación se encuentra directamente vinculada con la pérdida y el daño provocado. Wieviorka (citado por Blair, 2008) confirma que el ser víctima se define a partir de la pérdida, lo cual no se 
reduce a la "pérdida de vidas humanas sacrificadas en la guerra", sino a otra que abarca términos más amplios y que se expresa en "otras esferas de la vida social, produciendo una sumatoria de pérdidas, que exige para las víctimas, verdades, justicias y reparaciones más integrales" (Blair, 2008, p. 243a). Wieviorka enfatiza, asimismo, en el tipo de emociones generadas por las pérdidas que sufren las víctimas; esas no se definen en exclusiva por las emociones negativas del sufrimiento, sino que, por el contrario, "parecen corresponder no sólo a la mitad del sujeto, sino a la parte de sombra de su identidad" (Wieviorka, citado por Blair, 2008, p. 12). En otras palabras, "se reconoce que la pérdida es un factor constitutivo de la víctima, pero que define sólo una parte de su identidad, y que al ser reapropiada y dotada de nuevos significados por la víctima, se concibe como un elemento generador de acción" (Delgado, 2011, p. 47).

Los planteamientos expuestos abren un nuevo camino y conlleva a dar un lugar más protagónico a los sobrevivientes, un escenario donde se dote al individuo con herramientas para que pueda decir, qué lugar darle y cómo configurarse en dicho momento como sujeto político. Al respecto, DelgadoBarón (2015), propone:

La víctima, entonces, se constituye como sujeto a partir de lo que decide hacer con la experiencia negativa, con el sufrimiento padecido, y con la forma en que enfrenta - y ¿por qué no? - la forma como se supera la situación de violencia a la que ha sido sometida: "esta constitución de las víctimas como sujetos debe partir de una noción o significado de la figura de la víctima más inclusiva en cuanto a que ésta no es meramente una figura asociada a la decadencia, sino que por el contrario, acorde con Wieviorka, la víctima emerge como sujeto cuando la sociedad reconoce el sufrimiento que ha padecido y el impacto que éste ha generado en su vida" (Wieviorka, 2009, citado por Delgado, 2011, p. 47). En este sentido, parte del proceso de subjetivación política de las víctimas se origina en la necesidad de dotar a la noción de víctima de nuevos significados (p. 127).

Otra de las características que impregnan las conceptualizaciones e interpretaciones desarrolladas sobre la categoría víctima de la violencia sociopolítica es la concepción sobre el sujeto afectado. Los planteamientos han girado sólo en el componente de la pérdida-sufrimiento/daño y desconoce otros elementos del ser. En este sentido, "la víctima así definida, es mostrada, pensada y aprehendida como ser sufriente y vulnerado, mientras que la violencia se hace casi innombrable e inaprensible en sus causas" (Daza, 2006, p. 116). El planteamiento propone el siguiente reto: ¿cómo 
valorar la pérdida/daño? ¿cómo se ubica al sujeto desde una perspectiva colectiva, tal como lo plantea el marco normativo? la concepción de pérdida es subjetiva y su carga se determina por componentes como: historicidad, vínculos (afectivos, cognitivos), significancia. Lo anterior, imprime particularidades a la forma de elaborar el trauma, el daño, es decir, la pluralidad de las subjetividades, las cuales en la actualidad son abordadas a manera de molde en las estrategias de atención.

En relación con lo descrito, se evidencian acciones civiles que facilitan el camino para lograr la emancipación de las cosmovisiones impuestas y dinámicas institucionales de manera estratégica, es decir, en el marco de movilización brindado por lo jurídico intentan deslindar los límites establecidos a partir de acciones que los representa desde su sentí-pensar. A continuación, se describe la base del planteamiento descrito:

Organizaciones de víctimas como la Ruta Pacífica de las Mujeres y la Iniciativa Mujeres Colombianas por la Paz-imp, señalan la importancia de los desarrollos jurídicos en relación con la búsqueda de la verdad, la justicia y reparación de las mujeres víctimas del conflicto, para la construcción de una ciudadanía alternativa en donde la mujer se ha constituido en actor social clave con capacidad de negociación a través de "la politización del dolor y del sufrimiento [...] y de la apropiación del espacio público para la deliberación" (Ibarra, 2011, p. 270), como lo vienen haciendo las Madres de la Candelaria en la ciudad de Medellín, Antioquia (Delgado-Barón, 2015, p. 133).

Finalmente, los resultados evidencian que los procesos de significación y re-significación, las dinámicas de subjetivación y de-subjetivación política generadas en procesos de intervención a nivel psicosocial, sociojurídico y político, constituyen un pilar fundamental que emerge desde la reconstrucción de la memoria histórica (Villa, 2014), la alteridad y el reconocimiento del otro, mucho más allá del dolor. Lo planteado instituye un escenario de resistencia simbólica y una revaloración como sujetos políticos. A través de este reconocimiento se aporta a la construcción de una sociedad más justa en Colombia y se re-enfoca los procesos y concepciones de la reparación tanto individual como colectiva, tal como se evidencia en el estudio realizado por Villa y Insuasty (2015).

Asimismo, se evidencia que la institucionalidad es un escenario de producción semiótica que regula y normaliza narrativas, formas de expresión en el campo de la victimología de la población afectada por el conflicto armado. 


\subsection{Discusión y conclusiones}

Los efectos materiales e inmateriales del conflicto armado en Colombia han permitido la construcción de escenarios (marcos de referencia comunitarios, académicos, jurídicos, entre otros) que evidencian su impacto en las dinámicas de desarrollo comunitario, proyectos de vida colectivos e individuales e indudablemente en la cotidianidad de la población. Asimismo, su propia dinámica ha facilitado la puesta en escena de dispositivos de poder tanto en el campo legal como ilegal que in-visibilizan al igual que promueven modos de subjetivación, formas de reconocerse y auto-reconocerse impuestos, laboratorios sociopolíticos que tienen como resultado la emersión de nuevas ciudadanías a partir del afán de nombrar (dar identidad) a los afectados desde perspectivas geopolíticas que desconocen el enfoque territorial, regional y, por ende, pluri-étnico-multicultural.

Ahora bien, las diversas etiquetas dadas a la población afectada por el conflicto armado deben comprenderse y leerse en clave de los mecanismos de sujeción jurídica y las máquinas institucionales semióticas que determinan su denominación. Y en este punto es importante preguntarse y preguntarles a los académicos, si han consultado a la población afectada por el conflicto armado ¿cómo les gustaría ser nombrados?

En relación con lo expuesto, Acevedo (2012) también indica que los momentos históricos del país han permitido la visibilización de las víctimas del conflicto armado y hace pocos años la relevancia de su perspectiva, sus procesos de subjetivación, la puesta en escena de diversos tipos de memorias, actos de nombrar a través de la narración.

Los marcos de referencia construidos para la compresión de los efectos del conflicto armado han tenido como resultado el establecimiento de modelos de intervención que intentan comprender, intervenir y apoyar mediante procesos, la elaboración del trauma, las secuelas y un intento por reconfigurar las dinámicas de la cotidianidad, proyectos de vida colectivos e individuales. En este campo, los resultados permiten concluir que la intervención psicosocial dirigida a las víctimas debe centrarse desde una perspectiva relacional, dialéctica y subjetiva, permitiendo establecer acciones de atención personalizadas y ajustadas a sus necesidades y no como respuesta a una categoría jurídica. Por lo anterior, la reconfiguración de la experiencia (condición vs. situación) y su autorreconocimiento, se convierten en pilares fundamentales para lograr el empoderamiento y con ello, la des-victimización. 
En este punto, es importante mencionar que los principales hallazgos del presente estudio, permiten evidenciar los obstáculos que se generaron con la implementación de los marcos jurídicos y con ello, la visibilización de la realidad de los afectados por el conflicto armado al igual que los modos de atención y comprensión: el conflicto armado y sus efectos en la perspectiva de condición y no situación, la dimensión de salud mental de enfermedad y no desde un enfoque positivo, la victimidad de los sobrevivientes (antes de ser víctimas del conflicto armado, ya eran víctimas de una institucionalidad que no garantiza sus derechos, y se revictimizan por la misma institucionalidad, la cual, al intentar solucionar su ausencia por omisión o intención, generan mecanismos de reconocimiento y dispositivos de poder, materializados en políticas que agudizan su situación), el desconocimiento de la percepción de los principales actores (los afectados), los modos de subjetivación política e identidades impuestas, el establecimiento de mecanismos de verdad jurídica que en muchas ocasiones no coincide con la verdad social (los juegos de la verdad), el teatro administrativo establecido para que una persona del conflicto armado, sea reconocida en el estatuto jurídico como víctima (aquí es importante mencionar que existe víctimas reconocidas por el Estado y víctimas que se reconocen como víctimas pero que no gozan del estatus generado por la institucionalidad dado que no cumplen con los criterios establecidos a priori), entre otras tantas dificultades que darían una base para un libro. No obstante, es importante resaltar que la literatura presenta avances significativos que deben comprenderse a través del momento histórico que atraviesa el país por las dinámicas de los procesos de Paz. Muchos de los obstáculos mencionados han ido tomando otros matices; sin embargo, se evidencia una lentitud significativa en el muro de la institucionalidad.

Con el ánimo de "aclarar" lo que la Ley no deja claro, el Estado promueve la creación de un entramado técnico que permita identificar a quienes hacen parte del conjunto recién creado. Surgen así unos criterios operativos que, legitimados por las aparentes necesidades de un orden práctico idealizado (pero en la realidad colmado de averías, fracasos, ineficiencias y hasta corrupción), se proponen como guías para articular y dar forma concreta al marco de comprensión e identificación de las víctimas. Y es precisamente en función de esta racionalidad técnica que toman forma las vidas reales de aquellos que serán reconocidos o desconocidos como víctimas en Colombia (Tamayo-Nieto, 2016, p. 928)

En relación con lo expuesto, Tamayo-Nieto (2016) manifiesta una realidad que coincide con el sentir de la población afectada por el conflicto 
armado al igual que los resultados de los estudios que configuran el planteamiento abordado anteriormente:

Para el aparato estatal, la víctima pasó a convertirse en un sujeto jurídico $\mathrm{y}$ en un objeto de gestión y, por este doble movimiento, en un problema de verdad de carácter no solo normativo sino también administrativo (p. 924). Dicho planteamiento cobra relevancia en la medida que no se evidencia en la literatura informes o marcos de referencia que materialicen el impacto de las acciones establecidas (medidas) en los marcos jurídicos para la población, es decir, se desconocen los efectos en los sobrevivientes, aunque se observa que los factores de riesgo que dieron origen al conflicto armado persisten y las condiciones psicosociales de la población no han mejorado.

Adicionalmente, Tamayo-Nieto (2016), propone:

El discurso estatal es un decir que fracasa en sus pretensiones denotativas, aunque sea relativamente eficaz en el ámbito administrativo. La insistencia del Gobierno nacional en traducir a números la gestión y el proceso de reconocimiento de las víctimas expresa bien esta tensión entre la pretensión de exactitud y precisión burocrática, con la oclusión de los componentes existenciales del daño que se pretende reparar (p. 927).

Asimismo, Tamayo-Nieto (2016) expone una perspectiva de territorio y delimitación del universo de los sobrevivientes:

Es una categoría desterritorializada, no solo porque aquella máquina que la produce (el conflicto armado interno) persiste, sino porque presenta cualidades que abren el conjunto hacia nuevas conexiones (víctimas por vínculo civil, hijos resultado de violación y, de manera aún más abstracta, la noción de víctimas colectivas). El universo de las víctimas es desterritorializado porque está, por definición y a causa de sus condiciones de producción en el conflicto armado, abierto a la inclusión continua de nuevos elementos (p. 926).

De igual manera, Tamayo-Nieto (2016), realiza una crítica significativa sobre la construcción de conceptualizaciones que etiqueten a la población víctima del conflicto armado y como esto, influye en sus modos de ser, estar, reconocer y reconocerse, elaborar y reelaborarse:

La noción de víctima no es solo el producto de un discurso jurídico, sino también de un aparato administrativo y judicial que determina los procesos, los actos performativos y las condiciones de materialización de lo que se 
reconocerá como víctimas. "Víctima" es, entonces, un significante necesario para asegurar un lugar de articulación narrativa y enunciación política y, a su vez, un modo de otorgarle un estatuto jurídico a cierta población; pero es en los desplazamientos de ese significante entre las expresiones del trauma, las demandas políticas, las luchas ideológicas y los procesos administrativos y judiciales donde la noción de víctima se territorializa y desterritorializa incesantemente, lo cual obliga a realizar análisis situados y que eviten las generalizaciones acerca de la naturaleza y los modos de subjetivación de quienes acuden a tal categoría como lugar de enunciación (pp. 928-929).

No se puede perder de vista, la función que cumplen los sobrevivientes en el escenario del conflicto armado. Dicha función cobra relevancia desde el punto de vista del actor. Por ejemplo, para Tamayo-Nieto (2016):

El significante "víctima" no siempre es un lugar de singularización o empoderamiento, como algunos académicos pretenden mostrarlo, sino que, incluso, puede convertirse en un rótulo con el que el perpetrador asegura su dominio y extiende su poder (p. 932).

Para las mismas víctimas, es la posibilidad de levantar su voz, frente a dinámicas tanto estatales como ilegales que intentan silenciarlos y reposicionarse como sujetos políticos. Este reposicionamiento se realiza a través del acto de nombrar, de las narraciones que los visibiliza y con ello los posiciona como sujetos públicos.

Finalmente, el actual momento del país conlleva a reubicar el lugar que la institucionalidad ha intentado confinar a los sobrevivientes y reposicionarlos desde el discurso y la acción. Asimismo, es importante tener en cuenta:

- La subjetividad política de las víctimas, entonces, no ha tomado forma solo en la violencia, sino también en los procesos de articulación jurídica, gubernamental, humanitaria, académica y psicosocial, que se entrecruzan en la guerra, por lo que un verdadero trabajo de emancipación y empoderamiento político de ellas pasa por una crítica de los modos en que las hemos enmarcado como objeto de reflexión teórica y como sujeto jurídico-político. Es decir, pasa por una crítica de nuestros propios juegos de verdad. Tal vez por esto una práctica acostumbrada a la impugnación de sus propios límites y a la desnaturalización constante de sus sintaxis, como lo es la práctica artística, nos puede proporcionar algunos elementos para avanzar en el trabajo de deconstrucción de nuestros modos de inteligibilidad de la guerra y la violencia (TamayoNieto, 2016, p. 936). 
- La atención efectiva a las víctimas del conflicto armado es una responsabilidad no solo del Estado, sino de toda la sociedad colombiana en la perspectiva de la generación de tejidos sociales pacíficos.

- Los efectos psicosociales producidos por la guerra son incalculables a nivel material e inmaterial. No obstante, las limitaciones y procesos de re-victimización producidas por el lenguaje institucional y jurídico para tratar de generar una identidad (subjetividades), se convierten en un escenario de análisis e intervención para re-posesionar a la población afectada por la violencia sociopolítica desde su sentí-pensar y re-conocimiento.

- Empezar a navegar desde la orilla de los sobrevivientes e iniciar a construir desde su realidad permitirá establecer consensos y con ello, discursos que los represente y modelos de atención que respondan a la forma en que transitan por el dolor, sin politizar el dolor.

- La reconceptualización y resignificación de la noción de víctima, es pertinente señalar, como lo plantea Rancière, que el proceso de subjetivación política es un "proceso de desidentificación o de desclasificación", cuya lógica obedece a una heterología; es la lógica del otro la que opera según dinámicas de alteridad, en donde la subjetivación "nunca es la afirmación simple de una identidad, sino que siempre es a la vez una negación de una identidad impuesta por otro" (Rancière, 2006, citado por DelgadoBarón, 2015, p. 134).

- El medio ambiente, el componente eco, también ha sido víctima y aún sigue siendo desconocida. Generar un plan de intervención desde las siguientes perspectivas: ecosofía, ecología mental, geopolítica de las emociones, el sujeto no sólo visto desde el daño sino desde su historicidad, biopsicosocial.

\section{Referencias}

Acevedo-Arango, O. (2017). Episteme de la víctimidad: Reposicionar al sobreviviente y reparar a la víctima. Bogotá: Ediciones USTA

Acevedo, L. (agosto de 2012). Reflexiones en torno a la categoría de víctima: una mirada a las organizaciones de víctimas de crímenes de Estado en Medellín. Ponencia presentada en Terceras Jornadas Debates Actuales de la Teoría Política Contemporánea. Buenos Aires Disponible en http://www.academia.edu/1992644/Reflexiones_en_torno_a_la_categoria de_victima_Una_mirada_a_las_organizaciones_de_victimas_de_crimenes_de_Estado_en_Medellin 
Bárcena, F. y Mélich, J. (2003). La mirada excéntrica. Una educación desde la mirada de la víctima. En: La ética ante las víctimas (pp. 195-218). Barcelona: Anthropos.

Barros, M. A., \& Rojas, N. (2015). El rol de la mujer en el conflicto armado colombiano. (Tesis de posgrado). Maestría en Gobierno y Políticas Públicas, Universidad Externado de Colombia.

Carrizosa, C. (2010). El trabajo de la memoria como vehículo de empoderamiento político: la experiencia del Salón del Nunca Más. Boletín de Antropología, 25(42), 36-56.

Cifuentes, R. M. (2012). Investigación cualitativa: miradas desde el trabajo social. Revista Tendencias \& Retos, 17(2), 135-137.

Congreso de la República de Colombia. (10 de junio de 2011). Ley 1448 de 2011, por la cual se dictan medidas de atención, asistencia y reparación integral a las víctimas del conflicto armado interno y se dictan otras disposiciones. Diario Oficial 48.096

Daza, G. (2006). Las víctimas en la socialización. Nómadas, 25, 110-117.

Delgado-Barón, M. (2015). Las víctimas del conflicto armado colombiano en la Ley de Víctimas y Restitución de Tierras: apropiación y resignificación de una categoría jurídica. Perfiles Latinoamericanos, 23(46), 121-145.

Delgado, M. (2011). Las víctimas como sujetos políticos en el proceso de Justicia y Paz en Co-lombia: discursos imperantes y disruptivos en torno a la reconciliación, la verdad, la justicia y la reparación. (Tesis doctoral). Flacso - México.

Foucault, M. (2010). El orden del discurso (5 . ed.). Barcelona: TusQuets.

Jaime, H. (2003). El conflicto armado en Colombia. Revista de Derecho, 19(1), 119-125. Disponible en: https://search.proquest.com/docview/1435621183?pq-origsite=gscholar

Johnson, D. (2011). Impacto social de la Guerra de los Mil Días: Criminalidad. Revista UIS Humanidades, 24(2), 13-23. Disponible en: http://revistas.uis.edu.co/index.php/revista humanidades/article/view/2233

Murcia Peña, N., \& Jaramillo Echeverri, L. G. (2001). La complementariedad como posibilidad en la estructuración de diseños de investigación cualitativa. Cinta de Moebio, 12, 31-43. Disponible en: http://www.redalyc.org/html/101/10101204/

Nieto, P. (2010). Relatos autobiográficos de víctimas del conflicto armado: una propuesta teórico-metodológica. Revista de Estudios Sociales, 36, 76-85. Disponible en: http:// www.redalyc.org/html/815/81514696007/

Saavedra, T. R. (2005). La hermenéutica reflexiva en la investigación educacional. Revista Enfoques Educacionales, 7(1), 51-66. Disponible en: http://www2.facso.uchile.cl/ publicaciones/enfoques/09/Rios_N7_2005.pdf

Tabares Ochoa, C. M. (2011). Reflexiones en torno al devenir sujeto político de las víctimas del conflicto armado. Estudios Políticos, 38, 13-37.

Tamayo-Nieto, R. (2016). Ser re(des)conocido como víctima: las víctimas del conflicto armado colombiano en la obra Copistas. Palabra Clave, 19(3), 919-937. 
Valencia, O., \& Daza, M. (2010). Vinculación a grupos armados: un resultado del conflicto armado en Colombia. Diversitas: Perspectivas en Psicología, 6(2), 429-439. Recuperado de http://www.redalyc.org/html/679/67915140015/

Van Dijk, T. (1996). Análisis del discurso ideológico. Versión, 6(10), 15-42.

Villa, J. D. (2012). La acción y el enfoque psicosocial de la intervención en contextos sociales: Podemos pasar de la moda a la precisión teórica, epistemológica y metodológica. El Ágora USB, 12(2), 349-365.

Villa, J. D., \& Insuasty Rodriguez, A. (2015). Significados en torno a la reparación, la ayuda humanitaria, la indemnización y la restitución en víctimas del conflicto armado en el municipio de San Carlos. El Ágora USB, 15(2), 419-445.

Villa, J. D. (2013). The role of Collective Memory in Emotional Recovery of Political Violence in Colombia. International Journal of Psychological Research, 6(2), 37-49

Villa, J. D. (2014). Memoria, historias de vida y papel de la escucha en la transformación subjetiva de víctimas / sobrevivientes del conflicto armado colombiano. El Ágora USB, 14(1), $37-60$.

Villa, J. D. (2016a). Intervenciones psicosociales en el marco de acciones de reparación a víctimas del conflicto armado colombiano. Estudios Centroamericanos, 71(744), 81-104

Villa, J. D. (2016b). Perdón y reconciliación: una perspectiva psicosocial desde la noviolencia. Polis, Revista Latinoamericana, 15(43), 131-157

Villa, J. D. \& Insuasty, A. (2016). Entre la participación y la resistencia: reconstrucción del tejido social desde abajo, más allá de la lógica de reparación estatal. El Ágora USB, 16(2), 453-478.

Villa, J. D., Barrera, D., Arroyave, L., \& Montoya, Y. (2017). Acción con daño: del asistencialismo a la construcción social de la víctima. Mirada a procesos de reparación e intervención psicosocial en Colombia. Universitas Psychologica, 16(3), 1-13. doi. org/10.11144/Javeriana.upsy16-3.adac

Villa, J. D., Londoño, N., Gallego, M., Arango, L., \& Rosso, M. (2016). Apoyo mutuo, liderazgo afectivo y experiencia clínica comunitaria. Acompañamiento psicosocial para la "rehabilitación" de víctimas del conflicto armado. El Ágora USB, 16(2), 427-452.

Viloria, E. J, Pedraza, A. L, Cuesta, T. K, \& Pérez, C. K. (2016). Liderazgo informal en las organizaciones: reflexiones sobre su impacto e influencia en la competitividad. Clio América, 10(19), 31-42. Disponible en: http://revistas.unimagdalena.edu.co/index.php/ clioamerica/article/view/1658

Viloria, J., Daza, A. \& Pérez, K. (2016). Dinámicas e influencias de los grupos informales en las organizaciones. Ánfora, 23(40), 169-194. Disponible en: http://publicaciones. autonoma. edu.co/index.php/anfora/article/view/9/7

Yaffe, L. (2011). Conflicto armado en Colombia: análisis de las causas económicas, sociales e institucionales de la oposición violenta. Revista CS, O(8), 187-208. doi:http://dx.doi. org/10.18046/recs.i8.1133 


\section{ESTUDIOS EMPÍRICOS SOBRE INFANCIA}





\title{
9. Construcción social de subjetividades políticas de niños y niñas desde sus primeros años: narrativas colectivas de agenciamiento para la paz, en contextos de conflicto armado
}

\author{
María Camila Ospina-Alvarado ${ }^{25}$ \\ Sara Victoria Alvarado Salgado ${ }^{26}$ \\ María Alejandra Fajardo Mayo27
}

\section{Resumen}

Los niños y las niñas de la primera infancia construyen sus subjetividades políticas mediante los procesos de socialización en los que participan que favorecen su agenciamiento en entornos como la familia, la escuela y el barrio. El lenguaje, y las narrativas colectivas, en el caso de la investigación a la base del capítulo, se constituyen en procesos fundamentales para la configuración de sentidos, significados y prácticas que marcan la socialización en las familias que vivieron el conflicto armado, y en este sentido la configuración de subjetividades e identidades en los primeros años. Esta investigación retoma las narrativas no solo como una técnica de investigación, sino como una posibilidad de construcción de relatos y de instauración de nuevas formas de existencia, desde las memorias colectivas del conflicto armado y desde las trayectorias familiares en dicho contexto, para dar cuenta de historias alternativas en las que las potencias, los aprendizajes, las posibilidades de agenciamiento y la realización de sueños a partir de acciones cotidianas, que se constituyen en aportes para la construcción de paz, también tienen lugar.

Palabras clave: subjetividades políticas, primera infancia, narrativas colectivas, agenciamiento, construcción de paz, conflicto armado.

25 CINDE-Universidad de Manizales. Correo: mospina@cinde.org.co

26 CINDE-Universidad de Manizales. Correo: s.v.alvarado.s@gmail.com

27 CINDE-Universidad de Manizales. Correo: mafajardom@gmail.com 


\section{Abstract}

Children in early childhood build their political subjectivities through socialization processes that contribute to their agency, which take place within family, school and community. Language, and in this research collective narratives, are fundamental in the configuration of meanings and practices which influence socialization in families affected by the Colombian armed conflict, contributing to the constitution of children's subjectivities and identities. This research uses narratives not only as a research tool, but as a possibility to create stories as well as new ways of existence based on collective memories of the armed conflict, and on the family lives in that context; counter narratives in which potentials, learnings, agency, and dreams consecution through daily peace-building practices, also take place.

Keywords: political subjectivities, early childhood, collective narratives, agency, peace-building, armed conflict.

\subsection{Introducción}

El presente documento se enmarca en los resultados de una investigación titulada "Narrativas colectivas de paz y conflicto armado desde las voces de niños y niñas de la primera infancia, familias y agentes relacionales en el marco del posconflicto/posacuerdo" 28 desarrollada por el Centro de Estudios Avanzados en Niñez y Juventud (Universidad de Manizales - CINDE), en cinco ciudades de Colombia (Bogotá, Manizales, Medellín, Santa Marta y Villa Rica). Su foco principal fue la reconstrucción colaborativa de aquellas vivencias que se dieron en entornos de violencia armada, desde una perspectiva generativa; es decir, una perspectiva que permitiera develar historias alternativas que trasciendan la afectación y que resalten las potencias y posibilidades que desde sí mismos, desde sus interacciones y desde la vida cotidiana, los niños y las niñas de la primera infancia, junto con sus agentes relacionales, pueden identificar como aportes para la construcción de paces plurales.

Teóricamente, para el proyecto fue necesario el abordaje de seis ejes: una aproximación histórica al contexto del conflicto armado con el fin de comprender las causas de sus orígenes y de su sostenimiento a lo largo de

28 Investigación reconocida como mejor práctica de atención, cuidado y promoción del desarrollo integral a la primera infancia, por el Instituto Colombiano de Bienestar Familiar -ICBF- y la Corporación Juego y Niñez (24 de julio de 2018), en la categoría Investigaciones en Primera Infancia. 
más de 50 años; un abordaje de la primera infancia desde la perspectiva del desarrollo humano alternativo, entendiendo esta etapa del ciclo vital desde su relación con el contexto, con aproximaciones no lineales al desarrollo y en esta medida con los avances en formulación de política pública desde una perspectiva multidimensional y de derechos; el construccionismo social como una metateoría que brinda orientaciones para pensar la construcción social de la primera infancia y la construcción relacional y dialógica de la paz; la socialización política, como un proceso que favorece la comprensión de los niños y las niñas en sus primeros años de vida, como sujetos políticos, desde su participación en diversos entornos de interacción a partir de sus capacidades de acción y de agencia para transformar relaciones y situaciones; las narrativas colectivas y las memorias como instancias desde las cuales es posible revalorar los hechos del pasado, para descubrir nuevas connotaciones presentes que favorecen la reconstrucción comunal de sentidos y significados futuros; y la educación popular como espacio en el que confluyen lo ético y lo político, y en el que se reconoce al otro como legítimo más allá de su individualidad para configurar una comunidad desde la pluralidad y las diferencias.

Para los efectos de este capítulo, se expondrán los resultados alrededor de la categoría de construcción de paz, leída principalmente desde tres de los ejes teóricos mencionados, a saber: el construccionismo social, la socialización política, y las narrativas colectivas y las memorias.

\subsection{Metodología}

La metodología de la investigación fue de orientación cualitativa. En particular con un sustento hermenéutico y crítico, desde una apuesta epistemológica y metodológica hermenéutica ontológica política o hermenéutica performativa; el carácter ontológico responde a las posibilidades del ser dentro de la existencia, el carácter político a las posibilidades de acción comunal para la transformación de realidades y el carácter performativo a la relación entre sentidos y prácticas, entre lenguaje y acción social, o entre narrativas colectivas y prácticas de socialización política. La prioridad de la investigación fue conocer experiencias e historias de vida que permitieran generar reflexiones e interpretaciones en torno a las vivencias que ocurren en el marco de un fenómeno social como es el conflicto armado, y en esta medida poder acceder a comprensiones sobre lo que estas narrativas pueden aportar específicamente a los conocimientos que se vienen desarrollando alrededor de la construcción de paz. El objetivo principal de las interpretaciones propiciadas fue el de la transformación de realidades 
desde prácticas y acciones cotidianas, lo cual fue posibilitado a través de las narrativas colectivas.

El tipo de estudio fue el narrativo, desde el cual se propició el surgimiento de historias desde las voces de niños y niñas de la primera infancia junto con sus familias y agentes educativos que dieran cuenta de los sentidos y significados de sus experiencias de vida en el marco de contextos de conflicto armado. Para este fin, se diseñaron como instrumentos de recolección de narrativas colectivas 7 talleres creativos, para los cuales fue necesario disponer de espacios tanto dialógicos como lúdicos en los cuales se privilegiara el uso del lenguaje desde diversas manifestaciones (desde la palabra, el cuerpo, el arte) para la construcción y reconstrucción de historias y realidades de manera generativa y colectiva.

El trabajo de campo se desarrolló con 73 familias provenientes de contextos de conflicto armado, 60 niños y niñas de la primera infancia y 55 agentes educativas vinculadas en Manizales con el CDI San Sebastián y la organización Siervos Sin Tierra; en Bogotá con el CDI El Jardín de Sofí, ubicado en Ciudad Bolívar; en Villa Rica (Cauca) con el CDI el Guadual; en Santa Marta con el CDI Aeiotú; y en Medellín con la Corporación Creando Futuro.

\subsection{Resultados}

A continuación se presentan algunos de los resultados de la investigación alrededor de las prácticas cotidianas de construcción de paz en las que participan los niños y las niñas desde sus primeros años, dando cuenta del potencial de construcción social presente en las narrativas colectivas, del lugar del juego con otros en su constitución como sujetos políticos y de su agenciamiento como aporte a la construcción de paz.

\subsubsection{Construcción social de realidades desde las narrativas colectivas}

Posicionarse desde una perspectiva en la que el conocimiento y la realidad se construyen socialmente (Berger y Luckmann, 1968; Gergen, 2007) implica emprender un camino que conduzca hacia el reconocimiento de las relaciones como constitutivas de significados (Gergen, 2009, 2012) y por ende de subjetividades e identidades, y a la socialización como un proceso que permite la configuración de los sujetos, dentro realidades cambiantes, a las que se les pueden atribuir características particulares que dependen del tiempo, del lugar y de la persona que las interpreta, siendo así verdades socialmente relativas (Berger y Luckmann, 1968). De esta forma, se podría 
afirmar que es solo gracias al ser relacional y social que se logran compartir e instaurar verdades y realidades, que corresponden tanto a percepciones heredadas tradicionalmente (y que por su permanencia y aceptación a lo largo del tiempo se han convertido en discursos dominantes) como a posibilidades de deconstrucción de significados, a partir de la búsqueda cotidiana de nuevos caminos y otras voces que aporten a la configuración de sentidos que favorezcan el cuidado de las relaciones.

Lo más importante de esta posibilidad de reconstrucción y reinterpretación de significados es que se lleva a cabo de forma espontánea en los contextos de interacción de los sujetos, es decir, en los espacios que provee la vida cotidiana, manifestándose a través de pensamientos y acciones y sustentando de esta forma lo que se considera real (Berger y Luckmann, 1963). Como lo ha planteado Gergen (2012) la construcción de nuevos significados se da en la vida relacional y colectiva; es a través de las relaciones que es posible instaurar nuevas aproximaciones frente a la vida con correlato en la acción social. No estarían pues separados los sentidos de las prácticas y, en la práctica misma, es posible el cuidado creativo de las relaciones; es en el cuidado creativo de las relaciones del que participan los niños, las niñas y sus familias en el que encontramos su principal aporte a la construcción de paz.

Para Berger y Luckmann (1963) el lenguaje es el medio principal para acceder a la realidad, la cual desde un inicio se presenta necesariamente como objetivada para encontrar sentidos y significados que confieran una participación en la vida cotidiana; luego, se establece una relación recíproca con el mundo, desde la cual los sujetos pueden modificar realidades como manifestación de la pragmática, entendida como la intención de actuar con respecto a la realidad que se está percibiendo con el fin de modificarla.

El lenguaje se origina en la vida cotidiana a la que toma como referencia primordial; se refiere por sobre todo a la realidad que experimento en la conciencia en vigilia, dominada por el motivo pragmático (vale decir, el grupo de significados que corresponden directamente a acciones presentes o futuras) y que comparto con otros de manera establecida (Berger y Luckmann, 1963, p. 55).

En el proyecto se retoman postulados del construccionismo social (Gergen, 2007) entendido como una metateoría que da un lugar privilegiado a la posibilidad generativa, es decir, a la capacidad que tienen los sujetos para cuestionar y retar creencias y supuestos que han predominado en la cultura y en las diversas formas de vida social, trazando nuevos caminos para llegar a otras alternativas desde las cuales se puedan iniciar otras formas de acción e 
interacción. Más allá de un medio para acceder a la realidad, Gergen (2007; 2009) identifica el lenguaje y las prácticas relacionales que lo instauran, mantienen y resignifican, como procesos de construcción de las realidades relacionales; el lenguaje ya no solo representa la realidad, sino que instaura, crea, genera múltiples realidades posibles -en su carácter generativo-y liga los sentidos a las prácticas -en su carácter performativo-.

Una característica del lenguaje, que vale la pena resaltar desde la propuesta de estos autores, es la capacidad que tiene para trascender el aquí y el ahora. Algunas narrativas colectivas, resultantes del proceso investigativo, dan cuenta de las posibilidades de resignificar hechos pasados para apreciar desde otras perspectivas el presente, $y$ en esta medida tener nuevos referentes para construir futuros alternativos:

Ma.M.Mz.10.1729: Uno tiene que pensar en uno mismo, o sea, los deseos que uno tiene tratar de dejar lo malo, que son cosas que no nos dejan avanzar a nosotros mismos y de pronto nos traen conflictos con la familia.

In.EM.Mz.10.17: Alejar actitudes negativas.

Ma.BO.Mz.10.17: También alejándonos de las personas que tienen esas actitudes negativas.

In.EA.Mz.10.17: Dejando actitudes negativas, cambiando, alejándonos de las personas con esas actitudes.

Ma.BO.Mz.10.17: Sí, porque muchas veces uno puede tener muy buena energía y muy buenos pensamientos, pero hay personas que siempre están ahi para opacarle a uno los sueños, para opacarle a uno las cosas buenas que uno tiene, entonces alejarse no solo de cosas malas que uno tiene, sino también de las personas que tratan de opacarlo a uno también; hacer eso porque las energías de las otras personas también influyen en nosotros, es mejor tener al lado personas que lo motiven a uno a ser mejor cada día, a que uno cada dia pueda cumplir sus sueños y que si uno de pronto los tiene ahi

29 Esta nomenclatura se usa con el fin de guardar la confidencialidad y el anonimato con el grupo de participantes. Las primeras dos letras hacen referencia al tipo de actor: Ma corresponde a madre, Aa a abuela, No a niño, Na a niña, Pa a padre, Ea a agente educativa, Eo a agente educativo, In al equipo de investigación; las segundas dos letras corresponden a las iniciales del nombre; las terceras dos letras a la ciudad en la que se realizó el taller creativo en el que emergieron las narrativas colectivas, Mz Manizales, Vr Villa Rica, Sm Santa Marta, Bo Bogotá, Me Medellín; el primer número corresponde al mes; y el segundo número corresponde al año. 
estancados que uno tome la iniciativa, tener personas que le sirvan a uno para eso.

Aa.GC.Mz.10.17: Que también depende de uno, de que uno tiene que hacer cosas buenas, y también lo negativo y lo malo hacerlo a un lado.

Este diálogo como favorecedor de la emergencia de narrativas colectivas, en las que las familias provenientes de contextos de conflicto armado identifican vivencias comunes y aprendizajes, a través de la experiencia de las demás personas, da cuenta de una reflexión generada en torno a la posibilidad de soñar con futuros distintos a la violencia y a la capacidad que cada sujeto tiene de trabajar día a día, desde pequeñas acciones, para lograr ese futuro deseado. Particularmente esta narrativa colectiva habla de "dejar atrás" y "alejarse" de aquello que hizo daño o que aún en el presente quiere interferir con los planes familiares; "dejar atrás y alejarse" como acciones que posibilitan pensar en presentes desde los cuales se puedan sembrar otras actitudes que permitan cosechar futuros más amables. Otras narrativas señalan la importancia de generar acciones presentes para no repetir en sus hijos e hijas historias de sueños no realizados por las familias:

Aa.AB.Vr.6.2017: Uno quiere para sus hijos lo mejor, sino que uno muchas veces no les puede dar las carreras que ellas quieren porque todo es plata, las carreras son muy caras en la universidad, entonces uno hace el esfuerzo como para que ellas hagan un técnico, tengan al menos una tecnología (...).

Ma.YP.Vr.6.2017: Por lo menos yo no entré a la universidad ni nada de eso, pero gracias a Dios mi mamá me dio la oportunidad de terminar aunque sea el bachillerato, e hice cursos en el SENA y esos cursos me han servido para trabajar, por eso así mismo yo le digo a los niños que se superen, que sean alguien en la vida, para que no se queden así como yo que solo con el bachillerato, porque hoy en dia hasta para uno ser escobita tiene que tener el bachillerato.

Aa.AB.Vr.6.2017: Muchas veces uno tiene las cosas como frustradas porque uno no pudo ser lo que quiso. Yo también terminé mi bachillerato; en esa época mi esposo estaba comprando la casita, entonces no pudo hacer un préstamo para que yo pudiera seguir estudiando, porque a mi también me gustaba auxiliar de enfermería o profesora (...). Imagínese hay cosas que a uno se le quedan como frustradas, entonces uno quiere que lo que uno no fue al menos que los hijos lo alcancen (...). 
La construcción de narrativas colectivas y la conexión expresada en los diálogos anteriores entre los distintos participantes, pero también entre los distintos tiempos, pasados, presentes y futuros, más que pretender una descripción de la realidad, busca generar significados sociales que se instituyen gracias a los juegos del lenguaje que solo son posibles en los intercambios sociales (Wittgenstein, 1953, citado por Gergen, 2007). Para Gergen (2007) en el acto de narrar y en el ejercicio del diálogo se juega la relatividad de los significados los cuales pueden ser reconstruidos gracias a su carácter indeterminado y a la libertad que se le confiere a los individuos para reinventar sus historias, en lugar de adherirse a historias que se sospechaban invariables o definitivas. Es por esto que, cuando se propician indagaciones desde una perspectiva apreciativa, se reinventan relatos que logran reemplazar el énfasis desde la carencia o desde el déficit que culturalmente se le atribuye a las narrativas provenientes de contextos de conflicto armado; y a la vez se deconstruyen miradas deterministas en las que el pasado influye de manera lineal y unívoca en el presente de estas familias, favoreciendo procesos de resignificación presentes de las experiencias vividas en el pasado, que posibilitan la emergencia de horizontes futuros, más cercanos al cuidado de las relaciones, como expresión de prácticas cotidianas de construcción de paz. Esta posibilidad es vital para la construcción de sueños y futuros sin restricciones o límites, impuestos por el peso que trae consigo hablar solo desde la afectación o solo desde la reproducción de las violencias.

\subsubsection{Socialización política y construcción de subjetividades políticas de niños y niñas de la primera infancia desde el juego}

El desarrollo humano está influenciado no solo por características biológicas particulares, sino por las oportunidades de socialización que se dan en cada contexto relacional. Para el caso de los niños y las niñas de la primera infancia, estos contextos son principalmente el familiar, el escolar y el comunitario, entornos en los que además construyen sus subjetividades y tienen la posibilidad de constituirse como sujetos políticos, gracias a los vínculos y las interacciones que se generan con otros niños y niñas, familiares, docentes, cuidadores, vecinos, incluso con otros seres vivos, con la naturaleza y con las instituciones. Esta influencia se da de manera recíproca, es decir, que aunque los niños y niñas se ven permanentemente marcados por su contexto social, cultural y económico, ellos y ellas también generan transformaciones en las relaciones a partir de sus capacidades de acción y de agencia. Es en esta capacidad transformadora que se empieza a gestar en los primeros años de vida su constitución como sujetos políticos. 
Un ejemplo de esto lo presenta la siguiente narrativa colectiva, en la que el juego como modo principal de relacionamiento de los niños y las niñas, desde sus propias voces y motivaciones, favorece aprendizajes y pensamiento reflexivo en sus familias:

In: ¿Qué es lo que más les gusta de sus hijos o hijas?

Ma.EB.Sm.8.17: Que es muy juguetona, a ella le gusta jugar mucho

In: ¿a ti te gusta que ella sea juguetona?

Ma.EB.Sm.8.17: Sí, porque uno aprende con ella, a veces nos sorprende también y así la aprendo a conocer y me da una idea de cómo va a ser ella cuando esté grande

In: Y, ¿qué es lo que te sorprende de ella?

Ma.EB.Sm.8.17: Pues la forma como juega con las muñecas, empieza dizque vamos a jugar al caballito y empieza a jugar pero como si ya supiera muchas cosas

In: Se ve muy inteligente cuando está jugando

Ma.EB.Sm.8.17: Sí, eso es

Como ha sido mencionado, el juego es un pilar y un eje desde el cual se desarrollan los niños y niñas; este es un medio para su desarrollo físico, cognitivo y social y también se constituye en un fin al entenderse como una construcción social, pero también como el principal acto político desde el cual los niños y las niñas opinan, aportan y deciden desde sus posibilidades, intereses y experiencias. Las siguientes narrativas ilustran el lugar que tiene el juego en la cotidianidad de los niños y las niñas:

In.LC.Mz.9.17: ¿Qué es lo que más les gusta de su familia?

NaPI.MM.Mz.9.17: De mi familia me gusta jugar, me gusta querer a mi mamá. (...)

In.EM.Mz.9.17: A NoPI.JV.Mz.9.17 ¿qué es lo que más le gusta hacer con la familia, con la mamá, con el papá, qué es lo que más te gusta hacer? (...)

NoPI.JV.Mz.9.17: Mi papá jugó a la pelota.

In.LC.Mz.9.17: ¿Jugar al golf, fútbol?

NoPI.JV.Mz.9.17: Sí, fútbol. 
In.LC.Mz.9.17: A NaPI.SZ.Mz.9.17 ¿qué es lo que más le gusta hacer con la familia, con la mamita? (...)

NaPI.SZ.Mz.9.17: Pintar la casa (...)

In.LA.Bg.6.17: ¿A quién dibujaste?

NoPI.Bg.6.17: Mi mamá, mi papá y mi hermano.

In.LA.Bg.6.17: Y cuéntame ¿dónde viven?

NoPI.Bg.6.17: En la casa de abajo.

In.LA.Bg.6.17: ¿Y qué te gusta hacer con ellos?

NaPI.Bg.6.17: Jugar.

In.LA.Bg.6.17: ¿Y a qué juegan?

NaIP.Bg.6.17: Al río.

In.LA.Bg.6.17: ¿Y quiénes son ellos?

NaPI.Bg.6.17: Mi mamá, bebé, mi hermana.

In.LA.Bg.6.17: ¿Y qué haces con ellos?

NaPI.Bg.6.17: Jugar.

In.LA.Bg.6.17: ¿Y a qué juegan?

NaPI.Bg.6.17: A la comida.

NoPI.Bg.6.17: Mi mamá, mi papá y el bebé, y yo y mi tía.

In.LA.Bg.6.17: ¿Y qué te gusta hacer con ellos?

NaPI.Bg.6.17: Jugar a la rueda rueda.

El juego, al estar implícito en la mayoría de actividades y relaciones en las que participan los niños y las niñas en sus primeros años de vida, requiere una atención especial, para facilitar comprensiones acerca del valor que este acto político tiene para propiciar prácticas relacionales direccionadas a la construcción de paz. Para este fin, vale la pena rescatar los puntos de vista con respecto a las posibilidades del juego en la transformación social, por parte de algunas personas adultas (agentes educativas, madres) que comparten su cotidianidad con niños y niñas de la primera infancia:

IN1Vr: ¿Crees que los niños nos puedan enseñar algo para que los adultos construyamos la paz? 
Ea.SR.Vr.11.17: Algo fundamental que tienen los niños y que yo admiro mucho es ese sentido que tienen los niños que cuando pelean con un compañero y a los cinco minutos o al minuto ya están otra vez en su juego, y eso es algo que nosotros como adultos hemos perdido, que nosotros tenemos una dificultad con otro adulto y nos demoramos mucho en volver a conciliar, en cambio ellos inmediatamente vuelven otra vez y concilian, y no tienen que dialogar y perdonarse sino que inmediatamente continúan su relación normal, eso es lo que yo admiro mucho de los niños. (...)

In.Bg.9.17: ¿Y en el parque, cómo construyen paz?

Ma.Ar.Bt.9.17: Jugando con los niños, y pues pienso que se construye paz porque ya tienen otras mentalidades hacia el juego, no tienen otros pensamientos que digamos si ya los niños son adolescentes el pensamiento con el amigo de que el cigarrillo, el vicio que la cosa, sino que están concentrados en su parque, que juegan con los animalitos.

Para el equipo de investigación fue interesante explorar la forma como estos procesos se despliegan en la cotidianidad de los niños y las niñas de la primera infancia, de forma relacional, mediada por el conflicto, pero también por aquellos espacios y oportunidades que se crean para potenciar sus capacidades y reconocer sus titularidades, como un camino para la reivindicación de la posibilidad de participación política del ser humano desde sus primeros años de vida. Se parte de la idea de que permanentemente las niñas y los niños están participando e influyendo en sus entornos, razón por la cual es relevante visibilizar las voces y las acciones que se pasan por alto debido a la prioridad que se le atribuye al adultocentrismo en la configuración e interpretación de realidades. Dichas voces y acciones, como se muestra en la siguiente narrativa colectiva, están fuertemente marcadas por la creatividad en los primeros años, lo que da cuenta de que además del juego, el pensamiento creativo y la exploración en los niños y las niñas son prácticas agenciadoras de su constitución como sujetos políticos, en cuanto les permiten crear modos de relacionamiento que no habían sido imaginados antes en contextos marcados por las violencias:

In.LC.Mz.8.17: Cuando les preguntábamos qué hay por potenciar en ellos y ellas, ¿ustedes qué pensaron?

Ea.AL.Mz.8.17: Esos niños son imaginativos, creativos, ellos creen que pueden coger el mundo y manejarlo. Entonces qué bueno tener 
las herramientas para uno potenciar todo eso en ellos, que sean niños creadores, innovadores, que no sean personas que más adelante sigan como en la misma: para dónde va Vicente, para donde va la gente; no, que sean niños que inventen, que creen.

In.LC.Mz.6.17: ¿Cuáles son esas cosas lindas que habría que fortalecer en ellos?, ¿qué cosas lindas qué tienen ellos hay que fortalecerlas? (...)

PI.MM.Mz.6.17: Que a ella no le da pena de nada.

In.LV.Mz.6.17: Ella también es muy espontánea, me parece a mí, porque también uno al ser espontáneo es muy creativo, entonces fortalecer esa creatividad.

Ma.BO.Mz.6.17: Yo por ejemplo con NoPI.JV.Mz.6.17, él estaba muy chiquitico, y yo hace poquito leía algo que decía que un niño feliz tiene que ser cansón, para ser feliz tiene que ser un niño así, que todo lo coge, que todo lo explora, porque es verdad ellos están en una etapa de que todo lo quieren conocer, ellos quieren saber para qué es todo, entonces es por eso, por ejemplo mi sobrinita también es así, ella es un tornado, pero es la manera de conocer.

Esta apuesta por la visibilización de acciones políticas que surgen desde la primera infancia, y que se despliegan con el grupo de pares y en relaciones intergeneracionales, se comprende en la investigación a la base del presente artículo como aportes relevantes para la construcción de paz. En este sentido, vale la pena resaltar que lo político se entiende como una condición humana. Arendt (2005) expone la posibilidad que tenemos los seres humanos para crear o destruir la vida, cual camino se emprende, es una decisión política, siendo la acción la actividad política por excelencia. En este sentido, lo político se equipara a la posibilidad de pensar en el impacto que puede tener determinado acto en la vida y en el bienestar de otros; en palabras de la autora, en vivir, moverse y actuar sintiendo a los otros. A partir de esto se logra la creación y la construcción con otros y otras, incluso al estar expuestos a fuertes influencias contextuales como las del conflicto armado, teniendo en cuenta que los procesos de socialización desde una perspectiva política posibilitan la construcción de otros sentidos, otros significados y otras prácticas que conduzcan a la transformación social (Valencia-Suescún, Ramírez, Fajardo \& Ospina-Alvarado, 2015).

Propiciar estas comprensiones de la construcción de paz desde el juego, la creatividad y la exploración, en un presente alejado del contexto de con- 
flicto armado, implica reconocer la cotidianidad y los entornos relacionales como lugares con gran poder para emprender la construcción de relaciones alternativas a las violencias con los niños y las niñas, y visibilizar las actividades que se realizan con otros y otras, los pequeños actos que pueden transformar las vivencias en las familias, las escuelas y los barrios.

9.3.3 Capacidad de agencia en la primera infancia para la construcción de paz

Como se ha mencionado, en los procesos de socialización se generan y desarrollan capacidades que pueden favorecer la participación política para la transformación de realidades compartidas. Es a través de las prácticas dialógicas que se generan en estos espacios donde se construyen relatos que constituyen las subjetividades e identidades de los niños y las niñas. En esta medida, como lo hemos aprendido en la trayectoria como grupo de investigación ${ }^{30}$, se hace necesario identificar aquellos recursos y potencias -individuales, relacionales y colectivos- que han permitido que ellos y ellas, junto con sus agentes relacionales, superen el impacto que el conflicto armado ocasionó en sus vidas, dando lugar a su participación como sujetos políticos para la construcción de paz.

Dentro de las narrativas, que se construyeron en el marco de la investigación, se identifican algunas en las que se habla de los niños y las niñas desde su capacidad de agencia, es decir, desde la posibilidad que encuentran para opinar, actuar, pensar y proponer, haciendo uso de sus recursos, sus experiencias y sus perspectivas de vida, encontrando espacios para estar al margen de predeterminaciones que algunas veces se formulan por sus historias de vida o las de sus familias. Al respecto se encuentra el siguiente diálogo con unas agentes educativas, en el cual se destacan las capacidades y potencialidades de los niños y las niñas:

In: centrándonos en esas familias con las que ustedes trabajan día a día, y reconociendo que algunas de ellas provienen de contextos de conflicto armado ¿ustedes cómo describirían a los niños y niñas de la primera infancia que provienen de esas familias?

30 Para ampliar esta perspectiva revisar Alvarado, Ospina, Quintero, Luna, Ospina-Alvarado y Patiño (2012); Gómez, Ospina-Alvarado, Alvarado y Ospina (2014); Ospina-Alvarado (2015); Ospina-Alvarado, Alvarado, Carmona y Ospina (2017); Ospina-Alvarado, Alvarado y Fajardo (2018); Ospina-Alvarado, Alvarado y Ospina (2014); Ospina-Alvarado, Alvarado, Ospina y Gómez (2015); Ospina-Alvarado, Carmona-Parra y Alvarado-Salgado (2014); Valencia y cols. (2015). 
Ea.LA.Sm.8.17: Bueno pues son niños a los que aparentemente no les ha afectado. Por ejemplo NaPI.AC.Sm es un poquito tímida pero es por su personalidad, no porque sintamos que le haya afectado, es una niña bastante cariñosa, comparte.

Ea.LC.Sm.8.17: Pues yo siento que son niños muy íntegros, que a pesar de que hayan pasado por esta dificultad no se les evidencia que tengan secuelas; son niños participativos, se relacionan con sus compañeros y si son tímidos es por su personalidad, no recalcando que fueron víctimas del conflicto armado, son niños normales, que pueden relacionarse en cualquier espacio. Y la relación que tienen con su maestra es igual a la que se tiene con los otros niños. (....)

In: ¿Y cómo se relacionan esos niños con sus familias? ¿Con ustedes? (...)

Ea.LC.Sm.8.17: No PI.RA.Sm él también es un niño muy pilas, le gusta colaborar y siempre está atento a lo que la maestra le dice, lo mismo No.DH.Sm, es un niño muy cariñoso, es un niño que se integra fácilmente, es un niño muy líder que se involucra con sus compañeros.

Así mismo, los niños y las niñas eligen formas de interacción con los adultos, desde las cuales pueden establecer límites y propiciar prácticas relacionales en las que cuiden de sí mismos. Esto se evidencia en el diálogo con una madre:

In.Md.5.17: ¿Cómo es la relación de tu niño con las otras personas?

Ma.Md.5.17: (...) Él identifica, "ella es mi tía y mi tío y sólo le puedo abrir la puerta a los que yo conozco a mi tío, a mi tía y a mi prima, a nadie más le puedo abrir puerta", a los desconocidos que pasan por la calle, les dice "chao, pero tú eres desconocido, yo no puedo hablar contigo porque tú eres un desconocido", (...) y a los vecinos que ya más o menos conoce, "vecino ¿cómo amaneció?”.

Familias y agentes educativos que participan con los niños y las niñas en sus procesos de socialización reconocen en ellos y ellas su capacidad de agencia; logran nombrarles y relacionarse con ellos y ellas a partir de sus potencias y potencialidades, sin mantener narrativas dominantes de violencia y vulneración basadas en miradas deterministas y unívocas en las que se les considere víctimas o agresores porque sus familias provengan de contextos de conflicto armado. Además de esto, reconocen en los niños y las niñas los modos en los que son capaces de cuidar de sí mismos. La capacidad de agencia, desde los primeros años, se expresa en tener ideas, emociones, 
saberes y experiencias y en que estas puedan ser reconocidas por sus agentes relacionales; es una de las vías en las que desde los primeros años los niños y las niñas aportan a la construcción de paz.

\subsection{Discusión y conclusiones}

El lenguaje, como posibilidad de acción y de transformación en el encuentro con otros y otras, se acoge en los procesos investigativos, basados en las narrativas colectivas, como un elemento esperanzador dentro de las historias y las memorias que han sido construidas en entornos de violencia, desde la carencia, la afectación, la vulneración y la victimización, posicionándose como un recurso desde el cual es posible crear, a través de procesos relacionales y prácticas de acción colectiva, otros relatos que por prácticas culturalmente dominantes han sido silenciados o suelen tener menos relevancia.

En este sentido, la realidad manifiesta su carácter dinámico y moldeable en la cotidianidad y en las pequeñas acciones y prácticas relacionales que realizan los sujetos en su día a día; la realidad se encuentra a merced de las posibilidades que niños y niñas, junto con los adultos que hacen parte de su vida, encuentran para proveer a las situaciones otros sentidos y significados que no destacan las ausencias, sino que rescatan a través de su creatividad, su exploración y su relacionamiento a la vez ético y político, las prácticas de juego, las prácticas afectivas, las prácticas de cuidado, las prácticas de resistencia que también han estado presentes en los contextos de conflicto y de violencia.

Así como el pasado puede resignificarse en el presente, a partir del lenguaje y de las acciones compartidas, el futuro también puede visualizarse como un momento que no está predeterminado por el pasado o por perspectivas "fatalistas", que obedecen a concepciones lineales y deterministas del desarrollo, sino que pueden beneficiarse del lenguaje y de las prácticas relacionales, ambos presentes en las narrativas colectivas, al considerarlos como aquellos eslabones desde los cuales se construyen realidades que van más allá del aquí y el ahora.

Contemplar estas posibilidades necesariamente trae a colación el potencial de ser político que radica en cada sujeto, el cual se manifiesta de múltiples maneras dependiendo de las experiencias, los intereses y los marcos éticos bajo los cuales se opta por determinadas acciones y no por otras. En la primera infancia, el juego y sus aliados la creatividad y la exploración, son los vehículos mediante los cuales niños y niñas se 
relacionan y comunican genuinamente con pares y adultos y construyen relaciones desde las cuales también opinan, deciden, manifiestan afecto y deciden cuidar de sí mismos y de otros. En este sentido, el juego fue una estrategia fundamental para desplegar los talleres creativos y propiciar encuentros dialógicos, desde relaciones horizontales y en algunos casos intergeneracionales; pero también el juego fue fin en sí mismo, al entenderse como un acto desde el cual se proponen acciones y se tejen relaciones que aportan a la construcción de paz.

\section{Referencias}

Alvarado, S. V., Ospina, H. F., Quintero, M., Luna, M. T., Ospina-Alvarado, M. C., \& Patiño, J. A. (2012). Las escuelas como territorios de paz Construcción social del niño y la niña como sujetos políticos en contextos de conflicto armado. Buenos Aires: CLACSO.

Arendt, H. (2005). La condición humana. Barcelona: Paidós

Berger, P. y Luckmann, T. (1968). La construcción social de la realidad. Buenos Aires: Amorrortu.

Fajardo Mayo, M. A., Ramírez Lozano, M. P., Valencia Suescún, M. I., \& Ospina-Alvarado, M. C. (2018). Más allá de la victimización de niñas y niños en contextos de conflicto armado: potenciales para la construcción de paz. Universitas Psychologica, 17(1), 1-14. doi.org/10.11144/Javeriana.upsy17-1.mavn

Gergen, K. (2007). Construccionismo social. Aportes para el debate y la práctica. Bogotá: Universidad de Los Andes.

Gergen, K. (2009). Relational Being. New York, NY: Oxford University Press.

Gergen, K. (2012). Principios orientadores del construccionismo social. Chagrin Falls, OH: Taos Institute. Disponible en http://www.construccionismosocial.net/2012/05/taosinstitute.html

Gómez, A. H., Ospina-Alvarado, M. C., Alvarado, S. V., Ospina, H. F. (2014). Las infancias en el conflicto armado: potencias y subjetividades politicas. Pensar las infancias. Bogotá: Universidad Javeriana.

Ospina-Alvarado, M. C. (2015). Construcción social de las paces desde las potencias: niños y niñas de la primera infancia y sus agentes relacionales le cierran la puerta a Don Violencio. En D. F., Schnitman (ed.) Diálogos para la transformación: experiencias en terapia y otras intervenciones psicosociales en Iberoamérica. v. 2, pp. 34-53. USA: Taos Institute Publications/WorldShare Books.

Ospina-Alvarado, M. C., Alvarado, S. V., Carmona, J. A. \& Ospina, H. O., (2017). A Social Constructionist Approach to Understanding the Experiences of Girls Affected by Armed Conflict in Colombia. En: M. Denov, \& B. Akesson (eds.). Children Affected by Armed Conflict: Theory, Method, and Practice. New York: Columbia University Press. https:// cup.columbia.edu/book/children-affected-by-armed-conflict/9780231174732 
Ospina-Alvarado, M. C., Alvarado-Salgado, S. V., \& Fajardo-Mayo, M. A. (2018). Subjetividades políticas de la primera infancia en contextos de conflicto armado: Narrativas colectivas de agencia. Psicoperspectivas, 17(2). https://doi.org/10.5027/ psicoperspectivas-vol17-issue2-fulltext-1186

Ospina-Alvarado, M. C., Alvarado, S. V. y Ospina, H. F. (2014). Construcción social de la infancia en contextos de conflicto armado en Colombia. En V. Llobet (comp.) Pensar la infancia desde América Latina. Un estado de la cuestión. pp. 35-60. Colección Red de Posgrados en Ciencias Sociales. Argentina: CLACSO

Ospina-Alvarado, M. C., Alvarado, S. V., Ospina, H. F. \& Gómez, A. H. (2015). De la victimización a las potencias: niños y niñas en contexto de conflicto armado en Colombia como agentes activos en la construcción de paz. En D. Schnitman \& J. Sanhueza (ed.) Experiencias de prácticas dialógicas: Una revisión a partir de diálogos productivos. Universidad Aldolfo Ibánez - Red de trabajo para diálogos productivos.

Ospina-Alvarado, M. C., Carmona-Parra, J. A., Alvarado-Salgado, S. V. (2014). Niños y Niñas en Contexto de Conflicto Armado: Narrativas Generativas de Paz. Revista Infancias Imágenes, 13(1), 52-60.

Valencia-Suescún, M. I., Ramírez, M., Fajardo, M. A. \& Ospina-Alvarado, M. C. (2015). De la afectación a nuevas posibilidades: niñas y niños en el conflicto armado colombiano. Revista Latinoamericana de Ciencias Sociales, Niñez y Juventud, 13(2), 1037-1050. 


\title{
10. Agenciamientos sobre construcción de paz de niños en contextos de guerra en Colombia
}

\author{
Jaime Alberto Carmona Parra ${ }^{31}$ \\ Resumen
}

Investigación acerca de los agenciamientos sobre construcción de paz de niños y niñas en contextos de guerra en Colombia, realizada desde el interaccionismo simbólico, a partir de las narrativas de los niños y sus agentes relacionales. Los resultados muestran la capacidad de resistencia a la cultura de la guerra de los niños y sus mayores, a partir de los siguientes tópicos: agenciamiento y singularidad, comunidades como contextos de emergencia de los agenciamientos, interacciones de los niños con sus agentes relacionales, influencia de los niños en sus mayores, construcción de identidad familiar, los niños como soporte afectivo de los adultos, prácticas alternativas a la violencia en las familias y el sentido del autocuidado. En la discusión se subraya la capacidad de resistencia de los niños y sus agentes relacionales para romper la espiral de violencia agenciada por el Estado y los grupos armados ilegales en sus contextos y agenciar prácticas de construcción de paz.

Palabras clave: niñez, guerra, agenciamiento, interaccionismo simbólico, resistencia, paz

\section{Summary}

Research about the peacebuilding assemblages of children in war contexts in Colombia, made from symbolic interactionism, from the narratives of children and their relational agents. The results show the capacity of resistance to the war culture of children and their elders, from the following topics: agency and sungularity, communities as emergency contexts of the agencies, interactions of children with their relational agents, influence of children in their elders, construction of family identity, children as emotional support for adults, alternative practices to violence in families and the

31 Universidad de Manizales. Correo: jcarmona@umanizales.edu.co 
sense of self-care. The Discussion underlines the resilience of children and their relational agents to break the spiral of violence organized by the State and the illegal armed groups in their contexts and to promote peacebuilding practices.

Keywords: childhood, war, agency, symbolic interactionism, resistance, peace.

\subsection{Introducción ${ }^{32}$}

El conflicto armado colombiano no se desarrolla en las grandes ciudades y centros de poder, sino principalmente en los pequeños poblados rurales limítrofes con las selvas. Hay que resaltar que el $52.6 \%$ del territorio colombiano se encuentra cubierto por bosques naturales.

Es importante conocer este contexto para comprender que además de la inequidad, la corrupción, la impunidad y el fomento de una cultura de la ilegalidad por parte de las clases económicas y políticas y las mismas instituciones del Estado, y la falta de presencia de las instituciones del Estado en más de la mitad de su territorio, favorece el florecimiento de diferentes actividades económicas ilegales como la minería y la producción de drogas ilícitas, con la consecuente conformación de grupos armados ilegales, que cometen toda clase de delitos y atropellos contra la población civil, frecuentemente con la complicidad o la negligencia del ejército y la policía (cuando están presentes) y terminan naturalizando la ilegalidad y la violencia.

Algunas de las afectaciones de las niñas y los niños por el conflicto armado colombiano son: la muerte o heridas producto de acciones armadas, el reclutamiento a grupos armados ilegales y su utilización como soldados, o esclavos sexuales de los comandantes, la utilización de $\mathrm{NN}$ civiles para tareas

32 La investigación que se socializa en este capítulo es el resultado y el requisito de certificación del autor en el "Programa de Investigación Postdoctoral del Centro de Estudios Avanzados de la Universidad de Manizales y el Cinde" y su trabajo de campo se apoyó en el proyecto de investigación titulado "Procesos de construcción social de la niñez en contextos de conflicto armado en el Eje cafetero, Antioquia y área metropolitana de Bogotá: La paz, la reconciliación y la democracia desde la perspectiva de narrativas generativas de niños y niñas" dirigido por Maria Camila Ospina Alvarado y en el cual el autor del capítulo fue coinvestigador. Este proyecto se desarrolló en el marco del programa de investigación titulado "Sentidos y prácticas políticas de niños, niñas y jóvenes en contextos de vulnerabilidad en el Eje Cafetero, Antioquia y Bogotá: un camino posible de consolidación de la democracia, la paz y la reconciliación mediante procesos de formación ciudadana", desarrollado por el Consorcio "Niños, niñas y jóvenes constructores de paz: Democracia, Reconciliación y Paz", conformado por: Fundación Centro Internacional de Educación y Desarrollo Humano - Cinde, Universidad de Manizales, Universidad Pedagógica Nacional. 
de inteligencia y logística, la orfandad, la muerte, secuestro o desaparición forzada de otros adultos significativos o pares de su comunidad, las heridas, violaciones, vejaciones y humillaciones a otros cercanos o a ellos mismos, producto de ataques a la población civil, la destrucción del tejido social, el envenenamiento de las aguas y la destrucción de los recursos naturales, la introducción de las lógicas de la ilegalidad, la violencia, la corrupción, la intimidación y la desconfianza como elementos que se naturalizan en sus contextos, entre muchas otras.

Ese es el contexto de emergencia de las subjetividades, las identidades y los agenciamientos de las niñas, los niños y los agentes relacionales, que hacen parte de esta investigación, y es necesario mantener presente dicho contexto porque es el telón de fondo que permite dimensionar la significación y el alcance a las acciones y las narrativas de estos niños y sus agentes relacionales.

\subsection{Método}

Investigación realizada desde la perspectiva teórico metodológica del interaccionismo simbólico que propone abordar los fenómenos desde la perspectiva de los actores sociales, basada en las narrativas generativas de niñas y niños y sus agentes relacionales que han sido afectados por el conflicto armado en Colombia. Participaron niños y sus agentes relacionales en tres regiones del país: Bogotá, Medellín y el Eje Cafetero. La investigación se realizó en el contexto del Proyecto "Procesos de construcción social de la niñez en contextos de conflicto armado en el Eje Cafetero, Antioquia y Área metropolitana de Bogotá: la paz, la reconciliación y la democracia desde la perspectiva de narrativas generativas de niños y niñas", que fue parte del Programa "Sentidos y prácticas políticas de niños, niñas y jóvenes en contextos de vulnerabilidad en el Eje Cafetero, Antioquia y Bogotá: Un camino posible de consolidación de la democracia, la paz y la reconciliación mediante procesos de formación ciudadana", cofinanciado por Colciencias y el Consorcio Niños, Niñas y Jóvenes Constructores de Paz, de la Fundación Centro Internacional de Educación y Desarrollo Humano (CINDE), la Universidad de Manizales y la Universidad Pedagógica Nacional. A su vez la investigación se realizó en el contexto del Programa de Investigación Postdoctoral en Ciencias Sociales Niñez y Juventud que ofrecen la Pontificia Universidad Católica de Sao Paulo PUCSP, la Facultad Latinoamericana de Ciencias Sociales FLACSO, el Colegio de la Frontera Norte de México COLEF, el Centro Internacional de Educación y Desarrollo Humano CINDE y la Universidad de Manizales, avalados por el Consejo Latinoamericano de Ciencias Sociales CLACSO. 


\subsection{Resultados}

En virtud de la decisión metodológica mencionada, de ver el fenómeno desde el punto de vista de los actores sociales, a partir de este punto serán las narrativas las que pasen a un primer plano en el desarrollo del texto. El papel de los autores será ordenarlas, agruparlas, editarlas y hacer observaciones previas y posteriores a las mismas, con el propósito de contextualizarlas y contribuir para que el lector pueda comprender la significación y el alcance de las mismas.

\subsubsection{Agenciamiento y singularidad}

Vamos a observar diferentes formas de agenciamiento, empezando por las expresiones de sus singularidades y diferencias ante las mismas historias y las mismas circunstancias de vida. En este aspecto tomamos la propuesta de Guidens, en el sentido de pensar el agenciamiento en función de las decisiones de los sujetos que ante un mismo escenario pueden optar por dos o más patrones de comportamiento y eligen uno de ellos y no otros. Vamos a ver algunas narrativas de maestras y maestros de Bogotá, Antioquia y el Eje Cafetero que dan cuenta de estas diferencias entre dos niños afectados por la misma situación, incluso entre hermanos.

Yo tengo en mi aula una niña y un niño, ambos desplazados, pero en cuestión de comportamiento son totalmente diferentes, como dije anteriormente el niño es demasiado agresivo, la niña es muy calladita, muy calmadita, comparte mucho con los demás, es muy perezosita en sí, más bien perezosita para trabajar sola, en cambio en grupo le llama mucho la atención, es muy culta, es muy diferente al niño, bastante y es muy asadita ${ }^{33}$. (Profesora, Manizales, 2015)

Los desplazados de mi salón son niño y niña y sí son muy diferentes, totalmente. El niño es calmado, tranquilo, respetuoso, querido, colaborador, solidario; ese niño es un amor de muchacho...en cuanto a comportamiento y su forma de ser ese muchacho es un amor de muchacho, todos en el salón tienen que ver con él. Va, viene, le ayuda al uno, le ayuda al otro, le lleva al uno, le trae al otro, mejor dicho él es muy servicial y tiene como muchos principios, como muchos valores, se le ve que es un niño todo lindo. La niña es todo lo contrario. (Profesora, Armenia, 2015)

33 Impaciente. 
Yo tengo dos niñas, una es callada, extrovertida, poco sociable y todos los comentarios que hacen, ella cree que son para ella y la otra es al contrario, la otra es muy avispada, ahorita estamos ensayando un baile para mañana y ella es muy activa, entonces es todo lo contrario a la otra, una es muy activa y la otra es muy pasiva, muy centrada en ella. (Profesora, Bogotá, 2015)

Estos son solamente unas pocas narrativas de muchas otras que coinciden en la misma estructura. Podríamos decir que la mayoría de los profesores reconocen las profundas diferencias que hay en los niños que llegan a sus instituciones desterrados por la guerra. También hay algunos casos en los que la apreciación de los profesores se inclina de una manera decidida hacia la valoración de las potencias de estos niños.

\subsubsection{Las comunidades como contextos de emergencia de los agenciamientos}

En este apartado abordaremos las narrativas de las niñas, los niños y sus agentes relacionales relativas a sus interacciones en el contexto comunitario, las construcciones de vínculos con sus vecinos, las acciones conjuntas en función de objetivos comunes, los eventos y actividades que sirven de ocasión para el encuentro y la construcción de identidades colectivas.

\subsubsection{Fortalecimiento de interacciones en la comunidad como expresión del agenciamiento colectivo.}

Las narraciones de los docentes sobre las características de los contextos urbanos a los que llegan las niñas y los niños desplazados con sus familias corresponden a una realidad que ellos perciben desde su perspectiva, pero esa realidad vista desde dentro, a partir de las narrativas de los padres de estos niños, presenta matices que vale la pena considerar en la perspectiva de los agenciamientos, porque en estas narrativas es notoria la voluntad de construir tejido social comunitario y relaciones de solidaridad, de actividades comunes y disfrute colectivo, en medio de condiciones de violencias y adversidades generalizadas. Estas acciones conjuntas en las que se aprecia la valoración de lo colectivo, la capacidad de negociar con los otros y respetar diferencias tienen también un sentido político en el sentido fuerte del "entrenos" Arendtiano. La construcción del sentido de lo comunitario empieza por las acciones solidaridad que los recién llegados reconocen y agradecen:

Mire, por ejemplo el dueño de acá, él no es nada mío, nada de nosotros y nos permite vivir aqui en este ranchito. A uno la gente lo quiere y 
le ayuda, le regala ropita, mercadito de vez en cuando. Los vecinos. Me pongo a llorar y a veces me siento por allá y será que Dios lo escucha a uno, porque de repente llega alguien y le dice a uno "aquí le traigo una panelita o aqui le traigo estos panes" o asi y yo "ah, mi Dios le pague” (Madre de niña de ocho años, Armenia, 2015)

También los padres de los niños que han llegado desplazados se integran a la comunidad y vinculan activamente los actores educativos y otros profesionales de instituciones públicas, como apoyos para la resolución de sus problemas:

Pues si es en el colegio por ejemplo, es la coordinadora, que es psicóloga también, es pedagoga y tienen muchas cosas, nosotros le tenemos mucha confianza a ella y cuando tenemos así alguna dificultad le decimos es a ella, y ya pues en lo personal pues dialogamos (Madre de niño de 10 años, Manizales, 2015)

Las participación en actividades comunitarias es un elemento fundamental de construcción de un "nosotros" identitario como comunidad, en el que se puede asentar un elemento político de resistencia a las diferentes formas de violencia y afirmación de relaciones de convivencia pacíficas. Incluso podría decirse que de este fortalecimiento depende la posibilidad de que una comunidad asediada por diferentes actores armados, legales e ilegales, pueda declararse como comunidad de paz, como ha sucedido en algunos casos en Colombia. En las narrativas de algunos niños es notoria la importancia que tiene la participación de sus padres en las actividades comunitarias, lo cual más allá de los elementos identitarios comunitarios y familiares, seguramente también dejará una huella importante en su propia subjetividad pues mi mamá sí participa en actividades, ella pues, ella a veces que van a hacer alguna actividad del barrio para adornar el barrio, ella ayuda, ahi todos ponemos nuestro granito de arena.

Las tradiciones culturales son una ocasión especial para el fortalecimiento del tejido de las interacciones comunitarias y los actores sociales de manera intuitiva aprovechan, en el mejor sentido de la palabra, estos períodos especiales que les brinda su propia cultura para construir ese entre-nos. En las narrativas de los niños aparecen estos eventos cargados de una fuerza especial:

Por ejemplo, en navidad siempre hacemos las novenas, y pues cada uno, si uno quiere lee todo, también cuando hacemos Halloween que nos disfrazamos y que hacemos concursos de todo eso y ya, me gusta 
todas las cosas que hacen en el conjunto, cuando traen infladores que uno coge y salta adentro también traen de eso (Madre de niño de 11 años, Medellín)

Sí, porque por ejemplo estamos en diciembre entonces cada bloque tiene que participar en todo eso, pues también tiene que dar para refrigerio y todo eso, también tiene que leer la novena, los adultos son los que se hacen cargo porque uno no, uno solo va y ya (Madre de niño de 11 años, Bogotá)

Nosotros compartimos con los vecinos, pues por ejemplo nosotros cuando llega un diciembre y se hace la noche buena, pues nosotros compartimos, ellos comparten con nosotros (Madre de niña de 10 años, Medellín)

En las narrativas de los niños aparece más frecuentemente el juego, la diversión y disfrute en comunidad como ocasión de construcción y fortalecimiento de lazos, que el acompañamiento en la tristeza o el apoyo en la desgracia: Porque es muy divertido estar con mis amigos, con mi familia y pasando bueno (Niño de ocho años, Medellín, 2015)

La valoración y el disfrute de las actividades comunitarias no implica su idealización; los actores sociales de nuestra investigación, en sus nuevos contextos comunitarios, aprecian estas interacciones y trabajan por su fortalecimiento sin dejar de reconocer las diferencias y las tensiones que subsisten y aprendiendo a convivir con ellas

Pues muy bien, porque nosotros de pronto a veces, con cosas que comentarios que a uno no le gustan pero... igual somos vecinos, como que uno aprende a quererlos mucho, entonces es de parte de ellos o de parte de uno, entonces uno como que procura que si algo no le gusta, "chao nos vemos más tarde" o algo, pero no como peleando, o algo así, no. (Madre de niña de 12 años, Armenia, 2015)

\subsubsection{La interacción con agentes relacionales como fuente del agenciamiento}

En las siguientes narrativas de las madres aparece de una manera explícita la referencia al vínculo con sus hijas e hijos, como la motivación fundamental para tomar la decisión de alejarse de un contexto de guerra, aun renunciando a sus bienes y a su historia.

Toca estar pendiente de los niños, así como la edad del niño mío mayor ya se lo están llevando, a la edad de los nueve años se los 
están llevando engañándolos, que vea que nosotros vamos a pagar la familia, que vamos a dar yo no sé qué cosa, entonces los niños se convencen con nada y entonces ellos se van y dicen que sí, es la mejor vida entonces me voy, y entonces se los llevan. (Madre de niño de 12 años, Armenia, 2015)

En el caso anterior la motivación es el riesgo que corría el niño de ser vinculado reclutado por un grupo armado. En la narrativa siguiente es el riesgo que corre la vida de su pequeño hijo.

Pues ellos no saben nada de eso, pues porque como cuando yo me vine, mi hijo estaba de brazos, pero sin embargo a él me lo amenazaron, porque cuando yo vivía en la finca vinieron los paramilitares y me dijeron que si nosotros no nos íbamos que me mataban el niño y apenas me miraban el niño, entonces yo por eso más que todo me vine. (Madre de niño de 8 años, Manizales)

También, en la narrativa que sigue, los hijos aparecen como el elemento que motiva luchar por preservar la vida y escapar a los contextos de violencia:

Pues el mayor sí, porque el menorcito apenas tenía 9 meses y el mayor tenía 3 añitos cuando nos tocó venirnos, y nos tocó venirnos así con la mera ropa que teníamos (...) salimos de allá porque dije "si seguimos allá nos matan, y pues la vida del niño está todavía por delante" y entonces para el bien de él y el de nosotros también, nos desplazaron de allá. (Madre de niño de 10 años, Bogotá)

En la narrativa siguiente se ve de una manera clara la voz de aliento que el niño le da a su madre, y cómo es inminente la posibilidad de un segundo desplazamiento para poder escapar del grupo armado que lo quiere vincular.

Lo mismo, él no ha cambiado nada, y me dice que vamos a luchar, que vamos a ver qué hacemos. Alguien me dijo que habia uno que trabaja con Cordillera y que lo estaba buscando a él que para que le trabaje, que para manejarle platas y que lo anda buscando, y yo le dije a esa persona que ni le vaya a decir, que yo estoy por aqui porque esa gente es como el cáncer, a usted lo chantajean, le hacen lo que sea y usted tiene que hacer lo que ellos digan, o si no vea, es mejor así, a mi me da mucho miedo con eso. (Madre de niño de 12 años, Armenia, 2015)

En otros relatos relacionados con las interacciones familiares se puede observar el contraste entre las lógicas de guerra, totalitarismos, intolerancias, 
abusos de poder, agresiones y otras formas de violencia que rodean a estas familias y las dinámicas opuestas que se desarrollan en su interior.

El niño pequeño es muy tierno y él cada que yo estoy así lavando, va y se recuesta y dice "ay mamá tan linda" y al papá también, y él quiere mucho al papá y a mí también porque nunca nosotros hemos dicho malas palabras ni nada. Si los castigamos, los castigamos con alguna cosa que les guste, con la televisión, con eso lo castigamos, y yo les digo a ellos que tienen que aprender a ser obedientes y hacer caso, pero nunca maltrato ni a las malas palabras, como yo he escuchado mamás que les dicen malas palabras a los hijos, pero nosotros no somos de malas palabras (Madre de niño de nueve años, Bogotá)

La narrativa anterior es elocuente, como ejemplo emblemático para mostrar cómo, en un microgrupo familiar, se pueden desarrollar lógicas radicalmente opuestas a las de su entorno y la sociedad a la que pertenecen. Sin incurrir en idealizaciones ingenuas, ni pretender mostrar los casos como este como la vía para la construcción de la paz, no se pueden dejar de reconocer allí unas condiciones de posibilidad para una socialización más acorde con la formación de ciudadanos más afines con la construcción de formas de convivencia pacífica, que aquellos hogares en los que se continúan y se reproducen las violencias del entorno.

\subsubsection{Influencia de los niños en agenciamientos de los mayores}

La narrativa que sigue requiere una pequeña contextualización. Se trata de una madre que, producto del destierro, ha quedado en la miseria y en circunstancias de total adversidad. En la narrativa ella ilustra el esmero que hace su pequeña hija para darle ánimos y su voluntad de servirle de apoyo $\mathrm{y}$ aliento en ese momento. Aunque desde el punto de vista de los efectos prácticos el gesto de la niña es inocuo, logra su objetivo de estimular a la madre para seguir luchando.

Con las niñas, o sea nosotras en ese sentido nos hemos apoyado tanto, demasiado, porque mire que cuando tuve una caida, la niña más chiquita me decía "mire mami, tenga siempre una sonrisa". Y me empieza a contar chistes que para que se me quite la tristeza. Y me dice "mamá, ¿usted tiene platica?" Y le digo no. Me dice "tranquila mamá, que me voy a conseguir un trabajito y me gano tanto....... Y yo le llevo platica" y acá llego con 5.000 pesos....ella piensa que ya con eso tenemos. (Niña de ocho años, Medellín, 2015) 


\subsubsection{Construcción y fortalecimiento de la} identidad familiar en torno a signos de resistencia a la cultura de la ilegalidad y la violencia

La construcción de signos de diferenciación respecto de la cultura de la ilegalidad y la violencia generalizada en la que viven, puede ser un elemento identitario cohesionador, que nombra a un "nosotros" que se diferencia del exterior hostil, como un gesto de fortaleza y desafío, que anima a sus integrantes a ir más allá de su grupo de referencia.

Yo siempre les inculco a ellos mucha honradez, porque eso es lo más bonito que tiene uno primero, y que a uno pues que le tengan confianza donde sea, porque qué se gana uno, que uno tal cosa, y que tengan que estar a los cuatro ojos, o con los hijos que porque, "ay que pereza que esa gente venga aqui y que ahi mismo se nos llevan las cosas", no. En ese sentido si les he inculcado a ellas que no sean nunca así. (Madre de niña de 11 años, Bogotá, 2015)

Otros elementos identitarios del grupo familiar, para fortalecer su sentido de unidad colectiva, puede ser la capacidad para identificar situaciones potenciales de conflicto en el ámbito comunitario y eludirlas de tal manera que les permita mantener los vínculos cordiales con las demás personas. Pero también, -y en esto se subraya fuertemente el agenciamiento- el criterio para decidir en qué casos ese principio familiar tiene su excepción:

Nosotros somos buenos vecinos, como nosotros no nos metemos con nadie, ni nos gusta. Por ejemplo yo, vea, a mi no me gusta meterme en nada, ya que de pronto estén maltratando una mujer yo ya si me meto, pero de resto no. (Madre de niña de 9 años, Medellín)

También la solidaridad con los otros es mencionada con frecuencia como rasgo identirario, asociado a las estrategias radicales de resistencia frente a las dinámicas conflictivas en el escenario comunitario.

Pues que somos muy buenos vecinos, dicen que somos muy buenos padres porque nosotros no nos ven por ahi tomando, ni metidos en problemas, que porque es que yo mantengo es así encerrada y... y que por ejemplo la señora viene y me pida un favor, yo sí puedo se lo hago, si me pide un poquito de panela, yo se la doy y ya, y así. (Madre de niño de 8 años, Manizales, 2015) 


\subsubsection{El fortalecimiento de los lazos de afecto y solidaridad en la familia como estrategia de protección}

La apelación a la familia como referente fundamental de apoyo, en otro contexto podría ser discutible y problemático en el sentido de que puede debilitar el sentido ciudadano de sus integrantes. Sin embargo, en un contexto como este en el que los referentes sociales no operan, o están desvirtuados, el fortalecimiento de la unidad familiar puede servir de campo de neutralización de las violencias sociales y de desarrollo de subjetividades más compatibles con la solidaridad y otros valores democráticos.

Pues de pronto entre todos pasamos, o sea entre todos mi hija se va a acostar y "chao mami, la quiero mucho", y "yo también". O cuando me llaman acá al trabajo que tal cosa, y "chao mami, la quiero mucho", o sea de pronto de todos los problemas, de tantas cosas nos hemos vuelto como más unidos, y como yo les digo que tenemos que estar más unidos sea la situación económica, sea la situación familiar, lo que sea, tenemos que estar más unidos porque si no nos vamos a enloquecer. (Madre de niña de 12 años, Bogotá, 2015)

\subsubsection{Los niños como soporte afectivo de los adultos}

Para valorar de manera adecuada el apoyo que brindan los niños a los adultos en circunstancias tan complejas como el conflicto armado, hay que desprenderse de la visión racional adultocéntrica, que supondría un análisis de la historia y la filiación de los diferentes actores que intervienen en el conflicto armado en Colombia. Estos análisis, con frecuencia, desbordan la capacidad de los mismos académicos que no son expertos en el tema.

Los niños tienen su manera particular de percibir el conflicto armado y apoyar a sus agentes relacionales en los momentos cruciales, pero este apoyo no se centra en factores racionales, sino en factores emocionales. Las niñas y los niños tienen la capacidad de conectarse profundamente con los adultos significativos, de intuir los sentimientos profundos de ellos, incluso de anticiparlos y alentarlos a actuar en consonancia con ellos. En este sentido cumple la función que Enrique Pichon Riviere denomina "portavoz", que en momentos coyunturales de confusión puede ser de gran importancia.

Porque pues ellos son muy despistados, pero ellos están pendientes que yo llego a tal hora y si no llego: “¿mami por qué no ha llegado?” o "¿mami dónde está?" De pronto yo llego a veces y me encierro toda 
la tarde, "mami no esté triste, mami vamos a salir de ésta". (Niña de 11 años, Armenia, 2015)

Si bien los niños en cierto momento de su desarrollo cognitivo no tienen las condiciones para trabajar con abstracciones como paz, justicia, libertad, democracia, etc., en cambio desarrollan una poderosa intuición de los estados de ánimo de los adultos significativos y una habilidad asombrosa para influir sobre ellos de acuerdo con sus intenciones. Esta es una expresión clara de agenciamiento, que los adultos frecuentemente reconocen de manera retroactiva como fundamentales para la superación de momentos críticos relacionados con situaciones del conflicto armado.

Mi niña dice que a veces le gustaría estar en una parte que tuviera muchos árboles, que estuviera el río, el lago. Ella le pinta a usted un paisaje, que ella lo hace soñar. Ella cuando ve niños tan mal ella dice "ay mamá, que tristeza, niños que no van a durar 20 años, que pesar como les dañan la vida y uno sin poder hacer nada”. Es muy triste ¿cierto? (Madre de niña de 11 años, Bogotá)

En la siguiente narrativa, una madre describe de una manera detallada una escena cotidiana e íntima, que cobra todo su valor cuando se conoce el telón de fondo que constituye su contexto. Esos momentos los relata la madre como aquellos que le dan los ánimos, sin los cuales ella no podría superar los dolores y las pérdidas que ella y su esposo han sufrido por causa del conflicto armado.

Ah no, la que yo le digo, nos recostamos en el cama, ella me cuenta sus cosas, me dice que le gusta un niño de acá, del colegio, que él la mira, que ella también, y que a ella le da pena y se vuelve tímida; entonces conversamos de eso así, acostaditas las dos, y me monta el piecito, porque ella sabe que me gusta, y empieza y me hace asi en el cabello. (Madre de niña de 9 años, Medellín)

También en la construcción de ideales de futuro se pone en juego el agenciamiento de las niñas y los niños. Como habitantes de un universo simbólico, la construcción de nuestro presente, depende de las representaciones que tengamos del futuro. Una fantasía de un futuro deseable, puede ser para una niña la motivación para esmerarse en sus estudios y poner todo su empeño en su autocuidado y en el cuidado de los suyos:

Como digo yo, los papás son lo único que uno tiene en la vida, ¿por qué quién lo va a cuidar a uno después de que el papá o la mamá se muera?, nadie, antes quieren hacerle daño a uno. Yo quisiera, mejor 
estudiar por ellos, tenerlos en un lugar donde nadie me les hiciera nada, ni me les hiciera un daño, así, algo así, que a mí mamá no le toque trabajar ni a mi papá, que estuvieran siempre sentados, que coman frutas, que tomen vitaminas para que nunca les falte nada, y que nunca les falte la comidita obviamente. (Niña de 12 años, Bogotá, 2015)

Las niñas y los niños en su mundo infantil logran interpretar, con una lucidez extraordinaria, cuáles son sus posibilidades de incidencia en la realidad, en su realidad y logran hacer lo mejor cuando están en su elemento que es el juego. Efectivamente en la narrativa siguiente, como en la anterior, los niños logran con éxito brindarles a sus padres momentos de felicidad que se constituyen en el motivo para seguir adelante, a pesar de todas las atrocidades sufridas a causa de la guerra.

Pues sí, pues que nosotros mejor dicho que todos vamos a hacer todo juntos, hacer penitencias y que podamos jugar todos, y que la mamá ponga la penitencia y nosotros lo hacemos para disfrutar con la mamá, y mi mamá juega con nosotros así. (Niña de 11 años, Manizales, 2015)

En las narrativas infantiles, es notorio el esmero de las niñas y los niños por el autocuidado y el cuidado de los otros, también la satisfacción de sentirse incluidos en el compromiso por el cuidado de la familia y de la casa. Interpretan, a su manera, que puede ser deseable hacer sentir a los adultos que son pares suyos y que se pueden apoyar en ellos. Esto lo hacen desde su deseo, no se trata aquí de una coacción, con lo cual se subraya su valor como expresión de agenciamiento.

Cuidar a mis hermanitos, cuidar a que " $J$ " no se vaya a ir para el balcón que se cae de allá y ya. A veces mi mamá si me dice, "mami, ¿me va a barrer la casa que es que estoy muy cansada porque ya hice oficio?", entonces yo la barro y yo le ayudo a mi mamá (Niña de 9 años, Armenia, 2015)

Las circunstancias de la guerra favorecen la emergencia de dinámicas relacionales en las familias, en las que los padres no tienen dificultad para invertir los roles con sus hijos y en ciertas circunstancias dejarse aconsejar y estimular por ellos para lograr una meta.

Para una decisión en la que han participado mis hijos, más que todo las niñas, fue en apoyarme a terminar mi bachiller, pues yo ya terminé, me gradúo ahora en noviembre pero terminé a mitad de año, 
y pues a mí mis hijas me apoyaban mucho. Yo el año pasado a fines de año yo estaba decidida a retirarme, porque estaba muy enferma y la niña, la que vive conmigo, me dijo "mami no se vaya a retirar, mire que a usted le falta muy poquito, no haga, no cometa ese error (Madre de niña de 12 años, Bogotá, 2015)

En estos contextos de familias que han sufrido las violencias de la guerra, las chicas y los chicos en la adolescencia ya tienen la visión de un adulto y se convierten en apoyo para decisiones importantes de las familias.

Pues en mi caso es que mis hijos nos apoyaban a nosotros, para que nosotros consiguiéramos una casita, porque mi marido, pues no quería y mis hijos fueron los que más, más que todo los dos mayores, "que no, que consiguiéramos mejor una casita para no estar por ahi pagando arriendo", porque eso era muy, entonces a lo último él como que cedió y nos pusimos de acuerdo y la conseguimos. (Madre de niño de 12 años, Medellín)

\subsubsection{Prácticas alternativas a la violencia en la familia}

En un contexto donde la cultura de la intolerancia y la ilegalidad es agenciada por los representantes del Estado, en un país donde el presidente exhibe públicamente su desprecio por las decisiones de las altas cortes y donde todos los días los noticieros acompañan ese momento familiar con el espectáculo del lenguaje incendiario de las clases políticas y las repetidas noticias de sus actos de corrupción, el cultivo de prácticas de diálogo, concertación y solidaridad en las familias humildes es un fenómeno de resistencia y muestra de la capacidad de agenciamiento de las familias golpeadas por las furias de la guerra y por un contexto social adverso y hostil

Pues eso es de mucho dialogar, por ejemplo con los niños cuando ellos tienen problemas, por ejemplo como ayer en el colegio, ellos no pelean, y cuando sienten que necesitan ayuda buscamos... buscamos que las cosas salgan bien. (Madre de niño de 12 años, Manizales)

Las prácticas de concertación y negociación, de hacer concesiones y renunciar a algo para poder compartir con los otros, ciertamente no las han aprendido del contexto social y político de autoritarismo intolerancia e intransigencia. Son prácticas, se desarrollan, se cultivan y se transmiten a las nuevas generaciones en los espacios más cotidianos de la interacción familiar.

Casi siempre nos ponemos de acuerdo para ver casi los mismos programas, porque no más tenemos un solo televisor, entonces tenemos 
que ponernos de acuerdo para lo que va a ver uno y así. Y así cuando cuadramos, así como paseos, así que más que todo los domingos, entonces les preguntamos "a ver, si están de acuerdo nos vamos pa tal parte”, no es más. (Niña de 10 años, Medellín, 2015)

\subsubsection{El sentido del autocuidado}

En contextos de violencias generalizadas y en los que, gracias a la negligencia o complicidad de los agentes del Estado, proliferan distintas clases de empresas criminales, ciertas prácticas de los niños y sus familias, que en otros contextos podrían ser consideradas sintomáticas, pueden ser leídas como prácticas de resistencia, acordes con un deseo de preservar sus vidas y mantenerse al margen de la violencia y la criminalidad.

Ja, no en mi casa mantengo, nunca salgo de mi casa, de mi casa al colegio, y del colegio a mi casa y cuando me voy para donde mi prima y a donde la otra amiguita, de resto no. (Niña de 11 años, Bogotá, 2015)

El sentido del autocuidado en las niñas y los niños también se expresa en el sentimiento de la propia dignidad y la relación con su cuerpo. En función de ello se modulan los acercamientos y las distancias con los adultos y se asigna una significación $u$ otra a un agente educativo:

Porque, pues siempre yo soy con mis amigos, con mis amigas y el profesor siempre nos ha tratado de una manera, siempre ha estado con nosotros, nunca nos ha llegado a tocar a nosotras las niñas ni niños, siempre ha sido bien con nosotros, nunca nos ha llegado a tocar. (Niña de 11 años, Armenia, 2015)

El esmero puesto en la propia superación y en la construcción de una imagen de sí acorde con sus propios logros, produce efectos en el posicionamiento como sujeto en los vínculos con los otros, lo cual transforma en un sentido positivo las interacciones de una niña que no se resigna a las significaciones que le vienen de su condición de desterrada y violentada por el conflicto armado, y por el contrario empieza a construirse ella misma un nuevo ser y una nueva identidad en sus contextos escolares de interacción: "porque yo soy muy buena trabajando en matemáticas, porque llevo las notas bien, todo cinco, nunca me ha mandado notas, yo soy la más organizada en el cuaderno allá" (Niña de diez años, Medellín, 2015)

Cuando se le pregunta a una niña de ocho años sobre lo que le gustaría que dijeran de ella en su vecindario, responde desde sus 
expectativas infantiles y femeninas, con un claro sentido del contexto de riesgo en el que vive y de su alto sentido del autocuidado: "no pues, que ella es linda (risas), amable, no se mete con nadie, no tiene malos pasos y ya" (Niña de ocho años, Manizales, 2015).

\subsection{Discusión y conclusiones}

Las niñas y los niños y los agentes relacionales que participaron en este proceso de investigación, con sus agenciamientos, sus acciones de resistencia y la creación de nuevas significaciones acordes con la construcción de paz, muestran que el ser humano, desde la más temprana infancia, posee una vocación tansformadora y recreadora de su propia realidad socio-simbólica.

Desde una perspectiva determinista del desarrollo humano, estos niños y sus familias tendrían todas las condiciones para ser reproductores y amplificadores de la espiral de violencia en la que se han encontrado inmersos; sin embargo, en sus narrativas encontramos la afirmación de la vida, el autocuidado, el sentido del cuidado del otro, la valoración del fortalecimiento de las interacciones en el escenario familiar y comunitario, la importancia de la solidaridad, el sentido de la propia dignidad, el cultivo del diálogo, el apoyo de los niños a sus mayores y otros gestos contrarios al ambiente de autoritarismo, intolerancia, segregación, destierro, asesinato y otras múltiples formas de violencias de las que han sido víctimas.

La explicación de estos resultados de la investigación es, a la vez, un motivo de esperanza para un país como Colombia. Esta explicación nos dice que la acción humana no puede predecirse, ni condicionarse como el comportamiento animal y que justamente en las poblaciones de niñas, niños y agentes relacionales afectados por la guerra existen grandes potencias y posibilidades para la construcción de la paz y la reconstrucción del tejido social del país en el posconflicto.

Podría decirse que el Estado Colombiano y sus representantes, los partidos políticos y sus dirigentes, los aparatos económicos y sus empresarios, han mostrado históricamente una vocación decididamente violenta contra la mayoría de la población y además de ello pocos escrúpulos para hacer todo tipo de alianzas con empresas criminales y organizaciones al margen de la ley.

Si la sociedad colombiana reaccionara de manera mecánica a las violencias de las que ha sido objeto por parte del Estado, sus clases dirigentes y los grupos armados ilegales, quizás estaríamos ante una sociedad totalmente inviable. 
Podríamos afirmar que si Colombia sigue siendo un país viable, no es por la gestión del Estado, su clase política y económica, o por la voluntad de los grupos alzados en armas. La viabilidad del país solamente se puede explicar por la capacidad de resistencia de la mayoría de la población frente a las diferentes formas de violencias que han desplegado estos actores legales e ilegales que en cada territorio detentan el poder y ejercen la violencia.

Para efectos de la investigación sobre la paz, es hacia las comunidades más afectadas por la violencia y que luchan cada día para reconstruir sus proyectos de vida, hacia dónde se debe dirigir la mirada de los investigadores para entender ¿cómo se construye paz en contextos de violencia generalizada? ¿cómo se construye paz después de que la guerra ha desatado sus furias contra los más inocentes y vulnerables? ¿cómo se construye paz después de haber sido desterrados, humillados y ofendidos? ¿cómo se construye la paz desde las cenizas de la guerra?

\section{Referencias}

Bello, M. N. (2001). Desplazamiento forzado y reconstrucción de identidades.

Carmona, J. A. (2008) El Interaccionismo Simbólico y la investigación del fenómeno de los niños desvinculados de los grupos armados ilegales en Colombia: algunas consideraciones técnicas, metodológicas y epistemológicas. Revista Poiésis, 16. http://www.funlam.edu. co/poiesis ISSN2216 -1201

Carmona, J. A. (2013). Las niñas de la guerra en Colombia. Manizales: Centro Editorial Universidad Católica de Manizales 192 p.

Carmona, J. A. (2014). Definición de la situación de los menores desvinculados de los grupos armados ilegales en los actos jurídicos y sus efectos psicoeducativos. Estudios SocioJurídicos, 16(2), 163-177. Doi: dx.doi.org/10.12804/esj16.02.2014.05

Carmona, J.A., Bernal H.A., y Mejía, M.P. (2004). Psicología Social y Psicoanálisis: Pichón con Lacan. Medellín, Colombia: Fundación Universitaria Luis Amigó

Carmona, J. A. Moreno, F. y Tobón, J.F. (2012). Child Soldiers in Colombia: Five Views. Universitas Psychologica, 11(3), 755-768.

Carmona, J. A y Tobón J.F. (2007) Explicaciones del fenómeno de niñas soldados en Antioquia, Colombia: un análisis comparativo de la visión de las niñas desvinculadas de los Grupos Armados Ilegales y de los niños estudiantes de zonas rurales de Antioquia con un perfil psicosocial similar. Informes Psicológicos, 9 41-53, ISSN 0124-4906

Carmona, J. A y Tobón J.F. (2011) La desvinculación de 21 niñas soldado de los grupos guerrilleros y paramilitares en Colombia: interacciones y significaciones implicadas. Revista Colombiana de Ciencias Sociales, 1(2) 98-111. ISSN: 2216 -1201 I 
Carmona, J., \& Serna, I. (2017). Subjetivación política y configuración de identidades en niños y niñas y sus agentes relacionales, afectados por el conflicto armado: Posibilidades, potencias y resistencias. En M. Ospina, S. Alvarado, J. Carmona, \& A. Arroyo. Construcción social de niñas y niños en contextos de conflicto armado: desafios para los procesos de construcción de paz, reconciliación y democracia en Colombia (p. 324). Bogotá: Cinde.

Galicia, G. (2004). La formación de la identidad y la orientación educativa en la perspectiva narrativa de Bruner. Remo, 2(4), 13-19.

Giménez, G. (1992). La identidad social o el retorno del sujeto en sociología. Revista Versión, 2 (183-208). México: Instituto de Investigaciones Sociales

Lugo, V., Sánchez, P., \& Rojas, C. (Julio-Diciembre de 2018). La restauración con sobrevivientes del conflicto armado en Colombia: Una perspectiva de acción psicosocial. (U. d. Caldas, Ed.) Eleuthera, 19, 55-73. doi:10.17151/eleu.2018.19.4.

Moreno, M. (2009). Algunas reflexiones desde el psicoanálisis acerca de la guerra. Poiésis (17), 1-6. doi:https://doi.org/10.21501/16920945.177

Moreno, F. Carmona, J. A y Tobón, J. F. (2010) ¿Why do girls join Guerrilla and Paramilitary Groups in Colombia? Revista Latinoamericana de Psicología, 42(3), 453-467

Páramo, P. (2008). La construcción psicosocial de la identidad y del self. Revista Latinoamericana de Psicología, 40(3), 539-55 



\section{ESTUDIOS EMPÍRICOS SOBRE LA MUJER}





\title{
11. ¿Mujeres víctimas? Víctimas empoderadas, dolidas y emputadas
}

\author{
Gina Marcela Arias-RodríGueZ ${ }^{34}$
}

\section{Resumen}

Objetivo. Analizar cómo devienen en condición de víctimas empoderadas, dolidas y emputadas a partir de tres casos de mujeres víctimassobrevivientes-líderes y activistas por la paz en el movimiento de la Ruta Pacífica de las Mujeres. Metodología. Este proyecto de investigación siguió los principios de la investigación cualitativa, enfatizando en las prácticas propias de metodologías colaborativas, por lo que constituye una invitación a reflexionar sobre la producción de conocimiento de la mano de las comunidades y organizaciones sociales. Resultado. Las víctimas se posicionan de maneras muy distintas; estos posicionamientos subjetivos y políticos se expresan en demandas, expectativas, exigencias y disputas que se producen en lo que Gabriel Gatti (2014) ha denominado mundos sociales de víctimas y que se complejizan aún más en un escenario de transición política, como ocurre en el caso colombiano. Conclusión. Las mujeres víctimas se posicionan de distintan maneras, a pesar de su empoderamiento. Se constata que en Colombia persisten retos monumentales que garanticen el reconocimiento real de las víctimas, así como sus derechos a la verdad, la justicia, la reparación y garantía de no repetición.

Palabras clave: mujeres víctimas-líderes, políticas de reconocimiento, construcción de paz.

\section{Abstract}

Objective. To analyse how they become empowered, hurt and enraged, based on three cases of women victims-survivors-leaders and peace activists belonging to the Ruta Pacifica de las Mujeres movement. Methodology. This research project followed the principles of qualitative research, emphasizing on the practices of collaborative methodologies, hence constitutes an invitation to reflect about the production of knowledge that is in close contact with communities and social organizations. Result. Victims

34 Universidad Católica de Pereira. Correo: gina.arias@ucp.edu.co 
position themselves in different manners. This subjective and political positioning is expressed in demands, expectations and disputes which are produced in what Gabriel Gatti (2014) has denominated victims social worlds and complexified even more in a scenario of political transition as in the Colombian case. Conclusion. Women victims position themselves in multiple manners, despite their empowerment; it is evidenced that huge difficulties are yet to overcome in Colombia in order to guarantee the real recognition of victims, as well as their right to truth, justice, reparation and non-repetition guarantees.

Keywords: women victims-leaders, policy of recognition, construction of peace.

\subsection{Introducción}

"Quien ha sufrido un trauma se somete o se libera de su historia utilizándola.

Esa es su disyuntiva: o se ve obligado a repetir o

forzado a liberarse." (Molano, 2009: 31)

En L'èmergence des victims Michel Wieviorka (2003) expone que

La emergencia de la figura de la víctima marca una ruptura antropológica en el discurso de la modernidad planteando importantes cuestiones acerca de la naturaleza del sujeto-víctima y de su lugar en la cultura. Característicamente la modernidad constituye el ámbito de aparición de la víctima como sujeto social y, a la vez, individual. El concepto de víctima se prefigura paralelamente al de la humanidad y el Estado, como sujetos en el orden sociocultural desde mediados del siglo XIX. Después de las grandes guerras del siglo XX, la víctima no es ya abordada como el objeto de la violencia. La víctima sigue siéndolo cuando la violencia cesa y, en cierto modo, la violencia continúa en el estatuto identitatrio de la víctima. Ésta constituye, además, una auténtica encrucijada entre lo público y lo privado, lo universal y lo singular, lo generalizado y lo irrepetible. En su búsqueda característica de reconocimiento, la víctima hace identificable la violencia como negación del sujeto en todas sus formas posibles (p. 19).

Tres asuntos importantes para el abordaje de las víctimas como sujetos con especial reconocimiento en la modernidad. El primero de ellos tiene que ver con la noción de víctima como la conocemos en el mundo contemporáneo; ésta surge a partir del siglo XX con la Primera Guerra Mundial, 
pero es a partir de la década de los años 60 que se presenta una lógica del reconocimiento sobre estos sujetos como víctimas. Es, específicamente con el juicio a Adolf Eichmann en Jerusalén, cuando testigos y víctimas se hacen visibles.

Sin embargo, esta visibilidad no significa que las víctimas sean reparadas; para ello fue necesario el surgimiento de los estudios sobre los impactos traumáticos que dejan las violencias en los sujetos y un sistema jurídico que tipifique las violaciones a los derechos humanos, pondere los derechos y reparaciones a los que pueden acceder las víctimas, aunque en las Ciencias Sociales se ha abierto un interesante debate sobre la irreparabilidad del daño (Beristain, 2009).

Emerge entonces la figura de la víctima como "un personaje universal que ha alcanzado rango de estrella, en el firmamento de la era humanitaria y que son la coartada para el despliegue de la enorme red de asistencia del humanitarismo internacional" (Fassin y Rechtmann, 2011, citados por Gatti, 2014 , p. 283). Aunque esta figura, por absoluta que parezca, requiere que nos acerquemos a ella con la prudencia que permita relativizar nuestras propias convicciones. Incluso porque pueden aparecer falsas víctimas como consecuencia de la institucionalización de las maquinarias del humanitarismo; es por eso que a las víctimas se les pide que testimonien y afirmen su materialidad sufriente (Gatti, 2014).

Las víctimas han sido objeto de interés de las ciencias médicas y sociales - Psicología, Psiquiatría, Antropología, Sociología e Historia-, testificando y prescribiendo quién es víctima y quién no (Chaumont, 1997). Para ello, estos sujetos encarnan una serie de características que les permite acreditarse como tal-como víctimas- para acceder a reconocimiento y reparación, lo que puede ser leído desde las políticas de identidad y sus usos estratégicos.

El debate sobre las víctimas directas o indirectas, secundarias o covíctimas (Franco, 2013) o mejor, los sujetos que sobreviven a hechos de violencia y aniquilamiento de la existencia humana, son aquellos habilitados para hablar en nombre de los que ya no están, tal como lo que aprendemos de Auschwitz y como lo enseña Primo Levi (1987) en Los hundidos y los salvados, estos sujetos pueden estar habilitados para testimoniar. La figura del testigo superviviente central en la obra de Levi es fundamental para el trabajo aquí propuesto, mejor definido por Agamben (1998) como la paradoja de Levi El musulmán es el testigo integral, yo testimonio por el musulmán. Según Agamben, el superviviente es quien puede hablar pero no tiene nada interesante para decir, ¿qué entonces con los testimonios de los 
supervivientes que han visto y han presenciado el horror? Gatti responde con un interrogante ¿de qué pueden hablar los que, aunque lo rondaron, no experimentaron el horror hasta su extremo?

En algunos casos las mujeres fueron víctimas directas, la violencia sexual por ejemplo. En otros casos las mujeres son quienes presenciaron asesinatos de sus seres queridos, masacres o torturas. En esa vía, cobra sentido la noción de la mujer como testigo y por supuesto también, la mujer como víctima directa. De la obra de Levi también interesa su lucha contra las actitudes que borran a las víctimas, el blanqueo de la historia y sus enormes esfuerzos por tratar de comprender la condición humana y la barbarie (Galcerá, 2016).

Estos sujetos han sido objeto de interés de las ciencias sociales -Psicología, Psiquiatría, Antropología, Historia y Sociología- testificando y prescribiendo quién es víctima y quién no. Para ello, estos sujetos encarnan una serie de características que les permite acreditarse como tal-como víctimas-para acceder al reconocimiento y la reparación, lo que ha dado lugar al análisis desde las políticas de la identidad - primera y segunda victimología-, para comprender el proceso por el cual una persona deviene en víctima.

¿Qué problemas surgen de esto? Cuando los sujetos víctimas -en su condición individual o colectiva- se movilizan para exigir al Estado sus derechos, se pone de manifiesto la crisis y la incapacidad del Estado para resolver y satisfacer estas demandas. Las víctimas se convierten en un cúmulo de sujetos que desconfían de las acciones de éste y se posicionan desde la queja, el deseo de reconocimiento de su sufrimiento, hablando y actuando desde la discontinuidad en su trayectoria personal y el daño a las prácticas y experiencias cotidianas, haciendo énfasis en la violencia como negación de ellos como sujetos. Estas políticas del sujeto conllevan a una afirmación de la condición de víctima, entendida ésta como la subjetividad perdida, negada, instrumentalizada. Definida por Jacques Rancière (1995) como un no-ciudadano, un paria, un sujeto que no participa de lo público porque lo único que lo define es su condición de víctima como sujetos pasivos y vulnerables, sujetos expulsados de lo que permite el reconocimiento. No tienen palabra, sólo poseen desdicha.

De este modo, el sujeto víctima se construye a partir de la experiencia de dolor, sufrimiento y negación, una identidad negativa; pero es justamente esto lo que conviene problematizar desde las trayectorias de los sujetos víctimas como agentes y no sólo desde la negación. En los casos de las mujeres que se exponen aquí, es como si ambas condiciones de la identidad-positiva y negativa- coexistieran en ellas, primando más una que la otra en algunos 
casos, pero en definitiva las trayectorias de estas mujeres permiten evidenciar que no es posible analizarlos en términos absolutos, sino en los matices que cada caso permite observar.

Gabriel Gatti (2012) reconoce dos tendencias en el abordaje de este personaje -la víctima-. Por un lado, la aproximación francesa. Se proyecta sobre las víctimas un aparato que las imagina como figuras ligadas a la ciudadanía, el vínculo social, la asistencia social, las políticas públicas y sus burocracias. A los sujetos en posición doliente no se les expulsa, sino que se les asiste para reintegrarlos al conjunto. Pero, cuando estos sujetos víctimas reclaman, se ven con profundo recelo porque actúan en competencia directa con el ciudadano (soporte subjetivo del lazo social moderno de la sociedad a la francesa). La víctima se representa entonces en su "identidad negativa", el no ciudadano, inmadura, irresponsable, asistida, asentada en la queja.

Por otro lado, la aproximación anglosajona -completamente diferente de la anterior- considera al sujeto víctima no como un constructo social e histórico sino como una condición humana -por tanto universal y ahistórica-, en la que prima la experiencia individual de dolor y sufrimiento. Y, en su dimensión social, una mirada entre compasiva y clínica, propia de una cierta tradición liberal en la gestión de la cuestión social.

En el trabajo con las víctimas de la violencia sociopolítica en Colombia, se podría decir que tiene un poco de la una y de la otra. De la primera, la tradición francesa, porque las políticas públicas se dirigen a un sujeto víctima que es asistido con las "ayudas humanitarias"; incluso, que mendiga y es frecuentemente visto como "sospechoso" y, cuando se atreve a reclamar, como en los casos de las mujeres que aquí se expone, es mirado con recelo porque compite con "los ciudadanos de bien" o con los pobres históricos para acceder a los programas estatales, como es el caso de los siete millones de desplazados reportados en el Registro Único de Víctimas.

En esta concurrence de las víctimas también se presenta competencia y disputas entre ellas para acceder al capital simbólico que deviene de la utilización estratégica de tal categoría, para lograr identidad, reconocimiento y visibilidad. "El deseo de ser víctima invade, sí, la sociedad contemporánea: otorga reconocimiento, ayuda a salir de la invisibilidad social y colectiva... permite existir a quienes, si no, instalados en otras categorías, raramente resultan audibles. Hoy, ser víctima es nada más y nada menos que una vía de acceso a la condición de ciudadano" (Chaumont, 1997, p. 120).

Y tiene de la otra, la tradición anglosajona, en tanto reconoce las experiencias subjetivas de dolor y sufrimiento de las víctimas -muchas veces 
con la mirada patologizante de la psicología y la psiquiatría-, pero también enfatizando en cómo el sujeto agencia y gestiona su drama y su dolor.

Los trabajos de investigación sobre víctimas en Colombia son prolíficos; sin embargo, la legislación tiene una historia más reciente. La Ley 387 reconoce la categoría de desplazados forzosos sólo hasta el año de 1997; la Ley 975, de "Justicia y Paz", expone de manera muy superficial la reparación integral a las víctimas sólo hasta el año 2005 y dispuso medidas más centradas en los perpetradores, en este caso, las Autodefensas Unidas de Colombia (grupos paramilitares) que en las víctimas y la Ley 1448 delinea mecanismos y protocolos más concretos para la atención y reparación integral; no obstante, sigue siendo insuficiente para atender eficazmente a las ocho millones de víctimas de diversos delitos que se registran en Colombia. ${ }^{35}$ ¿Esto qué quiere decir? Víctimas ha habido desde hace mucho tiempo ${ }^{36}$; sin embargo, ha habido momentos clave de mayor visibilidad y escucha de las víctimas. Se resalta el periodo del proceso de negociación de La Habana (2012-2016), en el que las partes decidieron definir que éste sentaría sus bases en la "centralidad de las víctimas" para diseñar las disposiciones, mecanismos, protocolos, etc., en materia de justicia transicional; $y$, atención, reparación integral y garantías de no repetición.

A propósito de este vasto universo de víctimas en Colombia, se retoma a Gatti (2014) quien plantea que "se asiste a un espectáculo denso, el de un mundo de vida en explosión: el campo social de las víctimas. Es un mundo de vida con dolientes, con expertos, con estéticas, con circuitos de poder, con formas de entender el cuerpo... singulares, muy efervescente en materia legislativa, en movimientos, en lenguajes, y en formas de expresión artísticas. Muy rico. Pero cuando buscamos material teórico para pensarlo no encontramos siempre el adecuado" (p. 276).

Significa que las densidades y complejidades de los mundos sociales de las víctimas siguen convocando a los científicos sociales para hallar caminos más expeditos para su comprensión. En esa vía, es necesario comprender cómo cada sociedad problematiza, objetiva, trata y administra, de un modo

35 El Registro Único de Víctimas reconoce hechos de violencia con ocasión del conflicto armado: abandono o despojo forzado de tierras; acto terrorista, atentados, combates y hostigamientos; amenazas; delitos contra la libertad y la integridad sexual; desaparición forzada; desplazamiento; homicidio; minas antipersona, munición sin explotar, artefacto explosivo; pérdida de bienes muebles e inmuebles; secuestro; tortura; vinculación de niños, niñas y adolescentes.

36 La Comisión Histórica del Conflicto y sus Víctimas detalla qué tiempos considerar sobre los orígenes de la violencia en Colombia. Tiempo corto, intermedio y largo; no existe un consenso al respecto. 
u otro, a aquellos sujetos que son pensados como sufrientes. Examinar los lugares cambiantes o múltiples posicionamientos que asumen, reconociendo que la víctima ya no es otro radical, sino que es otro cercano (Fassin y Rechtmann, 2007).

Las víctimas están en el borde, pero no son un sujeto exterior a la sociedad (Simmel, 1998); están en el último extremo de la vida social, por eso merecen que se les trate, administre, y trabajen sobre ellas (moralmente, educativamente, sanitariamente, policialmente), para integrarlas, para acercarlas a un núcleo - ese lleno de ciudadanos normales- del que, al menos teóricamente, son potencialmente miembros (Fassin, 1999).

En la línea de lo que propone Gatti (2011), pensar sobre los mundos sociales de las víctimas, como espacios habitados por distintos agentes (incluso con excombatientes), implica reconocer tres aspectos:

- Es un espacio habitado por un sujeto ordinario, ya no necesariamente son héroes o mártires; al contrario, son sujetos comunes y corrientes: ciudadanos-víctimas.

- Las causas de ingreso a ese espacio se pluralizan. Si son ordinarios los sujetos, lo son los motivos por los cuales pueden ser reconocidos como víctimas. Así que, en el nuevo espacio de las víctimas, la concurrencia es masiva. Por ejemplo, ocho millones de víctimas en Colombia.

- El espacio de las víctimas se ha profesionalizado y ritualizado, presentándose así la cristalización del sujeto "víctima". De este modo, proliferan los profesionales para las víctimas (psicólogos, psiquiatras, antropólogos forenses, asistentes sociales, etc.). ${ }^{37}$

En esta vía, la literatura sobre la categoría víctima produce todo un aparataje sobre "los oficios de la desgracia", en el que experto y víctima conviven. Los primeros actúan en un "vivir para" (profundo sentido moral forjado en la sensibilidad por el dolor); la segunda, en "vivir de" (se funda y legitima en el saber experto). Podría decirse que hay un "saber ser víctima", una definición científico-técnica de lo que es ser víctima, en el sentido que hay víctimas que ni siquiera saben que lo son, como en el caso de muchas mujeres testimoniantes.

37 Se podrían ver, por ejemplo, los comunicados del Colegio Colombiano de Psicólogos solicitando a las universidades formar a los nuevos profesionales con herramientas y técnicas que se ajusten más a las necesidades de las víctimas, son los nuevos oficios soportados por las "técnicas morales" de la época que nos ha tocado vivir. 
En este aparataje surgen varios personajes:

- Ideólogos: aquí la práctica del conocimiento no es hacia la víctima-individuo. La interpretan más bien en su dimensión colectiva, proyectándola hacia su reconocimiento social, traduciendo su dolor en valores de convivencia asociados a pactos fundamentales de la sociedad. La figura de la víctima es central; se define la figura; se enumeran tipos; interesa que las víctimas se conviertan en víctimas-supervivientes, educadoras, dispuestas al cambio social. Tal como aparece en el texto del Acuerdo de Paz/2016.

- Políticos-mediadores: proceden de los movimientos sociales y son los encargados del cabildeo, de la incidencia. Hay políticos profesionales y los que se consideran mediadores que trabajan el vínculo entre la sociedad civil y la clase política, entre el entorno del reconocimiento social y el institucional de la víctima.

- Victimas educadoras: expertas y profesionalizadas, racionalizadas, políticamente despartidizadas, pasadas por el tamiz de los ideólogos y encausadas por los políticos-mediadores para ser moderadas, adecuadas para la comunicación pedagógica de su sufrimiento. Son ajustadas a su respectiva causa injusta estructural. Su profesionalización va encaminada a ser testigos de y dar testimonio sobre su dolor que, aunque único y personal, es universal.

Para el contexto concreto del conflicto armado en Colombia, es necesario considerar que en el lenguaje de los derechos humanos, lo que ha ocurrido ha sido catalogado como una "catástrofe humanitaria", por el enorme número de asesinatos, masacres y desplazados (Jimeno, 2008).

También resulta útil tomar los aportes de Alexander Jeffrey (2016) sobre el trauma cultural, definiéndolo como acontecimientos horrendos que dejan marcas indelebles en los sujetos de una colectividad, que marcan sus memorias y cambian su identidad futura de manera irrevocable. Lo define como un enfoque teórico que da cuenta de relaciones entre sucesos, estructuras, percepciones y acciones aparentemente no relacionadas entre sí; y, además, expone que es un concepto que ilumina "un dominio significativo de responsabilidad moral y acción política" (p. 193). Perspectiva bastante iluminadora para comprender las acciones políticas que las mujeres deciden emprender cuando son conocedoras y asumen las graves consecuencias que la guerra ha dejado en ellas, sus familias y comunidades.

Esta perspectiva es interesante, dado que permite contrastar con los procesos de intervención realizados desde las instituciones del Estado, en 
las que frecuentemente se revictimiza o se despolitiza al sujeto víctima, porque estas acciones se ejecutan de manera descontextualizada, promueven prácticas clientelistas o no se cumple lo que ha sido establecido en los proyectos de intervención (Villa Gómez, Barrera Machado, Arroyave Pizarro, \& Montoya Betancur, 2017). Conviene también mencionar que los procesos estatales operan desde lógicas universalizantes que difícilmente podrán resolver las demandas y exigencias de la diversidad de víctimas que la guerra ha producido en Colombia (Moreno, 2015).

De acuerdo con estas consideraciones conceptuales, se planteó analizar las trayectorias de tres mujeres víctimas del conflicto armado colombiano, que hacen parte de la Ruta Pacífica de las Mujeres, y cómo su pertenencia a este proceso organizativo les ha posibilitado transitar del dolor, que paraliza, a la politización del dolor como mecanismo de lucha para la exigencia de verdad, justicia y reparación. Los tres casos son distintos; los recursos subjetivos y políticos que ellas han movilizan son diferentes aunque se enmarquen en el mismo proceso organizativo político.

\subsection{Método}

Este trabajo de investigación se configuró a partir de la participación y militancia de la autora en la Ruta Pacífica de las Mujeres, y del proyecto de la "Comisión de la verdad de las mujeres víctimas del conflicto armado colombiano" en el que se retomaron mil testimonios de mujeres de todo el país, con los que se pretendió visibilizar los hechos de violencia dirigidos específicamente a las mujeres, quiénes fueron los responsables, cuáles fueron los impactos (físicos, psicológicos y políticos) y cuáles las estrategias de afrontamiento desarrolladas por las mujeres frente a estos hechos.

De la experiencia como documentadora surge el interés de interpretar las trayectorias de las mujeres que han sido víctimas de distintas formas de violencia en el marco del conflicto armado, pero que, a partir de su militancia y pertenencia a la Ruta, hicieron un tránsito de la condición de víctima para ser sobrevivientes del conflicto. Lo que se pudo advertir, a través de las historias de estas tres mujeres, es que, a pesar de su participación en un mismo movimiento, sus posicionamientos son distintos. Por ello, el reconocimiento de estas microhistorias se hace necesario para captar la complejidad de los impactos de la violencia en cada sujeto que ha pasado por estos acontecimientos.

Se abordó este proyecto desde perspectivas cualitativas, bajo los principios de metodologías colaborativas (Castillejo, 2009) y de ética de la 
escucha (Aranguren, 2010). No interesaba sólo tomar los datos precisos y relevantes para la investigación, sino construir un proceso conjunto, que implicó participar de distintos momentos de la movilización política que realizan estas mujeres, en el marco de la militancia en la Ruta Pacífica de las Mujeres. De este modo, las conversaciones, denominadas en el lenguaje académico como entrevistas, se desarrollaron en medio de los plantones y manifestaciones públicas, la construcción de un mural como elemento simbólico reparador en el municipio de Quinchía (Risaralda) y en el marco del desarrollo de la II Cumbre de Mujeres y Paz, que tuvo lugar en la ciudad de Bogotá, en septiembre de 2016, y la realización de talleres que tenían como propósito socializar y discutir con las mujeres que hacen parte de la RPM los logros obtenidos por la Subcomisión de Género, en el proceso de negociación de La Habana. Los municipios donde se desarrollaron estos talleres fueron: Supía y Riosucio (departamento de Caldas), Quinchía, Pereira y La Virginia (departamento de Risaralda). Agradezco a la coordinación y el equipo de trabajo de la Ruta, Regional Eje Cafetero, por su disposición para permitirme tomar insumos de estos talleres para el presente trabajo de investigación.

El procesamiento y análisis de los datos se realizó tomando la codificación abierta, axial y selectiva, propia de la teoría fundamentada. La separación de la información recabada en unidades concretas posibilita la disección de la información y, posteriormente, construir unidades de sentido que permitieron identificar cada uno de los momentos que han posibilitado el tránsito de víctimas a agentes en las historias de estas mujeres.

\subsection{Resultados}

Una radiografía general de la dramática situación de violación sistemática a los derechos humanos, con ocasión del conflicto armado en Colombia, se expone desde las indagaciones realizadas por el Centro Nacional de Memoria Histórica. El informe "¡Basta Ya! Colombia: memorias de guerra y dignidad” (2013) narra la multiplicidad de las memorias de la guerra, el sufrimiento y el dolor que hemos vivido en las últimas cinco décadas. La cuantificación del padecimiento se considera como un asunto de gran complejidad, a veces como un ejercicio de simplificación de una realidad, que es necesario pero que también lo es el dar lugar a las narrativas de quienes han padecido las múltiples formas de la violencia: el despojo y el desplazamiento forzado, el asesinato selectivo o en masacres, el exterminio de un partido político, la violencia sexual, las torturas y la desaparición forzada, el secuestro, las extorsiones, la intimidación, etc. Sumado a la impunidad y al fracaso de 
la democracia, nos ubican ante un panorama complejo que se refleja en algunos de los datos más aterradores que se dan a conocer en este informe.

La cuantificación de las violencias y las víctimas tiene algunas ventajas y desventajas. Por un lado, permite evidenciar la magnitud de esta catástrofe social, pero los números no siempre coinciden en los informes que produce cada institución u organización, lo que genera debates y también incertidumbres respecto al estado real de los hechos victimizantes. Como lo propone Jelin (2002) se sabe que nos enfrentamos a un campo de disputa en el que no existe consenso sobre esta cuantificación.

Por otra parte, los científicos sociales y los activistas defensores de derechos humanos proponen la necesidad de ir más allá de la cuantificación y prestar atención a las iniciativas de construcción de memorias colectivas, como mecanismos que emplean sujetos y comunidades para afrontar estos eventos traumáticos. Sobre todo, porque no todas las víctimas son tratadas con la misma relevancia y consideración; pareciera que algunas vidas valen más que otras, merecen más duelo que otras y sus pérdidas se lamentan más que otras (Butler, 2006). ${ }^{38}$

No es la intención de este escrito proponer un inventario de los hechos victimizantes; interesa dejar claro que el universo de las víctimas en Colombia es heterogéneo y complejo, lo que conduce a una serie de reflexiones que es necesario exponer aquí. La pregunta sobre qué, quién o quiénes han producido este universo de víctimas, ¿sobre quién (qué actor del conflicto) recae la responsabilidad de estos 50 años de violencia? Asimismo, considerar un solo actor como el máximo responsable de todas las violencias y de la producción de las víctimas, sería no solo injusto, sino que también oscurece el complejo panorama y las posibilidades de explicación que se busca. En esta vía, asumir ese gran universo de víctimas del conflicto armado en Colombia, implicaría también reconocer que los posicionamientos, trayectorias, intereses, expectativas de justicia y reparación serán diferentes.

Se eligieron tres casos de mujeres que fueron testimoniantes en la Comisión de la Verdad, que han transitado por la Ruta de distintas maneras, que de ciertos modos han politizado su dolor para convertirlo en su herramienta de lucha, que han incidido en sus entornos cotidianos (familiares, comunitarios y de militancia política), que conocen en profundidad los objetivos y plataforma política de la Ruta y se identifican con ellos. Ellas

38 Por ejemplo, no son tratadas con la misma consideración, por los medios de comunicación y las instituciones, las víctimas de secuestro de las FARC que los jóvenes que fueron asesinados bajo la estrategia de "falsos positivos". 
son distintas, tanto en las violencias que vivieron como en sus mecanismos de afrontamiento, y por su pertenencia a distintos grupos étnicos, religiosos y políticos. Respecto a su posición de clase, todas han vivido el peso de la violencia estructural, antes, durante y después de la guerra. Todas batallan cotidianamente y lidian con los insidiosos impactos de estas violencias, que de uno u otro modo se actualizan en el presente, complejizándolo y oscureciéndolo, en algunas de ellas.

Interesa evidenciar, en los relatos y las actuaciones de estas mujeres, el "trabajo" para forjarse como sujetos dignos, en un escenario signado por la violencia, cuáles han sido sus vulnerabilidades y cómo han lidiado con ellas; cómo su pertenencia a la Ruta Pacífica les ha permitido construir una comunidad emocional como recurso para su "recuperación" y como vehículo de recomposición cultural y política, en el entendido que "el proceso que permite sobrepasar la condición de víctima pasa por la recomposición del sujeto como ser emocional; esto requiere la expresión manifiesta de la vivencia y poder compartirla de manera amplia, lo cual, a su vez, hace posible recomponer la comunidad política" (Jimeno, 2008, p. 261).

A continuación, se describe brevemente a cada una de las mujeres, sus trayectorias y subjetividades.

Lisinia Collazos Yule ${ }^{39}$ : mujer indígena de 50 años, ha sido dos veces gobernadora del cabildo Kite-kiwe ${ }^{40}$ en el departamento del Cauca, sobreviviente de la masacre del Naya; integró el cuarto grupo de víctimas que visitó la mesa de negociación de La Habana. En el caso de Lisinia, se pudo observar el liderazgo dentro de su comunidad -desafiando su cultura al ser gobernadora-. Se opone con determinación a lo que no le parece justo (como cuando le dijo a actores armados ante las amenazas y la intimidación: "de aquí me voy pero yo vuelvo porque esto es mío". Es claro cómo su participación en la Ruta le ha posibilitado construir un capital político que hoy la posiciona, con pleno reconocimiento, en su región y a nivel nacional; por último, se observó cómo hizo posible rehacer la vida cotidiana ante lo pesado que puede ser el desplazamiento forzado, y vivir en condiciones de hacinamiento por más de tres años en "albergues temporales".

39 Se consultó con cada una de las mujeres sobre mantener sus nombres reales en estos escritos; todas accedieron, incluso pidieron no cambiarlos.

40 Tierra floreciente, traducción de la lengua nasa-yuwe. Surge del reasentamiento de los indígenas que tuvieron que desplazarse a partir de la masacre del Naya. El INCORA tuvo que adjudicarles estos predios por una acción de tutela que fue interpuesta en contra del Estado. En la actualidad se reconoce éste como el primer Plan Integral de Reparación Colectiva dado a partir de la Ley de Justicia y Paz o Ley 975 de 2005. 
En la trayectoria de Lisinia se observan distintos movimientos que contribuyen en su devenir como sobreviviente y en la politización de su dolor para erigirse como sujeto de dignidad. El primer posicionamiento de Lisinia, frente al asesinato de su esposo en la masacre del Naya, fue el de resistir a los actores armados y optar por defender sus derechos y los de sus hijos. "Sobreviví a la masacre del Alto Naya y sólo me quedaban dos opciones: quedarme llorando toda la vida o sacar a mis hijos adelante". A partir de este momento, ella, junto con tres mil desplazados del Naya, huyó a Santander de Quilichao y Timbío (departamento del Cauca), con la intención de proteger su vida y las de sus seres queridos. Mientras habitaban los albergues temporales, ellos se organizaban y asistían a talleres de derechos humanos. En este contexto Lisinia se fue posicionando y empezó a tener los primeros visos de reconocimiento sobre su liderazgo: "soy una memoria viva de lo que le hicieron a mi pueblo; mi misión es hacer visibles a las víctimas, que tengamos voz aunque los congresistas se tapen los oídos cuando les pedimos que nos oigan".

Después de permanecer por un periodo de tres años en el coliseo de Santander de Quilichao, algunas familias decidieron retornar a la tierra del Naya; sin embargo, ella, junto con 56 familias, tomó la decisión de organizarse para exigir un proceso de reparación colectiva, que contemplara la adjudicación de predios para su reasentamiento. En este contexto conoce la Ruta Pacífica de las Mujeres: "yo hago parte de la Ruta por allá desde el 2003 cuando los hechos victimizantes que nos ocurrieron, las que se nos acercaron fueron las mujeres de la Ruta y una organización que se llama Mujeres de Negro". Lisinia lideró el proceso de la Comisión de la Verdad de las Mujeres, realizado por la Ruta Pacífica en su territorio. Allí la reconocieron y ella se fue posicionando como lideresa: "para mi sorpresa, el día que las convoqué en Timbío había una fila que le daba la vuelta a la cuadra. Todas querían ser escuchadas; es que, cuando se guarda tanto adentro, el alma se muere. Lo digo por experiencia, porque yo me pude liberar y ya no me para es nadie".

Este proceso de aprendizaje y empoderamiento, sumado a sus capacidades personales y de liderazgo, hicieron posible que Lisinia se convirtiera en la primera gobernadora de su cabildo, desafiando el orden de género de su propio pueblo. En sus propias palabras: "me costaba pero para mí fue un proceso, fue un año de mucho conocimiento de nuestras leyes propias, pero también de conocer nuevas personas que me animaban, me felicitaban". Este reconocimiento le ha permitido posicionarse como una mujer visible, con voz y con capacidad para comunicar las necesidades de las víctimas, como 
lo hace la víctima educadora: "a mí la Ruta fue la que me postuló para ir a La Habana; no fue ni siquiera mi movimiento indígena".

Es importante mencionar que Lisinia hace parte de una iglesia evangélica, notándose un afrontamiento religioso que le ha posibilitado tramitar el dolor y la rabia, "y pido todos los días que el rencor no se meta en mi corazón".

La conjugación de todos estos elementos en la microhistoria de Lisinia, permite evidenciar cómo empieza a posicionarse incluso desde el momento de la masacre. Transita por una organización de mujeres que le proveyó de recursos cognitivos y emocionales, como conocer sus derechos y reconocerse como mujer, convirtiéndose en la primera gobernadora de su cabildo en dos ocasiones. Sin duda, Lisinia es un referente para las organizaciones de víctimas en el Cauca y en el país.

Cristina: mujer mestiza de 54 años, su hijo fue asesinado de manera extrajudicial en el marco de lo que en Colombia ha sido denominado como "falsos positivos", tratándose en realidad de ejecuciones extrajudiciales de jóvenes de estratos bajos y que fueron presentados por los militares como guerrilleros muertos en combate. Es militante del Partido Comunista-Zonal Risaralda- desde hace varios años. En ella se identificó su enojo e impotencia en la búsqueda de justicia y el "efecto dominó" que ha generado este hecho: posterior al asesinato de su hijo, el hermano menor de éste inicia un consumo abusivo de sustancias psicoactivas y es asesinado en las rencillas entre redes de microtraficantes.

Cristina sabía que había algo raro en el reporte de la Fiscalía, cuando la llamaron para decirle que su hijo había sido abatido con otros dos guerri1leros: "en el reporte de la Fiscalía decía que eran guerrilleros. En el reporte de la prensa decía que eran tres individuos armados, al margen de la ley. En el reporte de la prensa también está que debajo tenían los camuflados". La incomprensión se apoderaba de ella, "esa incertidumbre, esa zozobra", después empezaron a llegar los cuestionamientos, “¿cuándo se volvió mi hijo guerrillero?".

El primer movimiento en la trayectoria de Cristina puede verse como algo sutil; es cuando ella empieza a ver en las noticias los casos de los hijos asesinados de las Madres de Soacha y se presenta un destello de comprensión y de enojo en su lenguaje no verbal, " ¡Ah no!, yo ahora tengo muy claro qué pasó, es que siempre los muertos los pone el pobre... cuando se destapa el caso de los falsos positivos fue que respiré, porque mi hijo no era guerrillero y ahí empieza mi lucha". 
Cristina inicia todo su proceso de lucha y de exigir respuesta, por parte de las instituciones, para que se reconociera que su hijo no era guerrillero. De la confusión a la pregunta; de la pregunta a interpelar el dictamen de la Octava Brigada del Ejército Nacional; de la interpelación al enojo-rabia y de la rabia "y la putería" a reconocer la estrategia de los "falsos positivos".

En su proceso de lucha por la exigencia de verdad y justicia, Cristina se ha encontrado con la fría e inhumana burocracia institucional. Lo dice con tristeza y enojo:

"el proceso ha pasado por la Procuraduría; de la Procuraduría me contestan que es a la Procuraduría General de la Nación; allá mandé un derecho de petición porque en este país todo es así; así de buenas a primeras no lo atienden a uno jamás; entonces me mandaron a decir que eso lo habían pasado al Juzgado Penal Militar 53... hasta el día de hoy, nadie me responde nada. Alguien de la Procuraduría me dijo: "usted tiene cinco instituciones del Estado desgastándose por el mismo caso", y yo le dije: pues que se desgasten todas, que también respondan, porque mi hijo no era guerrillero".

En todo este proceso, Cristina es contactada por un concejal que le propuso exponer su caso al Colectivo de Abogados José Alvear Restrepo; allí conoce a otras madres que se encuentran en su misma situación y deciden organizarse en las ciudades de Manizales y Pereira. Se da cuenta que no es la única y que el proceso demanda acciones en conjunto para exigir esta verdad tan anhelada. La búsqueda por la verdad tiene dos sentidos: el político y el personal. El político se enmarca en un deseo de justicia para las víctimas; y el personal, que tiene que ver con encontrar sentido a lo ocurrido, como una forma de descansar y tener paz, como es frecuentemente llamado por las víctimas.

Cristina es militante del Partido Comunista y hace parte de la Ruta Pacífica de las Mujeres y, según ella, es lo que le alienta a seguir el proceso de búsqueda de justicia. Sin embargo, en la actualidad ella transita entre la tristeza y el enojo "el empute" al ver que el caso no prospera. El efectó dominó de la violencia en ella: el asesinato extrajudicial de su primer hijo, el asesinato de su segundo hijo por rencillas en redes de microtráfico, la drogadicción de su tercer hijo y una condición de salud delicada que enfrenta en la actualidad.

Cristina ha sido remitida a procesos psicoterapéuticos; sin embargo, ella refiere que son insuficientes: "ir a la psicóloga no me sirve, me ayuda 
más estas conversaciones, que ustedes saquen tiempo, hablar de todas estas cosas, pero esos tratamientos psicológicos no. Haberlas conocido a ustedes, la Ruta y a la gente del Partido Comunista me ha dado ánimos para seguir viviendo, para sobrellevar este dolor; entender que no solo soy yo, sino muchas otras madres que han vivido estas cosas tan duras".

María: mujer mestiza de 54 años, líder de la Asociación de Desplazados en el municipio de Supía, víctima de desplazamiento forzado y de violencia sexual, integrante de la Mesa Nacional de Víctimas. En el caso de María se notó su capacidad para reinventarse en la vida cotidiana, sacar adelante a sus cinco hijos, hacerse a un cargo de reconocimiento -la presidente de la organización de desplazados- y "moverse" estratégicamente en los escenarios de las víctimas reconocidas y escuchadas, como lo es la Mesa Nacional de Víctimas.

En la trayectoria de María se observa el drama económico, social y psicológico que han padecido más de siete millones de desplazados en Colombia. Su lucha por la sobreviviencia por sacar adelante a sus hijos, iniciarse como líder cuando apenas vivía del rebusque vendiendo empanadas en Supía (departamento de Caldas), ir escalando en las Mesas Municipal, Departamental y Nacional de Víctimas, le ha posibilitado posicionarse en el lugar ya no sólo de exigir por sus derechos, sino de luchar por los derechos vulnerados de otros que, como ella, han tenido que reinventarse la vida cotidiana.

María, desplazada de Chigorodó (departamento de Antioquia) tuvo que salir huyendo con sus cinco hijos porque guerrilleros de las FARC habían amenazado a su esposo. Buscó a su madre en un pueblo del departamento del Valle del Cauca; no contaron con suerte y decidieron seguir el camino hasta llegar a Supía; allá se enteró "de las ayudas del gobierno". En esta concurrencia de las víctimas (Chaumont, 1997) es que aparece la razón humanitaria (Fassin, 2010), resolver las necesidades básicas cuando la condición humana se degrada; no obstante, no basta con alivianar el sufrimiento y la voluntad de asistir a estos sujetos por su "incapacidad" para hacer frente a su desgracia, el problema es que la asistencia humanitaria no resuelve el estado de cosas de inequidad, despojo y miseria a la que han sido sometidos los desplazados en Colombia. En palabras de María: "Yo declaré en la Personería de Supía... y entonces pues... yo tuve que salir a las veredas a pedir para no dejar morir a mis niños de hambre... pedí, me colaboraban... hasta que vi lo de las ayudas".

Cuando se observa el drama de los testimonios de desplazados y desplazadas, aparece con recurrencia el tono nostálgico por la pérdida de una 
vida buena, sin sufrimientos, la tristeza por la vida perdida y que jamás se recuperará: "vivíamos muy bueno, mi esposo era un hombre muy responsable, no nos faltaban los cuatro o cinco litros de leche, la carne, ni la alimentación; vivíamos muy bueno". Por otra parte, la transformación de los roles en el hogar complejiza aún más la situación de desarraigo: "yo salía a vender torticas de chócolo, torticas de carne; las vendía en la calle; yo no sabía ni cobrar y me tocaba poner a vender las empanadas a los niños". Este tema de las reconfiguraciones familiares ha sido ampliamente abordado por Meertens (2003) exponiendo que las condiciones de precariedad laboral, las tensiones y ansiedades que devienen del desplazamiento, la nueva división sexual del trabajo para la supervivencia, pueden acentuar situaciones de violencia de género.

Respecto al liderazgo y al proceso organizativo, en María se da después de su desplazamiento y lo hace cuando se entera que existen instituciones que tienen que velar por los derechos de ella y de otros que se encuentran en su misma situación. La activación se da porque cree que pueden mejorar sus condiciones de vida. "Mira, yo allá en Chigorodó no tenía liderazgo de nada, fue después que declaramos acá que quisimos formar una Asociación, y así surgió la Asociación de Desplazados de Supía; yo ya llevaba un tiempito y los demás dijeron que querían que yo fuera la presidenta (sic)”. El proceso organizativo y el reconocimiento que sus compañeros hicieron del trabajo de liderazgo que realizaba posibilitaron su empoderamiento: "me siento muy bien en ser presidenta (sic), ayudar a otros, yo nunca había hecho eso... pero me siento bien porque uno aprende y tiene encuentros con mucha gente".

En la trayectoria de María hay un tema que aparece mucho tiempo después. Cuando llega a la Mesa Nacional de Víctimas y se encuentra en el capítulo especial de violencia sexual en el marco del conflicto armado, escucha testimonios de mujeres que vivieron estos hechos victimizantes. Fue el momento en el que pensó declarar lo que le había sucedido: "yo vine a declarar porque depronto me invitaron a una reunión de mujeres víctimas de violencia sexual, pero yo no lo había declarado todavía por miedo. María guardó silencio durante diecisiete años por miedo a ser juzgada por sus hijos; además, los guerrilleros que la violaron le advirtieron que no dijera nada. "La verdad, yo me sentía como muy oprimida, no sentía como la capacidad de hablarlo". Posterior a la declaración que Luz Dary logra hacer, como medida de reparación le sugieren realizar un proceso psicoterapéutico; sin embargo, ella refiere que éste no ha sido útil: "me tocaba ir hasta Manizales y yo no tenía la plata para estar yendo, además la psicóloga como que no me escuchaba, como que se quedaba dormida; yo no vi que eso me fuera a 
ayudar en lo que yo estaba sufriendo, en lo que yo necesitaba que ella me brindara el apoyo, yo eso no lo vi”.

En la actualidad, María continúa siendo la presidente de la Asociación; ella es la que escucha a las víctimas cuando la buscan, en esta especie de profesionalización de las víctimas (Gatti, 2014), ellas se convierten en víctimas que escuchan a otras víctimas, pero preocupa que ellas no tengan acceso a un proceso de acompañamiento psicosocial adecuado y oportuno que les permita tramitar sus propios dolores, máxime cuando son otras víctimas quienes buscan el apoyo en las líderes ya reconocidas: "la verdad, a mí me gusta mucho apoyar a las mujeres de este hecho, hay muchas que les pasaba igual que a mí, que no podían hablar, pero yo las animo para que den la declaración".

Finalmente, el afrontamiento religioso le ha posibilitado a María atenuar los sentimientos de odio y de venganza, aunque, como lo propone Sandrine Lefranc (2016) es un tema que aún es necesario seguir explorando, terreno en el que los profesionales de las Ciencias Sociales tendremos que cuestionarnos respecto a los procesos de perdón y reconciliación que, muchas veces, se les exige a las víctimas sin tener a cambio el conocimiento de la verdad y el acceso a la justicia. Sin duda, el campo abierto en el proceso de negociación entre el gobierno de Juan Manuel Santos y el antiguo grupo guerrillero FARC, a través de los procesos de justicia transicional, seguirá exigiendo rigor intelectual y posicionamientos ético-políticos con miras a revisar el complejo campo de las víctimas en Colombia.

\subsection{Discusión y conclusiones}

En las indagaciones con estas mujeres, analizadas a la luz del contexto colombiano, se observa un interés creciente por tomar en serio las afectaciones de la guerra en las mujeres y cómo ellas participan activamente en procesos de construcción de paz. Esto se hace evidente en el proceso de negociación de La Habana y que fue posible por la incidencia de las organizaciones de mujeres. Es importante señalar que en esta tendencia se enfatiza en la violencia sexual, el desplazamiento forzado y la transformación en los roles producto del desplazamiento.

En la historia del conflicto armado colombiano, como en otros conflictos, las mujeres han tenido una doble posibilidad de vinculación: como víctimas y como protagonistas para salir de la guerra y aportar en la construcción de paz. Sus tránsitos van desde el reconocimiento de ellas como víctimas hasta el posicionamiento político y su deseo de no ser tomadas solo como víctimas. De eso se trató este estudio. Del conjunto de mil testimonios to- 
mados para la Comisión de la Verdad de las Mujeres realizado por la Ruta Pacífica entre el año 2011 y el año 2013, me propuse profundizar en las trayectorias y los posicionamientos subjetivos y políticos de tres mujeres que aportaron su testimonio en dicha Comisión, mujeres que hacen parte de la Ruta y que han encontrado en su dolor y sufrimiento motivación para transformar sus vidas e incluso se han convertido en referente para otras mujeres y para otras víctimas.

En ese sentido, se observan estudios críticos que indagan y profundizan sobre los sentidos que circulan en las narrativas de las mujeres víctimas, los testimonios como texto y como performance, cómo se producen traducciones y alienaciones de los testimonios como producto de la administración institucional de las víctimas.

Por otra parte, las tres mujeres han encontrado en su pertenencia a la Ruta, una comunidad en la que se sienten acompañadas, en la que pueden desplegar su dolor pero también en la que han logrado tramitar las pérdidas de sus familiares o en la que pueden hablar tranquilamente de la violencia sexual.

En los tres casos hay una pieza del rompecabezas de la violencia armada en Colombia. En la historia de Lisinia, el telón de fondo es el desarrollo del paramilitarismo como estrategia antisubversiva. El proyecto paramilitar nace en el departamento de Antioquia (centro occidente colombiano), pero se expande por todo el territorio nacional hasta llegar a la región del Naya (sur occidente colombiano). El pueblo indígena Nasa, estigmatizado por ser auxiliadores de las guerrillas, es despojado de sus tierras y obligado a salir tras la masacre en la que muere el esposo de Lisinia; ella se ve obligada a desplazarse y sobrevivir con sus tres hijos. Allí empieza su liderazgo y su posicionamiento como líder.

En la historia de Cristina, los verdugos de su hijo son los militares que, en su afán por mostrar resultados, desaparecieron y asesinaron jóvenes humildes y los hicieron pasar por guerrilleros. Una de las estrategias más perversas de la actuación de las Fuerzas Militares y que ha sido conocida como el "escándalo de los falsos positivos". La lucha de Cristina inicia cuando vio en el noticiero la tragedia de las Madres de Soacha que estaban viviendo lo mismo que ella y que no descansan hasta que el nombre de sus hijos "sea limpiado" y se reconozca que no eran ni guerrilleros, ni paramilitares, ni delincuentes.

La historia de María es la de las vicisitudes de los seis millones de desplazados. Los ingentes esfuerzos de las madres para conseguir un techo, comida para sus hijos y sobrevivir a las hostilidades de las ciudades 
a las que llegaron. Sin ninguna comprensión de lo que le había ocurrido, un día escucha sobre unas "ayudas" del gobierno para los desplazados; ahí inicia su lucha.

En síntesis, tres historias de tres mujeres que se posicionan de manera distinta frente a las violencias ejercidas por paramilitares, agentes del estado y guerrilla de las FARC. Cada historia es diferente pero las tres tienen algo en común: las tres hacen parte del movimiento de mujeres, específicamente la Ruta Pacífica. Las tres refieren que en la Ruta han encontrado un escenario de escucha, de formación política, de acompañamiento, de encontrar en otras mujeres que, como ellas, han luchado y han sufrido y que no son las únicas. Una comunidad que les ha permitido dotar de sentido lo que les ha ocurrido y lo que nos ha ocurrido como país.

En los tres casos se observa el uso de la maternidad en el proceso de politización del dolor y como mecanismo para desarrollar sus luchas, lo que Robben (2006) ha denominado como "poder materno", a partir de su estudio sobre el caso de las Madres de la Plaza de Mayo.

En los tres casos se observa el uso estratégico de las categorías e identidades, como mujeres y como víctimas, afianzadas desde el reconocimiento de su identidad de género como mujeres y de sus roles como madres. Pero, no se quedan allí; trascienden en sus posicionamientos como líderes.

A pesar de que las luchas de estas tres mujeres transcurren por el movimiento de mujeres, específicamente la Ruta Pacífica, sus posicionamientos subjetivos y políticos son distintos. En el caso de Lisinia se cruzan su pertenencia étnica y sus creencias religiosas. En el caso de María se cruzan sus creencias religiosas, su pertenencia a otras instancias de participación como las Mesas de Víctimas; y en el caso de Cristina se cruza su militancia en el Partido Comunista, y la conciencia de su posición de clase, lo que constituye un elemento para comprender por qué a su hijo lo desparecieron y asesinaron, cuando ella dice "siempre los pobres llevamos la peor parte". Estas distintas trayectorias moldean sus posicionamientos frente al perdón, dejando entrever que los procesos de recuperación emocional discurren entre sus experiencias particulares de dolor pero que se potencian a partir de su participación en una organización, en este caso, la Ruta Pacífica de las Mujeres. Estas dinámicas de tejido entre el dolor individual y el trámite en lo colectivo se ha constatado en distintos estudios, como el de la Asociación de Mujeres del Oriente Antioqueño (Villa, 2016).

En las narrativas y posicionamientos de las tres hay un cuestionamiento de los valores patriarcales. En las tres se hace visible lo que los estudios 
feministas han nombrado como el continuum de violencias, es decir, que antes de las violencias que vivieron en el marco del conflicto armado, las tres refieren haber vivido otras formas de violencia en la pareja, la familia o la comunidad.

Finalmente, sobre la Ruta Pacífica de las Mujeres como propuesta de movilización social por la paz en Colombia, lo que ha posibilitado en el ejercicio de la política en clave femenina (Segato, 2016), ha buscado reconstruir lo que la guerra ha dañado y fragmentado, desde el ejercicio de lo político en lo cotidiano, donde las mujeres se vinculan desde lo afectivo y lo simbólico y no se constituye como un proyecto político burocrático y protocolar.

\section{Referencias}

Agamben, G. (2016). Lo que queda de Auschwitz. El archivo y el testigo. Pre-textos. España. 2000. Nueva Época, LXI(228), 191-210.

Alexander, J. (2016). Trauma cultural, moralidad y solidaridad. La construcción social del Holocausto y otros asesinatos en masa. Revista Mexicana de Ciencias Políticas y Sociales, LXI(228), 191-210.

Aranguren, J. (2010). De un dolor a un saber: cuerpo, sufrimiento y memoria en los límites de la escritura. Papeles del CEIC, 2(63), 1-27.

Beristain, C. (2009). Diálogos sobre la Reparación. Qué reparar en los casos de violaciones de Derechos Humanos. Quito, Ecuador: Ministerio de Justicia y Derechos Humanos.

Butler, J. (2006). Vida precaria. El poder del duelo y la violencia. Buenos Aires: Paidós.

Castillejo, A. (2009). Los archivos del dolor. Ensayos sobre la violencia y el recuerdo colectivo en la Sudáfrica contemporánea. Bogotá: Universidad de Los Andes.

Centro Nacional de Memoria Histórica. (2013). ¡Basta ya! Colombia: memorias de guerra $y$ dignidad. Bogotá: autor.

Chaumont, J. (1997). La concurrence des victimes. París: La Découverte.

Das, V. (2008). El acto de presenciar. Violencia, conocimiento envenenado y Subjetividad. En F. Ortega. Bogotá: Universidad Nacional de Colombia.

Fassin, D. (2010). El irresistible ascenso del derecho a la vida. Razón humanitaria y justicia social. Revista de Antropología Social, 19, 191-204.

Fassin, D. (1999). La patetización del mundo. Ensayo de antropología política del sufrimiento. En: M. Viveros, y G. Garay, (comp.) Cuerpo, diferencias y desigualdades. Bogotá.: Universidad Nacional de Colombia.

Fassin, D. y Rechtman, R. (2007). L'empire du trauma- tisme. Enquête sur la condition de victime. París: Flammarion. 
Franco, A. (2013). Daño y reconstrucción de la cotidianidad en covíctimas y sobrevivientes de minas antipersonal en Colombia. Nómadas 38, 115-131.

Gatti, G. (2014). Como la [víctima] española no hay. (Pistas confusas para poder seguir de cerca y entender la singular vida de un personaje social en pleno esplendor). Revista Kamchatka, 4, 275-292.

Gatti, G. (2011). El lenguaje de las víctimas: silencios (ruidosos) y parodias (serias) para hablar (sin hacerlo) de la desaparición forzada de personas. Universitas Humanísticas, 72, 89-109.

Gatti, G. (2012). La hipótesis V. Las víctimas y su victoria sobre el poderoso (y muy agencial) ciudadano. País Vasco: Centro de Estudios sobre la Identidad Colectiva, Departamento de Sociología. Universidad del País Vasco.

Galcerá, D. (2016). La pregunta por el hombre: Primo Levi y la zona gris. México: Anthropos.

Jelin, E. (2002). Los trabajos de la memoria. Buenos Aires: Siglo XXI.

Jimeno, M. (2007). Lenguaje, subjetividad y experiencias de violencia. Antípoda, 5, 169-190.

Lefranc, Sandrine. (2017). La venganza de las víctimas. Revista de Estudios Sociales, 60, 140-144.

Levi, P. (1989). En Los hundidos y los salvados. España: Muchnik Editores.

Congreso de la República de Colombia (10 de junio de 2011). Ley 1448 de 2011, por la cual se dictan medidas de atención, asistencia y reparación integral a las víctimas del conflicto armado interno y se dictan otras disposiciones. Diario Oficial 48.096

Congreso de la República de Colombia (18 de julio de 1997). Ley 387 de 1997, por la cual se adoptan medidas para la prevención del desplazamiento forzado; la atención, protección, consolidación y esta estabilización socioeconómica de los desplazados internos por la violencia en la República de Colombia. Diario Oficial 43.091.

Congreso de Colombia. (25 de julio de 2005). Ley 975 de 2015, por la cual se dictan disposiciones para la reincorporación de miembros de grupos armados organizados al margen de la ley, que contribuyan de manera efectiva a la consecución de la paz nacional y se dictan otras disposiciones para acuerdo humanitarios. Diario Oficial 45.980.

Meertens, D. (2003). Forced Displacement in Colombia: Public Policy, Gender and Initiatives for Reconstruction. En: Conference on African Migration in Comparative Perspective. National University of Colombia.

Moreno, A., Díaz, M. (2015). Posturas en la atención psicosocial a víctimas del conflicto armado en Colombia. El Ágora, 15(2), 193-213.

Rancière, J. (1995). La mésentente. Politique et Philosophie. París: Galilée.

Ruta Pacífica de las Mujeres. (2013). La verdad de las mujeres víctimas del conflicto armado en Colombia. Versión resumida, Tomos I y II. Ruta Pacífica de las Mujeres.

Segato, R. (2011). Género y colonialidad: en busca de claves de lectura y de un vocabulario estratégico descolonial. En K. Bidaseca y V. Vásquez Laba. (org.) Feminismos y 
poscolonialidad: Descolonizando el feminismo desde y en América Latina. (pp. 17-47). Buenos Aires: Godot.

Simmel, G. (1998). Les pauvres. París: PUF.

Villa Gómez, J. D., Barrera Machado, D., Arroyave Pizarro, L., \& Montoya Betancur, Y. (2017). Acción con daño: del asistencialismo a la construcción social de la víctima. Mirada a procesos de reparación e intervención psicosocial en Colombia. Universitas Psychologica, 16(3), 1-13. doi.org/10.11144/Javeriana.upsy16-3.adac

Villa Gómez, J.D. (2016). Perdón y reconciliación: una perspectiva psicosocial desde la noviolencia. Polis, Revista Latinoamericana, 15(43), 131-147.

Wieviorka, M. (2003). L'èmergence des victims. Sphera Pública, 3, pp. 19- 38. 


\title{
12. Devenir lideresa en el conflicto armado en Colombia: un tránsito de víctima a reclamante de justicia
}

\author{
Isabel CRistina Posada Zapata ${ }^{41}$ \\ Jaime Alberto Carmona Parra ${ }^{42}$
}

\section{Resumen}

En los conflictos armados, las mujeres tienen roles diferenciados por su género: como objetos de intercambio y lugar de inscripción de la fuerza del vencedor. Sin embargo, los acontecimientos de guerra han permitido la emergencia de nuevas configuraciones políticas en algunas mujeres que proponen escenarios de paz. Esta investigación se propuso comprender el proceso de devenir como lideresa en contextos de guerra, a partir de nuevas configuraciones de la subjetividad política y la ciudadanía. Se analizaron seis relatos de vida construidos en encuentros conversacionales, a través del método de la teoría fundamentada. Se encuentra que las mujeres lideresas transitan desde la enunciación de víctimas a la de reclamantes, y allí los acontecimientos de guerra y la asociación con otros hacen una inflexión en los significados atribuidos al rol y al ejercicio de la ciudadanía, cuestionando los esquemas de poder y generando transformaciones sociales que contribuyen para las paces.

Palabras claves: mujer líder, conflicto armado, subjetividad política, ciudadanía.

\section{Abstract}

In the context of armed conflicts, women's roles are differentiated by their gender: they are treated as exchangeable objects and a slate on which the strength of the victor is engraved. However, war events have allowed for the emergence of new political setups among a number of women, who propose peace scenarios. This study aimed to understand the process of becoming a female leader in war contexts by approaching it from the

41 Universidad de Antioquia. Correo: isabel.posada@udea.edu.co

42 Universidad de Manizales. Correo: jcarmona@umanizales.edu.co 
standpoint of the new setups of political subjectivity and citizenship. Six life stories built through conversations were analyzed via the methodology of grounded theory. This study found that female leaders transition from the enunciation of being victims to that of claimants. It is there where war events and their association with others make an inflection in the meanings attributed to the role and exercise of citizenship, thus questioning the power schemes and generating social transformations which contribute to peace.

Keywords: woman leader, armed conflict, political subjectivity, citizenship.

\subsection{Introducción}

Las víctimas en los conflictos bélicos se asocian con las personas que padecen consecuencias nocivas en su vida a causa de los enfrentamientos. De esta forma se expresa sobre ellas en Colombia (Ley 1448 de 2011) de Víctimas y Restitución de Tierras en Colombia, que las define como las personas que han sufrido daños, de forma individual o colectiva, en sus derechos, con ocasión del conflicto armado en el país (Colombia. Congreso de la República, 2017).

En este contexto, muchas de estas personas se han venido posicionando de formas diferentes, más activas y del lado de la reclamación de sus derechos, por lo que han preferido nombrarse desde el lugar de sujetos sobrevivientes, quienes, a partir del orgullo y la dignidad, han pasado de una enunciación de "víctima" a una como ciudadanos y líderes sociales que emergen como nuevas subjetividades políticas con nuevas prácticas ciudadanas (Delgado, 2015). Las iniciativas de estos ciudadanos se refuerzan en la colectividad, muchas veces sin el apoyo estatal o institucional, y se sitúan como movimientos paradigmáticos de resistencia social a la indiferencia (Carrizosa, 2011).

Comprender la forma como las personas reconfiguran su subjetividad a partir de la interacción social, pasando en este caso de víctimas a portavoces de la resistencia en escenarios de conflicto armado como el colombiano, requiere del reconocimiento de una realidad socialmente construida en la que algunos hechos son manifiestamente vividos con tal intensidad que su marca genera cambios profundos en la forma como se direcciona lo vivido y como cada uno se posiciona ante tal vivencia. Estos hechos, nombrados como acontecimientos, pueden llevar a un aniquilamiento del ser o a la emergencia de nuevas formas de acción política. La violencia puede configurarse así como elemento en el escenario de socialización política, 
donde nuevas subjetividades constituyen una forma de construcción de país y de nuevas formas de relación, aun en los contextos de desigualdad social y violencia (Patiño, Alvarado, \& Ospina, 2014), como en el caso colombiano. Las nuevas subjetividades políticas en estos contextos se caracterizan por su capacidad crítica, por su autonomía y por la conciencia de lo histórico y lo público, para así trabajar de forma colectiva por sociedades con una nueva y más justa distribución de poder (Alvarado, Ospina, Botero, \& Muñoz, 2008).

El sujeto político, en tanto resultado de operaciones históricas de poder, se refleja en los movimientos sociales como los feministas, que abogan por la deconstrucción de los marcos conceptuales con los cuales se categoriza la vida social, y que están atravesados por un sistema binario de género, donde el control y la fuerza de trabajo ha estado ligada a lo masculino, y donde se hace necesario plantear con toda su fuerza una ciudadanía diferenciada para una nueva distribución de poder (Villavicencio, 2014).

En el contexto de una afectación estructural por el sistema binario de género donde a los hombres se les encomienda lo público y lo político, y a las mujeres lo privado y lo doméstico, los escenarios de guerra afectan de forma especial a las segundas pues su fuerza como sujetos discursivos ya se ha visto disminuida por los roles asignados (Wallace, Nazroo, \& Bécares, 2016).

Diversas investigaciones han demostrado que las mujeres en los conflictos bélicos se exponen a una mayor incidencia de agresiones sexuales y familiares, condiciones de trabajo no digno, dificultades en su salud sexual y reproductiva y homicidios (Organización de las Naciones Unidas, 2016; Bastick, Grimm, \& Kuns, 2007). También se reportan cambios en la estructura familiar vivenciados de forma negativa (Guevara, 2016), y todo tipo de violencias ejercidas en contra de las mujeres, lo que implica consecuencias físicas, emocionales y sociales, así como en la distribución de poder en la sociedad en la que ellas viven (Fernández Villanueva, 2004). Estas violencias buscan de forma estratégica profundizar el dominio del otro, en este caso de las mujeres (Fernández Villanueva, 2007), cuyos cuerpos y tierras han sido usados en las guerras como objeto de confrontación, siendo la violación sexual un acto de dominación (Koulianou-Manolopoulou \& Fernández Villanueva, 2008), así como también un ejercicio de poder y una exaltación de la masculinidad como mecanismo de destrucción (Meertens, 2000). Las agresiones sexuales se agravan cuando se trata de mujeres indígenas, lo que aumenta su vulnerabilidad (Carmona, 2014). 
Como contracara de este escenario en el cual las mujeres son victimizadas como estrategia para mantener los esquemas patriarcales de poder, la literatura ha identificado otros actores sociales: las lideresas, como mujeres que integran sus necesidades y fortalezas con las de sus comunidades, proponiendo nuevas formas de relación y convivencia. Las acciones de estas mujeres pueden ser significadas como parte de un engranaje de resistencia política (Carmona \& Serna, 2017).

Algunas de las iniciativas de lideresas latinoamericanas que se han reportado corresponden al movimiento de mujeres indígenas en Guatemala que han exigido justicia por el terrorismo de Estado en el conflicto (Salamanca, 2015); o el agenciamiento de mujeres indígenas en México quienes han cuestionado los roles de género luego de sufrir violencias por el Estado, las guerrillas y los carteles de narcotráfico, expresando así nuevas subjetividades políticas (Lamas, 2016), o los movimientos indígenas en Brasil liderados por mujeres que luchan por el reconocimiento de las mujeres en la esfera de lo público, superando la subordinación y su invisibilidad como sujetos y ciudadanos dominados (Jacinto, Mara, \& Scheibe, 2014) (Mendes, Da Silva, Neves, \& Da Silva, 2014). En Colombia se cuenta con múltiples reportes, entre ellos el de la iniciativa de campesinos, casi todos mujeres de Granada-Antioquia, quienes abogan por un nuevo empoderamiento político como resistencia ante el desplazamiento, los asesinatos y las desapariciones sufridos en el conflicto (Carrizosa, 2011), o el caso de las Tejedoras de Mampuján, una poblado pequeño al norte del país, donde las mujeres sobrevivientes de los enfrentamientos armados y el desplazamiento forzoso han exigido a los responsables acciones de reparación por la destrucción del tejido social (Rojas, 2015).

Al evidenciar que las guerras tienen efectos en toda la población, pero, que ella afecta de forma diferenciada a grupos con vulnerabilidades estructurales, como las mujeres, se hacen más importantes los análisis sociales con un enfoque diferencial, que permitan comprender los procesos por los cuales se generan liderazgos que apuntan a la equidad y a la promoción de nuevos lugares de enunciación, donde las víctimas se reconocen también como sujetos políticos activos y transformadores de su entorno y se revalúen las condiciones de género que perpetúan las condiciones que legitiman las violencias (Meertens, 2004).

Por ello, en esta investigación se indagó en los discursos de algunas lideresas sociales colombianas, que habían atravesado la experiencia de la guerra, por los significados ligados a su ejercicio como ciudadanas y el 
proceso de construcción de sus nuevas subjetividades como mujeres, así como el aporte de sus prácticas a los procesos de construcción de paz en sus comunidades de base, todo ello partiendo de la base teórica del Interaccionismo Simbólico según la cual tales significados fueron construidos en la interacción con otros y en universos socialmente configurados.

\subsection{Materiales y método}

Para esta investigación se partió de los presupuestos del interaccionismo simbólico, desarrollado por la Escuela de Chicago desde los inicios del siglo XX y planteado como una visión humanística para la investigación en las Ciencias Sociales. Fue Herbert Blumer, uno de los discípulos de esta Escuela, quien formuló sus tres premisas básicas, que resumen los postulados de esta propuesta frente a la construcción de la realidad como lenguaje: en primer lugar, se afirma que el ser humano orienta sus actos hacia las cosas en función de lo que éstas significan para él. (...) La segunda premisa es que el significado de estas cosas se deriva de, o surge como consecuencia de la interacción social que cada cual mantiene con el prójimo. La tercera es que los significados se manipulan y modifican mediante un proceso interpretativo desarrollado por la persona al enfrentarse con las cosas que va hallando a su paso" (Blumer, 1982, p. 2).

De estas consideraciones se desprende que la persona es un ser activo que construye realidades simbólicas en la interacción con otros, y que son esos significados los que permiten comprender las acciones humanas. También se desprende que la subjetividad es una construcción, y que la interpretación y el carácter reflexivo de los seres humanos son los posibilitadores de ese posicionamiento frente a la realidad. Asumir estas concepciones implica, a su vez, una postura ética y política frente a la realidad: ética por el carácter reflexivo, y la libertad y creatividad con la que se nombra la capacidad humana en el lenguaje y sus consecuencias en las realidades construidas; y política porque le da a todos los seres humanos la potencia de ser constructores transformadores de las realidades sociales, interrogando las estructuras tradicionales de poder, donde sólo a unos se les ha dado el privilegio de pensar las realidades.

En coherencia con los postulados del interaccionismo simbólico, este proyecto se direccionó por los planteamientos metodológicos de la Teoría Fundamentada, propuesta inicialmente por los sociólogos Barney Glaser y Anselm Strauss, a mediados de la década de los años 60 en los Estados Unidos, y correspondiente a una teoría derivada de datos recopilados de manera sistemática y analizados por medio de un proceso de investigación 
(Strauss \& Corbin, 2002). En este método son los actores sociales los que se significan con sus palabras, y es con éstas con las que se desarrolla la teoría.

En cuanto a las interlocutoras en este proyecto, el grupo estuvo constituido por seis mujeres lideresas que se reconocieran como víctimas del conflicto armado, pertenecientes a diferentes etnias y grupos sociales del país, mayores de edad para el momento de la investigación. Se trabajó con casos de mujeres que, por sus características, sus experiencias y sus discursos representaran un paradigma de aquello sucedido a muchas otras en Colombia. Para el muestreo se usó la técnica del muestreo teórico, que evolucionó durante el proceso, buscando mujeres que por sus características ayudaran a saturar las categorías emergentes durante el análisis.

Para la recolección de información se usaron encuentros conversacionales guiados por listas de preguntas y tópicos bajo la técnica de entrevistas semiestructuradas y a profundidad, donde las mujeres compartieron relatos extensos sobre sus vivencias íntimas ligadas al acontecimiento del conflicto en Colombia, a su subjetividad y a sus prácticas políticas.

Para el análisis de los relatos se usaron las técnicas propuestas por la Teoría Fundamentada: codificación, a través de un análisis línea por línea de las transcripciones de las entrevistas; y categorización, donde se realizó una agrupación posterior en conjuntos que respondieran desde un momento inicial descriptivo. Para la sistematización de la información se usaron herramientas de Office, como el procesador de textos de Word, y la organización de códigos y categorías en el programa Excel.

En cuanto a las consideraciones éticas, esta investigación partió de una reflexión humanista que reconoce los derechos y legitimidad de las mujeres como sujetos discursivos y políticos. En todos los momentos de este proyecto se hicieron esfuerzos para garantizar la protección de la vida, la salud, la dignidad, integridad, libre determinación, privacidad y confidencialidad de la información personal de las interlocutoras. Se usó un formato de consentimiento informado donde se dieron a conocer a las mujeres las condiciones de su participación, así como la posibilidad de su retiro del proceso en el momento que así lo decidieran.

\subsection{Resultados}

Para dar cuenta de los resultados de esta investigación, se presentarán cinco apartados con las categorías descriptivas emergentes del análisis realizado a los relatos de las mujeres participantes. 


\subsubsection{Historias de lideresas: las identidades}

proyecto en la reconfiguración de las subjetividades.

De víctimas a sujetos de derechos

En la historia de las mujeres lideresas aparecen inicialmente relatos ligados a los roles establecidos tradicionalmente para ellas: ser hija, esposa, madre. Sin embargo, la vivencia de las violencias en el contexto del conflicto armado pareciera hacer un llamado a la emergencia de otras configuraciones subjetivas que interaccionan con un escenario social que clama por otras formas de estar. Tal es el caso de una de las mujeres participantes en esta investigación, quien tuvo que abandonar su pueblo de origen, por la orden de uno de los grupos armados irregulares de la región, luego que estos asesinaran a su madre, una empleada doméstica de una finca en que al parecer fue testigo de alguna de sus reuniones. Al regresar, se producen una serie de nuevas interacciones con nuevos actores sociales, lo que produce en ella una transformación significativa:

Después de 17 años regresé al pueblo, y ya me puse a averiguar qué había pasado, por qué la habian asesinado, quién, todas esas cuestiones. Pero, yo todo eso lo hice a partir que conformamos la organización de víctimas Ave Fénix, que yo fui una de las fundadoras de esa organización. Es que a nadie le podía seguir sucediendo lo que me sucedió a mí; la sociedad no podía seguir siendo tan indolente. (Entrevista personal, mayo de 2017)

Estas nuevas identidades, como víctimas reclamantes a partir de un proyecto de organización social, nacen a partir de la palabra, de la conversación, de la vinculación con un colectivo, de un reconocimiento que reconfigura la identificación de otras formas de estar en lo social, y que cuestiona la violencia normalizada como forma de relación legítima.

\subsubsection{La guerra como nuevo universo de} interacción: acontecimiento simbólico para la reconfiguración de subjetividades

La guerra parece ser vivida por las mujeres lideresas en una doble vía: como lugar de confrontación con el horror de la deshumanización, y de forma paralela como un acontecimiento que paradójicamente marca el punto de inflexión para la emergencia de nuevas subjetividades políticas, en una trama simbólica que confronta el rol y permite nuevas identidades sociales. 
En el plano de los horrores que se viven en las guerras, en Colombia la violencia política y estructural ha experimentado la degradación de las formas de confrontación, en las que no sólo se busca eliminar al enemigo, sino la generación de terror, de un miedo que hace que al narrar los hechos quien los haya vivenciado lo hable en voz baja, como quien intenta nombrar un tabú o como quien rememora lo que no tiene nombre. Así se sentía en las palabras de algunas de las lideresas sociales. Una de ellas expresaba en susurros uno de los primeros momentos de horror en su experiencia con la guerra, cuando su padre fue asesinado por negarse a vender su finca a uno de los grupos armados irregulares del conflicto:

A él lo mataron en la finca, de un empalamiento. ¿Usted sabe que es eso? Cuando yo me regresé a la casa uno de los tipos que le hizo 'eso' me dijo: ¿sabe qué?, a su papá lo acabamos de matar; y yo: ¿qué? ¿Lo acabaron de matar? Y es que él estaba hablando, pero se estaba muriendo. $Y$ nos dijeron que no podiamos hacer nada y nos obligaron a dejarlo ahi, para que se fuera muriendo lentamente. (Entrevista personal, abril de 2017)

Otra de las lideresas lo decía claramente al vincular la muerte de un ser querido con su surgimiento como activista social y política, en la defensa ya no sólo de sus derechos, sino de los de su comunidad:

Si no hubieran matado a mi hermano mi vida sería otra. Eso fue lo que me motivó y me dio fuerzas para reclamar el derecho que a la gente no le pase lo mismo (Entrevista Grupal, mayo de 2017).

Y una más hacía una reflexión magistral cuando se refería a su dolor y su transformación, cuando se le preguntaba por el lugar de todo lo vivido en la guerra para la emergencia de una identidad como lideresa, y un accionar como sujeto político:

Los seres humanos no planeamos, reaccionamos. Yo creo que la vida me ha dado mucha mierda, pero yo en algún momento tuve que decidir qué hacer con todo eso, y decidi unirme a otras y reclamar (Entrevista personal, junio de 2017).

\subsubsection{La legitimación de la otredad epistémica en lo} social: una realidad creada con mujeres que se asocian

El horror vivido bajo la identidad de víctima pareciera servir de escenario de aniquilación de cualquier asomo de subjetividad política reclamante de justicia. Sin embargo, en el caso de algunas mujeres aparece lo inédito, 
marcado por nuevos acontecimientos que resignifican la interacción social y el lugar frente a otro. Para ello, en el caso de las interlocutoras de esta investigación, cobra gran importancia la identificación de movimientos de mujeres que proponen un nuevo lugar de enunciación, y que de la pasividad hacen un tránsito al movimiento organizado que cuestiona los mecanismos de poder y el ejercicio de la violencia. Tal es el caso de una de las entrevistadas, quien tuvo la oportunidad de conocer a las Madres de la Plaza de Mayo en Argentina, hecho que la moviliza por el impacto de este movimiento social frente a la desaparición de jóvenes en ese país. Un año más tarde, su hijo, un adolescente de 15 años, es desaparecido por un comando irregular de fuerzas de extrema derecha en el Magdalena Medio:

Yo tuve la oportunidad de ir a Argentina, y conocí a las mujeres de la Plaza de Mayo; y eso fue un referente para cuando yo llegué a Medellín, y al año completico mi niño desaparece, mi niño tiene 18 años y medio desaparecido. Entonces fundé los miércoles en el atrio de la iglesia, con mi hijo desaparecido. Y en últimas yo me di cuenta que tenía que seguir trabajando por las víctimas de este país, y empecé a formar la organización (Entrevista personal, abril de 2017).

Lo que parecen indicar estas mujeres, es que hay una confluencia entre el horror de lo vivido y el encuentro con otras formas de ser mujer, articuladas en los movimientos sociales, que más allá de agrupaciones de personas, se configuran como un interlocutor simbólico que re-crea el rol y la identidad de estas mujeres como actores políticos, en una simbiosis donde lo comunitario toma toda su fuerza como representante de una subalternidad vinculada con lo femenino en resistencia.

\subsubsection{Nuevas formas de ser, estar y actuar: significados y prácticas ciudadanas en mujeres lideresas}

El colectivo juega un lugar protagónico en la emergencia de nuevos significados del ser social, se trata de la palabra que se resignifica en la horizontalidad de otras que han experimentado la guerra, lo que se revierte en las prácticas de ciudadanía donde el reclamo por los derechos se convierte en el objetivo articulador del liderazgo. Esto pone de manifiesto el inmenso poder de las organizaciones sociales como un otro que interroga lo establecido y que propone otras formas de relación, y otras formas de integrarse a lo social, a partir de relaciones donde el poder se redistribuye. La articulación con un movimiento social provee a las otroras víctimas pasivas de un lugar de nueva escucha, de cura, y de reificación de nuevas 
prácticas como ciudadano político, que no deja de reconocer los hechos vividos, pero que mira hacia adelante con la convicción de quien se sabe sujeto transformador y hacedor de nuevas realidades:

Es que yo me curé, yo renací, renacimos todas de las cenizas, porque el dolor, la tristeza, la rabia, el odio, la incertidumbre, la desesperanza era muy grande. Y entonces cuando me invitaron, él me convenció (refiriéndose a un estudiante universitario líder de procesos sociales en la región), y bendito sea, porque a partir de ahí me cambió la vida en todo sentido. Es que de eso tan terrible sacamos cosas buenas, salió una mujer que ni yo sabía que existía (Entrevista personal, mayo de 2017).

\subsubsection{Las nuevas paces: de la tramitación del conflicto hacia la reconfiguración de sujetos legítimos creadores de realidades}

Cuando se reconfigura el sujeto político, y se pone en cuestionamiento el ordenamiento de poder donde la violencia ha sido legitimada como forma de opresión y relación, aparecen las figuras de mujeres en resistencia, mujeres que hacen 'ruido' como forma de anteponerse al control y a la dominación. $\mathrm{Y}$ es que participar de las guerras como combatientes, o participar de los procesos de tramitación del conflicto como proponentes de otras formas de relación es transgredir el lugar destinado por la cultura de género esencialista, que ha dividido la esfera social en la dupla hombre/mujer, masculino/femenino, dominación/sumisión. La palabra de la mujer, como lo dicho, como sus actos, como su capacidad performativa, son la contribución de ellas a las nuevas paces, hacia la legitimidad de un ser que por derecho puede ser sujeto discursivo validado en lo público. Así lo narran las lideresas, cuando en sus frases dibujan el derrotero, los pasos y transformaciones vividas para pasar de la debilidad de un rol establecido socialmente a una potencia que se articula con otros para lograr un país distinto, más humano, más en paz:

Es que éramos mudos con respecto a lo que tiene que ver con la violencia, pero al organizarnos y educarnos, nos sensibilizamos frente al dolor, nos independizamos como organización e hicimos visible el dolor en la escena pública, nos volvimos no invisibles y desde el abrazo y la cooperación le apostamos a la memoria histórica, a la no repetición de los hechos violentos, es que ahora las mujeres estamos empoderadas, no tenemos miedo. (Entrevista personal, mayo de 2017)

Desde las organizaciones sociales, yo decía 'es que hay mucho por contar'y me invitaron al Senado de la República, y es ahídonde pensé 
en que no solo se tenían que reparar las víctimas sino los territorios como totalidad, de una forma más integral, y se volvieron a abrir muchos procesos para que la gente pueda documentar los daños sufridos, todo eso a partir de la incidencia de nosotros. (Entrevista personal, junio de 2017)

\subsection{Discusión}

En los resultados de esta investigación se hizo manifiesto el tránsito que hacen las mujeres que emergen como lideresas sociales desde su enunciación como víctimas de la guerra, hacia la reconfiguración de su subjetividad política y un devenir como lideresas. Ello implica una reconstrucción de la identidad y del sentido que se les dan a las acciones en el marco de lo comunitario y de su ser como mujeres. Algunas investigadoras han documentado el lugar de las mujeres en la guerra en Colombia, y su afectación en razón del dominio histórico por su rol, para el mantenimiento de las relaciones de poder (Meertens, 2000), y la supremacía de los hombres como rasgos naturales de su masculinidad (Fernández Villanueva, 2000), así como el culto a la virilidad y la fuerza como valores sociales (Carosio, 2015), y el desarrollo de transgresiones que desilusionan a los sujetos en tanto los confronta con una eticidad que desaparece con la brutalidad de quienes se nombran como civilizados (Moreno, 2009).

Sin embargo, en el marco de estas condiciones de violencia emergen, en algunas ocasiones, nuevas identidades en las mujeres, que pueden remitir a metáforas inéditas, que permiten otras identificaciones en la construcción de la realidad social (Fernández Villanueva, 2000), con una subjetividad que le añade a la identidad un compromiso personal frente a los fenómenos sociales y una mayor capacidad de agencia para la toma de decisiones (Romero, 2016), lo que en el caso de mujeres altamente impactadas por los conflictos bélicos, evidencia que su reconstrucción como actores políticos y de su ser como ciudadanas pareciera ofrecer una ruta de salida a esta condición (Posada, y otros, 2016), tal como lo expresaron las interlocutoras de esta investigación. Se trataría de una identidad proyecto, en el sentido de la asunción de la diversidad desde un feminismo que se esfuerza por redefinir la condición de la mujer en oposición directa al patriarcado (Castells, 2001).

Bajo la noción de la guerra como acontecimiento, los relatos de las mujeres participantes de esta investigación logran ubicar el conflicto armado como un momento de inflexión que interroga el rol tradicional de mujer, asumido hasta la experimentación de la violencia, y un trasegar desde la 
pasividad victimizante hacia el liderazgo, como forma de resistencia y acto performativo de nuevas subjetividades y realidades sociales. En este mismo sentido, investigadores de las Ciencias Sociales han realzado el lugar de los hechos históricos significativos, más aún en contextos de guerra, como lugar para la aniquilación del sujeto y la apatía social o para la emergencia de nuevos sujetos políticos, activos y transformadores de las condiciones de injusticia (Patiño, Alvarado, \& Ospina, 2014). Adicional a lo anterior, los eventos percibidos como devastadores parecieran impulsar en algunas personas un incremento de la capacidad reflexiva y subjetiva, y de asociación para fortalecerse desde el movimiento social (Bilbao, Páez, Da Costa, \& Martínez, 2013).

En lo narrado por las participantes es de resaltar el lugar del asociacionismo como estrategia para el fortalecimiento de los movimientos sociales que abogan por los derechos de los grupos tradicionalmente excluidos, en este caso las mujeres, en una estructura social patriarcal que les ha negado el lugar de lo público y el ejercicio de una ciudadanía activa. Los estudios demuestran que lo comunitario es revestido con el rol del interlocutor válido pero que, a su vez, valida el discurso de reclamación de justicia. Esto evidencia que, si se logra una alta cohesión con grupos y redes de referencia, se puede hacer frente a la fragmentación que se manifiesta con la sociedad en pleno (Ospina, Alvararado, Carmona, \& Arroyo, 2017), e incluso se llega a la restauración como un acto colectivo, que permite tramitar el sufrimiento y reconocer y validar las múltiples realidades sociales (Lugo, Sánchez, \& Rojas, 2018).

El cambio en el rol y la identidad de las mujeres lideresas, como otro de los hallazgos de esta investigación, implica a su vez un cambio en las prácticas de ciudadanía como reclamación de equidad y justicia para la construcción de nuevos universos de interacción social y escenarios alternos donde se redistribuyen los poderes políticos, ya no en razón de una categorización binaria del género. Ello implica un resurgimiento del poder transformador de las mujeres legitimadas como sujetos discursivos. Algunas investigaciones hacen énfasis en la relación entre tales transformaciones subjetivas y el rol protagónico de estos actores en la construcción de nuevas y más justas estructuras sociales (Alvarado, Ospina, Botero, \& Muñoz, 2008), lo que enfatiza el lugar preponderante de los movimientos sociales, que refuerzan la identidad de grupos en resistencia ante la exclusión, y que tienen así un objetivo común (Gunder, Fuentes, \& Saez, 1989), generando nuevos espacios de participación que promueven el fortalecimiento de las ciudadanías que emergen de la condición de subalternidad, como en el caso 
de los objetivos seguidos por muchos movimientos de mujeres (Jelin, 1994). Las ciudadanías emergentes constituyen un potente y necesario referente para analizar el lugar de lo político en los grupos en condición de mayor vulnerabilidad, de allí que cobra sentido dar lugar a lo que se ha nombrado como prácticas sociales postciudadanas, ciudadanías desde abajo o nuevas ciudadanías (Estévez, 2016).

En los hallazgos de esta investigación fue muy importante evidenciar el cambio de una mujer silenciada, a la de una mujer en resistencia, legitimada discursiva y políticamente, que deriva en propuestas de reestructuración social que cuestionan los discursos homogenizantes que fundamentan las violencias dirigidas hacia algunos grupos como forma de dominación. Las mujeres lideresas participantes en este proyecto manifestaron que sus nuevas acciones de ciudadanía generan otras formas de relación que visibilizan a los subalternos y que aportan las bases para la tramitación de los conflictos bélicos a través de la palabra y la negociación de las diferencias en escenarios de mayor paridad y confianza. Lo que se demanda en estos procesos es la inclusión de las mujeres en los asuntos públicos, reformulando así la relación entre el Estado, el individuo y lo político, incluyendo a sus instituciones (Sassen, 2016), que como tal involucra profundos cambios estructurales hacia sociedades menos violentas, esto es, sociedades que construyan paces. $\mathrm{El}$ accionar de las mujeres lideresas hacia la paz puede interpretarse como una respuesta subjetiva ante la opresión de los sistemas patriarcales, y como forma de reafirmarse como sujetos discursivos y políticos en la escena de lo público (Fernández Villanueva, 2011).

\subsection{A manera de conclusión}

La guerra ha sido experimentada de forma diferenciada por las mujeres en razón de los roles asignados por las estructuras sociales, que como forma de opresión excluyen a las mujeres del escenario público y político. Esta condición aumenta la vulnerabilidad de ellas en escenarios de conflicto armado, siendo su victimización una estrategia de dominio y de mantenimiento del patriarcado. Estos contextos pueden generar una aniquilación de los esfuerzos por la construcción de un sujeto político activo, pero también y paradójicamente pueden presentarse como un acontecimiento que ofrece nuevas significaciones que, en interacción con algunas mujeres, reconfigura su manera de ser y de estar en el mundo, generando nuevas identidades que como proyecto proponen transformaciones en las relaciones de poder, dando lugar a nuevas formas de configuración de la subjetividad política, en este caso, un compromiso renovado con los 
movimientos sociales que abogan por la legitimación de las mujeres como pares discursivos y de derechos.

Estos movimientos sociales ofrecen nuevas interacciones generando nuevos significados sobre lo público, y de allí consecuentemente emergen otras acciones ciudadanas encaminadas a confrontar la naturalización de las violencias hacia los subalternos, en este caso hacia las mujeres, que han vivido la degradación de las guerras y la violencia dirigida para la generación de marcas permanentes del horror. Al asociarse con otras mujeres se propone un nuevo lugar de enunciación, unas ciudadanías otras, que movilizan y recrean los roles establecidos para darle una fuerza de interlocución válida a los actores comunitarios, con la voz de lo femenino como resistencia.

Al reconfigurarse el sujeto político a partir de las nuevas identidades, y al cuestionar el ordenamiento legitimador de las violencias, las mujeres organizadas como lideresas contribuyen en la tramitación de los conflictos y a los movimientos que abogan por la generación de nuevas paces, incluyentes y participativas, que legitiman a todos como sujetos públicos, productos y productores de nuevas realidades sociales, donde vivir el conflicto sin aniquilarse sea posible.

\section{Referencias}

Alvarado, S. V., Ospina, H., Botero, P., \& Muñoz, G. (2008). Las Tramas de la Subjetividad Política y los Desafíos a la Formación Ciudadana en Jóvenes. Revista Argentina de Sociología, 11, 19-43. Disponible en: www.scielo.org.ar/pdf/ras/v6n11/v6n11a03.pdf

Bastick, M., Grimm, K., \& Kuns, R. (2007). Sexual Violence in Armed Conflict. Global Overview and Implications for the Security Sector. Geneva: Centre for the Democratic Control of Armed Forces.

Berger, P., \& Luckmann, T. (2001). La Construcción Social de la Realidad. Buenos Aires: Amorrortu.

Bilbao, M., Páez, D., Da Costa, S., \& Martínez, G. (Abril de 2013). Cambio en creencias básicas y crecimiento post estrés: un estudio transversal sobre el fuerte impacto de los hechos positivos sobre el bienestar. Terapia psicológica, 31(1), 127-139. Obtenido de http://teps.cl/index.php/teps/article/view/92/102

Blumer, H. (1982). El Interaccionismo Simbólico. Perpectiva y método. Barcelona: Hora S.A.

Carmona, J. (2014). Las niñas de la guerra en Colombia. Manizales: Centro Editorial Universidad Católica de Manizales.

Carmona, J., \& Serna, I. (2017). Subjetivación política y configuración de identidades en niños y niñas y sus agentes relacionales, afectados por el conflicto armado: posibilidades, potencias y resistencias. En M. Ospina, S. Alvarado, J. Carmona, \& A. Arroyo, Construcción 
social de niñas y niños en contextos de conflicto armado: desafios para los procesos de construcción de paz, reconciliación y democracia en Colombia (p. 324). Bogotá: Cinde.

Carosio, A. (2015). Misoginia y fascismo. Utopía y Praxis Latinoamericana, 20(68), 103112. Disponible en: http://www.redalyc.org/articulo.oa?id=27937090008

Carrizosa, C. (2011). El trabajo de la memoria como vehículo de empoderamiento político: La experiencia del Salón del Nunca Más. Boletín de Antropología, 25(42), 36-56. Disponible en http://www.redalyc.org/pdf/557/55722568001.pdf

Castells, M. (2001). La era de la información: economía, sociedad y cultura. (v. II) El poder de la identidad. México: Siglo XXI Editores.

Castoriadis, C. (1993). El inconsciente y la ciencia. Buenos Aires: Amorrortu.

Congreso de la República. (10 de junio de 2011). Ley 1448 de 2011 por la cual se dictan medidas de atención, asistencia, y reparación integral a las víctimas del conflicto armado interno y se dictan otras disposiciones. Diario Oficial 48.096.

Cortina, A. (1997). Ciudadanos del mundo. Hacia una teoría de la ciudadanía. Madrid: Alianza Editorial.

Delgado, M. (2015). Las víctimas del conflicto armado colombiano en la Ley de Víctimas y Restitución de Tierras: apropiación y resignificación de una categoría jurídica. Perfiles Latinoamericanos, 23(46), 121-145. Disponible en: http://perfilesla.flacso.edu.mx/ index. php/perfilesla/article/view/517/461

Estévez, A. (2016). ¿Derechos humanos o ciudadanía universal? Aproximación al debate de derechos en la migración. Revista Mexicana de Sociología, 78(1), 61-87. Disponible en: http://www.revistas.unam.mx/index.php/ rms/article/view/53476/47564

Fernández Villanueva, C. (2000). Sexo, rasgos y contextos: una visión crítica de la agresividad y su relación con el género. En A. Hernando (ed.) La construcción de la subjetividad femenina (pp. 144-186). Madrid: Instituto de Investigaciones Feministas. Universidad de Madrid.

Fernández Villanueva, C. (2004). Violencia contra las mujeres: una visión estructural. Intervención Psicosocial, 13(2), 155-164. Disponible en https://www.ucm.es/data/cont/ docs/701-2014-02-28-intervencion.pdf

Fernández Villanueva, C. (2007). Violencia y agresiones: pinceladas para una nueva perspectiva psicosocial interaccionista. En J. Romay Martínez, Perspectivas y retrospectivas de la Psicología social en los albores del siglo XXI (pp. 163-170). Madrid: Biblioteca Nueva.

Fernández Villanueva, C. (2011). Ni “almas bellas" ni "guerreros justos”: mujeres implicadas en violencia política. Cuestiones de Género: de la igualdad a la diferencia, 6, 75-95. doi: http://dx.doi.org/10.18002/cg.v0i6.3764

Guevara, R. (2016). Mujeres desplazadas por el conflicto armado. Situaciones de género en Cali y Popayán. Colombia. Disponible en: http://www.disaster-info.net/desplazados/ informes/asprodeso/mujeresdesplazadas.htm 
Gunder, A., Fuentes, M., \& Saez, J. (1989). Diez tesis acerca de los movimientos sociales. Revista Mexicana de Sociología, 51(4), 21-43. doi:10.2307/3540814

Jacinto, G., Mara, D. S., \& Scheibe, C. (2014). Limites e possibilidades da militância política em um movimento social rural de mulheres. Estudos Feministas, 22(1), 51-70. Disponible en http://www.scielo.br/pdf/ref/v22n1/04.pdf

Jelin, E. (1994). ¿Ciudadanía emergente o exclusión? Movimientos sociales y ONG en los años noventa. Revista Mexicana de Sociología, 56(4), 91-108. doi: 10.2307/3541084

Koulianou-Manolopoulou, P., \& Fernández Villanueva, C. (2008). Relatos culturales y discursos jurídicos sobre la violación. Athenea Digital. Revista de Pensamiento e Investigación Social, 14, 1-20.

Lafaurie, M., Calderón, A., Cuellar, J., Gómez, F., Gómez, M., \& Rojas, Y. (2009). Significados de 'la pareja' en proyectos de vida de jóvenes afectados(as) por el desplazamiento. Revista Colombiana de Enfermería, 4(4), 23-30. Disponible en: www.uelbosque.edu. $\mathrm{co} /$ sites/default/files/publicaciones/revistas/revista_colombiana_enfermeria/volumen4/ significados_pareja_proyectos_vida_jovenes_afectados_desplazamiento.pdf

Lamas, M. (2016). Mujeres guerrerenses: feminismo y política. Revista Mexicana de Ciencias Politicas y Sociales, 59(226), 409-424. Disponible en http://www.revistas.unam.mx/ index.php/rmspys/article/view/53668/48476

Lugo, V., Sánchez, P., \& Rojas, C. (2018). La restauración con sobrevivientes del conflicto armado en Colombia: Una perspectiva de acción psicosocial. Eleuthera, 19, 55-73. doi: 10.17151/eleu.2018.19.4.

Mead, G. (1982). Espíritu, persona y sociedad. Desde el punto de vista del conductismo social. Barcelona: Paidós Básica.

Meertens, D. (2000). Ensayos sobre tierra, violencia y género. Hombres y mujeres en la historia rural de Colombia 1939-1990. Bogotá: Universidad Nacional - Centro de Estudios Sociales.

Meertens, D. (2004). Género, desplazamiento, derechos. En M. Bello, Desplazamiento forzado: dinámicas de guerra, exclusión y desarraigo (pp. 197-204). Bogotá: ACNURUniversidad Nacional de Colombia. Disponible en: http://aprendeenlinea.udea.edu.co/ $\underline{\mathrm{lms} / \mathrm{moodle} / \text { file.php/232/Unidad 3/DonnyMeertens.pdf }}$

Mendes, M., Da Silva, S., Neves, R., \& Da Silva, T. (2014). A organização das mulheres extrativistas na região Sudoestemato-grossense. Estudos Feministas, 22(1), 71-89. Disponible en http://www.scielo.br/pdf/ref/v22n1/05.pdf

Moreno, M. (2009). Algunas reflexiones desde el psicoanálisis acerca de la guerra. Poiésis, 17, 1-6. doi: org/10.21501/16920945.177

Organización de las Naciones Unidas. (2016). La plataforma de acción de Beijing cumple 20 años. Disponible en: http://beijing20.unwomen.org/es/in-focus/armed-conflict

Ospina, M. C., Alvararado, S. V., Carmona, J. A., \& Arroyo, A. (2017). Construcción social de niñas y niños en contextos de conflicto armado: Desafios para los procesos de construcción de paz, reconciliación y democracia en Colombia. Bogotá: Cinde. 
Patiño, J., Alvarado, S. V., \& Ospina, M. C. (2014). Ampliación de sentidos sobre las prácticas políticas de jóvenes con vinculación a siete movimientos sociales en Colombia. Revista Latinoamericana de Ciencias Sociales, Niñez y Juventud, 12(1), 257-275. doi: $10.11600 / 1692715 x .12115101012$

Posada, I., Mendoza, A., Restrepo, C., Cano, S., Osorio, \& Isabel. (2016). ¿Qué hacer cuando estoy enferma? La búsqueda de alternativas para el bienestar en mujeres desplazadas, Medellín 2013-2014. Revista Facultad Nacional de Salud Pública, 34(2), 167-174. doi:10.17533/udea.rfnsp.v34n2a05

Rojas, M. (2015). Mampuján, en el acto de partir: el duelo como levantamiento y la comunidad en transición. Reconciliación y representación en Jean-Luc Nancy. Revista de Estudios Sociales, 51, 50-61. doi. org/10.7440/res51.2015.04

Romero, M. (2016). Identidades (Im)pertinentes: analizando la guerra y el poder desde la teoría feminista. El caso de las mujeres integrantes del Partido Comunista del Perú -Sendero Luminoso (PCP-SL) y del Movimiento Revolucionario Tupac Amarú (MRTA). (Tesis Doctoral). Universidad Complutense de Madrid.

Salamanca, C. (2015). Los lugares de la memoria y de la acción política en Guatemala. Justicia transicional, políticas del reconocimiento y ficciones de secularismo. Revista de Estudios Sociales, 51, 62-75. doi. org/10.7440/res51.2015.05

Sassen, S. (2016). Incompletud y la posibilidad de hacer ¿Hacia una ciudadanía desnacionalizada? Revista Mexicana de Ciencias Políticas y Sociales, 226, 107-140. Obtenido de http://www.revistas.unam.mx/index.php/rmspys/ article/view/53659/48465

Strauss, A., \& Corbin, J. (2002). Bases de la investigación cualitativa: técnicas y procedimientos para desarrollar la teoría fundamentada. Medellín: Universidad de Antioquia.

Teixeira, I., \& Oliveira, M. (2014). Práticas de cuidado à saúde de mulheres camponesas. Interface: Comunicacao, Saude, Educacao, 18(Sup 2), 1341-1354. doi: 10.1590/180757622013.0476

Villavicencio, L. (2014). Minorías étnico-culturales y derechos de las mujeres. Revista de Ciencia Política, 34(3), 605-621. Disponible en http://www.revistacienciapolitica.cl/rcp/ wp-content/uploads/2015/01/05_vol_34_3.pdf

Wallace, S., Nazroo, J., \& Bécares, L. (2016). Cumulative Effect of Racial Discrimination on the Mental Health of Ethnic Minorities in the United Kingdom. American Journal of Public Health, 106(7), 1294-1300. doi: 10.2105/AJPH.2016.303121 


\title{
13. La experiencia del teatro: resignificación de historias y configuación de subjetividades politicas de mujeres víctimas del conflicto armado
}

\author{
Magda Victoria Díaz Alzate ${ }^{43}$ \\ Mariana Yepes Bustamante ${ }^{44}$
}

\section{Resumen}

Este texto presenta hallazgos de la investigación cualitativa, con diseño fenomenológico, cuyo objetivo consistió en comprender las experiencias de resignificación y configuración de subjetividades políticas, a través del teatro, de un colectivo de mujeres víctimas de violencias en el conflicto armado colombiano. Las Peregrinas constituyen un caso prototípico, en tanto este grupo de mujeres utiliza el teatro testimonial como herramienta social para recuperarse de los traumas ocasionados por la guerra. A través del testimonio de tres mujeres de este colectivo, se encontró que la vivencia del teatro permite la construcción de la memoria colectiva, relaciones de sororidad y emergencia de capacidades para la compasión con otras mujeres víctimas, favoreciendo la resignificación de las historias de vida y la configuración de subjetividades políticas.

Palabras clave: experiencia artística, memoria, resignificación, subjetividad política.

\section{Abstract}

This paper presents findings from qualitative research with phenomenological design, whose objective was to understand the experiences of resignification and configuration of political subjectivities, through theater, a group of women victims of violence in Colombia's armed conflict. The Peregrinas constitute a prototypical case, while this group of women uses testimonial theater as a social tool to recover from the traumas caused by the

43 Universidad Católica Luis Amigó. Correo: magda.diazal@amigo.edu.co. 44 Universidad Católica Luis Amigó. Correo: coor.ghumana@amigo.edu.co. 
war. Through the testimony of three women of this group, it was found that the experience of the theater allows the construction of collective memory, relationships of sorority and emergence of capacities for compassion with other victimized women, favoring the resignification of life stories and the configuration of political subjectivities.

Keywords: artistic experience, memory, resignification, political subjectivity

\subsection{Introducción}

El conflicto armado colombiano ha dejado miles de mujeres víctimas con cuerpos violentados y traumas, secuelas no menos importantes que las desigualdades e injusticias que ha ocasionado este flagelo. Si bien la firma del acuerdo entre el Estado y las FARC-EP representa un hito histórico para tejer la paz, no es suficiente, como pacto social, para atender todas las consecuencias (Cogollo-Ospina y Durán-Palacio, 2015) que tuvo esta guerra. El Informe Nacional de Violencia Sexual en el Conflicto Armado (2017), expone que, al 20 de septiembre de 2017, se registran 15.076 personas que han sufrido vejaciones contra su libertad e integridad sexual; de esa cifra, el $91,6 \%$, son mujeres: niñas, adolescentes y adultas. Esta situación genera la necesidad de entender los cuerpos femeninos violentados como territorios que se viven y se habitan y con los cuales, las mujeres se relacionan con los acontecimientos cotidianos. De acuerdo con Butler (2010), el cuerpo en tanto permite la aparición frente al otro, deberá ser considerado como fenómeno social. También para Segato (2013), "en especial en el cuerpo femenino y feminizado, los enemigos de la red graban con saña las señales de su antagonismo [cursivas de cita original]" (p. 37). Estas señales son un mensaje político: su cuerpo, ese que habitan, realmente no les pertenece, es una extensión más del territorio, es vulnerable, disponible y explotable. Esta compleja violencia desafía las formas de comprensión y de acompañamiento psicosocial a las víctimas del conflicto armado, por lo que este mismo fenómeno de guerra entrelaza complejidades que exceden, incluso, el acuerdo de paz firmado, la ley de víctimas y los programas gubernamentales creados para la atención de las mismas.

Para Moreno Camacho y Díaz Rico (2015), es innegable que hay una apuesta en Colombia por la atención a las víctimas del conflicto armado; sin embargo, resaltan que aún en estos escenarios, los discursos tradicionales han imperado con propuestas generalizables de la intervención. La Psicología, que ha cargado con el lastre del deber de constituirse ciencia, también se 
permitió una forma de intervención desde el modelo biomédico, que termina siendo poco plausible para atender la complejidad humana (Díaz-Alzate y Arroyave-Hincapié, 2018), especialmente en un fenómeno con tantas aristas como el conflicto armado colombiano. Se asimila entonces atención para todas las víctimas (Ley 1448 de 2011) con tratamiento de la misma forma para todas las víctimas. No obstante la presencia de un protocolo oficial de atención a las víctimas, existen en la ciudad de Medellín otras formas de acompañamiento psicosocial alternativas, desde las artes, que han ayudado especialmente a las mujeres víctimas de la guerra a superar sus traumas y a resignificar sus historias de vida. A partir del conocimiento de estas otras formas de acompañamiento, surgió la pregunta de investigación: ¿De qué manera las experiencias teatrales de un colectivo de mujeres víctimas de violencias en el conflicto armado colombiano, facilita la resignificación de lo vivido y la configuración de sus subjetividades políticas? Los objetivos se orientaron hacia la comprensión del significado del teatro como parte del proceso de elaboración de las experiencias de violencias y cómo estas vivencias artísticas favorecen su estar ahora en el mundo.

La magnitud de los actos violentos cometidos contra las mujeres en el país, en razón del género, ha posibilitado develar la dignidad femenina para resistir y denunciar, a partir de la organización colectiva, las vivencias compasivas y la solidaridad entre mujeres, que aquí se trata desde el concepto de sororidad de Lagarde (2006), y que contiene la implicación ética y política en aquello que ocurre a cada mujer, para consentirse en el apoyo mutuo. Esta capacidad organizativa, desde el actuar para la dignificación de las mujeres, es uno de los aspectos rescatables de las artistas que participaron en la investigación, en la manera de juntarse para sanarse, denunciar y resistir. Los cuerpos aparecen como narración viva en las escenas de la obra Oscuro Claro ${ }^{45}$, que las ha convocado durante varios años, y que sirvió como camino para elaborar los daños causados por las violencias, que de otros modos no habían logrado narrar. El arte, permite que se cuente aquello que, de otra manera, resultaría imposible de contarse (Tolstoi, 1898).

El teatro testimonial como forma alternativa para resolver el dolor y el trauma psicosocial en el sentido de Ignacio Martín-Baró (1990), donde la herida es ocasionada socialmente y no tiene su origen en el propio individuo, trasciende la psicoterapia tradicional, en tanto, se centra en las capacidades

45 Obra de teatro escrita de manera colectiva por las tres mujeres artistas de Las Peregrinas. A través de esta obra, las artistas presentan las historias de vida marcadas por el conflicto armado, la manera en la que han tramitado sus dolores y la resignificación de los acontecimientos. Es la obra que ha servido como herramienta para su recuperación psicosocial. 
subjetivas para la reconstrucción de historias de vida, la confrontación con este trauma y para el acompañamiento compasivo entre las víctimas, que han mostrado tener estas mujeres. Es una propuesta de acompañamiento psicosocial que emana de la capacidad de contar historias, de tejer memoria y de denunciar, como formas posibles de transitar el dolor hacia la resignificación, además, que pone en tensión los programas para el acompañamiento de víctimas que tienen una concepción del trauma meramente individual. Si el trauma es entendido como psicosocial, la posibilidad de elaborarlo, podría entenderse como recuperación psicosocial (Lugo, Sánchez y Rojas, 2018), lo que implica, por un lado, reconocer la capacidad de agenciamiento de las mujeres víctimas para tomar decisiones frente a lo acontecido en sus cuerpos, y por otro, visibilizar la iniciativa de organización de quien dirige el colectivo Las Peregrinas, para que sirviese como herramienta social para tramitación del dolor.

Se presentará entonces, en este escrito, la capacidad de configurar la memoria como tejido colectivo, en dos sentidos: en su función reparadora (Centro Nacional de Memoria Histórica, 2013), y en su capacidad crítica (Barrero, 2015). La memoria así entendida permitió construir el sentido de la vivencia del teatro de las tres mujeres del grupo Las Peregrinas, en tanto escenario para rescatar la historia de violencia, entenderla, retejerla y resignificarla. La memoria como capacidad de crear, no solo como posibilidad de remembranza de hechos pasados, transcurre hacia la capacidad de "re-construir los procesos de interacción con el mundo social" (Torres, 2017, p. 26), y en el teatro testimonial, esta capacidad de crear permitió la reconfiguración de subjetividades de las mujeres artistas, en cuyas acciones y discursos se pueden leer claves de sujetos políticos, con características como la trascendencia de lo individual a lo colectivo, la reflexividad sobre su capacidad para transformarse y transformar, el reconocimiento de su posibilidad de construirse y reconstruirse, la capacidad de organización colectiva y de pensarse en el entre-nos (Arias y Villota, 2007).

\subsection{Método}

La investigación cualitativa, con diseño fenomenológico, permite develar la experiencia subjetiva de las participantes. Toda vez que aquí el concepto de experiencia es entendido desde Larrosa (2006) como "eso que me pasa" (p. 44), se halla en la fenomenología el método que permite acceder al significado sobre el teatro como acontecimiento transformador de vidas, de memorias y de configuración de subjetividades, puesto que la realidad le pertenece a la persona que la experimenta (Martínez Miguélez, 2006). 
Para lograr el objetivo general de este estudio se realizaron tres acciones específicas de indagación: describir los procesos de resignificación vivenciados en el teatro por el colectivo de mujeres, víctimas del conflicto armado, reconocer el teatro como posibilidad de configuración de subjetividades políticas de este colectivo de mujeres, y analizar en la creación teatral la resignificación de las historias vividas de las mujeres participantes en la investigación.

Se contó con los relatos de tres mujeres del grupo Las Peregrinas que encontraron en el teatro testimonial un camino para reconstruir sentidos de vida, expresarse y denunciar. Es un caso prototípico, porque se conforma como herramienta social, para que las mujeres víctimas de violencias en el conflicto armado colombiano, pudieran narrarse, tramitar sus dolores, transformar sus historias de vida y configurarse desde otro lugar diferente al sufrimiento que causó las violencias en ellas. A: creadora del colectivo, directora del grupo, psicóloga, docente, cantante y actriz. R: nacida en el Departamento del Chocó, sufrió múltiples desplazamientos forzados desde su niñez y en el año 2008 llegó a Medellín, es madre, empleada doméstica, actriz y sobreviviente. B: de la región del Urabá, ha tenido múltiples desplazamientos forzados en la zona rural y en la zona urbana, actualmente reside en Medellín, madre, actriz, ama de casa y sobreviviente.

Se eligió la entrevista como técnica para la generación de información, puesto que favorece la relación empática. Para Martínez Miguélez (2006), la entrevista en sí misma constituye un instrumento que en su sustento epistemológico conversa son las pretensiones de la investigación cualitativa. Por su carácter dialógico, permite el surgimiento de palabras propias para relatar las vivencias, y así, develar las experiencias en torno al teatro testimonial. Estas entrevistas cualitativas (Valles, 2002) fueron grabadas en audio y transcritas para conservar los detalles de las narraciones. El proceso analítico siguió las propuestas de Coffey y Atkinson (2003) y de Strauss y Corbin (2002), sobre codificación y categorización. Además, se apoyó en Martínez Miguélez (2006) para la contrastación, que en este caso se nombra como triangulación, primero con las participantes para corroborar las interpretaciones, validar y legitimar la construcción de sentidos; y triangulación con fuentes secundarias: marcos referenciales y docentes investigadores de la Línea de Investigación Problemáticas Psicosociales Contemporáneas ${ }^{46}$ (Seminarios de línea conjuntos, 22 de febrero y 1 de junio de 2018). Se

46 Pertenece al Grupo de Investigación Estudios de Fenómenos Psicosociales de la Facultad de Psicología y Ciencias Sociales de la Universidad Católica Luis Amigó. Actualmente se encuentra en categoría B Colciencias. 
acudió al software AtlasTi, y a matrices de análisis construidas por las investigadoras; se utilizaron citas, códigos, comentarios y memos.

\subsection{Consideraciones éticas}

Se siguieron los lineamientos deontológicos y bioéticos, contemplados en el capítulo VII de la Ley 1090 de 2006, que rige el actuar del psicólogo en la investigación científica. La metodología utilizada se basa en los principios de respeto y dignidad que salvaguardan el bienestar y los derechos de las mujeres participantes. Se contó con un acuerdo por escrito, mediante el consentimiento informado basado en la claridad de la información para un adecuado cumplimiento de los objetivos planteados; de esta manera, las participantes, pudieron conocer y aceptar los procedimientos con total libertad de elección.

\subsection{Resultados}

Se presentan dos categorías emergentes de los resultados de la investigación.

\subsubsection{Sobre la memoria y resignificación de la historia}

En el escenario del conflicto armado colombiano la memoria puede ser concebida como patrimonio público de la sociedad, un derecho y un modo de resistencia. Es la aguja que teje el entramado del proyecto de vida colectivo que se ha roto por causa de la guerra. La memoria para Barrero (2015) tiene una pretensión política y crítica en cuanto sirve de resistencia contra la impunidad y de soporte de la verdad pública. En este sentido, puede entenderse como una construcción colectiva, que no está contenida como verdad absoluta en ningún sujeto, lo que lleva, inevitablemente, a pensarla como un tejido en el cual se encuentran diferentes hilos-narrativos y agujas-subjetivas, que cumplen el papel de denunciar para resistir y para que no se repitan los vejámenes contra ningún ser humano. Además, la memoria se configura como reparadora (Centro Nacional de Memoria Histórica, 2013), en tanto, a partir del teatro testimonial, las mujeres han encontrado la forma de sanar las heridas. Han hallado una opción para reconstruir sus proyectos de vida y consolidar vínculos de compasión ${ }^{47}$, identificación y solidaridad con otras mujeres:

47 Aquí se habla de compasión en términos de Nussbaum (2008): “Si (...) sentimos compasión, esto obedece a que creemos que la persona no es culpable de sus dificultades o a que, aunque éstas se deban a cierto fallo suyo, nos parece que el sufrimiento no es proporcional al mismo" (p. 351). 
cuando uno está haciendo teatro, se mete, está en las escenas, es como si uno estuviera viendo eso, ahí en la vida real, ahí mismo, pues, son cosas que ya pasaron y todo eso, pero como que lo llevan a uno de vuelta a recordar, como a recordar esas cosas sin que a uno le duelan. (R, marzo 25 de 2017).

La función reparadora de la memoria permite la reconstrucción de vínculos sociales, en los cuales se comunica aquello que el miedo había acallado (Centro Nacional de Memoria Histórica, 2013). Cuando R habla de las historias dolorosas que ha convertido en escenas en la obra de teatro, dice: "Uno recuerda, pero sin ese dolor que le haga tanto daño a uno, uno transforma ese dolor. Si...ya no se siente dolor, ya como que hay una sanación" (marzo 25 de 2017). Además, lo que podría nombrarse como acción performativa de la construcción colectiva de la memoria, es que también permite el reencuentro con las prácticas ancestrales, con la cultura y el territorio: "es muy bonita [refiriéndose a la escena], a mí me gusta hacerla porque trae uno muchos recuerdos que a uno se le están perdiendo. Por ejemplo, yo recuperé mucho las curaciones ancestrales" (R, marzo 25 de 2017). Entrevistadora: ¿En qué consiste esta conexión con su territorio que ha sido posible a partir del teatro? Participante R: "yo de niña cantaba mucho y de cierto tiempo yo dejé de cantar...y ahora ya de vieja que estamos y empezamos a hacer teatro y empecé a cantar de nuevo" (marzo 25 de 2017). Este tejido de memoria, consiente precisar que una vez la víctima ha logrado dotar con otro significado su historia de vida, tendrá las herramientas para distanciarse del hecho victimizante, tal como lo demuestra $\mathrm{R}$ cuando manifiesta que se siente lista para hacer otro tipo de puesta en escena:

algo como cómico, no estar todo el tiempo con tanta tristeza porque si ya pasamos esa página, ya nos recuperamos, yo siento que es así, ya lo que nos dejó la guerra ya quedó atrás y ya hay que mirar hacia delante y hacer cosas diferentes. Está bien que uno en su momento vivió muchas tristezas y todo eso, pero ya eso son cosas que quedó [sic] atrás y ya, ya no es lo mismo y no porque uno se olvide, uno nunca olvida esas cosas porque, para olvidarse de esas cosas se le acabaría a uno la memoria, pero ya uno recuerda esas cosas sin que a uno le hagan más daño. (marzo 25 de 2017).

Cuando se presenta la memoria como derecho, es necesario reconocer que existe pluralidad de memorias, no se trata de una sola memoria, se trata de una gran riqueza de sentidos que le han permitido a la sociedad, tal como lo menciona Barrero (2015), combatir el cinismo y la impunidad, oponerse 
al olvido y al silencio. Es una afirmación que concibe a la memoria como una construcción, no como un artefacto-objeto contenido en la mente de los sujetos como verdad absoluta. Es un entramado de sentidos, una urdimbre que habla de los acontecimientos y que no valora una vivencia por encima de la otra. El teatro testimonial de Las Peregrinas, permitió que esta memoria fuera un derecho para las víctimas, y sirvió de "atajo" (A, refiriéndose al significado que le da al teatro, octubre 4 de 2017) para desatar los traumas psicosociales inscritos por la guerra en estas mujeres.

\subsubsection{Sobre la subjetividad politica. Entre-cruzando historias}

Arias y Villota (2007) reconocen cinco características del sujeto político. A la luz de dichas características se analizará la configuración de subjetividad política de las mujeres en el marco del conflicto armado colombiano.

- El sujeto político "Se interesa por trascender del ámbito individual al colectivo; del ámbito privado al público" (p. 41). Las mujeres de Las Peregrinas, en su defensa de la vida, deciden romper el silencio y salirse de sí para testimoniar en lo público, para pensar de forma colectiva, interactuando con otras mujeres, cuidando a otras mujeres: "una vez estábamos haciendo unas poquitas escenas... ahí en la Alpujarra...y después que terminamos salió una señora a decir que ella había vivido lo mismo y se subió a una tarima a contar la vida entera...y lloraba" (R, marzo 25 de 2017). Hay un deseo de que ninguna otra mujer repita su historia, la subjetividad política comienza a configurarse cuando estas personas más allá de quedarse arrullando su dolor, son capaces de anticiparse al dolor del otro y procura su protección.

- "Asume una actitud reflexiva sobre su condición de ser político" (p. 41). A través de la experiencia artística, las mujeres que han vivido la guerra, deciden contar sus testimonios, en este punto se puede hablar de reflexión llevada a la acción, estas mujeres se saben sujetos activos porque asumen una postura para abandonar la neutralidad, la imparcialidad. Esta reflexión, les permite la deliberación frente a lo ocurrido: "Cuando hacemos teatro sentimos como una alegría y a veces sentimos el dolor de los demás...había muchas mujeres que vivieron muchas cosas: que violaciones, que todo eso y uno como que siente todo ese dolor que ellas también pasaron" (R, marzo 25 de 2017).

- "Se asume como constructor de su propia realidad" (p. 41). Cuando R habla del teatro, expresa: "sensibiliza mucho, yo creo que el teatro sí cambia a una persona, sí la llega a cambiar porque yo era amargada, 
vea, yo era amargadísima, ni siquiera me gustaba que mi familia me visitara, ya cambié, ya soy diferente" (marzo 25 de 2018). La mujer halla lecho y comienza su proceso de configuración como el sujeto activo, colectivo, histórico y político. A describe parte del proceso de $\mathrm{B}$ en la vivencia teatral, reconociéndole su capacidad para reconstruirse y elaborar el dolor:

- B ha logrado en el teatro, ella lo dice muy lindo, tener un lugar fuera de su casa. Cada vez que cuenta la historia de cómo fue asesinado su padre, estando ella en el vientre de la madre, ella llora en escena y hubo un momento en el que yo le dije: "B, quitemos la escena, no tengo problema, quitémosla", y ella me dice: "no la vaya a quitar, a mí esto me sirve. Cada vez que lloro, sano". (octubre 4 de 2017).

- "Reconoce la responsabilidad que tiene frente a la necesidad de transformar la realidad" (p. 41). Las mujeres que participaron de este proyecto de investigación se reconocen como sujetos de derechos, pero también sujetos de deberes, saben que su deber con la sociedad civil es invitarla a escuchar de una forma poética, aquello que resulta inconmensurable. Estas mujeres dulcifican lo amargo a través del arte, no a través del engaño y son plenamente conscientes de que todo orden social es construido, incluso el patriarcal y, por lo tanto, es susceptible de ser transformado y ellas participan activamente de esa transformación:

- Un arte como el que a mí me interesa, es un arte a partir de lo testimonial, de las memorias de este país, en este caso de las mujeres de este país, porque esas memorias no circularían, no circulan fácilmente en otros escenarios distintos a los de quienes han vivido estas historias... si el arte no logra transformar el dolor en poesía, entonces para mí está siendo un arte panfletario. Sin el arte, estas memorias, estas historias no podrían estar en el ágora, en lo público. (A, octubre 4 de 2017).

- Para finalizar con las características, Arias y Villota (2007) proponen que "Esa transformación la logra mediante la acción organizada y reflexionada" (p. 41). En las narraciones de las tres mujeres entrevistadas, se develan dos acciones organizadas: una de estas acciones es la conformación del colectivo teatral Las Peregrinas donde estas mujeres denuncian lo atroz y absurdo de una guerra. La segunda acción organizada es la relación de sororidad que han establecido, es una alianza de fraternidad que permite sentir el dolor de otras mujeres, pero además de sentir dicho dolor, se intensifica el deseo de aliviarlo, de evitarlo o de eliminarlo por completo. 


\subsection{Discusión y conclusiones}

El teatro testimonial, como herramienta social, propone una manera de recuperación psicosocial de las mujeres artistas y víctimas, además, pone en tensión la manera tradicional de entender el actuar político. La práctica teatral de Las Peregrinas se concibe como forma loable de tramitación del dolor, que trasciende las posibilidades de la psicoterapia tradicional o de las pretensiones oficiales para la atención y acompañamiento a víctimas en su proceso de reparación y sanación de las heridas ocasionadas por las violencias en el conflicto armado colombiano. Esta capacidad transformadora, que no solo pasa por la resignificación de la propia historia de vida, sino que contiene en sí misma el interés político de actuación en otras mujeres para la no repetición, es descrita por Oliva (2016): "Las mujeres que han incursionado en la vivencia artística han contribuido en la transformación y construcción de nuevas identidades femeninas" (p. 71). Se parte del supuesto de que el arte es disidente, dado que no constituye la forma tradicional o el mecanismo formal que los seres humanos han utilizado para opinar, disentir, reflexionar su realidad, y en contextos políticos donde fácilmente se arremete, silencia o estigmatiza al discrepante, se asume el arte como forma de expresión y cambio.

Ello conversa con los hallazgos de la investigación, toda vez que la experiencia del teatro ha facilitado la comprensión desde otros lugares, de los daños ocasionados por la guerra y de la capacidad de agenciamiento de las víctimas para elaborar los traumas psicosociales ocasionados por este fenómeno. A través del tejido de memoria colectiva se halló la capacidad compasiva de sororidad (Lagarde, 2006) y la capacidad de reflexividad que permitió a las artistas salirse de sí, para conectarse son el dolor colectivo. En un trabajo de investigación realizado en España y nombrado [artefeminismo-tecnología]: laboratorios de ciudadanía, Creus (2013) dice que "la relación entre arte-tecnología-conocimiento, en manos de ciertas mujeres artistas se convierte, realmente, en un instrumento social y político de transformación" (p. 103). Allí narra cómo el empoderamiento femenino ha adoptado otros matices a través de la creatividad, la experimentación e innovación, y la manera cómo estas prácticas, que parecen ser espontáneas, resultan ser instrumentos de cambio para ellas y para quienes conforman su entorno inmediato.

La capacidad creadora de las mujeres del colectivo Las Peregrinas, convoca los cuerpos como narrativas expansivas de actuación que no se restringe a la distracción cotidiana del dolor. Es una experiencia contenida 
en los cuerpos, en términos de Larrosa (2006), para quien la experiencia no es eso que pasa, sino eso que me pasa. De allí que la experiencia artística, no solo favorezca la capacidad de tramitar el dolor, sino que se convierta en posibilidad performativa para la transformación de historias de vida y para la configuración de subjetividades resistentes y comprometidas con la construcción colectiva. Aquí se expone entonces una posibilidad de acompañamiento a las víctimas desde la perspectiva de aquellas estrategias que estiman el rescate de valores comunitarios, de organización relacional, a partir de una apuesta por el afrontamiento colectivo (Moreno Camacho y Díaz Rico, 2015). Cuando se entrecruzan historias, narradas a partir de la creación artística en el caso de Las Peregrinas, ocurre una conexión entre las personas que allí confluyen: "Cada historia, pese a ser una narración diferente, comparte elementos con otras, que permiten una identificación de colectividad" (Molina, 2010, p. 68). Además, aparece la comprensión de procesos de recuperación psicosocial (Lugo-Agudelo et al., 2018), en los cuales, la víctima se convierte en sobreviviente toda vez que actúa para transformar su historia, además, se dispone a ser acompañada por otros, que en este caso fue A, la directora del colectivo.

Asimismo, cobra sentido la organización del grupo teatral como herramienta social de tramitación de dolores de las mujeres víctimas del conflicto armado, si se entiende que la construcción de subjetividades es posible solo en esa interacción colectiva (Ospina-Alvarado, CarmonaParra y Alvarado-Salgado, 2014), y es plausible entonces comprender que la vivencia del teatro, favoreció el devenir de características de un sujeto político, en tanto éste se lee como una acción que les permite una forma de encontrarse en lo que las conecta como el hecho de ser víctimas y de ser humanas, pero que a su vez les permite ser distintas, distinguirse (Arendt, 2005) como textos diferenciados de una misma historia, a saber, el conflicto armado colombiano.

Lo aquí expuesto sirve como pretexto para próximas indagaciones sobre la relación entre experiencias artísticas y la resolución de traumas, entre acciones artísticas colectivas y configuración de subjetividades, además, la posible relación entre procesos de configuración de subjetividades políticas y la resolución de traumas causados por las múltiples violencias en contextos de guerra. 
Cátedra Colombiana de Psicología

Mercedes Rodrigo 2019

\section{Referencias}

Arendt, H. (2005). La condición humana. Barcelona: Paidós Ibérica.

Arias. G. y Villota, F. (2007). De la política del sujeto al sujeto político. Ánfora, 14(23), 39-52. Disponible en: http://www.redalyc.org/pdf/3578/357834254004.pdf

Barrero, E. (2015). Del discurso encantador a la praxis liberadora. Psicología de la Liberación. Aportes para la construcción de una Psicología desde el Sur [Versión digital]. Bogotá: Ediciones Cátedra Libre. Disponible en: http://www.catedralibremartinbaro.org/ pdfs/psicologia_de_la_liberacion.pdf

Butler, J. (2002). Cuerpos que importan: sobre los límites materiales y discursivos del "sexo". Buenos Aires: Paidós.

Centro Nacional de Memoria Histórica. (2013). ¡BASTA YA! Colombia: Memorias de guerra y dignidad. Informe General de Memoria Histórica. Bogotá: Imprenta Nacional. Disponible en: http://www.centrodememoriahistorica.gov.co/descargas/informes2013/ bastaYa/ basta-ya-colombia-memorias-de-guerra-y-dignidad-2016.pdf

Centro Nacional de Memoria Histórica. (2017). La guerra inscrita en el cuerpo. Informe nacional de violencia sexual en el conflicto armado. Bogotá: Imprenta Nacional. Disponibe en: http:/www.centrodememoriahistorica.gov.co/informes/informes-2017/ la-guerra-inscrita-en-el-cuerpo

Coffey, A. y Atkinson, P. (2003). Encontrar el sentido a los datos cualitativos. Estrategias complementarias de investigación. Medellín: Editorial Universidad de Antioquia.

Cogollo-Ospina, S. N. y Durán-Palacio, N. M. (2015). Paz y Posconflicto: compromiso de los ciudadanos para un horizonte imaginado. En: S.N. Cogollo-Ospina (coord.), Imaginar la paz en Colombia: cavilaciones desde la academia, (pp. 62-71). Medellín: Fondo Editorial Universidad Católica Luis Amigó.

Congreso de la República de Colombia. (10 de junio de 2011). Ley 1448 de 2011, por la cual se dictan medidas de atención, asistencia y reparación integral a las víctimas del conflicto armado interno y se dictan otras disposiciones. Diario Oficial 48.096.

Congreso de la República de Colombia. (6 de septiembre de 2006). Ley 1090 de 2006 por la cual se reglamente el ejercicio de la profesión de Psicología, se dicta el Código Deontológico y Bioético y otras disposiciones. Diario Oficial 46.383.

Creus, M. (2013). [arte-feminismo-tecnología]: laboratorios de ciudadanía. Artnodes: Revista de arte, ciencia y tecnología, 13, 103-110. Disponible en: https://www.raco.cat/index. php/ Artnodes/article/view/285099/372968

Díaz-Alzate, M. V. y Arroyave-Hincapié, M. (2018). Investigar en Psicología. Retos en un mundo cambiante. En S. N. Cogollo-Ospina y P. A. Montoya-Zuluaga (comp.), Situaciones y retos de la investigación en Latinoamérica, (pp. 204-220). Medellín: Fondo Editorial Universidad Católica Luis Amigó.

Lagarde, M. (2006). Pacto entre mujeres. Sororidad. Aportes para el debate, 123-135. Disponible en: https://www.asociacionag.org.ar/pdfaportes/25/09.pdf 
Larrosa, J. (2006). Sobre la experiencia. Revista Educación y Pedagogía, 18, 43-51. Disponible en: http://aprendeenlinea.udea.edu.co/revistas/index.php/revistaeyp/article/view/ $19065 / 16286$

Lugo, V., Sánchez, P. V. y Rojas, C. (2018). La restauración con sobrevivientes del conflicto armado en Colombia: una propuesta de acción psicosocial. Revista Eleuthera, 19, 55-73. Doi: $10.17151 /$ eleu.2018.19.4.

Martín-Baró, I. (1990). Psicología social de la guerra: trauma y terapia. San Salvador: UCA Editores.

Martínez Miguélez, M. (2006). Ciencia y arte en la metodología cualitativa. México: Trillas.

Molina, N. (2010). Reconstrucción de memoria en historias de vida. Efectos políticos y terapéuticos. Revista de Estudios Sociales, 36, 64-75. Disponible en: http:/www.scielo. org.co/pdf/res/n36/n36a06.pdf

Moreno Camacho, M. y Díaz Rico, M. (2015). Posturas en la atención psicosocial a víctimas del conflicto armado en Colombia. El Ágora USB, 16(1), 193-213. Disponible en: http:// www.scielo.org.co/pdf/agor/v16n1/v16n1a10.pdf

Oliva, P. (2016). Las mujeres y el arte como forma propia de deconstrucción: Un debate implícito. Revista rupturas, 7(1), 51-74. Disponible en: http://www.scielo.sa.cr/pdf/rup/ v7n1/2215-2989-rup-7-01-00051.pdf

Ospina-Alvarado, M.C., Carmona-Parra, J.A. y Alvarado-Salgado, S.V. (2014). Niños en contexto de conflicto armado: narrativas generativas de paz. Revista Infancias Imágenes, 13(1), 52-60. Disponible en: https://revistas.udistrital.edu.co/ojs/index.php/infancias/ article/view/7838/9773

Segato, R. (2013). Las nuevas formas de la guerra y el cuerpo de las mujeres. México: Tinta Limón.

Strauss, A. y Corbin, J. (2002). Bases de la investigación cualitativa. Técnicas y procedimientos para desarrollar teoría fundamentada. Medellín: Editorial Universidad de Antioquia.

Tolstoi, L. (1898). ¿Qué es el arte? Navarra: Universidad de Navarra.

Torres, L. (2017). Narrativas de la memoria: el poder del lenguaje en la construcción de sentido después de una masacre. Memoria y Sociedad, 21(42), 21-37. Doi: 10.11144/ Javeriana.mys21-42.nmpl

Valles, M. (2002). Entrevistas Cualitativas. En Centro de Investigaciones Sociológicas (ed.), Cuadernos Metodológicos 32 (pp. 1-195). Madrid: Centro de Investigaciones Sociológicas. 


\title{
14. Subjetividad de mujeres víctimas del conflicto armado
}

\author{
LUZ AdRIANA ArISTIZÁBAL BECERRA ${ }^{48}$ \\ Resumen
}

La violencia contra las mujeres es una expresión de la forma como se han construido y reconstruido las subjetividades, identidades y el tejido social. Este nicho de desigualdades que fluyen en la cotidianidad de muchas mujeres colombianas se hace claramente visible en los contextos afectados por la guerra. Con el objetivo de conocer cómo se definen a sí mismas las mujeres víctimas de la violencia, que formaron parte de grupos armados ilegales, se desarrolló un estudio cualitativo con un diseño narrativo y enfoque biográfico. Se entrevistaron cuatro mujeres que estaban en la cárcel y sus relatos visibilizaron las tres formas de expresión de sus subjetividades: 1. Sujeto violentado; 2. Sujeto en venganza y 3. Sujeto encarcelado. Queda claro que los vínculos afectivos (familia y sociedad) ejercen una fuerte influencia en la construcción de dichas subjetividades y por lo tanto es necesario trabajar desde la formación de los mismos, pero, a su vez, existe una agencia en cada mujer que posibilita la transformación independientemente de su punto de partida.

Palabras clave: mujeres, subjetividad, conflicto armado, violencia, venganza, víctima.

\section{Abstract}

Violence against women is an expression of the way in which subjectivities, identities and the social fabric have been constructed and reconstructed. This niche of inequalities that flow in the daily lives of many Colombian women is clearly visible in the contexts affected by the war. This study sought to know how women who are victims of violence who were part of illegal armed groups define themselves, and for which a qualitative study with a narrative design and biographical approach was developed. The life stories of women affected by violence, who at some point in their lives were part of the illegal armed groups, made visible the three forms of expression of subjectivities: 1. Violated subject; 2. Subject in revenge and 3. Subject

48 Universidad Autónoma de Bucaramanga. Correo: aristizabalb@gmail.com 
imprisoned. It is clear that the affective bonds (family and society) exert a strong influence in the construction of these subjectivities and therefore it is necessary to work from the formation of the same, but in turn there is an agency in each woman that enables the transformation independently from the starting point.

Keywords: women, subjectivity, armed conflict, violence, revenge, victim.

\subsection{Introducción}

El ingreso de las mujeres a los grupos armados ilegales (GAI) y el incremento de conductas delictivas en las mismas obedece a un cambio social más que individual, comprendido desde un proceso socio-histórico, cultural y político que merece ser estudiado a profundidad. Los análisis feministas apuntan a la existencia de un orden androcéntrico y patriarcal que, mediante las prácticas de subjetivación, constituyen la identidad de los sujetos. Desde esta posición se considera que la realidad social está construida por la acción de las personas y que por tanto hay que aproximarse a la comprensión de los movilizadores de dicha acción (Aristizábal, 2017).

Esta realidad hace visible una guerra que ha perpetuado las desigualdades en Colombia desde hace más de 50 años. Tal como lo mencionan Gallo y Jiménez (2002), la guerra ocurre porque existe un desacuerdo respecto de la distribución de recursos materiales o simbólicos que refleja diferentes tipos de intereses. Clausevitz (2008), por su parte, define la guerra como un acto de fuerza llevado hasta sus máximos niveles de crueldad y utilizado como recurso impositivo donde prima la propia voluntad sobre el otro (opositor), y cuya finalidad es hacer más vulnerable al opositor y si es posible destruirlo.

Esta guerra, producto del conflicto armado, muestra claramente las luchas de poder y las desigualdades de género que por décadas han afectado el tejido social haciendo más vulnerables a niños, niñas y mujeres que pasaron de ser actores pasivos (víctimas) a ser sujetos activos de la violencia (victimarios), sin que una categoría excluya a la otra. El sujeto que ingresa a la guerra debe tener condiciones especiales que implican un exhaustivo entrenamiento (Sampson, 2001). Estas condiciones pueden estar enmarcadas en la presencia de una figura de poder que denota el camino y las normas de acción, al igual que los vínculos que subyacen en esta interacción y que a su vez los lleva a la sumisión del otro. 
En este estudio, las mujeres se visibilizaron como sujetos víctimas de la violencia que durante décadas han sido silenciadas dentro de un orden androcéntrico y patriarcal que las excluye, desconociendo el poder transformador en sus prácticas de subjetivación. Autores proponen la denominación de sujetos afectados por hechos de victimización y no víctimas, como son nombradas desde la categoría jurídica, la cual hace alusión a la victimización como un acontecimiento más que como una condición (Moreno y Moncayo, 2015; Moreno y Díaz, 2016).

Los hallazgos que aquí se presentan están en el marco de la tesis doctoral intitulada Prácticas sociales que promueven el delito y/o el desistimiento en mujeres privadas de la libertad (Aristizábal, 2017). Dentro de la muestra que representaba dicho estudio, se estudiaron a profundidad cuatro casos de mujeres víctimas del conflicto armado (desmovilizadas) que fueron entrevistadas en la cárcel de Florencia (Caquetá). El objetivo principal de este estudio fue analizar la subjetividad de las mujeres víctimas del conflicto armado. Se pretendía explorar las prácticas de subjetivación que las llevaron a formar parte activa de grupos armados y la manera como el contexto y la historia afectaron su identidad. Se partió de la pregunta problémica: ¿Cómo se definen a sí mismas las mujeres, víctimas de la violencia, que formaron parte de los grupos armados?

\subsection{Método}

Tipo de investigación: estudio cualitativo con diseño narrativo, enmarcado en las perspectivas socioconstruccionista (Gergen, 1985; Ibáñez \& Jiménez, 2001), y de género (Harding, 2004; Pujal, 2005; Butler, 2001; Bodelón y Aedo 2015; Yagüe, 2007; Almeda, 2003). Desde esta posición se consideró que la realidad social está construida por la acción de las personas y que por tanto hay que aproximarse a la comprensión de esta realidad (Gergen, 1985; Ibáñez \& Jiménez, 2001; Burr, 1997; Potter, 1998).

Población y muestra: en la investigación macro de la cual se desprende este estudio (Aristizábal, 2017), se entrevistaron 94 mujeres en las cárceles de Barcelona (España), Oaxaca (México), Montevideo (Uruguay), Medellín y Florencia (Colombia). Para fines de este análisis, se seleccionaron cuatro mujeres entrevistadas en la cárcel de Florencia (Caquetá), quienes refirieron que habían pertenecido a algún grupo armado ilegal. El resto de las mujeres entrevistadas habían llegado a la prisión por otro tipo de delitos como: tráfico de drogas, homicidio, intento de homicidio, hurto, estafa, entre otros (Aristizábal y Cubells, 2018). 
El tamaño de la muestra no se fijó a priori (Neuman, 2009); se realizó un muestreo no probabilístico opinático o intencional donde se buscaron perfiles que atendieran a la diversidad de situaciones personales y psicosociales respecto al delito, pero finalmente este estuvo sujeto a la decisión voluntaria de cada una de las mujeres que fueron convocadas. Tal como lo propone Martínez, las entrevistadas fueron nombradas "invitadas a participar" (Martínez, 2012, p. 615), resaltando que la aceptación de cada informante fue un elemento conceptualmente imprescindible y éticamente intrínseco.

Procedimiento metodológico e instrumentos. Para este estudio, se trabajó con las narraciones de las cuatro mujeres que estaban en la prisión de Florencia en el año 2016. Esto no indica que fueron las únicas mujeres en la cárcel que habían sido parte de un grupo armado ilegal, sino que fueron las únicas que voluntariamente decidieron participar. Se estima que muchas de las mujeres afectadas por el conflicto armado, temen contar sus historias de vida, y que después sus relatos sean usados para trámites jurídicos que las perjudican. Aunque se les aclaró a las convocadas que sus relatos serían de uso exclusivo del investigador, muchas no accedieron por este temor, entre otros factores no mencionados.

El procedimiento metodológico se realizó a través de tres etapas: 1) Contacto con las autoridades competentes de la cárcel El Cunduy de Florencia, para explicar la finalidad del estudio y obtener el permiso de ingreso. Las mismas autoridades compartieron la información a las invitadas a participar, les dieron a conocer el consentimiento informado y registraron el nombre de quienes aceptaron ser entrevistadas para los fines respectivos; 2) Entrevistas a profundidad, con las respectivas firmas del consentimiento informado; 3) Análisis de los datos, redacción de informes y, 4) Presentación a las autoridades sobre los resultados, quienes compartirían la información con las internas.

El diseño narrativo se orientó bajo un enfoque biográfico (Bertaux, 1999; Cornejo, 2008) con entrevistas a profundidad sobre los relatos de vida de las mujeres entrevistadas. En cuanto al término usado en este estudio: "relatos de vida", en preferencia de "historias de vida", se destaca el aporte del sociólogo norteamericano Norman K. Denzin (1970) quien propuso una distinción entre life story (relato de vida) y life history (historia de vida), designando al primero como la historia de una vida tal como la cuenta la persona que la ha vivido, y el segundo referirlo a estudios de casos sobre una persona determinada, incluyendo no sólo su propio relato de vida, sino 
también otras clases de documentos; por ejemplo, la historia clínica, el expediente judicial, los tests psicológicos, los testimonios de allegados, entre otros. Bertaux (1999) y Cornejo (2008) refieren que los relatos de vida, son una herramienta incomparable de acceso a lo vivido subjetivamente, y la riqueza de sus contenidos es una fuente de hipótesis inagotable, pese a las dificultades metodológicas que se puedan presentar en la recolección y en el análisis.

Análisis y procesamiento de la información: se efectuó un análisis del discurso a través del Atlas.ti, centrando la atención en la forma en la que se produce el mensaje fruto del diálogo interpersonal en cada una de las entrevistas. El discurso de cada participante fue analizado a partir de las circunstancias contextuales que lo incluían: ninguna de sus palabras fue tomada en forma aislada. Se puso especial atención a todas las prácticas discursivas que hacían alguna referencia a la construcción de la subjetividad.

El interés fundamental no fue la medición, sino la comprensión de los fenómenos y los procesos sociales en toda su complejidad; es de primordial importancia el lugar que los participantes ocuparon dentro del contexto social, cultural e histórico del que forman parte (Crouch y McKenzie, 2006); de ahí el interés por conocer a profundidad los relatos de vida de diferentes mujeres en diferentes lugares de guerra.

Para el análisis se partió de un preanálisis organizando el material y definiendo los ejes de análisis en función de los objetivos de estudio, para proceder a la etapa de codificación en la que se transformaron los datos brutos (transcripción de los relatos de vida) a datos útiles (categorías emergentes del corpus). El nombre de las categorías fue dado a partir de las narrativas y la revisión bibliográfica. Las entrevistas fueron grabadas y después transcritas a través de Scribe Transcription Software, siguiendo los criterios de Jefferson (2004). Puesto que la forma de obtener el testimonio se basó en conversaciones abiertas, los párrafos seleccionados no tenían la forma de una respuesta explícita a una pregunta concreta sobre la subjetividad (Moreno, Carmona y Tobón, 2010).

Consideraciones éticas: todo este proceso quedó materializado en la firma de un consentimiento informado que previamente fue revisado por la comisión académica y de ética del doctorado del Departamento de Psicología Social de la Universidad Autónoma de Barcelona, a partir de los aspectos éticos pronunciados en la Declaración de Helsinki y otros (Acevedo, 2002). 


\subsection{Resultados y discusión}

La violencia contra las mujeres es una expresión de la forma como se han construido y reconstruido las subjetividades, identidades y el tejido social. Este nicho de desigualdades que fluyen en la cotidianidad de muchas mujeres colombianas se hace claramente visible en los contextos afectados por la guerra. Los relatos de vida de mujeres víctimas de la violencia, que en algún momento de sus vidas formaron parte de los grupos armados ilegales, visibilizaron las formas de expresión de subjetividades: 1. Sujeto violentado; 2 . Sujeto en venganza y 3 . Sujeto encarcelado (con limitaciones, y sueños frustrados).

Cada sujeto es el correlato de sus propias prácticas de subjetivación; por lo tanto, siempre que hay nuevas prácticas que crean las condiciones de posibilidad para la transformación, a través de las reglas y normas que rigen la situación, se generan nuevas formas de subjetivación que transforman a las personas (Aristizábal, 2017). Andrade y Moreno (2006) refieren que cada sujeto se constituye a partir del reconocimiento del otro; la formación del yo necesita de un otro para identificarse como unidad diferente; solo viendo lo que hace al otro puede dar cuenta de su singularidad.

Estas relaciones siempre estarán mediadas por filiación y tensión: el otro es necesitado por el sujeto para constituir el yo, quien será de ahí en adelante la representación de la organización coherente de los procesos de subjetivación (Andrade y Moreno, 2016). Las mujeres entrevistadas no se identificaron directamente como delincuentes, sino como víctimas de la violencia, de las desigualdades sociales que se presentan a su vez como prácticas.

El análisis del discurso de las mujeres afectadas por la violencia dejó ver claramente la construcción de una subjetividad, alimentada por tres estados o tres prácticas que las integran. Estas prácticas de subjetivación no declaran un estado estático ni jerárquico, sino que se producen y reproducen de forma dinámica en un periodo de tiempo que denominamos vida.

\subsubsection{Sujeto violentado}

Todas las mujeres entrevistadas expresaron ser violentadas desde sus hogares. En sus discursos se hizo presente diferentes tipos de violencia: física, psicológica, doméstica, económica, simbólica, entre otras. Lo que queda claro es que la violencia desde los hogares, se incorpora en sus estilos de vida hasta asumirla como propia, como natural, y a veces como necesaria. 
En otras palabras, un sujeto violentado es un sujeto que ha sido construido y reconstruido por prácticas que atentan contra su libre desarrollo.

Pues mi infancia fue muy dura. Mi mamá me abandonó cuando yo era una bebé. Pues... [llanto y silencio]... Tenía por ahi unos 3 años cuando inos dejó tiradas! A tres niños que ella tenía, nos amarró y nos dejó... Mi hermano pues tendría por ahí un año y mi hermano por ahí 5... Y pues fue muy duro porque yo tenía un hermano grande, después mi papá se consiguió otra señora y nos andaba muy duro. Esto... me violaron... Ya estaba más grande. Yo me acuerdo, yo tendría por ahí unos 6 años y abusaban de nosotros porque..., con mi hermana también... nos criamos solas, mi papá trabajaba mucho... y se iba con la... Mi papá tenía una entenada, él siguió con la entenada y la señora... y nos dejaba solas en esa casa... Y lo del vecino, pues iba y abusaba de nosotros. Incluyendo hasta un hermano grande, yo me acuerdo que abusaba de nosotras (Marisol, 50 años).

El anterior relato nos muestra claramente la perspectiva de una mujer que integra el concepto de "violencia" con "dureza" (palabra que repite tres veces en un solo párrafo: "duro"), y que finalmente traduce toda una etapa de su desarrollo en dicha denominación. Una mujer que fue abandonada, y que aunque fue un evento que ocurrió hace 50 años, a través de su llanto y silencio expresa que es una categoría que sigue vigente. Una mujer violentada que además de abandona, rechazada también asumió la violencia física: "nos amarró", y el abuso sexual como parte de su crecimiento.

No todas las mujeres entrevistadas, afrontaron todos los tipos de violencia, pero todas se constituían a sí mismas como sujetos violentados:

Mi vida no ha sido nada fácil, yo crecí en medio de la violencia y siempre teníamos que correr de un lado para otro. Yo vi como mataron a familiares y... a mi nunca me abusaron, pero yo si vi... Yo nunca me sentí una guerrillera, pero ... eso era... yo soy víctima de esta guerra (Clara, 39 años)

Moreno y Díaz señalan que la palabra "víctima" tiene una carga valorativa que está asociada a los efectos que trae para un sujeto el sometimiento a los actos de violencia, de modo que cuando se clasifica a los sujetos como víctimas existe el riesgo de que sean entendidos como representantes de una categoría predefinida y por ello se implementen soluciones estandarizadas para su tratamiento (Moreno y Díaz, 2016). Dicho reconocimiento implica 
el riesgo de que la clasificación como víctima sea llevada al ámbito de la subjetividad (Moreno, 2013). Otros autores argumentan que la forma como se rotula a las personas que han vivenciado un hecho de violencia, producto del conflicto armado, va a marcar sus futuras acciones consigo mismo y con los demás; en otras palabras, todas sus relaciones se verán afectadas (Martín-Beristain, 2004; Meertens, 2006; Estrada \& otros, s. f.).

Esta categoría de "víctima" resulta contradictoria, ya que al mismo tiempo que indica desvalimiento y pasividad, también otorgan cierta fuerza sobre sí mismos para cambiar sus historias. Mertens propone el rescate de las estrategias de supervivencia que dan cuenta del coraje y valor con el que se sobreponen a las experiencias de horror por las que han pasado las personas en situación de desplazamiento (Meertens, 2006) o cualquier tipo de acto de violencia al que han tenido que enfrentarse.

Yo me sali de la guerrilla por mi propia cuenta. Después de que yo me vengo, las FARC... - porque yo me deserté, soy desertora, ya no pertenezco a ese grupo, no soy activa, pero si pertenecí a un grupo. Entonces que pasa, a mis papás los echan de la región, la guerrilla; - digamos las FARC los hecha a ellos, porque yo habia sido de ese movimiento y ya al no pertenecer a ese movimiento, pensaron que yo me venía y me iba a entregar al ejército o quién sabe a hacer qué tantas cosas, porque ellos siempre dicen que uno ya viniendo de las FARC es un enemigo más para la guerrilla; entonces a mi papá lo echaron de la región; desde ese entonces andamos con la maleta al hombro, somos víctimas del conflicto armado... Yo pertenecí a un movimiento, pero un día tomé la decisión de salirme, yo no sé de donde tomé agallas..., pero lo hice... yo no quería que mis hermanos más pequeños siguieran mis pasos (Josefa, 41 años)

La realidad de los seres humanos se desarrolla en el entorno de significaciones que la conforman; de esta manera, si las personas definen una situación como real, será real en sus consecuencias (Thomas \& Znanieki, 2004). Aunque los factores externos ejercen una gran influencia en la construcción de la subjetividad, Fernández habla de la agencia como la capacidad que tiene el sujeto de liberarse de los condicionamientos automáticos externos, y lo cual le otorga una responsabilidad sobre sí mismo que finalmente se hace visible en la acción pública (Fernández, 2003). De esta forma, la subjetividad de las mujeres entrevistadas estuvo dada por una relación de significados y una agencia para construir dichos significados. 


\subsubsection{Sujeto en venganza}

Los relatos de las mujeres entrevistadas visibilizaron sentimientos y acciones de venganza que de una u otra forma estaban dados por la identificación como sujeto víctima de la violencia. Para comprender esta relación se hace necesario conocer qué significa la venganza para las mujeres participantes, y a su vez identificar los elementos que la hacen parte de su propia definición.

Había mucho odio dentro de mí... tenía odio contra ellos, contra mi familia, e incluso contra mí misma. Estaba harta de la vida que llevaba... todo era guerra, violencia, insultos, malos tratos [...] En la guerrilla tuve la opción de cobrar venganza por mis propias manos... y era algo que iba más allá de mí, que yo no podía controlar, pero quería que todos sintieran lo que yo estaba sintiendo (Rosa, 38 años)

Ramos (2004) refiere que la venganza es el deseo de hacer pagar al otro un daño producido que puede conducir a la destrucción. La venganza se satisface en el aniquilamiento del otro y se alimenta del odio, pasión que afecta al sujeto introduciéndolo en una espiral imparable de barbarie (p. 222). En el diccionario de la Real Academia Española se define la venganza como la "satisfacción que se toma del agravio o daños recibidos", y el verbo vengar "tomar satisfacción de un agravio o daño"; lo que corresponde a la expresión de Rosa y otras participantes quienes describen la venganza como la satisfacción del daño recibido. Entonces, surge el cuestionamiento: ¿dónde se produce el significado de esta aparente "satisfacción" denominada venganza?

Yo recogía aguamaza, vendía y..., hasta que... Yo no sabía de armas, no sabía de nada, no conocía nada... [...] Yo ya tendría por ahí unos 7 años. Entonces había un muchacho que era miliciano y me arregló una cicla, y me dijo: - En esta cicla, usted cuando mire un camión y que digan que los soldados o los paras, usted corre y me dice. Yo le dije que sí. Entonces... él me cuidaba. Entonces allá donde los viciosos, llegó un Señor y también abusó de mí. Entonces, un día él (que me cuidaba) no estaba, estaba en sus misiones guerrilleras, entonces me dijo: - Me contaron que por aqui violaron una niña. Entonces una mujer le dijo: - Pues fue a ella, a pataloca! (me decían pataloca, porque yo andaba rápido y descalza y todo). Y dijo:-Violaron a pataloca? Entonces yo mire que le dio..., se sentó conmigo y me dijo: -Usted qué piensa de eso? Yo le dije: —No, eso yo ya he pasado por mucho de eso. Pero a mí no me gusta eso. Entonces me 
dijo: - Usted está muy pequeña para que hagan eso con usted, pero usted un día va a cobrar eso. Yo le dije: -Sí. [...] Yo me fui ese día, y por la tarde vino y me dijo: -Pataloca, a usted le gustaría tener un arma? Yo le dije: —Sí. Me dijo: - A usted le gustaría andar uniformada y armada? Yo le dije: -Sí. Entonces dijo: —Yo me la voy a llevar. Y yo le dije: - Sí. Me llevó para la guerrilla y empecé a los 8 años. Allá sabía que me podía vengar de todo lo que me habian hecho y la vida me cambió (Marisol, 50 años)

Marisol representa claramente dos categorías directamente relacionadas: un sujeto violentado y un sujeto en venganza que constituyen su singularidad. Por lo tanto, podría decirse que la venganza no es solo el resultado de daño o agravio recibido, sino que además es una figura que se construye y asume como propia en la interacción con el otro. Este elemento no sería posible si no existieran las relaciones vinculares que la producen y sostienen. Frente a una acción violenta, un ultraje, o la puesta en peligro de la existencia de mínimo dos sujetos, la primera reacción es protegerse, defenderse, resguardarse; luego, si los afectos puestos en juego se descargan, se produce un desfogue y el afecto en buena parte se disuelve (Ramos, 2004). En concordancia con lo que otros autores mencionan, muchos niños y niñas se unen a los grupos armados porque quieren "defender" o "vengar" a sus familias frente a ataques del otro grupo (Coalición, 2003; Hernández, 2001; Carmona, Moreno y Tobón, 2011).

No hay un consenso generalizado sobre las razones que nos llevan a sobrepasar los límites del respeto hacia los demás hasta el punto de su aniquilación (Andrade y Moreno, 2016:98). Evidentemente la venganza, cuando se asume como propia, tiene diferentes formas de expresión que están mediadas por el tipo y la fuerza del vínculo. Entre más fuerte el vínculo afectivo, más fuerte la venganza.

...yo ingresé porque estaba dolida..., quería escapar, y por salir corriendo me metí en otro hueco peor [...], yo quería vengarme de quienes me hicieron tanto daño y de quienes mataron lo que yo más quería en este mundo (Josefa, 41 años).

La construcción de un opositor permite definir la identidad de un sujeto ya que proporciona la posibilidad de encararlo con valor (de sí mismo) (Eco, citado por Gallo, 2013). Gallo (2013) afirma que el concepto del enemigo se vuelve necesario, ya que permite reconocerse a sí mismo en relación con la presencia del otro, ese otro como diferente de mí y que da paso a la afirmación de sí mismo: la propia identidad es definida y justificada a 
partir de la existencia de dicho enemigo, que se convierte en un motivador de venganza y de acciones violentas. Así, la violencia construye una identificación como víctima, que a su vez se convierte en un argumento del ejercicio de la venganza.

\subsubsection{Sujeto encarcelado}

Las mujeres estaban encarceladas antes de entrar a la prisión, a través de vínculos que las encorsetaron en tanto que estaban reguladas por las normas sociales y los mandatos de género y las expectativas que estos generan (Aristizábal y Cubells, 2017). Hasta el momento hemos analizado un sujeto que se concibe como víctima de la violencia, con sentimientos de venganza y pareciera ser que dichas prácticas de subjetivación llevan a la construcción de una nueva categoría que en adelante se denomina "sujeto encarcelado".

No podría afirmarse que el origen y desarrollo de esta subjetividad está dado en las prácticas de violencia que se producen y reproducen a través de las relaciones vinculares con otros. Tampoco podría afirmarse que el sujeto encarcelado es explícitamente el resultado del sujeto violentado y en venganza, porque quizás la cárcel impuesta por las normas del sistema social, y las condiciones histórico-políticas y culturales en las que se han desarrollado sus vínculos, la hicieron vulnerable ante la violencia y los sentimientos de venganza que surgen en respuesta a la amenaza.

Partimos del supuesto que la subjetividad se construye a partir de la integración de diferentes elementos que se dan en la interacción de significados, y en su relación con el otro. Tal como lo mencionan Carmona, Moreno y Tobón (2011), el punto de mayor acercamiento entre la visión de los investigadores y los sujetos de estudio, se da en la importancia atribuida al papel que desempeñan las relaciones interpersonales cercanas. Por lo tanto, llegar a comprender la complejidad de la subjetividad implica el reconocimiento de los vínculos afectivos como figuras que construyen o destruyen.

Por allá (en la guerrila) se me compuso un poquito más la vida porque aprendí a manejar armas; me querían porque yo era guapa ... Hasta que... un comandante me embarazó. Yo tenía como 12 años y ya estaba embarazada. Él me dijo que me iba a llevar a hacer el legrado [...]. Y yo le dije: -Yo, yo hago lo que sea, pero yo no quiero hacer eso [...] Tuve ese niño, y me mandaron para los pueblos lejanos a hacer inteligencia, y tuve el niño. Hasta que tuve tres hijos de él. Entonces a lo último me dijo: - A mi me van a sancionar. Porque usted solo resulta embarazada. Y me van a sancionar y me van a dar consejo 
de guerra, y a los dos. A ese niño va a tocar que lo saque. Entonces yo le dije: -Ya estoy aburrida, mamada, yo desde que naci he sido sufrida. Yo no voy a matar un hijo, yo ya he hecho mucho daño y yo un hijo no lo voy a matar. Si usted me va a matar, máteme, o si nos van a matar, de una vez. Pero es su sangre y es mi sangre, y yo a mi sangre no le voy a hacer daño. Porque a mí, mi sangre me ha hecho daño y a míme duele eso. Y es un hijo y yo no voy a hacer eso. Y yo no me voy a hacer el legrado. [...] Él me convenció... (Marisol, 50 años)

El anterior testimonio nos muestra claramente el testimonio de una mujer encarcelada por los cánones de la belleza: me querían porque yo era guapa; una mujer encarcelada en la imposición del otro Yo, yo hago lo que sea...", "Él me convenció", una mujer que sometió su libertad al dominio del otro.

Si revisamos los anteriores testimonios, que fueron incluidos en otras categorías, también encontramos elementos que apuntan a la existencia de un sujeto encarcelado; mujeres encarceladas por la opresión de sus familiares y/u otros al ser violentada desde la infancia, encarceladas por los sentimientos de venganza que las llevan a desconocer sus acciones agresivas como propias y "perder" el dominio y control de sus impulsos, a "perder" la agencia para liberarse. El término "perder" se incluye entre comillas porque realmente no pierden dichas capacidades, solo se invisibilizan para dejar que otros promotores de acción las guíe.

El discurso de Marisol también trasciende el hecho de considerar que un sujeto que ha pasado por un hecho de violencia no tendrá en adelante otra opción de relación con los demás, por fuera de la identificación con la posición de víctima (Ordóñez y Moreno, 2013). Marisol usó su agencia para liberarse y, aunque posteriormente nuevos barrotes obstruían su visión, cabe resaltar la hazaña que la llevó a liberarse.

Yo me escapé y fui por mis hijos que ya estaban grandecitos... [...]. Cuando sali no encontraba trabajo.., no sabia qué era peor, si estar en la guerrilla o ser una mujer pobre. Busqué trabajo hasta en construcción y no porque yo era mujer. Pero Dios me ayudó y conocí personas que creyeron en mí..., que no me veían como guerrillera, como una peligrosa, sino como alguien que merece salir adelante (Marisol, 50 años)

Esta posición subjetiva en la que la mujer se halla entre dos barreras: pobreza - guerrilla (no sabía qué era peor, si estar en la guerrilla o ser una mujer pobre), la lleva a hacer una demanda al otro que, en palabras de 
Ordóñez y Moreno, es una "demanda de salvación, de rescate, de atención" (2013, p. 119). Esta demanda surge del posicionamiento como sujeto víctima, en venganza y encarcelado.

\subsection{Conclusiones}

El análisis de los relatos de vida de mujeres encarceladas, que fueron entrevistadas en este estudio, es el reflejo de las prácticas sociales que promueven la violencia en el país y fortalecen su réplica. La subjetividad de las mujeres ha sido construida a partir de una sociedad patriarcal que ha marcado sus normas de actuación y conduce a la formación de sujetos que se perciben a sí mismos como víctimas de la violencia, con sentimientos de venganza y encarcelados entre barreras que obstaculizan su libre desarro1lo. Si lográramos intervenir en el proceso a través del cual se construyen subjetividades más igualitarias (libres de violencia desde la cuna), todos asumiríamos la responsabilidad del cuidado del otro (Gilligan, 1982) que a su vez representa el abono de un tejido social más sólido y estable para el desarrollo sostenible de futuras generaciones.

Está claro que los vínculos afectivos (familia y sociedad) ejercen una fuerte influencia en la construcción de estas subjetividades y por lo tanto es necesario trabajar desde la formación de los mismos, pero a su vez hay una agencia en cada mujer que permite la transformación independientemente del punto de partida. Una comprensión de los participantes no como víctimas, sino como sujetos que reconozca su historia, sus tradiciones y sus costumbres, les otorga la responsabilidad en su proceso de reparación y restablecimiento de su ciudadanía (Jaramillo, 2006).

Tal como lo mencionan Ordóñez y Moreno (2013):

cuando un sujeto ha vivido algún tipo de hecho de victimización, éste empieza a formar parte de su historia de vida pero, sin embargo, el lugar que ocupa varía de un sujeto a otro; por lo tanto, lo que se pone en juego en la elaboración del hecho en sí mismo son los arreglos y mecanismos que tiene o construye cada sujeto. Dicha elaboración está atravesada por la relación del sujeto con su deseo y la relación con lo otro (p. 140).

De esta forma, aunque los hechos de violencia ejercen una fuerte influencia en las prácticas de subjetivación, no son condicionantes exclusivos; aparecen y reaparecen los vínculos afectivos y los significados que emergen en dichas relaciones elementos claves de producción y transformación. 
Las mujeres participantes de este estudio nos dejan ver que no toda subjetividad se construye sobre la base de la violencia y el odio, sino también sobre la base del amor (Rosolato, 2004). Las mujeres que se definieron a sí mismas como sujetos víctimas de la violencia, con sentimientos de venganza y encarceladas entre las barreras del sistema, son también mujeres que aman, que sueñan y que luchan por identificar y hacer uso de los recursos empoderadores que transforman. Tal como lo propuso Meertens (2006) es necesario rescatar las estrategias de supervivencia que dan cuenta del coraje y valor con el que las víctimas se sobreponen a las experiencias de horror por las que han pasado las mujeres afectadas por la violencia. La subjetividad no es una posición estática que acompaña durante toda la vida, es el resultado de múltiples interacciones entre significados que conllevan implícita la capacidad de ser renovados y transformados.

Comprender la subjetividad de las mujeres afectadas por la violencia, que formaron parte de un grupo armado ilegal, invita a reflexionar que toda mujer (por el hecho de ser mujer) podría estar en la misma posición de las mujeres participantes en este estudio. Las micro-violencias no son menos dañinas que las macro-violencias; ambas son consideradas como prácticas de subjetivación y ambas son el resultado de la interacción entre sujetos en su lucha por el poder, y mucho más cuando permean en una sociedad patriarcal como la nuestra. Transformar dichas prácticas resulta más complejo cuando los vínculos afectivos, elegidos en una esfera más profunda de significación, ejercen una tensión hacia la venganza y el encarcelamiento. En la línea de transformación, se hace necesaria la selección de vinculaciones que empoderen y promuevan prácticas de paz y no violencia.

\section{Referencias}

Acevedo, I. (2002). Aspectos éticos en la investigación científica. Ciencia y Enfermería, $8(1), 15-18$.

Almeda, E. (2003). Mujeres encarceladas. Barcelona, Ariel.

Aristizábal Becerra, L. (2017). Prácticas sociales que promueven el delito y/o el desistimiento en mujeres privadas de la libertad. (Tesis de Doctorado). Universidad Autónoma de Barcelona. Disponible en: http://hdl.handle.net/10803/457745

Aristizábal Becerra, L. A., \& Cubells Serra, J. (2017). Delincuencia femenina y desistimiento: factores explicativos. Universitas Psychologica, 16(4), 1-14. doi.org/10.11144/ Javeriana.upsy16-4.dfdf

Aristizábal Becerra, L., y Cubells Serra, J. (2018). Mujeres y prisión: un estudio con perspectiva de género en España, Uruguay, México y Colombia. Penalidad femenina. México: Editorial Universidad Nacional Autónoma de México. 
Andrade, K. y Moreno, M. A. (2016). Dinámicas subjetivas de combatientes en el conflicto armado colombiano. En: M. A., Moreno, J. J., Orejuela y T. Calderón (Eds.), Abordajes psicoanaliticos a inquietudes sobre la subjetividad III. (pp. 97-116). Cali: Editorial Bonaventuriana

Bertaux, D. (1999), El enfoque biográfico: su validez metodológica, sus potencialidades. Proposiciones, 29, 1-23.

Bodelón, E. y Aedo, M. P. (2015). Las niñas en el sistema de justicia penal. Anales de la Cátedra Francisco Suárez, 49, 219-236.

Butler, J. (2001). Mecanismos psíquicos de poder: teorías sobre la subjetivación (2a. ed.). Madrid: Editorial Cátedra.

Burr, V. (1997). Introducción al construccionisme social. Barcelona: UOC.

Carmona, J. Moreno, F. y Tobón, F. (2011). La carrera de las niñas en los grupos guerrilleros y paramilitares de Colombia: un estudio desde el punto de vista del agente. Medellín: Fondo Editorial Luis Amigó.

Clausevitz, K. (2008). De la guerra. Argentina: Terramar.

Cornejo, M., Mendoza F. y Rojas R. (2008). La investigación con relatos de vida: pistas y opciones del diseño metodológico. Psykhe, 17(1), 29-39.

Denzin, N. K. 1970. The Research Act. A theoretical Introduction to Sociological Methods. Chicago: Aldine.

Crouch, M., McKenzie, H. (2006). The Logic of Small Samples in Interview-based Qualitative Research. Social Science Information, 45(4), 483-499.

Estrada, Á., Ripoll, K., Rodríguez, D., Antholin, N., Céspedes, M. P. \& Acuña, M. (s. f.). Psicología social crítica: Estrategias para la atención del impacto psicosocial acumulado en jóvenes, y sus redes sociales, afectados por el conflicto interno en Colombia. Bogotá: Universidad de Los Andes - IDRC (Canadá).

Fernández, C. (2003). Psicologías sociales en el umbral del siglo XXI. Madrid: Editorial Fundamentos.

Hernández, E. (2001). Los niños y las niñas frente al conflicto armado y alternativas de futuro. Reflexión Política, 3(6), 1-11.

Gallo, H. y Jiménez, B. (2002). Dinámicas de guerra y construcción de paz. Estudio interdisciplinario del conflicto armado en la Comuna 13 de Medellín. Colombia: L. Vieco e Hijas Ltda.

Gallo, H. (2013). El lugar del enemigo. Revista Desde el jardín de Freud, 13, 137-144.

Gergen, K. (1985). The Social Constructionist Movement in Modern Psychology. American Psychologist, 40(3), 266-275.

Gilligan, C. (1982). In a Different Voice: Psychological Theory and Women's Development. Cambridge: Harvard University. 
Harding, S. (2004). The Feminist Standpoint. Theory Reader. Nueva York: Routledge.

Ibáñez, T. y Jiménez, B. (2001). Psicología social construccionista. Guadalajara: Universidad de Guadalajara.

Jaramillo, J. (2006). Reubicación y restablecimiento en la ciudad. Estudio de caso con población de desplazamiento. Universitas Humanísticas, 62(2), 143-168.

Jefferson, G. (2004). Glossary of Transcript Symbols with an Introduction. En G. H. Lerner (ed.) Conversation Analysis: Studies from the First Generation. (pp. 13-23). Philadelphia: John Benjamins.

Martín-Beristain, C. (2004). Enfoques y metodologías de atención psicosocial en el contexto del conflicto sociopolíticos. Bogotá: Terre des Hommes-Italia.

Martínez, C. (2012). El muestreo en investigación cualitativa. Principios básicos y algunas controversias. Cienc. Saúde colectiva, 17(3), 613-619.

Meertens, D. (2006). Reflexiones éticas, metodológicas y conceptuales sobre la investigación en desplazamiento y género. En M. N. Bello (ed.) Investigación y desplazamiento forzado. Reflexiones éticas y metodológicas (pp. 112-125). Bogotá: Red nacional sobre desplazamiento forzado en Colombia.

Moreno, F., Carmona, J. A. y Tobón, F. (2010). ¿Por qué se vincunlas las niñas a los grupos guerrilleros y paramilitares en Colombia? Revista Latinoamericana de Psicología, 42(3), 453-467.

Moreno, M. A. (2013). Psicoanálisis e intervención social. Revista CS, 11, 115-142.

Moreno, M. y Moncayo, J. (2015). Abordaje psicosocial. Consideraciones conceptuales y alternativas de análisis en el escenario de atención a víctimas del conflicto armado. En: Psicología social crítica e intervención psicosocial, 37-56.

Moreno, M. y Díaz, M. (2016). Posturas en la atención psicosocial a víctimas del conflicto armado en Colombia. El Ágora USB, 16(1), 193-213.

Neuman, W. L. (2009). Social Research Methods: Quantitative and Qualitative Methods (7 ${ }^{\mathrm{a}}$ ed.). Boston, MA, EE. UU.: Allyn \& Bacon.

Ordóñez, A. y Moreno, M. (2013). La victimización y sus implicaciones en las relaciones familiares. En: J. J., Orejuela y M. A., Moreno (eds.) Abordajes psicoanaliticos a inquietudes sobre la subjetividad. (pp. 113-142). Cali: Universidad de San Buenaventura.

Potter, J. (1998). La representación de la realidad: discurso, retórica y construcción social. Barcelona: Paidós.

Pujal, M. (2005). El Feminisme. Barcelona: UOC.

Ramos, C. (2004). Memoria, olvido, perdón, venganza. Revista Desde el jardín de Freud, 4.

Yagüe, C. (2007). Mujeres en prisión. Intervención basada en sus características, necesidades y demandas. Revista Española de Investigación Criminológica, 4(5), 1-24.

Rosolato, G. (2004). El sacrificio. Argentina: Nueva Visión. 
Cátedra Colombiana de Psicología

Mercedes Rodrigo 2019

Sampson, A. (2001). Reflexiones sobre la violencia, la guerra y la paz. Nómadas, 2, 5-15.

Thomas, W. \& Znanieki, F. (2004). El campesino polaco en Europa y en América. Madrid: Centro de Investigaciones Sociológicas. 


\title{
15. Narrativas para la emergencia de subjetividades y reconstrucción de tejido social: las mujeres afrocolombianas sobrevivientes de la guerra
}

\author{
Miguel Ángel Cárdenas Medina ${ }^{49}$ \\ Aida Milena Cabrera Lozano $0^{50}$
}

\begin{abstract}
Resumen
La guerra, como un fenómeno complejo, dejó secuelas en la organización de las comunidades, el territorio y las formas de interacción de miles de colombianos. En el desarrollo del conflicto armado muchas mujeres fueron expuestas a actos violentos y se han movido hacia nuevas formas de narrarse, como sujetos, desde la reconstrucción de su subjetividad y el ejercicio de su dimensión política. El artículo presenta las experiencias investigativas del proceso de análisis de las narrativas de las mujeres en el trasegar hacia nuevas configuraciones de la subjetividad y la resignificación de su territorio y experiencia de vida. Se resalta la importancia de la expresión de las emociones, el sentido del ritual, la conexión con la historia de la comunidad, la experiencia del liderazgo y la organización colectiva para el reconocimiento de los derechos como parte del proceso de reparación individual y colectiva. Emergen nuevas subjetividades que se expresan en la narración alrededor de lo que significa ser mujeres sobrevivientes de la guerra.
\end{abstract}

Palabras clave: subjetividad, mujeres, territorio, conflicto armado, narrativas.

\section{Abstract}

War as a complex phenomenon, left sequels in the organization of communities, territory and forms of interaction of thousands of Colombians. In the development of the armed conflict many women were exposed to

49 Corporación Universitaria Iberoamericana. Correo: miguel.cardenas@ibero.edu.co 50 Universidad Santo Tomás. Correo: aidacabrera@usantotomas.edu.co 
violent acts and have moved towards new ways of narrating themselves as subjects from the reconstruction of their subjectivity and the exercise of their political dimension. The article presents some results of the process of analysis of the narratives of women in the transition to new configurations of subjectivity and the resignification of their territory and life experience. The importance of the expression of emotions, the sense of ritual, the connection with the history of the community, the experience of leadership and the collective organization for the recognition of rights as part of the process of individual and social reparation are highlighted. New subjectivities emerge that are expressed in the narrative around what it means to be women survivors of war.

Keywords: Subjectivity, women, territory, armed conflict, narratives.

\subsection{Introducción}

Las mujeres inmersas en el conflicto armado colombiano han sido consideradas como las reparadoras del tejido social, esto debido al papel político que han asumido como líderes en la búsqueda de justicia y dignificación de sus derechos al interior de las familias y comunidades. Tras los múltiples hechos de violencia a los que se han visto sometidas y al afrontar diferentes condiciones como las que conllevan el desplazamiento forzado, las mujeres afrocolombianas han debido generar una reconfiguración en su perspectiva frente a la vida, su rol al interior de las familias y su actores sociales y políticos.

Estas condiciones se suman a la invisibilización que históricamente se mantenía de las mujeres víctimas de violencia en el conflicto armado, al evidenciarse en varios de sus relatos la naturalización de hechos violentos y las condiciones de re-victimización presentes en los procesos de atención que en primera instancia se brindaba a esta población (Cárdenas y Cabrera, 2016).

Los programas de atención integral a víctimas del conflicto armado se quedaban cortos al dimensionar y comprender los impactos que representaba para esta población las tácticas de poder e intimidación a las que eran sometidas, presentes al interior de las comunidades y poblaciones que debían afrontar este flagelo (Cabrera y Cárdenas, 2016). Estas condiciones se afianzaban en los actores sociales y las comunidades a través de memorias traumáticas, las cuales establecen recuerdos con un alto impacto emocional desde donde se construye la experiencia fenomenológica que se asociada al recuerdo vivido (Manzanero y Recio, 2012). 
A su vez, las memorias se mantienen presentes a lo largo de la vida y se transmiten de forma transgeneracional, lo que implica que los relatos asociados a situaciones traumáticas transitan de una generación a otra, asumiendo dimensiones mitológicas, siendo este uno de los aspectos que indica que la construcción narrativa de los sujetos no solo está basada en la propia experiencia sino que se encuentra permeada por aquellos relatos que se mantienen latentes en la historia de las relaciones sociales. (Cornejo y Faúndez, 2010).

Por lo tanto, la construcción social se conforma del saber compartido, a través de las memorias y relatos que se han ido conformando desde la historicidad y cultura presente en las comunidades donde se mantiene y reproduce diversas formas de comprender la realidad, lo cual implica que esta construcción se genere bajo dinámicas de interacción con un otro que a su vez co-construye nuevas formas de realidad (Gergen y Gergen, 2001).

En la construcción de la realidad el lenguaje juega un papel importante al permitir marcos de interpretación indispensables para enmarcar la experiencia colectiva al interior de la sociedad, emergiendo con uno de los productos de la interacción humana, desde donde se genera una articulación entre la semántica (formas de lenguaje) y la pragmática (procesos de interacción social), permitiendo la emergencia de modos lingüísticos que consolidan la realidad social. Estas relaciones de "intercambio lingüístico" visibilizan las experiencias de subjetividad de cada miembro social atribuyendo un lugar privilegiado para el desarrollo de la identidad y de la conciencia bajo un sistema relacional que establece formas de interconexión donde confluye la intersubjetividad que permite la emergencia lingüística social que es validado en la comunicación y en la interacción (Berger y Luckman, 1968).

En el caso de las mujeres afrocolombianas inmersas en el conflicto armado sus relatos han sido matizados por las experiencias traumáticas a las cuales fueron sometidas, pero a su vez se han constituido por los abordajes culturales, sociales, políticos e históricos que impregnan su construcción de la realidad, siendo un proceso de subjetivación el que emerge en el tránsito de su postura como agentes sociales y que determinan su forma de "ser" en los diferentes escenarios donde se desarrollan sus prácticas de relación. (Cabrera y Cárdenas, 2016).

La guerra y el conflicto armado, como un fenómeno complejo, dejaron secuelas en la organización de las comunidades, el territorio y las formas de interacción de miles de colombianos. Dimensiones como el tejido social, la identidad y los significados de los pueblos iniciaron un tránsito hacia 
la recuperación y la reorganización a partir de la activación de recursos individuales, culturales y comunitarios que requieren el acompañamiento de las ciencias sociales. Según Posada y Carmona (2018) "luego de los eventos bélicos, muchas de las víctimas poco a poco buscan un lugar desde el cual luchar por el derecho a la verdad, la justicia y la reparación" (p. 70), es decir después de la guerra, se inicia un trasegar hacia la configuración de un nuevo sujeto políticamente reconocido, en un territorio dotado de significados y con narrativas que integran a su historia las experiencias que deja el enfrentamiento armado.

Esta investigación se desarrolló con el fin de abordar las configuraciones narrativas en mujeres "víctimas" de violencia sexual en el marco del conflicto armado y en condición de desplazamiento en la ciudad de Bogotá, con el fin de visibilizar las voces que la guerra logró callar durante muchos años tras la intimidación y los juegos de poder y reconocer las luchas que han debido afrontar las mujeres afrocolombianas en la recuperación y transmisión de su identidad cultural a las próximas generaciones que han desplazarse y no han contado con la posibilidad de retornar a sus territorios de origen.

Como objetivo general se planteó diseñar una estrategia de inclusión social y reconciliación que contribuya a la atención y reparación integral de mujeres víctimas de violencia sexual en el conflicto armado y sus familias, y como parte de los objetivos específicos se planteó reconocer los mecanismos de reparación y reconciliación que permiten la emergencia de nuevas subjetividades por medio de la narrativa de un grupo de mujeres afrocolombianas en condición de desplazamiento forzado, sobrevivientes del conflicto armado colombiano ubicadas en la ciudad de Bogotá, identificar los procesos de subjetivación ligados a la territorialización en la vida después de la experiencia de la guerra y comprender los significados de la experiencia vivida a través de las narrativas individuales y colectivas. Para este fin se realizó un acercamiento a los movimientos sociales liderado por mujeres víctimas del conflicto armado (lideresas), que estuvieran realizando acciones conjuntas con la Defensoría del Pueblo en la ciudad de Bogotá.

En el camino de la construcción investigativa surgen preguntas alrededor de los procesos de inclusión social, los mecanismos y estrategias de reparación y reconciliación que permiten la emergencia de nuevas subjetividades y los nuevos significados que emergen en los procesos de reterritorialización. Aquí se hace un llamado a las dinámicas y recursos culturales desde los cuales se posibilita la acción colectiva de la reparación desde las fuentes que brinda la misma comunidad y las identidades que confluyen en el grupo social. 


\section{Hacia la reconstrucción de la subjetividad politica}

Para comprender cómo se han dado los procesos de reconstrucción de las subjetividades en las mujeres participantes de esta investigación, es indispensable reconocer la subjetividad como un proceso que implica la relación con el mundo social y no se alberga únicamente en el mundo intrapsíquico. La subjetividad puede ser comprendida como una parte del ser humano que integra procesos racionales y procesos emocionales (Jáidar y Alvarado, 2003), en ese sentido implica una visión amplia que escapa a la consideración reduccionista de la subjetividad como un proceso interno de cada persona y conecta con la idea de la construcción de la subjetividad desde la interacción con el otro. Para Güell (2002) la subjetividad es la red de percepciones, aspiraciones, memorias, saberes y sentimientos que impulsa al ser humano a actuar en el mundo. La ubica en un plano cultural que a su vez es inseparable del mundo individual de las personas, lo que la podría definir desde su ubicación intersubjetiva, es decir en relación permanente con el otro.

Como categoría psicológica, la subjetividad se reconoce desde la compleja conexión con el mundo social, la historicidad del sujeto y los diferentes contextos en los cuales se relaciona en tiempos y espacios concretos. La subjetividad así abandona la ubicación intrapsíquica atribuida por las corrientes psicológicas más antiguas y se abre paso al reconocimiento de su construcción social que implica una dimensión política en la medida en que el sujeto se abre paso hacia la participación y la visibilización social. De esa manera, hablar de subjetividad es hacer referencia a un proceso de construcción desde la relación, la historia, el lenguaje, la transformación, como agentes y dimensiones dinámicas de la construcción del ser humano, más allá de dimensiones estáticas e internas del sujeto. (Duque, Patiño, Muñoz, Villa y Cardona, 2016).

En este sentido la subjetividad promueve la producción y transformación de significados y hace parte de una compleja red de creación de sentido de las acciones y vivencias humanas, su base es experiencial y su configuración está impactada en gran medida por procesos emocionales más que racionales (Duque, et al., 2016). Para González (2013) la subjetividad es comprendida desde dos grandes ejes, por un lado, su configuración, como se ha mencionado anteriormente, desde el plano de lo social dado que no es posible la construcción del sujeto apartado de su realidad social, cultural e histórica; y por otra parte, el protagonismo que le atribuye a las emociones en la organización de la subjetividad como promotoras de la construcción 
del sentido de la vida humana. Es sobre estos dos preceptos que se asume la subjetividad en esta investigación: un proceso que trasciende lo individual y se ubica en el plano social en el cual se expresan mecanismos emocionales que permiten el reconocimiento y conexión con el otro.

Pero dado que se aborda la subjetividad en el contexto particular de las mujeres que han experimentado diversas condiciones de violencia por el conflicto armado, se asume que ha de existir una dimensión política de la subjetividad, ¿cómo surge entonces esta dimensión?.

En sí, la dimensión política de la subjetividad está anclada a un carácter social, lo cual implica el reconocimiento de la esfera pública de las acciones y comprensiones del sujeto y su posibilidad en el ejercicio de la libertad, la voluntad y la participación comunitaria. Para Díaz y Alvarado (2012) la subjetividad política se puede entender como "la acción de reflexividad que realiza el sujeto sobre sí mismo y sobre lo instituido, centrándose en el plano de lo público (lo que es común a todos) para desde allí protagonizar instituyente mente la política y lo político" (p. 115). De ahí que se comprenda la subjetividad política como mecanismo esencial de participación y reconstrucción del sujeto en la relación con la dimensión de lo público, procesos que se desarrollan como parte de la reterritorialización de las mujeres y la generación de nuevas significaciones para el sufrimiento y las situaciones atravesadas y puntuadas como difíciles. De esta manera “... la multiplicidad implicada en los procesos de configuración de subjetividades y en las formas de socialización política, no puede ser reflexionada por fuera de un contexto de relaciones culturales, históricas, económicas, que la determinan" (Alvarado, Ospina y García, 2012, p. 254).

En los casos de violencia a los que fueron sometidas las mujeres en el conflicto armado, el cuerpo asume especial significado ya que al ser el "primer territorio de poder de todo ser humano" (Díaz y Alvarado, 2012), se convierte en un espacio en el que se esperaría un ejercicio pleno de la libertad del sujeto, y por el contrario se atravesó la experiencia de daño al cuerpo, de objetivación de las violencias y de las resistencias. De acuerdo con Díaz y González (2005) la subjetividad, como la política, requiere del cuerpo del sujeto para expresarse, para relacionarse, el sujeto encorpado. El cuerpo es el medio para la expresión de la nueva configuración subjetiva que por medio del ritual expresa un componente político y que se moviliza hacia las acciones de resistencia y búsqueda de la reparación. El cuerpo es el móvil para el liderazgo de las mujeres que orienta la organización comunitaria hacia el beneficio mutuo y la posibilidad de una vida digna en 
el nuevo territorio (Posada y Carmona, 2018). Es el recurso para hacerse visible y pasar de una condición de víctima a una postura de sobreviviente, pero ante todo a una concepción como sujeto políticamente envestido.

En las mujeres víctimas de violencia sexual en el marco del conflicto armado, la identidad de la mujer no se transforma, cambian los procesos de subjetivación (Díaz, 2014) desde el trasegar por el territorio y por las experiencias de vida, esto permite que emerjan nuevas formas de posicionarse políticamente desde el ser mujer como expresión de la subjetividad política en las relaciones con la comunidad y con la institucionalidad. Se espera que con la reconstrucción de la subjetividad política las mujeres puedan encontrar un espacio de reconocimiento que se complemente con la sensación de seguridad y bienestar que esperaban encontrar en el nuevo territorio. Para las mujeres "la pérdida de referente territorial implica un proceso de transformación de la identidad que con frecuencia se redefine en la reterritorialización" (Ocampo y Forero, 2013, p. 51).

\subsection{Diseño metodológico}

La investigación contó con la participación de 50 mujeres autodenominadas "sobrevivientes del conflicto", afrodescendientes en condición de desplazamiento forzado y re-ubicadas en la ciudad de Bogotá, las cuales se encuentran vinculadas a diferentes grupos sociales que trabajan por la reivindicación de los derechos de las comunidades afrodescendientes víctimas del conflicto armado desde las localidades. En este caso se trabajó con dos colectivos de mujeres ubicados en la localidad de Usme (37 mujeres) y otro en la localidad de Antonio Nariño (13 mujeres y sus familias). Se retoman a su vez las experiencias de uno de los investigadores en el territorio de Apartadó - Antioquia para enmarcar el ejercicio de análisis de las narrativas con lideresas que aún se mantienen en el territorio, para brindar mayor soporte a la discusión.

La selección de la muestra fue intencional a partir de los criterios de inclusión establecidos por los investigadores. Se consideró como uno de los aspectos de selección de la muestra el trabajo con grupos a cargo de lideresas afrodescendientes, que estuvieran desarrollando acciones conjuntas con la Defensoría del Pueblo en pro del trabajo con víctimas en condición de desplazamiento.

Se realizó un abordaje de la problemática desde una perspectiva metodológica cualitativa, la cual permite producir datos descriptivos empleando como tipo de estudio la etnografía performativa (Denzin \& Lincoln, 2013). 
La etnografía performativa permite retomar elementos de los estudios performativos y de la etnografía, para lo cual se realiza un estudio de los grupos sociales en un determinado tiempo, donde se intentan visibilizar las perspectivas de los miembros de la comunidad a través del arte, con lo que se espera reconocer sus manifestaciones simbólicas e identitarias promoviendo una visión crítica de su realidad, reconociendo la naturaleza de su conocimiento desde el abordaje de sus prácticas culturales (Denzin y Lincoln, 2013, p. 99). Para esta investigación se desarrolló un trabajo orientado a la recuperación de prácticas ancestrales a partir de la memoria cultural de los participantes; por lo tanto, las acciones desarrolladas desde la etnografía performativa integraban estrategias que reunían los saberes transgeneracionales de las comunidades.

La recolección de la información parte de un ejercicio de observación participante con el cual se realiza un primer acercamiento a la comunidad para comprender sus prácticas rituales, narrativas y relacionales y diseñar así las diferentes estrategias de abordaje del ejercicio investigativo; esto debido a la apuesta investigativa que pretendía un abordaje de los actores sociales desde su cotidianidad, para lo cual se generaron acciones de acercamiento gradual al fenómeno que se pretendía abordar por parte de los investigadores, sin generar acciones que fueran intimidantes o ajenas a las estrategias de reparación que venían desarrollando las lideresas con los grupos, esto por las condiciones de la comunidad y las situaciones de amenaza que experimentaban algunas lideresas por las acciones realizadas con las comunidades (Vasilachis, 2006 y Ángel, 2011).

Desde los relatos que emergen en las mujeres afrodescendientes se accedió a las narrativas, como una forma de interacción y abordaje de la realidad, a partir del discurso el cual conforma una experiencia que construyen las formas sociales, siendo el recurso discursivo una manera de comprender, intervenir y transformar la realidad presente en los procesos comunitarios, generando una interacción social, abierta, que permite converger múltiples ejercicios co-constructivos entre interlocutores y co-narradores donde se establece un escenario relacional y simbólico que permite re-narrar las representación sociales presentes en las comunidades (Estupiñán, González y Serna, 2006).

En las narrativas presentes en las mujeres afrocolombianas se esperaba realizar un acercamiento a la construcción subjetiva, desde el reconocimiento de los bucles recursivos, que han realizado estos actores sociales en torno a las situaciones presentes en el conflicto armado, y la resignificación que 
han desarrollado de estas situaciones desde la construcción de historias que han generado acerca de sí mismos y del mundo (Echeverría, 2003).

\subsection{Resultados}

A partir del desarrollo de las técnicas de intervención empleadas se generó una codificación abierta, permitiendo que los códigos provengan de las lecturas y la formación teórica realizadas por los investigadores, así como del lenguaje y las expresiones utilizadas por los actores sociales. Los datos obtenidos permitieron construir las categorías que conformaron la matriz de análisis (Vasilachis, 2006).

En relación con la matriz se realizó un análisis categorial con el fin de establecer unidades de análisis para la descripción del contenido de los relatos, desde una representación simplificada del objeto de investigación (Abela, 1998).

El análisis de los datos se divide en tres apartados: La (re)construcción de nuevas subjetividades en las mujeres puntuadas como víctimas en el marco del conflicto armado; las narrativas alrededor del proceso de reconstrucción del tejido social y la experiencia de las mujeres como sobrevivientes a la guerra.

\subsubsection{La reconstrucción y emergencia de nuevas subjetividades}

Es a través de las configuraciones narrativas alternas o novedosas como se refleja el proceso de reconstrucción y emergencia de las subjetividades de las mujeres y la transformación de los significados que se le atribuyen a las experiencias vividas de las "víctimas" y sobrevivientes del conflicto armado. La subjetividad se alimenta de los relatos que encierran nuevos significados atribuidos a las experiencias y la migración hacia nuevas formas identitarias que les permiten posicionarse en el escenario social, comunitario, familiar y político. La emergencia de configuraciones subjetivas se conecta con el proceso de reterritorialización (Ocampo y Zuluaga, 2017) por el que atraviesan las comunidades en condición de desplazamiento forzado, en el cual se aproximan al arraigo con el nuevo espacio físico desde el cual pueden crecer como comunidad, a la vez que se va tejiendo el sentimiento de arraigo al nuevo lugar.

Algunos relatos reflejaban esta condición: "Yo tuve que sufrir muchas cosas antes de llegar acá, a mí me tocó salir corriendo ese día porque me alcanzaron a avisar que iban por mí; deje todo allá, salí con poquitas cosas y alcance a cargar al gato, yo sin él no me iba, yo me vine por tierra. Yo 
llegué en la noche y lo primero que me pegó fue el frío. No tenía mucha ropa para vestirme acá. Mientras viajabas un amigo me ayudó con un contacto y esa noche ella me recibió pero me dijo que el gato no lo podía tener allá, ella me dijo que me lo cuidaba y yo le creía. Al día siguiente me dijo que se le escapó y allí estaba yo, totalmente sola, eso no lo he podido soportar. Al pasar los días me dí cuenta que no era tan fea la ciudad, ya no me da tan duro, pero aún me estoy acomodando, uno extraña muchas cosas, la gente, la comida".

La subjetividad emerge en el nuevo territorio, que a su vez es el resultado de un proceso histórico en el cual se construyen los sentidos y significados del nuevo espacio físico (Ocampo y Zuluaga, 2017), con la trascendencia sobre lo geográfico y la consolidación de un sentido de comunidad (Montero, 2004). En este proceso es fundamental la experiencia de interacción con el entorno y el reconocimiento de una postura política que incide en el mejoramiento de sus condiciones y en el reconocimiento como sujetos plenos de derechos.

Esta ciudad ve al de afuera menos que ellos, vea usted; a mí me tocó pelear para que al niño me lo recibieran en el colegio, porque el recién llegado y me lo mandaron lejos de acá. Yo sí me fui y ahora me lo tienen cerca. Y no solo uno pelea por los hijos de uno, ese día también ayude a una muchacha de acá, es que sí hay para uno se puede para todos.

Así, las víctimas avanzan en la reconstrucción de sus vidas a partir de la resignificación de la experiencia vivida dejada atrás (Díaz y Díaz, 2017), la cual ha incidido en su identidad y en su configuración subjetiva. No obstante, existe una especie de sentimiento ambivalente que se debate entre el arraigo por el territorio perdido y el reconocimiento y significación de un nuevo espacio físico (López y Rodríguez, 2012).

Si esto no me hubiera pasado yo no sería tan fuerte, yo no podría ayudar a esa gente, mi vida no era así. Acá toca duro, pero también se puede hacer mucho.

Yo nunca pensé salir de allá. Yo solo estaba dedicada a la casa, aquí me tocó trabajar pero ya no me da miedo estar sola, yo sé que manejo mis cosas y eso me motivó a estudiar.

Se identifican varias fases en el proceso de emergencia de la subjetividad en las mujeres que han sufrido los daños de la guerra. Inicialmente la confusión y la desesperanza harán parte del proceso de duelo por el que 
atraviesan, duelo por los seres queridos, las interacciones, el estilo de vida y el territorio pasado. Posteriormente, se inicia un proceso de reconexión con los ancestros desde la añoranza de su vida pasada. Aquí se aproximan al rescate de tradiciones culturales, esencias mitológicas de los antepasados y de los clanes familiares que les permiten establecer poco a poco una nueva conexión con el pasado que asumirá una función reparadora y esperanzadora en la vida de las mujeres. Son los propios recursos psicológicos de las mujeres los que les permiten resignificar los horrores de la guerra (Arias, 2018) e identificar posibilidades en medio del sufrimiento por el que atraviesan.

"Yo nunca me imagine que a los 60 años fuera a vivir eso. Ellos me dijeron que había un familiar en Mosquera y que me había mandado a llamar porque necesitaba ayuda, yo me fuí. Allí me cogieron y me abusaron disque por estar con el grupo, pero yo no me quedé callada, ya no". Quien refiere su relato no puede contener el llanto e inician a cantar de manera conjunta por iniciativa del grupo "saaana, saaana, saaana, sana ya" (bis). Esta acción se ha convertido en una forma que emplea el grupo para acompañar el dolor que aún sienten las mujeres al retomar las situaciones que vivenciaron por acciones violentas.

Saber que otras mujeres lograron narrarse de manera diferente y seguir adelante con sus vidas, se presenta como un aliciente para aquellas que se encuentran sumidas en la desilusión y el sufrimiento. La conexión emocional con otros miembros de su nueva comunidad le dará sentido a su experiencia (Arias, 2017) y permitirá el tránsito hacia una condición de sobreviviente, un ser humano politizado. El sentimiento y la emoción tienen un papel principal (López, 2015) en medio del ritual, y su fuerza se muestra en la narrativa de las mujeres. La resignificación se acompaña de la posibilidad de apropiarse de un espacio físico en el cual se pueden desarrollar rituales y momentos de encuentro que les conectan con la tradición y con lo ancestral.

Las subjetividades están mediadas por la cultura, las costumbres, la mitología y los rituales que se muestran como formas de reparación individual y colectiva, y como recursos personales y comunitarios para la protección de la red vincular ante los efectos de la guerra. Es un proceso en el que el papel principal lo asumen las mujeres, las víctimas, quienes han estado en contacto directo con el escenario de la guerra y quienes buscan la validación de un rol político desde el cual puedan construir el tejido de la comunidad para recomenzar.

Finalmente, la emergencia de la nueva subjetividad, esa relación entre la afirmación individual y la construcción social del sujeto, que se estructura a 
partir de los contextos (Estupiñán, Hernández y Serna, 2017). La dimensión relacional que permite manifestación de una nueva forma de organización individual y social que se ha construido a partir del reconocimiento del sujeto como interlocutor válido con y para los otros. La conciencia de sí, constitutiva de la subjetividad, en esa conexión con el mundo social, migra hacia pensamientos y sentimientos alternos que reflejan la nueva realidad (Ocampo y Zuluaga, 2017), realidad que integra necesariamente la otredad y la resignificación de la experiencia.

\subsubsection{Las narrativas alrededor del proceso de reconstrucción del tejido social}

La narrativa es entendida como una organización de la experiencia vivida por medio de la cual se estructura una expresión de la identidad y de la interacción. Se organiza como la forma internalizada de la comprensión del mundo, pero también es la esencia posibilitadora del cambio desde su externalización e impacto sobre las relaciones (White, 1995). Las nuevas subjetividades se definen a partir de la transformación de los relatos de las mujeres alrededor de su experiencia en la guerra, para poder migrar hacia estructuras posibilitadoras, recursivas y generativas del discurso, que les permita narrarse y concebirse identitariamente de manera diferente y comprender el entorno como un ambiente que permita la nueva organización de la experiencia.

"Esa vez me reí mucho; nosotras estábamos iniciando a formar el grupo y nos imcumplieron en la alcaldía y nos fuimos a marchar. Ese día nos fuimos desde acá al centro para que nos escucharan allá y nos fuimos varias haciendo bulla. Cuando estábamos llegando nosotras sí vimos que nos grababan de un noticiero pero gritábamos más y habia mucha más gente. Cuando vimos en noticias decian que era una marcha de mujeres trabajadoras sexuales y saliamos nosotras, eso si fue el colmo".

La narrativa está vinculada con la mitología, que se configura a partir de construcciones discursivas y culturales, ricas y complejas en contenido, que muestran representaciones simbólicas de la cosmovisión de las personas y los grupos sociales. Son sistemas organizados de creencias desde los cuales se hace lectura de las realidades y se moviliza la acción en los diferentes contextos. La forma como se configura la mujer en la sociedad depende de las mitologías que se encuentren en ese saber implícito, colectivo, asumido por la individualidad como "verdad". En la mitología existe una inclinación 
marcada por lo femenino como alusión al origen y a la naturaleza de lo humano. En palabras de Jáidar y Tejada (2003) "los símbolos son infinitos, tantos como la vida misma ofrece; los encontramos en todos los mitos sobre la Madre-Tierra, la Madre Universal, devienen reconocibles y universales" (p. 80).

"Una acá se enfrenta a todo, hay muchos mitos de la mujer negra y sobre todos sexuales, ellos creen que nosotras somos sumisas y que solo podemos trabajar en las casas de familia y eso no es asi”."

"Cuando llegué a esta localidad yo tuve que enfrentar varias cosas, ser negra, mujer y desplazada. Cuando me metí en lo político, en la localidad me miraban raro, me decían que mejor me fuera a buscar qué hacer y que eso no era para mujeres como yo. Y casi gano, me faltó poquito, y como vieron que sí podía mover a la gente, hasta acá llegan para pedir ayuda".

Romper con las estructuras míticas determinadas por la sociedad, y migrar hacia nuevas configuraciones del ser mujer, ha sido uno de los grandes retos con que se han encontrado las mujeres en su proceso de reterritorialización. Sin duda, permitir la emergencia de nuevas configuraciones mitológicas permite la aparición de nuevas formas de subjetividad, novedosas maneras de narrarse a sí mismas y de posicionarse en el mundo social.

De acuerdo con Jimeno (2016) las narrativas sirven como referentes para comprender la formación de los sujetos y sus relaciones, son medios de expresión cargados de significado que dan cuenta de la mediación discursiva en el proceso de construcción de sujetos y de la incidencia y transformación del entorno social. Son la principal vía de acceso a la subjetividad. Para Díaz y González (2005), al narrar, el sujeto presenta un discurso mediante el cual se hace explícita la subjetividad. Pero la narrativa trasciende las palabras organizadas en el relato, implica la carga emocional, de la praxis, de los sentidos y significados.

Nosotras hemos logrado mucho, no ha sido fácil pero ya nos reconocen. Acá ya nos miran diferente. Cuando se cocina se le da parte hasta a los vigilantes de por acá y ellos son muchas veces quienes nos cuidan.

Si lo ve a él, al principio no le hablaba a nadie cuando venía a acompañarla a ella, pero él ya nos habla, es parte de nosotros, es de la familia. El la acompaña porque a ella la dejaron mal, después de todo la dejaron vivir y estamos con ella para que le hagan el tratamiento. 
En la posición como observadores participantes del proceso de reorganización de las mujeres se identificó la transformación de los relatos y su expresión por medio del ritual. Hablar de los hechos, del sufrimiento y del dolor, de las expectativas, de las necesidades, del pasado, el presente y del futuro, permitió a las mujeres desarrollar relatos alternos que las movilizan hacia la construcción de un futuro posible en el que puedan disfrutar de la paz, de los vínculos y del territorio. En palabras de Ocampo y Zuluaga (2017) "narrar toma un sentido singular, pues pese a los acontecimientos violentos las personas victimizadas aún se reconocen como seres de palabra, partícipes de una sociedad..." (p. 141).

A lo largo de los acercamientos con la población se pudo evidenciar cómo la reconstrucción de las memorias y la resignificación de los hechos las han fortalecido y les ha permitido realizar reflexiones orientadas a lograr un reconocimiento y control de sus vidas con un papel activo para superar la violencia y la desigualdad.

\subsubsection{Las mujeres como sobrevivientes de} la guerra: La pertenencia al territorio

Ocampo y Forero (2013) reconocen que el proceso de reterritorialización para las mujeres implica "la necesidad de significar un nuevo espacio para sí mismas; de crear nuevos vínculos e integrarse a una dinámica de vida en condiciones cambiantes; y de conseguir un modo de subsistencia" (p. 44). La llegada al nuevo territorio exige el desarrollo de nuevos aprendizajes y la generación progresiva de sentimientos de pertenencia e identidad con el nuevo espacio físico. Sin embargo, existe un hilo que conecta el presente con el pasado desde el plano cultural y por eso se mantienen prácticas rituales sobre tradiciones culturales o sobre formas del cuidado de la salud desde las tendencias tradicionales de sus regiones de origen (Posada et al., 2016).

"Estamos montando el Kilombo ${ }^{51}$ en el segundo piso, vamos a dejar un cultivo con las plantas que de verdad que curan y allá va a quedar una camilla para la partera. Estamos haciendo este espacio para curar no solo a nosotros sino que le sirva a la comunidad para cosas simples, un dolor de barriga, dolor de cabeza y cosas así. Aquí no solo queremos sanar el cuerpo sino sanarnos también desde el alma. Esto es lo que queremos que ellos no pierdan, cuando llegamos a Bogotá se olvidaron de quienes somos y les da pena contar todas las cosas que las abuelas les enseñaron. Los jóvenes no

51 Los kilombos son espacios de medicina ancestral que recoge los saberes ancestrales a través de generar medicina natural a bajo costo para las comunidades. 
se nos pueden perder acá, ellos deben seguir estudiando pero no olvidarse de quienes son".

La experiencia por la que atravesaron las mujeres en el marco del conflicto armado las posicionó como víctimas en diferentes niveles y sobre variadas formas de agresión. Pero la condición de víctimas no ha de mantenerse de manera permanente por tratarse de un constructo dinámico que no debería integrarse a la identidad para permitir el tránsito por el ciclo de la vida.

"Nosotras nos cansamos que nos dijeran las víctimas, nosotras ya no queremos ser así. Es que como si nosotras no pudiéramos sino quejarnos y no es así, cuando nos presentan como víctimas les decimos no, somos sobrevivientes del conflicto. Ya no callamos y con eso le quitamos el poder a quienes nos hacían sentir mal por lo que pasó, es que hasta nos daba vergüenza contar esto, ahora les decimos a ellos en su cara usted me hizo esto y lo voy a contar"

El rol de víctima implica un reconocimiento político que les abre las posibilidades a las personas para acceder a un proceso de reparación y de restitución de sus derechos. Sin embargo, se identificó un paso necesario en el proceso de emergencia de la subjetividad. Narrarse como víctima es narrarse desde el sufrimiento, el dolor y el miedo. Narrarse como sobreviviente es reconocerse desde la posibilidad y el futuro. Ser sobreviviente del conflicto ha permitido a las mujeres validar los recursos personales, familiares y comunitarios con los que cuentan para trascender hacia una mirada optimista de la vida.

\subsection{A manera de conclusión}

Las mujeres y las comunidades sobrevivientes del conflicto armado colombiano cuentan con mecanismos de reparación y reconciliación basados en su cultura, sus rituales y su mitología y expresados a través de narrativas organizadas que les han permitido ubicarse en un rol político de sobrevivientes de la guerra.

Esto les ha brindado la posibilidad de generar redes que favorecen el cuidado de sus miembros y les brinda seguridad para enfrentarse a las dinámicas cambiantes del territorio actual en el que habitan.

En la medida en que transitan por el camino de la reconstrucción de significados y el proceso de re-territorialización, permiten la emergencia de nuevas construcciones de su subjetividad y con ellas, del tejido comunitario. El simbolismo del ritual permite la aproximación a la emergencia de un nuevo 
posicionamiento en sus vidas para apoyar al otro a salir adelante en medio del conflicto desde la conexión emocional y la expresión de la experiencia vivida enmarcada en relatos posibilitadores que rescatan el aprendizaje más allá del sufrimiento. Así mismo, los rituales y saberes ancestrales les permite dejar un legado cultural a los miembros de las nuevas generaciones, pues los mantiene en estrecha conexión con sus raíces y se convierten en un elemento que evoca la memoria colectiva cultural.

La experiencia vivida se asume como parte de la existencia y se incorpora a la dimensión histórica de las comunidades y las personas. El pasado se reconoce desde la añoranza por lo perdido (territorio, vínculos, vida) en el trasegar hacia el reconocimiento de sí mismo en vinculación y relación con el otro, constitutivo de la nueva subjetividad.

\section{Referencias}

Abela, A. (1998). Las técnicas de análisis de contenido: una revisión actualizada. Centro Estudios Andaluces, 10(2). 1-34. Disponible en: http://public.centrodeestudiosandaluces. es/pdfs/S200103.pdf

Alvarado, S. V., Ospina-Alvarado, M. C. \& García, C. M. (2012). La subjetividad política y la socialización política, desde las márgenes de la Psicología política. Revista Latinoamericana de Ciencias Sociales, Niñez y Juventud, 10(1), 235-256.

Arias, G. (2017) Subjetividades y movimientos sociales: abordajes teóricos y metodológicos. En: A. Díaz, M. González, \& G. Arias (eds.) Subjetividades. Abordajes teóricos y metodológicos. Bogotá: Editorial Universidad del Rosario.

Arias, G. (2018). Notas sobre una Comisión de la Verdad desde las mujeres. Revista Eleuthera, 19, 186-209. doi: 10.17151/eleu.2018.19.11.

Berger, P. L. \& Luckman, T. (1968). La construcción social de la realidad. Buenos Aires: Amorrortu.

Cabrera Lozano, A., \& Cárdenas Medina, M. (2016). Nuevas subjetividades de las mujeres desplazadas en la ciudad de Bogotá, víctimas de actos violentos en el conflicto armado, y la definición de sus relaciones y estructuras familiares, a partir de la resignificación en su historia de vida [Ebook]. Bogotá: Corporación Universitaria Iberoamericana. Disponible en: http://repositorio.iberoamericana.edu.co/bitstream/001/249/1/Nuevas $\% 20$ subjetivi-dades $\% 20 \mathrm{de} \% 2$

Cárdenas Medina, M. A. \& Cabrera Lozano, A. M. (2016). Violencia sexual, un mecanismo de guerra. Revista Poiésis, 30, 36-43.

Cornejo, M, Faúndez, X., \& Besoain, C. (2017). El análisis de datos en enfoques biográficosnarrativos: desde los métodos hacia una intencionalidad analítica. Forum: Qualitative Social Research, 18(1), art. 16. Disponible en: https://doaj.org/article/ 0015991fcf584ab$\underline{09101 \mathrm{f} 89220 \mathrm{e} 96456}$ 
Denzin. N. \& Lincoln, Y. (2012). Manual de investigación cualitativa. Barcelona: Gedisa.

Díaz, A. \& Alvarado, S. (2012). Subjetividad política encorpada. Revista Colombiana de Educación, 63, 111-128.

Díaz, A. \& Díaz, J. (2017). Subjetividad política femenina: de los miedos a los posicionamientos. En: A. Díaz, M. González, \& G. Arias (eds.) Subjetividades. Abordajes teóricos y metodológicos. Bogotá: Editorial Universidad del Rosario.

Díaz, A. \& González, F. (2005). Subjetividad: una perspectiva histórico-cultural. Conversación con el psicólogo Fernando González Rey. Universitas Psychologica, 4(3), 373-383.

Díaz, A. (2014). Aportes para pensar sobre la subjetividad política femenina. Pedagogía y Saberes, 40, 87-96.

Duque, L., Patiño, C., Muñoz, D., Villa, E., \& Cardona, J. J. (2016). La subjetividad política en el contexto latinoamericano. Una revisión y una propuesta. Revista CES Psicología, 9(2), 128-151.

Echeverría, R. (2003). Ontología del lenguaje. Santiago: Dolmen.

Estupiñán, J., Hernández, A. \& Serna, A. (2017) Transformación de la subjetividad en la psicoterapia sistémica. Bogotá: Usta.

González, F. (2013) La subjetividad en una perspectiva cultural-histórica: avanzando sobre un legado inconcluso. Revista CS, 11, 19-42.

Güell, P. (2002). Subjetividad social: desafío para el nuevo siglo. Polis, Revista Latinoamericana, 1(2), 2-6. Disponible en: http://polis.revues.org/7853

Jáidar, I. \& Alvarado, V. (2003) Mujer, imagen y mito. En: I. Jáidar (ed.) Convergencias en el campo de la subjetividad. México: Universidad Autónoma Metropolitana. Clacso. http:// biblioteca.clacso.edu.ar/Mexico/dcsh-uam-x/20170524025027/pdf 476.pdf

Jimeno, M. (2016). El enfoque narrativo. En: M. Jimeno, C. Pabón, D. Varela, \& I. Díaz (eds.) Etnografias contemporáneas III: las narrativas en la investigación antropológica. pp. 7-21 Colección CES Bogotá: Universidad Nacional de Colombia.

López, G. (2015). Del guerrero al ciudadano. Experiencias y sentimientos sociales en la historia de los desmovilizados del conflicto armado. Editorial Académica Española.

López G. \& Rodríguez, A. (2012). El lugar de los sentimientos, el lugar de los vínculos. Reconfiguración de identidades en el marco del conflicto armado colombiano. Revista Colombiana de Ciencias Sociales, 5, 83-102.

Manzanero, A \& Recio, M. (2012). El recuerdo de hechos traumáticos: Exactitud, tipos y características Asociación de Médicos Forenses de Andalucía. doi:10.4321/S113576062012000100003

Montero, M. (2004). Introducción a la Psicología comunitaria. Desarrollo, conceptos y procesos. Buenos Aires: Paidós. 
Ocampo, M. \& Zuluaga, S. (2017) Reivindicarse a sí mismo: narrando subjetividades. En: A. Díaz, M. González, \& G. Arias (eds.) Subjetividades. Abordajes teóricos y metodológicos. Bogotá: Editorial Universidad del Rosario.

Ocampo, M., \& Forero, P. A. (2013). Desplazamiento forzado e itinerancias: mujeres reasentadas en la ciudad de Montería. La búsqueda incansable de un territorio de vida. Revista Tesis Psicológica, 8(1), 32-55.

Posada-Zapata, I. C., Mendoza-Ríos A., Restrepo-Correa, C., Cano-Bedoya, S. M., OrozcoGiraldo, I. C. (2016). ¿Qué hacer cuando estoy enferma? La búsqueda de alternativas para el bienestar en mujeres desplazadas. Rev. Fac. Nac. Salud Pública, 34(2), 167-174.

Posada, I. \& Carmona, J. (2018) Subjetividad política y ciudadanía de la mujer en contextos de conflictos armados. Revista Mexicana de Ciencias Políticas y Sociales, 233, 69-92.

Vasilachis, I. (2006). Estrategias de investigación cualitativa. Barcelona, España: Gedisa.

White, M. (1995). Reescribir la vida. Entrevistas y ensayos. Barcelona: Gedisa. 


\section{Los retos del empoderamiento. Las interseccionalidades entre el enfoque de género y diferencial}

\section{Diana BrITto Ruz ${ }^{52}$ \\ Resumen}

El empoderamiento ha sido acogido como una herramienta fundamental para responder al reto de la reparación de las mujeres víctimas. Sin embargo, no hay una única comprensión. Este concepto proviene del feminismo y fue difundido a través organismos de cooperación internacional como una forma de superar la pobreza de las mujeres y se ha incorporado a múltiples programas y proyectos que buscan dar respuestas a las mujeres desplazadas por el conflicto armado, pero ¿qué pasa con el empoderamiento cuando además de la condición de género hay otras que se cruzan como la pertenencia étnica o ser de un grupo etario en particular? Este estudio analiza en dos momentos un programa de base comunitaria que atiende mujeres desplazadas, afrodescendientes y adultas mayores.

Palabras clave: empoderamiento, enfoque de género, enfoque étnico, mujeres desplazadas, víctimas.

\section{Abstract}

Empowerment has been a key element in the challenge it poses to repair a woman victim. Nonetheless, there is more than one approach. This concepts has its roots embedded in feminism and has spread through organisms of international cooperation as a way to overcome women poverty and has incorporated multiple programs and projects that seek answers for displaced women by the armed conflict. However, what happens with empowerment when more than one dimension, beyond gender, as ethnicity and age group? This study analyses in two different moments, a community base project that provides aid to displaced women, afrodescendant and elderly.

Keywords: Empowerment, gender approach, ethnic approach, displaced women, victims. 


\subsection{Introducción}

El conflicto armado en Colombia se ha caracterizado porque de manera simultánea con el escalamiento de la guerra han surgido múltiples experiencias de construcción de paz. Y en este propósito han coincidido el gobierno, organizaciones de la sociedad civil, cooperantes internacionales y privados. Todos se han propuesto, desde distintas perspectivas, lograr que las mujeres no solo se recuperen del impacto desproporcionado que la guerra les infringió, sino que además salgan fortalecidas de esta terrible experiencia. Por esa razón, es común encontrar en los objetivos que se fijan en los proyectos y programas que las involucran, el de lograr el "empoderamiento".

Sin embargo, la comprensión sobre lo que es el empoderamiento no parece ser uniforme y se ha generalizado la idea de que es igual a autonomía económica, por ello, la oferta para las mujeres pobres en general, y las desplazadas en particular, usualmente se enfoca en el desarrollo de emprendimientos productivos que buscan lograr mejoras en la calidad de vida de las mujeres, lo cual obviamente no es despreciable. Sin embargo, el empoderamiento tiene que ver también con la autonomía política, cultural, social y física, que les permita a las mujeres hacerse cargo de si mismas, sus cuerpos, sus recursos y su vida. La razón por la que abordar solamente el aspecto económico no es suficiente, es porque esa apuesta está basada en que los ingresos económicos darán a las mujeres libertad, pero en la cotidianidad no funciona de esa manera porque al interior de los hogares ellas no gozan de iguales derechos que los integrantes masculinos (Kabeer, 2015).

No es gratuito que el objetivo de empoderar a las mujeres haya puesto todo su énfasis en el aspecto económico, pues surge justamente de la mano de las teorías del desarrollo de los años 80 y 90 que buscaban la superación de la pobreza a partir de la certeza de que las más pobres entre los pobres eran las mujeres, propendía por su inclusión y participación en economía y la política con base en la idea de que el principal factor de exclusión era su falta de poder. Sin embargo, para entender el empoderamiento es necesario tener una perspectiva compleja que permita verlo en distintas dimensiones y en una relación estrecha con la autonomía, no como un absoluto que se posee o no, sino como un proceso que puede tener más o menos desarrollo de acuerdo con la dimensión que se valore. En línea con lo planteado por (Posada \& Carmona, 2018), el empoderamiento puede ser entendido como una expansión de las capacidades de las mujeres. 
El empoderamiento se materializa entonces en la capacidad de reconocimiento propio, de interpretación de problemas en relación con el contexto y las estructuras de poder, y en la búsqueda de soluciones a partir de la posibilidad transformadora, emanada de un proceso de desarrollo personal que se proyecta a su esfera personal, familiar y el ámbito colectivo (Rowlands, 1998); y la autonomía, como el control sobre la propia vida y el cuerpo en aspectos económicos, políticos y socioculturales, no en aislamiento, sino a través del desarrollo de los medios materiales y no materiales para sobreponerse, y con ello reducir, la opresión que traen distintas formas de "poder sobre otros" (Meertens, 1994, Galtung, 1980) ${ }^{53}$.

Lo que suele encontrarse en los programas y proyectos que tiene por objetivo empoderar a las mujeres, es que se diseñen charlas y talleres que ilustren acerca de aspectos conceptuales y normativos; además, capacitaciones para el desarrollo de destrezas que les permitan incursionar con emprendimientos productivos o mejoren su empleabilidad. Este tipo de propuestas suelen implementarse usando metodologías de la educación popular, que buscan que las mujeres se transformen interiormente, generen conciencia y participen en los diversos escenarios de la vida social, tomando decisiones que permitan superar la injusticia e inequidad, y para ello se valen de la reflexión acerca de experiencias cotidianas, como una forma de comprender las condiciones que les afectan, con el fin de que desarrollen estrategias y habilidades para transformar la realidad opresiva que las discrimina y margina (León, 1998).

Esta idea del empoderamiento ha surgido de la mano del feminismo que a nivel mundial y pese a su gran acogida ha recibido críticas por parte de feministas negras quienes han señalado que se propone la noción de mujer unánime, que de nuevo cae en una visión binaria del mundo (hombres vs mujeres) poniendo a las mujeres y sus múltiples experiencias en una misma categoría. Lo que en términos de Ángela Davis sería expresado como que la opresión de clase, el sexismo y el racismo están unidos y dan lugar a una discriminación múltiple: por ser mujer, por ser de clase baja y por ser negra (Davis, 2004). Y más recientemente, la crítica al feminismo se ha profundizado desde las teorías poscolonialistas al señalar que desconoce las realidades de múltiples grupos humanos no occidentales, entre ellos los grupos indígenas y afrodescendientes. Las críticas también apuntan, a señalar que el enfoque de género y el empoderamiento se han convertido

53 En el anexo 1 aparece una matriz que plantea el desarrollo conceptual y operacional de estos conceptos, base de la encuesta sobre "autonomía y empoderamiento". 
en instrumentos despolitizados que no siempre dan cuenta del otras cosmogonías y prácticas culturales de esos grupos diversos (Choque \& Mendizabal, 2010).

Uno de los principales vehículos de difusión de las teorías del empoderamiento, principalmente enfocado en los países tercermundistas, o en términos de Boaventura de Sousa "los países del sur", es el Sistema de Naciones Unidas y las múltiples agencias de cooperación internacional. En el caso particular de Colombia, el sistema ONU y la cooperación internacional han jugado un papel fundamental en el marco del conflicto armado. A partir de la década de los años 90, el país viró drásticamente hacia la neoliberalización de la economía, al mismo tiempo que se incrementaba el efecto negativo del conflicto armado. Estas dos condiciones hicieron que cada vez menos el Estado se hiciera cargo de las múltiples demandas sociales, teniendo su peor momento durante la primera década del siglo XXI, periodo durante el cual, incluso el gobierno llegó a negar la existencia de un conflicto armado pese a la cifra creciente de víctimas y determinando que la situación de crisis humanitaria correspondía al efecto de una amenaza terrorista.

Ante este panorama, la cooperación internacional asumió, en alguna medida, la atención de la población víctima con la intención positiva de ayudar y respaldar el trabajo de múltiples organizaciones de la sociedad civil que se dieron a la tarea de llenar el vacío dejado por el Estado. Sin embargo, las organizaciones de la cooperación internacional tienen agenda propia y una visión del mundo que imprimen a sus actuaciones. El resultado, es que pese a que en los distintos proyectos que lideran está siempre presente el propósito del empoderamiento de las víctimas, no siempre logran el efecto restaurador en el sentido planteado por (Lugo-Agudelo, Sánchez-Agudelo, \& Rojas-Granada, 2018) y que significa recuperar el valor como personas y evitar que queden atrapadas en el daño sufrido.

\subsection{Método}

Esta es una investigación que se basa en información cuantitativa y cualitativa simultánea, las cuales constituyen una estrategia combinada de técnicas que se usan de manera complementaria. Es un estudio de caso que permite analizar variables constitutivas del fenómeno de la autonomía y el empoderamiento, en mujeres en situación de desplazamiento forzado en su contexto real. Se han utilizado múltiples fuentes e instrumentos para la recolección de la información en busca de mayor confiabilidad y validez. 
Es importante resaltar que buena parte de la información analizada es subjetiva, es decir, es lo que las mujeres han señalado como su percepción respecto a los diferentes temas indagados y, con base en estas percepciones, se construye el análisis en torno a las dos categorías analíticas centrales: autonomía y empoderamiento. Las fuentes de información son fundamentalmente dos: humanas, las mujeres mismas; y documentales: documentos escritos, periódicos, revistas y las páginas web de las organizaciones. Los instrumentos para la recolección de la información fueron: una encuesta que fue aplicada en dos momentos 2010 y 2017, talleres de cartografía social y discusiones grupales.

\subsection{Resultados}

La primera etapa de la investigación acerca de tres organizaciones de mujeres en situación de desplazamiento forzado indagaba por el empoderamiento de las mujeres víctimas en tres regiones de Colombia: Caribe, Andina y Pacífica; en ella se encontró que la organización que mayores dificultades presentaba para el empoderamiento era la del Pacífico, que tenía además una característica particular, la componían en un $67 \%$, de mujeres afrodescendientes, de las cuales, el 43\% provenían de zonas rurales del pacífico colombiano. De manera que en ellas se hacía manifiesta la forma como se sobreponen o intersecan una serie de vulnerabilidades que complejizan la experiencia del desplazamiento: ser mujer, ser rural y afrodescendiente (Britto, 2012). En la segunda fase del estudio se aplicó de nuevo la encuesta de autonomía y empoderamiento a las mujeres de la organización del pacífico colombiano, encontrando que actualmente un $77 \%$ de las mujeres encuestadas son afro, de zonas rurales de Cauca $(21,7 \%)$ y Nariño (43,3\%), han llegado paulatinamente a Cali desde el año 2011. El $32 \%$ está casada o en unión libre, es decir tienen pareja, lo cual representa un aumento del 5\% con respecto del primer estudio. E1 33.3\% son viudas, lo cual puede tener una estrecha relación con que son sobre todo población adulta mayor. E1 78,3\% no tiene educación o apenas primaria incompleta o completa, lo cual indica una muy baja escolaridad en la mayoría de las mujeres. Para el primer estudio el $70 \%$ de ellas eran mayores de 40 años y ahora son $86,6 \%$. Se redujo levemente la autoidentificación como cabeza de hogar, pasó de 93\% en primer estudio a 90\% en 2017.

A continuación, se presentan los resultados de las dos etapas del estudio, contrastando cada uno de los aspectos del empoderamiento y la autonomía, estudiados a través de la encuesta: 
En el cuadrante de autonomía emocional y física/ empoderamiento personal se indaga por el cuidado del cuerpo, decisiones sobre salud sexual y reproductiva, decisiones sobre su propia vida. Se encuentra que el 78\% de las mujeres expresa deseo de realizar cambios en su vida, sin embargo, el $85 \%$ espera que dichos cambios se den por intervención de otro, llámense gobierno, familia, Dios o alguien no determinado. Y dicha expectativa respecto al programa, es del $3.3 \%$, parecen no tener mucha esperanza de que a través del programa logren los cambios deseados. En la misma línea de autonomía emocional y física/relaciones próximas, que hace referencia a la participación de las mujeres en la toma de decisiones de la familia y a la valoración de su criterio por parte de quienes la integran. Tener la posibilidad de decidir libremente sobre el manejo de su tiempo. Las mujeres encuestadas consideran que sus criterios son altamente valorados o tenidos en cuenta en un $65 \%$, cifra similar a la del primer estudio. Respecto al uso del tiempo libre el $40 \%$ de las mujeres dicen dedicarlo a las tareas del hogar; ha habido aumento del $21.6 \%$ en el trabajo comunitario. En autonomía emocional y física/empoderamiento colectivo, que pregunta por la pertenencia a una organización, red o colectivo; si en ella se propician espacios para la toma de conciencia y formación en diversos aspectos personales, económicos, culturales y políticos; y, si las mujeres de la organización toman acciones para hacer valer sus derechos y tiene conciencia de los alcances de éstas. Los resultados muestran que el $28.3 \%$ de las mujeres encuestadas expresan estar actualmente vinculadas a alguna organización. Respecto al programa, consideran ser lideresas solamente el 1,6\%, mientras que en el primer estudio lo expresaron así el 13,3\%, en el primer estudio era muy poco, pero en el 2017 es casi inexistente el liderazgo de las mujeres en el programa. El $73.2 \%$ dicen que respecto al programa participan en lo mínimo y hacen lo que les piden en él. Y respecto a la formación que reciben, consideran de mayor utilidad la cultural $(46.6 \%)$ y la psicológica $(48.3 \%)$, respecto a la política la considera útil apenas el 13,3\%. En la autonomía económica/ empoderamiento personal, se explora si las mujeres tienen acceso al trabajo y manejan los recursos económicos que de él derivan; si tienen acceso a recursos financieros y a la toma decisiones sobre ellos. Los resultados muestran que la población de mujeres tiene decrecimiento en el manejo de los recursos económicos, solamente el $48 \%$, mientras que en primer estudio eran $68 \%$. Aumentó la cantidad de mujeres que dicen haber sido propietarias de tierra antes del desplazamiento, en primer estudio eran $81,7 \%$ y en $201793,3 \%$. No están bancarizadas el $95 \%$, ni tienen ahorros el $86 \%$, aunque esta cifra tiene aumento respecto al primer estudio que eran $92,4 \%$. Tampoco tienen créditos 91\%, ni deudas el 69\%. El 80\% dicen dedicarse 
al hogar. En autonomía económica/relaciones próximas, se explora si las mujeres aportan dinero a la economía familiar y forman parte activa en la toma de decisiones económicas. Si todas las personas de la familia aportan en lo relacionado con trabajo doméstico, se halló que la economía familiar actualmente es sostenida por los hijos (45\%). Ha bajado la capacidad económica de ellas y sus parejas, pues en el primer estudio las mujeres y sus cónyuges eran quienes sostenían el hogar en un 20\% comparado con el $3.3 \%$ de hoy. En cuanto a la carga que representa para las mujeres el trabajo doméstico hay un comportamiento similar al de primer estudio, con un $77 \%$ de ellas que realizan casi todas las tareas en casa. Los hijos varones y los esposos no asumen casi ninguna labor de cuidado doméstico. En autonomía económica/empoderamiento colectivo, indaga por saber si desde su organización se proponen actividades encaminadas a fortalecer la autonomía económica: proyectos productivos, microcrédito y capacitación para el trabajo. Los datos muestran que en fortalecimiento económico las mujeres reportan que la iniciativa que más ofrece el programa es el de emprendimientos con productos $61,6 \%$, la misma que era la más alta en el primer estudio. En segundo lugar, la formación para el trabajo con 50\%. Referencian haber realizado cursos de capacitación diversos, pero el 53\% no tienen una opinión sobre la utilidad de estos. Útiles los consideran solamente el $26 \%$, el principal obstáculo para ponerlos en práctica es la falta de recursos económicos 31,6\% que en el primer estudio eran el 58\%. Sin embargo, dicen que no han pedido apoyo económico para desarrollar emprendimientos productivos al programa $(91,6 \%)$ ni al gobierno $(81,6)$. Sí lo habían hecho en el primer estudio.

En lo correspondiente a la autonomía política/empoderamiento personal, explora si las mujeres conocen sus derechos y los hacen valer, si toman sus propias decisiones en materia política como pertenecer a un partido o movimiento, votar y a quién apoyar. Se encontró que hubo aumento versus el primer estudio en el desconocimiento en general de las leyes que les protegen y los mecanismos como la tutela. Un promedio del $95 \%$ los desconocen, y en primer estudio esa cifra era del $80 \%$. Sin embargo, el $65 \%$ actualmente consideran que la justicia es efectiva o medianamente efectiva. Esa cifra en el primer estudio era del $52 \%$. Su interés por la política es igual o menor a antes del desplazamiento con un $81,6 \%$, y en el primer estudio era $71,7 \%$, es decir, ha decaído. Dicen decidir por sí mismas en materia política el 63,3\% pero en primer estudio era el $73,3 \%$, prefieren que otros decidan por ellas un $32 \%$. En autonomía política/relaciones próximas, se preguntó acerca de aspectos relacionados con la violencia contra las mujeres en el ámbito 
doméstico, si eran capaces de reconocerla y proceder en concordancia con la ley cuando ella aparece. El resultado obtenido es que las mujeres encuestadas identifican poca violencia en su contra, incluso menos que en el primer estudio, las más altas son psicológica y sexual con $6,5 \%$, pero hay un cambio en los agresores, pues señalan que son sus hijos en un $6,6 \%$. Y han acudido a las autoridades un 5\%, y no han hecho nada al respecto un 6,6\%. El acceso a servicios del Estado como salud, educación y capacitación es calificado de manera divergente, es más difícil la capacitación $60 \%$, medianamente fácil la educación (40\%) y fácil la salud (45\%). El resultado de primer estudio es similar, excepto porque en esa oportunidad el servicio al que les parecía más fácil acceder era a la educación con 53,3\%. En lo que concierne a la autonomía política/empoderamiento colectivo, se indagó por la estructura de la organización, si tiende a ser plana y por la forma en que se toman de decisiones en ella; así también se preguntó por la participación en actividades políticas y si reconoce el alcance de las mismas, que puede ser local, regional, nacional e internacional. Se encontró que en el primer estudio el $61,7 \%$ se consideraban capaces de asumir roles de liderazgo en el programa, mientras que en el 2017 se sienten capaces solamente el $48,3 \%$. Para el 71,6\% el programa no es una organización política, mientras que en el primer estudio pensaban igual el 76,6\%. El 50\% piensa que el alcance de lo que hace el programa es local, de manera similar a lo que pensaban igual porcentaje en el primer estudio. Sobre la toma de decisiones en el programa indican que hay un pequeño grupo de personas que toman las decisiones, $35 \%$, o que lo hace una sola persona, $33 \%$, datos similares a los obtenidos en el primer estudio. Tampoco saben cómo se eligen quienes lideran el programa el 58\%. En general participan en procesos electorales un $90 \%$, una cifra mayor a la obtenida en primer estudio que era de $73 \%$, y votan sobre todo en las elecciones de tipo nacional 55\%.

En cuanto a la autonomía sociocultural/empoderamiento personal, la encuesta indaga por el nivel de información que manejan las mujeres acerca de la actualidad, si son capaces de entender y expresar opiniones en relación con los eventos de actualidad política, económica, social y cultural. Se encontró que en el primer estudio decían tener más información sobre política, economía y cultura, siendo levemente mayor la información en economía con un $11 \%$, pero es inferior a la de primer estudio, cuando era 33,3\%. En 2017 dicen que se informan diariamente un 51,6\%, siendo el principal medio la radio con $68,3 \%$. En general las mujeres piensan que su nivel de información ha mejorado con un $50 \%$, pero un $28 \%$ dicen que ha empeorado respecto a antes del desplazamiento. Y un 58\% expresa tener 
mejor información para participar. En la autonomía sociocultural/relaciones próximas, se preguntó acerca de si las mujeres toman decisiones sobre su credo y prácticas religiosas y culturales de manera independiente a lo que dicta su familia o pareja. Se halló que, a diferencia de la encuesta de primer estudio, en 2017 más mujeres identifican diferentes formas de participación política, siendo la más alta la votación para cargos públicos $83,3 \%$, movilizaciones, marchas y ser candidata o ejercer cargos públicos $56,6 \%$. A diferencia del primer estudio, cuando el 33,3\% decían tener obstáculos para participar en política, en 2017 esa cifra es de 51,6\%. Los principales obstáculos identificados son en su orden: falta de educación $25 \%$, falta de dinero $25 \%$, la edad 20\%. Expresan que ante un desacuerdo en las opiniones prefieren callar y mantenerse en su posición un $71,6 \%$, esa cifra en primer estudio era del $48,3 \%$, mientras que un $43,3 \%$ decían que discutían dando argumentos. Y en autonomía sociocultural/ empoderamiento colectivo, se exploró qué tanto las mujeres se mantienen al tanto de las actividades de la organización y si conocen a profundidad su historia, objetivos y filosofía. Si son capaces de presentar sus propios puntos de vista y de debatirlos al interior de la organización y en otros espacios políticos; si son capaces de asumir posiciones de liderazgo y conocen a profundidad la información de la organización. Al respecto se encontró que, sobre los objetivos del programa dicen conocerlos medianamente el $46 \%$, y poco $41,6 \%$, similar a las respuestas de primer estudio. Igualmente están medianamente informadas sobre el programa $51,6 \%$ y poco el $38,3 \%$. Y el $66,6 \%$ consideran que el liderazgo del programa es efectivo, superior al 48,3\% que lo expresó en el primer estudio. El 64,9\% se siente capaz para participar en espacios públicos en nombre del programa; pero prefieren no participar el 31,6\%. Se consideran en capacidad de asumir roles de liderazgo en el futuro un $56,6 \%$, menos que en primer estudio, que eran $66,7 \%$, y consideran que tienen poca influencia para elegir a las lideresas del programa el $45 \%$, e igual que todas el $31,6 \%$. En el primer estudio el $25 \%$ consideraban tener mucha influencia. La actividad pública del programa que más reconocen son las marchas $75 \%$ y en primer estudio el $66,7 \%$, creen que el impacto de las acciones es medio un $58 \%$ y mucho el $25 \%$, pero en primer estudio eran $40 \%$. Y sobre el impacto que el programa tiene en el contexto opinan que sobre todo genera conciencia sobre la situación de la mujer 93,3\% y en segundo lugar sensibilización sobre el desplazamiento con 91,6\%. Que en el primer estudio era la de mayor porcentaje con $90 \%$. Para el $95 \%$ el mayor beneficio de pertenecer al programa es que es un espacio para encontrarse con otras mujeres en su situación de desplazamiento y en segundo lugar que les asesoran y dan apoyo en temas personales, $88 \%$. En el primer estudio el 
mayor puntaje lo obtuvo que se mantienen informadas, $80 \%$, y el segundo conocer sus deberes y derechos $88,3 \%$.

La información recogida muestra que el programa ha promovido la organización de las participantes por "colonias", grupos de "paisanas" (personas que provienen de una misma zona), que han surgido de manera natural, pues la llegada a la ciudad obliga a las familias desplazadas a buscar la red de apoyo conformada por parientes o personas conocidas que han llegado antes a Cali, en el desplazamiento gota a gota que ha vivido el país. Se tienen cuatro colonias: Nariño, Valle, Chocó y Cauca. Esta dinámica de agrupación es especialmente significativa para la población afrodescendiente en la ciudad de Cali, pues no solo funge como red de apoyo primaria en el momento del desplazamiento, sino que corresponde a su lógica de vida comunitaria en la que predomina la familia extensa. Las colonias son el escenario en el que se recrea la experiencia cultural y el vínculo social de los territorios ancestrales, que no coincide con la noción moderna de la individualidad, sino que marca la pertenencia en relación con el colectivo (Urrea \& Murillo, 1999).

Al ser indagadas por la relación que tienen con la institucionalidad, entendiendo que la organización promueve el restablecimiento de derechos de la población desplazada y en tal sentido es fundamental el relacionamiento con distintos estamentos del Estado y en particular con las entidades que de primera mano deben velar por sus derechos. Los resultados arrojan que la relación más difícil la tienen con la Policía, expresan tener temor a ser agredidas y ven con profundo recelo la forma como, en sus palabras, "atropellan a los jóvenes de sus familias". Este sentimiento de lejanía y rechazo puede estar asociado a que sienten desconfianza hacia cualquier actor armado legal o ilegal, marcada por la experiencia vivida en sus territorios de origen, quienes les violentaron y obligaron a desplazarse fracturando el tejido social. Le sigue, en una calificación que va de regular a mala, la relación que tienen con la Unidad de Atención y Orientación a la población desplazada (UAO), hacen explícito el descontento por la precaria atención de esta institución, sin embargo, plantean que no presentan "quejas", pues temen el riesgo de perder los beneficios de la futura reparación. En este punto, y contrastando con la información obtenida en la encuesta, es posible establecer que las mujeres que participan en este programa actualmente no tienen claridad sobre la ruta de atención y que, aunque algunas ya han recibido la indemnización; que es el final de la atención y reparación en criterio del gobierno, es decir, ya no tienen la condición de víctima según la ley; continúan identificándose como tales. Y este punto es especialmente 
interesante, pues en un conflicto tan prolongado como el colombiano, en el que la ley 1448 de 2011 determinó que se podrán registrar víctimas desde el año de 1985, es decir hace más de 30 años, lo que ha sucedido es que la población víctima ha envejecido a la espera de una reparación que no parecen entender en los mismos criterios que establece la ley. Además, por las condiciones socioeconómicas del grupo de mujeres encuestadas (baja escolaridad, adultas mayores) les resulta especialmente difícil la comprensión y el acceso a los programas que el gobierno ofrece. Pero este dato también habla de la efectividad del programa en su propósito de empoderamiento, pues no parece haber combinado adecuadamente el trabajo psicosocial con el jurídico, de manera que aunque finaliza la etapa de restitución de derechos, que muchas veces se logra con una larga lucha jurídica en las distintas etapas de la ruta de atención y reparación, las mujeres no parecen reorganizar su proyecto de vida transformando la posición de víctimas, una labor que se supone se logra a través de las actividades que ofrece el programa de la organización.

\subsection{Discusión y conclusiones}

Estos datos muestran que, pese a lo esperado los dos momentos muestran que el programa parece haber perdido potencial "empoderador" y que las mujeres están en una situación de desesperanza profunda. Esto puede ser interpretado a la luz de:

- El efecto no deseado de la agenda temática de cooperantes: Una de las mayores debilidades que enfrenta el programa es la falta de recursos propios para la financiación de su funcionamiento, lo que le ha dado intermitencia en la operación y le ha obligado a plegarse a las condiciones que imponen las entidades financiadoras. Este "efecto no deseado de la cooperación internacional" impone una noción de sujeto y una lógica de operación que no resulta en procesos de empoderamiento, además de que, ha dado al traste con el proceso de empoderamiento que venía adelantando el programa, como lo muestran los resultados en los dos momentos del estudio. Además, la precariedad entendida como las múltiples necesidades -económicas, políticas y sociales-que no consiguen ser cubiertas por las mujeres, genera tensión al interior del programa entre el asistencialismo y el empoderamiento (Butler, 2010). Se encuentra entonces con un programa que se ha tornado especialmente de adultas mayores, rurales afrodescendientes con muy escaso nivel educativo. Esta particular situación, acorde con los resultados obtenidos en las dos fases del estudio, obliga a pensar 
que es necesario entender y replantear el empoderamiento, desde una perspectiva que ofrezca mayor complejidad y que puede ser dada por el enfoque de capacidades, tal y como lo propone Nussbaum (2006). Esta experiencia sugiere que el propósito de mitigar el impacto humanitario que el donante le impuso al programa desconoció el enfoque de acción sin daño al no medir las consecuencias de su intervención, como lo plantean Villa, Barrera, Arroyave, \& Montoya (2017).

- Políticas públicas individualistas que desconocen la cosmovisión de los grupos étnicos y comunidades. Los programas comunitarios de acompañamiento a las víctimas, con propuestas como "las colonias", tienen el potencial de dar respuestas más acordes con las características de los grupos étnicos y las comunidades. Sin embargo, la ruta de atención y reparación a las víctimas en la política pública está pensada en lógica individual, es decir, cada persona víctima en una relación directa con el Estado, lo cual tiene dos efectos negativos: de una parte, que la reparación integral, una a una cada víctima plantea una situación muy compleja al erario, toda vez que significa una cantidad ingente de recursos, al punto que el Estado ha determinado que se van a requerir décadas para lograr la reparación de todas las víctimas, y entre tanto, ellas envejecen esperando, suspendidas en la condición de víctimas. Y, de otra parte, no reconoce ni da un lugar preponderante a las cosmogonías de los pueblos étnicos ni de las comunidades, generando una doble victimización y desconfianza en el Estado.

- La institucionalidad local no interpreta adecuadamente las necesidades de las víctimas. Para las víctimas comprender el modelo de reparación integral propuesto por la política pública ofrece gran dificultad. El funcionariado es distante, insensible a las particularidades de la población, lo que pone con conflicto las necesidades de las víctimas y la recuperación psicosocial con una lógica administrativa que corresponde más a la lógica de servicios a clientes, lo cual está directamente relacionado con la lógica neoliberal, y que trae consecuencias como la despolitización de la población y la generación de mayores niveles de inequidad que aumentan el descontento general y le restan potencial a procesos de empoderamiento, poniendo a la población en una situación de competencia por beneficios y no de agentes activos en pro del goce de los derechos ciudadanos.

- Frágil empoderamiento hacia adentro. Los resultados muestran que en la organización estudiada el empoderamiento hay ido disminuyendo 
a lo largo del tiempo, generando un efecto de pasividad y desesperanza en las mujeres. Tal y como lo plantea el modelo de la autonomía y el empoderamiento, uno de los niveles es el empoderamiento colectivo que en el caso particular de la organización estudiada ha ido en desmejora entre una medición y otra. El gobierno del programa por parte deuna única persona, que además no es del grupo de las víctimas, aunado al giro que dio el programa en cuanto a la edad de las personas hay contribuido a acrecentar la dependencia y la expectativa de respuestas asistencialistas. El desarrollo de autonomía personal, política y sociocultural al interior del propio programa es indispensable, pero la dinámica que ha ido tomando la gestión de éste, con una única persona y no del colectivo de víctimas en el liderazgo ha ido en detrimento del empoderamiento colectivo.

- Mujeres afrodescendientes empoderadas no es simplemente mujeres empoderadas. La situación de las mujeres afrodescendientes víctimas se hace más compleja debido a que en la política pública de atención y reparación existe una contradicción interna, que no solo es un factor que complejiza los aspectos de sostenibilidad económica de la misma, sino que rompe con la promesa de diversidad e inclusión que es explícita en ella. El empoderamiento y la transformación de la injusticia contra las mujeres desplazadas exige un abordaje, por parte del Estado y de las organizaciones sociales de base, desde el enfoque de género y diferencial, para determinar distintos nichos de actuación en pro de las intersecciones que se gestan, como en este caso: mujeres, afrodescendientes, rurales, desplazadas y adultas mayores. Plantear la respuesta a las víctimas en una lógica comunitaria financiada por el Estado, podría no solo resolver parte del problema fiscal, sino que además ayudaría a fortalecer el tejido social, la inclusión, la reconciliación y la democracia. El empoderamiento, en este caso, debe posibilitar que las mujeres comprendan su propia historia y la violencia que han vivido más allá de los límites del conflicto armado reciente, para que definan la ruta a seguir en su proceso de superación de la victimización, accedan a recursos materiales y simbólicos para que puedan participar efectivamente en la toma de decisiones que tiene que ver con su propia vida y vivir en igualdad de condiciones con las demás personas (Nussbaum, 2006). 


\section{Referencias}

Britto, D. (2012). La Búsqueda de Justicia desde los Microespacios de la Política. Organizaciones de mujeres desplazadas en Colombia. Bogotá: OjoxOjo.

Butler, J. (2010). Marcos de Guerra. Las vidas lloradas. Barcelona: Paidós.

Choque, M., \& Mendizabal, M. (2010). Descolonizando el género a través de la profundización de la condición sullka y mayt'ata. Tinkazos, 13(28), 81-97.

Davis, Á. (2004). Mujeres, raza y clase. Madrid: Ediciones Akal.

Galtung, J. (1980). The True Worlds. A Transnational Perspective. New York, United States: Free Press.

Kabeer, N. (2015). Gender, Poverty, and Inequality: a brief History of Feminist Contributions in the field of International Development. Gender \& Development, 23(issue 2), 189-205. doi.org/10.1080/13552074.2015.1062300

León, M. (1998). Poder y Empoderamiento de las Mujeres. Bogotá: TM Editores.

Lugo-Agudelo, V., Sánchez-Agudelo, V., \& Rojas-Granada, C. (2018). La restauración con sobrevivientes del conflicto armado en Colombia: una propuesta de acción psicosocial. Revista Eleuthera, 19, 55-73.

Meertens, D. (1994). La autonomía y práctica social. Dilemas cotidianos de una estrategia de género en el desarrollo. En M. Barrig, \& A. Wehkamp (eds.), Sin morir en el intento. Experiencias de planificación de género en el desarrollo (pp. 49-71). La Haya, Países Bajos: Red entre mujeres.

Nussbaum, M. (2006). Las Fronteras de la Justicia. Consideraciones sobre la exclusión. Barcelona, España: Paidós.

Posada, I. C., \& Carmona, J. A. (2018). Subjetividad política y ciudadanía. Revista Mexicana de Ciencias Políticas y Sociales, IXIII(233), 69-92.

Rowlands, J. (1998). Empoderamiento y mujeres rurales en Honduras: un modelo para el desarrollo. En M. León, Poder y Empoderamiento de las Mujeres (pp. 213-245). Bogotá: Tercer Mundo.

Urrea, F., \& Murillo, F. (1999). Dinámica del poblamiento y algunas características de los asentamientos populares con población afrocolombiana en el oriente de Cali. Observatorio Sociopolítico y Cultural sobre "Desplazados, migraciones internas y reestructuraciones territoriales”. Bogotá: CES - Facultad de Humanidades

Villa, J., Barrera, D., Arroyave, L., \& Montoya, Y. (2017). Acción con daño: del asistencialismo a la construcción social de la víctima. Mirada a procesos de reparación e intervención psicosocial en Colombia. Universitas Psychologica, 16(3), 1-13. 


\section{ESTUDIOS EMPÍRICOS SOBRE OTRAS POBLACIONES}





\title{
17. Narrativas de sobrevivencia y restauración con personas afectadas por el conflicto armado en Caldas
}

\author{
Paula Vanessa Sánchez Agudelo $0^{54}$ \\ Nathalia AguirRe Alvarez ${ }^{55}$
}

\begin{abstract}
Resumen
Este capítulo presenta algunos de los resultados de la investigación realizada durante el año 2017, la cual pretendía comprender los procesos de sobrevivencia y restauración llevados a cabo por las personas afectadas por el conflicto armado en Caldas, mediante la construcción de espacios narrativos que promoviera el reconocimiento de la capacidad de agencia de las víctimas. Teóricamente, la investigación se sustenta en los planteamientos socioconstruccionistas desde los cuales la realidad se construye en la interacción, cotidianamente y a través del lenguaje. En lo metodológico es un diseño cualitativo con análisis narrativo. Como resultados, emergen las relaciones humanas como principal recurso para la sobrevivencia después de los hechos victimizantes, fuentes de sentido para darle un nuevo significado a la existencia en las que se configura la posibilidad de construir nuevas nociones de identidad, descripciones de sí mismos que trascienden el concepto de víctimas para denominarse de maneras más generativas. El proceso investigativo permitió comprender y enunciar algunas pistas para el acompañamiento psicosocial en términos de la restauración, sus implicaciones y posibilidades.
\end{abstract}

Palabras clave: psicosocial, relaciones, restauración, sobrevivencia.

\section{Abstract}

This article presents the results of the research developed during 2017, which was looking to understand the survival and restoration processes carried out for affected people by the armed conflict in Caldas - Colom-

54 Universidad Católica Luis Amigó. Correo: paula.sanchezag@amigo.edu.co

55 Universidad Católica Luis Amigó. Correo: nathalia.aguirreal@amigo.edu.co 
bia, through the construction of narrative spaces that promoted the recognition to agency of victims. Theoretically, the research is based in the socio constructionist assumptions from which the reality is constructed in the human interaction, daily, and through the language. Methodologically is a qualitative research, with narrative analysis. In the results, the human relationships emerge as the main resource for the survival after the victimizing facts of armed conflict, sources of sense in order to give a new meaning of the existence, in which new identity notions are constructed, transcending the concept of victims for defining themselves in a more generative way. The research process allowed to understand and raise some clue for the psychosocial accompaniment in terms of restoration, and its implications and possibilities.

Keywords: psychosocial, relationships, restoration, survivors.

\subsection{Introducción}

El conflicto armado colombiano ha sido conocido por las múltiples formas de violencia de las que se han servido los actores involucrados, el uso de la sevicia por parte de estos como forma de intimidación a las comunidades y la afectación de la población civil como principal víctima, dejando a su paso miles de personas afectadas.

Según el reporte a primero de mayo de 2018 de la Unidad Nacional de Víctimas, hay en Colombia 8.332.081 víctimas registradas del conflicto armado, el 17\% de la población colombiana, de las cuales el $89 \%$ han sido víctimas del desplazamiento forzado, $12 \%$ de homicidios y $5 \%$ de amenazas. Específicamente en Caldas se reportan 104.178 víctimas registradas, y en los municipios de interés de esta investigación, Manizales, 17.606 víctimas y San José con 206 víctimas. Manizales ha sido el principal receptor de población desplazada de todo el departamento de Caldas, pues en los últimos 30 años, el municipio ha expulsado 3.318 personas mientras que ha recibido 18.445 (2015).

A partir de la promulgación de la Ley 1448 de 2011, se dictaron medidas de atención, asistencia y reparación integral a las víctimas del conflicto armado en Colombia. Esta Ley considera como víctima "aquellas personas que individual o colectivamente hayan sufrido un daño por hechos ocurridos a partir del $1^{\circ}$ de enero de 1985 , como consecuencia de infracciones al Derecho Internacional Humanitario o de violaciones graves y manifiestas a las normas internacionales de Derechos Humanos, ocurridas con oca- 
sión del conflicto armado interno" $"$. Con la ley se crea la Unidad para la Atención y Reparación a Víctimas, una Unidad para la Restitución de Tierras y el Centro de Memoria Histórica, todas instituciones encargadas de contribuir al trabajo de reparación de las víctimas y la reconciliación social, y se pone en marcha desde el 2012 el Registro único de víctimas como medio de reconocimiento a las mismas y paso inicial para que cada persona afectada y casos colectivos pudieran comenzar su proceso de reparación. (Unidad Nacional para las víctimas, 2018)

Lo anterior tiene unas implicaciones jurídicas y políticas para las víctimas y la historia del país, y se entiende que a partir de la ley se otorga un reconocimiento por parte del Estado a las mismas como sujetos de atención y reparación. Sin embargo, el discurso de la víctima ha tenido otras implicaciones para las personas afectadas, entre estas, sentirse tratados, especialmente en los procesos psicosociales y de parte de algunos funcionarios de instituciones, como personas en una posición pasiva o inerme que no corresponde con los reales esfuerzos y las trayectorias de transformación que han construido para lograr sobrevivir y rehacer la vida. Lugo (2014) analiza las implicaciones del discurso de la víctima en el trabajo psicosocial con jóvenes excombatientes y aunque en ese caso las consecuencias tienen relación con lo que para ellos significó haber pertenecido a un grupo armado, su análisis también permite cuestionar lo que ha significado para las personas afectadas por el conflicto armado estar ubicados en el lugar de las víctimas. "La víctima, pareciera ser alguien indefenso, carente, dependiente, vulnerable, sin poder o control sobre su vida, incapaz y sometido (...). En otras palabras, es un discurso que resta poder, disminuye y marginaliza" (p. 147).

Se reconoce la importancia de esta denominación desde el punto de vista de la memoria histórica, lo político y jurídico para los procesos de reparación, pero también la connotación en la vulnerabilidad y carencia que provoca en las personas sobrevivientes y en quienes dirigen los procesos de atención, recreando como lo dice Lugo (2014) citando a Bateson (1980):

...el error epistemológico del mito del poder. Este mito, considera que hay unas personas que poseen el poder y se imponen sobre otras que no lo pueden tener. De esta forma se oculta una gran variedad de análisis sobre por ejemplo, las diferentes situaciones que facilitan que el daño ocurra, los diversos implicados más allá de los perpetradores

56 Llama la atención que según la ley no se reconocen víctimas antes de 1985, a pesar de un conflicto armado que lleva cerca de cincuenta años. 
de carne y hueso, el papel que juegan nociones como ideología o alienación. (p. 147)

Esta mirada crítica sobre el discurso de la víctima se advierte también en el informe del grupo de memoria histórica Basta Ya, para el cual, más allá de la connotación jurídica de la palabra víctima es importante el rostro y cuerpo de las personas que han sufrido y lo que sus corporalidades revelan como territorios también de una memoria de dignidad y resistencia. Así lo dice el informe:

Desde esta memoria emerge otra connotación de la palabra víctima: la víctima como protagonista, como agente social que desafía el poder, que reclama y reivindica, y que desde ese lugar no solo sobrevive y se rescata a sí misma, sino que transforma y construye una nueva sociedad.(Grupo de Memoria Histórica, 2013, p. 27)

Por lo anterior, y asumiendo que el lenguaje no es sólo representación sino también acción y performance, interesó a los propósitos de esta investigación comprender la dinámica de estas formas individuales y colectivas de agencia y resistencia, de organización y movilización, de protección y cuidado de las personas afectadas por el conflicto armado, no solamente de los hechos victimizantes sino especialmente del sentido que dichos hechos han tenido y de las acciones que los sobrevivientes (más que víctimas), han construido para afrontar su situación. La pregunta entonces que orientó la investigación fue ¿Cómo las personas afectadas por el conflicto armado en Caldas, han sobrevivido a los impactos de este y que recomendaciones habría que tener en cuenta para los procesos de atención psicosocial?

El objetivo principal del proceso fue comprender los procesos de sobreviviencia llevados a cabo por las personas afectadas del conflicto armado en Caldas, mediante la construcción de espacios narrativos de manera que se promoviera el reconocimiento de la capacidad de agencia de las víctimas, y de esta forma se lograra aportar a los procesos de atención psicosocial en el marco del post-acuerdo en Colombia.

\subsection{Metodología}

La investigación se inscribe en un marco epistemológico socioconstruccionista, que implica un cambio de la noción del conocimiento como representación a la idea de conocimiento como una construcción del mundo. Este movimiento ha tenido importantes consecuencias para la investigación en 
ciencias sociales, pues como lo plantea Gergen (2014) no se trata de iluminar los problemas existentes en la sociedad, sino de poder disponer prácticas que contribuyan a alcanzar mejores resultados, lo que es una concepción más proactiva de las ciencias sociales en tanto no enfatizan en lo que "es", sino en lo que "puede llegar a ser".

Tradicionalmente, la investigación científica ha encontrado sus beneficios en la predicción y el control, constituyéndose como reflejo de un estado de las cosas; mientras tanto, estos nuevos paradigmas que en la nominación de Guba y Lincoln se denominan "participativos" (2000), evidencian un compromiso con el mundo cambiante. Así mismo, la investigación socioconstruccionista configura tres características: la incitación a la resistencia y transformación de realidades; la construcción creativa de conocimiento, y la acción colaborativa con actores sociales que están por fuera de la academia, generando un cambio del conocimiento como posesión individual a algo inherente a las relaciones entre las personas.

Este tipo de investigación ha cobrado sentido con los sobrevivientes del conflicto armado, quienes verbalizan su malestar frente a las clasificaciones científicas de las cuales han sido objeto a través de métodos tradicionales que proponen el silenciamiento; de manera que se hace caso a las formas de investigación que tratan de reducir la distancia entre el científico y el participante, en palabras de Gergen "se trata mas exactamente de un movimiento de alejarse de la investigación sobre otros y pasar a la investigación con ellos" (2015, p. 345).

La investigación con sobrevivientes del conflicto armado puede considerarse como investigación relacional, lo que McName \& Hosking (2012) han planteado como más que una preocupación por el método, una orientación general que invita a considerar todas las actividades en las cuales los seres humanos participan, entre ellas la investigación, enfatizando en las formas en las cuales el proceso es llevado a cabo, la clase de interacciones derivadas, las prácticas y valores que quieren ser promovidos.

Se llevó a cabo investigación narrativa desde el enfoque centrado en la experiencia, que según Tamboukou (2015) hace énfasis en la interacción y co - construcción, con un interés particular más que en el contenido, en las consecuencias sociales de su producción. La construcción de narrativas de sobrevivencia es entonces una forma de asumir la apuesta socio construccionista de creación de realidades, pues bien implica poner en cuestión relatos en relación al déficit que han sido dados por sentado, y darle espacio a otras construcciones identitarias que aluden a sentidos más generativos, 
a partir de la narración como un proceso que posibilita la desestabilización del orden dado y abre paso a la construcción de historias alternativas, a la negociación y renegociación de significado.

Participantes: el proceso fue llevado a cabo con dos grupos de personas afectadas por el conflicto armado; el primer grupo conformado por 5 mujeres y 1 hombre de origen caldense que padecieron el desplazamiento forzado y posteriormente reconstruyeron sus vidas en la ciudad de Manizales; el segundo grupo conformado por campesinos residentes del municipio de San José Caldas, 8 mujeres y 1 hombre provenientes de diferentes zonas rurales del país, que después del desplazamiento forzado se ubicaron en veredas cercanas al municipio y donde han realizado su proceso de sobrevivencia.

Procedimiento: el trabajo de campo en la ciudad de Manizales se realizó a partir de la colaboración del Centro de Estudios sobre Conflicto, Violencia y Convivencia Social (Cedat) de la Unviersidad de Caldas, a través de quienes se realizaron contactos con líderes de organizaciones y grupos específicos de personas afectadas por el conflicto armado. Se realizaron unas primeras visitas de campo a la comuna Ciudadela del Norte donde se realizó una convocatoria abierta. En San José Caldas, se realizó la convocatoria a través de la Personería Municipal.

Una vez conformados los grupos, en la ciudad de Manizales se llevaron 10 encuentros narrativos y en San José 4; lo anterior dado que el primer grupo requería más tiempo para establecer relaciones de confianza, en tanto muchos no habían tenido contacto previo, mientras que en el segundo grupo había un relacionamiento anterior que facilitaba el trabajo.

Los encuentros narrativos fueron espacios para construir individual y colectivamente sentidos de sobrevivencia a través de la narración visual, oral y escrita de su experiencia, y socializada en espacios basados en el respeto y la confianza. Las técnicas son las planteadas por la terapia narrativa de Michael White y David Epston: Árbol de la vida (Denboroug, 2014), Bosque de la vida (Latorre, 2010), Ceremonia de Definición (White, 2000), Documentos terapéuticos (White \& Epston, 1993) y Libro de la vida ${ }^{57}$

Análisis narrativo: La totalidad de encuentros fueron grabados en audio y transcritos textualmente; se hizo uso del Software Atlas Ti para la codificación de la información escrita y visual. Los datos se analizaron no

57 Esta técnica no se encuentra referenciada por los autores, fue creada por el grupo de investigadores, inspirados en las otras metáforas, se trata de construir la historia de vida personal, reconociendo los momentos mas importantes y dividiéndolos en capítulos. 
solo enfatizando en el contenido, sino también poniendo especial interés en el "cómo" del proceso y las estrategias relacionales desplegadas para la construcción de las historias. Algunas de las preguntas a través de las cuales se interrogaron los datos fueron: ¿Por qué la historia es contada en esta forma?; ¿Qué es lo que se da por sentado?; ¿Cuáles son las dinámicas de poder que se presentan en los encuentros?; ¿Cuáles son las voces que se encuentran en los relatos?; ¿Cómo nos situamos los investigadores frente a estas historias?; ¿Qué es lo no dicho?

La validación del análisis, se hizo teniendo en cuenta los criterios enunciados por Riessman (1993): Persuasión, cuando los planteamientos teóricos son soportados por la evidencia de las historias de los participantes; Correspondencia, al regresar a los participantes y saber que piensan del análisis, lo que constituye una fuente de insight teórico, además de ser políticamente importante. Coherencia, global cuando la historia responde a los objetivos generales planteados, local cuando la estructura lingüística corresponde al contexto del narrador, y de tema cuando algunos fragmentos corresponden a un tema repetidamente y de manera importante; y Uso Pragmático, cuando el estudio empieza a ser la base para otros trabajos, en este caso el proyecto generó no solo respuestas sino también provocaciones que llevaron al planteamiento de una nueva fase de investigación.

Consideraciones éticas: Teniendo en cuenta el marco epistemológico de la investigación, las relaciones se establecieron desde la horizontalidad, para ello se dispuso de varias estrategias, la primera fue tener en cuenta a las personas para la planeación de aspectos logísticos, la segunda fue la participación narrativa de los investigadores en los encuentros; en tercer lugar, se firmaron consentimientos informados haciendo explicaciones extensivas de todas las implicaciones del proyecto, cuarto, el énfasis en lo generativo. Al finalizar el proyecto las relaciones entre los investigadores y participantes no terminan, sino que encuentra nuevos escenarios de configuración.

\subsection{Resultados}

Las narrativas emergentes en el proceso investigativo se mueven desde las historias de sufrimiento hacia las historias de sobrevivencia a partir de la pregunta inicial por cómo los participantes habían sobrevivido a la violencia, inquietud que ya provocaba en ellos una distinción, la sensación de una pregunta nueva. No nos estabamos preguntando ¿por qué paso? o ¿cómo paso?, sino por cómo lo habían afrontado y habían logrado no rendirse y no dejar de vivir una vida digna. 
En palabras de un participante:

Entonces es muy interesante y más ahora cuando lo ponen a uno "oiga, y ustedes cómo hicieron para sobrevivir" y uno, sí ve, verdad, cómo hemos hecho para sobrevivir después de tantos años. Esa es la parte más fundamental, somos capaces de volver a sonreír, de volver hablar y no todo el día llorando. (Sobreviviente hombre, 70 años)

Las narrativas construidas revelan un movimiento del sentido de la experiencia que primero relata el dolor vivído, como momento inicial de reconocimiento que permitió legitimar las diferentes trayectorias de dolor que implicó el desplazamiento forzado, reconocimiento que es fundamental para avanzar hacia la restauración, y el surgimiento progresivo de la voz de la sobrevivencia que se abrió paso gracias a la metodología misma y la relación que se fue tejiendo entre participantes e investigadores. Teniendo claro que los resultados hilvanan el proceso mismo, las narrativas presentadas se agrupan en tres categorías: La construcción del espacio narrativo, donde se analiza lo que metodológicamente porsibilitó trabajar en torno a los recursos y formas de afrontamiento de los participantes, narrativas de sufrimiento y transformación, asociadas con los efectos del desplazamiento, que a pesar de haber ocurrido 10 o 15 años atrás, todavía encuentran un lugar en las historias, junto a la transformación personal que se suscitó luego del evento, y las prácticas de sobrevivencia, que reúne las prácticas cotidianas y capacidades usadas por las personas y comunidades para la sobrevivencia.

\subsubsection{La construcción del espacio narrativo}

Los encuentros narrativos fueron espacios que se construyeron; no estaban dados previamente por la técnica, sino que se tejían al compás de la relación que entre investigadores y participantes surgía, en los cuales todos compartíamos las propias historias, algo de la propia vida. Se respetó también el silencio, sin imponer a nadie el deseo de contar, narrar, sino dejando que este fuera apareciendo. La potencia narrativa siempre estuvo conectada con el grado de confianza que se fue fortaleciendo tras cada encuentro.

Las preguntas fueròn una herramienta fundamental, fueron clasificadas en cinco tipos, la primera de ellas es la generatividad; teniendo en cuenta que la investigación pretendía profundizar en las categorías de sobreviviencia y restauración con población que ha estado expuesta al sufrimiento, las preguntas se dirigían a la búsqueda de recursos existentes, resistiendo los aspectos deficitarios que circundan el discurso en estos casos. Para Gergen 
(2007), esta característica tiene que ver con la capacidad de cuestionar supuestos predominantes sobre la naturaleza de la vida social, y en palabras de Schnitman (2005), es la posibilidad de expandir, transferir y crear nuevos significados y prácticas.

Otro tipo de preguntas fueron las preguntas orientadas a lo alternativo; estas invitaban a explorar significados otros de sí mismos y de la realidad, mientras se ponia en cuestión el conocimiento dominante sobre ser víctima, el dolor y el sufrimiento. Estas preguntas hicieron uso de recuerdos o sueños para encontrar nuevas definiciones. White \& Epston (1993) refieren que nunca se retoma toda la información de una experiencia, hay en ellas muchos elementos que son ignorados y olvidados; las preguntas centradas en aquellos aspectos contribuyeron a la creación de nuevos significados.

Se realizaron también preguntas reflexivas, que, como su nombre lo indica, son aquellas que promueven en los participantes un ejercicio de reflexión. Tomm (1987) enuncia que estas preguntas por lo general se orientan al futuro con el fin de que las personas se enfoquen en horizontes de posibilidad, durante el proceso este tipo de preguntas invitaron a los participantes a contemplar cambios en el contexto, a planificar, a anticipar, pero sobre todo a imaginar posibilidades.

Se realizaron preguntas de significado, aquellas que interrogan más que por explicaciones, por los significados que las personas dan a determinados aspectos. Estas preguntas fueron motivadas por la curiosidad genuina de la vida de los participantes, bajo la intención de comprender las ideas que direccionan sus vidas.

Finalmente, se realizaron preguntas de conexión; en un contexto narrativo de orden colectivo, las historias son los dispositivos que permiten conectar a las personas que participan. El carácter de resonancia que puede tener una historia en la vida de la persona genera conexión entre los participantes; estas preguntas permitieron identificar las formas en las cuales se conectaban los participantes, generando con ello una lógica de reconocimiento del otro en la propia vida y viceversa.

\subsubsection{Narrativas de sufrimiento y transformación}

La violencia experimentada en la mayoría de los participantes, asociada al desplazamiento forzado, marcó una huella de dolor, teniendo en muchos casos el carácter de acontecimiento, en el sentido que Veena Das (2008) propone, una vivencia que devastó con el mundo tal y como era conocido de forma abrupta. Ortega (2008) al revisar este concepto señala varios elementos 
que lo definen: la capacidad del acontecimiento de afectar el presente de manera silenciosa e imperceptible y moldear "futuros horizontes de expectativas" (p.31); la desestabilización de categorías sociales poniendo en riesgo la vida de las comunidades al amenazar con desaparecer los criterios que hacían posible el conscenso social y la contundente capacidad de este para proyectarse a futuros presentes y convertirse en un referente de legitimación.

El acontecimiento está vinculado entonces con las pérdidas humanas y materiales que dejó el hecho violento, y con los procesos de estigmatización y victimización en los que se ven inmersas las personas al afrontar el desarraigo que supone el desplazamiento. Uno de los hallazgos más importantes en estas narrativas es que el dolor se ha tramitado personal y familiarmente, y la historia de vida de cada participante es la trayectoria biográfica de este proceso, desdibujandose el origen social del sufrimiento y asumiendo como un padecimiento personal e ìntimo un sufrimiento de naturaleza social.

Además, llegar a la ciudad y comenzar el proceso para reclamar la indeminizaciòn o tener acceso a una vivienda expone a los sobrevivientes a nuevos procesos de victimización y por tanto de sufrimiento, provocando otras rupturas en el tejido social al dejar al sobreviviente tramitando de forma íntima y personal un suceso que involucra a otros actores sociales. Esto va generando la brecha visible que existe en el país entre quienes han vivido de forma directa el conflicto y quienes no lo han vivido.

Entrelazadas con estas experiencias de dolor, aparecen también los efectos relacionados con los aprendizajes, el desarrollo de habilidades, las transformaciones que han vivido con la llegada a un nuevo hábitat y las lecciones de vida, los cuales dejan entrever el temple de los sobrevivientes y la forma como la red de solidaridad que han tejido con otras personas, casi siempre familiares, vecinos u otras víctimas, ha hecho posible esta tranformación.

Además del dolor, estas narrativas dejan ver la capacidad que han tenido los participantes de renegociar su experiencia, resistiéndose a identificarse con esquemas violentos y la posibilidad que han forjado para "reescribir sus vidas" (White, 1993). Esta capacidad de transformación de los participantes no ocurre de forma aislada, se hace posible a través de las relaciones, pues este ejercicio de reescritura es posible al sentirse unidos a las vidas e historias de otros.

\subsubsection{Prácticas de sobrevivencia}

Las prácticas de sobrevivencia se entienden como respuestas espontáneas, no organizadas y cotidianas que se establecen con el fin de seguir existiendo, 
a pesar del dolor al cual se han visto expuestos. El principal recurso para desplegarlas han sido las relaciones humanas, puesto que son lo que ha permanecido ante la devastación y a partir de las cuales han emergido otras habilidades que los sobrevivientes no consideraban poseer previamente.

Las relaciones más importantes para la sobrevivencia son las familiares, especialmente las de los hijos, dado que estas últimas implican un carácter de cuidado y protección que configura el sentido de vida, y es uno de los principales elementos que se antepone a la idea de desfallecer en medio del sufrimiento.

También se consideran de gran importancia las relaciones con personas que estén o hayan experimentado situaciones similares, en tanto se comparten las historias propias y se escuchan las de los demás, lo que permite dar sentido a los acontecimientos en diferentes formas, pues la conexión narrativa que implica compartir historias permite asignar diversos significados a situaciones, personas, al sí mismo, de manera que es un marco para la redefinición. Para los sobrevivientes del conflicto armado, definirse en nuevas maneras es descubrir que hay opciones para nuevas concepciones del sí mismo y de la realidad, lo que podría definirse como conciencia del inacabamiento.

Otras prácticas de sobrevivencia que no fueron tan reiterativas, y que no aluden directamente a lo relacional pero se enmarcan en ello son la huida, el silencio, que no implica la ausencia de la voz sino el acallamiento de un diálogo que aunque no se expone existe; el recuerdo, dado que para algunos sobrevivientes la evocación de lugares y personas es una de las formas que se encuentra para seguir existiendo, y las rutinas, que son las que permiten organizar de nuevo la vida cotidiana y empezar a considerar un horizonte de futuro.

\subsection{Discusión}

\subsubsection{Las relaciones como principal recurso para la sobrevivencia}

Butler (2010) plantea la pregunta por aquello que pueda explicar "la capacidad de supervivencia de aquellos cuya vulnerabilidad ha sido explotada" (p. 85). En las narrativas de sobrevivencia, las relaciones humanas constituyen la respuesta.

A pesar del sufrimiento que le ha implicado a las personas directamente afectadas por el conflicto armado, derivado de las pérdidas humanas 
y materiales, las relaciones permanecen como un tejido que a pesar de debilitarse no se rompe, a ello se refiere Scarry (citada por Bruner, 1991), cuando expresa que el dolor radica en la destrucción de la conexión de las personas con el mundo personal y cultural, borrando el contexto que da sentido a las esperanzas y los anhelos; aun así los vínculos relacionales se anteponen cumpliendo una función, la de mantener los significados que dan sentido a la vida.

Desde este punto de vista, en el cual las relaciones, tal como plantea Gergen (2011), constituyen todo lo que es singificativo para los seres humanos; las relaciones protagónicas son las de la familia, y enfáticamente las que implican la noción de cuidado, como lo son las que se establecen con los hijos; confirmando lo planteado por Lopez y Rodriguez (2012) al señalar que la reconfiguración de la vida va acompañada de redes parentales que se hacen eficientes para recomponerse a través de nuevas formas familiares. Al respecto Butler (2010) afirma que el "yo" al estar vinculado con los "otros", hace parte de un "nosotros", en donde se reconoce como corresponsable de los demás; ese tejido relacional, aunque herido, se mantiene y se convierte en un dispositivo de resistencia y transformación. Particularmente la maternidad, al implicar una relación de cuidado, es una herramienta de resistencia, implica como dice Halbwachs (2002) reconocer que nunca estamos solos, que siempre llevamos en nosotros y con nosotros un número de personas inconfundibles, con quienes se construyen vínculos que trascienden el tiempo, el espacio y la existencia.

La sobrevivencia es un proceso colectivo, nunca individual, y esta concepción de ser relacional es planteada por Shotter (1993), el otro es el punto de partida del "yo", y solo juntos puede generarse significado. En este sentido, ser víctima, o ser sobreviviente son significados que adquieren sentido en relación con los demás. Los sobrevivientes refieren que es a partir de ciertas relaciones que han podido explorarse en dimensiones previamente insospechadas, es decir, se han redefinido a si mismos, siendo concientes de su inacabamiento, el individuo está implicado en interacciones que le permiten construir, reconstruir y transformar la identidad.

Lo sobrevivientes del conflicto armado han experimentado un proceso que en palabras de Deleuze y Guattari (2004) se define como nomadismo creativo, la posibilidad de redefinir el ser con la experiencia en vez de agenciarse en categorías y definiciones, lo que les ha permitido moverse de la posición de víctimas hacia el liderazgo del sobreviviente; pero como se viene planteando, el proceso es colectivo y social, pues se logra a partir 
de los puentes narrativos que se han podido establecer en el encuentro con los otros, en el exponer la historia, reconocer la del otro, a partir de ello definirse a si mismo, comprender al otro, y en esa lógica dar sentido a la experiencia como lo plantean Anderson y Gehart (2007), las historias son recursos comunales que constituyen fuentes de conocimiento.

Los sobrevivientes han evidenciado la intención de movimiento para relacionarse y posicionarse desde un lugar diferente al de víctimas, las nuevas posiciones son la de trabajador, capaz, colaborador; esta posibilidad de tomar nuevos lugares es planteada por Davies y Rom (1990) como una posibilidad humana de asumir posiciones cambiantes, que tiene la intención de performar la identidad de cierta forma. Esta posibilidad es lo que ha permitido la sobrevivencia, pues ha implicado un movimiento del sufrimiento hacia nuevas nociones de generatividad.

\subsubsection{Consideración sobre el trabajo psicosocial y la restauración}

La pregunta por la sobrevivencia a los participantes implicó comprender los alcances de los apoyos recibidos por el Estado y de los procesos psicosociales adelantados a través de las instituciones a cargo. Esto debido a que la mayoría de los participantes habían vivido el desplazamiento hacía diez años o quince años atrás, por lo cual su narrativa incluía también el proceso de reparación adelantado. Los resultados permiten reflexionar en torno a los retos que plantea el acompañamiento a personas que han experimentado los efectos del sufrimiento derivado de procesos sociopolíticos.

Como ya se ha expuesto en los resultados, la relación entre los facilitadores y los participantes se convierte en uno de los insumos mas importantes para lograr poner bajo sospecha todos aquellos direccionamientos que se hacen tradicionalmente desde el saber profesional, y que ubican en lugares de saber / ignorancia a los participantes; y por el contrario poner de relieve saberes - otros de los actores, y que al mismo tiempo generan dinámicas de reconocimiento, según Arroyave (2015) una valoración recíproca entre los individuos que permite el despliegue de sus posibilidades subjetivas y ser apreciado en su singularidad.

El sufrimiento provocado por la violencia se concibe como un proceso social, nunca un padecimiento personal, cuando se entiende de manera individual se pierde de vista las causas y consecuencias sociales y políticas, y se clasifica al individuo que sufre en esquemas psicopatológicos, que en vez de enunciar su agencia enfatizan la dificultad, lo que a su vez debilita 
la identidad. Esto Gergen (1996) lo reconoce como una consecuencia del discurso del déficit. Ospina, Carmona, y Alvarado (2014) reconocen la importancia de este tipo de comprensiones generativas en el trabajo psicosocial con niños excombatientes y al igual que esta investigación, centran su reflexión en las potencialidades individuales y colectivas de los niños en los procesos de construcción de Paz.

Los resultados revelan cómo los procesos de atención psicosocial suelen olvidar el origen social del sufrimiento y con ello la incidencia que la atención tiene sobre el tejido social, sobre la capacidad de las personas de volver a confiar en los demás y de hacer y vivir en comunidad. Este olvido se hizo evidente en las escasas narrativas de restauración que surgieron en la investigación, frente a la variedad y riqueza de las prácticas de sobrevivencia.

La diferencia de la restauración respecto a las prácticas de sobrevivencia es el carácter colectivo y dialógico que implica la misma y la participación de diferentes actores, incluidos profesionales, instituciones y población no víctima para que pueda llevarse a cabo; además, conlleva el reconocimiento del daño, pues se restaura algo que previamente ha sido dañado, tal como ocurre en el campo del arte (Lugo, 2014). Restaurar entonces supone acciones psicosociales que contemplen lo colectivo, que fomenten la capacidad de las personas de hacer cosas de manera conjunta, la posibilidad de construir relaciones con otros.

Los participantes interrogan la ausencia de reconocimiento de sus trayectorias de dolor en los procesos de atención institucionales, y revelan las estrategias que usan para defenderse de las instituciones o para lograr obtener lo que necesitan. Muy pocos consideran que el proceso ha logrado ser reparador y esta sensación de reparación esta asociada más con la obtención de vivienda otorgada por el Estado.

Desde la concepción relacional, lo psicosocial no se refiere a que los procesos sean grupales, sino como plantea Villa (2012) al marco ontológico que reconoce e integra el contexto, la historia, los derechos, y en este sentido, el mecanismo para llevarlo a cabo es el diálogo y la participación activa de los actores involucrados.

En el acompañamiento psicosocial no deben pensarse únicamente las víctimas del conflicto armado, es también importante empezar a vincular a todos aquellos que no se han visto afectados directamente, pero han tenido un papel importante en las formas de sobrevivencia, especialmente en los centros urbanos, dado que las posibilidades de redefinir la identidad también se concretan en el tipo de reconocimiento que los otros hacen de las perso- 
nas; además, enfocar la mirada solo a los sobrevivientes es un acto de no corresponsabilidad, pues ellos están en relación con grupos y comunidades que contribuyen u obstaculizan la reconstrucción del tejido social, tal como se evidenció en el proceso investigativo.

Villa (2012) plantea como uno de los aspectos más importantes para el trabajo psicosocial con víctimas, la promoción de prácticas relacionales basadas en el reconocimiento y la valoración del ser humano en ejercicio de construcción, esto en el contexto de la investigación ha implicado concebir a los participantes como interlocutores válidos que pueden enriquecer la versión que tienen de sí mismos, es decir, el trabajo se enfocó en el proceso de re significación, más que en un resultado específico, y de ello también se derivó la importancia de enfatizar en horizontes de posibilidad más que en nociones dadas, es decir, en vez de fijar la mirada en lo que "es", el espacio da apertura a lo que puede "empezar a ser", promoviendo la constitución política de los sujetos, que según Alvarado, Ospina y Fajardo (2018) se da a través del despliegue de la capacidad de agencia para transformar realidades y construir nuevas alternativas.

\subsection{Conclusiones}

El trabajo psicosocial con sobrevivientes del conflicto armado implica la construcción de escenarios que se configuren sobre tres nociones: la primera de ellas es la importancia otorgada a las relaciones que se construyen en los procesos, tanto entre los facilitadores y demás participantes como entre ellos mismos, pues solo en la confianza se anida la posibilidad de expresar en diversas formas, de reconocerse mutuamente, y a partir de allí resignificar la identidad, mientras se contemplan posibilidades futuras. Las relaciones entonces, se consideran el piso sobre el cual se construyen los procesos.

Como segundo elemento, y vinculado con el anterior se plantea la dirección generativa que se asume en los procesos, todo aquello que le permite al ser humano poner en cuestión los marcos explicativos que deterioran la percepción de sí mismos y de realidad para invitar al reconocimiento de todo aquello que ha permitido resistir la adversidad, es un dispositivo que contribuye a re-significar la identidad, evitando con ello la re-victimización que han implicado muchos de los escenarios de acompañamiento.

Finalmente, la importancia de lo colectivo en los procesos de restauración, donde no sólo las personas directamente afectadas por el conflicto armado participen, sino otros actores sociales diferentes, pues sólo reconociendo que el dolor que deja la guerra es un sufrimiento de naturaleza social, no 
personal o ìntimo, podremos abrir la capacidad de comprensión de las personas no víctimas y cerrar la brecha social entre quienes tienen memoria y han vivído la guerra y quienes no la han vivìdo, pero que hoy son requeridos a participar en la reconstrucción del tejido social.

\section{Referencias}

Anderson, H. y Gehart, D. (2007). Collaborative Therapy. New York: Routledge.

Arroyave, O. (2015). Memoria, reconocimiento y conflicto armado. En S. Cogollo, (ed.) Imaginar la paz en Colombia (pp. 33-48). Medellín: Fondo editorial Luis Amigó.

Bruner, J. (1991). Actos de significado. Madrid: Alianza editorial.

Butler, J. (2010). Marcos de guerra: Las vidas lloradas. México: Paidós.

Das, V. (2008). Lenguaje, subjetividad y experiencia de la violencia. En: F. A. Ortega, (ed.). Das Veena: Sujetos del dolor, agentes de dignidad. Bogotá: Pontifica Universidad Javeriana, UNal.

Deleuze, G. y Guattari, F. (2004). One Thousand Plateus. London: Continuum.

Davies, B. y Rom, H. (1990). Positioning: The Discursive Production of Selves. Journal for the Theory of Social Behaviour, 20(1), 43-63.

Denboroug, D. (2014). Retelling the Stories of our Lives. New York: W. W Norton \& Company.

Gergen, K. (1996). Realidades y relaciones: Aproximaciones a la construcción social. Barcelona: Paidós.

Estrada, A., Diazgranados, S. (Ed). (2007). Construccionismo social, aportes para el debate y la práctica. Universidad de Los Andes.

Gergen, K. (2014). From Mirroring to World- making: Research as Future Forming. Independent Social Research Foundation, London, UK. In press: Journal for the Theory of Social Behaviour.

Gergen, K. (2015). El ser relacional. Mas allá del yo y de la comunidad. Bilbao: Desclée De Brouwer.

Gergen, M. y Gergen, K. (2011). Reflexiones sobre la construcción social. Barcelona: Paidós Ibérica.

Grupo de Memoria Histórica (GMH). (2013). ¡Basta ya! Colombia: Memorias de guerra y dignidad. Bogotá: Imprenta Nacional.

Gobierno Nacional. Unidad para las víctimas. (2018). Siete años de cambios significativos para las víctimas del conflicto armado. Disponible en: https://www.unidadvictimas.gov. co/es/7anosley/ siete-anos-de-cambios-significativos-para-las-victimas-del-conflictoarmado/42519.

Halbwachs, M. (2002). Fragmentos de memoria colectiva. Athenea digital, 2, 1-11. 
Latorre, I. (2010). El árbol de la vida con trabajadores adultos. Procesos Psicológicos y Sociales, 6(1), 1-34. Disponible en www.uv.mx/psicologia/files/2013/06/El-arbol-de-lavida-con-trabajadores-adultos.pdf

Lincoln, Y. Guba. E. (2000). Paradigmatic Controversies, Contradictions, and Emerging Influences. En Handbook of qualitative research. SAGE.

López, G. Rodriguez, A. (2012). El lugar de los sentimientos, el lugar de los vínculos. Reconfiguración de identidades en el marco del conflicto armado colombiano. Revista Colombiana de Ciencias Sociales, 5, 83-102.

Lugo, V. (2014). Guerreros desarmados. Narrativas con jóvenes excombatientes de Colombia. (Tesis de Doctorado). Tilburg University y Taos Institute. Manizales, Colombia.

McNamee, S. and Hosking, D. M. (2012). Research and social change: A relational constructionist approach. New York: Routledge.

Ospina, M., Carmona, J. y Alvarado, S. (2014). Niños en contextos de conflicto armado: narrativas generativas de paz. Revista Infancias Imágenes, 13(1), 52-60.

Ospina, M., Alvarado, S y Fajardo, M. (2018). La niñez en contextos de conflicto armado comprendida desde el construccionismo social, la socialización política y las perspectivas alternativas del desarrollo humano: apuesta epistemológica desde el sur. En A. Ospina, S. Alvarado, J. Carmona, y A. Arroyo, A. (eds.). Construcción social de niñas y niños en contextos de conflicto armado. Manizales: Cinde, Universidad de Manizales, Universidad Pedagógica Nacional.

Riessman, C. (1993). Narrative Analysis. Boston: SAGE.

Schnitman, D. (2005). Afrontamiento de crisis y conflictos: Una perspectiva generativa. Sistemas Familiares, 21(1-2), 98-118.

Scarry, E. (1985). The body in pain. Oxford: University Press.

Shotter, J. (1993). Conversational realities. Constructing life through language. California: SAGE Publications.

Tamboukou, M. y Livholts, M. (2015). Discourse and Narrative Methods. California: SAGE Publications.

Tomm, K. (1987). La entrevista como intervención Parte II: Las preguntas reflexivas como forma de posibilitar la autocuración. Family Process, 26(2), 167-83.

Villa, J. D. (2012). La acción y el enfoque psicosocial de la intervención en contextos sociales: ¿Podemos pasar de la moda a la precisión teórica, epistemológica y metodológica? El Ágora USB, 12(2), 349-365.

White, M. Epston, D. (1993). Medios narrativos para fines terapéuticos. Barcelona: Paidós.

White, M. (2000). Reflecting - team work as Definitional Ceremony Revisied. Reflections on Narrative Practice: Essays and Interviews (pp. 35-38). Adelaide: Dulwich Centre Publications. http://www.metanoia.ac.uk/media/1518/white-m-reflectingteamwork.pdf 


\title{
18. Capacidades relacionales para la construcción de paz en lideres comunitarios
}

\author{
Nicolasa María Durán Palacio $0^{58}$ \\ Heidi SMITH PULIDO VARON ${ }^{59}$ \\ Resumen
}

La construcción de paz, demanda miradas que trasciendan visiones victimizantes de las comunidades y reconozcan el andamiaje subjetivo e intersubjetivo que estas poseen para sostener una apuesta de paz, posible y duradera. Este documento presenta los resultados de una investigación cualitativa realizada con líderes de la comuna 4 de Medellín, con diseño de grupos de discusión. En sus voces se destacan las capacidades relacionales de empatía, confianza y pensamiento crítico, necesarias para la asunción de la otredad en procesos comunitarios de edificación de convivencias pacíficas.

Palabras clave: líderes, construcción de paz, capacidades relacionales.

\section{Abstract}

The construction of peace, demand looks that transcend victimizantes visions of the communities and recognize the subjective and intersubjective scaffolding that they possess to sustain a bet of peace, possible and lasting peace. This document presents the results of a qualitative research conducted with leaders in the commune 4 of Medellin, with design of discussion groups. In their voices highlights the relational skills of empathy, trust and critical thinking, necessary for the assumption of otherness in community processes of building of peaceful coexistence.

Keywords: leaders, peace building, relational capacities.

\subsection{Introducción}

Las distintas formas de violencias vividas en Medellín, entre 1980 y 2005, le otorgaron el calificativo de la ciudad más violenta de Colombia y

58 Universidad Católica Luis Amigó. Correo: nicolasa.duranpa@amigo.edu.co

59 Universidad Católica Luis Amigó. Correo: heidi.pulidova@amigo.edu.co. 
de América Latina. Desde la perspectiva de sus habitantes, la exacerbación de la violencia vivida, la configuró como una urbe coartada por las disputas de control territorial y la implementación de un orden territorial, a través del poder armado que limitó drásticamente las libertades, la autonomía personal y comunitaria y constriñó la participación ciudadana (Centro Nacional de Memoria Histórica - $\mathrm{CMH}-$, 2017).

Los distintos actores armados (milicianos, guerrilleros, paramilitares, bandas delincuenciales), establecieron un sistema de normas que no sólo confinaron las dinámicas, costumbres e identidades colectivas de la ciudadanía (Londoño, 2016), sino que debilitaron ampliamente el derecho a la participación política. Muchos líderes y lideresas barriales, considerados por estos actores violentos como enemigos de su orden impuesto y obstáculo para el logro de sus propósitos, fueron amenazados, perseguidos, desplazados, sexualmente violentados, desaparecidos y asesinados (CMH, 2017).

Como alternativa de resistencia y sobrevivencia a la violencia vivida en la ciudad, líderes locales, comunidades y colectivos se organizaron para comprender la compleja situación social padecida y encontrar salida. En 1994, paralelo al proceso de negociación entre la administración municipal y los actores armados, bajo la asesoría del Instituto Popular de Capacitación -IPC-, se instaló en la Comuna 4, la Mesa de Trabajo por la Paz y la Convivencia, que articuló diferentes organizaciones y líderes comunales para el estudio, la formulación y priorización de los distintos conflictos económicos, políticos y militares que se presentaban en los 17 barrios que integran esta Comuna. En este proceso también se logró la construcción colectiva de propuestas y acciones de solución, condensado en el Plan de Desarrollo y Convivencia para la Comuna 4 (Alcaldía de Medellín, 2015).

Paralelamente a las acciones de intervención institucional para reestablecer el orden y la seguridad en los barrios, los diferentes liderazgos de la Comuna 4, participaron de manera activa en la creación de actos de resistencia invisibles y subterráneos (Uribe, 2006, como se citó en $\mathrm{CMH}$, 2017), no convencionales (tomas culturales y artísticas de los territorios comunitarios, carnavales por la vida, música, festivales, bazares, actividades lúdicas, deportivas y recreativas) como formas de oposición, respuesta, o rebelión a los ejercicios de dominio y control bélico de los actores violentos en sus comunidades. En estas acciones colectivas de resistencia y protección de su territorio en lo cotidiano, los líderes y lideresas hallaron los códigos de sobrevivencia, estrategias de negociación, desobediencia colectiva y desarrollaron argumentos críticos para cuestionar a los representantes de los 
grupos armados. Este carácter relacional de oposición a las violencias y de recuperación de convivencias pacíficas, resulta decisivo en la construcción de paz. La organización comunitaria orientada hacia la acción política, para la solidaridad y la defensa del territorio, constituye la principal herramienta para combatir los ejercicios de poder y control social autoritario de distinta procedencia.

En el marco de la implementación del Acuerdo de Paz, establecido entre la guerrilla de la FARC-EP y el gobierno colombiano, la construcción de una paz duradera y estable, requiere de acciones directas que promuevan convivencias pacíficas y cesen las violencias en los territorios, en las comunidades. Este tipo de acciones no sólo involucra la dejación de armas en el escenario político, sino de actitudes, aptitudes y comportamientos - no fundamentados en la violencia y el uso de la fuerza- - para edificar paz desde la diferencia, en los mecanismos de una democracia participativa, diálogo para la tramitación de conflictos, participación ciudadana, concertación con institucionalidad central, local y las comunidades.

Uno de los retos más grandes en el país es educar para valorar el conflicto, como oportunidad para crecer juntos reflexionando, dialogando y consensuando. Lo que está en juego en la construcción de paz es la capacidad de vivir todos juntos, y para ello hay que sacar a la gente de los actos de autoritarismo, de los fanatismos religiosos y políticos, de las lógicas justicieras, vengativas y de militancias, de las dicotomías bueno/malo y del bajo cumplimiento de la ley.

En el contexto de las acciones de participación política de los liderazgos de la Comuna 4 de Medellín, identificadas como prácticas de resistencia pacífica para enfrentar y superar las situaciones de violencia urbana, esta investigación se propuso reconocer las capacidades relacionales de los líderes de esta comunidad, propicias para la construcción de paz comunitaria. Este objetivo, se diseñó a partir de dos supuestos: en primer lugar, la convicción de que las sociedades son proyectos colaborativos, orientados al beneficio mutuo. Por lo tanto, las relaciones de cooperación social hacen posible para todos, una vida mejor de la que tendrían por sus esfuerzos individuales (Rawls, 2001). La idea central es que en la aspiración de edificar paz comunitaria, es preciso que las personas se junten en este propósito mutuo con la decisión de cooperar, dispuestos a usar sus capacidades constantemente para co-construir los principios éticos que orientarían sus actitudes, comportamientos y acciones comunales en la búsqueda de una sociedad pacífica. En segundo lugar, la estimación de que las personas poseen capacidades 
diversas, y que estas no son meros recursos humanos, sino facultades para actuar, que requieren ser realizadas a través de sus relaciones sociales y políticas, en las que puedan deliberar con otros la elección de una forma de vida en común y cuáles principios éticos y políticos deben regirla. En consecuencia con las suposiciones anteriores, este estudio constituye un aporte psicosocial a la construcción de paz en Colombia, en su dimensión práctica, del reconocimiento de las disposiciones subjetivas de los ciudadanos para vivir en paz.

\subsection{Método}

Al considerar que la construcción de paz no es un proceso automático e independiente, que acontece paralelo a las dinámicas de las comunidades locales, sino que es un asunto que se construye a partir de las subjetividades ciudadanas, en relación con las organizaciones e instituciones, en las cuales las personas se organizan comunalmente y actúan en sus contextos inmediatos de interacción, este trabajo asume un enfoque construccionista social, en el cual, fenómenos sociales complejos, como los procesos de paz, requieren de miradas holísticas, capaces de identificar en el reto de esta edificación, distintos niveles de juicio y de actuación, pero también reconocer que en la cotidianidad social, mantener dicotomías analíticas sobre la construcción de paz, es imposible. Esta edificación de una paz duradera en las cotidianidades de las comunidades, es exigente, en tanto precisa ser un proceso articulado de comprensiones y transformaciones personales, sociopolíticas, culturales y espirituales, que requieren de una imbricación sistémica, en la que la participación comunitaria es altamente significativa.

Además, metodológicamente, este trabajo asumió las premisas del interaccionismo simbólico, que sustentan la idea de que las realidades sociales son construcciones simbólicas, que se realizan en circunstancias históricas, sociopolíticas objetivadas. En consecuencia, existe una correspondencia entre los universos simbólicos que habitan los sujetos y las realidades sociales emergentes, fruto de las relaciones dialógicas, convergentes, complementarias y contradictorias (Ospina-Alvarado, Carmona-Parra y AlvaradoSalgado, 2014). En este sentido, los sujetos poseen capacidad de agencia, para participar activamente tanto en la creación como en la transformación de las situaciones comunes adversas. Teniendo en cuenta estas premisas, esta investigación, privilegió los discursos de 11 líderes comunitarios, habitantes de la Comuna 4 de Medellín, para identificar en ellos capacidades para la construcción de paz en sus contextos barriales. Para ello, se utilizó un diseño cualitativo de grupos de discusión configurados como un artilugio para la 
producción de discursos (Ibáñez, 1986) espontáneos sobre tópicos propuestos por las investigadoras, en el que el intercambio verbal constituyó su lógica.

El grupo de líderes comunales participantes, se conformó a partir de una invitación personalizada a 20 actores sociales, reconocidos en sus comunidades por sus labores de liderazgo, de los cuales 11 respondieron a la invitación. Luego de presentarles el propósito y objetivos de la investigación $y$, una vez obtenido su consentimiento voluntario, se elaboró con ellos un cronograma de encuentros para dialogar en torno a tres temas: construcción de paz, capacidades para la edificación de paz y liderazgos necesarios para cimentar la paz en la Comuna 4 de Medellín. Estos tópicos conversados a través de preguntas y actividades grupales provocadoras de la discusión, se debatieron durante tres meses, cada tema abordado en encuentros semanales, de cuatro horas de conversación. En total 12 sesiones de grupo de discusión, reflejado en 48 horas de debates grabados y transcritos en su completitud.

El estudio de la producción discursiva, se realizó mediante el análisis de contenido de los componentes semánticos de las discusiones temáticas, siguiendo los tres niveles de análisis del discurso, propuestos por Ibáñez (1986): nuclear, autónomo y sýnnomo. En el primer nivel se hallaron categorías analíticas de los temas conversados, tal y como los integrantes del grupo las presentaron y las definieron. En el nivel autónomo se identificaron las posiciones subjetivas respecto a cada tópico conversado, es decir, sus lugares de enunciación. Y en el último nivel o sýnnomo, se descubrieron las concordancias discursivas, que permitieron el reconocimiento de la unidad posible del discurso grupal, como texto y situación de grupo social en la comunidad. De los distintos horizontes de análisis pudieron identificarse tres capacidades personales, propicias para la construcción de paz en contextos comunitarios: empatía, confianza y pensamiento crítico. A su vez, en un nivel de análisis más complejo, se halló que estas capacidades tienen un mismo origen: surgen en relación y son necesarias para la vida en común.

\subsection{Resultados}

La noción de capacidades relacionales está íntimamente ligada a los procesos de desarrollo social y a la expansión de las libertades y oportunidades (Sen, 1997). Socialmente, estas capacidades destacan el carácter de agente que poseen las personas para interesarse e implicarse en la construcción de realidades locales inmediatas que promuevan paz y bienestar común. Como aptitudes, conocimientos y esfuerzos, estas disposiciones relacionales, aumentan las posibilidades de identificación de oportunidades, de solicitud 
de derechos y asunción de deberes, incrementando las facultades de acción real sobre todo aquello que en sus comunidades juzguen valioso y necesario para la edificación de convivencias pacíficas.

En el conjunto de las capacidades, identificadas en los líderes de la comuna 4 de la ciudad de Medellín, aparecen elementos que se articulan a las condiciones del contexto y se expresan en conocimientos, habilidades, actitudes y comportamientos que ponen de relieve una disposición para acompañar y favorecer la construcción comunitaria de la paz, entre ellas la disposiciones subjetivas para no albergar resentimientos, la coherencia entre el decir y el hacer, además del respeto por las ideas y opiniones diferentes a las propias: "De mí siempre podrán esperar que pueda ser capaz de escuchar las opiniones de todos, respetar las ideas" (G.D, líder comunitario, 26 años. Septiembre 16 de 2017). "Mi capacidad de no guardar rencor creo que es importante porque es un acto donde libero mis rencores y mi corazón y alma están en tranquilidad con el otro. Es decir, soy coherente con lo que digo y hago" (G.D, líder comunitaria, 36 años. Septiembre 16 de 2017).

Las capacidades de respeto por las diferencias, de no resentir del otro y la coherencia entre palabras y actos, crean las condiciones propicias para una convivencia pacífica en la que quepan todos, los iguales y los distintos, asumiendo la inevitabilidad del conflicto. Asimismo, estas disposiciones personales se expresan y afianzan en las relaciones cotidianas, en donde adquieren todo el sentido para la edificación de paz:

Si yo vivo en paz podré aceptar la diferencia con el otro: yo no puedo pedir que el mundo cambie si yo no cambio ¿esto qué es? Es aceptar que soy uno más en el planeta donde hay 6.000.000.000 de seres que rien, aman, luchan y tiene el mismo derecho que tengo yo a vivir cumpliendo el deber de respetar los derechos de 5.999.999.999 personas que me acompañan en este viaje. (G.D, líder comunitario, 50 años. Octubre 14 de 2017).

Asumir que la construcción de paz debe hacerse principalmente desde los territorios y las comunidades en sus cotidianidades, exige la convicción de que la vida de los actores sociales se pone en juego, en la posibilidad de construir paz aquí y ahora, especialmente en los contextos urbanos y rurales en los que más intensamente se han vivido las distintas violencias instaladas por la deshumanización de la guerra. En el discurso de los líderes esta oportunidad de construir paz comunitaria, precisa del fortalecimiento de las capacidades humanas en procesos de formación política y de participación efectiva en las decisiones públicas que afectan sus condiciones de vida. Se 
necesitan liderazgos, personas políticamente distintas que piensen y actúen frente a lo público como propiedad de todos que se debe respetar y cuidar. Para hacer esto posible, necesariamente debe existir una articulación entre la participación comunitaria informada y la institucionalidad municipal que requiere de la confianza ciudadana para funcionar. Esto supone el mayor reto para los líderes de la comuna 4:

Mis retos como líder frente a la construcción de la paz es estudiar más, hacer esas capacitaciones y diplomados que nos brinden la Alcaldia, Comfenalco o las Universidades para poder ayudar a todas las personas con las cuales tenemos en nuestro territorio, a que tengan muchas oportunidades para su desarrollo personal. Eso es muy importante para la paz, que uno sepa de lo que habla. (G.D, líder comunitaria, 45 años. Octubre 14 de 2017).

En consonancia con la oficina del Alto Comisionado para La Paz (OACP, 2015), la construcción de paz en el país requiere de transformaciones en las comunidades. Además de nuevas normas, leyes, programas, proyectos y ajustes institucionales para la implementación del Acuerdo final, se requieren de nuevas formas para relacionarse, cambios de actitudes, comportamientos y patrones culturales, que se han adquirido como individuos y como colectivo en medio de la guerra, y que han marcado los modos de relacionamientos y de hacer país.

En los discursos del grupo de discusión de los líderes participantes, se identificaron específicamente las capacidades de empatía, confianza y pensamiento crítico-reflexivo.

\subsubsection{Empatia}

En una doble dimensión, emocional y cognitiva, la empatía promueve y regula el comportamiento prosocial (Davis, 1983; Hoffman, 1990). La ausencia de una actitud empática en los sujetos, es predictora de la acción violenta, la indolencia y la incapacidad para la adhesión emocional (solidaridad). Los sentimientos de preocupación por el otro, la tristeza ante las situaciones de dolor de otra persona, además de la capacidad para comprender el punto de vista del prójimo, son los indicadores esenciales de la capacidad para empatizar con el sufrimiento ajeno.

Uno tiene que saber que también comete errores, reconocer mis propios errores antes de juzgar o lastimar a otra persona, incluso cuando esa persona ha hecho mal. Uno no es Dios para juzgar, uno no sabe si lo obligaron, si tenía odio en el corazón, por otras cosas 
de la vida, si lo amenazaron. (G.D, líder comunitaria, 57 años. Septiembre 16 de 2017)

Teniendo en cuenta que la convivencia humana es frágil y que requiere de cuidados y reconstrucciones permanentes, la empatía es fundamental en la edificación de paz, ella orienta sensiblemente las acciones personales y colectivas hacia la recuperación de la humanidad de todos los seres envueltos en el conflicto violento, tanto víctimas como victimarios: "Yo siento mucho pesar por esa gente. Creo que hacer tanto daño nunca los va a dejar tranquilos, entonces ellos también son víctimas" (G.D, líder comunitaria, 41 años. Septiembre 16 de 2017).

La empatía facilita la identificación con la experiencia del otro, el reconocimiento del semejante en su condición sintiente, permitiendo la ampliación del repertorio de respuestas prosociales para facilitar el perdón y la reconciliación. Cuando en una comunidad las personas poseen empatía, la cooperación y la superación de las fisuras del tejido social, pueden ser resueltas desde la familiaridad y con un sentido más auténtico de aceptación hacia las capacidades y limitaciones del otro. En este sentido, se vinculan empatía y compasión. No puede haber compasión sin sintonía emocional con la fragilidad de la condición humana. Tampoco es posible la empatía, cuando prima una visión de mundo en el que la vulnerabilidad es vivida desde la humillación y la vergüenza, en la que sólo hay cabida para los fuertes.

Conviene subrayar que la dimensión cognitiva de la empatía, ayuda a situar los liderazgos de la Comuna 4 en un espacio ético y relacional, en el que los marcos referenciales heredados de la tradición y la autoridad, pueden ser puestos en cuestión, reconocer específicamente que en toda acción humana acontecen intereses y ejercicios de poder que no están orientados exclusivamente hacia el bienestar común. Empáticamente, los actores sociales pueden deliberar sobre la idea del bien dispuesto por otros (autoridad, institucionalidad) y develar los inconvenientes o la peligrosidad de la confianza ingenua en esta presunción, que necesariamente exige obediencia y complacencia. En nombre del bien en Colombia, se han causado los mayores dolores y sufrimientos a comunidades enteras. La empatía permite, en un escenario relacional cotidiano, responder compasivamente al otro, a partir de su necesidad, limitación, sufrimiento y dolor, más no exclusivamente desde un deber moral impuesto socialmente o un respeto por la ley. En ocasiones, no todo lo legal es justo ni ético, ni toda moralidad proviene de la bondad.

Cuando acontece una genuina preocupación por el otro como motivación al liderazgo indicador positivo para la construcción de paz, es posible una 
respuesta empática, en la que, para el líder, es mucho más exigente relacionarse compasivamente con aquellos que han hecho daño en el contexto de la guerra y llegan a convivir en los contextos comunitarios de la ciudad, que comportarse en filiación afectiva con aquellos que son como él, con los que habita y comparte en su comunidad, con los recién llegados como víctimas a su colectividad barrial.

\subsubsection{Confianza}

La confianza es una condición necesaria para la vida social y desempeña un papel importante en la constitución de la esfera pública y en la configuración de sociedades en las que vale la pena vivir. Como capacidad relacional, facilita tejer relaciones durables y de reconocimiento recíproco, que favorecen las acciones de cooperación para beneficio mutuo. Sociopolíticamente, la confianza acontece en las sociedades con una distribución equitativa de los ingresos y en donde existen redes densas de asociaciones cívicas. Para establecer y mantener relaciones de cooperación y compromiso cívico en la construcción de paz, se precisa de la disposición para confiar en las personas de la comunidad inmediata, con el propósito de poner a funcionar en ella la participación democrática y la deliberación en la gestión de conflictos (Cogollo-Ospina y Durán Palacio, 2015).

Para los líderes de la Comuna 4 de Medellín, confiar siempre ha implicado asumir riesgos al creer en las promesas políticas, pero también supone oportunidades de intuir que más allá de las infamias de las guerras y las injusticias en sus territorios, se puede imaginar otro mundo posible

A veces es necesario crear razones utópicas. Esos sueños y esperanzas que nos permitan fundamentar y crear otras formas de vivir. Entonces yo les decía a ellos: la paz es un sueño posible, es decir, todos podemos vivir en paz y si seguimos pensando que es un imposible, ahi estaremos creando nuestros propios paradigmas y barreras que nos impiden crear esos escenarios donde podamos vivir en paz. Si generamos esas utopías y si las recreamos sinceramente, las podemos hacer posibles y dejan de ser utópicas para generar otras utopías". (G.D, líder comunitaria, 33 años. Octubre 14 de 2017).

En los procesos de construcción de paz comunitaria, la disposición subjetiva hacia la confianza interpersonal se vislumbra en dos sentidos: por un lado, la esperanza en la reciprocidad de reconocimientos e intercambios empáticos en las relaciones entre sujetos y grupos; y por otro, la promesa de construir compromisos cívicos, a pesar de la inexistencia de acuerdos 
de finalización de acciones violentas, entre actores sociales con una larga historia de confrontación bélica. Es justo ahí, en escenarios frágiles e inseguros como el posacuerdo en Colombia, que la confianza logra sostener las apuestas comunitarias de edificación cotidiana de paz, de modo que mantener la esperanza en esta construcción utópica supone, en los líderes comunitarios, la virtud de ser seres confiados, de creer en las propias capacidades para construir paz, traducidas en una seguridad ontológica que descansa, no en la formalidad de un proceso de paz desarrollado por el Estado y las FARC, sino en las propias experiencias cotidianas, en los hábitos y rutinas comunitarias, en el sentido de identidad que han construido y que les ha permitido permanecer, defender y reconfigurar su territorio, a pesar de las tragedias acontecidas en él.

Yo sí creo en la gente, claro somos capaces de hacer mucho mal, de exterminar todo si nos dejan. Pero también está ese lado bueno ese que puede crear, hacer cosas bonitas y buenas, cambiar y entender sus errores. Yo sí confío en eso. (G.D, líder comunitaria, 61 años).

No es fácil, incluso para uno que cree en la paz. Hay demasiado dolor, miedo, descontento con el gobierno, ¿pero, quién dijo que sería fácil? Nosotros pudimos ganarnos el derecho a trabajar y a vivir aqui cuando nos quisieron sacar de aquí, entonces ¿cómo no vamos a poder con esto? (G.D, líder comunitaria, 58 años. Octubre 14).

Hacer la paz representa riesgos que estos los líderes están dispuestos a asumir en la construcción de una paz duradera en sus comunidades: "ellos pueden traicionar la confianza, no todos van a cumplir lo acordado, es una posibilidad, pero por uno que cambie vale la pena el riesgo" (G.D, líder comunitaria, 33 años). La confianza en esta edificación comunitaria de paz, aparece como una capacidad relacional mediadora en la tensión permanente entre la contingencia y la seguridad, e intenta oponerse a las distintas formas del individualismo y al carácter frágil de los vínculos afectivos (Durán Palacio, 2015). La confianza ayuda a sostener el sentido de comunidad, a alimentar la esperanza en las potencialidades para sobrevivir a las acciones hegemónicas de poder y a enfrentar la incertidumbre que suponen todas las construcciones humanas.

\subsubsection{Pensamiento crítico}

Sobre la base del pensamiento crítico, se hallan complejos procesos sensitivos y afectivo-cognitivos, que estimulados por las experiencias relacionales y por las vivencias en el contexto social inmediato, configuran la 
capacidad de juicio y las percepciones que sobre el mundo tiene una persona. El pensar no sólo es una habilidad, sino una necesidad humana de darle forma a lo vivido y de hallarle sentido a las experiencias, a lo ya ocurrido. Contemplar el pensamiento crítico como una capacidad, significa, tal vez, la más política de todas las capacidades relacionales, significa concebirla como oportunidad de elegir con discernimiento, pero también como una manera de enfocar y vivir la propia vida.

A nivel personal, considero que la política ha sido un asco. Cinco años que estuve estudiando teatro y otros cinco años estudiando derechos humanos en la Corporación Mujeres que Crean para la Vida, me han enseñado que es el individuo el que toma sus propias decisiones, que soy yo la que decido y no a esperar un mesías que me solucione la vida. Yo empiezo a tomar decisiones a través del arte, de la cultura, de lo que me apasiona, de lo que he estudiado y empiezo a cambiar mentalidades. No decirle a la gente que tiene que pensar lo que pienso yo, pero siempre mantener argumentos y una posición abierta al cambio" (G.D, líder comunitaria, 50 años. Octubre 16 de 2017)

Como las otras capacidades antes mencionadas y halladas en los discursos del grupo de líderes comunitarios, el pensamiento crítico ocurre en un marco relacional, pero de modo específico el pensar críticamente como capacidad humana de cuestionar lo que ocurre entre semejantes, establece su propia dignidad. Asumiendo que existen unas mínimas distinciones entre sentir y pensar, el cultivo de la facultad del juzgar y evaluar lo que sucede, trae consigo grandes beneficios como: deshacer la vergüenza, resistirse al fanatismo, expandir la conciencia, desarrollar la creatividad y evitar caer en automatismos (Orange, 2012; Nussbaum, 2012).

Hablar ahorita del cumplimiento de objetivo del acuerdo de paz no es válido, porque eso se verá en el trascurrir de nuestras vidas, si en verdad asimilamos el mensaje, si cambiamos el lenguaje, las acciones de ver y de sentir las cosas, ya en el campo de los objetivos yo creo se proyectó el compromiso. El compromiso con cada uno de nosotros se demostró que la paz la construimos es nosotros, no tenemos que esperar que otro venga ... el Mesías, para mi eso es lo valioso, hasta el momento si somos capaces de cambiar los discursos". (G.D, líder comunitaria, 28 años. Septiembre de 16 de 2017)

No obstante, en los análisis del discurso del grupo, se identificó que esta capacidad de pensamiento crítico, es una de las más frágiles y lesionadas en el colectivo de líderes abordados. En la mayoría de sus posiciones, se 
hallan arraigados a valores tradicionales, conservadores que actúan como filtro para evaluar sus acciones y las de la comunidad, favoreciendo el sostenimiento de actitudes obedientes y complacientes que limitan el cambio y facilitan la cooptación de los liderazgos por discursos hegemónicos de poder, de carácter político y religioso. Asimismo, aparece la imposibilidad de discernir y tomar decisiones cuando existe conflicto entre los intereses del líder y la comunidad, lo cual actúa como desestimulante de la participación, la legitimidad y confianza en la comunidad.

\subsection{Discusión}

Los resultados destacan en los líderes de la comuna 4, un sustrato de capacidades relacionales que se han ido consolidando en la experiencia comunitaria, precedida de luchas territoriales y organización colectiva, para reivindicar derechos a una vida digna, a habitar sosegadamente la ciudad, sus barrios y a construir estilos de vida pacífica.

La mirada relacional que ha privilegiado este texto, a diferencia del Informe del Centro de Memoria Histórica (2017) sobre las memorias de la guerra urbana en Medellín, recalca que las acciones de resistencia, sobrevivencia y defensa de los escenarios comunitarios, obedecen más a un repertorio de capacidades relacionales presentes en los liderazgos sociales, y no tanto al poder de la organización civil con apoyo gubernamental. Han sido los hombresy mujeres líderes, a pesar de la amenaza constante del individualismo excesivo y de la inestabilidad de los vínculos afectivos en sociedades urbanizadas, como la de Medellín, quienes se han arriesgado a convocar y movilizar a los habitantes de sus comunidades a empoderarse de las situaciones límite, no solamente para resistirse y defender su territorio, sino para comprender que las distintas formas de violencia en sus contexto, afecta a todos en su condición humana. Las acciones de resistencia y sobrevivencia no surgen de las emociones de indignación y malestar, ellas emergen de situaciones relacionales en las que la empatía, la confianza interpersonal y la reflexión crítica las configura y las orienta.

En consonancia con la tesis de Rawls (2001), de que las sociedades son proyectos colaborativos para beneficio mutuo, cuando se vive en comunidad, los sujetos deben estar dispuestos a establecer conjuntamente principios ético-políticos que orienten sus modos de vida, sobre la base de la sensibilidad empática, la confianza y el juicio crítico. Estas son disposiciones subjetivas y capacidades (Nussbaum, 2012) de las que no puede prescindir la sociedad colombiana en su ideal de construir paz comunitaria, luego de 
un conflicto bélico de larga duración. En escenarios atrapados en lógicas de poder, como en la Comuna 4, es perentorio que se promueva en los ciudadanos, el cultivo del pensamiento crítico, facultad moral imprescindible en la constitución de sociedades auténticamente democráticas.

Así, las capacidades relacionales en la construcción de paz, tienen un papel protagónico en una sociedad donde la polarización política y la desconfianza interpersonal, profundizan la individualidad y fragilizan los lazos colectivos. La empatía, la confianza y el pensamiento crítico al surgir de experiencias relacionales, requieren de su cultivo y fortalecimiento desde el cuidado humano, la educación para el reconocimiento de la pluralidad, la solidaridad y la compasión. A pesar de que estas capacidades son desplegadas por el grupo de líderes de la Comuna 4 de la ciudad de Medellín, las dinámicas de violencia urbana, los discursos hegemónicos de poder y la fragilidad de las relaciones barriales han logrado lesionarlas, de modo que resultan perentorios procesos de acompañamiento psicosocial a los liderazgos, desde la óptica de aquello que son capaces de ser y de hacer en las cotidianidades de sus comunidades.

\section{Referencias}

Alcaldía de Medellín. Departamento Administrativo de Planeación (2015). Plan de Desarrollo Local Comuna 4-Aranjuez. Innovación y Desarrollo una apuesta colectiva por la vida, la paz y la movilidad social. Medellín. Colombia.

Centro Nacional de Memoria Histórica (2017). Medellin: Memorias de una guerra urbana. Bogotá: Panamericana Formas e Impresos.

Cogollo-Ospina, S. N. y Durán-Palacio, N. M. (2015). Paz y Posconflicto: compromiso de los ciudadanos para un horizonte imaginado. En: S. N. Cogollo-Ospina (coord.), Imaginar la paz en Colombia: cavilaciones desde la academia, (pp. 62-71). Medellín: Fondo Editorial Universidad Católica Luis Amigó. Disponible en: www.fundacionamigo.org/ wp-content/uploads/2016/04/libro-Imaginar-la-paz-en-Colombia.pdf

Davis, M. H. (1983). Measuring Individual Differences in Empathy: Evidence for a Multidimensional Approach. Journal of Personality and Social Psychology, 44(1), 113-126. doi: 10.1037/0022-3514.44.1.113.

Durán Palacio, N. M. (2015). La salud mental entre las fragilidades y las rupturas de vínculos afectivos. Revista Facultad Nacional de Salud Pública, 32(supl 1), S143-S153.

Hoffman, M. L. (1990). Empathy and Justice Motivation. Motivation and Emotion, 14(2), 151-172.

Ibáñez, J. (1986). Más allá de la sociología. El grupo de discusión. Teoría y crítica. Madrid: Siglo XXI. 
Londoño, H. (2016). Sistemas punitivos y derechos humanos. El caso de la Comuna 13 de Medellín. Bogotá: Ediciones Jurídicas Andrés Morales.

Nussbaum, M. (2012). Las fronteras de la justicia. Barcelona: Paidós.

Orange, D. (2012). Pensar la práctica clínica. Recursos filosóficos para el psicoanálisis y las psicoterapias humanistas. Chile: Cuatro vientos.

Ospina-Alvarado, M. C., Carmona-Parra, J. A. y Alvarado-Salgado, S. V. (2014). Niños en contexto de conflicto armado: narrativas generativas de paz. Revista Infancias Imágenes, $13(1), 52-60$.

Rawls, J. (2001). El derecho de gentes y una revisión de la idea de razón pública. Barcelona: Paidós.

Sen, A. (1997). Resources, Values and Development. Cambridge: Harvard University Press. 


\title{
19. Huellas silenciosas de
}

\section{una guerra que no se nombra. Análisis de representaciones en las bitácoras del Salón del Nunca Más, de Granada (Antioquia)}

\author{
Marda Zuluaga-AristizáBal ${ }^{60}$ \\ Resumen
}

El texto presenta resultados parciales derivados de la tesis doctoral Palabras para los ausentes. Análisis de las bitácoras del Salón del Nunca Más del municipio de Granada, Antioquia (Colombia) como género discursivo de transmisión y elaboración de un pasado violento. Con base en la lectura en profundidad de 233 bitácoras y 3 libros de visitas, y tomando como referencia las formulaciones de Ochs (2000), Ricoeur (2006) y Bruner (2002) acerca de los componentes de las narrativas, se identificaron seis tipos de representaciones: de suceso, de lugar, de actores, temporales, de acciones y valorativas. Se discute acerca de la casi total ausencia de representaciones concretas asociadas a la guerra, la preeminencia de una ideología católica y la posibilidad de entender el tipo de memoria que se realiza como una apuesta micropolítica que parte de la Asociación de víctimas por la vida -Asovida- del municipio de Granada.

Palabras clave: Conflicto armado colombiano, representaciones, ideología

\begin{abstract}
This paper presents partial results derived from the doctoral thesis "Words for the absentees. Analysis of the logbooks of the Salón del Nunca Más in Granada, Antioquia (Colombia) as a discursive genre and dispositif for the transmission and elaboration of a violent past". Based on the indepth reading of 233 logbooks and 3 guestbooks, and taking as reference the formulations of Ochs (2000), Ricoeur (2006) and Bruner (2002) about the
\end{abstract}

60 Universidad EAFIT. mzulua12@eafit.edu.co 
components of the narratives, six types of representations were identified: event, place, actors, temporal, actions and evaluative representations. It is discussed about the almost total absence of concrete representations associated with war, the pre-eminence of a Catholic ideology and the possibility of understanding the type of memory that is carried out as a micropolitical bet that starts from the Association of victims for life -Asovida- of the municipality of Granada.

Keywords: Colombian armed conflict, representations, ideology

\subsection{Las bitácoras del Salón del Nunca Más: una fuente de discursos y representaciones}

En el presente texto se presentan resultados parciales de la tesis doctoral Palabras para los ausentes. Análisis de las bitácoras del Salón del Nunca Más del municipio de Granada, Antioquia (Colombia) como género discursivo de transmisión y elaboración de un pasado violento. El objetivo general de la tesis es caracterizar las representaciones, narrativas y estructuras discursivas presentes en las bitácoras del Salón del Nunca Más — sitio de memoria del conflicto armado del municipio de Granada (Antioquia) - que autorizan su definición como un género discursivo de transmisión y elaboración de un pasado violento vinculado a dicho conflicto. Aquí daremos cuenta de algunos de los hallazgos relacionados con el tipo de representaciones que pueden identificarse con base en la lectura en profundidad de la totalidad de las bitácoras y los libros de visitas, cuyas entradas ${ }^{61}$ suman un total de 4589 textos: 2629 corresponden a las bitácoras y 1960 a los libros de visitas.

Granada es un pueblo con poco más de 20.000 habitantes $^{62}$, está ubicado a casi dos horas de la ciudad de Medellín y registra, según datos del Centro Nacional de Memoria Histórica, alrededor de 2.500 víctimas, entre muertos, desaparecidos, mutilados por minas, agredidos sexualmente, secuestrados (CNMH, 2016, p. 19). Los eventos violentos más reseñados en medios de comunicación son dos, ocurridos en el año 2000. El primero es una masacre perpetrada el 3 de noviembre de ese año por un apéndice del Bloque

61 Textos independientes que pueden leerse por separado.

62 De acuerdo con la página web oficial del municipio, "El total de la población es de 20.112 habitantes, distribuidos el $68 \%$ rural y el $32 \%$ urbano. Posee 52 veredas, un corregimiento denominado Santa Ana y 3 centros poblados que son: Los Medios, Galilea y la Quiebra". Tomado de: https://goo.gl/YDz6RC 
Cacique Nutibara de las $\mathrm{AUC}^{63}$, en la cual asesinaron a 19 personas que se encontraron en el camino, sin sistematicidad alguna (CNMH, 2016, p. 18). Poco más de un mes después, en retaliación por este acto, la guerrilla de las FARC realizó una toma armada del casco urbano del pueblo, que inició con la detonación de un carrobomba con $400 \mathrm{~kg}$ de explosivos y se prolongó por dieciocho horas en las que 500 hombres se enfrentaron con unos 40 policías que había en el comando y lanzaron artefactos explosivos que dejaron el pueblo semidestruido, un saldo de 20 muertos y decenas de heridos $^{64}$. Fue el inicio del período más crudo de una guerra que ya llevaba más de una década afectando al municipio, convirtiéndolo en el escenario de decenas de masacres, permanentes retenes ilegales, asesinatos selectivos y un estado de zozobra que provocó el desplazamiento del 70\% de la población y mantuvo el pueblo casi completamente aislado por los riesgos que suponía entrar o salir de él.

Allí, tiempo después de estos hechos, se conformó ASOVIDA, la Asociación de víctimas unidas por la vida ${ }^{65}$, en la que confluyen hombres y mujeres que han sido afectados de manera directa por la guerra. Tras un proceso de capacitación con el Centro de Investigación y Educación Popular —CINEP — que incluyó la formación como "promotores de vida y paz" y la realización de talleres en los que se promovía el valor de hacer memoria de los hechos vividos, nace, en el año 2009, el Salón del Nunca Más ${ }^{66}$. Dos son sus componentes principales: el muro situado en el costado opuesto a la entrada, tapizado con las fotografías de cientos de muertos y desaparecidos (imagen 1), y las bitácoras (imagen 2) correspondientes a cada uno de ellos. Hay un total de 290 fotografías que fueron llevadas de manera voluntaria por sus familiares, lo que quiere decir que está representado aproximadamente un $10 \%$ de las víctimas.

63 El periódico El Tiempo, de circulación nacional, registró así la masacre: https://www.eltiempo. com/archivo/documento/MAM-1256596

64 Noticia publicada en el diario El Tiempo dos días después de la toma guerrillera: https://www. eltiempo.com/archivo/documento/MAM-1299733

65 Asovida es el nombre de la asociación de víctimas del municipio de Granada, autodescrita como un proyecto "para trabajar en pro de la memoria de las víctimas del conflicto armado" (página web del Salón del Nunca Más, consulta realizada el 3 de marzo de 2017). Gloria Elsy Ramírez, su representante legal, indica que la Asociación se conformó en el año 2004 con un pequeño número de personas pero que, con el paso del tiempo, han llegado a contar con más de 300 miembros, en su mayoría mujeres (CNMH, 2016, p. 320).

66 Para conocer distintos aspectos del Salón del Nunca Más, se recomienda visitar el portal "Hacemos memoria", el cual ha reseñando y acompañado su labor por varios años: http:// hacemosmemoria.org/tag/salon-del-nunca-mas/ 
Reconstrucción de subjetividades e identidades en contextos de guerra y posguerra

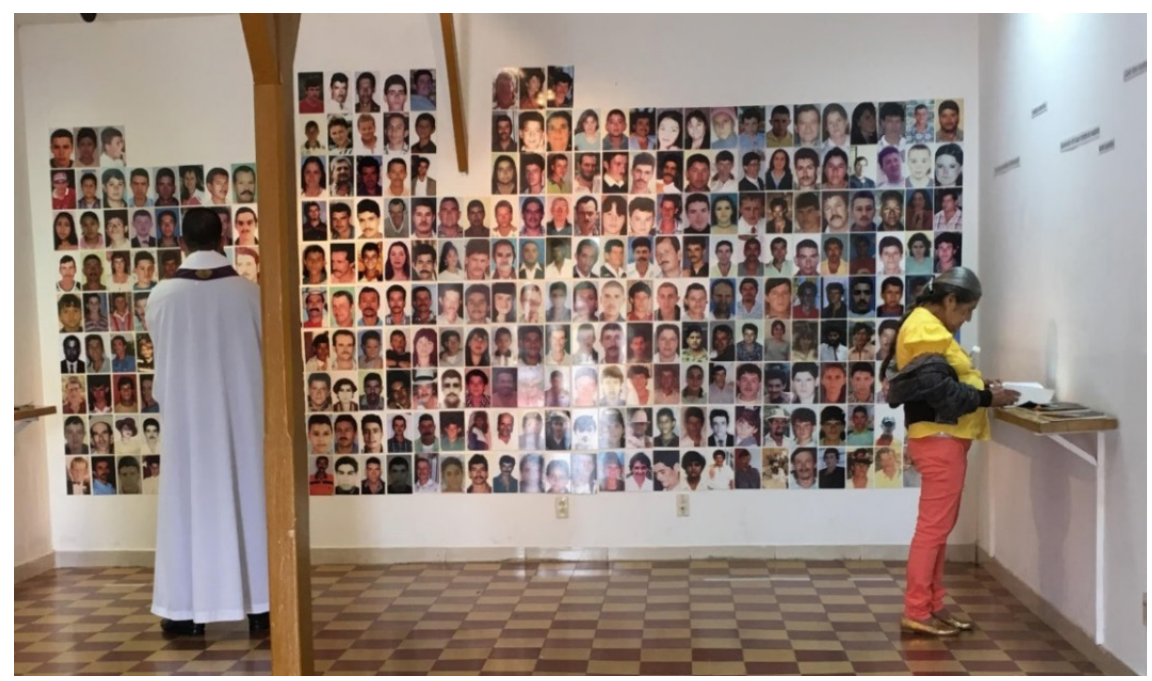

Imagen 1. Muro de fotos del Salón del Nunca Más. Foto tomada por Marda Zuluaga el 05/03/17

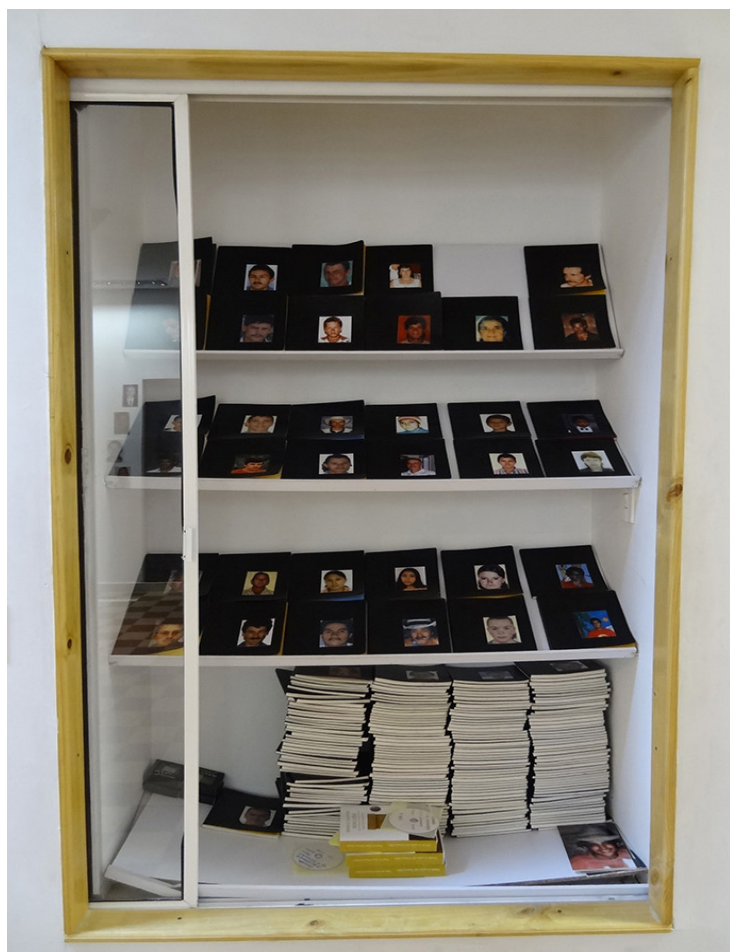

Imagen 2. Bitácoras. Foto tomada del portal Oropéndola, del Centro Nacional de Memoria Histórica 
Las bitácoras - cuadernos especiales asociados a víctimas de asesinato o desaparición forzada del municipio- están disponibles para que cualquier persona que asista al Salón del Nunca Más las lea o escriba en ellas, lo que les da un carácter inacabado y abierto al intercambio, al mismo tiempo que propicia un tipo asincrónico de interacción en el que familiares, amigos, vecinos y visitantes desconocidos se encuentran en la palabra escrita, convirtiendo la bitácora en un escenario simbólico en el que se dejan mensajes tanto para los ausentes (muertos y desparecidos) como para los vivos.

El interés central de la investigación estuvo puesto en la relación entre violencia, memoria y escritura y, más específicamente, en los modos en que una comunidad conformada principal -aunque no exclusivamente-por campesinos, niños, adolescentes y mujeres con posibilidades limitadas de acceso a la educación formal, se apropia de un dispositivo que exige de ellos la realización de un acto con el que están poco familiarizados para dar cuenta de sus experiencias y representaciones vinculadas a un pasado de violencia política. Esta es una de las principales particularidades del caso estudiado, pues se trata de una escritura no mediada por profesionales en talleres o programas de intervención ni acotada a encuentros específicos preparados con el fin de reunir testimonios, como es lo habitual en intervenciones de carácter psicosocial ${ }^{67}$. Aquí, las víctimas, familiares y visitantes escriben cuando quieren, realizando inscripciones de sentido en sus propios tiempos y contando con la posibilidad de leer las de otros, así como de volver al lugar para escribir nuevos mensajes e impresiones pasados meses o años desde sus primeros textos, lo cual posibilita rastrear transformaciones y recurrencias en el discurso.

Uno de los supuestos de partida consideraba que es posible distinguir, en esos registros escritos, representaciones sobre el conflicto armado, sus actores, sus causas y consecuencias en distintos niveles (personal, familiar, comunitario, social...) y, en esa medida, algunas de las preguntas que dieron origen a la investigación estaban orientadas a las formas en que estos asuntos eran aludidos, nombrados, descritos, interpelados o simplemente presentados, con el fin de dar cuenta de las características recurrentes de estas representaciones que permitieran deducir aquellas que pueden considerarse sociales en función de su carácter compartido por miembros de la comunidad granadina. Usamos el concepto de representación en

67 Para ejemplos de este tipo, véase la tesis doctoral de Patricia Nieto: Relatos autobiográficos del conflicto armado en Colombia. El caso reciente de la ciudad de Medellín (Universidad Nacional de La Plata, 2013). 
una acepción muy general, compartida por diferentes ciencias sociales y humanas, como la forma en la cual las personas, con base en sus referentes históricos y culturales, interpretan acontecimientos y situaciones y le dan sentido a su realidad. En lo que cualquier persona dice o manifiesta acerca de sus experiencias es posible detectar su sistema de valores, las ideologías a las que ha estado expuesto y su proximidad con ellas, el nivel o tipo de conocimiento a partir del cual configura lo que, para ella, "es" -o significa- dicho aspecto de la realidad, entre otras características que permiten la comprensión de fenómenos sociales. El discurso, el habla, la escritura, son prácticas de esas representaciones, las cuales podemos denominar sociales cuando son compartidas por grupos amplios que habitan un mismo territorio y contexto sociohistórico, de acuerdo con las formulaciones de Moscovici (1961).

\subsection{El análisis crítico del discurso como método de aproximación}

Las bitácoras del Salón del Nunca Más son asumidas como una fuente de representaciones y narrativas organizadas de tal modo que pueden ser definidas como un género discursivo particular de elaboración y transmisión de un pasado violento. Tal pasado violento determina la importancia del contexto, pues las bitácoras existen porque ha habido en Colombia un conflicto armado de larga duración que impactó de manera directa y masiva al pueblo de Granada y la región en la que está asentado. La importancia de esta dimensión sociohistórica justifica el uso del análisis crítico del discurso (ACD) como una forma de comprender algunos aspectos de una problemática social a partir de una producción discursiva que se da en ese contexto particular, sin el cual, simplemente, ni el Salón ni las bitácoras existirían.

El ACD, según van Dijk, no es tanto un método determinado de análisis sino una "... actitud, un movimiento en AD [análisis de discurso]: de querer centrarse en problemas sociales". (2007, p. 4). Parte del supuesto que el discurso es un hecho social, la puesta en acción de concepciones acerca de la vida, el mundo, la identidad propia y de los otros y, por lo tanto, prestarle atención y estudiarlo es una manera de develar lógicas de poder, estrategias para imponer maneras de concebir o posicionarse sobre temas concretos, ideas que orientan acciones, entre muchos otros asuntos que resultan relevantes para quienes pretenden comprender, interrogar $\mathrm{y}$, eventualmente, participar de la transformación de realidades sociales que generan violencia, exclusión, sufrimiento. 
El marco general de la investigación lo constituye el método analítico, definido como "la contrastación dialéctica entre la teoría y la práctica mediante el análisis del discurso" (Ramírez, Lopera, Zuluaga y Ortiz, 2017), definición lo suficientemente amplia como para afirmar que abarca diversos tipos de aproximaciones que, desde diferentes ciencias sociales, se hacen para comprender la realidad humana. El discurso es concebido como "toda expresión de una estructura subjetiva", con lo cual se dan a entender dos cosas: 1) que no hay subjetividad sin lenguaje, por lo cual cada sujeto, en el proceso de hacerse parte de un orden social, incorpora -al comienzo pasiva y después creativamente- los rasgos característicos de su contexto histórico y cultural; 2) que la subjetividad socialmente conformada se manifiesta (expresa) de muy diversas maneras: no sólo al hablar o escribir sino en las actitudes, comportamientos, selección de objetos, construcción de lugares, preferencias estéticas y toda una amplia gama de prácticas que tienen como base ideas acerca del mundo, de sí mismo y de los otros que se han configurado a partir de lógicas discursivas.

En relación con la identificación de representaciones, empleamos la perspectiva sociocognitiva de van Dijk, que centra su atención en las relaciones entre discurso (como acontecimiento comunicativo o, en nuestros términos, expresivo), cognición (como los modelos mentales de representación del mundo) y sociedad (haciendo énfasis en las relaciones de poder). De acuerdo con su modelo (2000, p. 58 y ss.), a partir de una gramática descriptiva se toman en consideración los que postula como principios comunes a todo análisis del discurso, lo que incluye el estudio de las producciones en su contexto de origen tal como son expresadas por sus agentes ${ }^{68}$, atender a sus modos de organización, el tipo de interacciones que se dan, los niveles y categorías que se derivan de lo expresado.

Con base en la lectura en profundidad de las bitácoras y tomando como referencia las formulaciones de Ochs (2000), Ricoeur (2006) y Bruner (2002) acerca de los elementos que componen una narrativa, se identificaron seis tipos de representaciones: 1) de suceso, es decir eventos y hechos acerca de los cuales hablan las bitácoras: serían las escenas y episodios de las narrativas; 2) de lugar, referidas a los escenarios reales e imaginados en los que transcurren los sucesos; 3) de actores, esto es, los personajes representados y que toman parte en los sucesos y acciones; 4) temporales,

68 Esta orientación metodológica implica la no alteración de los escritos de víctimas y sobrevivientes, pues sus modos de escritura, tanto en lo que concierne a la composición gramatical y sintáctica como a los elementos semánticos y ortográficos aportan pistas valiosas acerca del contexto y las características de los escribientes. 
vinculadas a los modos en que son referidos el pasado, el presente y el futuro, así como a conmemoraciones y fechas especiales que son marcadas en los relatos; 5) de acciones, reflejadas en prácticas y comportamientos; 6) valorativas, donde se agrupan ideologías, creencias y actitudes ante la realidad representada.

El corpus analizado se compone de 233 bitácoras manuscritas. Había, además, 20 bitácoras con la fotografía y el nombre pero que no tenían ninguna inscripción en el momento en que se tomaron las fotografías ${ }^{69}$. De las 233 bitácoras que fueron objeto de análisis, 196 corresponden a hombres y 76 a mujeres. En el caso de las bitácoras vacías la proporción relativa al sexo es similar: 17 hombres frente a 3 mujeres. Los tipos de victimización reportados en las fichas de registro incluyen homicidio (153), desaparición (57), masacre (8), atentado terrorista/toma guerrillera (2), falso positivo (1), muerte violenta (1), sin dato (11).

Para la realización del análisis del discurso se recurrió a la lectura en profundidad $^{70}$, se empleó el software $A n t C_{\text {Onc }}{ }^{71}$ y se diseñaron matrices de análisis, en primer lugar para ubicar los conceptos más recurrentes en los textos de las bitácoras y, en segundo lugar, para determinar su vinculación con los elementos constitutivos de las narrativas a partir de los cuales se caracterizaron los seis tipos de representaciones que se presentan en el siguiente numeral.

La aproximación a los textos de las bitácoras, además de haber sido autorizada en la asamblea de ASOVIDA realizada el 14 de febrero de 2017, partió de un profundo respeto por la dignidad de sus autores y las víctimas de asesinato y desaparición a quienes están dedicadas las bitácoras y, en esa medida, se hace en todo momento un tratamiento cuidadoso y humano de los relatos, los cuales no son tomados como meros datos de análisis sino como una parte fundamental en la elaboración y transmisión de un pasado

69 El trabajo de campo de la investigación se realizó entre enero y junio del año 2017.

70 El procedimiento de la lectura en profundidad consiste en una serie de lecturas minuciosas, atenta tanto a los detalles, particularidades y rupturas como a las recurrencias, reiteraciones y formas estereotipadas en que se organizan los discursos en todos los niveles (sintáctico, semántico y pragmático). De allí, según las orientaciones de Bolívar (2007), es posible extraer los tipos de gramática empleadas, la estructura interna, los posicionamientos subjetivos de los escritores, así como sus roles y sus grados de certeza, entre otras características que cobran relevancia justamente en la medida que emergen de la inmersión que en los textos se realiza.

71 AntConc es un software libre de análisis lingüístico que permitió perfeccionar el estudio mediante la búsqueda de las recurrencias de palabras y expresiones, así como la ubicación y visualización de los contextos en los que son enunciadas. 
violento que ha tocado las vidas de miles de personas en Colombia. Las bitácoras conforman una muestra significativa, no desde el punto de vista estadístico sino hermenéutico, en tanto reflejan representaciones, narrativas, creencias, comportamientos, actitudes, y, de manera amplia, posicionamientos subjetivos respecto a la realidad del conflicto armado colombiano.

\subsection{Hallazgos: una guerra apenas aludida y una religiosidad preponderante}

\subsubsection{Representaciones de suceso}

Una de las características principales de las narrativas es que suelen referirse a sucesos que, por algún motivo, son dignos de mención. De acuerdo con Bruner (2000, p. 31): "[...] la narrativa en todas sus formas es una dialéctica entre lo que se esperaba y lo que sucedió. Para que exista un relato hace falta que suceda algo imprevisto; de otro modo «no hay historia»". He aquí una de las razones que nos hacía suponer que los eventos de la guerra serían objeto de representación en las bitácoras. Sin embargo, estas menciones específicas son escasas y, cuando las hay no llegan a tener un contenido representacional explícito: salvo contadas excepciones, no hay descripciones de lo sucedido o relatos en los que se evoque cómo lo vivieron quienes estuvieron allí y se convirtieron en testigos.

La toma guerrillera, por ejemplo, que fue uno de los episodios más brutales que se presentó en el municipio, es mencionado una sola vez, de paso, en la bitácora 023HEQR, de quien en el comienzo alguien, al parecer su esposa, indica:

MURIO: 6 DE Diciembre: 2.000

EDAD: 30 Años

CON EL CARRO BOMBA

DE LA TOMA GUERRILLERA

Pese a ser una bitácora con un número de escritos superior al promedio ${ }^{72}$, ninguno de los textos evoca más allá de esta mención lo que pasó en esa jornada bélica y, como es una constante en la mayoría de las bitácoras, lo que ocupa las páginas no son casi nunca sucesos disruptivos, sino más bien aquellos cotidianos que nunca volvieron a ser iguales desde que el ausente,

72 Si se divide el número total de entradas entre el número de bitácoras, el promedio de textos que contiene cada una es de 11. 
a causa de la violencia de la guerra, dejó de estar en el mundo de todos los días. Ese silencio que es el sello de muchas bitácoras, más que indicar una carencia de representación, puede interpretarse como un vacío alrededor del cual empieza a girar todo, un vacío tan evidente e imponente que no se requiere - y que se evita, por razones diversas - nombrar.

Con las masacres, de las que se presentaron más de diez entre los años 2000 y $2004^{73}$ con un gran número de víctimas, sucede algo similar: prácticamente no son nombradas en las bitácoras, salvo dos casos (bitácoras 036MGL y 048AJA) en los cuales sólo se hace mención de aquella en la cual perecieron los dos hombres a las que pertenecen - masacre paramilitar del 3 de noviembre del 2000 y masacre de la vereda Minitas, perpetrada también por paramilitares el 5 de abril del 2001, respectivamente-.

Mientras que los sucesos de la guerra son representados de manera difusa, los correspondientes a la vida familiar, religiosa y escolar tienen un amplio despliegue: nacimientos, fiestas de quince años, fallecimientos, uniones; primeras comuniones, misas, bautizos; ingreso a la escuela y avance en los diferentes grados, reconocimientos o problemas escolares. Todo esto se cuenta, según se desprende del estilo epistolar predominante y de las declaraciones explícitas al respecto, para mantener a los ausentes al tanto de lo que pasa de este lado de la vida. Pero se hace, sobre todo, para expresarles y dejar constancia de que nada de eso que sucede se disfruta como se debería porque ellos hacen falta. Lo que se vuelve casi palpable es el estrago, ese vacío al que nos referimos antes y que se torna el centro alrededor del cual giran tanto una serie de acciones como muchos silencios:

Dario aunque aveces paresca esas heridas no sanan deltodo pero bueno ni modo la vida sigue no te imaginas como te recuerdo en fechas tan especiales como fue el bautismo de Soraya la primera comunión de caro y valén tu que siempre soñaste tanto con verlas crecer este año cumple 15 años tu hija que tanto soñabas con ver grande.

73 En el informe sobre Granada del Centro Nacional de Memoria Histórica se presentan los siguientes datos: "El Observatorio del Centro Nacional de Memoria Histórica registró diez masacres en Granada entre los años 2000 y 2004, con un total de 59 víctimas. En información de prensa y relatos de la población se reportaron tres más, una de ellas en 1993 con 6 víctimas, y otra en el 2000 en Altos del Palmar con 4 personas asesinadas. Adicionalmente, mientras el CNMH registra 17 víctimas en la masacre del 2000, los medios locales reportan 19, lo cual arroja un reporte de al menos 71 víctimas de masacres en el municipio de Granada" (CNMH, 2016, p. 177) Las masacres reportadas en el municipio, incluyendo una en 1993, serían 13 en total. 
Meda mucha tristeza saber que no estas con nosotros para compartir Juntos y ver crecer a nuestras hijas pero donde estes quiero que sepas que aunque eso no melo imagine q me tocara sola te prometo que voy a tratar y siempre e tratado de luchar por ellas con tu ayuda y la de papito Dios. (Bitácora 001IDAD, entrada 10).

Aunque los eventos concretos apenas se nombren, la guerra y la violencia sí se ven representadas como entidades generales, avasallantes $\mathrm{y}$, muchas veces carentes de sentido. Dos ejemplos:

Así como tu, ninguno de los que están y los que aún no están aquí merecian el horror de esta guerra sin sentido. Sin embargo debieron padecerla y hoy estamos recordando lo importante que Fueron para quienes tuvieron la oportunidad de conocerlos, ustedes aún viven en sus memorias. (Bitácora 123NAL)

$$
* * *
$$

Hermanito lindo, La violencia nos quito muchas oportunidades de vivir muchas cosas más. (Bitácora 155AMLM, entrada 3).

\subsubsection{Representaciones de lugar}

Como parte del reconocimiento del contexto es importante la identificación de lugares y escenarios en los que transcurren los eventos, los recuerdos y los anhelos de quienes escriben en las bitácoras. Una forma de presentar los hallazgos de las representaciones de lugar es yendo de lo más amplio y general —el mundo - a lo más íntimo — la finca, la casa-, pasando por las alusiones al cielo y al paraíso, lugares copiosamente referenciados en los que muchas personas imaginan que transcurre la vida extraterrena de sus seres queridos, desde donde pueden mirarlos, ayudarlos y, muy particularmente, leer los mensajes que devotamente les escriben. En el caso de las personas desaparecidas, el no-lugar en el que se los imagina adquiere los nombres de la incertidumbre: "donde sea que estés", "donde quiera que estés".

Las referencias al mundo se usan principalmente para marcar la distinción entre "este mundo", "la tierra", ese lugar donde ocurren las cosas de los vivos y se podría ser "el más feliz" si el ausente no hubiera partido, y el "otro mundo", allí donde se encuentran ahora los que han muerto y adonde se aspira a llegar para volver a reunirse alguna vez con ellos. Por su parte, Colombia, con nombre propio, es nombrado sólo dos veces en relación con una historia de "gente como zorros [que] matan a una ser humano" (Bitácora 034YJR, entrada 6) y con todas sus víctimas, por 
la que se le pide al ausente que rece (Bitácora 129GJRG). Otras formas en que aparece representado es como "país" y como "sociedad", en la mayoría de los casos asociado a su situación violenta y dolorosa ${ }^{74}$ : "En un lugar asi, como este entender de cerca, sin sufrirlo, lo atros de nuestra triste historia- la historia de un pais que solo a estado comulgando con la violencia, con actos de barbarie sin razón y significado". (Bitácora 128JACG, entrada 2).

Cuando comenzamos a acercarnos al entorno más propio, el pueblo, las referencias aumentan notoriamente en las bitácoras: "Granada" aparece en 31 ocasiones, "pueblo" en 32, "pueblito" en 2; "municipio" en 10. Granada se representa como el lugar de nacimiento, asiento de las veredas de las que son oriundos muchos de los ausentes o aquel adonde llegaron las familias tras un matrimonio o un trabajo. Para los visitantes que se expresan en los libros - en los que el número de veces que se usa el nombre del pueblo es muy superior: $376-$, Granada se presenta como un lugar digno de reconocimiento:

Granada que valientes son, recordar momentos como esto no es fácil y mas aún plasmarlos con imágenes y pensamientos. Luego de ese tormentoso momento me encuentro con grandes seres humanos, capaces de reconstruir, perdonar y sembrar AMOR.

Dios permita que sigan adelante. JAU 11-08-12 (Libro de visitas 2, entrada 86)

Cuando lo que se dice es "pueblo" y, en especial "pueblito”, la relación que se marca parece ser más entrañable, tanto en las bitácoras como en los libros de visitas. El "pueblito" es el lugar de la nostalgia, al que se pertenece y fue mancillado, el que se espera que pueda resurgir en la grandeza que tuvo para quienes lo habitaron en tiempos mejores y sobre el que se clama que no recaigan más males y violencia: "Estube en el salón de nunca mas y no sabia que existia me quede aterrado de ver como había quedado el pueblito donde nacimos cresimos y estan todos nuestros familiares muertos" (Libro de visitas 1, entrada 568).

Si la relación con el pueblo es entrañable, la que se ha establecido con el Salón del Nunca Más como sitio de conmemoración comparte, además de

74 Para establecer las asociaciones de palabras, además de los que se dedujeron de la lectura en profundidad, se recurrió a la herramienta de "Concordancia" del software AntConc, que permite visualizar en un listado el contexto de aparición de los términos clave que se buscan. 
esta característica, componentes de gratitud y admiración. El Salón se concibe como un espacio en el que siguen habitando los ausentes, a quienes se visita allí con mayor frecuencia y agrado que como se hace con aquellos que tienen tumbas en el cementerio. Esta apreciación nace tanto de comentarios realizados por las mujeres guía del Salón en algunas de los recorridos que observamos, como de una entrevista realizada con una joven para quien es mucho mejor acudir a un lugar donde ve fotos de sus seres queridos sonrientes y vitales que al cementerio, con su frialdad y con sus lápidas. En el caso de los desaparecidos, la importancia del Salón es aún mayor, pues es el único espacio en el que pueden encontrarse simbólicamente con ellos y expresarles su dolor, su incertidumbre, su esperanza.

Mención aparte merecen las numerosas referencias a los lugares que se asumen como habitados por los muertos, tanto víctimas como victimarios. En evidente asociación con las creencias religiosas compartidas por el grueso de la población granadina, el cielo, el paraíso, el más allá, "la eternidad", pero también lugares de castigo como el purgatorio o el infierno son nombrados una y otra vez en las bitácoras y en los libros de visitas. Las primeras referencias suman, entre todas, 445 apariciones y están cargadas de connotaciones positivas, representan un lugar mejor, sin sufrimiento, desde el cual el ser querido puede ver y escuchar lo que pasa en la tierra, así como interceder por los vivos. Sólo en dos ocasiones se imagina al familiar en el sitio de expiación y purificación del alma que representa el purgatorio en la religiosidad cristiana, con lo cual queda en evidencia que la muerte violenta se torna para los escribientes en una razón de suficiente peso como para que su ser querido haya accedido directamente al paraíso.

En el caso del infierno, lugar de castigo para quienes cometen pecados imperdonables, es mencionado en tres ocasiones, todas ellas indicando que es el lugar donde están o deberían estar aquellos que perpetraron los actos de violencia que culminaron con la pérdida del ser amado: “[...] papa el que te haiga matado Dios se lo llevara para el infierno (Bitácora 075DEHA, entrada 6)". Es claro que el cielo y el infierno marcan una distinción entre "ellos" y "nosotros", "buenos" y "malos", "víctimas" y "perpetradores" "lugares malditos" y "lugares sagrados", si bien el claro desbalance entre las menciones (445 frente a 3, en las bitácoras) permite inferir que para los familiares es mucho más importante recordar, honrar y mantener el contacto con sus ausentes que culpar o señalar a los responsables de los eventos de la guerra. En la tabla 1 se presenta una síntesis de las representaciones de lugar. 
Tabla 1. Síntesis de las representaciones de lugar

\begin{tabular}{|c|c|c|c|}
\hline & & Bitácoras & Libros de visitas \\
\hline \multirow{3}{*}{ Mundo } & Este mundo & 70 & 8 \\
\hline & Otro mundo & 4 & 0 \\
\hline & "del mundo" & 56 & 14 \\
\hline \multirow{7}{*}{ Contexto nacional } & Colombia & 2 & 96 \\
\hline & País & 12 & 52 \\
\hline & Sociedad & 3 & 29 \\
\hline & Granada & 31 & 376 \\
\hline & Pueblo & 32 & 368 \\
\hline & Pueblito & 2 & 3 \\
\hline & Municipio & 10 & 90 \\
\hline \multirow{5}{*}{ Salón del Nunca Más } & & & \\
\hline & Salón del Nunca Más & 3 & 41 \\
\hline & Salón: el, este & 7 & Pendiente \\
\hline & Este lugar, este sitio, aquí & 31 & Pendiente \\
\hline & Salón del Nunca Jamás & 3 & 8 \\
\hline \multirow{6}{*}{ Lugares imaginados } & Cielo & 383 & 11 \\
\hline & Paraíso & 8 & 3 \\
\hline & Más allá & 7 & Pendiente \\
\hline & Eternidad, eterno descanso & 47 & 6 \\
\hline & Purgatorio & 4 & 0 \\
\hline & Infierno & 3 & $1^{*}$ \\
\hline $\begin{array}{l}\text { Lugares de la } \\
\text { incertidumbre }\end{array}$ & $\begin{array}{l}\text { Donde estés, donde sea que estés, } \\
\text { donde quiera que estés }\end{array}$ & 135 & 0 \\
\hline
\end{tabular}

* La única mención al infierno en los libros de visita es metafórica: no el lugar de castigo cristiano sino una forma de referirse a la barbarie de la guerra: "Felicitaciones! por sensivilizar nuestros corazones y que nunca jamas se vuelba a tal infierno de guerra absurda" (Libro de visitas 2, entrada 558). Elaboración propia

\subsubsection{Representaciones de actores}

El tipo de actores, los "personajes" que figuran en las bitácoras son principalmente los ausentes, aquellos de y a quienes se habla, cuya representación está signada por la nostalgia y responde a las características propias de la evocación de los muertos amados, en la que se privilegian los rasgos de bondad, de nobleza, de apoyo y compañía, cuya pérdida ha vuelto la vida más difícil y más triste. Aunque entre las cosas que se cuentan sea posible leer una continuidad de la vida, con segundas nupcias, nuevos nacimientos, instalación - muchas veces forzosa - en otras ciudades, los mensajes dejan claro que, por más tiempo que haya pasado, el recuerdo triste y punzante 
de los que perecieron a causa de la guerra sigue ocupando un lugar central en la existencia. Un rasgo importante dentro de las representaciones de los ausentes es la frecuencia con la que les escriben hijos, nietos, sobrinos, primos y hasta amigos de los familiares que, aunque no los conocieron, tienen una nítida imagen de ellos que han construido a través de las historias que les cuentan.

Otra característica de las representaciones de actores, que está en perfecta consonancia con lo que vimos en las representaciones de suceso, es que los miembros de grupos armados son escasa y genéricamente mencionados, sin que la pertenencia concreta a uno u otro grupo (legal o ilegal) parezca relevante. Una niña, por ejemplo, le escribe a su padre - asesinado en una masacre paramilitar tres meses antes de que ella naciera-: "[...] los que te separaron de mí fueron los de la guerra..." (Bitácora 001IDAD, entrada 6). Otros se refieren a "esos malos", al genérico "guerrilla", sin especificar si es la de las FARC o la del ELN, o al conflicto armado: "Lastimosamente los conflictos Armados te llevaron a un abismo del cual jamas te volveremos haber..." (Bitácora 006FHG, entrada 4$)^{75}$. Las alusiones a los actores armados, además de ser inespecíficas, son poquísimas: la guerrilla es mencionada dos veces en uno de los libros de visitas, los paramilitares (bajo la expresión "paracos") una sola vez en la bitácora 036MGL, "los malos" y "los de la guerra", menos de diez veces en ambos formatos; en una ocasión (bitácora 014JHR) se habla de "señores de la muerte" y en otra (bitácora 023HEQR) de "los (h)omicidas".

En contraste con lo anterior, dios, la virgen, los ángeles, los santos y, en general, una serie de expresiones religiosas fuertemente ancladas en el catolicismo, son copiosas ${ }^{76}$ y sirven tanto como manifestación de resignación o aceptación de un destino que se asume como inevitable, por ejemplo: "...me gustaría mas que tu estuvieras aquí pero pá no te preocupes Que si Dios lo quiso asi es porque tenia que ser" (Bitácora 186JOGP, entrada 1); también para expresar consuelo o hasta regocijo porque la persona que perdió la vida se encuentra en un lugar mejor, deseable incluso desde la perspectiva de quienes habitan todavía "el valle de lágrimas" que es la vida terrena.

75 En las transcripciones de los textos se conserva la forma de escritura original, sin realizar ningún tipo de corrección lexicogramatical.

76 Sirva como ilustración el hecho de que Dios es nombrado en 117 de las 233 bitácoras analizadas, con un total de 976 menciones. Esto lo convierte en la palabra más usada en todas las bitácoras. 


\subsubsection{Representaciones temporales}

Los modos en que se representan el pasado, el presente y el futuro pueden caracterizarse del siguiente modo: un pasado feliz que contrasta con un pasado trágico, perceptible en expresiones tales como "cuando estabas" (referida a un pasado en que el ausente aun hacía parte de la vida) y "desde que te mataron" (que habla del momento en el que dejó de estar). El presente es un tiempo protagónico, pues una gran proporción de los textos se dedican a describir cómo son las cosas en el momento de la enunciación. En cuanto al futuro, sobresalen los anhelos basados en las creencias religiosas: reunión con el ser querido en el cielo o el paraíso; esperanza en un mundo sin tanta violencia.

Aunque las narraciones hagan referencia constante a hechos del pasado no tienen que ver exclusivamente con este sino que dan cuenta de cómo se percibe ese pasado desde el presente en que alguien lo cuenta y, en muchas ocasiones, también con el futuro imaginado, deseado o, incluso, con anhelos imposibles que buscan darle existencia así sea en el relato a unas formas de vida que habrían sido probables si la guerra no hubiera hecho parte de los sucesos vitales de estas familias y este pueblo. En este sentido, el modo verbal del subjuntivo, que expresa deseos, cosas posibles pero condicionadas, es la marca más evidente. Su forma de presentación más usual se da mediante el empleo del hubiera, con el que se formulan una amplia gama de deseos y expectativas acerca de cómo podría haber sido la vida sin los eventos de la guerra:

Querido suegro aunque no tuve la oportunidad de conocerte me huviera encantado pero yo se que donde quiera que te encuentres estas orgulloso de la nieta que tienes hubiera sido maravilloso que huvieras concido a tu nieta y me huviera encantado conocerte y compartir muchisimo tiempo con tigo.

En el caso de las personas desaparecidas, el subjuntivo es el lugar de una esperanza dolorosa: la de encontrar, al menos, los restos del ser querido: "Hija demicorazon nunca teolvido ciempre te lleva en mi corazon nunca descansare asta que tenga mis huesitos tullos en campo santo. hija te recuerdo acada momento a toda hora [...]" (Bitácora 074DMPN, entrada 2).

Por otra parte, la bitácora también sirve para llevar la cuenta de los años de ausencia, así como para conmemorar las fechas especiales: aniversarios de boda, cumpleaños, nacimientos. Es un repositorio que guarda las marcas de lo que importa. 


\subsubsection{Representaciones de actos}

Desde un punto de vista descriptivo, podemos identificar, de acuerdo con la teoría de los actos de habla de Searle (1990), una serie de enunciados en los que se reconocen acciones concretas. Decir algo es, al mismo tiempo, hacer algo, y aquello que nos da la posibilidad de reconocer qué es lo que hacen los emisores al decir algo, se conoce como fuerza ilocutiva. Searle distingue cinco tipos de actos de habla de acuerdo con la intencionalidad de quien produce un enunciado: a) representativos: describen estados de cosas del mundo. El hablante se compromete con la veracidad: aseverar, concluir, reclamar; b) directivos: buscan que el receptor haga algo: ordenar, pedir, solicitar, rogar, preguntar...; c) comisivos: comprometen al emisor a hacer algo: prometer, hacer votos, jurar, invitar...; d) expresivos: dan cuenta del estado psicológico de quien habla: agradecer, pedir disculpas, felicitar, condolerse, etc.; y e) declarativos/realizativos: con el que se identifican secuencias de palabras que cambian un estado de cosas en el mundo: bautizar, despedir a alguien de un trabajo, declarar la paz o la guerra. Su posibilidad de realización depende del lugar simbólico del hablante y de que se den las condiciones apropiadas.

Dependiendo del tipo de escribiente que se analice, además del propósito discursivo particular que esté procurando cumplir, se realizan cuatro de los cinco tipos de acto de habla mediante una amplia gama de verbos/acciones, tal como se muestra en la tabla 2.

La gama más amplia de actos desplegados la encontramos en aquellos que se agrupan como expresivos, lo que se deja ver la imponente emocionalidad que se juega en los intercambios posibilitados por las bitácoras, aun si estos se dan en diferido (entre los escribientes y lectores visitantes) o son intercambios truncados (entre los escribientes y el destinatario, imposibilitado para leer y para responder).

\subsubsection{Representaciones valorativas}

Este tipo de representaciones se encuentra vinculado a las ideologías, las creencias y las actitudes asumidas por las personas respecto de su propia experiencia y realidad. La ideología dominante, como se ha hecho evidente, es la de la religiosidad católica. Esta permea los propósitos de quienes lo administran y encuentra en las bitácoras una vía para expresarse y mostrarse ante los ojos de los visitantes, que son tanto habitantes del pueblo como gente llegada de otras ciudades y países. La resignación, más que el perdón, es lo que se percibe en las alusiones religiosas, así como la asunción 
Tabla 2. Actos representados en las bitácoras

\begin{tabular}{|l|l|l|}
\hline \multicolumn{1}{|c|}{$\begin{array}{c}\text { Tipo de } \\
\text { participante }\end{array}$} & $\begin{array}{c}\text { Propósito discursivo } \\
\text { que cumple }\end{array}$ & Tipos de acto de habla que realiza \\
\hline $\begin{array}{l}\text { Familiar / Visitante } \\
\text { cercano (amigo, } \\
\text { vecino...) }\end{array}$ & $\begin{array}{l}\text { Elaboración de un pasado } \\
\text { violento (duelo y resignificación) }\end{array}$ & $\begin{array}{l}\text { Expresivos: } \\
\text { extrañar, recordar, acongojarse, sentir rabia/tristeza, } \\
\text { aceptar, desear, lamentar, rechazar, reflexionar, } \\
\text { añorar, agradecer, reconocer, desahogar, culpar... } \\
\text { Directivos: } \\
\text { pedir, rogar, preguntar, solicitar... }\end{array}$ \\
\hline Familiares & $\begin{array}{l}\text { Creación y conservación del } \\
\text { vínculo afectivo con el sujeto } \\
\text { de la bitácora }\end{array}$ & $\begin{array}{l}\text { Comisivos: } \\
\text { prometer, jurar... } \\
\text { Expresivos: } \\
\text { presentarse, empatizar, }\end{array}$ \\
\hline Familiares & $\begin{array}{l}\text { Información de los sucesos } \\
\text { familiares relevantes }\end{array}$ & $\begin{array}{l}\text { Representativos: } \\
\text { informar, dar a conocer, contar... }\end{array}$ \\
\hline $\begin{array}{l}\text { Visitantes cercanos, } \\
\text { visitantes lejanos }\end{array}$ & Expresión de pesary solidaridad & $\begin{array}{l}\text { Expresivos: } \\
\text { condoler, comprender, reconocer, solidarizarse, } \\
\text { afligirse, cuestionarse... } \\
\text { Directivos: } \\
\text { pedir, rogar, preguntar, solicitar... }\end{array}$ \\
\hline $\begin{array}{l}\text { Familiares, visitantes } \\
\text { cercanos, visitantes } \\
\text { lejanos }\end{array}$ & $\begin{array}{l}\text { Búsqueda de favores divinos y } \\
\text { protección }\end{array}$ & $\begin{array}{l}\text { Directivos: } \\
\text { pedir, rogar, solicitar, suplicar... }\end{array}$ \\
\hline
\end{tabular}

de que el muerto se halla en una mejor condición y tiene la posibilidad de interceder por los vivos.

Además de las actitudes señaladas, la ideología dominante se expresa también en el tipo de creencias y conocimientos que se revelan en los textos, asociados en su inmensa mayoría a la fe en una vida ulterior que explica además la aparente certeza que tienen quienes escriben de que sus mensajes son recibidos, escuchados, por sus seres queridos. La bitácora se asume como un medio a través del cual se habla con los ausentes y, en consonancia con esto, hay formas de dirigirse a los sujetos de la bitácora de manera directa, como si se diera por sentado que los mensajes van a ser leídos por ellos, o despedidas en las que se dan las gracias por haber escuchado:

Hola hermano terrecuerdo mucho sufruo mucho su ausiencia tepido que desdel el cielo estes rrogando por tus padres y hermanos te pido que rueges por todas tu familia gracias hermano te que remos mucho y lastima que se nos fue anque yo note pude conocer se que tus [ves] lo que te estoy copiando yege a tu corazón hermanochao hermano a te queremos mucho con todo el corazón (Bitácora 073DJAN, entrada 1). 
En cuanto a las reacciones y valoraciones que buscan provocarse en los visitantes encontramos que, desde las fotos que le dan rostro a los muertos y desaparecidos (estrategia por lo demás generalizada en memoriales alrededor del mundo) hasta el tipo de escritos que se encuentran en las bitácoras y son elegidos para leerse en voz alta, hay una búsqueda por generar una reacción emocional, de compasión y solidaridad con lo que, más allá de dar información precisa acerca de los acontecimientos históricos, se revela un propósito por insistir en la dimensión humana y personal de las consecuencias de la guerra.

\subsection{Discusión}

Aunque en un principio se pretendían identificar las representaciones acerca del conflicto armado, que pudieran ser extraídas de la lectura en profundidad de las bitácoras, ese mismo procedimiento reveló que hay otros asuntos que son de gran relevancia para la población granadina, formando parte de sus representaciones sociales vinculadas a la guerra, aun si no se refieren directamente a la guerra misma. De hecho, esa fue una de las revelaciones más llamativas: la guerra no es el asunto central acerca del cual se habla en las bitácoras. Es la causa, la razón detrás de los escritos, lo que da pie a la existencia de esa intimidad pública pero, como suceso representado, es difuso.

Un hecho que puede influir en esta característica de la representación difusa de la guerra lo encontramos en el discurso que acompaña las visitas guiadas al Salón. Las mujeres que han estado vinculadas a él desde el principio usan recurrentemente una palabra (que es común en los grupos de víctimas del país): dignificar. Cuando explican a qué se refieren aluden a que una de las funciones del lugar es que se conozcan las verdaderas historias de los que ya no están (por muerte o desaparición), a que se limpien sus nombres $^{77}$. La apuesta, según ellas, ha sido por un trabajo de dignificación en el que el dolor es lo compartido, más allá de que algunas de las personas a las que allí se conmemora hayan tenido una vinculación directa con los grupos armados que se disputaron el control del municipio. No se trata, por tanto, de una memoria militante, y en esto son enfáticas quienes realizan las guías:

Nosotros acá estamos dignificando a esas personas... o sea, acá no se permite que alguien venga y señale alguno de esos rostros que hay

77 Inforiente. «Salón del Nunca Más, dolorosamente hermoso para recordar la guerra». Acceso el 3 de febrero de 2017. http://www.verdadabierta.com/despojo-de-tierras/2624-salon-delnunca-mas-dolorosamente-hermoso-para-recordar-la-guerra 
ahi. ¿Qué este era esto o aquello? Qué pena, era un ser humano. No tenemos derecho nosotros a decir nada ${ }^{78}$.

¿Nos encontramos, entonces, ante una experiencia "despolitizada"? ¿O pueden rastrearse otras formas de vérselas con lo social y lo político -tal vez desde una perspectiva micro-? Para Blair (2011), el terreno de la memoria y la subjetividad, en especial en las prácticas no oficiales de la memoria, hacen parte de una "política alternativa", alejada del Estado y sus grandes procesos. El poder así descentrado "se concibe como un poder en red, atravesando la vida social" (Blair, 2011, p. 23), y lo político de esas memorias "se expresa en lugares y en espacialidades diferentes, más cercanas, más familiares, más vecinales, más cotidianas (esto es, más micro) donde también se construyen relaciones de poder y desde las cuales se pueden entonces, organizar acciones de resistencia" (Blair, 2011, 23).

Con base en ese planteamiento, puede pensarse que la apuesta "política" del Salón no apunta tanto a establecer divisiones entre víctimas y victimarios concretos como a promover la reconciliación y el rechazo unánime a la guerra a partir del énfasis puesto en el dolor y la destrucción que los afectó a todos. De ese modo, lo que se privilegia (por encima de intereses ligados a grupos o partidos que juegan en la gran política tradicional) es la posibilidad de restablecer los lazos de convivencia cotidiana, propósito que puede considerarse del orden de lo micropolítico en los términos planteados por Blair.

Lo anterior es una manifestación que confirma y complementa el hallazgo de Moreno, Carmona y Tobón (2010) y el grupo de estudios reseñados en su artículo, según el cual la apatía por lo político (tradicional) y lo ideológico (de los movimientos armados) es un rasgo común entre infantes y adultos excombatientes desmovilizados de grupos armados ilegales. Encontramos aquí que tal apatía es compartida también por población víctima no combatiente. Tal característica, que parece ser un rasgo común en amplias colectividades del país, torna particularmente relevantes las reflexiones de Ospina-Alvarado, Alvarado y Fajardo (2018, p. 32), según las cuales:

“[...] la socialización política abarca aquellos procesos que le permiten a los sujetos constituirse como humanos, participar en la construcción y deconstrucción del mundo de significados y transformar las prácticas relacionales que se están tejiendo con el otro, con la otra y con lo otro [...]”.

78 Gloria Quintero, entrevista por Marda Zuluaga, 13 de enero de 2017. 
Es importante resaltar que, si bien la lectura de los textos confirma que no se realizan señalamientos relativos a la pertenencia política o eventuales militancias de personas representadas por las bitácoras, las creencias religiosas atribuidas a uno u otro actor político sí se vuelven determinantes a la hora de elegir representantes de gobierno local o nacional, o apoyar iniciativas en las que participan organizaciones de izquierda, como el caso de los Acuerdos de paz con la guerrilla de las FARC. La influencia de la ideología religiosa sobre el ejercicio de lo político aun en la actualidad es un asunto que merecería mayor profundización, poniéndolo en relación con los procesos históricos de la lucha interpartidista que caracterizaron el período de La Violencia, en los cuales las posturas de los clérigos ejercieron también un fuerte influjo sobre la población (Bushnell, 1994). La construcción de paz como señalan Ospina-Alvarado et al. (2018) pasa por lograr trascender los modelos de socialización y educación en los que no se desarrolla una perspectiva crítica en los ciudadanos, por lo cual es preciso reconocer y ampliar las experiencias basadas en las pedagogías críticas y de educación popular:

Estos nuevos espacios no tienen nada que ver con los positivismos que han generado el temor a la nota y a la evaluación; se trata de procesos transitorios y en permanente cambio; no es una mirada final, no es la mirada de la teleología religiosa [...] (Ospina-Alvarado et al., 2018, p. 229)

El silencio, la omisión, las alusiones sutiles no son cosa solamente de las bitácoras. En una conversación que sostuve con una adolescente que escribió mucho, cuando era niña, en las bitácoras de su padre y varios tíos a los que no alcanzó a conocer, me decía que la muerte de todos ellos es un tema del que casi no habla con su madre y con sus hermanas. Tampoco suele comentarlo con los pocos amigos que refiere tener. Para ella, es un hecho central, que evoca constantemente y que, en sus palabras "la marcó", pero el dolor que le produce es tanto que lleva una vida entera optando por el silencio. Tal silencio y la toma de distancia pueden verse como formas de "gestionar" su propio sufrimiento, lo indecible, en términos de Pollak (2010[1986]). Desde la perspectiva de Ortega (2008, p. 46), “[...] esos silencios no son producto de memorias reprimidas que habitan el inconsciente ni constituyen rupturas en la capacidad expresiva del lenguaje. Son, ante todo y por muy paradójico que parezca, apropiaciones del dolor y estrategias de agenciamiento".

La escasez - casi ausencia- de referencias concretas a la guerra abre interrogantes respecto a los efectos sobre los sujetos de una exposición 
constante a ella: ¿hay temores tan afincados tras las décadas de confrontación entre distintos grupos que las personas siguen optando por el silencio como forma de protección? ¿Puede tratarse de una naturalización del fenómeno que vuelve de cierto modo innecesario nombrarlo, en tanto es un supuesto básico que se asume como compartido? ¿Es reflejo de una falta de formación histórica y política que hace parte de las lógicas mismas de la guerra y la postura que ha asumido el estado colombiano durante la mayor parte de la misma? (Zuluaga, 2015). Son asuntos que quedan abiertos y que requerirían otro tipo de aproximaciones para lograr una mayor comprensión de un fenómeno cuyas causas y consecuencias seguirán siendo objeto de interés en un país que parece no poder escapar a una y mil versiones de la guerra.

\section{Referencias}

Blair, E. (2011). Micropoliticas de la(s) memoria(s): El sentido político de la dignidad. Desde la Región, 54, 19-30.

Bolívar, A. (2007). El análisis interaccional del discurso: del texto a la dinámica social. En A. Bolívar (Comp.) Análisis del Discurso. Por qué y Para qué. Caracas: Los Libros de El Nacional.

Bolívar (Comp.) Análisis del Discurso. Por qué y Para qué. Caracas: Los Libros de El Nacional.

Bruner, J. [2002] (2013). La fábrica de historias. Derecho, literatura, vida. Buenos Aires: Fondo de Cultura Económica.

Bushnell, D. (1994). Colombia: una nación a pesar de sí misma. De los tiempos precolombinos a nuestros dias. Bogotá: Planeta.

Centro Nacional de Memoria Histórica. (2016). Memorias de guerra, resistencia y reconstrucción. Bogotá: CNMH - Colciencias - Corporación Región.

Centro Nacional de Memoria Histórica. (2014). Salón del Nunca Más, Granada, Antioquia. Arcadia. Disponible en: http://www.revistaarcadia.com/impresa/especial/articulo/tressalon-del-nunca-mas-granada-antioquia/39006

Inforiente (5 de agosto de 2010). Salón del Nunca Más, dolorosamente hermoso para recordar la guerra. Verdad abierta. Recuperado de: http://www.verdadabierta.com/despojode-tierras/2624-salon-del-nunca-mas-dolorosamente-hermoso-para-recordar-la-guerra

Jelin, E. (2002). Los trabajos de la memoria. España: Siglo XXI.

López Franco, S. (2016). Discurso y cognición. Modelos mentales. Material de trabajo para cursos de posgrado. Inédito.

Moreno Marín, F., Carmona Parra, J.A., Tobón Hoyos, F. (2010). ¿Por qué se vinculan las niñas a los grupos guerrilleros y paramilitares en Colombia? Revista latinoamericana de Psicología 42(3), 456-467. 
Moscovici, S. (1961). El psicoanálisis, su imagen y su público. Buenos Aires: Huemul.

Nieto, P. (2013). Relatos autobiográficos del conflicto armado en Colombia. El caso reciente de la ciudad de Medellín. (Tesis de Doctorado). Universidad Nacional de La Plata, La Plata, Argentina. Disponible en: http://sedici.unlp.edu.ar/handle/10915/30199

Ochs, Elinor. (2000) Narrativa. En: Van Dijk, T.A. (Comp.). El discurso como estructura y como proceso. Barcelona: Gedisa.

Ospina-Alvarado, M. C., Alvarado, S. V. y Fajardo, M. A. (2018). La niñez en contextos de conflicto armado comprendida desde el construccionismo social, la socialización política y las perspectivas alternativas del desarrollo humano: apuesta epistemológica desde el sur. En: M. C., Ospina-Alvarado, S. V., Alvarado, J. A., Carmona y A., Arroyo Ortega (eds.). Construcción social de niñas y niños en contextos de conflicto armado: narrativas generativas para la construcción de paz. pp. 29-59. Bogotá: Universidad Pedagógica Nacional; Fundación Centro Internacional de Educación y Desarrollo Humano CINDE; Manizales: Universidad de Manizales; Bogotá: Colciencias.

Ospina-Alvarado, M. C., Alvarado, S. V., Ospina, H. F., Ramírez, M. P., Fajardo, M. A., Urrego, A. M., Sánchez, M. C. (2018). Procesos de construcción de paz, democracia y reconciliación con niñas y niños en contextos de conflicto armado. En: M. C. OspinaAlvarado, S. V. Alvarado, J. C. Carmona y A. Arroyo Ortega (eds.) Construcción social de niñas y niños en contextos de conflicto armado: narrativas generativas para la construcción de paz. pp. 199-311. Bogotá: Universidad Pedagógica Nacional.

Ramírez, C. A., Lopera, J. D., Zuluaga, M., y Ortiz, J. (2017). El método analítico: Formalización teórica. Bogotá: San Pablo-EAFIT.

Ricoeur, P. (2006). La vida: un relato en busca de narrador. Ágora Papeles de Filosofía 25(2), 9-22.

Searle, J. (1990). Actos de habla. Ensayos de filosofía del lenguaje. Barcelona: Cátedra.

Tamayo Gómez, H. (2013). Desde el Salón del Nunca Más. Crónicas de desplazamiento, desaparición y muerte. Medellín: El propio bolsillo.

Van Dijk, T. A. (1980). Estructuras y funciones del discurso. México: Siglo XXI.

Van Dijk, T. A. (1997). Discurso, cognición y sociedad. Signos. Teoría y práctica de la educación, 22, 66-74.

Van Dijk, T. A. (2012). Discurso y contexto. Un enfoque sociocognitivo. Barcelona: Gedisa.

Zuluaga Aristizábal, M. (2015). ¿Y cómo es posible no saber tanto? Tensiones y vicisitudes en la reconstrucción oficial de la memoria histórica del conflicto armado en Colombia. Medellín: Eafit. 


\title{
20. Representaciones sociales del enemigo como barreras psicosociales para la construcción de la paz y la reconciliación en Colombia
}

\author{
JuAn DaVid VILla GómeZ ${ }^{79}$ \\ Resumen
}

El presente texto se enmarca en una investigación más amplia, denominada "Barreras psicosociales para la paz y la reconciliación en Medellín y tres municipios de Antioquia". Para este capítulo se tomaron 43 entrevistas en profundidad, a participantes de la ciudad de Medellín. Desde el enfoque hermenéutico, se hizo un análisis del discurso, en el marco de la investigación cualitativa. Después del análisis intra e intertextual y la codificación teórica de primero y segundo nivel, se constituyeron las categorías de análisis, presentando en este texto: las representaciones sociales del enemigo; analizada desde la Psicología social crítica, identificando lo ideológico y construcciones psicosociales que constituyen barreras para la construcción de la paz. Se han identificado y comprendido discursos, según su posición frente al proceso de negociación del conflicto armado entre el gobierno colombiano y las FARC (acuerdo, desacuerdo y ambivalente). Algunos (participantes en desacuerdo) construyen un enemigo absoluto (FARC), al que se atribuyen todos los males y un estatuto identitario de inhumanidad, por lo que no sería posible ni permisible una negociación con él. Mientras que se minimiza la acción de los paramilitares y se exalta la de la Fuerza Pública. Otros (participantes de acuerdo) representaban de manera más incluyente y humana a este adversario, legitimando algunos de sus objetivos e intereses, lo que hace posible negociar con ellos.

Palabras Clave: representaciones sociales, conflicto armado, paz, Psicología social crítica, barreras psicosociales para la paz.

79 Universidad Pontificia Bolivariana, Medellín. Correo: juan.villag@upb.edu.co 


\section{Abstract}

This text is part of a broader research called "Psychosocial barriers for peace and reconciliation in Medellin and three municipalities of Antioquia" For this chapter, 43 in-depth interviews were taken, from participants in the city of Medellin, conducting a discourse analysis from the hermeneutic approach, within the framework of qualitative research. After the intra and intertextual analysis and the theoretical coding of first and second level, the categories were constituted. For this text we present the category of social representations of the enemy, analyzed from critical social psychology that identifies ideological elements and psychosocial constructions that constitute barriers for the construction of peace. The discourses have been identified and understood according to their position regarding the negotiation process of the armed conflict between the Colombian government and the FARC (agreement, disagreement and ambivalence). Some (participants in disagreement) build an absolute enemy (FARC), to which are assigned all the evils and an identity statute of inhumanity, so it would not be possible or permissible to negotiate with him. While the action of the paramilitaries is minimized, and the action of the Public Force is exalted. Anothers (participants in agreement) represented in a more inclusive and humane manner this adversary, legitimizing some of its objectives and interests, which makes it possible to negotiate with them.

Keywords: Social representations, armed conflict, peace, social critics psycologhy, Psychosocial barriers for peace.

\subsection{Introducción}

El presente texto, se inscribe en un proceso de investigación más amplio, realizado por el área de Psicología social de la Universidad Pontificia Bolivariana (Grupo de Investigación en Psicología: sujeto, sociedad y trabajo) y de la Universidad de San Buenaventura (Grupo de estudios clínicos y sociales en Psicología), denominado "Barreras psicosociales para la construcción de la paz y la reconciliación en Medellín y tres municipios de Antioquia"; que pretende indagar sobre la forma como en la sociedad civil colombiana se han construido estas barreras, que contribuyen a una historia de intentos parciales y/o fallidos de construcción de paz en Colombia. Se analizaron 43 entrevistas en profundidad a diversos participantes de la ciudad de Medellín sobre sus representaciones sociales en torno al conflicto armado, los actores armados y el proceso de negociación entre el gobierno de Juan Manuel Santos y las Fuerzas Armadas Revolucionarias de Colombia (FARC). 
De acuerdo con Galtung (2003), el cese al fuego, el desarme y desmovilización de un grupo armado no siempre llega a feliz término; es apenas uno de los pasos para construir paz. El riesgo de reactivación del conflicto está latente, especialmente, durante los primeros 5 años, luego de firmado el acuerdo; en ciertos contextos, fácilmente puede convertirse en el "antes de una nueva violencia". Sobre todo, cuando no se atienden dimensiones fundamentales que le subyacen: la violencia estructural y la violencia cultural, que no desaparecen tras la firma de un tratado y pueden ser factores para el resurgimiento de la confrontación armada. Sería ingenuo creer que, con la firma del acuerdo, se obtendría la paz y la reconciliación (Cogollo Ospina y Durán Palacio, 2015).

El conflicto palestino-israelí, las tres guerras de los Balcanes en los años 90, el caso de Ruanda y otros países africanos; o la degradación de las violencias en Centroamérica, evidencian los riesgos de no abordar las dimensiones estructurales y culturales que subyacen al conflicto armado (Blanco $\&$ de la Corte, 2003; Maoz \& Eidelson, 2007). En el caso específico de la violencia cultural, es fundamental atender a las representaciones sociales, significados, imaginarios, simbología, mitos, tradiciones, discursos construidos que pueden legitimar la violencia directa como medio para dirimir los conflictos. En muchos casos, discursos políticos de algunas élites en el poder intentan construir imaginarios que sean favorables al mantenimiento del conflicto y a la eliminación del adversario para lograr una supuesta estabilidad (Bar-Tal, 2013).

Así, se construyen estrategias de manipulación e ideologización, fomentando la mentira institucionalizada, desarrollando campañas de propaganda y desinformación que polarizan la población, ocultando intereses y motivaciones reales que subyacen al conflicto (Martín-Baró, 1989). De acuerdo con diversos autores, este tipo de proceso psicosocial tiene como objetivo conquistar la mente y el corazón de la sociedad civil y erigir una opinión pública que legitime y justifique la violencia (Martín-Baró, 1989; Blanco \& De la Corte, 2003; Correa, 2006, 2008; Borja, et. Al. 2009; Cárdenas, 2013).

En este proceso se parte de la manipulación del miedo, la incertidumbre y la vulnerabilidad; puesto que se va construyendo una amenaza hostil. Es decir, un enemigo que encarna todos los males y el riesgo de destrucción de identidades, estilos de vida, valores y tradiciones; razón por la cual, se justifica su eliminación y la continuación del conflicto. No obstante, para dicha justificación, es necesario que, a ese 'otro', devenido enemigo demonizado, se le niegue su subjetividad humana; presentándolo como objetivo a erradicar; lo que termina cerrando cualquier posibilidad de diálogo, 
legitimando el uso de la violencia contra él (Blanco \& De la Corte, 2003; Blanco, 2007; Korstanje, 2014).

De acuerdo con Daniel Bar-Tal (1998, 2010, 2013, 2017), se construyen bases cognitivas y epistémicas que proveen explicación, racionalización, legitimación y justificación para metaobjetivos de élites sociales y políticas, para las cuales el conflicto armado es funcional. Constituyendo narrativas que proporcionan una historia coherente acerca de la secuencia histórica y la experiencia colectiva del conflicto, enfocando en un grupo externo al propio todas las responsabilidades de los sufrimientos padecidos y la amenaza a la sociedad; se enfatiza en la sobrevivencia del grupo, que se asume como vocero y representante de todos, utilizando convicciones morales que movilizan una buena parte de la población y crean una conciencia social hegemónica para definir el futuro y mantener un orden social establecido.

Se trata, entonces, de la construcción de marcos de significado y representaciones sociales, desglosadas en narrativas colectivas del pasado, creencias sociales y orientaciones emocionales colectivas, que están a la base de la deshumanización y polarización social que obturan posibilidades de paz. (Blanco \& De la Corte, 2003; Bar-Tal, 2010, 2013). Los sujetos son efectivamente manipulados por esta desinformación y propaganda, que configura representaciones que incitan a diferencias irreconciliables; de tal manera que, al exacerbar emociones colectivas de odio, miedo, vulnerabilidad, incertidumbre, ira y rabia, se limitan las posibilidades de abrir escenarios propicios para la paz (Correa, 2006, 2008; Bar-Tal \& Halperin, 2011; Halperin \& Bar-Tal, 2014).

Bar-Tal (1998, 2013), Correa (2006, 2008); Cárdenas (2013) y Bekerman \& Zembylas (2010), afirman que medios de comunicación y, en los últimos tiempos, redes sociales (Marín y Quintero, 2018) juegan un papel clave en decisiones sociales y políticas que pueden implicar la prolongación de conflictos; puesto que exacerban estrategias de ideologización que contribuyen a la generación y fortalecimiento de climas emocionales de odio e ira y a la circulación de narrativas y representaciones que fortalecen la imagen de enemigo absoluto: deshumanizado en su condición y deslegitimado en sus aspiraciones (Blanco, 2007; Angarita, et al., 2015, Gallo, et al., 2018). Al mismo tiempo, los objetivos del propio bando son percibidos y valorados como justos y esenciales, desde una dimensión moral, reivindicando una posición de víctimas, desde la que intentan garantizar protección ante una inseguridad real o percibida. De allí que estos discursos demanden unidad y homogeneidad en torno a la patria, como una falacia de paz que se consuma con la salida de escena del adversario (Bar-Tal, 1998, 2010, 2013, 2017). 
Diversos autores, desde una perspectiva sociocognitiva, han empleado el término 'barreras sociopsicológicas para la resolución del conflicto', para dar cuenta de esta serie de operaciones de orden psicosocial relacionadas con su mantenimiento e intratabilidad (Maoz \& Eindelson 2007; Bar-Tal, 2010, 2013; Halperin \& Bar-Tal; 2011; Bar-Tal \& Halperin, 2014; Nasie, Bar-Tal, Pliskin, Nahhas \& Halperin, 2014). Sostienen que, en medio de conflictos prolongados, sujetos individuales y grupos sociales pueden construir un repertorio cognitivo, que se congela, se ancla y se institucionaliza, como significación social, constituyendo un ethos del conflicto como infraestructura sociopsicológica, base de la violencia cultural, que legitima la violencia directa y armada (Galtung, 2003).

En perspectiva psicosocial y sociohistórica, se evidencia un proceso circular en que las subjetividades son tanto configuradas por el repertorio cultural como configuradoras de éste, en el seno de una matriz relacional; donde lo social, lo político, lo mediático, lo económico y lo militar juegan un papel direccionado por lo ideológico, posibilitando la construcción de representaciones sociales en torno al conflicto, la paz y la reconciliación (Barrera Machado y Villa Gómez, 2018). Por ello, para Cogollo Ospina y Durán Palacio (2015), es fundamental transformar mentalidades, imaginar y construir más y mejores argumentos, disponerse a construir una ciudadanía política donde no se impongan argumentos y esté dispuesta a entablar procesos de reconciliación; lo que permite superar esa lógica que construye al enemigo absoluto, con quien no se puede dialogar ni construir conjuntamente.

Es importante, por tanto, en el contexto colombiano, preguntarse por la construcción de las representaciones sociales que deslegitiman al adversario y sobrevaloran al grupo, construyendo al enemigo absoluto, al que se dirigen el odio, la rabia y el miedo, beneficiando a sectores sociales que intentan garantizar la prevalencia de sus intereses. Blair (1995), Angarita Cañas, et al. (2015), Gallo, et al. (2018), entre otros, han abordado la problemática de la construcción de este enemigo en discursos políticos del Estado y los actores armados. También Correa (2006, 2008), García Marrugo (2012), Cárdenas (2013), entre otros, han realizado análisis del discurso sobre estos mismos temas en la prensa y los medios de comunicación.

De otro lado, investigaciones como las de López López, et al. (2014, 2016); Alzate, Durán \& Sabucedo (2009); Alzate, Vilas, Gómez \& Sabucedo (2015) y Alzate y Dono (2017) se han centrado en el perdón y la reconciliación, evidenciando una tendencia más alta en la población colombiana a 
perdonar a paramilitares y Fuerzas Armadas que a las FARC, y en el caso de las investigaciones de Alzate, las dificultades que se evidencian en la ciudad de Medellín para dar pasos hacia la reconciliación. Así pues, en Colombia se observa la necesidad de seguir indagando sobre estos temas, que deben ser objeto de la investigación académica y científica, acercándose a este tipo de procesos psicosociales y culturales, que instauran representaciones, discursos y prácticas sociales que impiden la transformación del conflicto armado.

Lo vivido en torno al proceso de negociación política con las FARC, el plebiscito convocado por el gobierno del presidente Juan Manuel Santos y la victoria del NO, como una reprobación de los acuerdos alcanzados, y la posterior campaña electoral para congreso y presidencia de la República en 2018, son un inmejorable escenario para profundizar en este tema. Puesto que todo esto redunda en un riesgo real y latente de reactivación de nuevas formas de violencia, recrudecimiento del conflicto armado por otras vías o degeneración de formas de violencia política hacia procesos de violencia social y delincuencial. De allí la importancia de esta investigación y de este texto, que se centra en la construcción de representaciones sociales en torno a un enemigo absoluto; puesto que a partir de este análisis se puede identificar y comprender la forma como estas construcciones sociales se erigen como barreras para la construcción de la paz. Pero, por otro lado, también indagar y reflexionar sobre otras representaciones y marcos de sentido diferentes, que pueden promoverse y traducirse en propuestas concretas para la construcción de un ethos psicosocial favorable a la paz.

\subsection{Método}

Se realizó una investigación cualitativa desde el enfoque hermenéutico con un interés crítico social (Vasco, 1990). El problema de investigación implicó un acercamiento desde las formas de comprensión e interpretación del sujeto participante (Bonilla-Castro \& Rodríguez, 1997). Además, se desarrolló una mirada transdisciplinar, en el marco de la Psicología social crítica, que posibilita una relectura de las categorías trabajadas por Bar-Tal $(1998,2013,2017)$, pasando de una mirada sociocognitiva a una mirada desde el realismo crítico de la Psicología social latinoamericana (Blanco y Gaborit, 2016).

Para recoger la información, se llevaron a cabo 43 entrevistas semi-estructuradas en profundidad, a personas de la ciudad de Medellín, ciudadanos de clase media, no miembros de partidos políticos ni de movimientos sociales ni ONG ni colectivos de acción política, que quisieran compartir su posición 
en relación con los acuerdos de Paz entre la guerrilla de las FARC-EP y el Gobierno Santos en el año 2016. Las entrevistas se realizaron durante el año 2017, en un muestreo no probabilístico, intencional y de bola de nieve. Los discursos de los participantes se categorizaron en tres grupos: personas que se mostraron de acuerdo con el proceso de negociación, personas en desacuerdo y las que tenían posición ambivalente.

El proceso de producción de los resultados se hizo a través del análisis de discurso hermenéutico (Martínez Migueles, 2006), en un procedimiento categorial por matrices, avanzando de manera analítica intratextual, intertextual y de codificación teórica de primero y segundo nivel (Flick, 2004; Gibbs, 2012). La interpretación desarrolló procesos inductivos y deductivos hasta llegar a los textos que constituyen los resultados de la investigación; de los cuales se presenta en este capítulo, la categoría: "representaciones sociales sobre la construcción del enemigo", las cuales se analizaron en relación con las FARC como contraparte del Estado y la sociedad en Colombia, confrontadas con las de otros actores armados del conflicto (paramilitares y Fuerza Pública). Lo que permitió teorizar sobre obstáculos y posibilidades en la construcción de paz, según estas representaciones sociales emergentes en los discursos de los participantes.

\subsection{Resultados}

\subsubsection{Participantes en desacuerdo}

El proceso de construcción de la representación social de enemistad se constituye en un marco de comprensión y acción para bloquear o promover procesos de construcción de paz. Comenzando con los participantes en desacuerdo, se puede afirmar que el primer elemento que emerge es la forma en que referencian a los diversos grupos armados. Es decir, cuando se les pide un primer referente significativo alrededor de estos, para referirse a las FARC acuden a calificativos que esencializan y definen una representación congelada e inmóvil (Bar-Tal, 2010, 2013, 2017); evidenciada en la deslegitimación como adversario y su calificación como seres que encarnan y personifican la maldad, llegando a una "satanización" de los miembros de este grupo.

Para estos participantes, las FARC son una mafia, una empresa delincuencial, son sanguinarios y califican sus acciones como atroces. Se encontraron seis grandes denominaciones que estos participantes utilizan para referirse a las FARC: terroristas, secuestradores, asesinos, delincuentes, mafiosos y 
narcotraficantes; son quienes han realizado los mayores daños colectivos en el país: han destruido los pueblos, han bloqueado la educación, y han acabado con la familia, por tanto, no tienen corazón y son malos por naturaleza; sólo quieren la guerra y sus acciones son sin sentido y sin razón, son una especie de no-humanos, incapaces de cualquier sensibilidad. Desde este punto de vista y desde esta construcción de la representación social del enemigo: ¿Cómo negociar con seres que encarnan la maldad en sí misma? Desde allí, plantear una negociación política con estos actores, no sólo es problemático, sino inviable. Se podría comprender la negativa absoluta de una parte de la sociedad a negociar con este actor armado, puesto que incluso esto implicaría traicionar los propios principios:

Secuestran, matan inocentes, inundan las calles de armas, hacen que los niños, que no tienen ni para estudiar, se los llevan y los vuelven malos; violan, dañan lagos, también sacan minas ilegales, contaminan, retrasan el avance el país... (E9 Medellín). ¿Las FARC qué hacen? matar, violar (...) ellos están en su mundo y ¿qué quieren? hacerle daño al pueblo y montarse al poder para seguir haciendo de las suyas. (E13 Medellín).

Contrasta esto con la forma como han construido las representaciones sociales de los paramilitares. Quienes no son definidos desde una esencia, sino desde la diferenciación entre sus acciones y su humanidad: se reconocen sus actos de violencia, pero, éstos pueden terminar legitimados, puesto que su razón de ser ha estribado en combatir al actor que es definido como enemigo. Así pues, o bien, legitiman sus acciones, sin importar los crímenes de lesa humanidad o las cifras de violaciones, masacres, homicidios, desplazamiento y despojo de tierras, donde han tenido una participación mayor (Cfr. CMH, 2013); o bien, los toleran, puesto que el fin de acabar con las FARC, ameritaba 'soportar' estos excesos como "daños colaterales" (E3 Medellín):

Por un lado, sentir que no estaban haciendo las cosas bien, pero estaban haciendo algo bueno (...) no de una forma correcta. Entonces, no sé qué decir, jeso! Precisamente porque estaban haciendo algo bueno, pero no bien. (E37 Medellín). Para mí, defienden al país, sus personas, al ambiente, me parece y he percibido que nos cuidan, nos protegen, pero no porque es mi grupo, ¿me entiendes?, tampoco es una cosa así: ¡qué rico el paramilitarismo! ¡No! Simplemente han sido los que nos han brindado más tranquilidad, de pronto por eso (E35 Medellín). 
Para estos participantes, los paramilitares no son tan malos porque se habla muy poco de ellos en los medios de comunicación. De allí que afirmen no conocer tan claramente sus acciones, no identificar, por ejemplo, cuáles fueron sus masacres o la forma cómo operaron y se expandieron en el país, ni los vínculos con sectores políticos ni con el narcotráfico, salvo cuando se habla de las Bacrim, que para muchos de ellos corresponden más a delincuencia organizada, que al paramilitarismo. Por todo esto, han podido llegar a pensar que los grupos paramilitares han hecho mucho menos daño que las FARC, e incluso, en algunos casos, pueden llegar a atribuir sus acciones a las guerrillas y no diferenciarlos como grupos con intereses, acciones y procesos diferentes, puesto que terminan asimilando que todos los grupos armados son rebeldes ante el Estado y que, en últimas, todos son lo mismo:

(...) Los paramilitares: no he escuchado mucho de ellos, realmente no sé: es algo parecido a las FARC, pero obviamente no es la misma alianza, pero es algo similar. Pero realmente yo de los paramilitares, ahi sí como que corta (risas), si los he escuchado, pero... casi como que no (...) Obviamente en las noticias se escuchan también que los paramilitares, que no sé qué, o sea, yo he escuchado, pero yo no le paro bolas a eso (...) entonces me imagino que son malos, porque si no fuese así, no dirían eso, pero realmente no sé (E33 Medellín). Del paramilitarismo no he escuchado que haya tanta matazón y tanta violencia, yo pienso que se ha generado precisamente por los otros grupos, porque ellos claro, van en contra de los otros (...) he escuchado poquito, pero no le he parado muchas bolas. Yo no veo ese grupo como muestran a la guerrilla, yo no veo ese grupo así (E35 Medellín).

De otro lado, en relación con la Fuerza Pública, los participantes en desacuerdo tienden a darles un lugar preponderante. En primer lugar, puede afirmarse que existe una identificación con las Fuerzas Armadas (FFAA) como parte del endogrupo (Blanco, 2007; Bar-Tal, 2010), como parte de un 'nosotros'. Mientras las FARC son definidos con el pronombre 'ellos', es decir, los que no son como nosotros, un otro lejano, desconocido, que además hace daño; las FFAA son representadas como parte integral del 'nosotros'. Y en este caso, su función específica es cuidar, proteger y garantizar 'nuestra' seguridad,

Nos cuidan, porque inclusive por el ejército nosotros también pasamos momentos buenos, porque mientras están viviendo una guerra, nosotros estamos acá bien. Por ejemplo, en diciembre pasamos una 
navidad bien, entonces, o sea, yo lo que conozco del ejército es algo que nos ayuda a nosotros, a los colombianos (...) (E33 Medellín). Son personas abnegadas, por vocación como es un médico, un sacerdote, un profesor, también deben sufrir mucho por dejar su familia, mientras nos defienden (E34 Medellín). Arriesgan su vida por el país y eso es algo que no cualquiera lo hace y me siento muy orgullosa de tener personas asi en Colombia (...) la verdad me parece que son personas que le han hecho bien al pais, yo soy muy patriota y me siento muy orgullosa (E37 Medellín).

La construcción de la representación social de los miembros de las FFAA, como aquellos que son capaces de entregar la vida 'por nosotros', confluye en una palabra: 'héroes'. Para estos participantes, son los adalides que salvaguardan la identidad, la estabilidad, el orden social y los valores. Dentro de este marco de significación, se pasa por alto cualquier acción que implique un ataque a la población civil o violación de derechos por parte de la Fuerza Pública como las ejecuciones extrajudiciales, mal llamados, falsos positivos. En sus relatos se puede inferir este sesgo: o bien se desconocen, o bien, no se les ha prestado la suficiente atención y se relativizan:

Cuando han tenido que hacer daño es porque les toca, porque son cosas que tienen que hacer, por el objetivo que tienen y porque en el aérea donde ellos disparan o hacen algo, involucran a mucha gente; pero afortunadamente no han sido muchos civiles, sino los mismos de las FARC, paramilitares y los del ELN, son muy poquitos civiles que han caído. Qué pesar, pero ¿qué pueden hacer ellos?... ¡Nada! ¡Daños colaterales! (E21 Medellín). No puedo decir que por las caidas de civiles voy a cogerles bronca, pues eso lastimosamente pasa; y yo sé que en su pensamiento está el proteger y lo hacen a como dé lugar; tendría que ser que se volvieran contra nosotros, como el ELN o las FARC, para decir que se me va a quitar el sentimiento de gratitud y admiración por ellos (E37 Medellín).

Y no falta quien afirme que son acciones ejecutadas por el "enemigo", es decir, las FARC, para poder atribuírselas a las FFAA y con ello, enlodar su nombre, tal como lo evidencia este diálogo entre entrevistador y participante:

- E- ¿Crees que los falsos positivos en realidad fueron de las Farc?

- P- ¡Eso, eso!

- E- ¿Por qué crees eso? 
- P- Por lo mismo que te dije, porque ellos son malos y quieren ocultarse en otra gente.

- E- Pero los falsos positivos, lo denunciaron las mismas familias de las víctimas

- P- Para mí eso son mentiras, son falsos.

- E ¿Son mentiras de quién?

- P- De las FARC

- E- ¿Así lo diga la mamá?

- P-Sí (E13 Medellín).

Toda esta representación social no permite reconocer nada positivo, ni en las intenciones ni en las acciones de ese enemigo. Al punto de atribuirle, también, algunas de las acciones que fueron cometidas por otros actores. Todo esto entronca con la forma como, según Bar-Tal (1998, 2010, 2013, 2017), Bilali (2012), Bilali \& Ross (2012), se construye esta representación social en contextos de conflicto de larga duración. Frente al adversario se desconfía absolutamente, se experimenta hostilidad, porque se le define desde un lugar de no-humano, de 'otro' demonizado, incapaz de sentimientos (Maoz $\&$ Eidelson, 2007), que siempre podría tener una trampa debajo de la mesa:

- P: Gas, eso no es de personas. [Sentimiento de asco]

- E: ¿No es de personas?

- P: No es de personas conscientes.

- E: Entonces ¿Es de qué?

- P: De gente mala, gente sin pudor, sin respeto a la vida, no son agradables. (E9 Medellín).

Incluso uno de los participantes, con un nivel de reflexión sobre este proceso reconoce:

(...) ¿Sabes qué? Las FARC representan el arquetipo del enemigo en los corazones de los colombianos, entonces, nos dan la posibilidad de tener a quien señalar, a quien odiar; eso es la posibilidad que nos dan las FARC, lastimosamente, cierto (E3 Medellín).

El proceso que se ha llevado a cabo comienza con la exacerbación de la gravedad de los daños cometidos, pero también con la asignación de responsabilidades; pues, se les atribuye el comienzo, mantenimiento y degradación del conflicto (Bilali, 2012). Por tanto, no existe claramente, de parte de estos participantes un reconocimiento a la dimensión política de las 
FARC. Las FARC serían los principales responsables del conflicto armado y quienes más daño han hecho, los califican como el peor de los actores armados, considerando que no le aportan nada al país. De allí que, algunos pueden llegar al extremo de afirmar cosas como que deben ser eliminados, combatidos hasta el final, sin importar las consecuencias que esto pueda traer para las víctimas, para el país,

(...) Deshacerse de los guerrilleros, es decir gusanos, como sacando gusanos, tenemos que ir sacando, esa parte ahí; porque los militares están autorizados (E26 Medellín).

- E: ¿Cuándo te nombran las FARC que se te viene a la mente?

- P: Que son personas malas, que NO deberían de existir.

- E: ¿No deberían existir?

- P: ¡NO! Y no les debieron haber dado esa oportunidad [Refiriéndose al proceso de paz]

- E: ¿Por qué? ¿Para ti ellos que merecían?

- P: La Muerte (...) ¡Si! Sin distinción, todos. Porque solo estaban para secuestrar y matar. Entonces ahora, les perdonan todo, no pasa nada, los que están en las cárceles, van a salir y no pasa nada, Son muchas cosas, que no deberían ser (E21 Medellín).

Así pues, estos participantes descalifican a las FARC como contraparte y desconocen sus objetivos, puesto que su única meta sería la consecución del poder para dominar y oprimir al pueblo, incluso, el proceso de paz sería una trampa para ese fin, ya que este grupo armado es mentiroso y engaña al país. De acuerdo con Bar-Tal (1998, 2010, 2013, 2017), la deslegitimación del adversario pasa por la descalificación de los objetivos que se propone. De tal manera, que sus propósitos legítimos, políticos y sociales, son minimizados, ocultados, ignorados, descalificados, puesto que serían una trampa que oculta sus verdaderos intereses; es decir su fin último: la eliminación de un orden social, de los representantes del grupo contraparte y la desestructuración de sus proyectos de vida. Y cuando se hacen contrapreguntas, afirman no saber, no haber leído, no tener información, o como la siguiente participante; a pesar de recibir, en clase, información alternativa sobre el conflicto armado, no puede dejar de relacionar todo lo que ha sucedido con la única responsabilidad de las FARC:

Todo lo relaciono con las FARC, todo lo relaciono con ellos; porque por ejemplo hay en clases que se han tocado esos temas, pero yo no dejo de relacionar a las FARC todo el tiempo, no logro hacer la 
clasificación [para diferenciar los diferentes grupos armados], pues estos hacen esto y ellos hacen esto, iNo! Sin embargo, que yo haya visto no, es desde pequeñita que lo evidencié, pero viéndolo en las noticias (E39 Medellín).

Esto se fundamenta en una convicción y una creencia que se ha ido tejiendo durante décadas: el daño que han hecho las FARC se representa como realizado contra toda la colectividad, contra el país en general, punto de vista que emerge, según estos participantes, por la vasta información que han obtenido por los medios de comunicación:

Por lo que he escuchado, ellos quieren hacerse sentir en el gobierno, ellos hablan de paz, que se desmovilizan, pero para mí no son todos (...) Porque no todos van a entrar al gobierno, entonces se desmovilizarán unos y otros quedarán bajo cuerda. (E14 Medellín). Las imágenes que recuerdo son del mal que hacen, cosas buenas no. Radio, tv, periódico, redes sociales dicen mucho, que mataron no sé cuántos soldados... (E9 Medellín). Que si no hicieron estos hechos de lesa humanidad, entonces, hasta van a tener derecho a un partido, a postularse y todo. ;Imagínese, cómo vamos de mal! (E31 Medellín).

En relación con las FARC, hay un matiz en los relatos de algunos (3 personas): en los que establecen una distinción entre combatientes rasos, especialmente aquéllos que fueron reclutados de manera forzada, y comandantes; quienes, en términos generales, son el objetivo más frecuente de los calificativos y significados que se han desarrollado en este texto hasta ahora. Es decir, cuando se habla de las FARC como actor armado, en algunos casos, se identifica con mayor claridad a sus comandantes, mientras los rasos, pueden ser identificados como víctimas: están allí engañados u obligados:

(...) eso, porque hay gente que está allá obligada, que se fueron para allá obligados (E25 Medellín). Me imagino que también los tratan mal, porque, si a los niños desde pequeños se los llevan y los empiezan a tratar así, con mano dura, entonces, me imagino que cuando estén grandes también, que cuando hagan algo malo, de pronto los matan (E33 Medellín).

El segundo matiz, se da en una representación social que ubica a las FARC como grupo que, en sus comienzos, tuvo una lucha justa e intentaba transformar la injusticia, pero que, en el proceso histórico se fueron pervirtiendo y se convirtieron en narcotraficantes y terroristas, lo cual deslegitima sus objetivos, aunque al comienzo estos pudieran haber sido justos: 
Me parece que vale la lucha social, pero cuando tu lucha social la vuelves narcotráfico, terrorismo y delincuencia, ya simplemente eres un grupo organizado delincuente y aqui en Colombia eso paga (...) Grupos guerrilleros tuvimos hace muchos años, hasta que se convirtieron en terroristas y como tales nos han hecho mucho daño (E36 Medellín).

\subsubsection{Participantes de acuerdo y ambivalentes}

Ahora bien, en este tipo de representación ligada a la construcción de una memoria colectiva en torno a las FARC, el relato suele ser monolítico; y emerge como plantilla narrativa generalizada en el marco de esta investigación, puesto que también es compartida por los participantes que están de acuerdo con el proceso de negociación y por aquéllos que se han mostrado ambivalentes. La diferencia que se presenta en quienes han manifestado acuerdo y también en aquellos ambivalentes, estriba en que ese giro que habrían dado las FARC, no les quita que sigan teniendo objetivos políticos en relación con la transformación social y la búsqueda de justicia y equidad.

De igual manera, la representación social construida en torno a las Fuerzas Militares tiene una connotación muy generalizada en todos los participantes, así lo han expresado también quienes están de acuerdo y ambivalentes, para los que, las FFAA ofrecen protección, seguridad y cuidado, y un lugar heroico en sus representaciones:

Las personas que están ahí realmente están expuestos a dar la vida por el pais, es de admirar, y como decía ahora, habrá corruptos, algunos policías o militares, pero creo que en general son personas que están expuestas por nosotros, por Colombia, por la patria, incluso como les dicen a ellos, dan la vida por la bandera, por todo un país (E10 Medellín).

Ahora bien, hay un matiz entre uno y otro grupo de participantes. Mientras quienes estaban en descuerdo con el proceso de paz no logran tomar distancia para analizar las acciones violatorias de la Fuerza Pública, tal como se enunció anteriormente, ya que se han centrado en la acción de las FARC; los participantes que manifestaron acuerdo también reconocen que las FFAA y el Estado han sido actores del conflicto armado y también han tenido un papel en el inicio, mantenimiento y degradación de este.

El ejército también es corrupto y está permeado por un montón de influencias: y a sea particulares, de gente adinerada y políticos; porque el ejército es esa espada sin ojos que tiene el Estado para hacer sus cosas de vez en cuando; me explico, en el ejército no se 
va a cuestionar a los superiores, el ejército hace. Está bien, está mal, no me importa, sigo órdenes, y ese principio lo han utilizado como defensa en muchas circunstancias y cosas feas que se les han descubierto, pues es la excusa perfecta para hacer cualquier cosa, cualquier tipo de acto inhumano (E32 Medellín).

Además de lo anterior, y en relación con los grupos paramilitares, la mayoría de estos participantes no les reconoce legitimidad. Afirman que han tenido un papel preponderante en la barbarie del conflicto, reconociéndolos como actores iguales o peores a las FARC, al atacar a la población civil y producir zozobra, terror, muerte y destrucción.

Los paramilitares han hecho lo mismo que la guerrilla: matar, extorsionar, por ejemplo, en los pueblos son los que mandan: el pelado no puede tener el cabello largo, no puede tener barba, son estereotipos y entonces si es marihuanero le dan de baja y hacen limpieza social, eso es lo que conozco; sobre todo que hacen limpieza social de ese tipo (...) Y eso es inaceptable: nada que tenga que ver con dañar a otro es legítimo (E1 Medellín).

Los matices emergentes en quienes están de acuerdo nos introducen en la forma como estos participantes han construido las representaciones sociales sobre las FARC como actor político y armado, que tiene objetivos y propuestas, pero que también ha hecho daño a la sociedad. De tal manera que, si bien pueden reconocer acciones violentas y violatorias de los derechos por parte de las FARC, pueden distinguir estas acciones de las personas, con lo cual, no aparecen en sus discursos calificativos ni esencializaciones como las que se analizaron con el grupo de participantes en desacuerdo. En este caso, se reconocen, también, objetivos sociales y políticos, que les permiten ser interlocutores en una negociación para transformar el conflicto armado:

Hoy en día es algo muy discutible porque, frente a crímenes de la humanidad, masacres que han perpetrado, es muy dificil decir que hay un punto exacto que legitime su causa, pero quizás siga siendo como esa velita de que el pueblo todavía les importa, que se ha ido difuminando a lo largo de la historia por cuestiones de dinero, droga; y quizás en el fondo, todavía tratan de buscar un mejor futuro del país (E32 Medellín). Esa pregunta es muy compleja porque si bien es legitimo, y eso está en la constitución, el pueblo tiene derecho a ser insurgente. El punto es que ellos se han salido mucho de esa línea. Digamos que en su momento las Farc estaban bien, pero se salieron (E38 Medellín). 
Esto se sintetiza en una diferenciación importante, mientras para el primer grupo de participantes las FARC son un grupo delincuencial que actúa movido por intenciones malignas, es decir, un grupo terrorista; para los segundos es un grupo armado, que si bien ha desarrollado acciones violentas contra la población y, pudo haber perdido su norte revolucionario, sigue manteniendo unas demandas políticas, económicas y sociales; y por lo tanto, estos puntos de vista tendrían que ser incluidos en el marco del debate democrático. Para quienes están de acuerdo, el proceso de paz posibilita que se deje atrás el medio que hace daño (las armas y las acciones violentas contra la población y contra el Estado), para asumirlo por la vía de la acción política; por esto, respetan fines, objetivos y sobre todo la humanidad de los integrantes de las FARC, lo que de una $u$ otra forma abre puertas en el imaginario colectivo para respaldar un acuerdo de paz con ellos.

El problema es la lucha armada y su posterior degradación. Pero reconocen que, en un proceso de negociación política del conflicto y su inclusión dentro del juego democrático, ellos pueden cambiar y ser encauzados por otro camino. Así pues, se puede evidenciar una 'humanización' de estos combatientes, que se complementa con una mirada crítica al "establecimiento" social y político en el país, hacia los poderes económicos y políticos tradicionales y hacia el Estado; reconociendo, además, que el Estado, los gobiernos y la clase política han tenido responsabilidades en el marco del conflicto armado.

No digo que esté completamente de acuerdo [con las FARC], pero por lo menos era una alternativa a la ideología que se tenía, porque ser estrictamente conservadores tampoco le ha traído cosas muy positivas a Colombia. (E20 Medellín). Lo que pasa es que las Farc son como usted o como yo, son personas comunes y corrientes, la mayoría son campesinos, personas que vieron eso como una salida. Ha habido frentes, unos más crueles, más violentos y otros que no cometieron tanto crimen (E38 Medellín).

Del otro lado, para la mayoría de quienes están de acuerdo, toda la oposición al proceso de negociación, el odio exclusivo a las FARC, la tolerancia con los paramilitares, la dificultad que como nación estamos teniendo para resolver el conflicto armado pasa, de acuerdo con algunos de sus discursos, por formas de persuasión y manipulación que se han construido históricamente desde algunos políticos y medios de comunicación; que han logrado construir esa imagen de enemigo que justifica la violencia:

Creo que ha sido necesario para el gobierno crearnos un enemigo público, al cual se le hayan atribuido una cantidad de acciones en 
contra del pueblo (E7 Medellín). Caracol y RCN, pues, medios más pequeños también lo cubren, pero no lo cubren desde una perspectiva tan ... ya sabes, desde solo un punto de vista, o sea, estos medios son "el Estado es bueno, las Farc es mala"; y ahora que hago memoria, siempre ha sido asi y me estoy dando cuenta de lo horrible que es eso (E32 Medellín).

De otro lado, estos participantes afirman que se habla muy poco de los paramilitares en estos medios de comunicación masiva. Que no se conocen sus acciones de la misma manera, lo que ha podido llevar a pensar que han hecho mucho menos daño que las FARC. García Marrugo (2012) en su investigación, al analizar los titulares y el contenido de noticias sobre las FARC y los paramilitares en 4 grandes periódicos del país, concluía que, para los primeros, tanto los titulares como las noticias identificaban en primera línea al agresor, que era descrito en términos calificativos, atribuyéndole una maldad intrínseca; mientras que, con los segundos solían ser más difusos para asignar responsables, calificar y definir la acción y el autor. Todo esto puede recogerse en el siguiente relato, donde el participante puede dar cuenta de sus confusiones y luego de sus claridades en torno a la problemática del conflicto armado y sus actores:

Yo pensaba que la guerrilla era una sola organización, no varias; y claramente súper demonizada por los medios de comunicación. En cambio, los paramilitares, yo pensaba, que eran como paramédicos que apoyaban al ejército, que eran menos; pues los medios no mostraban a los paramilitares como algo malo. Uno se da cuenta de este tipo de cosas: es increíble cómo los medios de comunicación llegan a hacer eso, que a fin de cuentas están dominados por las familias ricas de mi país. Entonces obvio, la guerrilla va a ser el enemigo y los paramilitares van a ser una respuesta justificada a las acciones de la guerrilla [...] (E16 Medellín).

Esto concuerda con lo afirmado anteriormente por los participantes en desacuerdo para quienes los medios de comunicación eran su fuente principal en torno al conflicto.

\subsection{Discusión y conclusión}

Se ha trabajado en este texto una de las categorías de análisis, tanto desde el marco teórico, como desde los discursos de los participantes: la construcción de la representación social del enemigo en Colombia. Desde lo que emerge en la investigación, puede afirmarse que los discursos de los 
participantes, ciudadanos de la ciudad de Medellín, de clase media, del común, no insertos en movimientos políticos ni sociales, algunos profesionales, amas de casa, estudiantes, comerciantes, entre otros, puede comprenderse la forma cómo se han construido los discursos sobre el proceso de negociación política del conflicto armado en Colombia, las dificultades que como nación estamos teniendo para la construcción de la paz y la forma como se han desarrollado los hechos políticos en los últimos años: la oposición férrea de una parte de la sociedad y sus representantes políticos al proceso de negociación con las FARC, la posterior definición del plebiscito a favor del NO, la configuración del Congreso y la elección para la presidencia al representante del partido político que enarbolaba estos intereses.

No podría afirmarse si ha existido manipulación o cuáles han sido los procesos exactos por los cuales el país ha llegado a este estado de cosas, que puede ir conduciendo a un callejón sin salida en relación con la violencia y la guerra como forma de dirimir conflictos sociales, políticos y económicos. Pero los participantes, dentro de los grupos que hemos categorizado, ofrecen algunas pistas, especialmente cuando se analiza el papel de medios de comunicación, y más recientemente de redes sociales en este proceso de construir un enemigo único y absoluto (Correa, 2006, 2008; García Marrugo, 2012; Angarita Cañas, et al., 2015; Marín y Quintero, 2018); con el cual, luego de haberle referido todos los calificativos posibles de maldad e inhumanidad, esta representación parece volverse contra nosotros como nación. Porque nos hacemos incapaces de humanizar y reconocer en ese 'ellos', a un posible otro con el que se puede negociar, legitimando algunos de sus propósitos, acciones e intereses.

Todo lo planteado en la introducción por autores que han trabajado sobre los conflictos de larga duración, la base epistémica y cognitiva que da piso a la legitimación de la guerra y la construcción de barreras psicosociales para la paz y la reconciliación (Bar-Tal, 1998, 2003, 2010, 2013, 2017; Fernández, 2006; Blanco, 2007; Bilali, 2012, entre otros), parece ser correlativo a lo que los participantes de esta investigación han expresado en las entrevistas y conversaciones que se han tenido con ellos.

Según estos autores, en sociedades atravesadas por conflictos de larga duración, que han derivado en conflictos destructivos y degradados (Fernández, 2006) y se llega a escenarios de polarización social que obstaculizan la construcción de la paz, es frecuente que una parte de la sociedad civil se involucre en el mismo, desde posturas que les identifican con una de las partes; mientras definen al contrario como el portador de todos los males 
para esa sociedad (Bar-Tal, 2013). Con esa representación social del enemigo como parte de la vida cotidiana, se hace mucho más difícil y complejo adelantar una negociación política que pueda ofrecer una salida no-violenta al conflicto armado (Bar-Tal, 1998, 2010, 2013, 2017; Barrera Machado y Villa Gómez, 2018).

El documental “Apuntando al Corazón” de Catalina Gordillo y Bruno Federico (2014), rastrea algunos de los elementos del proceso comunicativo, persuasivo y publicitario que se implantó en Colombia desde el 2002. En el mismo, el periodista, docente e investigador Omar Rincón, apunta que el éxito que tuvo esta campaña, además de lograr una admiración por las FFAA, es haber logrado una relación entre la identidad de ser colombiano y el odio a las FARC y su identificación como enemigo absoluto.

La contrastación de los discursos de los participantes, en esta investigación, abre una oportunidad para debatir una representación social común en Colombia, y es aquélla que ha negado la existencia de conflicto armado en el país: si las FARC son un grupo terrorista, mafioso, delincuencial, si está conformado por seres malignos, sanguinarios y monstruosos, al no tener un estatuto de humanidad y la legitimidad de un 'otro' que también porta intereses y aspiraciones, este grupo se reduce a un enemigo absoluto (Angarita et al., 2015; Gallo, et al., 2018) que debe ser eliminado. Es decir, no hay conflicto armado, sino una "amenza terrorista". Lo no-humano, siempre será más fácil de ser eliminado. De allí que, en contextos de conflictos degradados (Fernández, 2006; Bar-Tal, 1998, 2010, 2013), los otros, los enemigos sean representados con condiciones de cosas, objetos o animales como: ratas, perros, basura, gusanos, cucarachas, etcétera.

De otro lado, también, al seguir los discursos de los participantes que mostraron acuerdo con el proceso de negociación, al saber que no son militantes y que no están enarbolando las ideas de ningún partido político; y que por la complejidad de sus puntos de vista y discursos, no podrían ser clasificados como personas de izquierda (como tampoco quienes están en desacuerdo podrían clasificarse como de derecha); por estas razones, por la forma como se acercan a la problemática, la generación de una cierta mirada crítica y un distanciamiento frente a lo que se intenta plantear de manera hegemónica, nos dan algunas pistas para la transformación de la violencia cultural y la construcción de cultura de paz en Colombia, que debe construirse desde abajo (Cogollo Ospina y Durán Palacio, 2015). Esto implica que en escenarios como los que se han presentado, donde existe un nivel de deshumanización del 'otro' enemigo, es clave construir 
una subjetividad política, una ciudadanía, que pueda estar por fuera de órdenes hegemónicos establecidos y generar prácticas sociales más allá de los escenarios tradicionales de participación, incluyendo la vida cotidiana, las solidaridades sociales y otras distribuciones del poder (Posada Zapata y Carmona Parra, 2018).

En este sentido, el reconocimiento de objetivos al adversario, su humanización y su lectura desde la semejanza, como alguien que también es de los nuestros, pero que ha tenido puntos de vista diferentes y acciones equivocadas; la diferenciación entre la acción delictiva, la violación del derecho, la acción violenta, de la persona o grupo que la ejecuta; el reconocimiento de las dos partes en conflicto y la mirada a las acciones de violencia de ambas partes, aceptando responsabilidades en todos los lados. Y, por tanto, una mirada compleja que va más allá del binomio buenos y malos, de quién tendría 'licencia' para matar y quién no; es decir, el planteamiento que define, desde una ética muy básica, un principio en el que la violencia y la guerra no son los caminos para dirimir los conflictos armados y la vida es el principio más fundamental para respetarse, es decir, que no existen 'buenos muertos'. Todos estos elementos que pueden inculcarse, formarse y construirse en una sociedad, pueden ser pista para la Psicología, la Psicología social y la academia para trazar programas, proyectos y procesos que contribuyan a la transformación de esa cultura de violencia y desarrollar culturas de paz, que permitan superar la legitimación psicosocial y cultural del conflicto armado, y reconocer que como nación se pueden tener otras formas de dirimir diferencias y problemáticas.

En este sentido, siguiendo a Bar-Tal y Bennick (2004) y a Lugo-Agudelo, Sánchez-Agudelo y Rojas-Granada (2018, p. 62) es fundamental que se puedan desarrollar procesos que impliquen "cambios profundos en las motivaciones, concepciones, creencias, actitudes, objetivos, emociones y relaciones, no solo de los directamente involucrados, sino también de la sociedad en general respecto al conflicto"; lo cual, según los discursos analizados y el proceso que se viene desarrollando en esta investigación, se convierte en un imperativo para el desarrollo de una intervención psicosocial en Colombia que implique restauración, reconciliación y paz. 


\section{Referencias}

Alzate, M., Durán, M., \& Sucedo, J. (2009). Población civil y transformación constructiva de un conflicto armado interno: aplicaciones para el caso colombiano. Universitas Psychological, 8(3), 703-720.

Alzate, M., Vilas, X., Gómez, C., \& Sabucedo, J. (2015). Aportes psicosociales de la población civil para la reconciliación de un país en conflicto. In S. Collogo (Ed.), Imaginar la paz en Colombia: cavilaciones desde la academia (pp. 49-57). Medellín: Fundación Universitaria Luis Amigó.

Alzate, M. y Dono, M. (2017). Reconciliación Social como estrategia para la transformación de los conflictos sociopolíticos, variables asociadas e instrumentos de medición. Universitas Psychologica, 16(3), 1-10.

Angarita Cañas, P. E., Gallo, H., Jiménez, B., Londoño, H., Londoño, D., Medina, G., Mesa, J... y Ruiz, A. (2015). La construcción del enemigo en el conflicto armado colombiano: 1998 - 2010. Medellín: Silaba.

Bar-Tal, D. (1998). Societal Beliefs of Intractable Conflcits. International Journal of Conflict Management, 9, 22-50.

Bar-Tal, D. (2010). Culture of Conflict: Evolvement, Institutionalization, and Consequences. Personality, Human Development, and Culture: International Perspectives on Psychological Science, 2, 183-198.

Bar-Tal, D. (2013). Intractable Conflicts: Socio-Psychological Foundations and Dynamics. Cambridge: University Press.

Bar-Tal, D. (2017). Intractability. En H. Giles \& J. Harwood (Eds.) Encyclopedia of Intergroup Communication. New York: Oxford University Press.

Bar-Tal, D. \& Bennink, G. (2004). The Nature of Reconciliation as an Outcome and as a Process. From Conflict Resolution to Reconciliation. New York: Oxford University Press.

Bar-Tal, D., \& Halperin, E. (2014). Barreras sociopsicologicas para la paz e ideas para superarlas. Revista de Psicología Social, 29(1), 15-30.

Barrera Machado y Villa Gómez (2018). Barreras psicosociales para la construcción de la paz. El Ágora, 18(2), Aceptado, en prensa.

Bekerman, Z., \& Zembylas, M. (2010). Fearful Symmetry: Palestinian and Jewish Teachers Confront Contested Narratives in Integrated Bilingual Education. Teaching and Teacher Education, 26, 507-515. http://doi.org/10.1016/j.tate.2009.06.010

Bilali, R. (2012). The Downsides of National Identification for Minority Groups in Intergroup Conflicts in Assimilationist Societies. British Journal of Social Psychology, 53(1), 21-38. http://doi.org/10.1111/bjso.12012

Bilali, R., \& Ross, M. (2012). Remembering Intergroup Conflict. The Oxford Handbook of Intergroup Conflict, 123-135. 
Blair, E. (1995). La imagen del enemigo ¿un nuevo imaginario social? Revista de Estudios Políticos, 6, 47-71.

Blanco, A. (2007). La condición de enemigo. El ocaso de la inocencia. En M. Cancio, \& L. Pozuelo, Política criminal en vanguardia (pp. 259-305). Madrid: Thompson/Civitas.

Blanco, A., \& De la Corte, L. (2003). Psicología social de la violencia: introducción a la perspectiva de Ignacio Martín Baró. In I. Martín-Baró, Poder, ideología y violencia (pp. 9-62). Madrid: Trotta.

Blanco, A. y Gaborit, M., (2016). La racionalidad inmanente a la Psicología como ciencia y como profesión En: I, Martín- Baró. Realismo crítico: fundamentaciones y aplicaciones (pp. 3-75). San Salvador: UCA Editores

Borja, H., Barreto, I., Alzate, M., Sabucedo, J., \& López, W. (2009). Creencias sobre el adversario, violencia política y procesos de paz. Psicothema, 21(4), 622-627.

Bonilla-Castro, E. \& Rodríguez, P. (1997). Más allá del dilema de los métodos. Bogotá, Colombia: Grupo Editorial Norma.

Cárdenas, J. D. (2013). Opinión pública y proceso de paz: actitudes e imaginarios de los bogotanos frente a la paz de La Habana entre el gobierno colombiano y la guerrilla de las FARC. Ciudad Paz-ando, 6(1), 41-58.

Centro Nacional de Memoria Histórica, CMH. (2013). ¡Basta ya! Colombia: memorias de guerra y dignidad. Bogotá: Imprenta Nacional.

Cogollo Ospina, S.N. y Durán Palacio, N. (2015). Paz y posconflicto: compromiso de los ciudadanos para un horizonte imaginado. En: S. N. Cogollo Durán, (ed.) Imaginar la paz en Colombia: Cavilaciones desde la Academia, (pp. 62-71). Medellín: Fundación Universitaria Luis Amigó.

Correa, M. (2006). Desinformación y propagada: estrategias de gestión de la comunicación en el conflicto armado. Reflexión Política, 8(15), 94-106.

Correa, M. (2008). El lenguaje de los medios que intensifica el conflicto armado colombiano. Reflexión Política, 10(19), 106-113.

Fernández, J. (2006). Ser humano en los conflictos. Madrid: Alianza Editorial.

Flick, U. (2004) Introducción a la investigación cualitativa. Madrid: Morata.

Gallo, H., Jiménez, B., Londoño, D., Mesa, J. A., Ramírez, M. E. y Ramírez, D. (2018). Discursos de enemistad. Pronunciamientos sobre los medios de comunicación y las ONG en el conflicto armado colombiano, 1998 - 2010. Medellín: Editorial Universidad de Antioquia.

Galtung, J. (2003). Violencia Cultural. Bizkaia: Gernika Gogoratuz. Centro de Investigación por la Paz. Fundación Gernika Gogoratuz.

García Marrugo, A. (2012). The Texture of Ideology: Demostrating bias in the Representation of the Internal Conflicto in the Colombian Press. (Tesis de doctorado). Departamento de Lingüística de la Facultad de Ciencias Humanas, Macquarie University, Sidney, Australia. 
Gibbs, G. (2012). El análisis de datos cualitativos en investigación cualitativa. Madrid, Ediciones Morata.

Halperin, E., \& Bar-Tal, D. (2011). Socio-psycological Barriers to Peace Making: an Empirical Examination within the Israeli Jewish Society. Journal of Peace Research, 48(5), 637-651. http://doi.org/10.1177/0022343311412642

Korstanje, M. (2014). El miedo político bajo el prisma de Hannah Arendt. Revista SAAP, 18(1), 99-126.

López-López, W., Sabucedo, J. M., Barreto, I., Borja, H. y Serrano, J. (2014). Discourse as a Strategy for the Construction of Peace Cultures. Psychosocial Approaches to Peacebuilding in Colombia. New York: Springer International Publishing.

López López, W., Andrade, A., \& Correa-Chica, A. (2016). El proceso de pedir perdón como condición necesaria para la construcción de paz en medio del conflicto armado en Colombia. Revista Argentina de Clínica Psicológica, XXV (2), 187-194.

Lugo-Agudelo, V., Sánchez-Agudelo, P. V. y Rojas-Granada, C. (2018). La restauración con sobrevivientes del conflicto armado en Colombia: una propuesta de acción psicosocial. Revista Eleuthera, 19, 55-73. doi: 10.17151/eleu.2018.19.4.

Maoz, I., \& Eidelson, R. (2007). Pshychological Bases of Extreme Policy Preferences: how the Personal Beliefs of Israeli-Jews Predict their Support for Population Transfer in the Israeli-Palestinian Conflicto. American Behavioral Scientist, 50(11), 1476-1497.

Marín, A. F., \& Quintero, J. M. (2018). Confianza en el proceso de paz en Colombia en twitter. Revista Mexicana de sociología, 115-137.

Martín-Baró, I. (1989). La violencia política y la guerra como causas de trauma psicosocial en El Salvador. En I. Martín Baró (ed.) Psicología social de la guerra: trauma y terapia en el Salvador (pp. 66 - 87). El Salvador: UCA Editores.

Martínez Miguelez, M. (2006). Ciencia y arte en metodología cualitativa. México: Trillas.

Nasie, M., Bar-Tal, D., Pliskin, R., Nahhas, E., \& Halperin, E. (2014). Overcoming the Barrier of Narrative Adherence in Conflicts Through Awareness of the Psychological bias of Naive Realism. Personality and Social Psychology Bulletin, 40(11), 1543-1556.

Posada Zapata, I. y Carmona Parra, J. (2018). Subjetividad política y ciudadanía de la mujer en contextos de conflictos armados. Revista Mexicana de Ciencias Políticas y Sociales, LXIII(233), 69 - 92. doi: 10.22201/fcpys.2448492xe.2018.233.57835

Vasco, C.E. (1990). Tres estilos de trabajo en ciencias sociales. Bogotá: CINEP. 


\title{
21. Emociones sociales que constituyen barreras psicosociales para el perdón y la reconciliación en Medellín
}

\author{
Carlos Esteban Estrada Atehortúa ${ }^{80}$ \\ Juan Fernando Oliveros Ossa ${ }^{81}$ \\ Leidy Paola Rentería Hernández ${ }^{82}$
}

\section{Resumen}

El presente escrito, producto de investigación, tuvo como finalidad comprender la forma en que las emociones sociales pueden constituir barreras psicosociales para la paz y la reconciliación, en Medellín. En este estudio participaron 43 ciudadanos de la ciudad de Medellín, de diversos estratos socioeconómicos. Se indagó por las emociones expresadas en función del momento coyuntural que vive el país y de la necesidad de construir una sociedad democrática que trascienda los ciclos sucesivos de violencia. La información fue analizada en un proceso matricial y categorial, acompañado de un análisis en codificaciones teóricas de primero y segundo nivel para la producción de resultados, discusión y conclusiones. Emergen emociones de miedo, desconfianza, rabia y odio en relación a lo que hemos denominado como la construcción social del otro -desvinculado del conflicto armadocomo amenaza.

Palabras clave: emociones sociales, miedo, odio, rabia, desconfianza, perdón, reconciliación y post acuerdo.

\section{Abstract}

The purpose of this paper, product of research, was to understand the way in which social emotions can constitute psychosocial barriers to peace and reconciliation in Medellin. In this study, 43 citizens from the city of Medellín, from different socioeconomic strata, participated. We asked for the emotions expressed in terms of the current situation in the country and the

80 Universidad de San Buenaventura - Medellín. Correo: carlos.estrada@usbmed.edu.co

81 Universidad de San Buenaventura - Medellín. Correo: juanferoliveros@gmail.com

82 Universidad de San Buenaventura - Medellín. Correo: leidyp.renteria@gmail.com 
need to build a democratic society that transcends the successive cycles of violence. The information was analyzed in a matrix and categorical process accompanied by an analysis in theoretical codings of first and second level for the production of results, discussion and conclusions. Emotions of fear, distrust, anger and hatred emerge in relation to what we have termed as the social construction of the other - disengaged from the armed conflict - as a threat

Keywords: Social emotions, fear, hatred, anger, distrust, forgiveness, reconciliation and post agreement.

\subsection{Introducción}

El conflicto armado en Colombia ha perdurado por más de 50 años, lo que supone un proceso prolongado de guerra, violencia y mentira que han sufrido de manera directa 8.679.002 personas, según el Registro Único de Víctimas (Unidad Para las Víctimas, 2018); aproximadamente el 18\% del total de la población colombiana ha sufrido un hecho victimizante, viéndose lesionada en su condición de humanidad y dignidad (Villa, 2013). Más allá del número de víctimas, se encuentra la historia vivida por cada una de ellas, con sus familias y cercanos, que tratan de humillación, impotencia e indignación por hechos como asesinatos, torturas, desplazamiento y desapariciones forzadas, masacres, secuestros, extorsiones, ejecuciones extrajudiciales, violaciones y abusos sexuales, a las que se vieron sometidas.

Este contexto se acerca a lo que Bar-Tal \& Halperin (2013), entienden como conflictos prolongados en el tiempo que se van sedimentando como conflictos intratables, en tanto dos o más grupos perciben sus metas en directa oposición de unos con otros. Además, de acuerdo con los autores, son conflictos de naturaleza violenta, en que ninguna de las partes gana y tampoco se dispone a la conciliación para alcanzar la paz, se perciben como irresolubles y las diferentes partes del conflicto apelan a estrategias militares y psicológicas para alcanzar sus fines, degradando el conflicto y dejando secuelas en la población que lo vive.

La violencia vivida en Colombia ha durado el tiempo suficiente para arraigarse en la idiosincrasia de la población (Velasco, 2018); generaciones que nacieron en este contexto belicoso comprenden el mundo a partir de éste, sosteniendo las lógicas del conflicto y entendiendo el mismo como irresoluble. Este proceso según el cual se instauran lógicas relacionales y personales, que erigen fronteras infranqueables en los procesos y acercamientos a la posibilidad de paz, ha sido abordado por Bar-Tal $(2007,2010)$ como barreras 
socio-psicológicas para la paz y la reconciliación; barreas que se componen de procesos de memoria, de creencias sociales y de emociones compartidas por diferentes sujetos y grupos, y que en general dificultan el trámite pacífico del conflicto y su consiguiente resolución; perpetuando de esta manera la violencia como forma de relación regular y normal en la cultura.

En el marco de este conflicto armado, a partir del año 2012 se inició el proceso de negociación para un acuerdo de paz entre la guerrilla más antigua de Colombia, las FARC-EP (Fuerzas Armadas Revolucionarias de Colombia - Ejército del Pueblo) y el gobierno nacional de Colombia, que supuso la terminación del conflicto entre estos dos actores. Este acuerdo, se firma el 26 de septiembre de 2016, en Cartagena de Indias (Colombia), en cabeza del presidente Juan Manuel Santos y de Rodrigo Londoño Echeverri, comandante en jefe de la guerrilla de las FARC-EP. Tras cuatro años de negociaciones en La Habana (Cuba), este acontecimiento constituyó un hito para la superación de las dinámicas belicistas que habían dominado durante décadas.

Este proceso de paz buscó ser refrendado por el gobierno a través de un plebiscito, convocado para el 2 de octubre del año 2016, buscando el respaldo ciudadano de los acuerdos de la Habana (Presidencia de la República, 2016). Al momento del escrutinio triunfó el NO, con una mínima diferencia porcentual (0.5), por lo cual los ciudadanos no respaldaron los acuerdos de paz.

Este plebiscito por la paz dejó en evidencia la alta polarización que como país se vive, las campañas manipularon emociones como el miedo, la rabia y el odio (Valencia Tello, 2017) a través de lógicas como la enunciada por el gerente de la campaña a favor de la no refrendación de los acuerdos, Juan Carlos Vélez, el cual manifestó que se promovió una estrategia que resultó exitosa: se había logrado que la "gente saliera a votar verraca"83 (E1 Colombiano, 2016).

Tanto la negociación como los acuerdos de paz fueron un escenario político que se vivió en términos afectivos y emocionales (Hernández, 2017). Emergió la alegría y la esperanza en algunos sectores del país frente a la posibilidad de construir un mejor porvenir; algunos periódicos titulaban a propósito de esto que La firma de la paz es una alegría colectiva para todos los colombianos (El País, 2016); En Los Pozos, Caquetá, renace la esperan-

83 En el contexto colombiano la palabra "verraco" hace referencia a enfado, enojo, disgusto o rabia. 
za tras la firma de la paz con las FARC (Noticias Caracol, 2016). De igual manera emergen otras emociones, como la incertidumbre y la desconfianza, amparada en la percepción de injusticia: La paz, el pesimismo y el odio en Colombia" (Barbosa, 2017); Incertidumbre, la sensación que reina a un año de la firma de la paz (Osorio, 2017); A días del plebiscito, Colombia se debate entre la certeza de la guerra y la incertidumbre de la paz (Durán, 2016).

Además de este contexto emocional, la relación entre emociones y conflicto armado (guerra) ha sido estudiada en el marco de las ciencias sociales, en la que se reconoce que el daño y el dolor causado por las dinámicas del conflicto, dejan secuelas emocionales que arraigan crisis y tensiones que contribuyen a la desesperanza aprendida y a la naturalización del conflicto; por lo que para la reconciliación y eventual convivencia entre colombianos en un escenario de paz, se requiere de la participación de voluntades libres de disturbios emocionales como el rencor (Aguilera, 2003).

También se propone que ante los acontecimientos atroces de la guerra, las víctimas presentan una dificultad para visualizar una salida negociada al conflicto, por lo que se nubla pensarse una sociedad que trascienda los límites de la guerra (Hewitt et al., 2016). Claro está que este tipo de procesos no afecta únicamente a las víctimas directas, de hecho, en contextos de guerra se producen subjetividades sociales y políticas, en las que se aprenden formas de convivencia basadas en la violencia como parte de la cotidianidad, lo cual incide de forma directa en la promoción de disposiciones afectivas para que el conflicto armado sea deseable y prolongable, mientras que las soluciones pacíficas son vistas como una postura débil, de rendición y sumisión (Cárdenas, 2013).

En este sentido, emociones como el miedo y el odio, que promueven el mantenimiento del conflicto, son alentados de manera sistemática por las élites del país, de tal manera que se legitiman las lógicas violentas y se propende precisamente por la aniquilación del otro visto como enemigo (Velasco, 2018; Villa, 2016). Por su parte, la desconfianza, además que emerge como una de las principales afectaciones a las dinámicas relacionales de los grupos humanos, en el marco del conflicto (Aguilera, 2003; CNMH, 2014; Hewitt et al., 2016; y Cárdenas, 2013), limita el acercamiento tan necesario para producir la asociación para la acción política en escenarios públicos (Posada \& Carmona, 2016), desvinculando a los sujetos y desarticulando posibles acciones transformadoras.

Es así como las emociones y sentimientos pueden avivar y consolidar el conflicto impidiendo su superación (Huyse 2003), alimentadas por el 
establecimiento de estrategias comunicativas y de manipulación mediática que configuran la imposibilidad de construir sociedad con el adversario (Zuleta, 2015). Así, el conflicto armado se ha revestido de algunas emociones arraigadas por la idea de destrucción del enemigo como una forma legitimada para el control territorial, y que han traído como consecuencia la ruptura del tejido social (Villa, 2013).

Es de esta manera que el complejo entramado emocional se constituye como escenario afectivo favorable a la consolidación de las lógicas del conflicto; estas barreras emocionales acompañan los procesos en que se reafirman los valores patrióticos, se reivindican determinadas víctimas, se construyen memorias parciales y manipuladas, se promueven emociones exacerbadas (como el odio y el miedo), y se legitime la venganza, la rendición y/o la eliminación del adversario, que en Colombia, históricamente han sido prácticas en las élites políticas que se concretan en la contraposición a los procesos de paz adelantados con los grupos al margen de la ley, entorpeciendo los procesos y limitando la construcción del perdón y la reconciliación desde la no-violencia (Villa, 2016).

Es así como las emociones juegan un papel relevante en la comprensión de las dinámicas del conflicto, y particularmente en las consideraciones en torno a los procesos de perdón y reconciliación. A propósito de esto, se ha dicho que, para algunas víctimas, el perdón y la reconciliación se entienden como un tránsito de emociones negativas a positivas que viabilizan el restablecimiento de vínculos, y que sólo se posibilitan en tanto estén acompañados de procesos de justicia restaurativa o distributiva (CastrillónGuerrero et al., 2018).

En este sentido, el perdón y la reconciliación son también procesos emocionales que suponen el tránsito y la superación de emociones como el odio, el miedo y la desconfianza, a procesos de solidaridad, empatía y confianza. Estos procesos suponen la reconstrucción del tejido social que ha sido lastimado, en el marco de procesos de memoria, verdad y justicia (Bueno, 2006). Aunque no siempre perdón y reconciliación se presenten de manera simultánea, en tanto el perdón no es necesario para la convivencia, la reconciliación si lo es, en la medida en que supone la interacción entre los diferentes participantes del conflicto (Cortes, Torres, López, Pérez, \& Pineda, 2015).

Dado este contexto, el momento histórico de país clama por comprensiones que le apuesten a la superación de las lógicas del conflicto, y en esta medida se hace pertinente y relevante comprender las emociones sociales 
que constituyen barreras psicosociales para el perdón y la reconciliación como un aporte analítico a la realidad sociopolítica actual, evitando así el mantenimiento dichas barreras, en tanto éstas aumentan los riesgos de perpetuación, reforzamiento y conservación de diferentes formas de violencia. En ese sentido, la responsabilidad colectiva con la construcción de paz corresponde a un asunto al cual esta investigación aporta en el sentido de posibilitar comprensiones emocionales que den lugar a la transformación social, la reconstrucción del tejido social y el afianzamiento de formas de relacionamiento sustentados en la tranformación emocional, la desnaturalización de la violencia y el respeto por la dignidad humana

Es así que el presente estudio se inscribe en el campo de la Psicología social en perspectiva colectiva, y entenderá las emociones sociales como un fenómeno que se construye y se constituye en la interacción humana y así, son producciones históricas y culturales que comparten los sujetos, en función del contexto compartido (Ahmed, 2015; Boiger, \& Mesquita, 2012; Fernández, 2009, 2000; Jasper, 2011; Orgakova, Borgeaud, \& Scherer, 2009). Las emociones, en perspectiva colectiva, suponen una interrelación entre situación, emoción y objeto hacia el cual se dirige la emoción, por lo que se entiende que toda emoción se produce en situación y se orienta a algún objeto, de tal manera que al hablar de alguno de estos componentes, se hace referencia al sistema mismo completo.

A partir de allí, esta investigación buscará comprender las emociones sociales en tanto se constituyen como barreras psicosociales para el perdón y la reconciliación en Medellín, en el marco del proceso de paz entre la guerrilla de las FARC-EP y el estado Colombiano.

\subsection{Metodología}

Este proceso de investigación se inscribe en las lógicas de la investigación cualitativa (Creswell, 1994; Valles, 2000), con enfoque interpretativo (Vain, 2012), en tanto es de nuestro interés las producciones de sentido elaboradas por los participantes, en términos de las emociones que enuncian en su discurso sobre los actos de violencia en Colombia, y los actores que las perpetuaron (bien sea de origen guerrillero, paramilitar o estatal); en otras palabras, asumimos que las personas son creadoras de su propia realidad social.

El diseño específico es el estudio de casos múltiples, por lo que para la selección de los participantes se abordaron ciudadanos del común, de estrato socioeconómico medio, que no perteneciesen a partidos políticos, movimien- 
tos sociales ni de ONG ni a colectivos de acción política. El muestreo se realizó en bola de nieve (donde los participantes nos ponían en contacto con otros posibles participantes), siguiendo un criterio intencional (Hernández, Fernández \& Baptista, 1991), de acuerdo con la capacidad narrativa de los participantes, en función de diversas categorías sociales: trabajadores, amas de casa, miembros de organizaciones sociales, estudiantes universitarios, trabajadores independientes, desempleados, entre otros.

La metodología de investigación es guiada por la fenomenológica hermenéutica; lo que supone un análisis cualitativo de los hechos, abordados como vivencias y experiencias propias mediante diferentes narrativas expresadas por los participantes y que son recogidos en 43 entrevistas a profundidad, semiestructuradas (Bonilla-Castro y Rodríguez, 1997). Así, se da cuenta de la forma por la cual los investigadores se acercan a la comprensión de la problemática, desde la cosmovisión y lectura de los mismos sujetos y sus interpretaciones del mundo (Bonilla-Castro y Rodríguez, 1997).

La información fue abordada desde el análisis del discurso en términos de la hermenéutica (Martínez, 2015), en un proceso matricial y categorial, con codificación de primer y segundo orden (Flick, 2004); a partir de allí se producen categorías emergentes que dan cuenta de las interpretaciones que los participantes hacen de sus emociones en relación con el conflicto armado en Colombia y de los diferentes actores que le componen. Se proponen las categorías de miedo, odio, rabia y desconfianza como barreras emocionales para el perdón y la reconciliación, que al ser puestas en tensión y discusión posibilitan una categoría axial denominada El otro como amenaza: donde se enlazan las emociones.

\subsection{Resultados}

\subsubsection{Miedo: sobrevivencia a pesar de los vínculos deteriorados}

Para los participantes de la investigación el miedo se constituye como una barrera emocional para el perdón y la reconciliación en tanto erige fronteras, por momentos infranqueables, entre los diferentes sectores o grupos humanos involucrados anteriormente en el conflicto armado. Esta forma de actuar del miedo en los sujetos se concreta en doble vía; por un lado, se entiende que garantiza la vida individual, como mecanismo de supervivencia ante posibles amenazas, al mismo tiempo que desconecta y reduce las posibles interacciones con otros, condición necesaria para la construcción de procesos de reconciliación. 
En este sentido el miedo se produce como la protección de la vida o estrategias de sobrevivencia ante aquel otro - excombatiente- que es percibido como amenazante. Esta dinámica también condiciona las formas de relacionamiento social, lo que implica una mayor reserva en términos de la interacción y de la comunicación: cuidado de ser prudente, respetuoso (...) no simplemente decir cosas al aire y cosas que pueden generar problemas, el sentimiento de tener cuidado, cuidado por la protección de la vida (E43). Traspasar el límite comunicacional y relacional, con las personas que otrora participaron del conflicto armado, es percibido como una cuestión amenazante de la integridad: más avispado el que le ponga problemas a una persona de estas (...) [dado que los excombatientes] son personas potencialmente peligrosas (E43).

Por otro lado, este miedo que sugiere la protección de la vida también silencia, limita y coarta la libertad de expresión: muchas veces quiero escribir algo sobre eso [la polarización de país] pero siempre termino borrándolo quizás por ese miedo a la recriminación (E22), por lo que la comunicación se ve limitada, se acallan las voces, que entienden que las posibles consecuencias de su accionar son adversas para su integridad o para su vida en comunidad; el señalamiento que acusa también es objeto de miedo.

De igual manera, el miedo condiciona las relaciones al distanciamiento, a la ruptura del vínculo social: no, mi amor. Es mejor callar que locamente hablar (...) Pero si me toca de vecino, ah no, él sigue su vida y yo sigo la mía (E5). La vida en comunidad no sería posible de no ser precisamente por los vínculos, las interacciones cara a cara tan necesarias, que el miedo coacciona, diluye y reduce a la sumatoria de individuos en un espacio físico: [sentiría menos miedo], si uno tiene una comunicación no muy grande [pero], digamos que ellos le compartan información, ya uno va a estar como con miedo (...) si uno ve que la cosa es muy maluca uno se pasa (E33); si uno está enterado [de lo que hacen los excombatientes] de pronto si sentiría un poquito de desconfianza y miedo (E15).

\subsubsection{Desconfianza: limitando la credibilidad}

La desconfianza por su parte es vivida como la credibilidad desmoronándose, tanto en las instituciones, como en los actores que han estado o estuvieron vinculados al conflicto y en el futuro mismo del proceso de paz. Se mira a los otros y al devenir con duda, recelo y sospecha; se cuestiona la posibilidad de perdón y reconciliación, atribuyendo esta desconfianza a características de las partes implicadas en el conflicto. 
Los participantes perciben con duda la capacidad de transformación de las personas desvinculadas del conflicto armado y su nuevo rol como sujetos alejados de las dinámicas de la guerra, ejemplo de ello, se cree sobre las FARC-EP, en el contexto de negociación que: umm, (son) pura guerra, a ellos no les ha importado sino la guerra, y supuestamente dicen de algo de que cese al fuego, y hoy dicen cese al fuego, y en la mañana y en la noche están secuestrando, están matando (E14). La credibilidad se desmorona, los desvinculados del conflicto no son vistos como sujetos transformados y transformadores: yo digo que la sociedad ya no les cree a ellos ya perdieron la credibilidad, ellos perdieron eso. (E13). La imagen del otro es entendida como estática, inmutable y a favor del conflicto.

Por su parte, la desconfianza en torno a la idea de futuro se acerca al fatalismo: [la única posibilidad que yo veo] es un renacimiento, una cosa así que acabarán con todo el mundo, con toda una generación y que volvieran a nacer, y que viniese una generación nueva y que comenzásemos a encaminarlos (E30). Se entiende que existen dificultades para la construcción de credibilidad en el excombatiente, el clima emocional se tiñe de desesperanza donde ningún camino que implique la transición negociada y pacífica al conflicto sea posible.

De ese modo, la desconfianza se alimenta también de una sospecha acerca de la posible reincidencia por parte de los excombatientes en acciones bélicas: (...) lo que viene pasando ahora con la entrega de las FARC no ha terminado todavía y posiblemente de pronto no termine, (...) las FARC descansan 1, 2, o 3 años, luego vuelven y arrancan otra vez. (E26). Los procesos de reincorporación a la vida civil de los excombatientes no son asumidos por los participantes como una estrategia fiable, que permita configurar una resignificación del excombatiente como un sujeto transformador, que brinde garantías de seguridad para vincularse a la sociedad.

Desde esta perspectiva, la desconfianza en la escena de procesos de reconciliación, en el marco del proceso de paz no brinda garantías para la superación del conflicto armado, de acuerdo con los participantes, en tanto los discursos de perdón y reconciliación por parte de los excombatientes no son considerados sinceros: yo personalmente, no les creo. Para mí todo es un pantallazo (E29). El proceso de paz es percibido por los participantes como un escenario de mentiras y falsedades, donde no existe una disposición honesta y transparente por parte de los diferentes actores para enfrentarse a los procesos de perdón y reconciliación. 
Es de esta manera como la desconfianza socava la posibilidades para la reconciliación y el perdón, en tanto el otro, que ha transitado por las lógicas del conflicto y la guerra, es visto con recelo y duda, tanto en sus intenciones como en sus acciones; obturando el posible encuentro y la disposición para la construcción de relaciones sociales y comunitarias, que no se permiten el prescindir de la confianza y la solidaridad para su consolidación y superación de la violencia.

\subsubsection{Rabia y enojo: secuelas del daño ocasionado}

Los daños causados en el marco del conflicto armado por parte de los diferentes actores involucrados, permiten la emergencia de la rabia, el enojo y el resentimiento. La atmósfera de rabia que cobija a los participantes es dirigida afectivamente hacia lo que se percibe o se entiende como deudas impagables e irreparables ${ }^{84}$ para con las víctimas directas de la guerra, como lo son la muerte y la desaparición de sus familiares: (...) ellos no me van a devolver a mi hijo o a mi hija, no me van a devolver a toda mi familia; las personas que me han generado todo esto, no se les puede perdonar nada (E39). Esta deuda, al no poder ser condonada a través del perdón, se asienta en los participantes obstaculizando la resignificación del dolor y la pérdida, vinculada con la percepción de un agravio sin justicia.

La rabia se manifiesta de forma visceral hacia el victimario, demandando formas de justicia a modo de retaliación, en lógicas punitivas. La rabia y el enojo no necesariamente requieren una experiencia directa victimizante; requiere la idea de otro malo que ha hecho un daño inconmensurable: $A m i$ si me mataron a un hermano. No supe quién. (...) Yo decía: malditos, hijueputas. De todo les decía. (E30); (...) muchas personas que ellos asesinaron, víctimas, no van a poder ver a su familiar (...) y ese trauma no se lo van a quitar, (...) entonces que paguen el resto de su vida por lo que hicieron (E42).

Así, la rabia exacerba la irritabilidad de los participantes ante la percepción de impunidad, quienes conectan de forma personal las deudas de los excombatientes con las víctimas como un asunto que se asume como propio.

84 Por deudas impagables puede comprenderse que a pesar de que exista un marco legal amparado en la Ley 1448 de 2011 y en los Acuerdos de la Habana, específicamente en el punto referido a las víctimas, es necesario reconocer que los crímenes cometidos en el conflicto armado son considerados por algunas personas como abominables; los daños son sentidos como irreparables y las consecuencias funestas tienen un valor superior a cualquier medida de carácter económica o restrictiva para quienes causaron daño en la integridad física o moral de las personas con motivo del conflicto armado. En este sentido, la relación del daño con su reparación se constituye en sentido estricto como una deuda impagable. 
De esta forma, aunque se desconoce al excombatiente, se le juzga y se le condena, lo que también levanta más la barrera emocional para la reconciliación, en tanto se rechaza la presencia del otro y se vive como agravio la posible convivencia con éste, y se ve en él una libertad inmerecida:

(...) son personas muy dañinas, muy tóxicas, que no merecían estar al lado de nosotros y tomarse un café, sabiendo que son capaces de matar a tantas personas, inclusive jugar con la cabeza de esa persona, o reírse y violar a su esposa y a sus hijas (E42).

Para los participantes el otorgamiento de oportunidades a los excombatientes se entiende como una desfachatez que legitima el delito y puede incentivar comportamientos criminales en la sociedad. Esta idea, por un lado mina la confianza en las instituciones puesto que, según el imaginario de los participantes, en vez de ser castigados y censurados los excombatientes, son premiados; y por el otro, airean la situación de rabia en tanto se percibe un trato injusto en los diferentes sectores de la población:

Entonces hagamos una cosa si es un incentivo y cada vez que yo haga lo que haga, el día de mañana me van a decir entreguen las armas (...) entonces metamos a todas nuestras hijas allá, y el día de mañana simplemente venga, ya nos van a dar oportunidad, nos van a dar casa, carro, beca (...) simplemente se pasó y se borró todo lo que pasó (...) (E27)

Además de esto, en las expresiones de los participantes se da cuenta de una relación cercana entre las emociones de rabia e indignación. Para los participantes, es indignante la concesión de oportunidades a quienes, a su juicio, no las merecen. Esta indignación, se exaspera cuando es acompañada de la negación de oportunidades para otros, en beneficio de los excombatientes: (...) vemos como muchas personas de estratos bajos no se les garantiza todo lo que se les debe garantizar por derecho, entiendo entonces que eso cause indignación, puesto que a ellos se les debe garantizar lo mismo (que a los desvinculados del conflicto) (E22). En un contexto como el colombiano, donde hay altos índices de desigualdad, pobreza y desempleo, resulta complejo para los participantes comprender por qué el gobierno debe priorizar a los excombatientes, en tanto se considera que estos representan la imagen del enemigo o el "malo".

De esta manera, la rabia y el enojo participan del clima emocional en el cual el desvinculado del conflicto armado es segregado en términos simbólicos de la posible conformación de comunidad; se ve como un su- 
jeto indigno de articularse a las lógicas comunitarias y sobre él recaen la mirada inquisitiva que distancia más, que abre más brechas emocionales en el tránsito a la reconciliación y al perdón. La rabia puede convertirse en odio cuando se exacerba la emoción a un punto de considerar la eliminación y exterminio del enemigo como única opción para remediar la situación conflictiva del excombatiente. La rabia genera una demanda a su objeto, sean los excombatientes o el gobierno, mientras en el odio esta demanda se extingue.

\subsubsection{Odio y negación de humanidad}

El odio se presenta como una emoción compartida que vincula el dolor vivido en la guerra con el deseo de venganza o retaliación hacia los victimarios, como única alternativa válida para expiar las culpas de las acciones violentas. Esta emoción sugiere que algunos participantes desean la eliminación a los excombatientes para vengar el daño causado: (...) son personas malas, que no deberían de existir (...) [merecen] la muerte. Si, sin distinción, todos (E21).

Esta emoción se ampara en la constitución de aquellos sujetos desvinculados del conflicto armado, como enemigos; es al otro distinto y amenazante al que se odia, en la medida en que es desconocido como sujeto; uno, no como nosotros, no Colombiano: Sí, sí, yo creo que muchos colombianos sentimos odio... (E42). Por demás, ese otro que es deshumanizado, es entendido sin posibilidad de derechos, y así los participantes pueden justificar su sufrimiento, e inclusive, su muerte:

- Entrevistador: ¿Qué piensas tú que se debería hacer con estos actores armados?

- Participante: matarlos a todos ju, ju, ju, ju (...) (E25)

Se construye de esta manera una justificación de la limpieza social, pues se estima que el objeto de odio (los excombatientes) es perjudicial para la sociedad por lo que sería preferible matarlos. El odio imposibilita la reinserción de los excombatientes en la sociedad, sustentando la idea de destierro, un participante menciona, a propósito de las FARC: (...) no sé, desterrarlos para que no sigan haciendo nada, cooperando para que el gobierno no los tenga ahi (...) pues si que desaparezcan porque lo que han hecho está mal (E39). En ese orden de ideas, el deseo y exterminio por parte de algunos participantes no solamente hace referencia a la eliminación del adversario, sino también a la motivación imperante de alejarlos de los vínculos sociales y comunitarios. 
Cuando habita la emoción de odio no se tolera la presencia o cercanía del excombatiente, en cuanto se considera que este no merece estar en sociedad. El rechazo y la excusión son completas, sin posibilidad de resignificación, así: Me mencionan los paracos y a mí lo primero que me genera es muchísimo odio. Y tengo pues la grosería en la boca pa'mentárselas. Pero, otra forma que pueda desaparecer este sentimiento, no. No creo (E41). Así mismo, en tanto esta emoción se vive, la percepción de justicia se presenta como una forma de venganza: es que vea si por mi fuera, yo mandaría a cascarlos, en serio los odio, odio los soldados demasiado (E39).

En esta medida, el odio se manifiesta como una barrera emocional para el perdón y la reconciliación en cuanto irradia resentimientos, exclusión y polarización que impiden generar los vínculos. Esta barrera para el relacionamiento con el otro imposibilita la materialización del perdón: llega un punto en que odia tanto a una persona que no es capaz de perdonarla, porque uno simplemente no es capaz, y cuando son tantos millones de víctimas (...) y desde hace tantos años (...), es muy complicado (E42). Incluso, se llega a decir que Porque si no fuera odio [lo que sentimos], sería mucho menos dificil de perdonar (E42).

El odio, que obnubila la posibilidad de empatía, posibilita que no se perdone a quien no se humaniza; a quien no se reconoce como sujeto. De igual forma, el desvinculado del conflicto es despojado de su dignidad y del cuidado y protección de su vida. La reconciliación claudica ante el odio, pues éste suscita deseos de venganza, ajusticiamiento y muerte hacia un otro atribuido como ilegítimo. La construcción de una imagen del enemigo, como herencia cultural de la guerra, mina las posibilidades de paz ante una atmósfera sombría y cargada de hostilidad ante quien busca reincorporarse y reconciliarse con la sociedad.

\subsubsection{El otro como amenaza: donde se enlazan las emociones}

Los relatos de los sujetos participantes de la investigación tienen como eje común la idea construida del excombatiente (personas desvinculadas del conflicto armado, bien sea paramilitares, guerrilla o ejército) como amenaza potencial y latente, como sujetos que son portadores de alguna forma siempre plausible de maldad, no se despojarán de su carácter violento. Al excombatiente se le atribuye una imagen negativa inmutable, que se funde con la rabia, el odio, la desconfianza y el miedo, configurando una atmósfera afectiva que limita las posibilidades para el perdón y la reconciliación. En este sentido, la idea según la cual el excombatiente es percibido como una amenaza, constituye una barrera psicosocial para la paz, el perdón y la 
reconciliación, pues condiciona las interacciones sociales, los vínculos y la convivencia, con un otro que investido por una historia imaginada es visto como enemigo: ¿cómo de buenas a primeras van a entrar a la sociedad sabiendo que son delincuentes? (E21).

A partir de la prolongación del conflicto, los múltiples daños causados por las partes implicadas y las memorias construidas alrededor de la violencia, se ha posibilitado la construcción de una historia imaginada del otro en tanto enemigo, al cual se le atribuyen características amenazantes vinculadas a la generación de inseguridad, miedo, desconfianza y odio, les hace ser objeto de exclusión y rechazo. La posibilidad de la convivencia con estos para los sujetos participantes incomoda y limita la posibilidad de la convivencia pacífica, tal como lo narra un participante:

Ay sí, digo que no voy a estar como segura. Con ninguno (...) personajes con una vida me imagino que llena de cosas, como violentas (30E); por todas las cosas que han hecho, terrorismo, como le decía, al principio iniciaron bien y ya después como mal (E12); como uno no sabe nada, entonces ellos son los malos (E19).

Los excombatientes son vistos por los participantes del estudio como un grupo homogéneo, por lo cual generalizan las acciones e intenciones -usualmente teñidas de maldad- al colectivo, sin matizar en aspectos personales o situacionales; todo esto en un horizonte histórico que se perpetúa.

De esta manera, para los participantes, los excombatientes no se despojarán de su carácter violento; se considera que éstos van a continuar la lucha armada y se desconfía de su proceso de reincorporación a la vida civil. El carácter violento atribuido a quien ostentó las armas, imposibilita el reconocimiento de éstos como un "otro legítimo"; en ese sentido, el desconocimiento, rechazo y posible exterminio de los excombatientes se encuentra legitimado en una idea imaginada: mucha gente dice a veces que a ellos como que los maten, que los torturen y así, porque merecen sufrir tanto como ellos hicieron sufrir a la gente (E30).

Es de esta manera que se articulan el miedo, la desconfianza, la rabia y el odio para constituirse barreras emocionales para el perdón y la reconciliación pues no permiten que se trasciende la mirada en relación con las transformaciones que los excombatientes puedan tener. La idea imaginada del excombatiente como enemigo no deja de existir para gran parte de la sociedad que los recibe, reafirmándose a través de la evocación de memorias, imágenes estereotipadas y creencias que arraigan una idea polarizada del otro. 


\subsection{Discusión y conclusiones}

La construcción del otro como amenaza y enemigo permite la emergencia de un "otro ilegitimo" que no es humanizado. Dicha deshumanización es también posible en tanto se desconozca la otra polaridad del excombatiente de la que no se habla: de sus emociones, sentires, derechos, merecimiento de la vida, aunado al desinterés que se tiene por las situaciones que puedan afectarle a éste, o incluso poner en riesgo su vida, en estos términos. Para Ahmed (2015) "el estableciendo de fronteras entre el endogrupo y el exogrupo define "el yo y los otros" en donde los yoes hacen parte del endogrupo y la amenaza hace parte del exogrupo" (p. 90); por tanto es comprensible que al malo, se le excluya, distancie y aleje.

En esta medida, el desvinculado del conflicto armado es portador de un estigma que funge como señal que marca ante la sociedad (Mesa, 2017), que categoriza, limita y determina lo que se puede esperar de un sujeto individual o colectivo (Callejas y Piña, 2005), permitiendo que se induzcan reacciones particulares sobre estos. El estigma que portan los excombatientes, sumado a las condiciones previas de exclusión social, "los ha desprovisto de historia, conocimientos, capacidades y significados: sus cuerpos son vaciados" (Mesa, 2017, p.126).

En concordancia con esto, Riezler (1959) argumenta que el "miedo a lo desconocido" se manifiesta fuertemente en tiempos de crisis. Por tanto, en presencia del miedo ningún espacio físico genera seguridad, y se particulariza tomando como objeto al diferente. En este sentido, "mientras más grande sea el miedo al intruso (es decir a lo diferente) más altas serán las barreras defensivas que levanta cada grupo social" (Rojas, 2008, p.155156). Según, Lizaralde (2012), el miedo propicia memorias de terror que se performatizan en la interacción con los otros, especialmente, con los que son considerados"extraños". Por su parte, Ahmed (2015) mantiene que en tanto se construye una idea imaginada de los otros, éstos se perciben temibles en la medida en que se cree ponen en riesgo al yo. En otras palabras, el miedo es una emoción intensa que advierte que el sujeto ha atribuido un significado de peligro a una situación que se percibe como "amenaza vital" (Lira, 1989). La amenaza pone entonces en riesgo la vida personal y la integridad de quienes en un caso hipotético compartan el mismo territorio y barrio con el excombatiente. Lira (1989), a propósito de esto sostendrá que la amenaza se concibe como situaciones que impliquen la muerte física y la agresión, poniendo en riesgo la integridad del sujeto (1989). El miedo, sirve para protegerse del otro como un peligro (Ahmed, 2015). 
Por su parte, la desconfianza vivida hacia las instituciones y hacia los excombatientes, implica un repertorio de acciones de sobrevivencia vinculadas al rechazo y la exclusión, la indiferencia, el desinterés y la segregación. Así, el atributo del excombatiente es portado como amenaza, e influye directamente en las formas de relacionamiento y en la percepción de la sociedad civil respecto de los procesos sociales. Ejemplo de ello, para los grupos al margen de la ley, serían los procesos de desarme, desmovilización y reintegración (DDR) (Theidon y Betancourt, 2006).

A propósito de esto, Roldán (2013) y Castellanos (2015) plantean que las percepciones de civiles frente a los procesos de DDR están mediadas por la evitación en la interacción, la segregación y la ausencia de voluntad para acogerlos en sociedad. Por lo que la mirada de sospecha y duda pulula en las acciones necesarias para el desescalamiento de las lógicas de la guerra.

En términos de la rabia y el enojo, en cuanto emoción vivida en el ámbito político, toma tonalidades de ira, indignación, cólera, entre otras, por lo general estando relacionada con situaciones de injusticia (Nussbaum, 2014; Petersen, 2006; Roldán, Giraldo \& Martínez, 2017). Según algunos autores, la impartición de justicia parece necesaria para disminuir las cargas que se ponen sobre el ofensor y en este sentido, "cuando la rabia se mengua a un nivel suficientemente bajo, la sociedad como un todo, como también las víctimas, pueden obtener una vida normal' (Petersen, 2006).

Sáenz (2017), partiendo de lo que plantea Nussbaum, expresa las dificultades vinculadas a la emergencia de la rabia entendida como emoción política que toma su curso a través de la venganza como acción o fantasía. La exigencia de una retribución del daño, los pensamientos mágicos (fantasías) dirigidos a infringir sufrimiento a los ofensores (excombatientes) y la degradación de los culpables suponen características de la rabia en la esfera pública (Sáenz, 2017). En este sentido, se nombra la rabia como una emoción cercana a la indignación. A diferencia de la ira y de expresiones más exacerbadas cercanas al odio, la rabia se orienta a una demanda hacia el futuro y delimita la necesidad de buscar la atribución de responsabilidades entre los implicados (Sáenz, 2017).

Por demás, también habría que señalar que la imagen del enemigo suscita sentimientos de odio que conllevan consigo acciones de venganza, que no posibilita la eliminación del conflicto, sino que lo mantiene en el tiempo. En sincronía con esto, Valencia-Tello (2017) afirma que el rencor puede tomar el tránsito hacia la retaliación, lo cual incrementa la violencia. El odio se posiciona en un consenso social como un afecto relacional que busca la 
destrucción del otro, lo cual imposibilita la comprensión del enemigo como legítimo (Sierra, 2007). Así, el odio posibilita el sendero de las guerras, en la medida en que nutre las acciones de ensañamiento y retaliación, que para Bolívar y Flórez (2004), posibilitan ingresar en la lógica de la interacción social en que circulan discursos de venganza hacia una comunidad y los grupos armados.

En este clima emocional compuesto de miedo, ira, odio, indignación y desconfianza (que es promovido desde élites políticas, que recurren a la propaganda (Cogollo \& Durán, 2015), para la perpetuación de las dinámicas de guerra), constituye dinámicas de relación entre sujetos singulares y plurales, que se erigen como barreras para el encuentro con el otro visto como legítimo y posibilite lugares y escenarios de encuentro. Esta argamasa emocional separa los cuerpos que a la distancia son vistos con recelo y sospecha, con temor y desconfianza, puesto que luego de más de 50 años de separación, el estar juntos en la diferencia es la novedad y la convivencia el reto de lo inhóspito. Estas barreras emocionales para el perdón y la reconciliación se sedimentan con el paso del tiempo, por lo que se hacen necesarias acciones que procuren el tránsito de éstas a lógicas de solidaridad y convivencia pacífica.

En términos emocionales, también se han de visibilizar a futuro apuestas que procuren el tránsito de estos afectos a otros que promuevan la convivencia, tal como la solidaridad, la esperanza, la confianza y el amor. En este sentido Beristain (2010) asegura que la tramitación psicosocial de la rabia, por ejemplo, supondría una política que dé mayor espacio a la atención de escucha y empatía por las emociones que se consolidan en la sociedad.

\section{Referencias}

Aguilera, A. (2003). Las secuelas emocionales del conflicto armado para una política pública de paz. Convergencia, 31, 11-37.

Ahmed, S. (2015). La politica cultural de las emociones. Ciudad de México: Programa Universitario de Estudios de Género de la UNAM.

Barbosa, F. (27 de junio de 2017). La paz, el pesimismo y el odio en Colombia. El Tiempo.

Bar-Tal, D. (2007). Sociopsychological Foundations of Intractable Conflicts. American Behavioral Scientist, 50(11), 1430-1453.

Bar-Tal, D. (2010). Culture of Conflicto: Envolvement, Institutionalization, and Consequences. Personality, Human Development and Culture. International Perspectives on Psychological Science, 2, 183-198. 
Bar-Tal, D., y Halperin, E. (2014). Barreras sociopsicologicas para la paz e ideas para superarlas. Revista de Psicología Social, 29(1), 15-30.

Beristain, C. (2010). Manual sobre perspectiva psicosocial en la investigación de derechos humanos. Bilbao: Hegoa.

Boiger, M. \& Mesquita, B. (2012). The Construction of Emotion in Interactions, Relationships, and Culture. Emotion Review, 4(3), 221-229.

Bolívar, I., y Flórez, A. (2004). La investigación sobre la violencia: categorías, preguntas y tipo de conocimiento. Revista de Estudios Sociales, 17, 32-41.

Bonilla-Castro, E. y Rodríguez, P. (1997). Más allá del dilema de los métodos. Bogotá: Norma.

Bueno, A. (2006). La reconciliación como un proceso socio-político. Aproximaciones teóricas. Reflexión política, 15, 64-78.

Callejas, L., y Piña, C. (2005). La estigmatización social como factor fundamental de la discriminación juvenil. El Cotidiano, 134, 64-70.

Cárdenas, J. (2013) Opinión pública y proceso de paz: actitudes e imaginarios de los bogotanos frente al proceso de paz de La Habana entre el gobierno colombiano y la guerrilla de las FARC. Revista Ciudad Paz-ando, 6(1), 41-58.

Castellanos, C. (2015). Percepciones frente al proceso de reintegración de las y los desmovilizados en Bogotá: ¿Se está contribuyendo a una reconciliación social? (Trabajo de Pregrado). Pontificia Universidad Javeriana, Facultad de Ciencias Sociales, Bogotá, Colombia.

Castrillón-Guerrero, L., Riveros, V., Knudsen, M., López, W., Correa-Chica, A., y Castañeda, J. (2018). Comprensiones de perdón, reconciliación y justicia en víctimas de desplazamiento forzado en Colombia. Revista de Estudios Sociales, 63, 84-98.

Creswell, J. (1994). Research Design. Qualitative \& Quantitative Approaches. Thousand Oaks: Sage.

Cogollo, S. N. \& Durán, N. (2015). Paz y posconflicto: compromiso de los ciudadanos para un horizonte imaginado. En: S. N. Cogollo (coord.), Imaginar la paz en Colombia: cavilaciones desde la academia. (pp. 62-71). Medellín, Colombia: Fundación Universitaria Luis Amigó.

Cortes, A., Torres, A., López, W., Pérez, D. y Pineda, C. (2005). Comprensiones sobre el perdón y la reconciliación en el contexto del conflicto armado colombiano. Psychosocial Intervantion, 25, 19-25.

Durán, P. (25 de septiembre de 2016). A días del plebiscito, Colombia se debate entre la certeza de la guerra y la incertidumbre de la paz. New York Times. Disponible en: https:// nyti.ms/2MmKDPA

El Colombiano (6 de octubre de 2016). Estábamos buscando que la gente saliera a votar verraca. Juan C. Vélez. El Colombiano. Disponible en: https://bit.ly/2dxy6ZD

El País (4 de septiembre de 2016). Alvaro Uribe responde por qué se opone al acuerdo de paz. El País. Recuperado de: https://bit.ly/2t5drGN 
Cátedra Colombiana de Psicología

Mercedes Rodrigo 2019

Fernández, P. (2000). La afectividad colectiva. México D. F.: Taurus.

Fernández, P. (2009). Lo psicosocial. El alma pública, 4, 42-49.

Flick, U. (2004). Introducción a la investigación cualitativa. Madrid: Morata.

Hernández, M. (2017). El triunfo del No: la paradoja emocional detrás del plebiscito. Revista Ciudad Paz-ando, 10(2), 92-96

Hernández, R., Fernández, C. \& Baptista, P. (1991). Metodología de la investigación (2a . ed.) México: McGraw-Hill.

Hewitt, N., Juárez, F., Parada, A., Guerrero, J., Romero, Y., Salgado, A., y Vargas, M. (2016). Afectaciones psicológicas, estrategias de afrontamiento y niveles de resiliencia de adultos expuestos al conflicto armado en Colombia. Revista Colombiana de Psicología, 25(1), 125-140.

Huyse, L. (2003). The Process of Reconciliation. En: D., Bloomfield, T., Barnes, and L., Huyse, (eds.) Reconciliation After Violent Conflict, a Handbook. Estocolmo: International IDEA.

Jasper, J. (2011). Emotion and social movements: twenty years of theory and research. Annual Review of Sociology, 37(1), 285-303.

Lira, E. (1989). Psicología del miedo y conducta colectiva en Chile. Boletín de Avepso. Disponible en: https://bit.ly/216rSn1

Lizarralde, M. (2012). La escuela y la guerra, las memorias entre el miedo y el silencio. Praxis Pedagógica, 12(13), 90-103.

Martínez, M. (2002). Hermenéutica y análisis del discurso como método de investigación social. Paradigma, 23(1), 1-13.

Mesa, J. D. (2017). Hacia una nueva mirada de la reintegración de desmovilizados en Colombia: conceptos, enfoques y posibilidades. Revista CS, 23, 105-133.

Noticias Caracol. (27 de septiembre de 2016). En Los Pozos, Caquetá, renace la esperanza tras la firma de la paz con las FARC. Noticias Caracol. Recuperado de: https://bit.ly/2JFAZtB

Nussbaum, M. (2014). Emociones políticas: ¿Por qué el amor es importante para la justicia? México: Paidós.

Orgakova, A., Borgeaud, P. \& Scherer, K (2009). Language and culture in emotion research: a multidisciplinary perspective. Social science information, 48(3), 339-357.

Osorio, M. (23 de noviembre de 2017). Incertidumbre, la sensación que reina a un año de la firma de la paz. El espectador. Recuperado de: https://bit.ly/2B61K41

Petersen, R. (2006). Justicia, rabia, castigo y reconciliación. En F. Cante, y L. Ortiz. (2006). Umbrales de reconciliación, perspectivas de acción política noviolenta. Bogotá: Universidad del Rosario.

Posada, I. C. \& Carmona, J. A. (2018). Subjetividad política y ciudadanía de la mujer en contextos de conflictos armados. Revista Mexicana de Ciencias Políticas y Sociales, $233,69-92$. 
Presidencia de la República (30 de agosto de 2016). Decreto 1391 de 2016, por el cual se convoca a un plebiscito y se dictan otras disposiciones. Diario Oficial 49981.

Riezler, K. (1959). Psicología social del miedo. Revista del Centro de Estudiantes de Filosofia y Letras, 14, 102-116. Disponible en: https://bit.ly/2MsjWZH

Rojas, G. (2008). Apuntes sobre linchamiento y la construcción social del miedo. Tramas, $30,135-158$.

Roldán, O., Giraldo, Y. N., \&, Martínez, M. L. (2017). La emoción como estrategias movilizadora de la acción política de niños, niñas y adolescentes. Revista Lasallista de Investigación, 14 (2), 152-159.

Roldán, L. (2013). La inclusión laboral de los desmovilizados del conflicto en Colombia: Auténtico mecanismo emancipador de la violencia en Colombia. Universitas estudiantes, 10, 107-123.

Sáenz, M. J. (2017). La reconsideración de la ira como emoción política. Sobre Anger and Forgiveness de Martha Nussbaum. En: Diánoia, 62(79), 217-226.

Sierra, A. (2007) Los discursos del odio. Cuadernos del Ateneo, 24, 5-17

Theidon, K. y Betancourt, P. (2006).Transiciones conflictivas: combatientes desmovilizados en Colombia. Análisis político, 19(58), 92-111

Unidad Para las Víctimas. (2018). Registro Único de Víctimas (RUV). Recuperado de: https:// www.unidadvictimas.gov.co/es/registro-unico-de-victimas-ruv/37394

Vain, D. (2012). El enfoque interpretativo en investigación educativa: algunas consideraciones teórico-metodológicas. Revista de Educación, 4, 37-46. Disponible en: http://fh.mdp.edu. ar/revistas/index.php/r_educ/article/viewFile/83/146

Vallés, M. (2000). Técnicas cualitativas de investigación social: reflexión metodológica y práctica profesional. Madrid: Síntesis, S.A.

Valencia-Tello, D. (2017). Las emociones en el proceso de paz colombiano. Revista da Faculdade de Direito UFPR, 62(1), 231-254.

Velasco, M. (2018). La reconciliación tras un conflicto armado: El caso de las escuelas de Perdón y Reconciliación en Colombia. En F. Quiles, A. C. Quiñones, C. Y. Cruz, \& C. Padilla. (eds.) Como Bálsamo de Fierabrás Cultura en tiempos y territorios en conflicto. (pp. 374-391). Sevilla, España: Cuadernos del aula.

Villa, J. D. (2013). The role of collective memory in emotional recovery of political violence in Colombia. International Journal Of Psychological Research, 6(2), 37-49.

Villa, J. D. (2016).Perdón y reconciliación: una perspectiva psicosocial desde la no violencia. Revista Latinoamericana, 15(42), 131-157.

Zuleta, E. (2015). Colombia: violencia, democracia y derechos humanos. Bogotá: Ariel 


\title{
22. "Ser víctima", "Violencia sociopolitica" y "Paz": lo que piensan los habitantes de una zona implicada en el asunto
}

\author{
Julio César Moreno CorReA ${ }^{85}$ \\ Wilson Miguel Salas Picón ${ }^{86}$
}

\section{Resumen}

Barrancabermeja ha vivido las expresiones violentas del conflicto sociopolítico y sus efectos, presentando el fenómeno de haber sido simultáneamente emisor y receptor de personas desplazadas. En sus habitantes se ha generado una manera de pensarse a partir de una particular lectura del fenómeno de la violencia, que estaría relacionada con su actitud hacia los procesos de paz. ¿Cómo se perciben los habitantes de Barrancabermeja respecto de ser víctimas? ¿Cuáles son sus concepciones sobre la violencia sociopolítica y sobre la paz? Con el objetivo de describir las concepciones de "violencia sociopolítica", "ser víctima" y "paz", se aplicó un cuestionario desde la técnica de redes semánticas naturales a 146 personas que han vivido en Barrancabermeja u otro municipio del Magdalena Medio, en los últimos 10 años, o más de la mitad de su vida, mayores de edad, y que expresaron su consentimiento para participar en el estudio (108 mujeres, 38 hombres, edad media 25,79 años). Los términos más asociados a "violencia sociopolítica" ( $\mathrm{J}=249)$ fueron "corrupción" (39\%), "maltrato" $(19 \%)$, "vulneración de derechos" (18\%), "sociedad" (13\%) y "política" (10\%). Para "ser víctima" (J=225) el resultado fue: "vulnerable" (28\%), "maltrato" (27\%), "violencia" (22\%), "dolor" (18\%) y "sufrimiento" (14\%). "Paz" (J=176) estuvo asociada a "tranquilidad" (67\%), "armonía" (33\%), "amor" (28,8\%), "respeto" (24\%) y "libertad" (14\%). Hacia la "paz" hay un mayor

85 Universidad Cooperativa de Colombia Sede Barrancabermeja. Correo: Julio.Moreno@campusucc.edu.co

86 Universidad Cooperativa de Colombia Sede Barrancabermeja. Correo: Wilson.Salas@campusucc.edu.co 
consenso grupal que en "violencia sociopolítica" y "ser víctima". Los valores $\mathrm{J}$ y porcentaje de las palabras tope indican que la mayor producción frente a estos dos últimos conceptos, más que una riqueza conceptual, podría significar disparidad sobre su comprensión. Los conceptos de "paz" señalan su percepción como una dimensión subjetiva: cuatro de los cinco topes aluden a emociones o estados personales, y uno a la relación con los demás (respeto). En "violencia sociopolítica" la conceptualización sí se encuentra frente al otro, pero los términos presentados no necesariamente son antónimos de los de "paz".

Palabras clave: violencia sociopolítica, ser víctima, paz, redes semánticas, conflicto, desplazamiento.

\section{Abstract}

Barrancabermeja has experienced the violent expressions of the sociopolitical conflict, and its effects: the phenomenon of having been simultaneously emitter and receiver of displaced people is observed. Its inhabitants have generated a way of thinking, based on their reading of the phenomenon of violence, which would be related to their attitude towards peace processes. How do the inhabitants of Barrancabermeja perceive themselves as victims? What are their conceptions about sociopolitical violence and about peace? With the aim of describing the conceptions of "sociopolitical violence", "being a victim" and "peace", a questionnaire was applied to 146 people who have lived in Barrancabermeja or another municipality of Magdalena Medio region, in the last ten years, or more than half of their life, of legal age, and who expressed their consent to participate in the study (108 women, 38 men, average age 25.79 years) using the natural semantic networks technique. The terms most associated with "sociopolitical violence" ( $\mathrm{J}=249)$ were "corruption" (39\%), "abuse" (19\%), "violation of rights" (18\%), "society" (13\%) and "policy"(10\%). For "being a victim" (J $=225)$, the results were: "vulnerable" $(28 \%)$, "abuse" $(27 \%)$, "violence" (22\%), "pain" (18\%) and "suffering" (14\%). "Peace" (J=176) was mostly associated with "tranquility" (67\%), "harmony" (33\%), "love" (28.8\%), "respect" (24\%) and "freedom" (14\%). There is a greater group consensus towards "peace" than to "socio-political violence" and "being a victim". The J values and percentage of the top words indicate that the higher production in these last two concepts, rather than a "conceptual wealth", could mean disparity in their understanding. The concepts associated to "peace" indicate its perception as a subjective dimension: four of the five top words refer to emotions or personal states, and only one to the relationship with 
others (respect). In "sociopolitical violence" the conceptualization does meet the other, but the terms presented are not necessarily antonyms of those of "peace".

Keywords: socio-political violence, being a victim, peace, semantic networks, conflict, displacement.

\subsection{Introducción}

La violencia sociopolítica en Colombia ha generado efectos tanto en lo material como en lo inmaterial, dado que su impacto se evidencia en la salud mental de los habitantes de cada uno de los 32 departamentos que conforman el territorio, y en las rupturas de las dinámicas cotidianas, proyectos de vida, formas de alteridad, producción en los modos de subjetivación, modos de ser y pensarse, reestructuración de las dinámicas comunitarias y sociales, revaloración del sujeto político, entre otras tantas afectaciones que deben ser visibilizadas dado su nivel de significancia para el establecimiento de acuerdos de paz, estables y duraderos. La violencia sociopolítica en Colombia se caracteriza a nivel territorial por tener particularidades en su génesis, permanencia y efectos. Por ello, su lectura y comprensión debe iniciar a través de un análisis centrado en el territorio, lo local, sus dinámicas, sus discursos (Carvajal-Pardo, 2007), al igual que en cada uno de los actores participantes de manera directa o indirecta. Para Carvajal-Pardo (2007), desde la perspectiva griega, la violencia sociopolítica es producto del conflicto, y esta tiene su origen en un desequilibrio en la sociedad entre "Dike, la Justicia, y Eunomia, el Buen Gobierno" (p. 10).

En concordancia con lo expuesto, la región del Magdalena Medio, conformada por 9 departamentos y 31 municipios, no ha sido ajena a la realidad del país, habiendo sido uno de los escenarios más golpeados por el conflicto armado, al igual que sus dinámicas-efecto y la ausencia de una institucionalidad estatal. Barrancabermeja es uno de los municipios que conforman dicha región, territorio que ha vivido las expresiones violentas del conflicto sociopolítico y sus efectos: en el municipio se observa el fenómeno de haber sido simultáneamente emisor y receptor de personas desplazadas; en sus habitantes se ha generado una manera de pensarse, a partir de una particular lectura del fenómeno de la violencia, que estaría relacionada con su actitud y percepción hacia procesos de paz.

De acuerdo con la Conferencia Episcopal (noviembre de 2006), en Barrancabermeja se expresan características que le han significado estar implicado en el conflicto vivido en Colombia: la ocupación de su territorio estuvo 
marcada por eventos que conllevaban una fuerte tensión social, por ejemplo "la colonización de baldíos, el exterminio de etnias aborígenes, la conquista del siglo XIX, la navegación de vapor, la forma violenta de explotación de los recursos naturales y la explotación petrolera en manos de extranjeros" (p. 3); en el municipio se han generado ofertas de servicios como la salud, la educación, el sistema jurídico, ligadas a la presencia de la empresa petrolera, a partir de lo cual se entiende que reciba alto número de migrantes, quienes buscan una oportunidad laboral, o de atención a sus necesidades, provenientes no sólo de los municipios aledaños de la región, sino de otras regiones colombianas. Aprile-Gniset (1997) presenta ejemplos de cómo estas dinámicas contribuyeron en la transformación de caserío de pescadores a una urbe, a lo largo del siglo XX. En las dos últimas décadas del siglo anterior, se registró en Barrancabermeja la presencia y, más aún, el control políticomilitar de grupos insurgentes como el ELN, las FARC y el EPL; el cambio de siglo trajo una disputa por el poder, con el consecuente escalamiento del conflicto armado, entre estos grupos y las Autodefensas Unidas de Colombia (AUC), grupo paramilitar que afianzó su presencia en diferentes zonas de Colombia, y que en este municipio llegó a ser el nuevo actor al margen de la ley dominante (Conferencia Episcopal, 2006, p. 6). La presencia de los grupos paramilitares en el casco urbano y la permanencia de la insurgencia en el sector rural ocasionó numerosos enfrentamientos, a partir de los cuales la población civil se vio seriamente afectada; las partes mantienen hoy día, bajo nuevas denominaciones, el interés por el dominio del territorio, pues esto implica el control del microtráfico local, de las rutas de la coca, el robo a los poliductos nacionales, la minería ilegal, lo que deriva en amenazas a líderes sociales, asesinatos selectivos, confinamiento de asentamientos humanos rurales $\mathrm{y}$, por consiguiente, el desplazamiento de pobladores.

Las premisas expuestas, al igual que los 50 años de violencia sociopolítica del país, permitieron dar origen a un escenario de diálogos nacionales de paz y con ello, el establecimiento de unos acuerdos con el grupo FARC-EP. A más de un año de su implementación, se evidencian grandes deficiencias $\mathrm{y}$ escenarios de riesgo que se convierten en foco para un nuevo brote de violencia. Frente a dicho planteamiento, Corporación Regional para la Defensa de los Derechos Humanos (Credhos) (5 de mayo de 2017) ratifica lo mencionado:

La implementación de los acuerdos y la construcción de la paz en la región del Magdalena Medio hoy encuentra muchos obstáculos que ponen en riesgo y afectan considerablemente los derechos civiles y políticos así como también los derechos económicos, sociales, 
culturales y ambientales (Desca), como son: el incumplimiento del gobierno en la Zona Veredal Transitoria de Normalización, ubicada en el corregimiento de Carrizal, Remedios (Antioquia); la seguridad de las comunidades a los largo de la región, las garantías a las y los defensores de los derechos humanos, la continuidad del conflicto armado, la presencia de actores armados tales como: las Fuerzas Militares y sus organismos de seguridad, la guerrilla del ELN y el paramilitarismo representado en las "AGC/Clan del Golfo/Oficina de Envigado"; y adicionalmente el alto índice de desempleo, la crisis de la salud, problemática del agua, la crisis en la vivienda, entre otros (párr. 1) [...] Estas afectaciones que agravan los derechos humanos en su integralidad no permiten que la población vea el postacuerdo como un periodo de oportunidades, sino por el contrario hay desesperanza, desconfianza y temor en sus territorios (párr. 2).

La realidad expuesta evidencia fuertes afectaciones respecto a la implementación de los acuerdos de paz, al igual que su futuro, de seguirse presentando los factores de riesgo mencionados.

Los modos de ser y pensar (esquemas de pensamientos) de las personas, afectados no sólo por las dinámicas de la violencia sociopolítica sino también por los marcos normativos establecidos por la institucionalidad, afectan la actitud que se tenga hacia las diversas situaciones que han de vivirse en la cotidianidad (Morris y Maisto, 2011); entre estas puede estar el vivir situaciones de conflicto, encontrarse con antiguos actores armados que ahora buscan regresar a la vida civil, recibir indicaciones hacia la convivencia, compartir con personas afectadas física, emocional y socialmente por el conflicto armado. La importancia de estos esquemas conlleva a que sea relevante identificar y comprender la forma en que las personas piensan sobre determinados aspectos de la vida, pues le implican una particular disposición hacia estos (Ajzen, 1987); por lo tanto, para promover acciones hacia la superación del conflicto y sus efectos, es necesario conocer cómo están significados en el discurso de los habitantes de Barrancabermeja expresiones como "ser víctima", "violencia sociopolítica" y "paz".

González (3 de enero de 2015) realiza un análisis semántico sobre los discursos y textos producidos sobre los acuerdos de paz, teniendo como resultado "la semántica del proceso de paz". El análisis estadístico textual realizado, permite realizar las siguientes afirmaciones: El corazón de los acuerdos son las comunidades; el componente de participación es fundamental para mantener vivos los acuerdos. Asimismo, González indica: 
Estos métodos de análisis cuantitativo permiten ver cuáles son los conceptos o campos semánticos más reiterativos pero también nos permiten descubrir lo que no se dice. No se habla de un cambio de modelo económico, solo se encuentra una vez la palabra "expropiación" y dos veces "extinción de dominio". No existe el concepto de "lucha de clases" ni de "ricos versus pobres". No se usa la palabra "pobres" sino que se habla de "pobreza". De hecho, en los comunicados se habla de "erradicación de la pobreza rural, lucha contra la pobreza y la desigualdad o la generación de ingresos" (3 de enero de 2015, párr. 5).

Cualquier proceso de paz debe fundamentarse desde lo local y hacer vida el concepto de participación en los procesos; el fundamento de esta premisa incluye el conocer cómo piensan las personas sobre determinado aspecto. En los habitantes barramejos se ha generado una manera de pensarse, a partir de una particular lectura del fenómeno de la violencia, al igual que de los mecanismos jurídicos establecidos por la institucionalidad. Esta tendencia cognitiva estaría relacionada con su actitud y percepción hacia procesos de paz. A partir de lo anterior, surgen los siguientes interrogantes: ¿cómo perciben los habitantes de Barrancabermeja el ser víctima? ¿Cuáles son sus concepciones sobre la violencia sociopolítica y sobre la paz? Finalmente, construir la paz, amerita la comprensión y transformación de significados que se han ido elaborando por las dinámicas del conflicto armado y los marcos jurídicos establecidos por la institucionalidad para su abordaje, los cuales juegan un papel fundamental en la cognición social de los ciudadanos y en las dinámicas de relacionamiento y reconocimiento (Farfán-Quijano, 2017).

\subsection{Método}

Se desarrolló un estudio descriptivo, transversal, para cumplir el objetivo de describir las concepciones de "violencia sociopolítica", "ser víctima" y "paz" en habitantes de Barrancabermeja. El muestreo fue no probabilístico; los sujetos debían cumplir con las condiciones de ser mayores de edad, manifestar su consentimiento para participar en el estudio y haber vivido en Barrancabermeja u otro municipio aledaño en la región del Magdalena Medio, en los últimos 10 años, o más de la mitad de su vida. En total participaron 146 personas, 108 mujeres y 38 hombres, cuya edad media fue de 25,79 años.

Para la recolección de la información se empleó la técnica de redes semánticas, la cual “constituye un recurso empírico de acceso a la organización 
cognitiva de los significados, a través de los significantes empleados, considerando que el universo cognitivo que de ahí resulta, es fruto también de aprendizajes sociales" (Vargas-Garduño, Méndez-Puga y Vargas-Silva, 2014, p. 3). Vera-Noriega, Pimentel y Batista de Albuquerque (2005) manifiestan que los estudios sobre redes semánticas pueden constituir un camino para conocer el pensamiento colectivo desde la memoria semántica. Se aplicó un cuestionario en el que se pidió a los participantes escribir cinco términos que asociaran a cada palabra estímulo presentada, y luego calificar cada término según su grado de relación con la palabra estímulo, asignando números del 1 al 5, siendo 1 el valor correspondiente a la palabra más relacionada, y progresivamente hasta el 5 como el valor para la menos relacionada de las que hubiera escrito en cada caso. Los términos presentados como estímulo fueron "violencia sociopolítica", "ser víctima" y "paz"; antes de estos se presentó un estímulo no relacionado con el estudio, a manera de entrenamiento.

Los resultados se analizaron siguiendo la propuesta de Hinojosa para el tratamiento de redes semánticas naturales; es decir, se establecieron los términos resultantes (ajustando imprecisiones ortográficas, coincidencia de palabras y expresiones extensas), para poder organizarlos primero en orden decreciente de frecuencia, y luego por mediana creciente (Hinojosa, 2008, p. 143). Adicionalmente se estableció el número total de términos generados a partir de cada palabra estímulo (valor J) y el porcentaje de los participantes que aludió al mismo. Con base en esos datos, se obtuvo el conjunto de términos con mayor frecuencia de asociación a los de interés para el estudio.

\subsection{Resultados}

En primer lugar, se presenta la caracterización del grupo participante, posteriormente se muestran los resultados frente a los términos "violencia sociopolítica", "ser víctima" y "paz", arrojados por el análisis de redes semánticas naturales, esto es, los valores J (total de términos), los términos de mayor frecuencia (presentados con valores superiores al 6\%), y la indicación de los cinco términos más frecuentes para cada caso.

\subsubsection{Caracterización de los participantes}

El grupo estuvo compuesto por una mayoría de mujeres (74\%). La edad mínima fue 18 y la máxima 72 , con un promedio de 25,79 y una desviación típica de 10,20. La mayor parte de los participantes han alcanzado estudios universitarios $(69,86 \%)$ y habitan en el sector urbano $(93,84 \%)$. Fue indagado si los participantes se consideraban víctimas del conflicto armado 
en Colombia, a lo que 55 (el 37,7\%) respondieron afirmativamente. Sin embargo, sólo 17 de ellos han interpuesto alguna denuncia o declaración ante la autoridad competente como víctima por hechos relacionados con el conflicto armado. La proporción de mujeres que se consideró víctima $(39 \%)$ es ligeramente superior a la de hombres (34\%).

Tabla 1. Caracterización de los participantes

\begin{tabular}{|c|c|c|c|}
\hline \multicolumn{2}{|r|}{ Variables } & $f$ & $\%$ \\
\hline \multirow{3}{*}{ Sexo } & Hombre & 38 & 26,03 \\
\hline & Mujer & 108 & 73,97 \\
\hline & Total & 146 & 100,00 \\
\hline \multirow{6}{*}{ Edad } & 25 o menos & 101 & 69,18 \\
\hline & 26 a 35 & 23 & 15,75 \\
\hline & 36 a 45 & 13 & 8,90 \\
\hline & 46 a 55 & 5 & 3,42 \\
\hline & 56 o más & 4 & 2,74 \\
\hline & Total & 146 & 100,00 \\
\hline \multirow{6}{*}{ Nivel educativo } & Primaria & 2 & 1,37 \\
\hline & Bachillerato & 15 & 10,27 \\
\hline & Tecnólogo & 21 & 14,38 \\
\hline & Universitario/pregrado & 102 & 69,8 \\
\hline & Posgrado & 6 & 4,11 \\
\hline & Total & 146 & 100,00 \\
\hline \multirow{3}{*}{ Ubicación vivienda } & Rural & 9 & 6,16 \\
\hline & Urbano & 137 & 93,84 \\
\hline & Total & 146 & 100,00 \\
\hline \multirow{7}{*}{ Condición laboral } & Estudiante & 93 & 63,70 \\
\hline & Desempleado & 9 & 6,16 \\
\hline & Empleado & 28 & 19,18 \\
\hline & Trabajador independiente & 10 & 6,85 \\
\hline & Labores domésticas del propio hogar & 4 & 2,74 \\
\hline & Jubilado o pensionado & 2 & 1,37 \\
\hline & Total & 146 & 100,00 \\
\hline \multirow{3}{*}{$\begin{array}{l}\text { ¿Usted considera que ha } \\
\text { sido víctima del conflicto } \\
\text { armado en Colombia? }\end{array}$} & Sí & 55 & 37,67 \\
\hline & No & 91 & 62,33 \\
\hline & Total & 146 & 100,00 \\
\hline
\end{tabular}




\begin{tabular}{|c|c|c|c|}
\hline \multicolumn{2}{|r|}{ Variables } & $f$ & $\%$ \\
\hline \multirow{3}{*}{$\begin{array}{l}\text { ¿Ha interpuesto alguna } \\
\text { denuncia o declaración ante } \\
\text { la autoridad competente? }\end{array}$} & Sí & 17 & 11,64 \\
\hline & No & 129 & 88,36 \\
\hline & Total & 146 & 100,00 \\
\hline
\end{tabular}

Fuente: elaboración personal.

\section{Violencia Sociopolitica}

En el caso de "violencia sociopolítica" resultaron 249 términos que al menos una vez fueron mencionados por algún participante (valor J). Una vez hecho el conteo de frecuencias, se observó que hubo un término que destacó sobre los demás: "corrupción" con 39\%, es decir, 4 de cada 10 participantes asocian la violencia sociopolítica a la corrupción que ocurre en Colombia. Los siguientes términos en la lista fueron maltrato (19,2\%), "vulneración de derechos" (18,5\%), "sociedad" (13\%) y "política" (10,3\%). Se presentan los términos que obtuvieron un porcentaje superior al $6 \%$ en el grupo frente al término de este apartado (tabla 2).

Tabla 2. Análisis de redes semánticas para violencia sociopolítica

\begin{tabular}{|l|c|c|c|}
\hline \multicolumn{1}{|c|}{ "Violencia sociopolítica" (J=249) } & $\mathbf{f}$ & $\%$ & Mediana \\
\hline Corrupción & 57 & 39,0 & 2 \\
\hline Maltrato & 28 & 19,2 & 3 \\
\hline Vulneración de derechos & 27 & 18,5 & 1,5 \\
\hline Sociedad & 19 & 13,0 & 3 \\
\hline Política & 15 & 10,3 & 2 \\
\hline Agresión & 14 & 9,6 & 2 \\
\hline Violencia & 14 & 9,6 & 3 \\
\hline Abuso & 13 & 8,9 & 2 \\
\hline Desigualdad & 12 & 8,2 & 2 \\
\hline Víctimas & 12 & 8,2 & 2 \\
\hline Desplazamiento & 12 & 8,2 & 3 \\
\hline Lucha & 12 & 8,2 & 3 \\
\hline Pobreza & 11 & 7,5 & 3 \\
\hline Daño & 10 & 6,8 & 3 \\
\hline Discriminación & 10 & 6,8 & 3 \\
\hline Poder & 10 & 6,8 & 3 \\
\hline Muerte & 9 & 6,2 & 2 \\
\hline Injusticia & 9 & 6,2 & 3 \\
\hline Destrucción & 9 & 6,2 & 3 \\
\hline Guerra & 9 & 6,2 & 3 \\
\hline
\end{tabular}

Fuente: elaboración personal 
"Corrupción", "sociedad" y "política", entre la lista de los 10 primeros términos presentados, parecen estar más asociados a causas de la violencia, mientras que los siete términos restantes hacen referencia a los efectos. Esto podría considerarse una expresión de la percepción que se tiene de las múltiples afectaciones por causa de la violencia: hay más variedad de términos para nombrar sus diferentes efectos, mientras que la causa está más asociada a lo relacionado con el Estado y la desigualdad social. Así mismo, entre los tres términos indagados, este presenta el valor J más alto.

\subsubsection{Ser víctima}

Los participantes emplearon 225 términos para referirse a "ser víctima"; de ellos el más frecuente fue "vulnerable" $(28,1 \%)$, seguido por "maltrato" (26,7\%), "violencia" (21,9\%), "dolor" (17,8\%) y "sufrimiento" $(14,4 \%)$. En este caso no se aprecia un término que muestre alguna ventaja significativa en frecuencia respecto de los otros, pero sí llama la atención que los 10 primeros términos sobrepasan el $10 \%$, y están cerca los unos de los otros; en total 18 términos obtuvieron valores superiores al $6 \%$

Tabla 3. Análisis de redes semánticas para "Ser víctima"

\begin{tabular}{|l|c|c|c|}
\hline \multicolumn{1}{|c|}{ "Ser víctima" (j=225) } & $\mathbf{F}$ & $\%$ & Mediana \\
\hline Vulnerable & 41 & 28,1 & 2 \\
\hline Maltrato & 39 & 26,7 & 3 \\
\hline Violencia & 32 & 21,9 & 2 \\
\hline Dolor & 26 & 17,8 & 3 \\
\hline Sufrimiento & 21 & 14,4 & 2 \\
\hline Daño & 20 & 13,7 & 2 \\
\hline Abuso & 19 & 13,0 & 3 \\
\hline Perjuicio & 17 & 11,6 & 3 \\
\hline Agresión & 15 & 10,3 & 2 \\
\hline Violación de derechos & 15 & 10,3 & 2 \\
\hline Afectado & 14 & 9,6 & 2 \\
\hline Tristeza & 14 & 9,6 & 3,5 \\
\hline Desplazado & 13 & 8,9 & 2 \\
\hline Indefenso & 11 & 7,5 & 2 \\
\hline Injusticia & 11 & 7,5 & 4 \\
\hline Agredido & 10 & 6,8 & 2 \\
\hline Violación & 10 & 6,8 & 3 \\
\hline Victimario & 9 & 6,2 & 2 \\
\hline
\end{tabular}

Fuente: Cuestionario redes semánticas 
Frente a "ser víctima" se aprecian términos referidos a la percepción singular y colectiva de los efectos de la violencia. "maltrato", "violencia", "abuso", "perjuicio", "agresión" y "violación de derechos" son términos en cuya definición está implicada la acción entre víctima y victimario, mientras que "vulnerable", "dolor", "sufrimiento" y "daño" se refieren principalmente al estado de la víctima. Un valor J más reducido que en el caso anterior muestra un mayor acuerdo en la manera de comprender el ser víctima, que en referirse a la violencia sociopolítica; sin embargo, no aparecen términos con porcentajes de frecuencia muy altos, lo que quiere decir que hay muy variadas formas de percibir(se) a las víctimas en relación con lo que se observa en el contexto social de los participantes del estudio.

\subsubsection{Paz}

Frente al término "paz" se presentó un menor valor J (176) y se observaron porcentajes en las frecuencias más altos en los diez primeros términos usados que en los casos anteriores. "Tranquilidad" (67,1\%) muestra una mayoritaria tendencia para referirse a la paz; "armonía" (33\%), "amor" $(28,8 \%)$, "respeto" (24\%) y "libertad" (14\%) completaron los cinco primeros términos de la lista. 18 términos alcanzaron valores superiores al $6 \%$

Tabla 4. Análisis de redes semánticas para "Paz"

\begin{tabular}{|l|c|c|c|}
\hline \multicolumn{1}{|c|}{ "Paz" (j=176) } & $\mathbf{F}$ & $\%$ & Mediana \\
\hline Tranquilidad & 98 & 67,1 & 2 \\
\hline Armonía & 48 & 32,9 & 3 \\
\hline Amor & 42 & 28,8 & 3 \\
\hline Respeto & 35 & 24,0 & 3 \\
\hline Libertad & 21 & 14,4 & 2 \\
\hline Tolerancia & 20 & 13,7 & 3,5 \\
\hline Felicidad & 18 & 12,3 & 4 \\
\hline Equidad & 17 & 11,6 & 3 \\
\hline Acuerdos & 16 & 11,0 & 3 \\
\hline Igualdad & 16 & 11,0 & 3 \\
\hline Unión & 15 & 10,3 & 2 \\
\hline Calma & 14 & 9,6 & 3,5 \\
\hline Sin violencia & 13 & 8,9 & 3,5 \\
\hline Bienestar & 12 & 8,2 & 2 \\
\hline Reconciliación & 12 & 8,2 & 4 \\
\hline Esperanza & 10 & 6,8 & 3 \\
\hline Justicia & 10 & 6,8 & 3 \\
\hline Serenidad & 9 & 6,2 & 2 \\
\hline
\end{tabular}

Fuente: elaboración personal 
Las dos terceras partes de los participantes coinciden en entender la paz como tranquilidad; en este caso es muy clara la referencia a un estado subjetivo como principal asociación de paz (tranquilidad, armonía, amor), y a una manera de relacionarse con los demás (respeto). Otros términos que aparecen con porcentajes superiores al 10\% aluden a condiciones para la paz: tolerancia, acuerdos e igualdad.

\subsection{Discusión}

Un aspecto que ha generado dificultad para asuntos como la atención y reparación es la definición de lo que se entiende por víctima. De acuerdo con la Ley 1448 de 2011, las víctimas son

aquellas personas que individual o colectivamente hayan sufrido un daño por hechos ocurridos a partir del $1^{\circ}$ de enero de 1985 , como consecuencia de infracciones al Derecho Internacional Humanitario o de violaciones graves y manifiestas a las normas internacionales de Derechos Humanos, ocurridas con ocasión del conflicto armado interno (art. 3).

Las personas afectadas por el conflicto armado han estado asociadas a diversos conceptos: con el "ocupante sin lugar" en los procesos de justicia transicional, con la figura de "testigo" - y en este sentido, con una parte más activa - en los procesos penales, como "sobreviviente", e incluso como sujeto de "orgullo y dignidad" (Guerrero, 2007; Booth, 2007; Wieviorka, 2009, citados por Delgado, 2011, pp. 37-38). En relación con esta última acepción, recientemente se habla de las víctimas como "sujetos de justicia", "testigos históricos de excepción", "portadores de memoria" y portadores de una "superioridad moral" en relación con sus victimarios (Villa et al., 2007; Cepeda, 2006, citados por Delgado, 2011, p. 40).

En los hallazgos del presente estudio el término "daño" aparece en sexto lugar en el análisis de "ser víctima"; lo que parece ser más relevante para la población es la percepción de vulnerabilidad, que no necesariamente deriva en un daño físico, pero sí implica una afectación psicológica, de tal suerte que podría considerarse a la víctima no solo a quien recibe directamente el daño, sino que es suficiente con saberse vulnerable (y esto es posible a partir de ver los efectos de la violencia sobre los más inmediatos: familiares y vecinos). En este sentido, habría una crítica a la concepción de víctima, y se señala la necesidad de incluir la percepción de vulnerabilidad como un criterio adicional a la definición. En otras palabras: en Colombia, de 
alguna manera todos somos víctimas, pues el grado de vulnerabilidad ante el conflicto no dejó a ninguno excluido. La premisa expuesta, reafirma el marco empírico que se ha venido construyendo con relación a la noción de víctima desde una dimensión situacional y no condicional. Asimismo, abre la puerta para el planteamiento de un criterio temporal de victimización en tres niveles: antes (ausencia de garantías, sensación de vulnerabilidad), durante (conflicto armado) y después (mecanismos institucionales, ausencia de la garantía de derechos).

Ahora bien, para construir un escenario territorial de paz se requiere la construcción de marcos de referencia desde el sentir-pensar (memorias semánticas) de los actores involucrados ${ }^{87}$, sus discursos y dinámicas, modos de subjetivación, significación y resignificación, dado que constituyen la base para establecer acuerdos de paz desde lo local, participativos y territoriales (multiculturales), tal como lo plantea la irenología.

$\mathrm{El}$ art. $22^{\circ}$ de la Constitución Política reconoce la paz como un derecho y un deber de obligatorio cumplimiento; el término es mencionado 13 veces en la carta magna, la mayoría de ellas para referirse a ausencia de conflicto bélico ("tiempos de paz"); sin embargo, de acuerdo con los resultados, las personas de la región hacen una comprensión de paz como algo más allá del fin del conflicto, y está referido a la tranquilidad, la armonía, el amor, el respeto y la libertad. Si se piensa esta noción de paz, combinada con los hallazgos frente al término "violencia sociopolítica", en los cuales se hace mención mayoritariamente a la corrupción, puede inferirse que las personas ven afectada su tranquilidad a raíz de las actuaciones dolosas de agentes estatales ("política" y "vulneración de derechos"), por tanto la dimensión de la paz como deber del Estado pasa no solo por encontrar salida al conflicto interno del país, sino principalmente por el buen ejercicio del deber público, de modo que el ciudadano no se sienta vulnerable (recuérdese la noción de víctima observada en el estudio) ante las acciones del mismo Estado.

La violencia sociopolítica, desde la orilla de las organizaciones de los derechos humanos, se define como una relación de fuerza intencional, tensión y afectación de carácter político, social que involucra a varios actores y cuyo objetivo es modificar o mantener un modelo de Estado o colectivos

87 Es importante superar las etiquetas del modelo de justicia retributiva "víctima y victimario" y migrar a una dimensión mucho más relacional, eje central de la justicia restaurativa dado que uno de los efectos más notables de la violencia sociopolítica es la escisión de la cotidianidad y por ende, las relaciones comunitarias, alteraciones en el proyecto de vida individuales y comunitarios y una reconfiguración del ser 
humanos con una identidad definida (Gómez, 2006; Banco de Datos de derechos Humanos y Violencia Política Cinep, 2009; Camilo, 2002). El hecho de que el término "corrupción" haya emergido con tanta claridad como el más frecuente ante la violencia sociopolítica, da cuenta que la comunidad tiene una comprensión de cómo existe la mencionada relación de fuerza apalancada desde quienes se supone están para garantizar sus derechos. De lo anterior se entiende por qué palabras como "guerra" y "muerte" aparecen con menos frecuencia que aquel término.

Es importante indicar que el estudio estuvo limitado a los datos obtenidos en Barrancabermeja, por tanto, sus resultados no han de considerarse un reflejo del panorama nacional; así mismo cabe recordar que obedeció a un muestreo no probabilístico. Sin embargo, lo hallado permite comprender cómo en este territorio - cuyos habitantes son hijos, o nietos de migrantes de otras regiones del país - las personas se han dispuesto con una manera particular de pensar estos asuntos vigentes en un momento en el que el país afronta la realidad de la implementación de lo acordado con el grupo de las FARC.

\subsection{Conclusiones}

La descripción de las redes semánticas para los tres términos en estudio muestra que hacia el término "paz" hay un mayor consenso grupal que lo observado en "violencia sociopolítica" y "ser víctima". Los valores J y el porcentaje de las palabras tope indican que la mayor producción frente a estos dos últimos conceptos, más que una "riqueza conceptual", podrían estar mostrando disparidad sobre su comprensión por las múltiples formas en que afectan a la población.

Los conceptos de "paz" señalan su percepción como una dimensión subjetiva: cuatro de los cinco topes aluden a emociones o estados personales, y uno solo a la relación con los demás (respeto). En "violencia sociopolítica" la conceptualización sí se encuentra frente al otro, pero los términos presentados no necesariamente son antónimos de los de "paz". En cuanto a "ser víctima", las palabras halladas muestran tanto a la acción entre uno que agrede y otro que padece, como el efecto de la acción violenta. La comparación entre los resultados muestra un mayor acuerdo entre los participantes para entender la paz como tranquilidad. Suele pensarse la paz como antónimo de la violencia, pero no es lo que se observa en la red semántica; la paz no es ausencia de guerra. La violencia sociopolítica no requiere del uso de armas, sino que es sentida primordialmente como el ejercicio indebido del 
poder para el lucro de algunos. La corrupción estatal genera condiciones que hacen sentir vulnerable al ciudadano, lo que rompe con su tranquilidad en los diferentes aspectos del ejercicio de su ciudadanía.

Entonces, haciendo una elaboración con el resultado de las redes semánticas, podríamos ilustrar la situación así: la comunidad anhela un estado de tranquilidad, que cree posible construir a partir del respeto, el establecimiento de acuerdos, con principios como la equidad, el amor y la unión; pero percibe que es vulnerable frente a la acción del otro, que puede ser el mismo representante del poder estatal, cuyas acciones pueden ser violentas, conllevando dolor y sufrimiento, y que es causado principalmente por la corrupción, que se expresa en la vulneración de los derechos.

Como corolario con base en los valores J y los porcentajes en cada red semántica, lo siguiente: ¿Acaso es más fácil ponernos de acuerdo en lo que consideramos paz que en la violencia? ¿Hay muchas formas de hacer violencia, pero muy pocas para hallar la paz?

\section{Referencias}

Ajzen, I. (1987). Attitudes, Traits, and Actions: Dispositional Prediction of Behavior in Personality and Social Psychology. Advances in Experimental Social Psychology, 20(1), 1-63. DOI: https://doi.org/10.1016/S0065-2601(08)60411-6

Aprile-Gniset, J. (1997). Génesis de Barrancabermeja. Barrancabermeja: Instituto Universitario de la Paz.

Banco de datos de derechos humanos y violencia política Cinep. (2009). Noche y Niebla; Panorama de derechos humanos y violencia política en Colombia, 39 [Versión electrónica]. Disponible en: https://www.nocheyniebla.org/wp-content/uploads/u1/39/ Niebla39.pdf

Carvajal-Pardo, A. (2007). Semántica y pragmática de la guerra y de la paz. Usos discursivos del presidente Uribe para incidir en el conflicto armado colombiano. Perspectivas internacionales, 3(2), 7-38.

Camilo, G. A. (2002). Salud Mental y Derechos Humanos en un contexto de violencia sociopolítica. Bogotá: ARFO.

Corporación Regional para la Defensa de los Derechos Humanos - Credhos (5 de mayo de 2017) Magdalena Medio, crisis social y política en el centro de la paz. Agencia Prensa Rural [Boletín electrónico]. Disponible en https://prensarural.org/spip/spip.php? article21437

Conferencia Episcopal de Colombia. (noviembre de 2006). Barrancabermeja: en medio del conflicto del Magdalena Medio. RUT informa: Sobre desplazamiento forzado en Colombia, 27 [Boletín electrónico]. Disponible en http://www.disaster-info.net/desplazados/ informes/rut/estudio15/estudio15_barranca.pdf 
Delgado, M. (2011). Las víctimas como sujetos políticos en el proceso de Justicia y Paz en Colombia: discursos imperantes y disruptivos en torno a la reconciliación, la verdad, la justicia y la reparación. (Tesis de doctorado) Ciencias Sociales. FLACSO, México.

Farfán-Quijano, N. (2017). La paz y las redes un análisis de significados a través de textos (Tesis de pregrado). Universidad Santo Tomás. Colombia.

Gómez, O. (2006). Voces de memoria y dignidad. Módulo Aspectos psicosociales de la reparación integral. Bogotá: ARFO.

González, M. (3 de enero de 2015). La semántica del proceso de paz. El Espectador [Edición digital]. Disponible en https://www.elespectador.com/noticias/politica/semantica-delproceso-de-paz-articulo-535993

Hinojosa, G. (2008). El tratamiento estadístico de las redes semánticas naturales. Sociotam, $18(1), 133-154$

Morris, C. y Maisto, A. (2011). Introducción a la Psicología. México: Pearson.

Vargas-Garduño, M., Méndez-Puga, A., y Vargas-Silva, A. (2014). La técnica de las redes semánticas naturales modificadas y su utilidad en la investigación cualitativa. IV Encuentro Latinoamericano de Metodología de las Ciencias Sociales, 27 al 29 de agosto de 2014, Heredia, Costa Rica. La investigación social ante desafíos transnacionales: procesos globales, problemáticas emergentes y perspectivas de integración regional. En Memoria Académica. Disponible en: http://www.memoria.fahce.unlp.edu.ar/trab eventos/ev.8204/ev.8204.pdf

Vera-Noriega, J., Pimentel, C. y Batista de Albuquerque, F. (2005). Redes semánticas: aspectos teóricos, técnicos, metodológicos y analíticos. Ra Ximhai, 1(3), 439-451. 


\title{
23. La construcción del enemigo en pilotos militares colombianos ${ }^{88}$
}

\author{
Katerine Andrade Gordillo $0^{89}$ \\ Manuel Alejandro Moreno Camach0 $0^{90}$ \\ JoHn AleXANDER Quintero TORREs ${ }^{91}$
}

\section{Resumen}

El objetivo de la investigación fue analizar la construcción de enemigo en un grupo de pilotos de combate, que participaron en operaciones de guerra. Para ello, se propusieron tres categorías de análisis: la construcción del enemigo en los procesos de socialización militar, en el ejercicio del rol militar, y las transformaciones a partir de las negociaciones de paz. Es un estudio cualitativo a través de entrevistas semiestructuradas a siete pilotos. En el análisis se tuvieron en cuenta dos dimensiones: el discurso institucional y su apropiación singular. En los resultados se destaca que la construcción del enemigo inicia desde el proceso de socialización militar por medio del entrenamiento para el combate, a partir de procedimientos institucionales para la formación del carácter y el ajuste a la doctrina, aunque en el ejercicio del rol militar cada piloto hace una apropiación singular del adversario. Prevalece la concepción de un enemigo absoluto, frente al cual se expresa superioridad y opera el imperativo de ser aniquilado. El enemigo otorga sentido a la existencia y a la función del rol militar, y contribuye a la legitimación de identificaciones y modos de satisfacción que se ponen en juego en la vida de los combatientes. Asimismo, se pudo evidenciar que los acuerdos de paz han propiciado transformaciones en la construcción del enemigo, aunque también ratifican la concepción que operaba en la guerra, en tanto se entienden como consecuencia de una victoria militar.

88 Las apreciaciones de este escrito son propias de los autores y no comprometen la posición y el pensamiento del Ministerio de Defensa, ni del Comando General de las Fuerzas Militares, ni de la Fuerza Aérea Colombiana. El documento hace parte de un ejercicio exclusivamente académico.

89 Universidad de San Buenaventura Cali. Correo: katerineagh@hotmail.com

90 Universidad del Valle. Correo: moreno.manuel@correounivalle.edu.co

91 Universidad de San Buenaventura Cali. Correo: jaqtorre@usbcali.edu.co 
Palabras clave: conflicto armado, construcción de enemigo, Fuerzas Militares, acuerdo de paz.

\section{Abstract}

In this paper we analyze the construction of the enemy in a group of combat pilots, who participated in war operations. Three categories of analysis were proposed: construction of the enemy in military socialization processes, construction of the enemy in military role, and transformations of it because peace negotiations. It was a qualitative study through semistructured interviews to seven pilots. Two dimensions were taken into account for analysis: institutional discourse and its singular appropriation. The results highlight that construction of the enemy starts from military socialization process, through combat training. Although in military role performance every pilot makes a singular appropriation of the adversary. The conception of absolute enemy prevails, against which superiority and annihilation desire is expressed. The enemy gives meaning to military role, and contributes to legitimation of war identifications. Peace agreements have led to changes in enemy construction, although they also ratify the conception of enemy that operated in war times, insofar agreements are understood as a consequence of military victory.

Key words: Armed conflict, construction of enemy, military forces, peace agreement.

\subsection{Introducción}

El conflicto armado interno en Colombia ha sido extenso, su historia y su dinámica han contribuido a la construcción de una noción de enemigo desde la cual se justifica el combate militar. Esta investigación surgió de la inquietud por esa construcción subjetiva de enemigo que elaboran los pilotos militares, por considerarla fundamental para proponer una lectura comprensiva de la guerra, desde las diferentes perspectivas que se ponen en juego en su discurrir.

Teniendo en cuenta que cada actor en el conflicto tiene una construcción de enemigo estructurada sobre la cual se justifica el combate, consideramos pertinente indagar ¿Cuál es la construcción de enemigo de un grupo de militares, pilotos de combate, en el conflicto armado colombiano?

En este orden de ideas, el objetivo de esta investigación fue analizar la construcción de enemigo en un grupo de militares, pilotos de combate, 
que participaron en operaciones de guerra. Para ello, propusimos tres categorías de análisis: la construcción del enemigo en los procesos de socialización militar; la construcción del enemigo en el ejercicio del rol militar; y las transformaciones en la construcción del enemigo a partir de las negociaciones de paz.

El concepto de enemigo, ha sido abordado teóricamente por diferentes disciplinas, pero existen pocos estudios empíricos en la materia. En esta introducción proponemos una síntesis de las principales perspectivas que orientaron nuestro abordaje del concepto. Partimos de la reflexión políticosocial, para posteriormente avanzar en la elucidación del concepto desde la perspectiva psicoanalítica.

El enemigo desde el análisis político-social. En la reflexión política encontramos un acercamiento al término enemigo realizado por Schmitt, quien define el enemigo como "un conjunto de hombres que siquiera eventualmente, de acuerdo con una posibilidad real se opone combativamente a otro conjunto análogo" (Smith, citado por Delgado, 2011, p. 58). Desde esta perspectiva, sólo es enemigo aquel que es enemigo público, pues todo cuanto se hace en contra de ese grupo de personas adquiere un carácter social. Por tanto, la construcción de la imagen del enemigo está relacionada con la característica acechante y de amenaza para la sociedad que éste implica. La condición para que se genere un enemigo, entonces, es que exista una oposición religiosa, moral, económica o ética que puede terminar en una barrera política (Lujan \& Silva, 2014; Vidal, 2004).

Rivas (2002) propone que la construcción del enemigo ha dejado de ser exclusiva de los militares que combaten en la guerra, pasando a ser parte de una construcción de la sociedad, basada en la percepción de una imagen común de otro, construida por la confrontación. En este sentido, existen representaciones colectivas relacionadas con el conflicto y el enemigo que conforman la memoria colectiva y que pueden generar una construcción social del enemigo (Blair, 1995; Vidal, 2004). Dichas representaciones son construidas por grupos de personas y son alimentadas durante los conflictos (Lozada, 2004; Vite, 2015).

Tortosa (2003) afirma que hay enemigos reales y enemigos construidos socialmente. A los enemigos reales los relaciona con la envidia, la codicia, la arrogancia y la prepotencia; son generados mediante relaciones entre personas. Las personas pueden encontrarse en bandos diferentes, y por ello pueden tener conflictos de diverso orden (económico, político, social). A su vez, los enemigos construidos, que pueden terminar siendo reales tam- 
bién, están relacionados con aquellos que se han declarado y convertido en enemigos en el campo de batalla.

En el caso de Colombia, se trata de un enemigo construido socialmente, declarado en el campo de batalla, que se ha convertido en un enemigo real, en la medida que se encuentran bandos diferentes con un conflicto económico, social y político, utilizando la arrogancia y la prepotencia para atacar el otro.

En los discursos en torno a la guerra, la lógica de la diferenciación nosotros-ellos, contribuye con los procesos de reafirmación de la identidad. El otro, se define en palabras para denigrar y diferenciarse del nosotros. Por esta vía se configuran ideas de patriotismo y se consolida la caracterización de un enemigo común, que se experimenta como extraño y diferente, del cual hay que distanciarse y al que se debe vencer (Castellón, 2014). La construcción del diferente inicia con la interacción entre actores, ya que dependiendo de cómo se conciben unos a otros se puede determinar si son amigos o enemigos. De allí parte la manera como se representan el yo y el otro. Dicha representación implica el elemento discursivo para dar cuenta de la posición de cada uno (Green \& Bogard, 2012).

De esta manera, sobre la noción de enemistad recaen procesos sociales como la polarización. En ella se evidencia la postura de un grupo que supone una referencia negativa a la postura de otro, por lo que es percibido como enemigo. El resultado de ello es la instalación de una percepción estereotipada del tipo: nosotros-ellos. Por esta vía se cultiva la cohesión al interior de cada grupo y se alimenta el conflicto entre los opuestos; hay una percepción de más distancia y diferencia, acentuando las semejanzas endogrupales y las diferencias exogrupales. Es por ello que, en muchas ocasiones la polarización fractura el tejido social, disminuyendo el diálogo entre polos, legitimando la violencia contra el otro y generando un hermetismo colectivo al interior de los grupos sociales (Alzate, Duran, \& Sabucedo, 2009; Domínguez, 2008; Egan, 2007; Lozada, 2004).

\section{La perspectiva psicoanalítica sobre la construcción del enemigo.} Freud hace la contraposición de los términos enemistad-amistad, y argumenta que el hecho de que exista la amistad, no significa que la enemistad se haya eliminado, sino que puede haber una especie de camuflaje que esconde humillación y ultraje por medio del amor al prójimo; pues es probable que la enemistad se encuentre reprimida o se haya sublimado. Una enemistad supone la oposición entre dos elementos, que en ocasiones generan escenarios propicios para la guerra, la cual es desarrollada y se mantiene fundamentada en un apasionamiento por combatir al otro, sin 
tener en cuenta los medios, y donde la palabra no sirve como canal para la reconciliación (Gallo, 2016).

En 2015 fue publicada la investigación La construcción del enemigo en el conflicto armado colombiano 1998-2010, realizada por un grupo interdisciplinar, en el que participaron psicoanalistas de orientación lacaniana (Angarita et al., 2015). Esta investigación constituye el antecedente que inspira la formulación de nuestro estudio sobre la construcción del enemigo en pilotos militares colombianos. Dicha investigación se trazó como objetivo describir la estructura de la construcción del enemigo mediante el análisis de documentos producidos por diferentes actores de la confrontación. Entre los resultados encontrados se observa que la elaboración de la concepción de sí mismo contribuye de manera importante a la construcción de un enemigo, ya que es por medio del lenguaje que se puede construir una posición diferente de sí. Así mismo, se destacan tres dimensiones para pensar el problema: el enemigo visto como otro, que no se inscribe dentro del pensamiento político propio; el enemigo que se genera a través del vínculo con la población, con el objetivo de construir un enemigo conjunto por medio de la reivindicación de la causa legítima que justifica las propias acciones; y el enemigo visto como un individuo lejano del cual no se puede hacer una representación porque se encuentra excluido.

A su vez, entre en el análisis se destaca la propuesta de diferentes tipos de enemigo que coexisten en el discurso de los actores del conflicto: el enemigo contingente, que puede darse de acuerdo a las diferentes circunstancias y los beneficios que ofrezca, puede o no existir y puede ser interno o externo; el enemigo político, que tiene una connotación simbólica y como tal se le otorga el lugar de sujeto de discurso con el que se puede dialogar; el enemigo necesario, que tiene connotación de amenaza (terrorista), y por tanto se construye como autorización para obrar bélicamente, pues toda acción queda legitimada con el fin de destruirlo; y el enemigo absoluto, que se caracteriza por una presión militar, con una intención razonada de aniquilación más que de sometimiento (Angarita et al., 2015; Gallo, 2013).

En esta misma línea de análisis, otros autores han mostrado que en el conflicto armado colombiano, el enemigo político ha pasado, por medio del discurso, a ser un enemigo absoluto que ha sido desprovisto de su condición de humano, sobre el cual solo hay dos opciones: matar o morir. Todo en cuanto se relaciona con este enemigo queda autorizado, ya que frente a este hay un deseo de aniquilación (Mesa \& Ruíz, 2013).

Con todo ello es posible decir que la construcción del enemigo ocurre por la oposición entre dos elementos, se desarrolla y mantiene por un apa- 
sionamiento por combatir al otro, donde la palabra no sirve como medio de reconciliación. En dicha relación sólo existen intercambios de elementos destructivos. En este sentido, la existencia del enemigo, permite la constitución de sí mismo, ya que sin la existencia del otro, no se puede construir el yo en términos de lo diferente.

El enemigo cumple una función social y política, su lugar se hace necesario, ya que permite la identificación propia, cohesiona y legitima la forma de operar. De hecho, al analizar la subjetividad implicada en los actores de la guerra, se evidencia la importancia de la agresividad en la formación del yo (Andrade \& Moreno, 2017), dado que la diferenciación entre sí mismo y el otro, permitirá al sujeto entender la unidad propia y el yo intentará constituirse como diferente del otro, como una forma narcisista de diferenciación.

\subsection{Método}

La investigación fue realizada desde un paradigma cualitativo teniendo como base tres categorías de análisis relacionadas con los objetivos específicos. El propósito fue realizar una aproximación a la construcción del enemigo mediante el acercamiento con el sujeto y la realidad social que vive el piloto de combate en el ámbito militar. La aproximación fue realizada a través de procedimientos de análisis de discurso. La recolección de datos fue efectuada mediante una entrevista semi-estructurada que se aplicó a siete pilotos de combate de la Fuerza Aérea Colombiana, que han participado en operaciones de guerra. El análisis de la información fue realizado mediante el software Atlas.ti para la codificación y categorización de las entrevistas.

En consecuencia, la investigación se desarrolló con un enfoque cualitativo. Así mismo, se propendió por un abordaje interpretativo, ya que se buscó comprender teniendo en cuenta la experiencia subjetiva de cada militar. En este sentido, se analiza el objeto de estudio mediante una aproximación hermenéutica, buscando la compresión del fenómeno y favoreciendo la interpretación del mismo (Gadamer, 1999).

El análisis de la construcción del enemigo se llevó a cabo mediante tres dimensiones: el proceso de socialización militar, el ejercicio del rol como militar y las transformaciones en el contexto actual, que corresponden a los objetivos propuestos para la investigación.

El proceso de socialización militar hace referencia a la formación que ha tenido cada militar en una escuela de formación con el fin de aprender aspectos del discurso institucional como la doctrina de combate, el discurso 
de sus superiores y los ideales legitimados en dicho contexto; y aspectos de la apropiación singular como la sumisión y la adherencia a normas, la posición frente al enemigo y el conocimiento del enemigo a partir de diferentes medios de información.

El ejercicio del rol como militar hace referencia al momento en el cual el militar realiza operaciones de combate y ejerce su rol. En este sentido se busca verificar aspectos institucionales como las reglamentaciones y leyes; y aspectos singulares como las experiencias de guerra, los enfrentamientos, y la identificación, tanto horizontal como vertical.

Las transformaciones relacionadas con los acuerdos de paz, implican las modificaciones frente a la posición que tienen los pilotos con respecto a su enemigo en el contexto de la negociación y firma de los acuerdos de paz con las FARC-EP.

Las anteriores dimensiones de análisis son transversalizadas por dos aspectos: por una parte, el discurso institucional, definido como los procesos de formación, la información, la doctrina, la reglamentación y normatividad que la institución proporciona a los militares para el desarrollo de su misión. Por otra parte, la apropiación singular, caracterizada por la posición personal que toma cada militar frente al discurso institucional que se le es transmitido, de manera que se encuentra su perspectiva frente al enemigo y las experiencias que ha tenido frente a éste.

El análisis de la información se llevó a cabo en dos momentos: inicialmente se realizó una identificación de categorías emergentes y su frecuencia, con el objetivo de encontrar la relevancia de las mismas. Esta operación no constituyó el centro del análisis, sino un procedimiento para clasificar y organizar la información. En segunda medida se utilizaron estrategias cualitativas tomadas de la teoría fundamentada: la primera de ellas fue el método comparativo constante, donde se busca comparar y desarrollar categorías relacionadas con el objeto de investigación, se buscaba encontrar sucesos en los datos recolectados para generar las categorías y por medio de la comparación se construyeron las categorías o clases. Posterior a este proceso, se buscó delimitar las categorías a través de la teoría (Schettini \& Cortazzo, 2015).

La población que participó en el estudio, estuvo constituida por siete militares, pilotos de combate de la Fuerza Aérea Colombiana (tabla 1). El tiempo de servicio de los pilotos varía entre 7 y 23 años. El proceso de selección de los participantes fue a conveniencia, y se tuvo en cuenta que 
hubieran participado en operaciones militares en el conflicto armado colombiano; también debían estar activos en la institución. De igual manera, se tuvo en cuenta el interés por participar en el proceso de investigación, para tal fin se presentó a los potenciales entrevistados un formato de consentimiento informado explicando el objetivo de la investigación y las consideraciones éticas tenidas en cuenta. Con su aprobación procedimos a realizar las entrevistas.

Tabla 1. Participantes

\begin{tabular}{|c|c|c|c|c|}
\hline Seudónimo & Grado & $\begin{array}{c}\text { Edad } \\
\text { (años) }\end{array}$ & $\begin{array}{c}\text { Tiempo de } \\
\text { servicio (años) }\end{array}$ & Nivel Educativo \\
\hline Rapaz & Teniente Coronel & 41 & 23 & Profesional \\
\hline Arpía & Mayor & 37 & 18 & Profesional \\
\hline Halcón & Mayor & 37 & 18 & Profesional \\
\hline Mirage & Capitán & 32 & 12 & Profesional \\
\hline Drako & Capitán & 29 & 10 & Profesional \\
\hline Bronco & Teniente & 27 & 8 & Profesional \\
\hline Tucano & Teniente & 30 & 7 & Profesional \\
\hline
\end{tabular}

\subsection{Resultados y discusión}

A continuación presentamos los principales hallazgos, de acuerdo con cada una de las categorías de análisis propuestas.

\subsubsection{Procesos de socialización militar}

Está dimensión apunta a la observación de procesos institucionales, definidos por Blair (1999) como mecanismos cuyo propósito es que "todos piensen lo mismo" (p. 184), de manera que la diferencia entre cada persona tienda a cero.

Con respecto al discurso institucional, y teniendo en cuenta la preparación para ser militar y piloto de combate, se encontraron alusiones a las características de la formación del militar y su doctrina del enemigo, de modo que se describen importantes competencias como la disciplina, el carácter, el honor, la capacidad de manejar la presión, el compromiso, la capacidad de sobrevivir y de tomar decisiones de manera madura durante una misión de combate, apegarse a la planeación y ser capaz de modificarla, en caso de ser necesario. Estas cuestiones han sido señaladas por investigadores que concluyen que las personas que van a la guerra cuentan con características específicas que implican un entrenamiento exhaustivo 
y con restricciones sociales al interior de las escuelas de formación, que finalmente producen un aislamiento de los futuros militares (Borrero, 1990; Sampson, 2000).

Así mismo, durante la formación los pilotos aprenden de la doctrina del enemigo, acerca de la futura misión que cumplirán, las adversidades y las situaciones complejas que deben aprender a sortear. Al conversar acerca de la doctrina enuncian: ...nosotros también tenemos doctrina en las escuelas de formación... recibimos instrucción de quien es el enemigo y como combatirlo... (Rapaz).

La doctrina es definida como el "conjunto de conocimientos y saberes; de principios, normas, reglas, criterios y creencias adoptados oficialmente por las FFMM con el objeto de orientar el empleo del poder militar para la seguridad, defensa y demás intereses de la Nación" (Fuerza Aérea Colombiana [FAC], 2013, p.53). Incluye la formación acerca del conflicto armado, con respecto a quién es el enemigo y cómo se debe combatir. Un ejemplo de las actuaciones basadas en la doctrina, es que antes de la operación no se debe hablar del enemigo, ni desprestigiarlo, ni menospreciarlo; de hecho, se trata de que pocas personas tengan conocimiento de la operación. Como propone Tzu (2003), en las operaciones militares conocer al enemigo es tan importante como conocerse a sí mismo, para encontrar un punto débil que atacar. Así los expresan los pilotos entrevistados: ...desde la escuela a usted le recalcan mucho quien es el enemigo, por ejemplo nosotros nos centramos mucho en el conflicto interno... (Arpía).

En el discurso institucional brindado en la formación militar, también se encontraron menciones relacionadas a la función constitucional de las Fuerzas Militares, orientada a cumplir el objetivo de desarticular y desestabilizar al enemigo. Los entrevistados comparten que la misión es constitucional y contempla salvaguardar la soberanía, el orden constitucional y la integridad territorial (Arpía). De esta manera, en el discurso de los sujetos se encuentra una identificación con la idea de que las FFMM son el brazo armado del Estado para hacer cumplir la constitución y defender sus intereses, por ejemplo a través de la neutralización del enemigo. Esto está contemplado en el Artículo 217 de la Constitución Política de Colombia (República de Colombia, 1991).

En tensión con esta posición de los pilotos entrevistados, también se encuentran denuncias sobre la legitimidad de las acciones implementadas por las FFMM. Blair (1999), por ejemplo, afirma que la violencia que han ejercido los actores militares en Colombia no ha sido legítima, ya que en 
el enfrentamiento se han confundido los límites de lo legal y lo ilegal, lo público y lo privado.

Se evidencia entonces cómo el marco normativo desde el que operan los pilotos militares establece la función de desarticular y desestabilizar al enemigo. En cuanto a ello, diferentes analistas proponen una lectura sobre la importancia de utilizar las armas para lograr realizar operaciones que sean estratégicas y desequilibren a sus contrincantes, que dobleguen la voluntad del enemigo y finalmente logren suprimirlo (Castro, 2001; Clausewitz, 2008). En este sentido, resaltan en las enunciaciones de los sujetos tres aspectos: la satisfacción que sienten al doblegar al enemigo; la búsqueda de una desintegración física y moral del enemigo; y lograr una persecución incansable del enemigo, para robarle la tranquilidad (Blair, 1999; Domínguez, 2008; Ramírez, 2008).

Por su parte, del lado de la apropiación singular, los pilotos hacen alusión con gran frecuencia a que son instrumentos para cumplir órdenes superiores. El cumplimiento de las órdenes en la milicia es uno de los pilares fundamentales, se cimienta en la sumisión e implica obedecer a las órdenes que se reciben de los superiores. Los pilotos de combate perciben que son utilizados como armas de una decisión del presidente o de la administración de turno, escogida democráticamente por el pueblo. En dichas decisiones no hay mucha injerencia de los pilotos, ejecutan su misión con sumisión, basados en las órdenes que les dan sus comandantes. Lo anterior es ilustrado por Sampson (2000), cuando afirma que una de las condiciones primordiales de un ejército que ingresa a la guerra es la figura del jefe o comandante, quien siempre pedirá obediencia y frente al cual los subordinados serán sumisos casi sin límite. Y como expresa Blair (1999), dicha voluntad legitima la dominación que ejerce el superior.

Es así como los pilotos entrevistados afirman: Nosotros simplemente somos como sus armas, ellos nos van a emplear para cumplir una misión o unos objetivos... (Mirage). El enemigo lo estipulan más arriba [altos mandos], como tal no es decisión de nosotros. Nosotros sencillamente lo que hacemos es cumplir con los requerimientos de ellos de la mejor manera posible (Bronco).

Pese a esto, los pilotos expresan que hay una satisfacción al cumplir las misiones con responsabilidad, seguridad, profesionalismo, manejando la presión y la adrenalina; así estas impliquen complejidad, deben tener la capacidad de tomar decisiones adecuadas, basados en la formación que han recibido. Por tanto, esta subordinación se da con una convicción de estar 
haciendo lo correcto y en cumplimiento de una misión en una dinámica de grupo. Es así como, de acuerdo con Browning (citado por Pecaut, 2013), se actúa por la obediencia a la autoridad, el conformismo y en el afán de mantener el grupo cohesionado. Sin embargo, más allá de la coerción que tiene lugar en la masa que es el grupo militar, cada sujeto accede a una satisfacción íntima que se pone en juego en el desarrollo de sus funciones.

A su vez, también se encuentran alusiones a la idea de que se debe ser superior al enemigo, lo cual opera como premisa fundamental en el posicionamiento personal frente al enemigo. En este sentido, en las conversaciones manifiestan que lo más importante en el combate aéreo es ser superiores en cuanto a precisión y poder militar. Para lograr esto, las FFMM han hecho misiones estratégicas que han resultado en grandes golpes a cabecillas, desestabilizando al enemigo, provocando que se oculte, minimice y pierda su capacidad de agruparse. Dicha estrategia, puede relacionarse con la capacidad disuasiva que nombra Blair (1999) afirmando que la tenencia de recursos le permite hacer valerlos frente al contrincante. De tal manera que las misiones hacen parte del ritual demostrativo donde se enseñan al enemigo los recursos con los que cuenta. En palabras de los entrevistados: al fin y al cabo lo que le importa a la parte aérea, es la superioridad aérea y la precisión (Mirage). Frente a esto, Freud (citado por Castro, 2005), destaca que el objetivo fundamental de la guerra es lograr la superioridad, buscando el reconocimiento y demostrando dicha superioridad al enemigo (Castro, 2001).

Relacionado con el querer ser superior al enemigo, se encuentra que los pilotos de combate hacen alusiones a que se requiere conocimiento $y$ experiencia para las operaciones, para llegar a la superioridad. De esta manera, se sugiere que efectuar operaciones más profesionales y mantener el entrenamiento en éstas, requiere del conocimiento que se alcanza por medio del estudio que deben tener al interior de los escuadrones. Para tal fin, es necesario que el grupo de pilotos promueva el estudio de diversas materias relacionadas con las misiones, el estudio de las lecciones aprendidas y experiencias de otros pilotos que se toman como un aprendizaje para sí mismos. Ésta es una responsabilidad compartida, el piloto se encarga de su estudio y el escuadrón asegura que cada piloto entrene y practique las maniobras de cada aeronave. Dado que en las operaciones ...ya es muchísimo más importante poner en práctica todo el conocimiento, toda la experiencia $y$ todo el estudio que uno tiene (Bronco).

De igual forma se encuentra que hay referencias, con menor frecuencia, a que las Fuerzas Militares están al servicio de la comunidad como forma 
de apoyar el progreso del país y la importancia del reconocimiento y admiración por otras personas, lo cual se relaciona con la credibilidad que tienen las FFMM frente a la sociedad civil.

\subsubsection{Ejercicio del rol como militar}

En el ejercicio de la labor militar la institución provee información del enemigo para realizar operaciones con liderazgo y amparo legal. Por esta vía se encontraron dos grupos de hallazgos: el primero hace referencia al tipo de formación que requieren los pilotos, de manera que se encuentra la importancia del conocimiento del enemigo, la cual ya había sido tenido en cuenta anteriormente. Sin embargo, es importante agregar que existen diversas fuentes de información para desarrollar este conocimiento, entre las que se destacan: los Briefing o reuniones de planeación de operaciones, las cuales se efectúan por los grupos de inteligencia proporcionando toda la información del enemigo, el objetivo militar, la estructura, entre otros; y los comandantes, que brindan las recomendaciones necesarias e imparten órdenes frente a la misión.

Clausewitz (2008) propone que el conocimiento que se tiene del enemigo constituye el fundamento de los planes y acciones, ya que a partir de este conocimiento es que se toman decisiones en el teatro de guerra. Así, la planeación de operaciones aparece como el proceso que ocurre antes de la acción bélica. Después de proporcionada la información acerca de enemigo, se hace una planeación táctica y técnica del ataque. En esta dinámica aparece la figura del líder dentro de la institución. El líder toma decisiones, planea y ordena, debe ser capaz de tomar decisiones seguras, ágiles y efectivas, $\mathrm{y}$ también debe tener el nivel de responsabilidad para asumir las consecuencias de sus decisiones, manejar la presión de sus comandantes y compañeros para cumplir la misión.

Por otro lado, el segundo grupo de hallazgos hace referencia a las afirmaciones relacionadas directamente con el enemigo. Los pilotos de combate hacen referencia a que el enemigo es compartido y conocido por los miembros de las Fuerzas Militares, manifiestan que el enemigo es general, se habla de él y es conocido, no sólo por los miembros de las Fuerzas Militares, sino que los colombianos observan cuáles son sus actos. Lo anterior alude a la producción de un estereotipo, que permite la percepción común del enemigo, ya que se puede ver un marco colectivo de sentido que genera una cohesión social, sentido de pertenencia e identidad militar (Blair, 1999). 
Igualmente, hay alusiones por parte de los pilotos de combate a la premisa de que se deben cuidar del enemigo. Afirman que los pilotos de combate son un blanco, ya que el enemigo gozaría de hacerle daño a un piloto de la FAC, dado que sienten rencor por los integrantes de las Fuerzas Militares y pueden existir sentimientos de venganza. Uno de los entrevistados afirma: para ellos, hacerle daño a una aeronave y más a un piloto de la FAC, sería algo formidable; una manera de demostrar que todavía están vivos y que ellos tienen poder para hacerlo (Halcón). En esta afirmación, se puede ver de forma clara una de las características que proponen Spillmann y Spillmann (citados por Blair, 1995) acerca del enemigo: la anticipación negativa, la cual consiste en que todo lo que hace el enemigo tiene como objetivo destruir.

Por su parte, en su dimensión de apropiación singular, la mayor alusión a la que hacen referencia los pilotos de combate en sus conversaciones, es que el enemigo actúa mal, hace daño, causa dolor, viola los DDHH y el $D I H$. En este caso, se puede encontrar congruencia con lo propuesto por Spillmann y Spillmann (1991) acerca del enemigo: se asimila al mal, algo demoniaco, de manera que todas las actuaciones que personifique son malas y por tanto hay que atacarlo (Blair, 1995, 1999). Los pilotos consideran que los grupos armados al margen de la ley reconocen que hacen daño al país y son conscientes del mal que generan, utilizando el terrorismo para someter y flagelar a la población, generando miedo en las personas, mediante la ejecución de masacres, secuestros de personas, reclutamiento de menores y extorsiones que afectan a la población civil.

$\mathrm{Al}$ referirse a las actuaciones del enemigo, los pilotos de combate afirman que el enemigo tiene ideales desenfocados y sin coherencia, por su falta de educación. Es así como afirman que el enemigo está conformado por seres humanos cualquiera, pero que han tenido otro tipo de enseñanzas que no son las más adecuadas, así que es posible que lo que necesiten sea educación, pues están centrados en la ambición y la sensación de poder que han alcanzado con el terrorismo. De esta manera afirman: "creo que sus ideales están un poco desenfocados, ellos tiene unos ideales de un tipo de gobierno diferente, ellos son comunistas (Halcón)"; “...yo creo que es por falta de educación, de pronto también por ambición de muy pocos (Mirage)"; "algunos cabecillas tienen estudios y enmascaran el narcotráfico con una ideología, entonces dicen que es la opresión del gobierno (Bronco)".

En suma, los pilotos justifican su acción contra el enemigo que combaten fundamentándose en la maldad de sus acciones y en lo que denominan los ideales desenfocados. Y ello está en la base de lo que consideran que se 
merece su enemigo: ellos deben ser juzgados y retribuir el daño que han hecho al país. Dado que han violentado los Derechos Humanos y el Derecho Internacional Humanitario, los entrevistados afirman que sus enemigos han cometido delitos de lesa humanidad, generando gran cantidad de víctimas. Por esos actos deben ser juzgados, de tal manera que se sometan a la legalidad colombiana e internacional y paguen con cárcel cada delito que planearon y ejecutaron. Así mismo, consideran que debe haber una retribución del daño, reconociendo sus actos, reparando las víctimas, realizando trabajo social y ayudando a las personas.

En este orden de ideas, en términos generales, los pilotos construyen un enemigo absoluto. De esta manera, expresan la dicotomía que alienta sus acciones de guerra. En el combate está siempre en juego su vida frente a la vida de sus enemigos. De esta manera, si el enemigo ataca siempre se debe responder combatiendo, así las consecuencias de este combate sean la muerte del otro. Este enemigo absoluto puede evidenciarse en los relatos de los pilotos: si no es la vida del enemigo es la vida de ellos (Halcón). Es inevitable que vayamos a entrar en un combate, para eso nos entrenaron, ese es nuestro trabajo, como el médico hace cirugías, el militar hace la guerra (Rapaz); entonces si ellos quieren afectarnos toca responder (Halcón). Tendría que matarlo (Bronco). Toca darlo de baja, el primer tiro al aire y a los pulmones, porque es él o yo; en esas situaciones de combate siempre es usted o el enemigo [...] (Arpía).

A su vez, ese enemigo que actúa mal, tiene unos ideales desenfocados y merece justicia, es también un enemigo necesario, es decir, una alteridad construida que justifica la función de los pilotos militares, por tanto es un enemigo que, pase lo que pase, siempre va a hacerse existir. Es así como los militares expresan que, independientemente del nombre bajo el que se presente o los ideales que orienten la acción, siempre habrá un enemigo que combatir. Señalan que la existencia del enemigo es cíclica, que todo el tiempo ha existido y que va cambiando, pero la amenaza sigue y por tanto siempre existe alguien a quien combatir.

El tercer tipo enemigo encontrado en las afirmaciones de los pilotos de combate, es el enemigo político, una persona diferente de sí mismo con cosas positivas. No obstante, es la concepción que menos alusiones tiene, ya que la mayoría de las apreciaciones del enemigo se enmarcan en los aspectos negativos y con menor frecuencia expresaron que son personas como cualquiera, que han vivido situaciones diferentes, y tienen una ideología y pensamiento diferente a la propia. A partir de esta posición se puede generar 
una característica positiva del enemigo, relacionada con su capacidad de adaptarse muy rápido al entorno cambiante de la guerra.

\subsubsection{Transformaciones relacionadas con el proceso de paz}

Los procesos de paz del gobierno colombiano con grupos insurgentes tienen un impacto trasformador en la construcción del enemigo que elabora el piloto de combate de la Fuerza Aérea. Los diálogos de negociación con el enemigo, ponen en el horizonte de su discurso la idea de paz: para todos los colombianos y todos los miembros de las Fuerzas Militares, la paz es algo que anhelamos (Halcón). Lo mejor de una guerra es evitarla, o sea, nadie quiere ir a la guerra, eso es una verdad absoluta (Arpía).

Pese al anhelo manifiesto de paz, el discurso del militar también deja entrever que el gasto anímico que trae consigo la guerra deja unos rasgos que se resisten a ser negociados y, otros, de difidencia. A saber, el reconocimiento de la victoria militar oficial como motor inicial de la negociación y la desconfianza en el proceso de paz. Estos aspectos, condujeron a caracterizar dos dimensiones emergentes en el discurso de los entrevistados: por un lado, la victoria de las Fuerzas Militares y su preparación para desempeñar otros roles. Por otro lado, las dificultades de la consolidación de la paz debido a la desconfianza en el proceso.

La apreciación a la que más hicieron referencia los pilotos de combate en el discurso institucional, es que las Fuerzas Militares obtuvieron la victoria militar frente al enemigo, de esta forma, afirman que ganaron la guerra debilitando al enemigo. Con aquello se logró que el enemigo accediera al diálogo y a resignar la idea de tomarse el poder por vía armada. Como acto simbólico, el Presidente de la República ordenó otorgar a los miembros de las Fuerzas Militares la orden presidencial Victoria Militar, como gesto de retribución a los militares en la consecución de la paz.

El discurso institucional sesga la visión sobre los procesos de paz ya que el entrenamiento es tan cerrado, exhaustivo y basado en los aspectos militares, que no existe cabida para pensar en algo distinto que la victoria militar (Borrero, 1990). Se observa pues, una actitud etnocéntrica basada en la demonización del enemigo (Blair, 1999).

En un posible escenario de posconflicto los pilotos ven a las Fuerzas Militares en un futuro lo suficientemente preparadas para el conflicto internacional. Conciben la participación de la institución en probables conflictos internacionales, basados en los estándares internacionales (OTAN), como una expresión más del cumplimiento de su función de ejercer la soberanía 
y defensa de la nación. Para este fin, la FAC ya ha empezado a entrenar en ejercicios internacionales, buscando fortalecer su capacidad de combate aire-aire y aire-tierra.

Frente a esto, Blair (1999) propone que se deben construir nuevos universos simbólicos para compartir entre los militares, de manera que se pueda generar una nueva identidad que no implique la interiorización de la violencia, sino que se convierta en una violencia politizada. Ello implica tramitar los sentimientos que se ponen en juego en la transición de la guerra a la paz (López \& Rodríguez, 2012, 2016). Así cada militar que ha encontrado su satisfacción pulsional en la misión de combate debe buscar una nueva forma de satisfacer su deseo.

A su vez, en los pilotos se pueden encontrar valoraciones de confianza $y$ desconfianza sobre los procesos de paz. Las valoraciones de confianza evidenciaron que algunos pilotos se muestran positivos frente a los acuerdos de paz e inquietos por lo que pueda venir en el futuro. Su tranquilidad consiste en entender que la paz es la mejor opción para el país y que hay personas bien preparadas liderando la negociación.

En contrapartida están también las valoraciones de desconfianza frente al proceso, que manifiestan que se ha realizado de manera deshonesta y enviando un mensaje equivocado al país. Consideran que el proceso ha permitido que el enemigo siga efectuando actos delincuenciales y no se les ha frenado, y que además es un diálogo injusto después de que las Fuerzas Militares ya llevaban una ventaja militar superior que se hubiera podido continuar hasta que el enemigo aceptara las condiciones del Estado.

El tiempo de trayectoria de los pilotos militares, genera un sesgo en su posición positiva o pesimista frente a los proceso de paz. Los pilotos con más tiempo de servicio tienden a observarlos de forma negativa, probablemente por el arraigo al pensamiento militar o por los periodos arduos de confrontación armada que experimentaron. Como menciona Blair (1999), se trata de referentes larga y profundamente arraigados, sumados a la cuestión del honor y la legitimidad que está amarrada al hecho de ser militar. Ello implica un reto de cara a la construcción de procesos de perdón y reconciliación desde la perspectiva de la noviolencia (Villa, 2016).

Aunque los pilotos coinciden en que un acuerdo de paz es lo mejor para el país, valoran como algo injusto cualquier tipo de concesión que se le pueda otorgar al enemigo. Se perciben como premios o prebendas no merecidas y como un mensaje equivocado a la ciudadanía: "fuera de las prebendas que 
se les da y van a tener, porque la imagen que le estás dando a las personas normales, es que paga más ser guerrillero que ser una persona de bien" (Bronco). Estas apreciaciones son comprensibles si tenemos en cuenta el contexto de socialización para la vida militar, pero requieren de un trabajo de resignificación de cara a la construcción de paz (Cogollo \& Durán, 2015; López, 2015), y la configuración de un nuevo rol para las fuerzas militares en el país.

En conclusión, se observa en los pilotos militares dos posiciones, una negativa frente al futuro que le espera a Colombia y una positiva frente a lo que puede ofrecer la FAC con sus capacidades. Los procesos de resocialización que requiere esta transición hacia la paz, implican la modificación de identidades militares que se han construido con base en el marco de la confrontación. Y ello es pertinente tanto del lado de los militares, como de los excombatientes de los grupos armados ilegales (López \& Rodríguez, 2016; Moreno, 2014). Sin embargo, se puede observar que los pilotos conciben nuevas formas de identificación para ser militar y esto es un aspecto relevante a la luz del posconflicto que se encuentra en implementación por parte del gobierno colombiano.

\subsection{Conclusiones}

La construcción del enemigo cumple una función en la constitución de la identidad de los actores de la guerra. Construir un enemigo permite la diferenciación y el reconocimiento a partir de la comparación con otro. Ello cumple una función social y política, por ejemplo, en el caso de las Fuerzas Militares, da cuenta de la manera en que el Estado actúa frente a lo que puede ser considerado una amenaza para su soberanía.

La sumisión, como eje fundamental de la milicia dentro de una institución total como lo son las Fuerzas Militares, favorece que la construcción del enemigo singular sea coherente con el enemigo institucional. No sólo porque la institución forme a los militares en este aspecto, sino porque por identificación el sujeto se apropia de dichos rasgos y los toma para sí. De esta manera, los militares se identifican tanto con sus superiores, como con sus pares, garantizando con ello que sus acciones se realicen en nombre de un ideal común.

La guerra es constituida por un discurso donde se utilizan mociones agresivas que permiten a los militares desenvolverse en el ámbito del combate, pues quien no tiene un enemigo al que atacar, no tiene motivo para participar en la guerra. 
En el rol que cumplen los pilotos de combate se encuentran características que alimentan la confrontación de un enemigo construido por las Fuerzas Militares. La vocación de servicio, la entrega, el sacrificio, la búsqueda de reconocimiento, el arriesgar su propia vida por otros y su entrega a la patria, son justificaciones que delimitan muchas de las acciones contra el enemigo. En tanto que características propias del rol militar, tienen grandes implicaciones a la hora de atacar al adversario.

Cuando se arriesga la propia vida para atacar a otro, se observa de fondo un apasionamiento, una insistencia que no se detiene y que imprime a los actores de la guerra un impulso por continuar la confrontación. Ello se alimenta de la implicación subjetiva que está articulada a la construcción del enemigo que ha hecho cada uno como sujeto, y como integrante de una institución.

El enemigo es visto como amenazante, asociado a lo negativo, causante de mal, generador de daño y caos, es aquel que quiere atacar a los miembros de las Fuerzas Militares, tiene ideales desenfocados y es interpretado por los pilotos como inferior a sí mismos. Por tanto, lo que se puede hacer con él es deshumanizarlo, desarticularlo, derribarlo, aniquilarlo, acabarlo y desaparecerlo. Esto instaura una concepción de enemigo absoluto, contra el que no queda salida porque no se puede estar con él en el mismo lugar físico: "o es él o soy yo". Por esta vía emerge la pasión, el deseo y el goce a través del cuerpo del otro; lo pulsional que se pone en juego en el combate se satisface en la aniquilación del otro.

Frente al enemigo existe un discurso deslegitimador, asociado la atribución de características negativas. Se puede inferir que dicho discurso tiene sus bases desde la constitucionalidad que nombran frecuentemente los pilotos de combate, que les permiten ejecutar acciones de guerra de manera legal, mientras que su enemigo siempre será relacionado con acciones ilegales e inconstitucionales. De esta manera, la justificación de las acciones propias no sólo se basa en las acciones negativas del otro, sino que reposa en la premisa de que son legales y constitucionales.

Por otra parte, es importante resaltar que dicho enemigo es compartido y conocido por todos los miembros de las Fuerzas Militares, se caracteriza por ser cambiante, pero también por ser necesario. Aquel contra el que lucha el militar, es necesario para existir como militar, para hacerse a una identidad y por tanto a un rol. Es así que, si el enemigo actual desaparece, se opera con la convicción de que aparecerá otro en su reemplazo. 
En la actualidad, el principal enemigo contra el que otrora luchaban los militares ha firmado un acuerdo de paz, por tanto, aunque expresan que debe ser eliminado, en el marco del proceso y en el aspecto jurídico se expresa que el enemigo debe recibir un castigo por el daño causado: debe ser juzgado, debe pagar con cárcel y debe retribuir de alguna forma el daño causado a la población. Esto sugiere que si no se puede lograr la aniquilación y la superioridad propia frente a la del enemigo por vía bélica, la confrontación continuará en campo discursivo, en el escenario de postconflicto, expresada en la lucha por garantizar que el adversario pague por sus acciones de alguna manera. Probablemente los militares buscarán la ratificación de su superioridad frente al enemigo por medio de la privación de su libertad, mientras ellos continúan con su misión de manera libre.

Es preciso resaltar que en las entrevistas se encontró un número mínimo de alusiones al enemigo político, aquel del cual se es consciente de que es diferente, pero al que se le trata como persona y se le otorga de la dignidad de sujeto de palabra. La prevalencia de alusiones al enemigo absoluto sobre el enemigo político da cuenta de cómo la pasión, el deseo, lo irracional, lo inconsciente, entran a jugar en la guerra como recurso fundamental del sujeto que participa en ella.

Esta negación del estatuto político del enemigo en el discurso de los pilotos de combate contrasta con lo encontrado por Angarita, et al. (2015) al analizar discursos de los actores del conflicto armado. Quizá esta diferencia radique en que los discursos analizados en dicha investigación fueron declaraciones públicas calculadas racionalmente, que generalmente estaban orientadas a la necesidad de justificar la confrontación bélica, la mayor parte de las veces desde un escenario de lo políticamente correcto. En nuestra investigación, al indagar en la dimensión subjetiva de los actores de la guerra se denota que el discurso se relaciona con lo negativo del enemigo asimilándolo al perdedor y mostrando una posición más ligada al plano pasional del enemigo absoluto y necesario que a su estatuto político. Ello induce a pensar que la dimensión política del enemigo aparece con mayor facilidad en discursos calculados, utilizados como recurso en el conflicto. Las declaraciones de los pilotos de combate muestran que, en el aspecto singular, la guerra moviliza otra satisfacción en la que no hay cabida para pensar en una solución por medio de la negociación, la cual es descartada como primera opción.

En este contexto surge otro interrogante, el hecho de que la mayor cantidad de alusiones frente al enemigo absoluto corresponden a sujetos que 
llevan más tiempo de servicio en la operación militar contra el enemigo, por tanto vivieron la época cruda de la guerra, donde los ataques de los grupos ilegales se presentaban todo el tiempo, en todo momento y lugar; en comparación con los pilotos de menor edad y por tanto menos tiempo de servicio, entre los cuales se encontraron alusiones acerca del estatuto político del enemigo. Lo anterior podría dar cuenta del peso que tiene la experiencia en combate y la participación en operaciones donde la guerra estaba en su punto máximo y donde la exposición a la muerte se realizaba a diario, esto es, los primeros años de la década del 2000, en los que el conflicto armado colombiano tuvo su punto de mayor recrudecimiento.

En conclusión, para contribuir a desmontar la dinámica de la guerra que se ha desarrollado en los últimos 60 años, es necesario fomentar la construcción de un enemigo político, que haga contrapeso a la construcción del enemigo que ha sido cultivada, reforzada y alimentada en la experiencia de guerra de una generación de militares, quienes de cara al posconflicto deben asumir nuevos roles y nuevas posiciones frente a aquel que otrora fue su enemigo total.

\section{Referencias}

Alzate, M., Duran, M., \& Sabucedo, J. (2009). Población civil y transformación constructiva de un conflicto armado interno: aplicación al caso colombiano. Universitas Psicologyca, 3(8), 703-720. Disponible en: http://revistas.javeriana.edu.co/index.php/revPsycho/ article/view/617

Andrade, K., \& Moreno, M. (2017). Dinámicas subjetivas de combatientes en el conflicto armado colombiano. In M. A. Moreno Camacho, J. J. Orejuela Gómez, \& T. Calderón García (eds.), Abordajes Psicoanalíticos a Inquietudes sobre la Subjetividad III (pp. 97-116). Cali: Editorial Bonaventuriana. Retrieved from http://www.editorialbonaventuriana. usb.edu.co/index.php/libros/inv/item/376-abordajes-psicoanaliticossubjetividad-3

Angarita, P., Gallo, H., Jimenez, B., Londoño, H., Londoño, D., Medina, G., ... Ruíz, A. (2015). La construcción del enemigo en el conflicto armado colombiano 1998-2010. Medellin: Sílaba Editores.

Blair, E. (1995). La imagen del enemigo: ¿un nuevo imaginario social? Estudios Politicos, 6, 47-71. Disponible en: http://aprendeenlinea.udea.edu.co/revistas/index.php/estudios politicos/article/view/15666

Blair, E. (1999). Conflicto armado y militares en Colombia. Cultos, símbolos e imaginarios. Medellín: Editorial Universidad de Antioquia.

Borrero, A. (1990). Militares, política y sociedad. Revista Colombiana de Sociologia, 1(1), 77-88. Disponible en: https://revistas.unal.edu.co/index.php/recs/article/view/8730 
Castellón, L. (2014). Los lenguajes de la guerra: construcción política del enemigo en las guerras de independencia de México y Venezuela (1809-1820). Anuario de Historia Regional y de Las Fronteras, 20(1), 41-71. Disponible en: http://revistas.uis.edu.co/ index. php/anuariohistoria/article/view/4647

Castro, M. (2001). Del ideal y el goce. Bogota: Universidad Nacional de Colombia.

Castro, M. (2005). Transgresión, goce y profanación. Bogota: Universidad Nacional de Colombia.

Clausewitz, K. (2008). De la Guerra. Buenos Aires: Ediciones Terramar.

Cogollo, S., \& Durán, N. (2015). Paz y posconflicto: conpromiso de los ciudadanos para un horizonte imaginado. In S. N. Cogollo Ospina (ed.), Imaginar la paz en Colombia. Cavilaciones desde la academia. (pp. 62-71). Medellín: Fondo Editorial Luis Amigó.

Delgado, M. (2011). El criterio amigo-enemigo en Carl Schmitt. El concepto de lo político como una noción ubicua y desterritorializada. Cuaderno de Materiales, 23, 175-183. Disponible en: http://www.filosofia.net/materiales/pdf23/CDM11.pdf

Domínguez, J. (2008). Cultura e imaginarios de la vida guerrillera. Revista Humanitas, $1(2), 127-144$.

Egan, D. (2007). Frantz Fanon and the construction of the colonial subject: Defining "The enemy" in the Iraq War. Socialism and Democracy, 21(3), 142-154. Disponible en: https:// www.tandfonline.com/doi/abs/10.1080/08854300701599858

Fuerza Aérea Colombiana [FAC]. (2013). Manual de Doctrina Aérea y Espacial (MADBA) (4 ed.). Colombia: Comando Fuerza Aérea Colombiana. Disponible en: https://www.fac. mil.co/manual-de-doctrina-básica-aérea-y-espacial-mabda

Gadamer, H. (1999). Verdad y Método Tomo I (8 $8^{\mathrm{a}}$ ed.). Salamanca: Ediciones Sígueme.

Gallo, H. (2013). El lugar del enemigo. Desde el Jardin de Freud, 13, 137-144. Disponible en: https://revistas.unal.edu.co/index.php/jardin/article/view/40701

Gallo, H. (2016). Guerra y subjetividad. In Nueva Escuela Lacaniana - NEL (ed.). Guayaquil. Disponible en: http://ix.jornadasnel.com/template.php?file=Plenaria.html

Green, D., \& Bogard, C. (2012). The making of friends and enemies: assesing the determinants of international identity construction. Democracy and Security, 8(3), 277-314. Disponible en: https://www.tandfonline.com/doi/full/10.1080/17419166.2012.715469? scroll $=$ top\&needAccess $=$ true

López, G. M. (2015). Carta a un ciudadano de Colombia: inflexiones para una paz factible. In S. N. Cogollo Ospina (ed.), Imaginar la paz en Colombia. Cavilaciones desde la academia. (pp. 123-128). Medellín: Fondo Editorial Luis Amigó.

López, G. M., \& Rodríguez, A. (2012). El lugar de los sentimientos, el lugar de los vínculos. Reconfiguración de identidades en el marco del conflicto armado colombiano. Revista Colombiana de Ciencias Sociales, 3(2), 270-289. Disponible en: http://www.funlam.edu. co/revistas/index.php/RCCS/article/view/890/839 
López, G. M., \& Rodríguez, A. (2016). Desarrollo, sentimientos sociales y diálogo transformativo: una propuesta para la comprensión del proceso de DDR en Colombia. Revista Fundación Universitaria Luis Amigó, 3(1), 81.88. Disponible en: http://www.funlam. edu.co/revistas/index.php/RFunlam/article/download/1896/1516

Lozada, M. (2004). El otro es el enemigo: imaginarios sociales y polarización. Revista Venezolana de Economía y Ciencias Sociales, 10(2), 195-209. Disponible en: http://saber. ucv.ve/handle/123456789/13628

Lujan, H., \& Silva, R. (2014). De enemigos a adversarios: La transformación del concepto de "lo político" de Carl Schmitt por Chantal Moufee. Andamios, 11(24), 83-102. Disponible en: http:/www.scielo.org.mx/scielo.php?pid=S1870-00632014000100005\&script=sci abstract

Mesa, J., \& Ruíz, A. (2013). Consideraciones sobre el enemigo público en Colombia 19982009. Boletín de Antropología Universidad de Antioquia, 28(45), 40-61. Disponible en: https://aprendeenlinea.udea.edu.co/revistas/index.php/boletin/article/view/17767

Moreno, M. (2014). Otra oportunidad. El paso a la vida civil de jóvenes desvinculados de grupos armados ilegales en Colombia. Cali: Editorial Bonaventuriana. Disponible en: http:// www.editorialbonaventuriana.usb.edu.co/index.php/libros/inv/item/6-psicologia/244otra-oportunidad

Pecaut, D. (2013). Desdibujamiento de la oposición “amigo enemigo" y "banalización" de las prácticas atroces. A propósito de los fenómenos recientes de violencia en Colombia. Analisis Politico, 26(78), 3-26. Disponible en: https://revistas.unal.edu.co/index.php/ anpol/article/view/43572/44858

Ramirez, M. (2008). Psicoanalistas en el frente de batalla. Affectio Societatis, 5(9), 1-4. Disponible en: http://aprendeenlinea.udea.edu.co/revistas/index.php/affectiosocietatis/ article/view/5335/4689

República de Colombia. (1991). Constitución Política de Colombia.

Rivas, J. (2002). Conflicto armado y militares en Colombia. Cultos, símbolos e imaginarios. Reflexión Política, 4(7). Disponible en: http://www.redalyc.org/articulo.oa?id=11040710

Sampson, A. (2000). Reflexiones sobre la violencia, la guerra y la paz. In A. Papacchini, D. Henao Restrepo, \& V. M. Estrada (eds.), Violencia, guerra y paz: Una mirada desde las Ciencias Humanas. (pp. 71-99). Cali: Universidad del Valle. Disponible en: https:// searchworks.stanford.edu/view/4753195

Schettini, P., \& Cortazzo, I. (2015). Análisis de datos cualitativos en la investigación social. La Plata: Universidad Nacional de La Plata. Disponible en: http://sedici.unlp.edu.ar/ handle/ 10915/49017

Spillmann, K., \& Spillmann, K. (1991). L'image de l'ennemi et l'escalade des conflits. Revue Internationale Des Sciences Sociales, 127.

Tortosa, J. (2003). La construcción social del enemigo. Convergencia Revista de Ciencias Sociales, (33), 177-195. Disponible en: https://convergencia.uaemex.mx/article/view/1588 
Tzu, S. (2003). El arte de la guerra. Biblioteca Virtual Universal. Disponible en: http://www. biblioteca.org.ar/libros/656228.pdf

Vidal, R. (2004). El “otro" como enemigo. Identidad y reacción en la nueva "cultura global de miedo." Nomadas, 9. Disponible en: https://dialnet.unirioja.es/ejemplar/82059

Villa, J. D. (2016). Perdón y reconciliación: una perspectiva psicosocial desde la noviolencia. Polis, 15(43), 131-157. Disponible en: https://journals.openedition.org/polis/11553

Vite, M. (2015). Mexico, the construction of enemies througt social protest: Some reflections. Critical Sociology, 42(4), 661-677. Disponible en: http://journals.sagepub.com/doi/abs/ $10.1177 / 0896920515570500$ 


\title{
24. Construcción de paz y conflictos socioambientales en Sumapaz
}

\author{
Diana Carolina Urbina Vanegas ${ }^{92}$
}

\section{Resumen}

La región del Sumapaz es un territorio rico en biodiversidad y fuentes hídricas, allí se ubica el páramo Sumapaz, considerado como el más grande del mundo. Ha sido un escenario central en el conflicto armado, debido a luchas agrarias generadas a mediados del siglo XX en oposición a la concentración de la tierra de los latifundistas y por el surgimiento de movimientos insurgentes en pleno auge del frente nacional. En el 2016, la firma del acuerdo de paz con las FARC permite pensar una transformación, sin embargo se han puesto en evidencia conflictos ambientales preexistentes y se han fortalecido disputas territoriales entre las comunidades, el Estado y las empresas que promueven la extracción de diferentes recursos. Este artículo describe conflictos socioambientales que se presentan en la localidad 20 de Bogotá, Sumapaz y en el municipio de Pasca de la provincia de Sumapaz. De igual forma, se consideran algunas de las estrategias implementadas por las comunidades para enfrentar los impactos socioambientales en el contexto del posacuerdo. Se acude al recorrido y a la observación participante como estrategia de acercamiento al territorio y a las memorias construidas por líderes, colectivos y movimientos sociales que habitan la región.

Palabras clave: conflictos socioambientales, posacuerdo, paz.

\section{Abstract}

The Sumapaz region is a territory rich in biodiversity and water sources, where Sumapaz páramo is located, considered the largest in the world. It has been a central scenario in the armed conflict, due to agrarian struggles generated in the mid-twentieth century in opposition to the land concentration of landowners and the emergence of insurgent movements, when national front was in full swing. In 2016, the signing of the peace agreement with the FARC allows us to think about a transformation, however pre-existing environmental conflicts have been highlighted and territorial disputes between communities, the state and companies that promote the extraction

92 Universidad Piloto de Colombia. Correo: durbina17@upc.edu.co 
of different resources, have been reinforced. This article describes socioenvironmental conflicts that occur in locality 20 of Bogotá, Sumapaz and in Pasca, municipality of Sumapaz province. Likewise, some of the strategies implemented by the communities, to deal with the socio-environmental impacts in the context of the post-agreement, are considered. Participation in the route and participant observation are used as a strategy to approach the territory and the memories built by leaders, groups and social movements that inhabit the region.

Keywords: socio-environmental conflicts, post-agreement, peace

\subsection{Introducción}

Para iniciar, es importante tener en cuenta que Sumapaz ha forjado una larga tradición de luchas agrarias. Desde comienzos del siglo XX las comunidades campesinas se agremiaron contra el despojo de tierras por parte de los latifundistas. En esa época se destaca el trabajo realizado por Erasmo Valencia reconocido lider campesino que le da inicio al Partido Agrario Nacional en los años 20. Con la muerte del candidato liberal Jorge Eliecer Gaitán en el 48, se da inicio al denominado periodo de La Violencia, el cual se va a caracterizar por la persecución de liberales, miembros del movimiento agrario y del partido comunista. Aun con la llegada del Frente Nacional en el 58, va a continuar la persecución en la región contra aquellos que proponen una transformación al modelo de concentración de la tierra. En este contexto toma fuerza el liderazgo de Juan de la Cruz Varela, quien va a trabajar de la mano con Valencia hasta convertirse en un lider con gran acogida en el sector campesino. Varela va a ser el encargado de liderar el movimiento agrario y de apoyar las consignas del Partido Comunista Colombiano, orientadas a defender la región de las amenzas provenientes del gobierno, de los latifundistas y de monopolios extranjeros, un proceso a partir del cual van a surgir los primeros movimientos guerrilleros en la región (Varela y Duque, 2010).

Con el paso del tiempo, en la región han hecho presencia diferentes actores centrales para el conflicto armado: las Fuerzas armadas revolucionarias de Colombia-FARC, los operativos militares contra las FARC desde los años 60 y los grupos de autodefensas que entran con fuerza en el año 2000. Hay que resaltar que el punto estratégico en el que se ubica Sumapaz, le convierte en un corredor central para el conflicto ya que conecta el Caquetá, el Meta, Bogotá y los departamentos de Cundinamarca, Huila y Tolima. Las FARC se han caracterizado por realizar acciones para obtener recursos por medio de la extorsión y el secuestro, haciendo presencia en la zona rural de 
Bogotá, en el Tolima, en el Meta y en municipios como Cabrera, Fusagasugá, Pasca, Arbelaez, San Bernardo, entre otros. Por su parte, las Autodefensas quienes actuan para bloquear la actuación de las FARC, han operado a partir de homicidios, amenazas a lideres sociales y a las autoridades municipales. Estas actuaciones, junto a los operativos militares dispuestos para enfrentar la resistencia campesina en los 40 y a las FARC desde los 60, han dejado grandes marcas tanto en el territorio como en la población que allí habita (Observatorio de Derechos Humanos y DIH, 2002).

Otro de los actores afectados por la guerra ha sido el medio ambiente y aquí se debe recordar que la zona del páramo es una de las más afectadas debido a las confrontación entre grupos armados, la construcción de asentamientos y rutas, la tala de árboles, entre otras (Observatorio de Derechos Humanos y DIH, 2002). De forma posterior a la firma del acuerdo con las FARC se esperaría un cambio en esta condición, sin embargo lo que ha ocurrido es que ante el retiro de las FARC, varios son los actores que buscan aprovechar los beneficios de esta región, entre ellos los asociados al turismo y las multinacionales que entienden la gran riqueza que alberga esta zona estratégica del país. De forma paradójica, el acuerdo se ha traducido en un incremento de la deforestación, pérdida de la biodiversidad, especulación de la tierra, aumento de cultivos ilícitos y expansión de las zonas agropecuarias en diferentes partes del país (Semana, 2018a). Bajo estas condiciones, los parques nacionales considerados como áreas protegidas, se encuentran en riesgo de desaparecer dado que es importante garantizar la conectividad que hay entre ellos. Hay que resaltar que uno de los principales obstáculos que se presentan, son las políticas de estado que hasta la fecha han dado prioridad a un modelo de desarrollo extractivista, lo cual va en contravía de la sostenibilidad de los ecosistemas (Semana, 2018b). De forma adicional, Sumapaz se une a las zonas en riesgo debido a la aprobación de proyectos enfocados a la exploración y explotación de hidrocarburos mediante técnicas convencionales y no convencionales-Fracking (Semana 2017a, 2017b y 2017c). Bajo estas condiciones, el reto consiste en realizar seguimiento a la delimitación del páramo, identificar actividades realizadas por los habitantes que atenten contra la sostenibilidad del ecosistema y fortalecer los procesos sociales que se manifiestan en contra de la explotación de la región.

Al realizar una revisión documental, es posible identificar que en los últimos cinco años se han venido realizado investigaciones sobre los conflictos socioambientales en Colombia desde múltiples perspectivas. Respecto a las propuestas para mitigar dichas problemáticas, en el año 2013 se propende por fortalecer la investigación, la educación ambiental y la conservación de 
ecosistemas (Ardila, 2013; Olivos, Aragonés y Navarro, 2013; Cárdenas, 2013), resaltando el rol central que ocupa la mujer rural en dichas labores (Ardila, 2013; Zuluaga y Arango, 2013) y la importancia de crear estrategias para fomentar la participación y la acción colectiva (Salazar, 2013). De igual forma, se advierte sobre la necesidad de formalizar actividades informales de minería (Guiza, 2013), sistematizar experiencias de comercio justo en las zonas rurales, fortalecer la siembra, el consumo de especies y adecuar áreas para actividades pecuarias (Coscione, 2013; Tovar y Alvarado, 2013).

Para el año 2014, a diferencia del año anterior, se encuentra un mayor interés por visibilizar herramientas de tipo legal, social, político y cultural implementadas por los movimientos sociales enfocadas en fortalecer la gobernanza (Corredor, 2014; Molina , 2014) y las estrategias implementadas por comunidades indígenas para enfrentar el modelo de desarrollo (Ramos, 2014). Por otra parte, se plantean estrategias para mitigar los efectos negativos que ha tenido la minería sobre el territorio (García, García y Agudelo, 2014), resaltando los retos de la consulta previa en Colombia (Hillón, 2014) y promoviendo la implementación de modelos agroecológicos respetuosos con las particularidades culturales (Avellaneda, Torres y León, 2014). De igual forma, se encuentran propuestas enfocadas a fortalecer la educación ambiental por medio del estudio de la percepción actual del medio ambiente (Medina y Páramo, 2014) y de la inclusión de los marcos normativos correspondientes en el desarrollo de los currículos (Paz, Avendaño y Parada, 2014).

Respecto al año 2015, se hace un mayor énfasis en recurrir a metodologías cualitativas y a la investigación acción participativa para identificar la percepción de los habitantes frente a la calidad de recursos y así establecer estrategias de acción (Acosta, Benavides y Sierra, 2015; Egio, Torrejón, Muñoz, \& Cumplido, 2015; Granada \& Molina, 2015). Igualmente se sugiere abordar el despojo de tierras, la privatización del agua y el impacto de la agroindustria desde una perspectiva etnográfica (Ojeda, Petzl, Quiroga, Rodríguez y Rojas, 2015; Jaramillo, Londoño y Sánchez, 2015). Es por esto que, las propuestas buscan identificar estrategias de resistencia frente a la expansión minera y visibilizar el impacto de la pequeña minería (Lopera, 2015; Quiñones, 2015), identificar prioridades socioambientales en zonas de conflicto (Negret y Torres, 2015), promover la diversificación de cultivos para de garantizar la soberanía alimentaria (Ávila y Carvajal, 2015), mejorar instrumentos normativos para el control ambiental (Alzate, 2015) y promover la participación y la educación jurídica ambiental (Munévar y Gonzaga, 2015). 
Ya en el 2016, las propuestas se orientan en su mayoría a resaltar acciones comunitarias frente al extractivismo y otros conflictos socioambientales. Aquí se destacan las movilizaciones, tutelas, titulaciones colectivas, articulación con redes transnacionales, uso de plataformas web colaborativas, acciones de fortalecimiento y gobernanza ambiental (Sañudo, Quiñones, Copete, Díaz, Vargas y Cáceres, 2016; Paz, 2016; Quiñones, Menéndez y Herrera, 2016; Güiza, Rodríguez, Ríos y Moreno, 2016). Otras propuestas se enfocan más en aspectos técnicos que permitan identificar conflictos por medio de la geografía (Vargas y León, 2016), articulación entre autoridades, intrumentos, políticas, problemáticas territoriales y comunidades (Acevedo y Flórez, 2016; Bayona, 2016) y estudiar las condiciones del agua, el aire y los suelos que pueden verse afectadas (Agudelo, Quiroz, García, Robledo y García, 2016 y Guzmán, Nava y Bevilacqua, 2016).

Finalmente, en el 2017 se reconoce una intensión por ampliar la perspectiva desde la cual se abordan los conflictos socioambientales, reflejada en estudios que abogan por la diferencia cultural (Basto, 2017), la articulación de actores para fortalecer la gobernanza del agua (Rincón, Lara, Castro y Rojas, 2017), el análisis de la escala geográfica, política y temporal (Osejo y Ungar, 2017) y el fortalecimiento de redes (Parra y Gitahy, 2017). De igual forma, se busca incidir en el marco normativo al estudiar la relación entre el POT y la transformación comunitaria (Perez, 2017), la relación entre el estado, los conflictos y la violencia (Zárate, 2017), la sustituibilidad frente a la explotación (Trujillo, Losada y Rodríguez, 2017) y al sugerir la complementariedad entre la norma y la legitimidad social (Munévar, González y Henao, 2017). Desde un enfoque distinto, se porpone el análisis de la huella hídrica (Tovar, Trujillo, Muñoz, Torres, Zárate, 2017) y de la percepción de riesgo en relación con el apego del lugar (Muñoz y Arroyave, 2017).

\subsection{Marco conceptual}

Abordar la reconstrucción del tejido social en un contexto afectado por la guerra, requiere la consolidación de un modelo social que permita afianzar la interrelación entre el ser humano y el entorno. La perspectiva ecológica de Bronfenbrenner (Herrero, 2004) puede aportar a este propósito, sin embargo aún se evidencia una dificultad para entender la interconexión entre las problemáticas socioambientales y los conflictos políticos, económicos y territoriales. Es por esto que, es importante incorporar la propuesta de la ecología política (Leff, 2004) desde la cual se cuestiona la racionalidad científica que sustenta las prácticas ecológicas actuales. Esta racionalidad 
es la que ha conducido a configurar modelos de desarrollo centrados en el extractivismo, el dominio de la tierra y en la priorización del beneficio económico por encima de la sustentabilidad y la protección de los ecosistemas. A su vez, esta crisis ambiental ha fortalecido los movimientos ambientales que llegan a cuestionar eslabones fundamentales de la sociedad capitalista por medio del desarrollo sustentable, el respeto por el orden natural, el rescate de valores sociales, la aticulación con el entorno y la organización a través de procesos más democráticos y participativos.

Para incorporar a los planes de desarrollo este cambio de perspectiva, es necesario reconocer y apoyarse en las diferencias culturales que le han dado forma a los territorios en disputa, si lo que se busca es garantizar la participación de las comunidades o como lo plantea Alimonda (2017), reconocer los nuevos sujetos políticos que hacen presencia a partir del giro eco-político que ha surgido en las últimas décadas en Latinoamerica. Dicho reconocimiento pasa por el otorgarle un lugar central a las identidades de las comunidades, desarrollar un pensamiento crítico que permita construir alternativas y especialmente consolidar una epistemología crítica que permita cuestionar las categorías que sostienen el orden social actual.

En este sentido, la interculturalidad (Walsh, 2008) propende por desarrollar escenarios en los cuales se reconozcan como válidos los saberes populares. En relación a las problemáticas socioambientales (Leff, 2004), el saber de los pueblos indígenas, de los campesinos y de las mujeres no solo es válido sino que se requiere con urgencia, para evitar la depredación de los ecosistemas, entender que tanto los seres humanos como la tierra son sujetos de derecho, promover valores comunitarios orientados al bien común, garantizar la soberanía alimentaria y el Buen Vivir. Todos estos elementos le dan forma al pensamiento crítico latinoamericano del que habla Escobar (2017), el cual se caracteriza por el desarrollo de la autonomía, la comunalidad, la territorialidad y por una profunda conexión con la tierra que expresa toda la riqueza de la cosmovisión africana y latinoamerciana. Por esta razón, es fundamental identificar redes comunitarias (Montero, 2004) con el fin de trascender la simple identificación de problemáticas para pasar a la consolidación de propuestas que sean sostenibles en el tiempo.

En línea con la formación de una epistemología crítica, se propone ampliar la perspectiva sobre la paz y el conflicto, conceptos que no pueden seguir siendo antagónicos, en lugar de esto deben entenderse como complementarios y como parte de integral de un proceso de paz estruc- 
turalmente imperfecto (Muñoz y Molina, 2010). En el cual, el conflicto no se asume como algo negativo sino como la posibilidad de ampliar escenarios democráticos, aprender a partir de la diversidad y gestionar consensos entre las partes implicadas (Cascón, 2001). De igual forma, es necesario poner en cuestionamiento los conceptos que se han construido sobre la política, la democracia, la ciudadanía y la participación(Carmona y Posada, 2018; Cogollo y Durán, 2015; Insuasty y Villa, 2016), que en muchos casos se quedan cortos para entender la diversidad cultural. De esta manera, se puede afianzar la capacidad de los nuevos sujetos políticos para incidir en los asuntos públicos y así ampliar los escenarios de resistencia. Esta propuesta es acorde con las multiples perspectivas que se presentan frente a los conflictos socioambientales, dada su complejidad no existe una postura única frente a los impactos durante y después de la firma del acuerdo de paz.

\subsection{Metodología}

Para el desarrollo de esta investigación, se parte de los principios de la investigación cualitativa y de la observación participantes, entendiendo que la dimensión subjetiva, la interacción y las vivencias cotidianas permiten acceder a la perspectiva de los actores implicados (Galeano, 2003; Guber, 2001). Desde aquí, se proponen los recorridos como estrategia metodológica para acercarse al territorio, reconocerlo, identificar sus historias y actores representativos. Al considerar que el Sumapaz cuenta con un imporante legado indígena, desde una perspectiva intercultural las caminatas se abordan como Zunas que para los Muiscas significan el gran camino, así se rescata su carácter sagrado, la búsqueda del equilibrio y la interconexión con el medio promovida por los primeros pobladores. En este sentido, caminar se entiende como un "mecanismo de afirmación del sujeto y de su independencia como individuo, a la vez que un medio de interacción con sus congéneres y con el entorno" (Alcaldía Mayor de Bogotá y Secretaría Distrital de Ambiente, 2015, p. 15).

En esta etapa de investigación se presentan los resultados del recorrido realizado en la localidad 20 de Bogotá, Sumapaz junto a 3 líderes comunitarios pertenecientes a una organización de turismo comunitario. Y en segundo lugar, el acercamiento al municipio de Pasca, perteneciente a la provincia de Sumapaz, donde se establece contacto con 2 líderes comunitarios que integran una organización enfocada en la educación ambiental y el fortalecimeinto de los habitantes del sector. 
Cátedra Colombiana de Psicología

Mercedes Rodrigo 2019

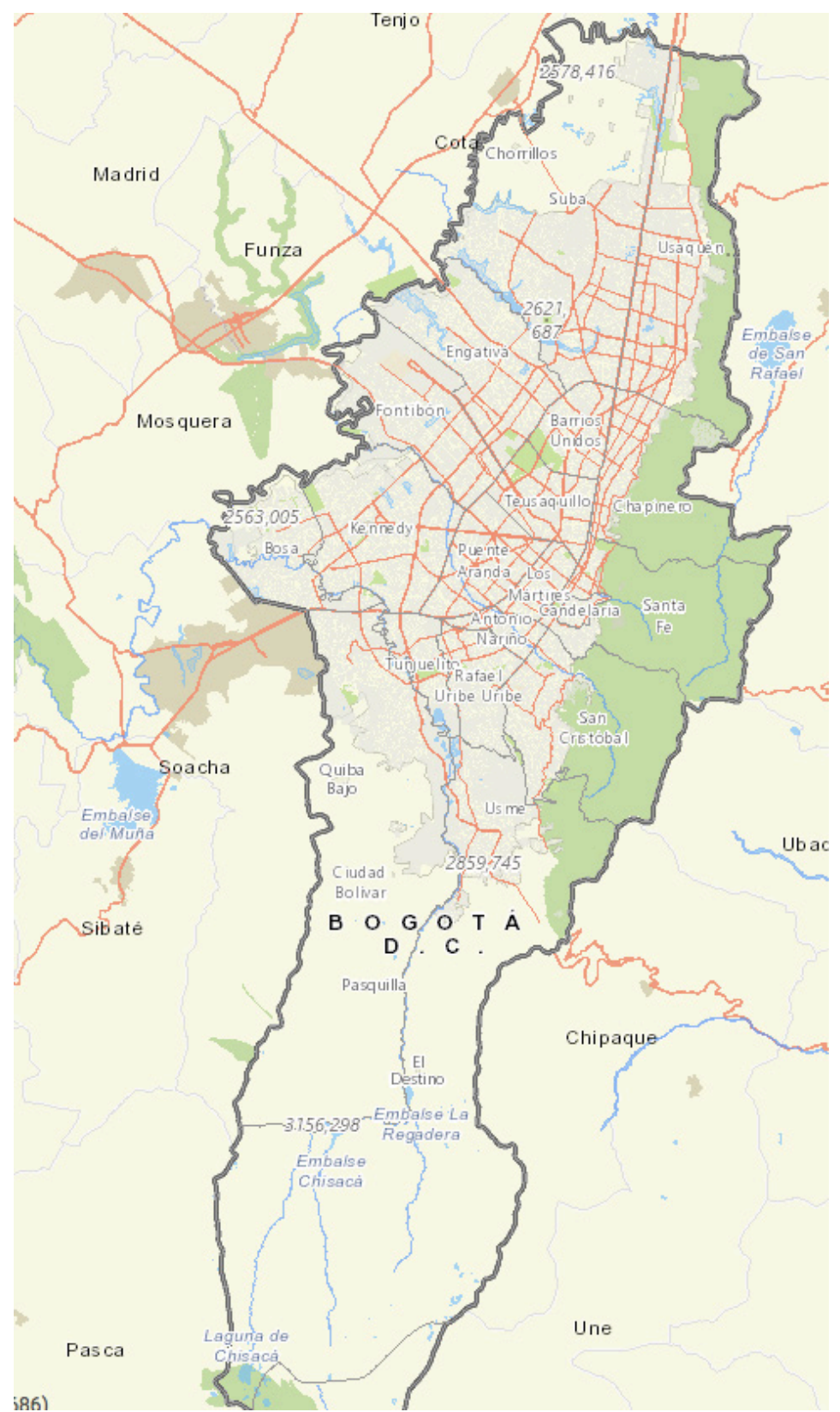

Figura 1. Mapa de Bogotá y detalle por localidad Fuente: mapasbogota.gov.co 


\subsection{Resultados}

Sumapaz: el páramo más grande del mundo

Cuando se piensa en Bogotá para muchos es difícil dimensionar la complejidad que alberga este entramado urbano, sus múltiples contrastes y la posibilidad de encontrar ecosistemas que se interconectan para garantizar la sostenibilidad de la vida en la ciudad. El recorrido por la localidad de Sumapaz ha permitido vivenciar de forma directa las principales problemáticas que afectan la ciudad y la importancia de generar alternativas para preservar los recursos no renovables que se encuentran en riesgo.

El punto de partida es Ciudad Bolivar, allí sobre la cima de una montaña donde se puede divisar la Avenida Boyacá limitando con Usme, nos encontramos de frente con una de las consecuencias que ha dejado el modelo de desarrollo extractivista en la ciudad, el Parque Minero industrial. Ciudad Bolivar logra condensar diversas problemáticas sociales, desde los años 80 esta localidad se consolida como alternativa para acoger a cientos de campesinos afectados por la violencia y el desplazamiento. El crecimiento de la ciudad y las condiciones morfológicas del territorio, van a conducir a la creación de un proyecto destinado a la explotación de arenas y a la obtención de material de contrucción, en el cual van a participar industrias internacionales como Cemex, Holcim y a nivel nacional la Fundación San Antonio, las cuales han adquirido el derecho de explotación minera durante 150 años. A parte del grave daño ambiental que se genera al desviar el cauce del río Tunjuelo, se puede entender la afectación sobre la población que allí habita y que a futuro debe ser reubicada en otro sector, se nombra la Operación Nuevo Usme como opción para realizar dicho traslado. Al preguntar por la postura de la comunidad, encontramos que hay poca o nula información respecto al proyecto que se ejecuta en ese sector, una de las estrategias que se ha utilizado es la construcción de un gran muro que impide al transeunte visibilizar la explotación que allí se está presentando.

Si bien existen procesos de resistencia liderados por organizaciones como Territorio Sur y Asamblea Sur, se han presentado muertes selectivas que han frenado la lucha social y en otros casos se han asignado recursos, por ejemplo para pintar el mural, que terminan desviando los objetivos iniciales de transformación social o, como lo expresa el líder que guía el recorrido: "los encaramelan". 
Avanzando en el recorrido, llegamos al Relleno Sanitario Doña Juana que se inaugura en los años 80 , su nombre ha sido objeto de múltiples interpretaciones dentro de las cuales se encuentran las siguientes:

Allá, por allá en la montaña, en la parte alta, hay un árbol seco, ahí están las ruinas de una casa y ahí vivía una bruja que se llamaba Doña Juana, y Doña Juana se encargaba de adivinar la suerte y las infidelidades de muchos de los hombres de este sitio, con tan mala suerte que, para la época, por religión católica, fue condenada por ese tipo de cosas, y la quemaron allá, amarrada de ese árbol, o sea la quemaron al lado de su casa. Y fue quemada ahí, la señora Juana. La otra, es la de la cosmovisión o la cosmogonía, si miráramos esta montaña desde el otro lado, tiene forma de mujer (líder comunitario).

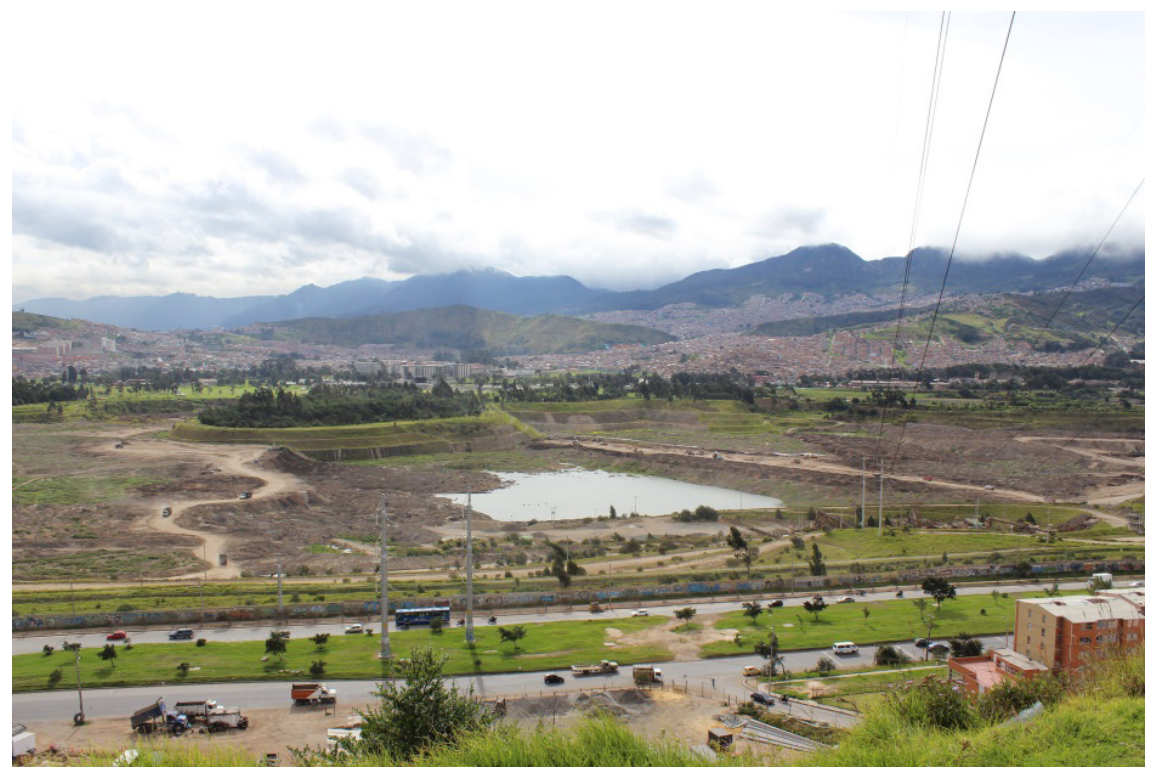

Imagen 2. Parque minero industrial

La problemática socioambiental que se ha generado aquí radica principalmente en la falta de sostenibilidad del proceso que se lleva a cabo para recolectar y procesar los residuos sólidos. Este botadero de basura que se construyó sobre las quebradas Trompeta, Chuscales y Hierbabuena, recibe aproximadamente 8 mil toneladas de basura al día provenientes de Bogotá y de los municipios cercanos, la cual al no ser tratada adecuadamente se 
convierte en foco de infecciones y plagas que afectan a las comunidades cercanas. Adicionalmente, los lixiviados resultantes se botan en la quebrada La Hierbabuena. Al comprender que los residuos pueden ser aprovechables para garantizar un beneficio económico y la disminución del impacto ambiental, surge la siguiente pregunta ¿Por qué en Bogotá no ha cambiado el modelo? $\mathrm{Al}$ respecto los líderes comunitarios plantean que eso se desprende de la administración público privada que genera ganancias de aproximadamente 578.400 millones, beneficiando principalmente empresas privadas como Lime y Ciudad Limpia, las cuales hacen uso de terrenos públicos para la recolección de la basura. En otras palabras, como plantea uno de los líderes "nosotros pagamos para olernos nuestra propia basura. Así de básico y sencillo". A diferencia de lo que planteaba la administración anterior con el proyecto Basura Cero (vender residuos a Japón y Brasil y generar una planta de energía), la respuesta de la alcaldía ha sido sugerir la ampliación del botadero en un área de 8 kilómetros. Esto sin duda, ha generado diversos enfrentamientos entre campesinos y la fuerza pública, campesinos que ya están cansados de vivir al lado de este relleno sanitario. Frente a esta situación, los líderes plantean que la salida por el momento está en continuar con acciones pedagógicas que nos permitan identificar nuestro lugar en la cadena de producción de residuos, promover la separación desde la fuente, incentivar el consumo responsable y afianzar los lazos con las asociaciones de recicladores.

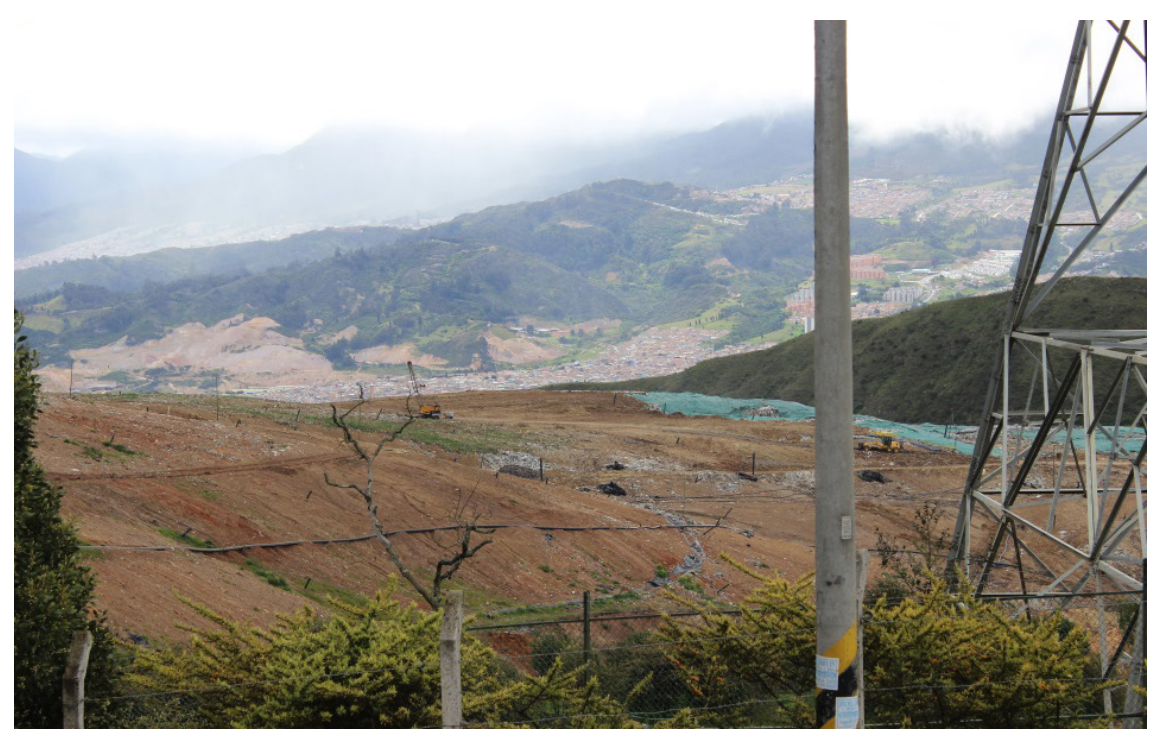

Figura 3. Relleno sanitario Doña Juana 
La tercera parada se realiza en el Embalse de La Regadera, allí se hace una reflexión sobre el manejo del agua y sobre la importancia de cuidar este recurso que se está agotando rápidamente. La Regadera se crea en los años 40 como un proyecto hídrico liderado por Colombia y Alemania, con el fin de solucionar el manejo de las aguas del sur de la ciudad, este embalse se encarga de recoger las aguas que provienen de Sumapaz. Actualmente la multinacional Emgesa proyecta realizar una hidroeléctrica en el Sumapaz que permita manejar el recurso hídrico de la región sur y garantizar la venta de energía a latinoamérica. Diversos sectores se han manifestado en contra de esta decisión debido al impacto ambiental que puede generar y a la afectación económica de los campesinos. De esta manera, se pone de manifiesto la disputa que se está generando por el recurso hídrico:

Aquí arriba ya ondean banderas americanas, y banderas japonesas, peleándose por el páramo más grande, o sea, esta es la fábrica de agua más importante que tiene el planeta tierra y la tenemos nosotros. Era la paradita técnica para hablar lo que se llama la gobernanza del agua, porque así no lo vendieron para Latinoamérica, y es el gran proyecto que tiene Emgesa. Y no vienen como lo hicieron hace 500 y pucho de años, que vienen en La Niña, La Pinta y la Santa María. No. Ahora llegan al aeropuerto, y ya no vienen ni por oro ni por esmeraldas ni por carbón ni por petróleo ni nada de esa vaina, ellos vienen por esto, porque quien tenga el poder de esto, en las siguientes generaciones, tiene el poder absoluto (Líder comunitario).

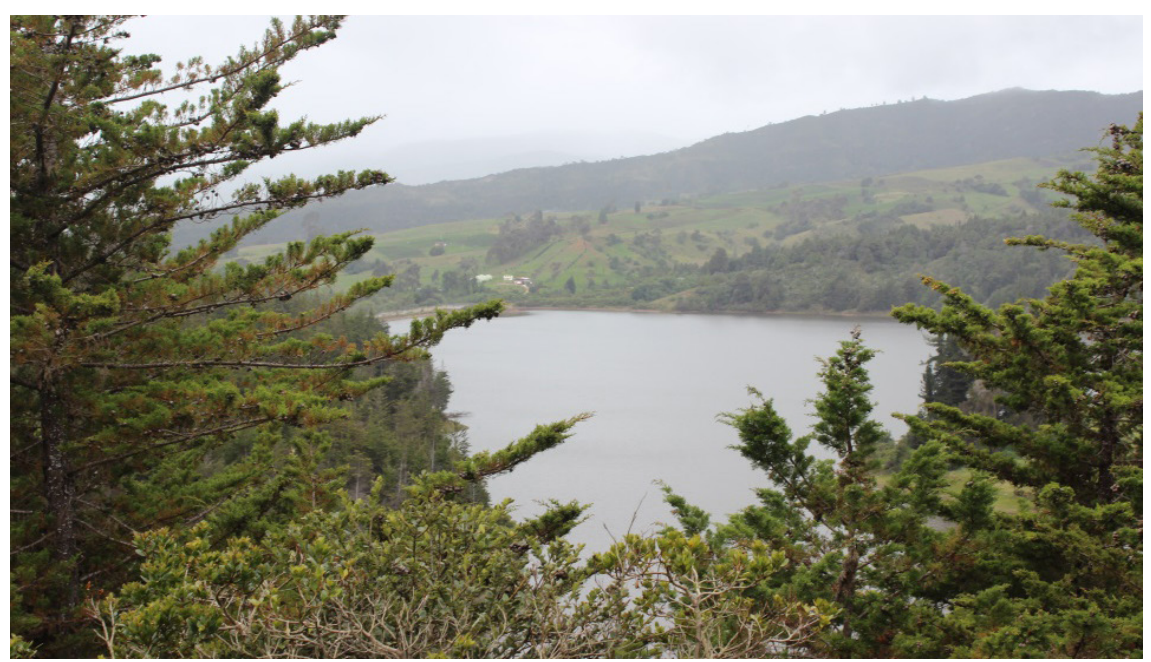

Imagen 4. Embalse La Regadera 
En relación con el posacuerdo y la construcción de paz, es necesario mencionar que el Sumapaz anteriormente era inaccesible debido a la presencia de grupos armados y que gracias al acuerdo de paz ahora se ha abierto al mundo. Un aspecto que es positivo en la medida que permite pensar en proyectos productivos diferentes y en el fortalecimiento del turismo. Sin embargo, la entrada de proyectos que benefician a particulares, por encima de las necesidades de la comunidad, pone de manifiesto un aspecto contradictorio:

Digamos que medianamente y ecosistemáticamente se mantenía. Ahorita que no hay nadie que proteja esto, pues todo el mundo subió el tractor y rompió el páramo, y todo mundo está construyendo, y ya los ricos se vienen a montar sus challets en la parte sur, y ahorita están buscando la forma de patrocinar con el proyecto Rape, todo lo que tiene que ver con ciclo montañismos de la parte alta, todo lo que tiene que ver con cuatrimotos y todo ese cuento, por el páramo. Y pues la famosa vía Bolivariana que, usted recordará, va a atravesar, comunicar Bogotá-Caracas por todo el páramo del Sumapaz (Líder comunitario).

En la medida que continuamos el recorrido, encontramos diversos tipos de cultivos que permiten ver cómo la mano del hombre ha ido invadiendo poco a poco la zona de páramo. Si bien se han realizado acciones importantes para delimitar el páramo, la falta de presencia directa por parte de las entidades responsables conlleva a que diversos actores entren de forma indiscriminada. Otra de las causas puede encontrarse en el analfabetismo de las comunidades campesinas que los lleva a tumbar árboles y frailejones para sembrar papa. Poco a poco los límites trazados por los campesinos se van corriendo, afectando directamente al páramo, el cual puede tardar en regenerarse de 2 a 3 años. Con la llegada del posconflicto, también se develan este tipo de problemáticas socioambientales que invitan a indagar por el tipo de alternativas que se les puede brindar a las comunidades para que su actividad económica sea ambientalmente sostenible; sin embargo lo que se encuentra es que el sector de la agricultura ha quedado en segundo plano y esto se traduce en el empobrecimiento del sector campesino.

Mientras se mantenga esa presión, el movimiento de ciudad que hemos hablado allá abajo, pues obviamente, todo este ecosistema tán frágil se verá vulnerando, que los campesinos tendrán que buscar escenarios dónde subir, y ¿dónde van? Pues pa'l páramo. ¿Qué hay en el páramo? Pues el agua. Y si rompemos los frailejones, pues no hay agua. Y si no hay agua, pues no hay vida. Es una cadena, obviamente, cultural que tienen que venir a ver (Líder comunitario). 
Antes de ingresar al páramo, nos reunimos para escuchar instrucciones y allí nos preguntan: ¿Qué es lo primero que uno hace al llegar a un lugar? Yo opto por conestar: Saludar. Después realiza una siguiente pregunta ¿Y qué más? Le respondo: Pedir permiso. Y efectivamente, él reitera la necesidad de ser respetuosos con el espacio que vamos a visitar, así que realiza un saludo en lengua Muisca y nos invita a recordar el propósito que nos ha llevado hasta ese lugar, el cual ya sea de índole personal y/o académico debe cumplirse hasta el final. En la medida que avanzamos nos reciben cientos de frailejones, lo cual interpreto como la puerta de entrada al páramo. Al ascender, la niebla se vuelve cada vez más intensa, la brisa y la ligera lluvia que cae logra congelarnos los huesos, lo cual tan solo es una prueba para el que quiera conocer las exhuberantes lagunas cargadas de historias y mitologías.

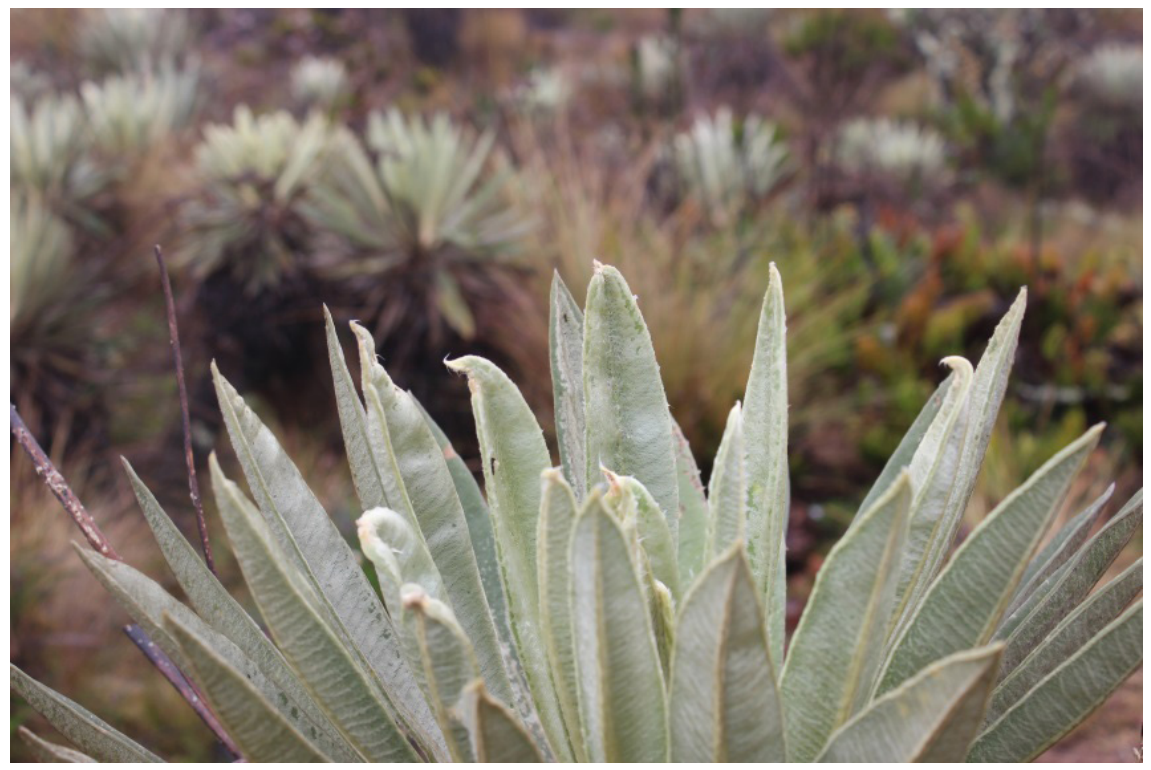

Figura 5. Frailejón. Páramo de Sumapaz

Pasca: en busca de una pedagogía para trascender

Pasca es un municipio que pertenece a la provincia de Sumapaz y se encuentra aproximadamente a dos horas de Bogotá, saliendo por la autopista sur. Su importancia arqueológica se comienza a develar en 1969, momento en el cual campesinos de la región descubren la balsa de oro muisca, pieza 
precolombina de gran importancia (Red cultural del Banco de la República en Colombia, s. f). Pasca no solamente es reconocida por su legado indígena, junto con otros municipios de Sumapaz también ha sido escenario central del conflicto armado y de fuertes luchas y reivindicaciones de las comunidades campesinas que habitan este territorio.

De acuerdo con los proyectos adjudicados en el territorio nacional para la exploración y producción de yacimientos no convenionales (Fracking) y yacimientos convencionales (petróleo), la división territorial permite entender que el bloque COR 4 y COR 33 (COR: Cordillera Oriental), afectaría directamente al municipio de Pasca. En el 2014, la filial colombiana de la empresa canadiense Canacol Energy adquiere los contratos para la exploración de nuevos bloques, dentro de esos el COR 4 (Canacol, S.F; Dinero, 2014). En cuanto al COR 33, la Agencia Nacional de Hidrocarburos por medio de la Resolución 419 del 2010, adjudica a la sucursal colombiana de la empresa canadiense Alange Energy Corp el contrato de dicho proyecto (Agencia Nacional de Hidrocarburos, 2011).

$\mathrm{Al}$ respecto, siguiendo la conversación entablada con líderes del sector, se entiende que desde hace aproximadamente 20 años se cuenta con estudios que reconocen la existencia de petróleo en la región. Sin embargo, con el proceso de paz se genera un aspecto contradictorio que lleva, por un lado a un proceso de apertura de la región, permitiendo la entrada de ciudadanos y la posibilidad de ampliar los proyectos turísticos, pero por otro lado se incrementa la inversión de multinacionales en proyectos como los mencionados anteriormente que van en detrimento de la red de ecosistemas. Al indagar por la responsabilidad institucional en dicha problemática, los líderes manifiestan que no existe un apoyo por parte de entidades como la CAR y la Alcaldía.

Por esta razón, resulta interesante conocer las estrategias implementadas por las comunidades y líderes del sector para buscar una solución a la problemática social y ambiental. En el caso específico de los líderes con los cuales pude conversar, es posible identificar cuatro estrategias desarrolladas a lo largo de los últimos años. La primera consiste en cuestionar categorías tradicionales y en este punto uno de los líderes menciona que es importante ampliar la visión de desarrollo que se encuentra en la base de los proyectos que se implementan en el país, dado que si continúa la noción de desarrollo asociada exclusivamente a la economía y al dinero en el marco del posacuerdo y del extractivismo, a futuro las comunidades no van a tener recursos para comer. Al plantear ese cuestionamiento, menciona que se necesita una 
"pedagogía para trascender", para permitir a la población comprender su situación y posteriormente tomar decisiones. En este sentido, si Colombia continúa afianzando un modelo de desarrollo a partir de la minería, se estaría reforzando la dependencia y el endeudamiento. Al respecto, propone generar acciones para garantizar la "integridad del campesino, del campo y del medio ambiente en los próximos cuatro años".

En este punto y para articular con la estrategia de la Consulta popular, es necesario mencionar que el pasado 17 de junio del 2018 en Colombia se llevaron a cabo las elecciones presidenciales y esto se dio en el marco de la oposición entre dos visiones de país la de los partidos de derecha y de izquierda. Al ganar la propuesta asociada a la derecha, desde la cual se propone la continuidad del modelo extractivista en los siguientes 4 años, se entiende la importancia de vigilar la integridad del territorio y de complementar el mecanismos de la consulta popular con un proceso pedagógico que dote de herramientas a la comunidad para comprender la importancia de las decisiones que están tomando. Esto se presenta como un proceso urgente en aquellas regiones de Cundinamarca donde los habitantes se manifestaron en contra del Fracking en las consultas populares y posteriormente votaron en su mayoría a favor del gobierno que aspira en la presidencia a darle continuidad a dicho modelo, como es el caso del municipio Arbeláez y gran parte del departamento de Cundinamarca. Un aspecto que a primera vista resulta contradictorio, pero que más allá pone de manifiesto la dificutad que tienen las comunidades para realizar una lectura crítica sobre el proceso de paz que se busca implementar en el país.

La consulta popular que se se iba a realizar en Pasca, el 6 de Agosto del 2017, fue suspendida por el Consejo de Estado debido a una acción de tutela interpuesta por la Asociación colombiana de ingenieros de petróleos (ACIPET). En esta, se argumenta que es necesario revisar la pregunta de la consulta que se pretende desarrollar debido a que en caso de que el municipio diga No a las actividades de transporte de hidrocarburos corre el riesgo de perder el abastecimiento de combustibles como la gasolina y el ACPM, lo cual para los promotores de la consulta es un argumento que carece de sentido ya que se entiende que por hicrocarburos se hace referencia al petróleo y al gas (Semana, 2017d). La respuesta hasta este momento se encuentra aplazada y con el nuevo gobierno se enfrenta a un nuevo reto, la regulación sobre la consulta popular que se busca implementar y la falta de recursos que arguye el Ministerio de Hacienda para llevarla a cabo. Adicionalmente, aquellos municipios donde la comunidad votó en contra de la explotación, se enfrentan al reto de garantizar el sostenimiento de dicha consulta. 
En tercer lugar, se ubica como estrategia el reconocimiento y la vinculación a redes comunitarias, dentro de las cuales se puede destacar la Red nacional en democacia y paz. En el año 2007, la red se consolida con el fin de articular el trabajo de diversas organizaciones que venían trabajando en pro a la paz y el medio ambiente. Esto permite ver que a lo largo de los últimos años la movilización se ha ido ampliando en la región y que existe un interés por fortalecer el tejido social (Red Nacional en Democacia y Paz, s.f).

Finalmente, la última estrategia que logra articular todas las anteriores, corresponde a la propuesta educativa. Como se pudo observar, lejos de buscar frenar el desarrollo del municipio, lo que buscan los promotores de la consulta popular es posicionar una visión de desarrollo en equilibrio con las comunidades y el medio ambiente. Para que esta visión se pueda posicionar, los líderes comunitarios consideran que es necesario consolidar un proceso educativo basado en los prinicipio de la educación popular y en un reconocimiento del contexto rural que implica considerar la importancia del trabajo en red, del cuidado de la tierra y de la vida. De esta manera, afirman que en los próximos cuatro años es necesario reforzar la formación de niños y jóvenes, para que en las "próximas elecciones la juventud se levante" (Líder comunitario).

\subsection{Conclusiones}

A partir de los casos estudiados, se devela que en Colombia nos encontramos viviendo un proceso de paz contradictorio y conflictivo, protagonizado por multiplicidad de actores en diferentes ámbitos sociales, con nociones muchas veces opuestas frente a lo que se espera para el desarrollo de la paz en el país ¿El camino hacia la paz es de índole netamente económico o requiere la participación de los diferentes actores implicados? Quizá más allá de hablar de paz, sea necesario pensar en procesos de convivencia en escenarios cotidianos, construidos desde un enfoque de derechos.

Los actuales conflictos socioambientales de Sumapaz son el resultado de luchas históricas originadas por el control de la tierra. $\mathrm{O}$, si somos más específicos, luchas libradas entre sectores campesinos que buscan la distribución equitativa de la tierra y sectores que creen en el desarrollo por la vía de la inversión público privada. Bajo este esquema, la construcción de la paz no es posible si no se modifica el modelo de desarrollo extractivista que ha dominado en el país hasta el momento, dadas las problemáticas que se generan a nivel social y ambiental. 
En este sentido, desde un enfoque de derechos e intercultural es necesario considerar que el modelo extractivista afecta la interconexión entre ecosistemas, la salud de los habitantes, la calidad del suelo, del agua y el aire, lo que se traduce en un modelo que no es sostenible y que no permite el desarrollo económico de sus habitantes. Por el contrario, lo que se evidencia es el beneficio de empresas privadas y multinacionales a partir de la extracción y venta de recursos públicos. El resultado de dichas inversiones no se está viendo reflejado en proyectos que fortalezcan la salud, la educación, el trabajo y la cultura. Por el contrario, lo que se logra ver en los territorios visitados es el desconocimiento de la población frente a los proyectos que se llevan a cabo y la ausencia de herramientas para entender la complejidad de las problemáticas que se avecinan.

Es por esto que, se sugiere fortalecer las siguientes estategias encontradas: 1) Ampliar la propuesta de desarrollo que se ha construido para los territorios, basada en un modelo estractivista, lo cual se puede complementar con la revisión crítica de la política, la participación, la democracia, la ciudadanía y el conflicto (Carmona y Posada, 2018; Cogollo y Durán, 2015; Insuasty y Villa, 2016; Muñoz y Molina, 2010). 2). Construir una propuesta pedagógica rural, urbana y popular que promueva la integridad de sus habitantes, el consumo responsable, la articulación entre organizaciones y logre supllir el analfabetismo político. 3). Promover acciones ciudadanas que protejan la consulta popular, el territorio, la vida de sus habitantes y garanticen el fortalecimiento de redes.

\section{Referencias}

Acevedo, D. y Flórez, G. (2016). Estudio de los instrumentos normativos de ordenamiento ambiental del municipio de turbo (Antioquia), en el marco de las políticas de ordenamiento ambiental de Colombia. Revista Luna Azul, 42, 167-184.

Acosta, C., Benavides, J. \& Sierra, C. (2015) Analisis cualitativo del deterioro de la calidad del agua y la infeccion por helicobacter pylori en una comunidad de alto riesgo de cáncer de estomago (Cauca, Colombia). Salud y Colectividad, 11(4), 575-590.

Agudelo, C., Quiroz, L., García, J., Robledo, R. y García, C. (2016). Evaluación de condiciones ambientales: aire, agua y suelos en áreas de actividad minera en Boyacá, Colombia. Revista de Salud Pública, 18(1), 50-60.

Alcaldía Mayor de Bogotá y Secretaría Distrital de Ambiente (2015). Zuna, pasos que nos develan Bogotá. Bogotá: autor.

Alimonda, H. (2017). Ecología política latinoamericana y pensamiento crítico: vanguardias arraigadas. Desenvolv. Meio Ambiente, 35, 161-168. 
Alzate, L (2015). Minería de oro en el marco de la inseguridad normativa, los grupos de interés y las zonas de exclusión. Revista opinión jurídica, 14(28), 117-133.

Agencia nacional de hidrocarburos (2011). Contrato de exploración y producción de hidrocarburos. Disponible en: http://www.anh.gov.co/Asignacion-de-areas/Relacion-de-areasasignadas/Contrato\%20EanP\%20TEA/Anexo\%20A.pdf

Ardila Cortés, E. (2013). Caracterización socioambiental de la localidad 20 de Bogotá, Colombia. Ambiente y desarrollo, 17(33), 13-29.

Avellaneda, L., Torres, E. \& León, T. (2014). Agricultura y vida en el páramo: una mirada desde la vereda EL Bosque (Parque Nacional Natural de los Nevados). Cuadernos de Desarrollo Rural, 11(73), 105-128

Ávila, A., Carvajal, Y. (2015). Agrocombustibles y soberanía alimentaria en Colombia. Revista Cuadernos de geografia, 24(1), 43-60.

Red cultural del Banco de la República en Colombia (s. f). La balsa Muisca y El Dorado. Disponible en: http://www.banrepcultural.org/coleccion-arqueologica/balsa-muisca

Basto Torrado, S. (2017). El conflicto socioambiental del páramo Santurbán. Un análisis bioético con enfoque de ecología política. Revista Colombiana de Bioética, 12(1), 8-24.

Bayona, P. (2016). CAR y comunidades indígenas en el ordenamiento ambiental territorial: Propuestas para la determinación de competencias en el post acuerdo. Bitácora Urbano Territorial, 26(2), 121-128.

Canacol (31 de enero de 2014). Canacol Energy adquiere los bloques COR4 y COR12, duplicando su posición prospectiva de "shaleoil" en el Valle del Magdalena de Colombia. Disponible en: www.canacolenergy.com/i/pdf/nr-esp/1-31-2014_spanish.pdf

Cárdenas, M. (2013). La gestión de ecosistemas estratégicos proveedores de agua. El caso de las cuencas que abastecen a Medellín y Bogotá en Colombia. Gestión y Ambiente, 16(1), 109-121.

Carmona, J. y Posada, I. (2018). Subjetividad política y ciudadanía de la mujer en contextos de conflictos armados. Revista Mexicana de ciencias políticas y sociales, 63(233), 69-92.

Cascón, P. (2001). Educar en y para el conflicto. Cátedra UNESCO sobre Paz y Derechos Humanos. Barcelona. España.

Cogollo, S. N. y Durán, N. M. (2015). Paz y posconflicto: compromiso de los ciudadanos para un horixonte imaginado. En: S. N. Cogollo Ospina (ed.) Imaginar la paz en Colombia: cavilaciones desde la academia. pp. 62-71. Medellín: Fondo Editorial Luis Amigó.

Corredor, D. (2014). Estrategias de control ciudadano: una aproximación a la intervención megamineria en Cajamarca, Tolima, 2007-2013. Revista Ópera, 14, 71-94.

Coscione, M. (2013). Comercio justo y relevo generacional: la experiencia colombiana de la asociación de jóvenes agricultores del Valle. El Ágora. USB, 13(2), 487-504.

Dinero (31 de enero de 2014). Canacol adquirió dos nuevos bloques. Disponible en: https:// www.dinero.com/empresas/articulo/bloques-adquiridos-canacol/191372 
Egio, C., Torrejón, E., Muñoz, A y Cumplido, L. (2015). Identidad, reconocimiento y participación. Ordenamiento territorial y justicia ambiental en las zonas rurales de Medellín (Colombia). Anagramas, 14(27), 123-144.

Escobar, A. (2017). Desde abajo, por la izquierda, y con la tierra: la diferencia de Abya Yala/ Afro/ Latino/ América. En: H. Alimonda, C. Toro, y F. Martín. Ecología política latinoamericana: pensamiento crítico, diferencia latinoamericana y rearticulación epistémica. Buenos Aires: CLACSO.

Galeano, M (2003). Diseño de proyectos en la investigación cualitativa. Medellín: Fondo Editorial Universidad EAFIT.

García, C., Garcia, M. \& Agudelo, C. (2014). Evaluación y diagnóstico de pasivos ambientales mineros en la Canteravilla Gloria, en la localidad de Ciudad Bolívar, Bogotá D. C. Tecnura, 18(42), 90-102.

Granada, H. \& Molina, C. (2015). Conocimiento y valoración de la calidad ambiental de la Reserva Forestal Bosque de Yotoco: perspectiva psicoambiental. Psicología desde el Caribe, 32(3), 442-458.

Guber, R (2001). La etnografía. Método, campo y reflexividad. Bogotá: Norma.

Güiza, L. (2013). La pequeña Minería en Colombia: una actividad no tan pequeña. Revista Dyna, 80(181), 109- 117.

Güiza, L., \& Rodríguez, C., \& Ríos, B. y Moreno, S. (2016). Género y empoderamiento comunitario en un contexto de posconflicto: el caso de Vergara, Cundinamarca (Colombia). Revista Estudios Socio-Jurídicos, 18(2), 115-144.

Guzmán, B., Nava, G. y Bevilacqua, P. (2016). Vigilancia de la calidad del agua para consumo humano en Colombia: desafíos para la salud ambiental. Revista Facultad Nacional de Salud Pública, 34(2), 175-183.

Herrero, J. (2004). La perspectiva ecológica. En: Introducción a la Psicología comunitaria. Ed. UCO. 2004. Barcelona. España

Hilton, Y. (2014). La consulta previa en la solución de conflictos socioambientales. Revista de Derecho, 41, 83-111.

Insuasty, A. y Villa, J. D. (2016). Entre la participación y la resistencia: reconstrucción del tejido social desde abajo, más allá de la lógica de reparación estatal. El Ágora. USB, 16(2), 453-478.

Jaramillo, J., Londoño, N. y Sánchez, G. (2015). Agroindustria azucarera y Anca tradicional en el norte plano del Cauca (Colombia). Perspectivas históricas y claves etnográficas. Colombia. Memoria y Sociedad, 19(39), 30-47.

Leff, E. (2004). Racionalidad ambiental. La reapropiación social de la naturaleza. México: Siglo XXI editores.

Lopera, G. (2015). La parte alta del cerro es para los pequeños mineros. Sobre la vigencia del régimen minero especial para Marmato y su influencia en la construcción de territorialidad. Colombia. Revista Derecho del Estado, 35, 101-150 
Media, I. \& Paramo, P. (2014). Percepción de los habitantes de Bogotá sobre la calidad ambiental, grado de optimismo y atribución de responsabilidad sobre su deterioro. Acta Colombiana de Psicología, 17(1), 105-118.

Molina, D. (2014). Gobernanza ambiental en Colombia, la acción estatal y de los movimientos sociales. Ambiente y Desarrollo, 34, 27-42.

Montero, M. (2004). Introducción a la Psicología comunitaria. Desarrollo, conceptos y procesos. Argentina: Editorial Paidós.

Munévar, C., González, L. y Henao, A. (2017). Conflictos socioambientales: entre la legitimidad normativa y las legitimidades sociales. Caso mina la Colosa, Cajamarca (Tolima, Colombia). Luna Azul, 44, 165-176.

Munévar y Gonzaga. (2015). Origen y transformación del conflicto ambiental: análisis de los procesos de participación y educación en dos estudios de caso. Civilizar, $15(28), 47-60$.

Muñoz, L. y Arroyave, O. (2017). Percepción del riesgo y apego al lugar en población expuesta a inundación. Pensamiento Psicológico, 15(2), 79-92.

Muñoz, F. y Molina, B. (2010). Una cultura de paz compleja y conflictiva. La búsqueda de equilibrios dinámicos. Revista paz y conflictos, 3, 44-61.

Negret, F. y Torres, C. (2015). Prioridades socioambientales para un territorio en paz. Bitácora Urbano Territorial, 25(1), 153-164.

Observatorio de Derechos Humanos y DIH (2002). Panorama actual de la región del Sumapaz. Vicepresidencia de la república de Colombia. Serie geográfica, 8. Disponible en: http://historico.derechoshumanos.gov.co/Observatorio/Publicaciones/documents/2010/ Estu_Regionales/04_03_regiones/sumapaz/sumapaz.pdf

Ojeda, D., Petzl, J., Quiroga, C., Rodríguez, A. y Rojas, J. (2015). Paisajes del despojo cotidiano: acaparamiento de tierra y agua en Montes de María, Colombia. Revista Estudios Sociales, 54, 107-119.

Olivos, P., Aragonés, J. y Navarro, O. (2013). Educación ambiental: itinerario en la naturaleza y su relación con conectividad, preocupaciones ambientales y conducta. Revista Latinoamericana de Psicología, 45(3), 503-513.

Osejo, A. y Ungar, P. (2017). ¿Agua sí, oro no? Anclajes del extractivismo y el ambientalismo en el páramo de Santurbán. Universitas Humanistica, 84(84), 145-166. doi:10.11144/ Javeriana.uh84.ason

Parra-Romero, A., \& Gitahy, L. (2017). Movimiento social como actor-red: ensamblando el Comité para la defensa del Agua y del Páramo de Santurbán. Universitas Humanística, 84, 113-139. doi.org/10.11144/javeriana.uh84.msar

Paz, L., Avendaño, W. \& Parada, A. (2014). Desarrollo conceptual de la educacion ambiental en el contexto colombiano. Revista Luna Azul, 39, 250-270

Paz, M. (2016). Redes transnacionales de organizaciones indígenas. Análisis del uso de las redes en conflictos socioambientales. Revista de Estudios Sociales, 55, 63-72. 
Pérez, N (2017). Desarrollo rural y movilización social en la zona rural de la Subcuenca del Río Pance (Cali, Colombia). Revista CS, 21, 69-96.

Quiñones, A. (2015). Geopolítica de los conflictos socioambientales: Resistencia a la expansión minera. Colombia. Memoria y Sociedad, 19(39), 73-92

Quiñones, A., Menéndez, A. y Herrera, H. (2016). Resistencias 2.0: Nuevas prácticas comunicativas e informacionales para confrontar el extractivismo minero en Colombia. Anagrama, 15(29), 51-70.

Ramos, A. (2014). Pueblos indígenas y el rechazo al mercado. Revista de Antropología Social. 23, 29-53.

Red nacional en democacia y paz. Disponible en: https://rndp.org.co/

Rincón, A., Lara, D., Castro, I., y Rojas, C. (2017). Conflictos socioambientales y servicios ecosistémicos en la cuenca del río Orotoy: reflexiones para su gestión. Ambiente y Sostenibilidad, 6, 3-16.

Salazar, C. (2013). Participación y acción colectiva en los movimientos globales de ecoaldeas y permacultura. Revista Latinoamericana de Psicología, 45(3), 399-411.

Sañudo, M., Quiñones, A., Copete, J., Díaz, J., Vargas, N. y Cáceres, A. (2016). Extractivismo, conflictos y defensa del territorio: El caso del corregimiento de La Toma (CaucaColombia). Desafios, 28(2), 367-409.

Semana (2017a). El fracking amenaza al páramo más grande del mundo. Disponible en: https://sostenibilidad.semana.com/medio-ambiente/articulo/fracking-llegaria-al-paramode-sumapaz-y-chingaza/37359

Semana (2017b). El petróleo amenaza el páramo, el agua y la seguridad alimentaria. Disponible en: http://sostenibilidad.semana.com/medio-ambiente/articulo/alcalde-de-pascapetroleo-amenaza-paramo-agua-y-seguridad-alimentaria/37894

Semana (2017c). El peligro de querer extraer petróleo en el Sumapaz. Disponible en: http:// sostenibilidad.semana.com/medio-ambiente/articulo/sumapaz-y-las-peligrosas-intenciones-de-sacar-petroleo-en-este-paramo/38176

Semana (2017d). Consejo de Estado suspende la consulta popular en Pasca. Disponible en: http://sostenibilidad.semana.com/medio-ambiente/articulo/consulta-popular-en-pascaes-suspendida-por-el-consejo-de-estado/38281

Semana (2018a). La paradoja de la paz: cuatro historias de destrucción ambiental tras el acuerdo con las Farc. Disponible en: http://sostenibilidad.semana.com/medioambiente/articulo/deforestacion-en-colombia-despues-del-acuerdo-de-paz-con-lasfarc $/ 41088$

Semana (2018b). Posconflicto en Parques: recuperar lo que nunca fue nuestro. Disponible en: http://sostenibilidad.semana.com/medio-ambiente/articulo/deforestacion-en-parquesnacionales-despues-de-la-paz-con-las-farc/41095

Walsh, K. (2008). Interculturalidad, plurinacionalidad y decolonialidad: las insurgencias político-epistémicas de refundar el Estado. Tabula Rasa, 9, 131-152. 
Tovar, N., Trujillo, J. y Muñoz, S., Torres, M. y Zárate, E. (2017). Evaluación de la sostenibilidad de los cultivos de arroz y palma de aceite en la cuenca del río Guayuriba (Meta, Colombia), a través de la evaluación de huella hídrica. Orinoquia, 21(1), 52-63.

Trujillo Quintero, H. F., Losada Cubillos, J. J., \& Rodríguez Zambrano, H. (2017). Amazonía colombiana, petróleo y conflictos socioambientales. Revista Cientifica General José María Córdova, 15(20), 209-223. doi.org/10.21830/19006586.181

Varela, L. y Duque, D. (2010). Juan de la Cruz Varela. Entre la historia y la memoria. Alcaldía Mayor de Bogotá. Universidad Antonio Nariño.

Vargas, Y. y León, N. (2016). Exploración y explotación de petróleo: enfoque geográfico de los efectos ambientales en el Piedemonte llanero. Perspectiva Geográfica, 21(2), 199-22

Zárate, C. (2017). Estado, conflictos ambientales y violencia en la frontera Amazónica de Brasil, Colombia y Perú. Colombia. Revista de Paz y Conflicto, 10(1), 113-136.

Zuluaga, G. \& Arango, C. (2013). Mujeres campesinas: resistencia, organización y agroecología en medio del conflicto armado. Cuadernos de Desarrollo Rural, 10(72), 159-168. 


\title{
25. Narrativa identitaria de un fotógrafo de guerra colombiano. Estudio de caso desde una perspectiva transdisciplinar
}

\author{
Mary Natalia Ortegón Cifuentes ${ }^{93}$ \\ Daniel EnRique Monje AbriL ${ }^{94}$
}

\begin{abstract}
Resumen
Esta investigación está realizada por un equipo transdisciplinar de profesionales de la Psicología y las artes. El estudio aborda las múltiples narraciones que construyen los roles asignados/asumidos de los fotógrafos de guerra colombianos durante la desintensificación del conflicto armado. Metodológicamente se utilizaron herramientas provenientes del interaccionismo simbólico para analizar una serie de seis entrevistas realizados a un fotógrafo de guerra colombiano.

Palabras clave: fotografía, guerra, interaccionismo simbólico, rol, narrativas

\section{Abstract}

This research is carried out by a transdisciplinary team of psychology and arts professionals. This research addresses the multiple narratives that construct the assigned / assumed roles of Colombian war photographers during the de-escalation of the armed conflict. Methodologically, the study takes tools from the symbolic interactionism's theory to analyze a series of six interviews conducted with a Colombian war photographer.
\end{abstract}

Keywords: Photography, war, symbolic interactionism, role, narratives

\subsection{Planteamiento del problema}

Esta investigación, así como todas las que este equipo transdiciplinar ha realizado, reconoce que las identidades se construyen entre la voz del otro y la propia. Entonces, "la pregunta ¿quién soy? se transforma en ¿quién estoy siendo? en un momento y contexto particular de la existencia" (Toledo, 2012,

93 Institución Universitaria Politécnico Grancolombiano. Correo:mortegon@poligran.edu.co

94 Universidad Manuela Beltrán. Correo: daniel.monje@docentes.umb.edu.co 
p. 47). En muchas ocasiones, los roles que se construyen durante periodos de crisis se mantienen después de finalizados estos. Un ejemplo muy claro se puede encontrar en algunos fotógrafos de guerra colombianos, quienes tuvieron un rol particular en el conflicto armado de nuestro país y que, como todos los que vivieron esta experiencia, deben resignificarla hoy en día.

$\mathrm{Al}$ interior del cuerpo social de la fotografía habitan diversos roles que se han construido, desde los primeros tiempos de la fotografía, en un proceso histórico que convierte la temática de las imágenes en lo que define al fotógrafo como individuo en su campo. Dentro de todo el universo de roles posibles, en este complejo campo, existe uno que es prácticamente tan antiguo como la fotografía misma: se trata del fotógrafo de guerra.

Uno de los antecedentes más importantes de la presente investigación tuvo lugar en el año 2009, en una escuela de fotografía muy reconocida de la ciudad de Bogotá. En esta época, uno de los investigadores que forma parte de este proyecto se encontraba estudiando fotografía. Además de los cursos fundamentales de teoría, práctica e historia de la fotografía, también tomó lecciones sobre fotografía de moda, de reportaje, de publicidad, de comida y, por supuesto, de fotoperiodismo y guerra. La mejor y más consecuente manera de explicar la naturaleza de las narrativas identitarias de los fotógrafos de guerra es a través del siguiente ejemplo, narrado por él:

El curso estaba dirigido por un fotógrafo bogotano que ha cubierto, no solamente el conflicto armado colombiano, sino otros eventos violentos en América Latina y el Caribe. No vale la pena decir quien es, porque hoy en día está retirado, pero yo me había inscrito por el prestigio que el señor tenía en el medio. Era un hombre de aproximadamente cuarenta años, con apenas algunas canas en su descuidada barba, vestía ropa juvenil pero visiblemente costosa, con una apariencia a todas luces construida para dar una imagen de agilidad y arrojo. Los asistentes formaban un grupo variopinto conformado por jóvenes profesionales de la fotografía, el cine y el periodismo. Como en todos los cursos de fotografia comenzamos hablando de la luz y de su importancia en la fotografía: todos los cursos comienzan de esta forma, no importa el tema y todos siguen con una breve descripción de la cámara. Poco a poco el profesor comenzó a desviarse del tema técnico y comenzó a hablar sobre la verdad en la fotografía y el papel de los profesionales en la construcción de la sociedad. Para la mitad de la clase estábamos embobados escuchándole hablar del funcionamiento del campo de la fotografía de guerra y su historia, desde 
las primeras imágenes de Roger Fenton en 1855 hasta los trabajos de influyentes fotógrafos contemporáneos como Miller o Nachtwey. Mientras se desarrollaba el tema el profesor adornaba la clase con anécdotas pintorescas, atrevidas y emocionantes de Robert Capa. Nos contó cómo retrató la guerra civil española, la segunda guerra mundial y varios los conflictos en Asia, nos habló de cómo conquistaba a todas las mujeres a su alrededor y otros temas similares. Por casi dos horas el profesor nos contó una vida vertiginosa, emocionante y demasiado corta, que acabó cuando pisó una mina antipersonal en Vietnam. Acercándose al final de la clase el profesor, con aire solemne dijo: "Ian Fleming el famoso autor de libros como Casino Royale, Dr. No y Desde Rusia con Amor, basó el personaje de James Bond en su amigo personal, Robert Capa." Inmediatamente, en mi mente, Capa, pasó de ser uno de los más grandes maestros de la fotografía a ser un semidios de la imagen.

Esta misma historia, está siendo contada constantemente, todos los días a todas horas, en miles de escuelas de fotografía alrededor del mundo. La figura de Capa funciona como el más importante mito aleccionante para la formación de nuevos fotógrafos documentales, de guerra y fotoreporteros. De la reflexión sobre esta experiencia nace la pregunta problema que da inicio al proceso investigativo, y que está enfocada hacia la comprensión del rol asignado/asumido en los fotógrafos de guerra en el contexto colombiano, desde una mirada relacional. ¿Cómo comprender las formas y estructuras de las construcciones identitarias posibles en quienes se denominan fotógrafos de guerra en el conflicto armado colombiano?

A partir de esta pregunta se propuso, como objetivo general, comprender la construcción del rol asignado/asumido en los fotógrafos de guerra en el contexto colombiano y se plantearon dos objetivos específicos: 1) Identificar la configuración de los sistemas de significado en las redes relacionales emergentes donde aparece el rol asignado/asumido de estos fotógrafos; 2) Analizar la relación entre el rol asignado/asumido por los fotógrafos de guerra y los procesos culturales emergentes en el contexto Colombiano.

\subsection{Metodología}

Está investigación se realizó utilizando principalmente metodologías cualitativas, para distinguir la el punto de vista y la voz individual del fotógrafo que ha visto el conflicto armado colombiano a través del visor de su cámara. Igualmente, y de acuerdo a las teorías postestructuralistas que 
definen el marco teórico del proyecto, se ha decidido utilizar el interaccionismo simbólico como metodología de investigación.

Según Herbert Blumer, el término interaccionismo simbólico funciona como una etiqueta para identificar distintas aproximaciones al estudio de la conducta y los grupos humanos. Se ha construido tomando como base tres simples premisas: 1) Que los seres humanos se relacionan con las cosas con base en el significado que las cosas tienen para ellos; 2) el significado de estas cosas es derivado de, o proviene de, la interacción social que uno tiene con sus semejantes; 3 ) estos significados se manejan, y se modifican, a través de un proceso interpretativo utilizado por la persona mientras interactúa con las cosas que se encuentra (Blumer, 1986). En otras palabras, la conducta de las personas se halla vinculada al significado que tengan las cosas, "lo que significan las cosas para el sujeto va a depender de su interacción social con otros actores de su entorno y, en definitiva, de los significados aprendidos en su experiencia social interactiva" (Pons, 2010, p.24). Para una persona, el significado de una cosa crece en la medida que otras personas interactúan con la persona en relación a la cosa (Blumer, 1986). Por lo tanto, los significados que tienen determinadas las cosas para una persona, como: una fotografía, una cámara, un conflicto armado, una relación de pareja, una amistad, una historia, un personaje mitológico, etc., pueden ser usados para construir un conjunto de narrativas que le permitan reflexionar sobre los roles asumidos/ asignados en determinados momentos y contextos particulares de su existencia.

Desde esta metodología se desprenden implicaciones ideales para esta investigación, principalmente el reconocimiento de un interlocutor social activo, que tenga la capacidad de responsabilizarse de su acción social, puesto que "para la comprensión de su comportamiento no podemos prescindir de su punto de vista, lo cual exige el uso de estrategias que permitan evidenciar la visión del actor sobre el fenómeno en el que participa" (Ospina, Carmona \& Alvarado, 2014, p. 55).

\subsection{Población y Muestra}

Antes de iniciar el presente análisis, se realizó una base de datos detallando los profesionales más destacados del medio de la fotografía de guerra en nuestro país, en la que se ingresó información sobre las siguientes categorías: 1) Edad y años de experiencia laboral en la fotografìa de guerra; 2) Formación en fotografía y capital cultural; 3) Descripción general de la obra; 4) Aspectos estéticos de la obra; 5) Medios donde publica y capital simbólico de estos medios; 6) Reconocimiento, (capital simbólico); 7) 
Eventos crìticos relacionados con el conflicto armado; 8) Autopercepción expresada en medios (entrevistas, artículos y libros); 9) Percepción y crítica de la obra; 10) datos de contacto. A partir de esta base de datos se eligió a un fotógrafo, de la ciudad de Bogotá, que se identifica a sí mismo como fotógrafo de guerra, que ha cubierto el conflicto armado colombiano y que manifestó estar de acuerdo con el ejercicio autorreflexivo que implica participar en una investigación con la metodología propuesta.

\subsection{Recolección de los datos}

Se realizaron seis entrevistas semiestructuradas, que en total suman 9 horas 15 minutos.

Entrevista 1. Se realizó con el objetivo de desarrollar un encuadre para la investigación a partir de la historia de vida del fotógrafo y el planteamiento de los parámetros sistémicos de la investigación. Entrevista 2. Se realizó con el objetivo de discutir el problema del mito en las formaciones sociales de los fotógrafos de guerra a través de la figura de Robert Capa. Entrevista 3. Se realizó con los objetivos de discutir el contínuo vulnerabilidad-generatividad en referencia al ejercicio profesional del fotógrafo $\mathrm{X}$ y discutir el papel del sujeto de estudio dentro del análisis sistémico. Entrevista 4. Se realizó con los objetivos de discutir el problema de la relación de fotógrafo y aparato fotográfico desde la perspectiva de Vilém Flusser, la comunicación análoga y digital en el ejercicio de la fotografía a partir de la teoría de la comunicación de Paul Watzlawick. Entrevista 5. Se realizó con el objetivo de analizar momentos puntuales en la historia de vida del fotógrafo $\mathrm{X}$ donde el contínuo vulnerabilidad-generatividad hayan sido afectados por el ejercicio de comunicación (digital y análoga) que se realiza a través de la cámara. Entrevista 6. Se realizó con el objetivo de generar un primer cierre a partir del análisis de los aspectos de aprendizaje, de noticia de la novedad y de crecimiento tanto de investigadores como de sujeto de estudio. En esta sesión se realizó una discusión sobre la responsabilidad ética, tanto de investigadores como de sujeto de estudio, y los aspectos que puedan resultar trascendentes en materia de generación de nuevo conocimiento a partir de la presente investigación.

\subsection{Análisis y procesamiento de la información}

Posterior al proceso de transcripción de las entrevistas, se realizó un análisis hermenéutico interpretativo de las categorías deductivas usando el software Atlas Ti versión 7.5. 
Categoria de análisis

Para este análisis se determinaron 7 categorías de análisis, descritas a continuación.

\section{Contexto socio-histórico}

Situándonos en las ideas de Berger y Luckmann, podemos definir que no hay pensamiento humano que esté inmune a las influencias ideologizantes de su contexto social (1994, p. 24). Por lo tanto, se convierte en una de las tareas más importantes de esta investigación encontrar las narrativas que producen las diferentes representaciones "de la relación imaginaria de los individuos con sus condiciones reales de existencia" (Althusser, 1989, p. 42).

Rol asignado y rol asumido

Los roles son "tipificaciones de los quehaceres propios y de los otros" (Berger y Luckmann, 1994, p.95) que podemos identificar como funciones dentro de una narración determinada. Los roles son de naturaleza dinámica e histórica, se forman relacionalmente entre las diferentes narraciones con las que interactúan los individuos. Cuando las narrativas que asignan los roles a los sujetos son percibidas como externas a ellos se habla de rol asignado; cuando las narrativas provienen privilegiadamente de narraciones producidas por los mismos sujetos se habla de rol asumido.

\section{Sistema de significados}

Son los procesos a partir de los cuales los humanos le damos sentido a la experiencia vivida o por vivir (Hernández, 2010), adquieren la forma de creencias, mitos y epistemes que operan como marcos de referencia, en correspondencia con las diversas lógicas del sentido, para organizar los elementos de la vida subjetiva y las interacciones con los pares. Se presentan en forma de ecosistemas de ideas, donde múltiples intercambios de sentidos entre los actores definen la dimensión y forma del sistema mismo. Estos sistemas, gracias a su naturaleza subjetiva y variable, ofrecen marcos diversos para la articulación de los significados dependiendo del contexto y el momento histórico determinado donde se aplican.

\section{Emergencia del cambio}

Todo proceso inherente a la vida, que permita la transformación, evolución-especialización y complejización, es el cambio. Aunque genera múltiples evidencias, en el contexto actual debemos asumir que este se figura 
al interior de la narrativa de la persona que está siendo entrevistada, y en ocasiones, de los individuos que están aplicando la herramienta, puesto que tanto en escenarios de terapia como de investigación, siempre debe existir la pregunta por el cambio. La respuesta a este interrogante se atraviesa por los aspectos teóricos y metodológicos que idealmente se entrecruzan y retroalimentan uno sobre otro (Rodriguez, Estupiñan y Niño, 2018).

Hablamos del cambio como un proceso emergente, para así poder reconocer su momento específico al interior de la narración de la historia de vida de los participantes en la intervención e igualmente reconocer la multitud de causas, muchas de ellas imperceptibles, por las que emerge. Teniendo en cuenta todo lo anterior podemos afirmar que el cambio es una puntuación del observador, una diferencia o una noticia en la que encuentra algo nuevo en lo que observa.

En nuestra investigación tuvimos en cuenta tres tipos diferentes de cambio, produciendo tres códigos, que conforman una sola familia: un primer tipo de cambio, representado en el enunciamiento de cambios de comportamiento; un segundo tipo, representado en el enunciamiento de cambios en las pautas relacionales $y$, un tercer tipo, representado en el enunciamiento de cambios en los significados.

\section{Impacto de las imágenes}

El producto del oficio del fotógrafo de guerra tiene como objetivo generar un cambio en las diferentes narrativas sociales asociadas a los conflictos armados. Como lo expone Vilém Flusser en su libro, Filosofia da caixa preta (2005), las imágenes tienen como función informar (en el sentido marxista del término) el mundo, siendo especialmente efectivas en este sentido aquellas que Walter Benjamin (1989) denominó imágenes técnicas. Dentro de esta categoría la más importante, por la facilidad que tiene para ser copiada y distribuida, por su fácil lectura y por el poder que tiene de producir narrativas no lineales, es la fotografía. Hemos definido el impacto de las imágenes como el efecto que las imágenes producidas por el fotógrafo $\mathrm{X}$ tienen en las narrativas de los medios de comunicación, los actores del conflicto y el grupo social cerrado que conforman los fotógrafos de guerra.

La cámara

Para Vilém Flusser la cámara es un "juguete que traduce el pensamiento conceptual en fotografías" (2005, p.5), un aparato técnico que requiere de la alegría creadora (Vertov, 1977, p.17), que solamente el creador humano 
puede proveer, para producir imágenes. Todas las fotografías son el producto de la interacción entre las narrativas de una persona con las narrativas de una máquina, articuladas en un gesto técnico (Flusser, 1994). En este código, encontramos todas las narrativas que provienen de la unión entre la cámara y el fotógrafo.

\section{Expresividad plástica}

El pensamiento estético es una narrativa que proviene en la interacción de varias narrativas. En los diferentes intercambios de capitales, simbólicos, culturales y económicos, entre, creadores, críticos y audiencia (Bourdieu, 2010), emerge una narrativa que se encuentra estructurada como una retórica (Barthes, 1994). La expresividad plástica opera en la construcción del relato desde los paradigmas de la narrativa artística hacia otros regímenes específicos de lo sensible, como los campos sociales, la política y la economía. La expresividad plástica es la manifestación de figuraciones en el relato de un "sistema de evidencias sensibles que pone al descubierto al mismo tiempo la existencia de un común y las delimitaciones que definen sus lugares y partes respectivas" (Ranciere, 2009, p.16).

\section{Consideraciones éticas}

Este proyecto, así como los temarios de las entrevistas y el consentimiento informado, fueron aprobados por el Comité de Bioética de la Universidad Manuela Beltrán, según acta de evaluación No. 29-0829--2016 del día 29 de agosto de 2016.

\subsection{Resultados}

De acuerdo a la metodología planteada se presentan a continuación los aspectos más relevantes del análisis realizado en relación con cada uno de los códigos previstos.

\section{Contexto socio-histórico}

El fotógrafo X se percibe como externo a los procesos socio-históricos colombianos, como si fuera un testigo que no tiene injerencia en los resultados de los procesos.

Entonces me doy cuenta que, que de pronto uno también ... de que pue, puede llegar a ser falso ese cuento de que uno está detrás de la cámara y que uno no quiere estar. ¡No!, uno quiere estar ahi de testigo de las cosas, de estar ahí, de estar metido, de vivirlas, de, de... 
Percibe un fuerte entramado de relaciones de poder, que controlan el destino en el cual los fotógrafos operan como entes teleológicos, que simplemente deben cumplir con su función de producir los documentos, mientras el conflicto se desarrolla como si fuese una tragedia griega.

...de los antinarcóticos en el Guaviare. Entonces simplemente a mí no me decían nada. Los gringos tenían la información. Entonces un helicóptero, más de dos cogían donde montarme... y llegamos a un sitio...

En varias ocasiones, durante las entrevistas, es posible percibir esta particular percepción frente al contexto socio-histórico colombiano. Se trata de un conjunto de historias inmensas que se escriben en el Palacio de Nariño y otros escenarios donde se maneja el poder. Un buen ejemplo de esto sucedió en medio de la liberación de Ingrid Betancourt, donde describe el lugar donde las fuerzas del Estado ubican a todos los fotógrafos: ... los que estábamos tomando fotos ese día casi en el mismo sitio, en un área de no más de... no sé, ocho, diez metros cuadrados, todos los fotógrafos y camarógrafos.

$\mathrm{O}$ el cubrimiento de un ataque de una de las guerrillas al ejército: $Y$ digamos que no hubo fotos de eso porque fuimos a Tres Esquinas y no, cuando empezaban a llegar los cadáveres de soldados [ríe] ellos se las ingeniaron y nos tramaron y dejaron las, nos encerraron las cámaras [ríe] ;las cámaras!

En los tres ejemplos anteriores es posible identificar una idea de nación regida por un poder intangible, esta visión también lo lleva a interpretar el conflicto como un campo de trabajo: Yo siempre diría acá, como fotógrafo documental, que hemos documentado, hemos documentado cómo esta guerra, que ya sabemos que es bien atípica, que no es la guerra convencional, no es esto no es cubrir la guerra de Vietnam ni, ni la segunda guerra, ni donde la gente casi que con cita sabían en qué lado se iban a dar machete o iba a haber muertos y que era muy fácil conectarse con las imágenes de guerra. ...Las agencias pedían siempre lo mismo, inclusive un primer plano y ahí alguien llorando atrás"

Por lo tanto se percibe que los autores que controlan las armas, la política y los medios, son entes externos, que la sociedad ha diseñado un lugar especial para los fotógrafos, y que esta es una percepción que se extiende a otros momentos de su carrera fotográfica, no solamente a su participación en el conflicto armado. 


\section{Emergencia del cambio}

Se encontraron tres momentos en la narración del fotógrafo X, que son significativos para esta investigación.

El primero está marcado por la muerte del padre, el cambio de universidad y de carrera, y sobretodo el no saber qué hacer con su vida: Mi papá de pronto in... de pronto fue el único momento que, en que... me fundía obviamente muy feliz. Yo tengo toda la secuencia de fotos de él... caminando con mi mamá en Guatavita... "...la relación fue durísima con él, con... Él se va un día acá que... ya iba tomado y... le da un infarto y... me vio a mí y me dice "ino, yo a usted no lo quiero ver!", porque yo era contradictor total de él, de las ideas políticas..." ... "Mi papá muere en ese año, en el 85, el año de Armero, de eso que yo me fui de la casa, que fue cuando... dejé administración de empresas y no sabía qué hacer en la vida.

En un segundo momento, va a dedicarse de lleno a la fotografía y va a cubrir el conflicto armado: Del papel que me tocó jugar en la familia que era tan distinto y todo eso. Y por eso hablo que la fotografía ; claro!, para mí cumple un papel importantísimo de... al menos de poder tener una profesión, desarrollarme en ella y de pronto de jugar un rol en la sociedad, en la familia, en la célula más pequeña..." ... "Claro, claro y yo ya empecé a cambiar porque yo era un poquito... no suicida pero sí era... muy arriesgado con, con, con el oficio eh... muy ágil, muy... de meterme en todos lados, como que uno... no medía.

Este momento comienza a disolverse al mismo tiempo que nacen sus dos hijas y gradualmente sus prioridades comienzan a cambiar. ... así como yo soñaba con publicar, veía los créditos de León Dario Peláez, José Miguel Gómez, son unos fotógrafos que admiraba, y yo iuy!, yo soñaba con eso y de pronto ya después uno se cansa de publicar...

FInalmente nos encontramos con el momento actual, en el ya no se encuentra laborando como fotógrafo de guerra, y se ha desatado una fuerte crisis, en la que ha encontrado nuevas narrativas en la religión, el trabajo y su familia: Yo ahorita vivo tal vez de pronto en la crisis ya sobre eso y mucha gente me dice: ipero oiga!, usted es uno de los mejores fotógrafos y no está haciendo fotografia... Pero pues digamos que la gestión está llenando eso un poco. Eh... ahorita estoy de pronto viviendo una crisis, me desespero allá en la oficina, me... enloquezco, me paro cada quince minutos, ;no me aguanto el escritorio!... Pero la tengo y a mis hijas y el poder consolidar esta relación que tengo, que sí veo que tiene como unos elementos de pronto un poco más ya... de estabilidad. 


\section{La cámara}

La relación con la cámara está definida en gran medida desde el carácter técnico de la producción de imágenes. Es posible encontrar, durante las entrevistas, varios momentos donde se ejemplifica una simbiosis entre humano y cámara, algunos más literales como: y al final la cámara se volvió como una especie... una parte del cuerpo. ... Una comunión con la cámara jbrutal!

Y otros que solamente sugieren la fuerza del vínculo entre fotógrafo y cámara: ... hay veces que yo salgo, fumo, tomo tinto... no sé qué hacer, jestoy sin cámara! ...hay momentos como cuando uno toma una fotografía buena, hay algo que a uno le dice ifuf!, ; la tengo! O sea, de un día de disparar 300, 400 fotos. Es eso mismo, es eso mismo, de, de decir oiga, yo hago bien este oficio porque lo hago, eh... como... como una catarsis a lo que yo siento, entonces estoy plasmando ese sentimiento, esas cosas internas que yo tengo, ese dolor, de pronto esa tristeza ... yo sentí que me encarrilé en algo y le encontré un sentido a la vida pero... Pero sí, yo diría que fue rápida y, intensa!, intensa, es como mí, ;mi primer amor!, es un amor que se sufre, que es dramático y todo eso y... Y claro, entonces el enamoramiento con la fotografía no es cualquier enamoramiento, cuando uno se enamora de sus aparatos...

En varias ocasiones pudimos observar que la cámara y los lentes determinan la posición del fotógrafo en el mundo, tanto en la vida como en las narraciones que se producen: ...la fotografía es de sitio, es de lugares, es espacial.

Este posicionamiento, determinado por el punto de vista de la cámara, también afecta el punto desde donde el fotógrafo se se posiciona frente al conflicto armado: Yo trataba de ver en gran angular porque si me detenía a mirar detalles, jno sé! Vi un detallito de... vi unas medias como cuando uno va a viajar y las dobla bonito y hace el rollito.

Sistema de significados

Una de las narrativas que más aparece durante las entrevistas, en boca tanto del entrevistado como de los investigadores, es la de Robert Capa. El fotógrafo X reconoce abiertamente la influencia de este mito, tanto en él como en sus compañeros: la vida de Capa yo creo que está en todos los fotógrafos que hacemos como fotografía documental o que registramos... Uno, no mirando la vida de Capa, ;claro que se identifica con él! Porque... porque él... Uno está inmerso en el material, en el soporte, en el documento, en la cámara, en mirar una foto, en seleccionar y todo eso. 
Además de esto reconoce su oficio como especial y privilegiado, que en ocasiones lo ubica como un testigo preferencial de la realidad colombiana: el fotógrafo también tiene unos privilegios inmensos, uno como fotógrafo habla... yo hablaba con Santos, yo hablaba con Raúl Reyes largo, yo he hablado con Joaquín Gómez, he hablado con... con Llinás, he hablado con ... pues también obviamente los campesinos, con los indigenas y todo esto también y... iEs un privilegio inmenso!

Teniendo en cuenta lo anterior, y reconociendo que existe una ecología de ideas y puntos de vista (medios, círculo social, familia, periodistas, etc.) es posible percibir que él considera su punto de vista como particularmente más importante que otros y que, al mismo tiempo, no es tan apreciado como debería ser: se me hace que los colombianos no nos gusta mostrarnos y sin ese mostrarnos en el espejo no va a haber un, un proceso de perdón, de memoria, todas esas cosas...

\section{Rol asignado y rol asumido}

Uno de los momentos más interesantes de las entrevistas se dió cuando el fotógrafo $\mathrm{X}$ manifestó que su encuentro con este género de la fotografía fue accidental, desvirtuando el preconcepto que teníamos sobre una vocación: por ejemplo en mi caso, que también fue como un poco, digamos accidental, porque empecé a trabajar en Arauca y todo lo que ya habíamos contado en otras charlas y como que se me asignó como fotógrafo, digamos entre comillas de guerra, pero pues bueno, igual a nosotros nos ha tocado hacer moda y otras muchas cosas alrededor de...

Sin embargo, cuando habla de la fotografía, sin género, en varias ocasiones manifestó que desde muy temprano en su vida sabía que quería dedicarse a este oficio: y me soltaron por ahi una camarita de a rollo de 110, y... yo me enloquecí con eso, yo creo que ese día me volví yo fotógrafo.

En numerosas ocasiones manifestó como el rol de los fotógrafos cambia constantemente a causa de la irrupción de nuevas tecnologías, dinámicas sociales y tendencias económicas, inclusive manifestando una intensa preocupación por el futuro: se mandaban los fotógrafos a cubrir el Tour de Francia, ise mandaba!, mandaba Cromos a los fotógrafos a cubrir Miss Universo, jahora nadie manda nada a dada! Entonces es, pues se está perdiendo, se está diluyendo, no sé para dónde va ... yo pienso que va más para ese campo de... de la fotografía artística, es decir, es... de hecho los periodistas están tomando fotografias, ya los roles se... se cambian. Entonces... no, está cambiando dramáticamente, dramáticamente, a pesar de que están trabajando gente muy calificada. 
Aunque es importante recalcar que en todas sus narraciones asume roles adicionales al oficio de la fotografía, ubicándose a sí mismo dentro de una mitología personal mucho más grande que la fotografía del país: Tal, tal vez yo entro un poco más allá del discurso y entro como más al alma de las personas. ... Yo no soy frí, yo no soy cerebral, no soy... No, yo me compenetro mucho con la gente. ...soy muy versátil también...

\section{Impacto de la imagen}

Es importante por comenzar enunciando que el fotógrafo $X$ es consciente del impacto que sus imágenes han tenido en el contexto nacional: ... yo abría una revista Credencial, había fotos mías; o abría una Cromos, o había fotos mías; o abría cualquier revista y había fotos mías. Fue un gran despliegue y me empiezan a llegar premios y cosas de estas, reconocimientos, eh... además se volvió un afiche, ese de 2600 metros más cerca de las estrellas... Esa foto de diez mil euros; esa foto tiene un récord de, de venta. ... ya me había graduado y me gané un premio Simón Bolívar de periodismo y... Pues sí, con esas fotos me envían, me invitan a mí a una bienal muy, muy, тиy importante de fotografía a la que aqui ha ido creo que sólo Oscar Muñoz y artistas inclusive, la ... el libro que les mostré. Y pues yo... bueno, eso fue algo bien bonito, ¿no?

No obstante, es necesario mencionar que lo acompaña una inmensa preocupación por que sus imágenes permanezcan en la memoria de los colombianos: ... volviendo a todo el cuento de eso sí, si se marca una diferencia y de pronto eso la hace como merecer un, un espacio en la historia de la fotografía colombiana... Digamos, yo sé ubicar bien, bien mis fotografías y... pero, pero el día que muera no, no están debidamente clasificadas...

\section{Expresividad plástica}

En todas las entrevistas, el fotógrafo X demostró un inmenso conocimiento sobre arte e imagen y de la relación existente entre todos los aspectos de la vida humana y lo estético, sobre todo en lo relacionado con las partes más espirituales de la existencia: El placer estético es algo como muy grande, puede ser tan grande como una caricia, un beso, hacer el amor y, y más con la fotografía análoga, con, tú pones ahí el papel y va saliendo la cubeta y la figura, eh... era... una magia ¿no?”... “... no se puede desmeritar, demeritar el valor de la fotografía como sentido de la belleza... de la belleza, la estética, la espiritualidad ¿no?, entonces eso. ¡Pinto es luz!, luz, ese soy yo, luz. 
En muchas ocasiones manifestó una preocupación por la ética de los creadores de imágenes, sobre todo en lo que respecta a los valores estéticos de sus colegas: ... una razón para estar diseñados, las que sean, todos sencillos a pesar de que sean bien barrocos, es ibien barrocos!, las cosas, los aparatos ahora son llenos de cosas tontas, o sea, son cosas... pero igual son fáciles, eso... si uno se pone juicioso ya...

\subsection{Discusión}

Es importante comenzar expresando que existen numerosos investigadores reflexionando sobre los diferentes actores del conflicto. Se encuentran investigaciones como la de Andrade y Moreno (2008), un trabajo muy valioso revisando desde el psicoanálisis a los combatientes; o el de Villa, Barrera, Arroyave y Montoya (2017), revisando los procesos de reparación psicosocial de las víctimas, así como los artículos de Posada y Carmona (2018), Aguirre (2018) y Villa (2018) focalizados en otros procesos relacionados con las víctimas. Estas son, entre otras, algunas de las valiosas investigaciones que profesionales de todas las ramas de las ciencias humanas han desarrollado en los últimos años, a partir de la desintensificación del conflicto armado y la desmovilización de algunos de los grupos. En todo este ecosistema de investigaciones resulta imposible ubicar al sujeto de esta investigación, pues se está excluyendo de las dualidades víctima/victimario, combatiente/civil, gracias a lo cual nos es posible enunciar las narrativas que le son particulares y que normalmente no son tomadas en cuenta.

A pesar de que en la Psicología, hasta el momento, el fotógrafo de guerra no ha representado un campo de interés, investigadores de otras disciplinas de las ciencias humanas, como las ciencias de la comunicación, el periodismo, el derecho y hasta las artes, han abordado este punto de vista en repetidas ocasiones. Muchos de estos enfoques guiados por el poder que tienen sus imágenes en una sociedad como la nuestra, puesto que, como lo expresa el fotógrafo de guerra Stephen Ferry "la fotografía es una herramienta esencial, en primer lugar, para conseguir evidencias y, luego, para exponer lo que está pasando" (Ordóñez y León, 2013, p.64).

\subsection{Conclusiones}

Las múltiples narrativas que convergen en la emergencia de los distintos roles del fotógrafo X, tanto en el conflicto, como en su familia, la ciudad y su grupo social, nos ha llevado a cuestionar los sistemas de significado en las redes relacionales emergentes donde aparece el rol de fotógrafo de 
guerra. Si bien es cierto que, como lo afirma, Soulages (2014): "el cuerpo del fotógrafo ya no es autónomo, es el cuerpo del ejército que (lo) gobierna; el fotógrafo no es más que la parte fotográfica del dispositivo de guerra" (p. 7). Sin embargo, es importante recalcar que esta no es la única narrativa que define al fotografo $X$, que esta parte del dispositivo de es capaz de reflexionar sobre las imágenes que ha producido en su contexto social y además resignificarlas dentro de su historia de vida.

Resulta evidente que el momento actual por el que está pasando el conflicto presenta similitudes estructurales con el momento por el que está pasando el fotógrafo $\mathrm{X}$, se encontraron múltiples elementos dentro de las entrevistas que permiten establecer las conexiones entre el rol asignado/ asumido por los fotógrafos de guerra y los procesos culturales emergentes en nuestro contexto.

Finalmente, se hace necesario manifestar que a pesar de que resulta imposible comprender la totalidad de las narraciones que construyen el rol asignado/asumido de los fotógrafos de guerra colombianos, hay algunas narrativas que sobresalen y llaman la atención de los investigadores, entre las que se pueden enumerar: la intención de ayudar al proceso de establecimiento de una paz; la posibilidad de convertirse en testigo de otras narrativas a través de la fotografía; mitologías como la de Robert Capa, Gerda Taro o Cartier-Bresson; la posibilidad expresiva plástica que ofrece el medio, inclusive en época de guerra; la relación estético-laboral que propone la cámara al fotógrafo, y sobre todo, la posibilidad de ocupar un lugar en un campo social como la fotografía de guerra.

\section{Referencias}

Andrade, K., y Moreno, M. (2018). Dinámicas subjetivas de combatientes en el conflicto armado colombiano. En M. Moreno, J. Orejuela y T. Calderón (eds.) Abordajes psicoanalíticos a inquietudes sobre la subjetividad III (p. 99). Cali: Editorial Bonaventuriana.

Aguirre, N. (2018). Después de la guerra: el individuo, el grupo y la relación de confianza. Revista Tendencias \& Retos, 19(2).

Althusser, L. (1989). La filosofía como un arma para la revolución (18 ${ }^{\mathrm{a} .}$ ed.). México: Siglo XXI Editores.

Barthes, R. (1994). The semiotic challenge (2 $2^{\mathrm{a}}$. ed.). Berkeley: University of California Press.

Benjamin, W. (1989). Discursos interrumpidos I. Buenos Aires: Taurus.

Berger, P., y Luckmann, T. (2001). La construcción social de la realidad (17 $7^{\mathrm{a}}$. ed.). Buenos Aires: Amorrotu editores. 
Bourdieu, P. (2010). El sentido social del gusto. Elementos para una sociología de la escritura. Buenos Aires: Siglo XXI.

Blumer, H. (1986). Symbolic interactionism. Nueva York: Prentice Hall.

Flick, U. (2012). Introducción a la investigación cualitativa ( $3^{\mathrm{a}}$. ed.). Disponible en https:// ebookcentral-proquest-com.loginbiblio.poligran.edu.co

Flusser, V. (2005). Filosofia da caixa preta. Rio de Janeiro: Relume Dumará.

Flusser, V. (1994). Los gestos. Barcelona: Herder.

Hernández, A. (2010). Vínculos, individuación y ecología humana. Bogotá: U. Santo Tomás.

Ordóñez, G., y León, C. (2013). La fotografía: entre la emoción y la información. Chasqui, 121, 63-67.

Pons, J. (2010). La aportación a la Psicología social del interaccionismo simbólico. Edupsykhé: Revista de Psicología y Psicopedagogía, 9(1), 23-42.

Posada, I., \& Carmona, J. (2018). Subjetividad política y ciudadanía de la mujer en contextos de conflictos armados. Revista Mexicana de Ciencias Politicas y Sociales, 63(233). doi: 10.22201/fcpys.2448492xe.2018.233.57835

Rancière, J. (2009). El reparto de lo sensible. Santiago de Chile: LOM Ediciones.

Rodriguez, D., Estupiñan, J., y Niño, J. (2018). Modelos contextuales de formación de terapeutas desde un enfoque sistémico y ecológico. Bogotá: Universidad Santo Tomás.

Roldán, I., Giraldo, D., y Flórez, M. (2008). Impacto del conflicto colombiano en los periodistas. Revista Colombiana De Psiquiatría, 31(1), 66-80.

Soulages, F. (2014) Arte fotográfico y política. Calle 14: Revista de investigación en el campo del arte, 9(14), 14-28.

Toledo, M. (2012). Sobre la construcción identitaria. Atenea (Concepción), (506), 43-56.

Villa, J., Barrera, D., Arroyave, L., y Montoya, Y. (2017). Acción con daño: del asistencialismo a la construcción social de la víctima. Mirada a procesos de reparación e intervención psicosocial en Colombia. Universitas Psychologica, 16(3), 1-19.

Villa, J. (2018). Intervenciones psicosociales en el marco de acciones de reparación a víctimas del conflicto armado colombiano. ECA: Estudios Centroamericanos, 71(744), 81-85. 

VI. METAANÁLISIS 



\title{
Metaanálisis
}

\author{
Jaime Alberto Carmona ParRa ${ }^{95}$ \\ Mariela Narváez Marín ${ }^{96}$ \\ Ana Sofía Gaviria Cano ${ }^{97}$
}

Reconstruir la identidad y el tejido social en el contexto actual que vive nuestro país, después del turbulento período de conflicto con los grupos armados al margen de la ley, implica algo más que la voluntad de las partes. Es una tarea a la cual estamos convocados todos y cada uno de los habitantes del territorio. Parte importante de este grupo está representada por la academia que debe, desde su quehacer investigativo, aportar nuevas luces para contribuir al manejo de las diferentes situaciones de tal manera que conduzcan a una lectura más objetiva e imparcial de este fenómeno, facilitando abordajes más efectivos. Como investigadores y profesionales de la Psicología del siglo XXI, estamos llamados a asumir una postura frente a lo que ha sido el conflicto armado en nuestro país y a las implicaciones que tiene la construcción de la paz.

Siendo este un tema de múltiples aristas, son muchas las disciplinas, enfoques y campos que han realizado diferentes lecturas de esta realidad, tratando, entre otras tareas, de comprenderla, explicarla, describirla y denunciarla. La Psicología, como disciplina y profesión, no se ha quedado al margen de los acontecimientos; por ello, producto del trabajo investigativo, social y comunitario, hoy recoge diferentes formas de acercamiento a esta compleja experiencia de hombres, mujeres, niños y niñas, en el marco del conflicto y de los esfuerzos por una Colombia en paz.

En este sentido, la Cátedra Colombiana de Psicología Mercedes Rodrigo, versión 2019, se convierte en una oportunidad y en una responsabilidad social, política y formativa, al proponerse como contexto de socialización y debate de diversos resultados investigativos sobre dicha realidad. Es así como este libro recoge tres grandes fenómenos estudiados: el lugar y el papel de las mujeres en el conflicto, la importancia de las experiencias relacionales en contextos de conflicto, posturas sobre el deber ser de la intervención psicosocial, y las posibilidades y limitaciones que enfrenta

95 Universidad de Manizales. Correo: jcarmona@umanizales.edu.co

96 Universidad de Manizales. Correo: maye888@gmail.com

97 Universidad Católica de Pereira. Correo: ana.gaviria@ucp.edu.co 
la reconciliación y la construcción de paz. En estos trabajos se abordan: la subjetividad, las emociones, el liderazgo, el empoderamiento, las interacciones, la identidad, la resignificación, las condiciones de género, étnicas y sociopolíticas, así como aquellos aspectos psicosociales involucrados en la vida de los colombianos, en esta historia de conflicto.

Este libro recoge 21 investigaciones, quince de ellas de carácter aplicado y cinco de tipo documental, en las que se han utilizado metodologías cualitativas, principalmente las narrativas como estrategia que permite a los sujetos una expresión libre de sus vivencias, pensamientos, emociones, imaginarios, subjetivaciones y propuestas frente a las problemáticas planteadas.

Para la recolección de la información se recurrió a las entrevistas semiestructuradas y a profundidad y ,en menor medida, a narrativas colectivas, grupos de discusión, encuestas, talleres grupales, cuestionarios y observación participante. La mayoría de los estudios tuvieron como población objeto a las mujeres, seguida de grupos heterogéneos, niños y niñas y, en menor medida, a los hombres.

La mujer ha sido la principal protagonista en este proceso lo cual evidencia el reconocimiento de su papel, más que como víctima, como líder y gestora en los escenarios de conflicto, reconciliación y construcción de paz. Conocer las subjetividades de las mujeres fue el objetivo de varias investigaciones: en cuatro reclusas, en Medellín y Florencia (Aristizábal); en 50 mujeres afrodescendientes reubicadas en Bogotá (Cárdenas, Cabrera y Barrero); en 3 mujeres del grup de teatro Las Peregrinas de Medellín (Díaz y Yepes) y en una revisión documental (Pérez y Salas).

Sin lugar a dudas, las mujeres en el marco de conflicto armado han tenido experiencias de vulneración, dolor, pérdida, exclusión, violencia física, psicológica, doméstica, económica, simbólica, entre otras innumerables formas de trato inhumanas. A pesar de estos hechos, muchas de ellas han logrado transitar del lugar de víctima a la reconstrucción subjetiva, al resignificar su propia historia y configurar su dimensión política. Como lo plantea Aristizábal: los vínculos afectivos (familia y sociedad) ejercen una fuerte influencia en la construcción de estas subjetividades, ya que se construyen a partir de la integración de diferentes elementos que se dan en la interacción de significados, y en su relación con el otro. La subjetivación Es el recurso para hacerse visible y pasar de una condición de víctima a una postura de sobreviviente, pero ante todo a una concepción como sujeto políticamente envestido. 
La subjetividad se alimenta de los relatos que encierran nuevos significados atribuidos a las experiencias y la migración hacia nuevas formas identitarias que les permiten posicionarse en el escenario social, comunitario, familiar y político (Cárdenas, Cabrera y Barrero). A lo largo de los acercamientos que estos investigadores tuvieron con las mujeres afrodescendientes se pudo evidenciar cómo la reconstrucción de las memorias y la resignificación de los hechos las han fortalecido y les han permitido realizar reflexiones orientadas a lograr un reconocimiento y control de sus vidas con un papel activo para superar la violencia y la desigualdad. Narrarse como víctima es narrarse desde el sufrimiento, el dolor y el miedo. Narrarse como sobreviviente es reconocerse desde la posibilidad y el futuro.

Esa posibilidad de tener un futuro diferente fue reportada en las investigaciones de Posada y Camona, Aristizábal, Cárdenas y Barrero, quienes reconocen en los relatos de las mujeres que, tras reponerse de su experiencia en el conflicto, han pasado a ser promotoras de transformaciones sociales y de construcción de paz, líderes en sus comunidades, sensibles y solidarias frente a las experiencias de otras mujeres. Esto también ha sido posible gracias a los diferentes escenarios de reparación que se han producido para la escucha, el apoyo y su participación en organizaciones sociales y/o culturales, que han sido un lugar y un espacio para la expresión de emociones, la simbolización, la vivencia de un sentido comunitario y la organización colectiva, tal como lo proponen los estudios de Arias y el de Díaz y Yepes. Pero, además, como lo alerta Britto, es necesario un compromiso más decidido y una atención integral en el que se visibilice la institucionalidad y la colectividad en pro de la reparación y la atención, con enfoque de género y diferencial, ya que solo de este modo se podrán acompañar y sostener procesos de empoderamiento.

Esos procesos de empoderamiento se han intentado pero no han dado el resultado esperado, fue lo que encontró Britto al investigar "los retos del empoderamiento". Ello se debe a que la política del Estado está pensada en lógica individual, lo que demanda una cantidad ingente de recursos y demasiado tiempo. Adicionalmente, no reconoce ni da un lugar preponderante a las cosmogonías de los pueblos étnicos ni de las comunidades, generando una doble victimización y desconfianza en el Estado.

El papel de víctima ha tenido varias lecturas en los resultados de las investigaciones realizadas por Atehortúa en el Oriente Antioqueño, Aguirre y Sánchez en Manizales, Moreno en Barrancabermeja, Arias en Supía, Riosucio, Quinchía, Pereira y La Virginia, y Posada y Carmona en Medellín. 
Encuentran que la categoría de víctima encierra una naturaleza emocional y conlleva una carga simbólica y política. Víctima no siempre es un lugar de singularización o empoderamiento, como algunos académicos pretenden mostrarlo, sino que, incluso, puede convertirse en un rótulo con el que el perpetrador asegura su dominio y extiende su poder. Las reconstrucciones subjetivas sirven, en beneficio de inventario, como plataformas de acercamiento al pathos que configura el ethos de la víctima, es decir, a las sensaciones, sufrimientos y emociones que se desprenden de la condición de víctimas y que precisamente estructuran esta identidad (Atehortúa). Por el contrario, como lo reportan Posada y Carmona, la persona es un ser activo que construye realidades simbólicas en la interacción con otros, y que son esos significados los que permiten comprender las acciones humanas. Las mujeres líderes transitan desde la enunciación de víctimas a la de reclamantes, y allí los acontecimientos de guerra y la asociación con otros hacen una inflexión en los significados atribuidos al rol y al ejercicio de la ciudadanía, cuestionando los esquemas de poder y generando transformaciones sociales que contribuyen para la paz.

Para los niños y las niñas, el juego, el pensamiento creativo y la exploración son prácticas agenciadoras de su constitución como sujetos políticos, en cuanto les permiten crear modos de relacionamiento que no habían sido imaginados antes en contextos marcados por las violencias. Como lo sustentan Ospina-Alvarado, Alvarado y Fajardo, en su investigación realizada con niños y niñas de Bogotá, Manizales, Medellín, Santa Marta y Villa Rica: “en la primera infancia, el juego y sus aliados, la creatividad y la exploración, son los vehículos mediante los cuales niños y niñas se relacionan y comunican genuinamente con pares y adultos y construyen relaciones desde las cuales también opinan, deciden, manifiestan afecto y deciden cuidar de sí mismos y de otros. Para los niños y niñas de su estudio, el juego fue fin en sí mismo, al entenderse como un acto desde el cual se proponen acciones y se tejen relaciones que aportan a la construcción de paz.

De igual manera, Carmona en su investigación "Agenciamientos sobre construcción de paz de niños en contextos de guerra en Colombia" encontró que el juego, la diversión y el disfrute en comunidad fueron reportados como estrategias que utilizan los niños como ocasión de construcción y fortalecimiento de lazos, en lugar del acompañamiento en la tristeza o el apoyo en la desgracia. Anota que, justamente en las poblaciones de niñas, niños y agentes relacionales afectados por la guerra existen grandes potencias y posibilidades para la construcción de la paz y la reconstrucción del tejido social del país en el posconflicto. 
En cuanto a las experiencias relacionales en los contextos de conflicto, las investigaciones de Atehortúa; Ospina, Alvarado, y Fajardo; Zuluaga; Peña, y Valencia, reconocen que los procesos de resignificación, adaptación y transformación se logran de forma más efectiva desde prácticas relacionales en las que organizaciones, familia y comunidad se convierten en red de apoyo para resistir y/o generar nuevas formas de relación. En estos escenarios el lenguaje cumple un papel fundamental ya sea a través de los relatos, la escritura, el juego, entre otras formas de encuentro colectivo. En varias ciudades se han organizado sitios de encuentro que permiten a las personas una expresión de sus emociones, y lograr una resignificación de su experiencia, como en el caso de la Ruta Pacífica de las Mujeres, donde las 3 personas objeto de la investigación realizada por Arias, informan que allí encontraron un escenario de escucha, de formación política, de acompañamiento, de encontrar en otras mujeres que, como ellas, han luchado y han sufrido y que no son las únicas. Una comunidad que les ha permitido dotar de sentido lo que les ha ocurrido y lo que nos ha ocurrido como país.

El teatro es otra forma de expresarse y dotar de sentido diferente la experiencia. Díaz y Yepes entrevistaron a tres mujeres del grupo de teatro Las Peregrinas, de Medellín, quienes reportaron que la vivencia del teatro les permitió la construcción de la memoria colectiva, relaciones de sororidad y emergencia de capacidades para la compasión con otras mujeres víctimas, favoreciendo la resignificación de las historias de vida y la configuración de subjetividades políticas. A partir del teatro testimonial, las mujeres han encontrado la forma de sanar las heridas.

Así mismo, en las bitácoras del Salón del Nunca Más (Granada, Antioquia) se han convertido en un escenario simbólico en el que se dejan mensajes tanto para los ausentes (muertos y desparecidos) como para los vivos (Zuluaga). La apuesta ha sido por un trabajo de dignificación en el que el dolor es lo compartido, más allá de que algunas de las personas a las que allí se conmemora hayan tenido una vinculación directa con los grupos armados que se disputaron el control del municipio.

Varias de las investigaciones aquí expuestas llaman la atención sobre las formas adoptadas de la intervención psicosocial. Celis, propone una mirada crítica que centre su atención en el malestar desde una comprensión de los procesos colectivos. Britto, por su parte plantea que en dichas intervenciones deben converger diferentes instancias, a la vez que debe contemplar un enfoque integral. Pérez y Salas proponen centrarse en una perspectiva relacional, dialéctica y subjetiva. Y Aguirre y Sánchez manifiestan la ne- 
cesidad de vincular las relaciones con otros, la colectividad y la identidad como elementos claves para la intervención psicosocial. En general, coinciden en darle relevancia a las necesidades reales de los actores y superar los modelos hegemónicos centrados en perspectivas asistencialistas y de carácter económico-político.

Hay otra mirada del conflicto, desde otros actores y situaciones: los conflictos socioambientales, los pilotos de la Fuerza Aérea Colombiana y un fotógrafo de guerra. En el primero, Urbina encontró que es necesario tener en cuenta los procesos extractivistas (caso de Pasca, Sumapaz) que afectan la interconexión entre ecosistemas, la salud de los habitantes, la calidad del suelo, del agua y el aire, lo que se traduce en un modelo que no es sostenible y que no permite el desarrollo económico de sus habitantes, afectando la convivencia, lo que lleva a nuevos conflictos.

Para los pilotos de la FAC, entrevistados por Andrade, Moreno y Quintero, el enemigo otorga sentido a la existencia y a la función de su rol militar, y contribuye a la legitimación de identificaciones y modos de satisfacción que se ponen en juego en la vida de los combatientes. Expresan satisfacción al cumplir las misiones con responsabilidad, seguridad y profesionalismo. Si bien, luego de los acuerdos de paz se presenta una transformación en su concepción, se ratifican en la necesidad que el enemigo reciba unas consecuencias por sus acciones.

La visión del conflicto que tiene el fotógrafo entrevistado por Ortegón y Monje es la de un espectador. Se percibe como externo a los procesos sociohistóricos colombianos, como si fuera un testigo que no tiene injerencia en los resultados de los procesos. Simplemente debe cumplir con su función de producir los documentos, mientras el conflicto se desarrolla como si fuese una tragedia griega.

La reconciliación y la construcción de paz se reconocen como procesos sociales complejos y multivariables, los cuales han sido objeto de estudio y sobre los que se encuentran resultados investigativos desde tres posturas: una que identifica barreras psicosociales para que estas se logren; mientras que otros, por el contrario, reconocen posibilidades relacionales para hacer frente a una construcción pacífica. Una tercera postura, evidenciada en otro estudio, llama la atención sobre la importancia de hacer una mirada crítica de la intervención psicosocial, ya que esto puede hacer la diferencia entre la repetición del conflicto y el cambio hacia la consolidación de una convivencia en paz. Otra por su parte, reconoce que pese a la firma de los acuerdos, se configuran nuevos conflictos. 
En el primer caso, las investigaciones de Estrada y Villa estuvieron centradas en el marco de los procesos de negociación acontecidos en los últimos tiempos, e identifican representaciones sociales de ciudadanos con baja credibilidad y pocas posibilidades de diálogo sobre quienes se reconocen como enemigos o adversarios, experimentando incluso emociones de miedo, rabia o amenaza. Solo un grupo de participantes lograban reconocer un posible acuerdo. Cabe anotar que en ambas investigaciones los participantes fueron ciudadanos que han vivido de forma indirecta el fenómeno del conflicto.

En el segundo caso, en oposición a los hallazgos anteriores, el estudio de Durán y Pulido, revela como resultados una postura favorable, centrada en relaciones de empatía, confianza y pensamiento crítico como posiciones asumidas por líderes comunitarios, es decir, formas propositivas de resistencia a los contextos de violencia.

En el tercer caso, Celis propone para la intervención psicosocial poner de relieve la comprensión de los procesos colectivos desde las expresiones de malestar, entendiendo la tensión entre memoria, duelo y olvido, como formas alternativas a miradas patologizantes propias de las lógicas capitalistas.

En el cuarto caso, Urbina identifica como factor que sostiene el conflicto, la lucha por el control de la tierra. Ante lo cual emergen tres estrategias basadas en la transformación del modelo de desarrollo, la pedagogía y la consulta popular para promover la integridad de los habitantes.

Como se desprende de los hallazgos reportados en las investigaciones, la situación es muy compleja como lo es el reto de intervenirla. Estos resultados son apenas una mínima muestra de la realidad que se vive en el posconflicto, pero que pueden ser un insumo para la psicología y la academia para trazar programas, proyectos y procesos que contribuyan a la transformación de esa cultura de violencia y desarrollar culturas de paz, que permitan superar la legitimación psicosocial y cultural del conflicto armado, y reconocer que como nación se pueden tener otras formas de dirimir diferencias y problemáticas. 


\section{Reseña}

Este libro contiene 21 productos de investigaciones sobre la construcción y reconstrucción de subjetividades e identidades en contextos de guerra y posguerra en Colombia, escritos por investigadores de los programas que pertenecen a la Asociación Colombiana de Facultades de Psicología ASCOFAPSI, como un aporte a la construcción de la paz que se está consolidando en Colombia, con la cual estamos comprometidos decididamente los investigadores y los académicos del País.

Los productos de nuevo conocimiento que aquí se compilan fueron socializados en el contexto de la Cátedra Colombiana de Psicología Mercedes Rodrigo 2019, que fue coordinada por la Universidad de Manizales y la Universidad Católica de Pereira.
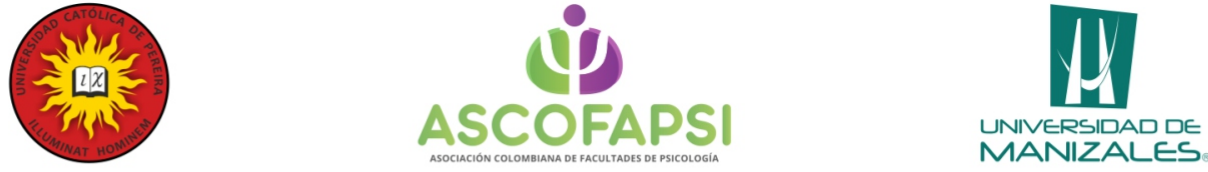

Reconstrucción de subjetividades e

identidades en contextos de guerra y posguerra

Cátedra Colombiana de Psicología Mercedes Rodrigo - 2019

(C) Universidad de Manizales

Facultad de Ciencias Sociales y Humanas

Escuela de Psicología

(C) Universidad Católica de Pereira

C) Asociación Colombiana de Facultades de Psicología

Fondo Editorial, Universidad de Manizales

Carrera 9 No. 19-03

Conmutador 8879680

www.umanizales.edu.co

Manizales, Colombia

Mayo de 2019

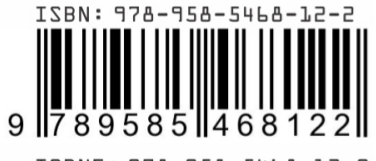

